\title{
Das Herz in der ägyptischen Literatur des zweiten Jahrtausends v. Chr.
}

Untersuchungen zu Idiomatik und Metaphorik von Ausdrücken mit $j b$ und $h i t j$

Dissertation zur Erlangung des Doktorgrads

an der Philosophischen Fakultät der Georg-August-Universität Göttingen

vorgelegt von

María Isabel Toro Rueda

aus Madrid (Spanien)

Göttingen 2003 
1. Einleitung

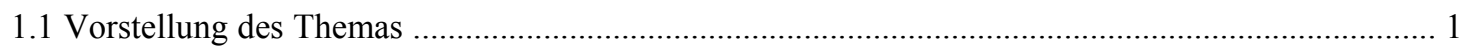

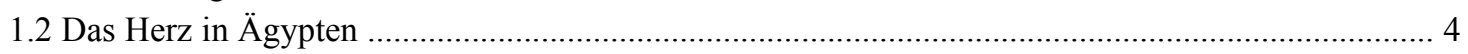

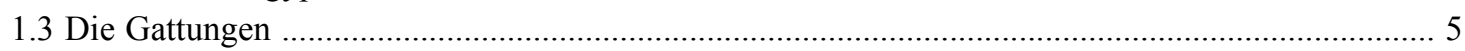

1.3.1 Zum Problem des Gattungsbegriffs ............................................................................. 5

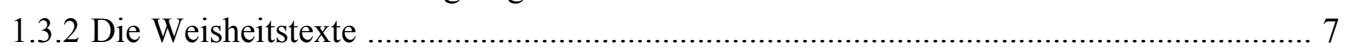

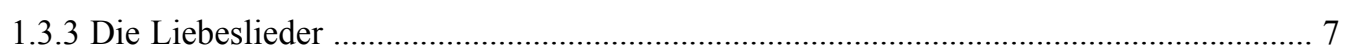

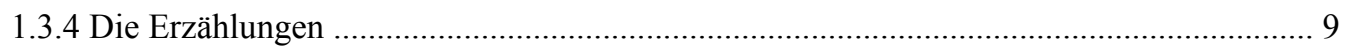

1.3.5 Eine Hypothese a priori ..................................................................................... 9

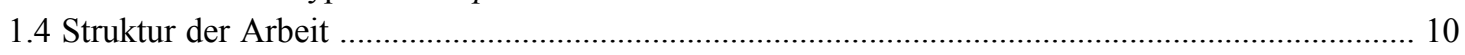

1.5 Hinweis zur grammatischen Aufbereitung und philologischen Erklärung der Textbeispiele .... 11

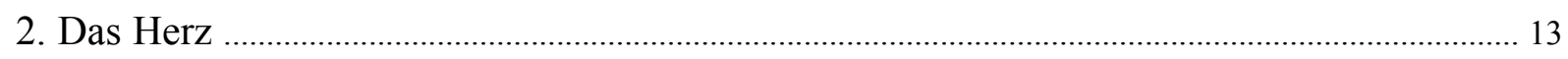

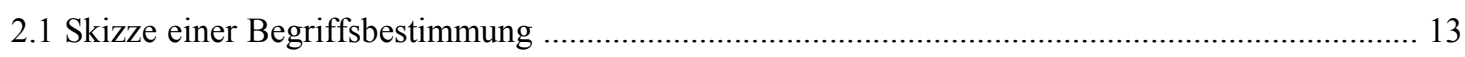

2.2 Das Herz in Kollokationen und Redensarten des Deutschen ............................................................. 14

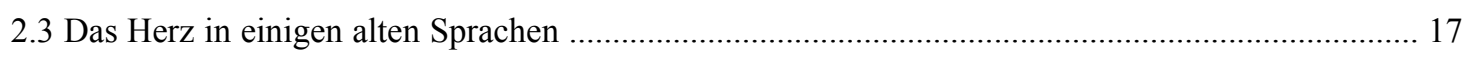

2.3.1 'Herz' im Indoeuropäischen und im Afroasiatischen ...................................................... 17

2.3.2 'Herz' im Lateinischen ...................................................................................... 18

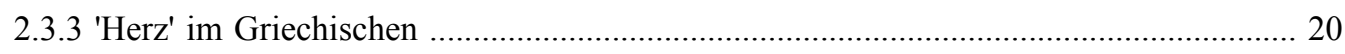

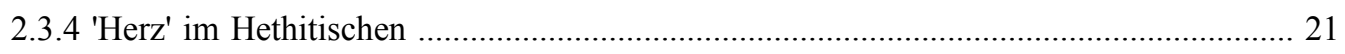

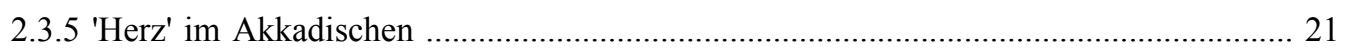

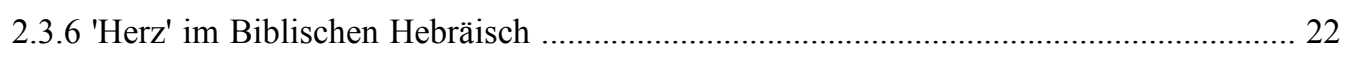

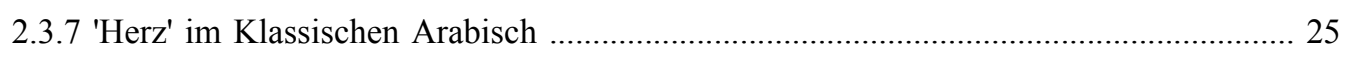

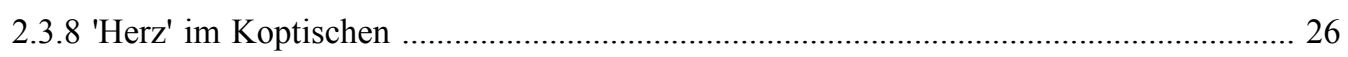

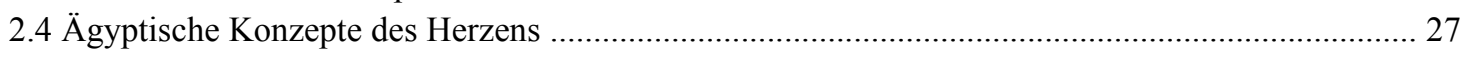

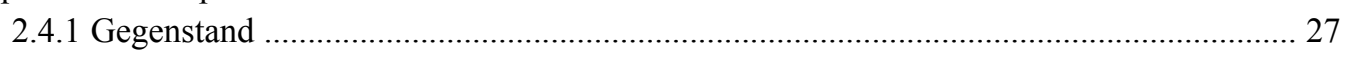

2.4.2 Die vorkommenden Formen .......................................................................................... 27

2.4.3 Versuche zur eindeutigen Klärung der Semantik ...................................................... 30

2.4.4 Ägyptische und ägyptologische Konzepte ………….................................................. 34

2.5 Randbemerkung: Hypothesen zur Etymologie der Wörter für 'Herz' ............................................ 38

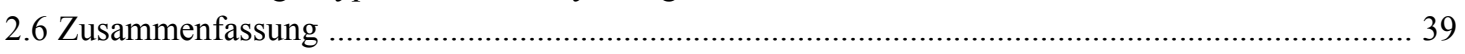

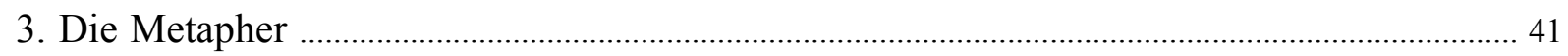

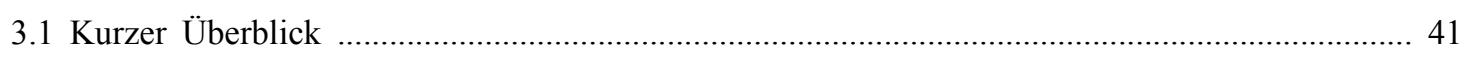

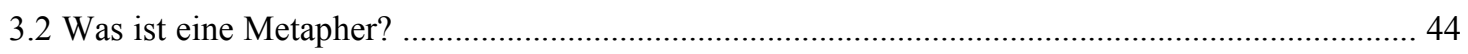

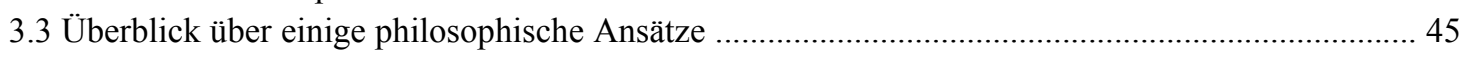

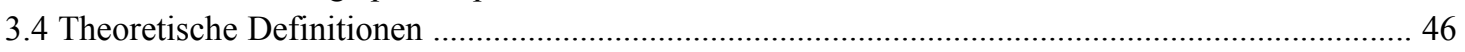

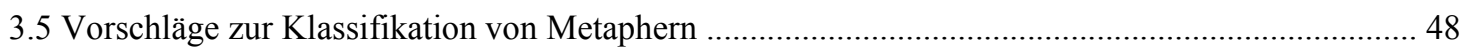

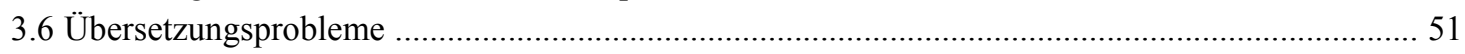

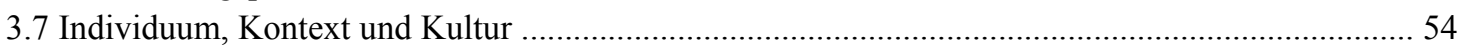

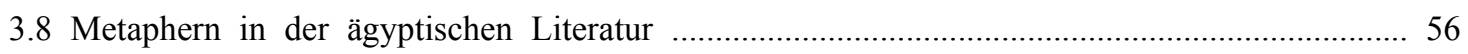




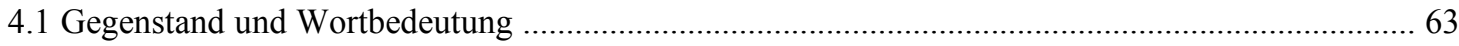

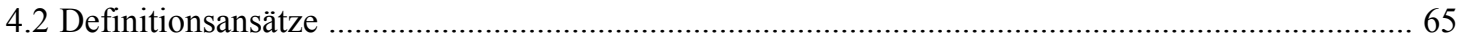

4.3 Anthropologische Konzepte über den kulturspezifischen Charakter von Emotionen ......................... 69

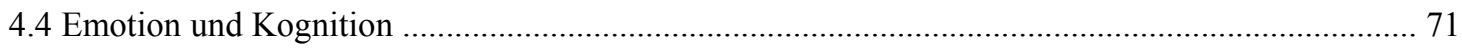

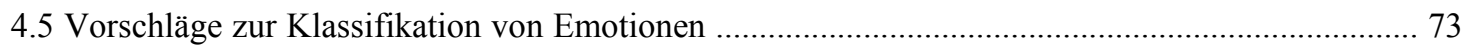

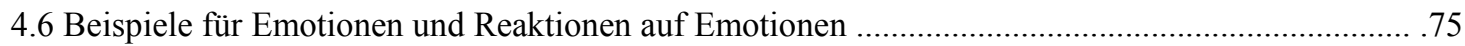

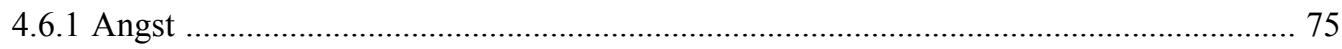

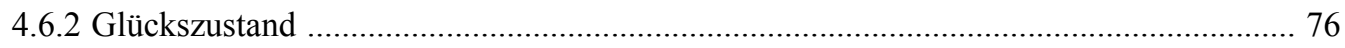

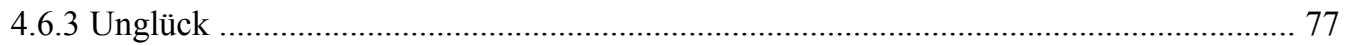

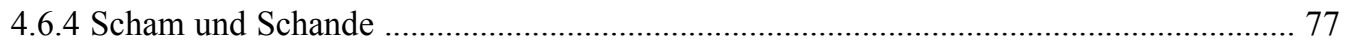

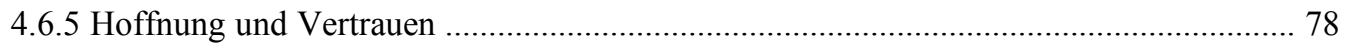

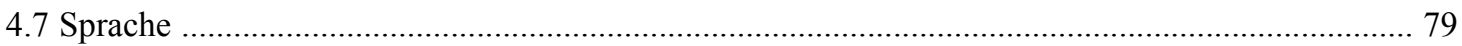

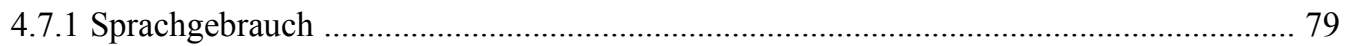

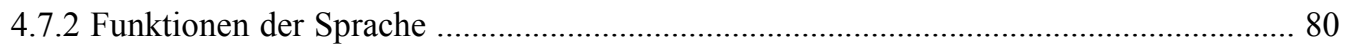

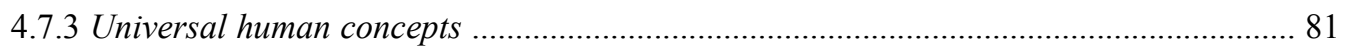

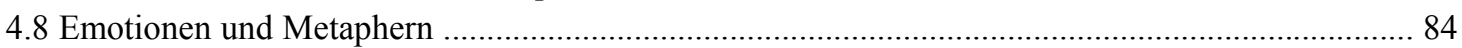

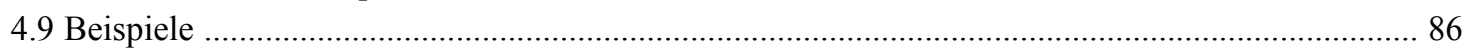

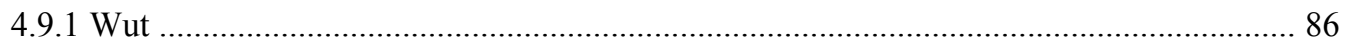

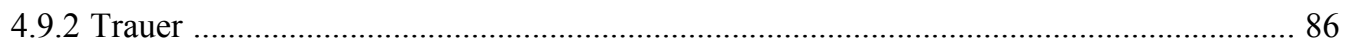

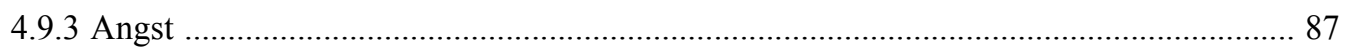

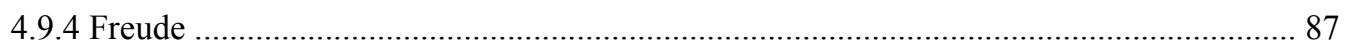

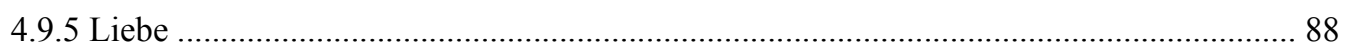

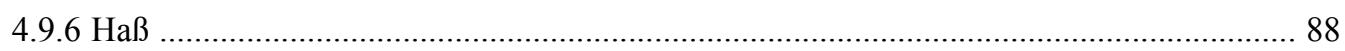

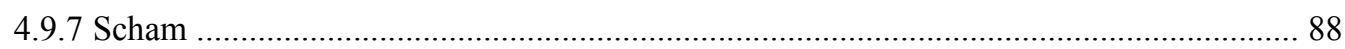

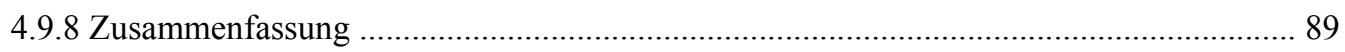

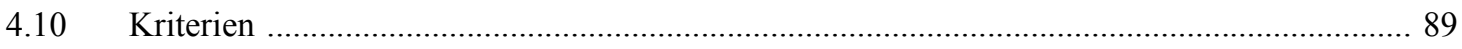

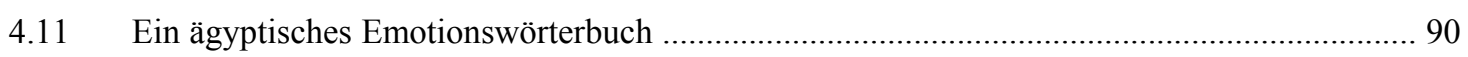

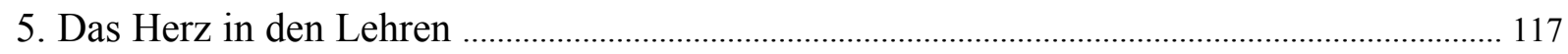

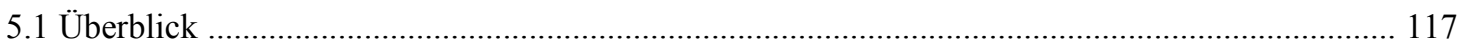

5.2 Zum Verwendungsumfang von $j b$ und $h 3 t j$ in den Lehren ....................................................... 118

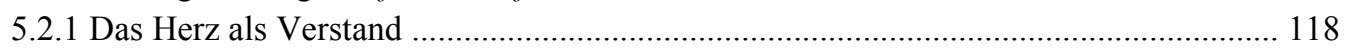

5.2.2 Das Herz und die Persönlichkeit ............................................................................... 120

5.2.3 Das Herz und Emotionen ........................................................................................... 120

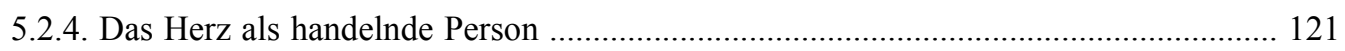

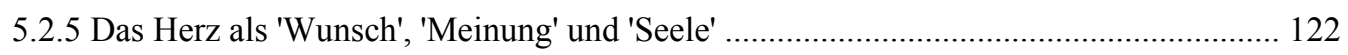

5.2.6 Das Herz als Körperorgan ..................................................................................... 122

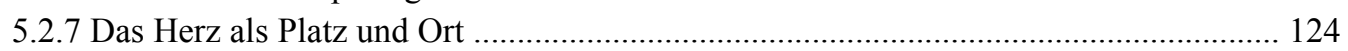

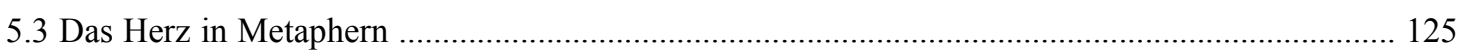

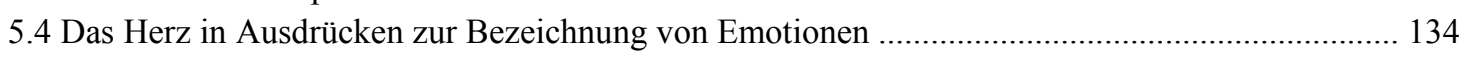

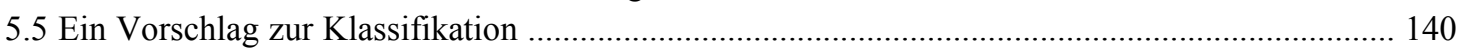

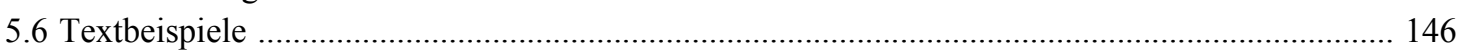

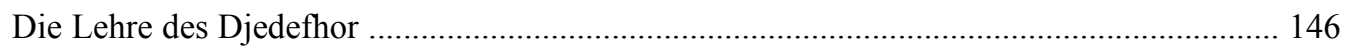

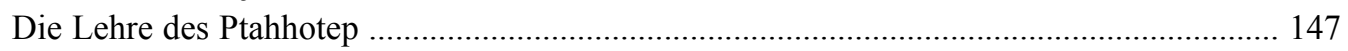

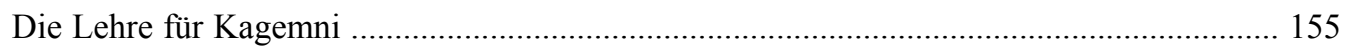

Autobiographie des Mentuhotep .................................................................................. 156

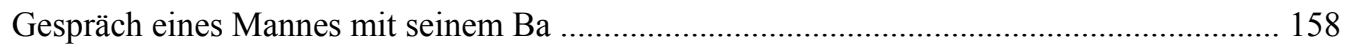

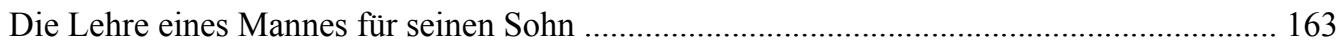

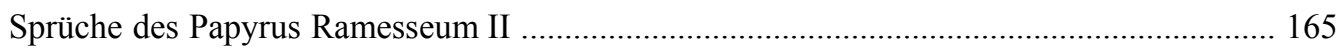

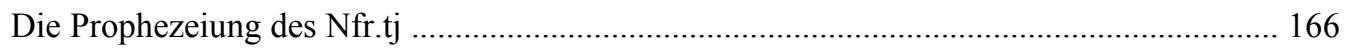




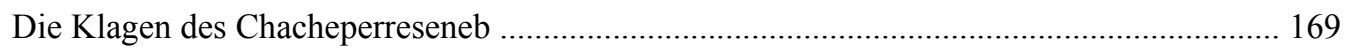

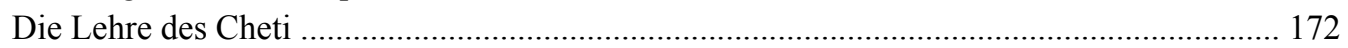

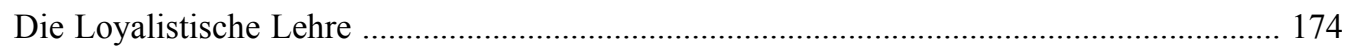

Aus der Autobiographie des dritten Gottesvaters des Amun, Namens Nefer ....................... 177

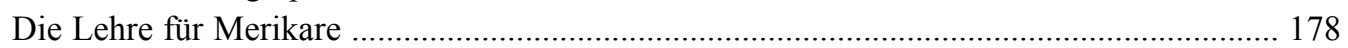

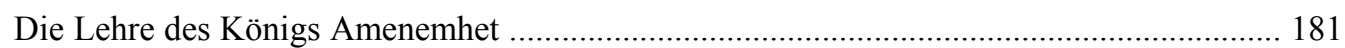

Brief des Menna an seinen Sohn Paj.jrj ............................................................................ 184

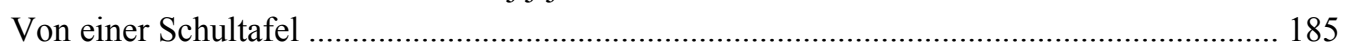

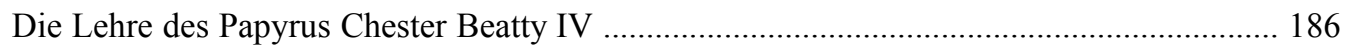

Die satirische Streitschrift des Papyrus Anastasi …………............................................. 188

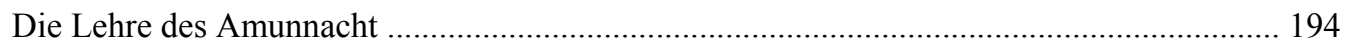

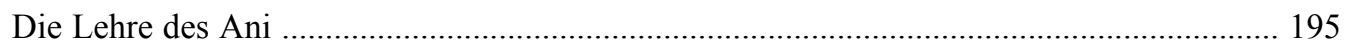

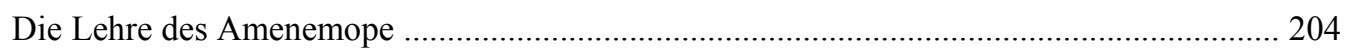

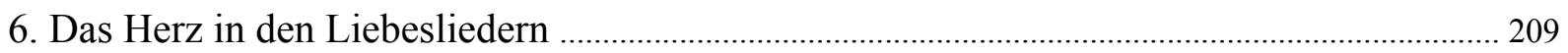

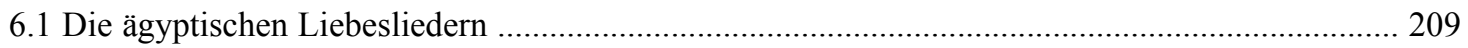

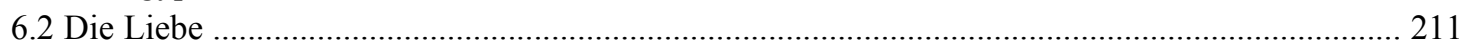

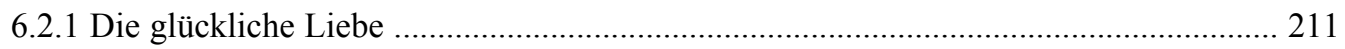

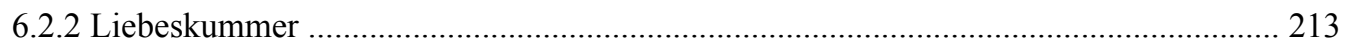

6.2.3 Besondere Zustände in Zusammenhang mit der Liebe ............................................... 215

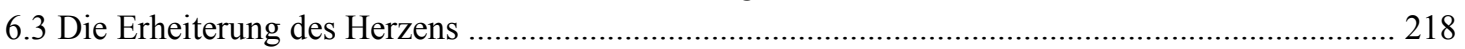

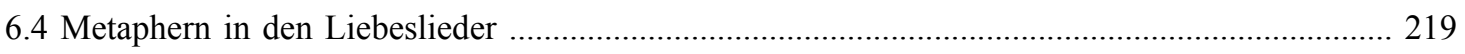

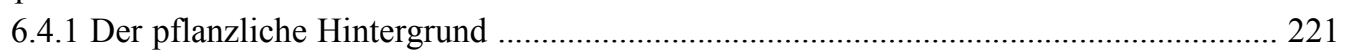

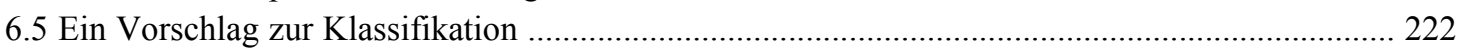

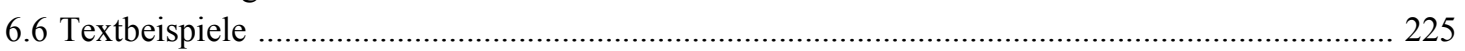

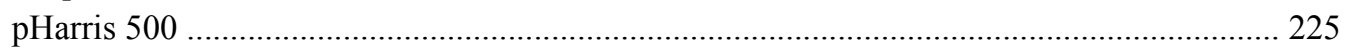

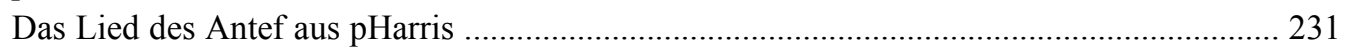

Das Blumenlied des pHarris ......................................................................................... 234

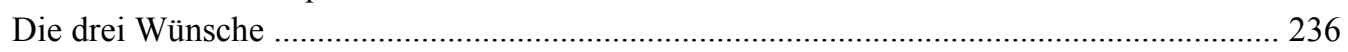

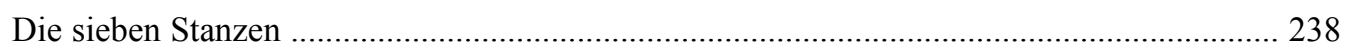

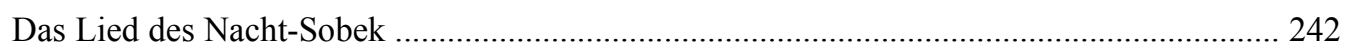

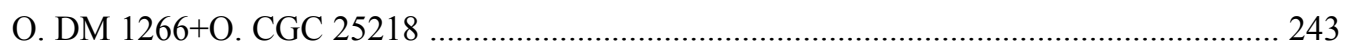

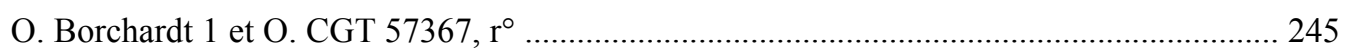

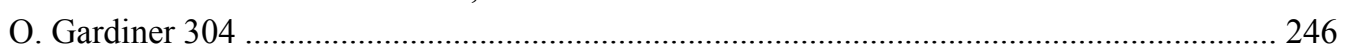

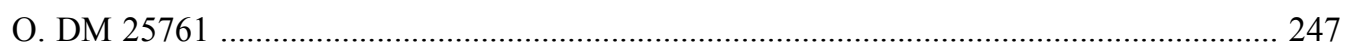

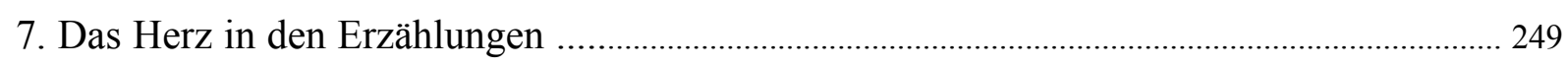

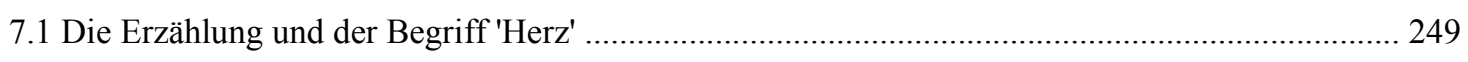

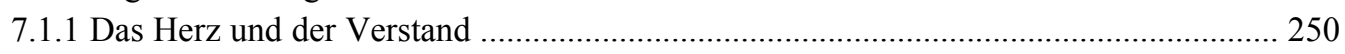

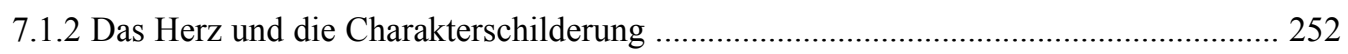

7.2 Emotionaler und nicht-emotionaler Zustand des Herzens ........................................................... 253

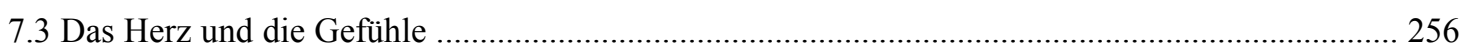

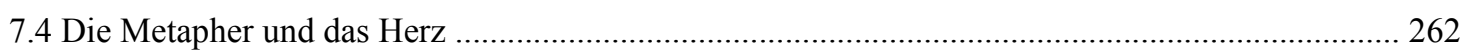

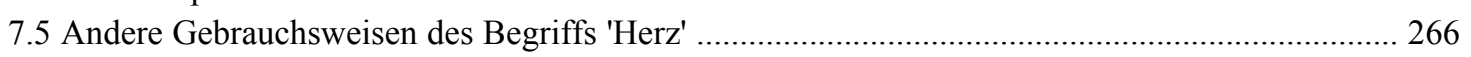

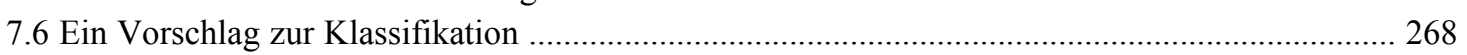

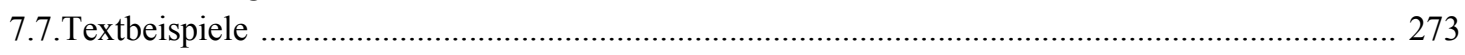

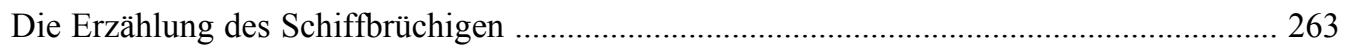

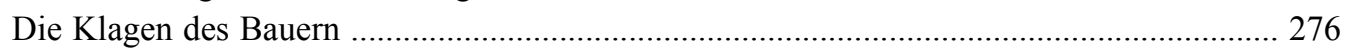

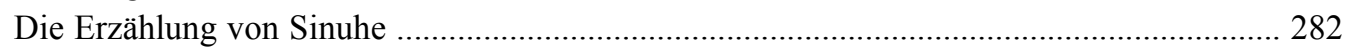

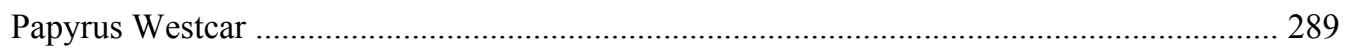

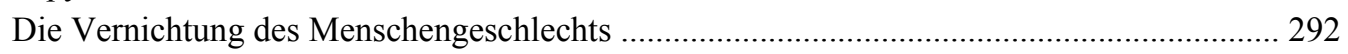




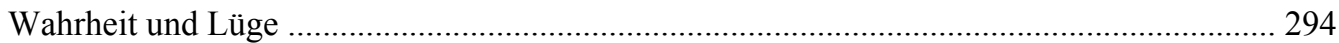

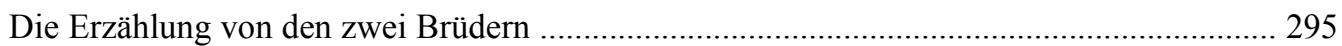

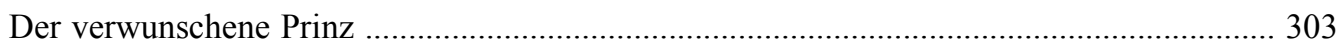

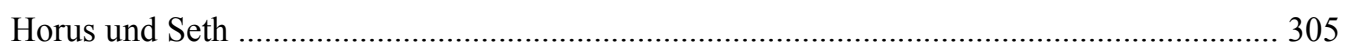

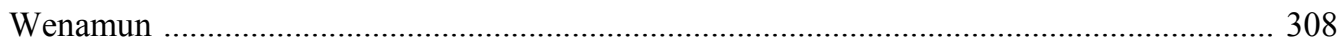

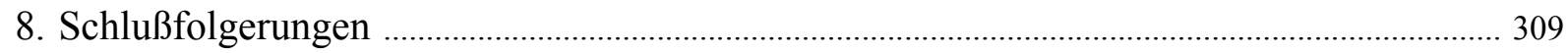

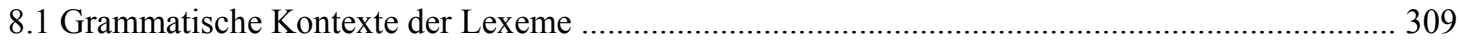

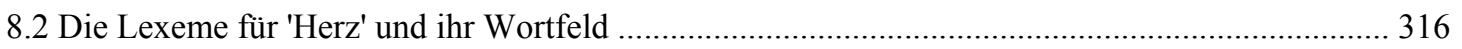

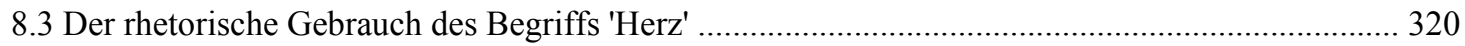

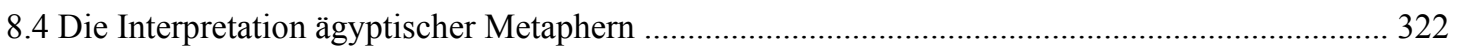

8.4.1 'Herz' in Metaphern zum Ausdruck von Emotionen ..................................................... 322

8.4.2 Die übersetzungssprachliche Wiedergabe der ägyptischen Lexeme für 'Herz' .............. 323

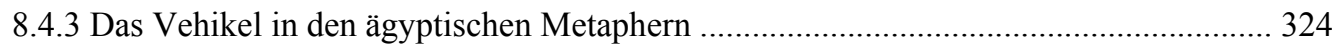

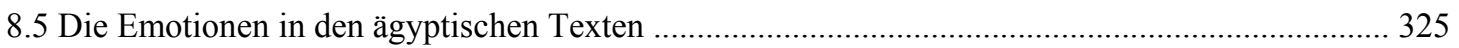

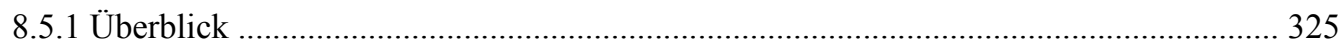

8.5.2 Emotionen und Reaktionen auf Emotionen in den ägyptischen Texten ........................ 327

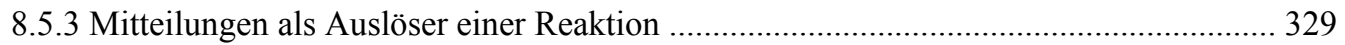

8.5.4 Eine Tabelle der ägyptischen Determinativen für Emotionswörter ............................... 330

8.6 Ägyptische Kollokationen zum Ausdruck von Charakter, Gefühlen oder allgemeinen Zuständen 333

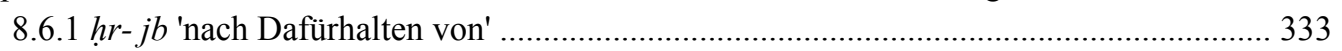

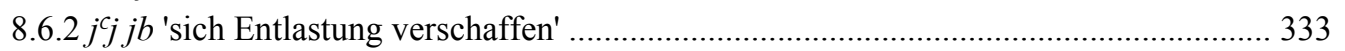

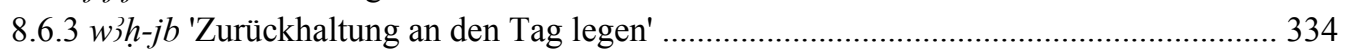

8.6.4 sndm-jb 'mit einer guten Nachricht beglücken' nd $\underline{d} w-j b$ 'von einer schlechten Nachricht erschüttert sein' .......................................................................................... 334

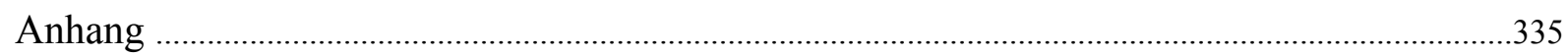

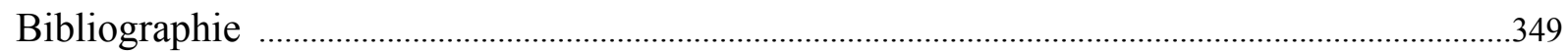

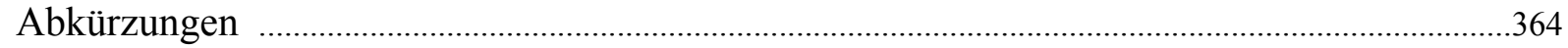




\section{Kapitel}

\section{EINLEITUNG}

\begin{abstract}
"Da man schon von den ältesten Zeiten an das Herz für den Sitz der Seele und insbesondere des Willens und der innern Empfindung gehalten hat, so hat solches zu vielen figürlichen R.[edens] A.[rten] Gelegenheit gegeben, worin Herz zwar seine eigentliche Bedeutung behält, die ganze Redensart aber doch eine Figur ist. Die Angst möchte ihm das Herz abstoßen, sagt man von einem sehr hohen Grade der Angst. Es will ihm das Herz abstoßen, von einem Menschen, welcher eine unruhige Begierde blicken lässet, ein Geheimnis zu entdecken. Der Gram frißt ihm das Herz ab, verkürzet sein Leben. Einem das Herz schwer machen, traurige Empfindungen in ihm erwecken. Nun ist mein Herz leichter, wenn diese Empfindungen gehoben oder vermindert werden. Nun da ist mir ein rechter Stein vom Herzen, in eben diesem Verstande. Es ist mir so enge um das Herz, wenn man eine geheime Sorge, einen geheimen Gram empfindet. Ich rede, wie es mir ums Herz ist, wie ich es empfinde. Ich weiß, wie es ihm ums Herz ist, was er empfindet. Wie warm mir um das Herz! Mein Herz will mir brechen, von einem hohen Grade des Kummers, des Grames, der Wehmut. Dieser Brief brach ihm das Herz. Darum bricht mir mein Herz gegen ihn (über ihm,) daß ich mich sein erbarmen muß, Jer. 31, 20. Es ist ihm an das Herz gewachsen, von einem hohen Grade der Liebe, der Neigung gegen eine Sache. Das Geld ist ihm eben nicht an das Herz gewachsen. Die Hand, oder auch ohne Artikel, Hand über Herz legen, seinen Empfindungen Raum geben. Ihr Kind ist zwar ungehorsam gewesen, aber ein Vater legt dich Hand übers Herz. Der Gram zerreißt mir das Herz, von einem hohen Grade des Grames. Da ward mein klopfenden Herz Furcht und Angst zerrissen."
\end{abstract}

(Adelung, Grammatisch-kritisches Wörterbuch, 1796, Bd. 2, Sp. 1145).

\subsection{Vorstellung des Themas}

Verbindungen zwischen dem Begriff 'Herz' und Konzepten wie 'Denken' bzw. 'Kognition' und 'Gefühl' bzw. 'Emotion' beschränken sich nicht auf Beispiele aus heutigen Zeiten, sondern lassen sich auch bei den antiken Griechen oder in außereuropäischen Kulturen finden. Aus diesem Grund erscheint die Herausbildung von mit dem Wort 'Herz' gebildeten Metaphern, die ebenfalls in den unterschiedlichsten Kulturen auftreten, besser verständlich. Diese Art, wie solche Metaphern in den einzelnen Sprach- und Kulturgemeinschaften verwendet werden, kann ganz unterschiedlich sein. Beispielsweise bedeutet das kalte bzw. schneebedeckte Herz im Arabischen 'Feigheit', im Deutschen aber 'Teilnahmslosigkeit', 'Gefühlskälte', oder 'Herzlosigkeit'. 
Die Symbolik des Herzens im europäischen Raum untersucht Hillman $1981^{1}$ in seinem Vortrag "The thought of the heart". Er stellt drei unterschiedliche Vorstellungen des Herzens heraus:

"First: my heart is my humanity, my courage to live, my strength... My most noble virtues emanate from the heart: loyalty, heroic boldness, compassion. Let us call this the heart of the Lion, Coeur de Lion. Second: my heart is an organ of the body. It is a muscle or a pump, an intricate mechanism and secret holder of my death. Let us refer to this pumping heart as the heart of Harvey. Third: my heart is my love, my feelings, the locus of my soul and sense of person. It is the place of intimate inferiority, where sin and shame and desire, and the unfathomable divine too, inhabit. Let us call this personal heart, the heart of Augustine."

In dieser Arbeit wird nur die Verbindung des Herzens mit Emotionen untersucht. Es ist jedoch wichtig festzustellen, daß darüber hinaus sowohl die Emotion als auch das Herz einen weiter gefaßten Sinn enthalten.

Die Emotionen sind zahlreich, seien sie positiv oder negativ. Wenn eine Person etwas empfindet, äußert sich dies durch eine körperliche Reaktion. Diese Reaktion ist auf einen Körperteil fokussiert, z.B. Bauch, Auge, Gesicht und Herz. Man darf also sagen, daß das Herz nicht der einzige Körperteil ist, der auf eine Emotion reagiert. Man kann jedoch davon ausgehen, daß der Hintergrund einer Emotion das kordiologische Herz ist (siehe dazu ausführlich weiter unter Kapitel 2).

Es wäre auch ungenau, zu behaupten, daß die Herzmetaphorik sich nur mit Emotionen in Verbindung bringen läßt. Metaphern, die mit dem Begriff 'Herz' gebildet werden, dienen ebenso dazu, einen Charakterzug oder einen seelischen Zustand auszudrücken. Diese Art der Ausdrücke ist seit langer Zeit in den unterschiedlichsten Kulturen bezeugt.

Bei den alten Griechen kann der Beginn des Auftretens derartiger Metaphern bereits in der Ilias und Odyssee ausführlich beobachtet werden. Der homerische Mensch befindet sich - wie es von altphilologischer Seite beschrieben wurde - in einem "Konzert von Regungsherden". ${ }^{2}$ Dieser Ausdruck ist eine Beschreibung des 'Leiberlebens', welches mit den verschiedenen Worten für das Leibesinnere und für den Brustbereich ausgedrückt wird. Die Begriffe für das Herz in der altertümlichen griechischen Kultur waren $\kappa \alpha \rho \delta i ́ \eta, \varepsilon \tau o \rho, \kappa \hat{\eta} \rho, \theta v \mu o ́ \varsigma$ und $\varphi \rho \varepsilon \varepsilon \varepsilon \varsigma$. Der Begriff $\kappa \alpha \rho \delta i ́ \eta$ ist - so heißt es immer wieder - bei Homer nicht klar definiert. Es wird in der Bedeutung 'innere Brust' benutzt und als Ort von Gefühlen wie Zorn oder Mut, und als Ort des Denkens, Wollens und Vorstellens verstanden.

Auch in den asiatischen Kulturen ist der Begriff des Herzens nicht nur für die Äußerung der Gefühle genutzt, sondern auch des Denkens und des Geistes. ${ }^{3}$ In Indien wird das Herz

1 Hillman (1981: 137).

2 Schmitz (1996: 14).

3 Siehe dazu etwa die Ausführungen zu dem chinesischen Wort xin 'Herz' bei Roetz (1984: 260). 
ebenso mit Gefühlen und Gedanken verbunden, während gleichzeitig eine MikroMakrokosmos-Lehre präsent ist. ${ }^{4}$ Zum Herzen als Ort der Gedanken und der Gefühle führt Avalon aus (1975: 10):

"Das Vedische System postuliert das Herz als den Hauptsitz für das Bewußtsein - einen Überrest dieser Vorstellung bewahren wir noch in der Redensart 'Nimm es zu Herzen', 'Lerne mit Herz'."

Das Herz als Ort der Emotionen tritt anscheinend in jeder Kultur zu allen Zeiten auf, was in folgenden Kapiteln vorgestellt wird.

Zwischen den Gefühlen und dem Herzen entwickelt sich ein Prozeß, in dem das Wort "Herz" dazu dient, emotionale Zustände auszudrücken. Aufgrund dieses Gebrauchs des Wortes entsteht eine Art der Metapher, die man Herzmetapher nennen kann.

Man soll aber nicht glauben, daß alle Metaphern, die eine Emotion wiedergeben, exklusiv mit dem Wort Herz (bzw. den entsprechenden Lexeme anderer Sprachen) gebildet werden. Im Gegenteil, der Begriff 'Herz' wird nicht nur in Zusammenhang mit Emotionen metaphorisch gebraucht. Der Prozeß, in dem sich die Ausdrücke für Emotionen und des Begriffes 'Herz' in der Form einer Metapher verwirklichen, kann mit dem folgenden Schema skizziert werden:

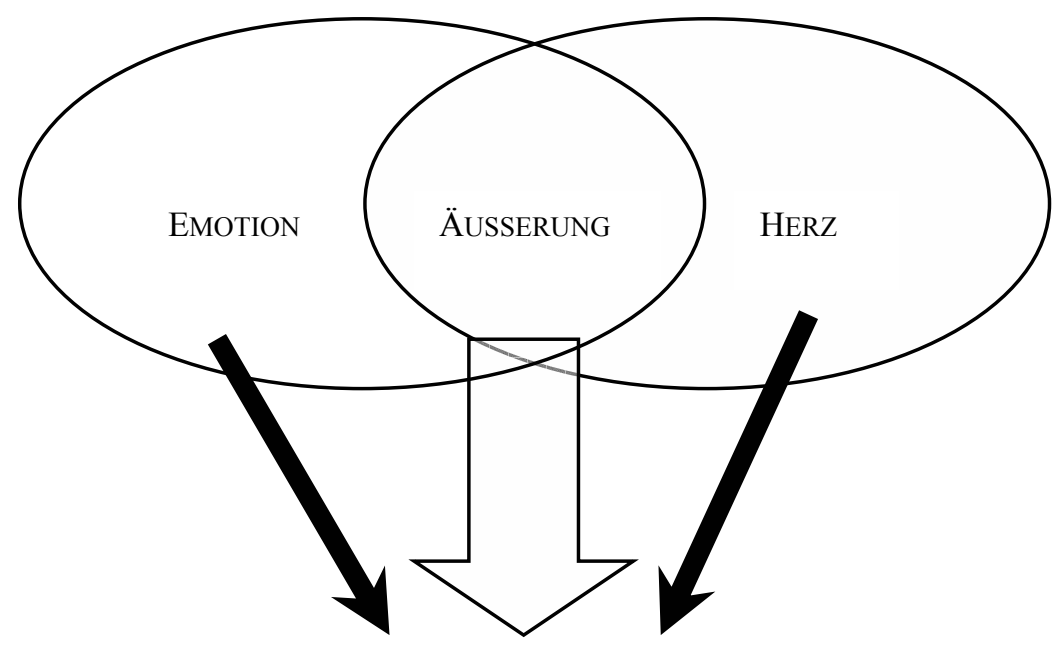

METAPHER

Um diesen Typ der Emotionsmetaphern besser verstehen zu können, werden in der vorliegenden Untersuchung die unterschiedlichen Emotionen und ihre möglichen Reaktionen sowie ihre Definitionen und Klassifikationen dargestellt. Bezüglich des Begriffs 'Herz' werden seine in unterschiedlichen Zeiten und Kulturen bestehenden Konzepte vergleichend vorgestellt.

4 Dazu Pott (1996: 138) und Avalon (1975: 10). 


\subsection{Das Herz in Ägypten}

Über den ägyptischen Begriff des Herzens wurde bereits in der Vergangenheit viel geschrieben. Die erste spezielle Arbeit über das Thema wurde 1930 von Piankoff veröffentlicht. Er bearbeitete die Terminologie des Wortes und sammelte die mit $j b$ und $h 3 i j$ gebildeten Ausdrücke und ihre unterschiedlichen Bedeutungen in verschiedenen Textgattungen. Seine Schlußfolgerungen lassen sich folgendermaßen zusammenfassen:

$\Rightarrow$ Zum philologischen Aspekt: der Terminus hỉtj in Alten und Mittleren Reich bezeichnete das Herz als körperliches Organ von Menschen sowie Tieren, während der Terminus $j b$ sich auf den Verstand und die Seele bezogen habe. Seit dem Neuen Reich wird der Begriff $h 3 t j$ häufiger verwendet. In den koptischen Texten wird $j b$ nicht mehr gebraucht.

$\Rightarrow$ Zum religiösen Aspekt (vor allem in Bezug auf die Pyramidentexte): beide Termini können als Synonyme gebraucht werden.

$\Rightarrow$ Zum philosophischen Aspekt: Das Konzept des Herzens beeinflußte möglicherweise die spätere griechische Philosophie.

Lichtheim (1988: 45) beschrieb das Herz als "einen inneren Motor, Sitz der Willens und der Initiative". Ihr Untersuchungsgegenstand war in erster Linie das Herz, das in den Inschriften des Alten Reichs als zum König gehörig erscheint. Unter seinem Einfluß handelt der König, wobei das Herz die Funktion "Leiter des Königs" angenommen habe. Diesen Prozeß, durch den das Herz zum Leiter wird, versteht Lichtheim als "Entdeckung des Selbst" (1988: 145).

Assmann (1996: 149) definierte das Herz als "das wichtigste und das problematischste Organ des Körpers. Es ist das Wichtigste, weil es das Zentrum der Person bildet und für Kohärenz, Bewußtsein, Identität, Verantwortlichkeit und Zurechnungsfähigkeit sorgt, und es ist das Problematischste aufgrund seiner Unstetigkeit, seiner Neigung zu Unruhe, zum Davonlaufen unter dem Einfluß starker Emotionen und Leidenschaften wie Furcht, Schrecken, Liebesverlangen, Sehnsucht und Heimweh".

Junge (2003: 113-122) vertieft in seiner vor kurzer Zeit erschienen Arbeit über die Lehre Ptahhoteps u.a. die Themen über das Herz. Interessant dabei ist es, nicht nur die unterschiedlichen Wiedergaben von $j b$ (mit einigen von denen stimmen die in dieser Arbeit vorgeschlagenen Übersetzungen und Interpretation überein, z.B.: "Sinn", "Stimmung") als "das Organ der rationalen Einsicht; Geist und Bewußtsein" und " der Ort der irrationalen Regungen" zu übersetzen, sondern auch der Zusammenhang mit der klassischen Philosophie. Junges Interpretation vom Vermögen des "Herzens" Jab $(j b)$ "entspricht in gewisser Weise dem, was in der klassischen Philosophie als Vermögen der "Seele" diskutiert wird" (Junge 2003: 121). Er vergleicht das Konzept der menschlichen Psyche in Ptahhotep mit denen von Platon und Aristoteles. Bei Ptahhotep und Aristoteles kann gesagt werde, daß sie symmetrische Varianten eines Konzepts von der seelischen Innensteuerung bieten. Bei beiden 
wird im Lauf der Jahre eine Gemeinsamkeit auftreten, und zwar die Interpretation des Herzens als Ort der Seele (Junge 2003: 122).

Die oben genannten und viele weitere Arbeiten reflektieren den Umstand, daß das Herz in der ägyptischen Kultur und Literatur ein sehr beliebtes Thema ist. Der Grund dafür liegt in der häufigen Verwendung dieses Begriffes und in seiner Funktion zur Identifikation des Verstands, der Seele, des Charakters und der Gefühle einer Person. Zahlreiche ägyptologische Studien konzentrieren sich auf das Konzept des Herzens als Verstand, und sie beschäftigen sich vor allem mit den Weisheitstexten, wodurch andere Textsorten, in denen das Herz als Ort des Gefühls verwendet wird, unangemessen in den Hintergrund treten.

In dieser Arbeit werden die in den ägyptischen Texten gebrauchten Metaphern mit Hinweisen auf die philosophischen Konzepte und rhetorischen Figuren aus der klassischen Literatur (z.B. Quintilian oder Aristoteles) sowie anhand der modernen wissenschaftlichen Arbeiten von Autoren(inn)en wie Wierzbicka oder Ricoeur analysiert. Speziell für Metaphern in ägyptischen Texte wird auf das Werk von Grapow (1924) über die bildlichen Ausdrücke zurückgegriffen. Er sammelte zahlreiche Beispiele für Metaphern sowie für Vergleiche und ordnete sie nach zwei Klassifikationsgruppen, nämlich 'Natur' und 'Menschen'. Diese beiden Konzepte wurden von ihm als tertium comparationis oder, wie es in der neueren allgemeineren Literatur heißt, Vehikel angewendet. Obwohl die Arbeit von Grapow zahlreiche Beispiele enthält, fehlt bei ihm eine gründliche Interpretation der Metaphern, die nur oberflächlich erklärt wurden. Aus diesem Grund kann Grapows Zusammenstellung Arbeit lediglich als Einführung in dieses Thema verstanden werden.

\subsection{Die Gattungen ${ }^{5}$}

\subsubsection{Zum Problem des Gattungsbegriffs}

Die Definition der ägyptischen Literatur und deren Einteilung in Gattungen wurde und wird heute noch kontrovers diskutiert. ${ }^{6}$ Während man sich früher damit begnügte, alles, was schriftlich fixiert wurde, als Literatur anzusprechen, ${ }^{7}$ erreichte die Diskussion mit der Rezension der Abteilung Literatur des Handbuches der Orientalistik von Assman (1974) ab den 70er Jahren eine Wendung hin zu einer literaturwissenschaftlichen Professionalisierung. Die Auslegung der Literatur - unabhängig von der Gattungsfrage - wurde je nach der

5 Die Klassifikation der literarischen und nicht-literarischen Texte, nach Gattungen ist kein einfaches Thema. Deswegen ist die Bemerkung wichtig, daß weder eine Definition des literarischen Textes noch die Gattung das Ziel dieser Doktorarbeit ist. Die Behandlung der Texte in verschiedenen Gruppen erfolgte zunächst allein nach praktische Gesichtspunkten. Allerdings stellt sich später heraus, daß sich je nach vorläufiger Textsorte durchaus eine spezifische Verwendung der Lexeme für 'Herz' abzeichnet. Das zeigt, daß die Unterteilung wohl doch gewisse historische Realitäten wiederspiegelt.

6 Siehe Loprieno (1996).

7 Brunner (1980); Burkard (1993). 
historischen oder politischen Informationen der Quelle vorgenommen. Einerseits wurden die literarischen Texte gemäß ihres politischen Inhalts als Medien einer Propaganda angesehen. ${ }^{8}$ Andererseits wurden sie gemäß der historischen Frage mit zwei Konzepten, nämlich Realität und Fiktionalität, in Verbindung gebracht. ${ }^{9}$

Durch den Systematisierungsversuch von Assmann (1974) entwickelte sich eine theoretische Auseinandersetzung mit der ägyptischen Literatur. Er unterschied zwischen Gebrauchstexten und funktionalen Texten. Nach Assmanns Modell schlug Baines (1982: 3144 und 1990: 55-72) seit den 80er Jahren einen neuen Weg für die Interpretation der narrativen ägyptischen Texte vor, der in Verbindung mit dem amerikanischen New Criticism steht. Parkinsons Definition aus den 90er Jahren (1996: 137-155 und 1999: 63-82), die von dem New Historicism beeinflußt ist, konzentrierte sich auf den Kontext und die Funktionalität der Texte. Seine Arbeit basiert auf dem von Posener (1951: 27-48 und 1952: 117-120) zusammengestellten Textkorpus, das die ägyptische Literatur primär in Weisheitstexte und Erzählungen einteilte.

Unter Zuhilfenahme theoretische Überlegungen aus anderen Disziplinen vertiefte sich die Debatte über die Literarizität ägyptischer Texte. So fand das Modell von Iser (1989: 108-228; 1990; 1991: 13-16 und 504-515), in dem die Anthropologie berücksichtigt wurde, auch in der Ägyptologie Anwendung. Der Begriff "Fiktion" ist auf der Grundlage dieses Modells anhand der ägyptischen Reiseerzählungen von Moers eingehend diskutiert worden. ${ }^{10}$

Die in dieser Arbeit bearbeiteten Texte lassen sich also in Übereinstimmung mit neueren ägyptologischen Studien als Literatur im eigentlich Sinne beschreiben. Es handelt sich dabei um die drei folgenden Gattungen: ${ }^{11}$

(1) Weisheitstexte,

(2) Liebeslieder,

(3) Erzählungen.

8 Posener (1956); Williams (1964: 14-39); Helck (1972); Thériault (1993: 151-160); Parkinson (1996: 139ff.); id. (1999: 72 f.); Simpson (1996: 435-443); Loprieno (1996: 521).

9 Moers (2001: 38 f.) mit weitere Literatur.

10 Moers (2001: 19ff.).

11 Die Klassifizierung der ägyptischen Texte im Zusammenhang mit dem Thema dieser Arbeit stellt eine Problematik aufgrund der zahlreichen Belege und der Gattungsfrage dar. Da der Begriff "Herz" gebraucht wurde, um Charaktereigenschaften auszudrücken, schlug Assmann (1996: 145) die folgenden Gattungen gemäß der Art der Äußerung über die ägyptischen Vorstellungen der Identität und Integrität vor:

$\Rightarrow$ Hymnen, die sich auf die Personalität einer Gottheit beziehen.

$\Rightarrow$ "Verklärungen", die sich auf die Personalität eines Toten beziehen.

$\Rightarrow$ Flüche, Bedrohung und Beschimpfungen, die sich auf eine lebende Person sowie auch auf feindliche Dämonen und Götter beziehen.

Der Grund, sich nicht für die von Assmann vorschlagenden Gattungen zu entscheiden, liegt am Thema dieser Arbeit, in der der Begriff "Herz" nicht nur im Zusammenhang mit Charaktereigenschaften gebracht wird, sondern auch mit den Emotionen, dem Willen oder der Seele u.a. 
Der Inhalt der Weisheitstexte unterscheidet sich deutlich von dem der Liebeslieder. Ob die in dieser Arbeit ausgewählten Erzählungen, wie die Erzählung des Sinuhe, des Wenamun und des Schiffbrüchigen sowie die Zweibrüdergeschichte und der beredte Oasenmann, als Gattung definiert werden können, ist der Kern einer noch längst nicht abgeschlossenen literaturwissenschaftlichen Diskussion, die in dieser Arbeit nicht berücksichtigt wird. Die drei hier behandelten Textsorten werden als eher lose Gruppierungen gemäß ihres Inhalts verstanden.

\subsubsection{Die Weisheitstexte ${ }^{12}$}

Die Weisheitstexte haben im Ägyptischen eine eigene Bezeichnung, nämlich sbjj.t. ${ }^{13}$ Diese Art von Texten werden durch ihren Inhalt charakterisiert ${ }^{14}$, in denen die Verhaltensweisen eines Menschen in Zusammenhang mit der Gesellschaft beschrieben werden. Eine wichtige Rolle dabei spielt das universale Ordnungsprinzip, genannt Maat. ${ }^{15}$ Die hier vorgestellten Lehren werden entweder ins Mittlere Reich oder ins Neue Reich datiert. In den frühesten Vertretern ${ }^{16}$ dieses Genres ist das Ziel, das Muster eines idealen Menschen sowie die Regeln des Benehmens, der Höflichkeit und der Etikette der politischen Gesellschaft darzustellen. Nach den Umwälzungen am Ende des Alten Reiches und im Lauf der Ersten Zwischenzeit dienten die Weisheitstexte dazu, die folgenden politischen Veränderungen festzustellen. Im Mittleren Reich wird die Loyalität zum Königtum thematisiert, wobei die Lehren z.B. des Amenemhets I. oder die für Merikare als Vorbild für die Nachfolger gedacht sind. In Neuem Reich tritt die Frömmigkeit als das zentrale Thema der Lehren auf. ${ }^{17}$ Der Mensch handelt gemäß Gottes Willen, wobei das Maatprinzip in Gott personalisiert wird. Die Lehren aus dem Korpus der Weisheitstexte bildeten nicht nur einen wesentlichen Gegenstand der ägyptischen Erziehung, sondern es wurden auch Passagen von ihnen in Autobiographien, Erzählungen oder königlichen Dokumenten verwendet.

\subsubsection{Die Liebeslieder ${ }^{18}$}

Eine ganz andere Gattung stellen die Liebeslieder dar, die durch intensive Gefühlsausdrücke charakterisiert sind und vor allen in der Epoche vom Beginn der 19. bis zur zweiten Hälfte der 20. Dynastie ${ }^{19}$ überliefert wurden. Sie stammen aus dem thebanischen Bereich und sind durch fünf Textzeugen bzw. -gruppen überliefert, nämlich pHarris $500^{20}$, Liebeslieder Kairo ${ }^{21}$,

12 Siehe unter Lehre, in: L̈̈ III, 964-992.

13 Brunner (1988); Hornung/Keel (1979); Burkard (1977).

14 Loprieno (1988: 15, 18 und 85); Assmann (1974: 118-126).

15 Assmann (1988: 98 und 1990).

16 Zur Datierung der Lehre des Ptahhoteps siehe Junge (2003: 146 Anm. 2).

17 Sternberg el-Hotabi (1991: 192).

18 Siehe Schlichting, in: $L \ddot{A}$ III, 1048-1054.

19 Zur Datierung siehe Fox (1985: 182, 195 ff.).

20 Budge (1923: pl. 41-46); Fox (1985: 370-382 und 26); Schott (1950: 46 und 56); Hermann (1959: 142); Lichtheim (1973-80, II: 190). 
pTurin $1966^{22}$, pChester Beatty $\mathrm{I}^{23}$ und eine der sogenannten Miscellanies (pAnastasi II, vso $5,1^{24}$ und Ostraka aus Deir el-Medineh). ${ }^{25}$ Die Texte wären nach Fox oder Assmann als Literatur zur Unterhaltung (shmhm-j $b^{26}$ ) zu bezeichnen. ${ }^{27}$ Guglielmi (1996: 342) vermutet, daß die Bezeichnung ganz allgemein die thematisierten Erscheinungen dieser "Gegenwelt" zum Berufs- leben der ägyptischen Elite wiederspiegelt. Die Themen dieser Gattung sind u.a. die Einzigartigkeit der oder des Geliebten, die Schönheit oder die Sehnsucht nach der oder dem Geliebten. ${ }^{28}$ Zentraler Gegenstand sind die Liebe und die Leidenschaft der geliebten Personen. Ihre Gefühle, Wünsche und Hoffnungen werden beschrieben. Gedichte zeichnen sich durch einen besonderen Stil aus. ${ }^{29}$ In den ägyptischen Liebesliedern stehen die beiden Geliebten miteinander im Dialog, in dem sie ihre emotionalen Zustände äußern. Das Ziel dieser Texte ist nicht, eine Moral zu vermitteln, von der eine Belehrung erwartet wird. Die Intention der Gedichte ist eher künstlerischer Natur denn pragmatisch. Das Auftreten der Liebespoesie ist im Wesentlichen auf das Neue Reich beschränkt, was Fox (1985: 183-184) mit der Revolution der Amarna-Zeit begründet, in der man selbst familiäre Situationen des Herrscherhauses mit einer Art Intimität darstellte. Das Ergebnis davon sei eine spontanere und flüssigere Literatur und Kunst gewesen. ${ }^{30}$

Es ist auch vermutet worden, daß für die Herausbildung der Textsorte "Liebeslied" vorderasiatischer Einfluß verantwortlich gewesen sein könnte. ${ }^{31}$

In Zusammenhang mit den Liebesliedern müssen die Hafnerlieder gestellt werden, obwohl hier nur das Hafnerlied des Antef behandelt wird (L-10). Diese Gattung läßt sich mit dem Totenkult in Verbindung bringen. Lichtheim (1945) behauptet, daß die Szene des Banketts und des Liedes einen funerären Charakter besitzt. Diese Auffassung wird von Fox (1982) später geteilt. ${ }^{32}$ Die Quellen stammen aus dem Mittleren Reich, der XVIII. Dynastie, der Amarnazeit und der Post-Amarnazeit. Sie befinden sich in Gräbern; besonders wichtig sind

21 Fox (1985: 29-44); Davis (1980: 111-114).

22 Fox (1985: 389-393); López (1992: 133-143); Schott (1950: 58); Vernus (1992: 83).

23 Gardiner (1935); Fecht (1963: 71-74); Assmann (1991: 899-904); Fox (1985: 200).

24 Erman (1901: 147); Fox (1985: 78).

25 Borgouths (1983: 113); Meeks in: LÄ III, 1048f.; Hermann (1959: 4-8).

26 "Herzenserheiterung", "Herzensfreude", "Sprüche der großen Herzensfreude" oder "Lieder der Herzensfreude", siehe Kapitel 6.3 Die Erheiterung des Herzens.

27 Fox (1983: 289 und 367, Anm. 37); id. (1985: 55); Assmann (1991: 900); Fisher-Elfert (1992: 72 f.).

28 Siehe Guglielmi (1996: 343-344) mit weiterer Literatur dazu.

29 Larthomas (2001: 446).

30 Siehe Kapitel 6.1 Die ägyptischen Liebeslieder.

31 Goldwasser nach mündlicher Mitteilung.

32 Siehe Kapitel 6. shmh-jb. 
das Grab des Neferhotep (TT 50) ${ }^{33}$ aus der XVIII. Dynastie und das Grab des Djehutimes (TT 32). ${ }^{34}$

\subsubsection{Die Erzählungen ${ }^{35}$}

Die in dieser Arbeit unter dem Titel "Erzählungen" gesammelten narrativen Texte bilden an sich keine völlig homogene "Gattung". ${ }^{36}$ In Unterschied $\mathrm{zu}$ den anderen beiden hier behandelten Textgruppen, den Weisheitstexten und den Liebesliedern stellen die unter dieser Bezeichnung gesammelten Texte Geschichten dar. Der Inhalt von ihnen - unabhängig von einer Fiktionalität - besteht aus einer vermutlich alltäglichen Lebensart der Ägypter. Es werden Situationen dargestellt, in denen die Verhaltensweise und Emotionen eines Menschen oder Gottes beschrieben werden. All dies wird durch eine narrative Form mit Dialogen - und manchmal auch Kommentaren - eines Erzählendens mitgeteilt.

\subsubsection{Eine Hypothese a priori}

Die Untersuchung der ägyptischen Texte wird in dieser Arbeit aus zwei Gründen eingegrenzt:

Die bloße Zahl der ägyptischen Texte macht es unmöglich, daß sie in ihrer Gesamtheit ausgewertet werden können.

$>$ Der gewaltige diachronische Kontext ist auf einen immer noch umfangreichen Ausschnitt, nämlich den Zeitraum vom Alten Reich bis zum Neuen Reich eingegrenzt worden.

Aus diesem Grund wurden bestimmte Gattungen ausgewählt, um sie genauer untersuchen zu können und gleichzeitig die Arbeit überhaupt in einem vernünftigen Umfang zu Ende zu bringen. Die Wahl der drei vorgestellten Gattungen - Lehren, Liebeslieder und Erzählungen beruht auf folgenden Gründen:

$>$ Die sehr unterschiedlichen Inhalte der Texte sollten ein gewisses Spektrum an unterschiedlichen Texten abdecken, um zu vermeiden, womöglich nur wenige, textsortenspezifische Beispiele zu finden.

$>$ Einige a priori Hypothesen über das mögliche Ergebnis könnten folgendermaßen aussehen:

- In den Weisheitstexten sollten eher wenige Emotionen vorkommen, da Emotionen normalerweise nicht gelernt, sondern von einer Person empfunden werden und in komplexen Gesellschaften vielleicht damit $\mathrm{zu}$ rechnen ist, daß Emotionen im "öffentlichen Leben" (das der Hauptgegenstand der ägyptischen Lehre ist) nicht unkontrolliert vorkommen sollen.

33 Osing (1992).

34 Kakosy \& Fabian (1995: 211-225).

35 Siehe Brunner, in: $L \ddot{A}$ III, 1067-1072.

36 Siehe dazu Loprieno (1996). 
- In den Liebesliedern sollten, wenn typologische Ähnlichkeiten mit entsprechenden Beispielen gemäß der europäischen Kultur und Literatur vorhanden sind, zahlreiche Herzmetaphern vorkommen.

- Die Erzählungen sollten eine mittlere Position zwischen den oben genannten Gattungen einnehmen, da in ihnen die Emotionen durch die Erfahrung eines Menschen beschrieben werden.

\subsection{Struktur der Arbeit}

Die folgende Arbeit ist in zwei Hauptteile gegliedert: drei Kapitel behandeln den Begriff 'Herz', die Metaphern und die Emotionen in einer allgemeineren Perspektive; drei weitere Kapitel besprechen die ägyptischen Texte. Diese Struktur ermöglicht, zuerst einen Überblick über die wichtigsten Konzepte zu gewinnen, um dadurch die ägyptischen Texte besser analysieren zu können.

Die Übersetzungsvorschläge werden allesamt durch Glossierungen erläutert. Im Fließtext werden für die Beispiele die Siglen W (für Weisheiten), L (für Liebeslieder) und $\mathbf{E}$ (für Erzählungen) verwendet, damit ihre Übersetzung und Glossierung im Anhang des entsprechenden Kapitels einfach gefunden und überprüft werden kann. Die mit Asterisk versehenden Beispiele enthalten das Lexem ḩitj.

Der Inhalt der einzelnen Kapitel läßt sich folgendermaßen zusammenfassen:

- In Kapitel 2 werden die unterschiedlichen Bedeutungen der Worte für 'Herz' in verschiedenen ausgewählten alten und modernen Sprachen und Kulturen dargestellt, mit dem Zweck, die zeit-, raum- und sprachübergreifenden Ähnlichkeiten des Wortsinnes zu belegen.

- In Kapitel 3 werden einige neuere Ansätze zu einer Theorie der 'Metapher' vorgestellt und Definitionen sowie Klassifikationskriterien für Metaphern geboten.

- In Kapitel 4 werden Emotionen analysiert. Ausgehend von dem Unterschied zwischen Emotion und Charakter, wird eine Definition versucht. Es wird das Konzept der Emotion im Zusammenhang mit dem Individuum und mit unterschiedlichen Kulturen dargestellt, ebenso wie die unterschiedlichen vorgeschlagenen Klassifikationen (basic emotions) der Emotionen. Besondere Beachtung kommt der körperliche Reaktion einer Person auf eine Emotion zu, die mit der ägyptischen Beschreibung einer möglichen emotionalen Reaktion verglichen wird. Dafür wird auch der Zusammenhang zwischen der Emotion eines Individuums und seiner Äußerung untersucht, die möglicherweise in Form einer Metapher erscheinen kann. Der gegenseitige Einfluß dieser drei Konzepte - Emotion, Metapher, Sprache - wird ebenso berücksichtigt. 
- In Kapitel 5 werden einschlägige Passagen ägyptischer Weisheitstexte behandelt. Dabei werden Übersetzungen und Glossierungen sowie Kommentare zu den in ihnen enthaltenen Emotionen und Metaphern geboten.

- In Kapitel 6 werden die Liebeslieder nach demselben Schema wie die Weisheitstexte untersucht.

- In Kapitel 7 werden die Erzählungen vorgestellt. Auch hier stehen die Beispiele am Ende des Abschnitts.

- Das Kapitel 8 enthält die Schlußfolgerungen, die sich als Resultat der Untersuchung ergeben haben.

- Am Ende der Arbeit wird ein Anhang in Form eines Wörterbuches angeschlossen, der die mit den Wörtern $j b$ und $h i ̉ j$ gebildeten Ausdrücke enthält.

\subsection{Hinweis zur grammatischen Aufbereitung und philologischen Erklärung der Textbeispiele}

$\mathrm{Da} ß$ die in dieser Arbeit übersetzten ägyptischen Texte aus einem langen, vom Alten Reich bis zum Neuen Reich reichenden, Zeitraum stammen, macht sich auch an der Glossierung bemerkbar.

- Das präteritale, adverbiale oder nominale $s \underline{d} m . n=f$ des Alt- und Mittelägyptischen wird durch PRÄT. glossiert, während das neuägyptische präteritale $s \underline{d} m=f$ als PAST. notiert ist.

- Das alt- und mittelägyptische $j w$ wird als (dummy) Topik (TOP.) analysiert, während es im Neuägyptischen eine andere Funktion besitzt und bei seiner Verwendung als Konverter durch CONVRT., beim Auftreten als Teil der Konjugationsbasis für das Präsens I oder Futur III durch KB. verkürzt wird.

Die Glossierung für das Wort ḩ̉tj muß ebenfalls erklärt werden. In den Texten wird es einfach als Substantiv (SBST.) glossiert. Da das Wort als eine Ableitung von dem femininen Substantiv ḩ3.t (Nisbe-Adjektiv) aufzufassen ist oder zumindest aufgefaßt werden kann, sollte die Glossierung eigentlich SBST.-FEM.-ADJVR. lauten. Aufgrund des häufigen Auftretens des Wortes in den Texten und aus Platzgründen wird es als SBST. abgekürzt. 



\section{Kapitel}

\section{DAS HERZ}

Herz: (engl.) heart; (anat.) Cor, Cardia; muskuläres Hohlorgan mit d. Aufgabe, durch wechselnde Kontraktion (Systole) u. Erschlaffung (Diastole) v. Vorhöfen und Kammern den Blutstrom in den Gefäßen in Bewegung zu halten; liegt umgeben vom Herzbeutel im Mediastinum auf d. Zwerchfell u. zw. den Lungen. Durch e. Scheidewand (Septum) wird das Herz in eine linke (linkes H.) u. eine rechte Hälfte (rechtes H.) geteilt, jede Hälfte wieder in eine obere, muskelschwächere Abteilung, Vorhof (Atrium), u. eine untere, muskelstärkere Abteilung, Kammer (Ventriculus; dabei ist die linke Kammer muskelstärker als die rechte). Die Grenze zw. Vorhof und Kammer ist außerdem gekennzeichnet durch den Sulcus coronarius, die Grenze zw. den Kammern durch die Längsfurche (Sulcus interventricularis ant. u. post.); in den Furchen verlaufen die ernährenden Gefäße des Herzens, die Koronararterien bzw. -venen. Drei Schichten der Herzwand: Herzinnenwand (Endokard), Mittelschicht (Myokard) u. Außenschicht (Perikard). In die Vorhöfe münden rechts die V. cava sup. u. inf. sowie der Sinus coronarius, links die Vv. pulmonales. Aus den Kammern treten rechts der Truncus pulmonalism, links die Aorta aus. Das Herz besitzt vier Klappen (Valva cordis), Endokardduplikatoren, die am Herzskelett angeheftet sind. Die Segelklappen (Valva atrioventricularis dextra u. sinistra) sind Verschlußeinrichtungen zW. Vorhöfen u. Kammern; rechts dreizipflig: (Valva) Tricuspidalis, links zweizipflig; (Valva) Mitralis. Die freien Ränder der Klappensegel sind durch die sehnigen Chordae tendineae mit den Papillarmuskeln verbunden, deren Kontraktion ein Rückschlagen der Klappen in die Vorhöfe während der Systole verhindert. Die Taschenklappen (aus je drei halbmondförmigen Semilunarklappen bestehend) sitzen am Beginn des Truncus pulmonalis u. der Aorta: Valva trunci pulmonalis u. Valva aortae (Pulmonalis-, Aortenklappe). Sie verhindern während der Diastole den Rückstrom des Bluts in d. Kammern. Vgl. Herztöne, Erregungsleitungssystem, Muskelgewebe, Herzohren, Blutkreislauf.

(Pschyrembel Klinisches Wörterbuch, 257., neu bearbeitete Auflage, bearbeitet von der Wörterbuch-Redaktion des Verlages unter der Leitung von Helmut Hildebrandt, Berlin \& New York: Walter de Gruyter 1994: 618-619)

\subsection{Skizze einer Begriffsbestimmung}

Wer erfahren möchte, was das Herz ist, und zu diesem Zweck ein modernes medizinisches Wörterbuch konsultiert, stößt auf Definitionen, die etwa so aussehen mögen wie das diesem Abschnitt vorangestellte Zitat. Dabei handelt es sich freilich um eine fachsprachliche Begriffsbestimmung, die in ihrer um Exaktheit bemühten Detailgenauigkeit deutlich über das sprachliche und sachliche Standardwissen medizinischer Laien hinausgeht und für die in dieser Studie verfolgten Ziele einerseits - hinsichtlich der anatomischen Aspekte - unnötig minuziös ist, während sie andererseits alle nicht-physiologischen Gesichtspunkte vollständig unberücksichtigt läßt.

Allgemeine Nachschlagewerke definieren das Substantiv Herz als Ausdruck für das Organ, das "beim Menschen und bei verschiedenen Tiergruppen das zentrale 
Antriebsorgan des Blutkreislaufes" (Wahrig 2000: s.v. Herz ) darstellt. Das ist zweifellos so etwas wie eine alltagssprachliche Grundbedeutung, allerdings besitzt das neuhochdeutsche Wort Herz noch weitere Verwendungsweisen, je nachdem ob man es als Organ oder als Seele der Person versteht. So läßt sich etwa nach Auskunft des Dudens (1989 s.v. Herz) zwischen einem kardiologischen und einem kordiologischen Herz unterscheiden. Im kardiologischen (physiologischen) Sinn steht Herz für "das Organ, das den Blutkreislauf durch regelmäßige Zusammenziehung und Dehnung antreibt und in Gang hält", das kardiologische Herz kann also pumpen oder versagen, palpiert, askultiert, biopsiert oder sogar transplantiert werden. Im kordiologischen Gebrauch hingegen enthält Herz in erster Linie metaphorische Bedeutungen, so daß man sagen kann "das Herz singt, lacht, jubelt, weint, erwacht, erblüht, klagt, bebt, zerspringt, blutet, schlachtet, bricht, wird geschenkt, ausgeschüttet, verloren, im Sturm erobert. Es ist treu, trotzig, falsch, abgründig, sitzt am rechten Fleck, aber zittert auch, oder dreht sich gar im Leibe herum" (Nager 1993: 27).

Das Herz gilt also nicht nur als der biologische, sondern auch als der moralische und emotionale Mittelpunkt des Menschens. Dieses Phänomen begegnet nicht nur in unseren modernen Gemeinschaften, sondern läßt sich durch viele Zeiten hindurch im Gedankengut verschiedener Kulturen belegen. Beispielsweise erwähnt Schipperges (1989: 145) eine Textstelle am Anfang eines Traktates des altdeutschen Codex Germanicus Monacensis 835 mit dem Titel Das geistlich Kloster, die lautet: "Ein friedsam Herz ist ein geistlich Kloster/ drinnen Gott selber der Abt ist/ Bescheidenheit ist darin die Äbtissin." Die Bedeutungen und Verwendungsweisen von Herz sind überaus vielfältig, weswegen sie in dieser Arbeit in mehreren Abschnitten vorgestellt werden. Zunächst wird eine Auswahl deutscher Ausdrücke mit dem Wort Herz präsentiert, in einem zweiten Abschnitt wird exemplarisch auf die Bedeutung und Verwendung der unserem Herz entsprechenden Wörter in anderen Kulturen und Sprachen eingegangen; und zum Schluß werden einschlägige Beispiele aus ägyptischen Quellen gebracht.

\subsection{Das Herz in Kollokationen und Redensarten des Deutschen}

Die Anzahl von Kollokationen (konventionalisierten Mehrwortausdrücken), Sprichwörtern und Redensarten, in denen das Herz eine Rolle spielt, ist außerordentlich groß. Schipperges sammelt in seiner Arbeit über das Herz (1989: 13-15) zahlreiche solcher Ausdrücke, von denen einige hier wiedergegeben werden:

"Für das modische «Oben ohne» zum Beispiel sagt man im Oberdeutschen: «mit bloßem Herzen gehen». Und wem das Herz voll ist, davon geht der Mund über oder aber die Augen, man kann und man muß sein Herz öffnen, aber auch verschließen. Es kann einer oder eine einem ans Herz wachsen; es wird jds. Herz an etwas hängen, sich ein Herz fassen. 
Die Angst will einem das Herz abschnüren; der Gram frißt das Herz ab. (...) Man kann aber auch ganz «nach eines Herzen» sein, ad voluntatem alicuius, wie der Lateiner sagt. Man läßt sein Herz bei jemandem oder aber reißt ihn aus seinem Herzen. Man packt eine Aufgabe mit ganzem Herzen oder erledigt sie nur halbherzig. Man nimmt sein Herz in beide Hände, besonders wenn einem die Sache am Herzen liegt. Dazu stehen wir dann mit Herz und Mund; sind dabei ein Herz und eine Seele. Man legt die Hand aufs Herz, will man etwas «aus vollem Herzen» bezeugen; man tut's von Herzen gern, meint es herzlich gut, kann herzhaft reden, sich freuen herzinniglich.

(...)

Es gibt Zustände, die einem nun wirklich «zu Herzen gehen»; oft genug hat man etwas «auf dem Herzen» oder «nimmt sich ein Herz» oder verschließt es im Herzen. Dann fällt es sich aufs Herz, oder es wird wieder leichter ums Herz. Eine Last liegt auf dem Herzen, ein Stein fällt vom Herzen; das Herz ergießt sich; man schüttet es aus, das liebe Herz. Das Herz erkaltet schließlich im Leibe. Der Mensch stirbt, wenn der Tod ihm ans Herz tritt, (...).

Das Herz wird groß, der Mensch großherzig. (...) Da erscheint es nun in voller Fülle: das Vaterherz, das Mutterherz, ein Bruderherz, die Herzensfrau, das Herzenskind, der Herzensfreund. (...) Worte wie: Herzensergießung, Herzfrömmigkeit, Herzgedanke, Herzspiele, Herzgespräch, Herzschrein, Herztür, herztreulich, Herzverdruß, Herzvergnügen, Herzzwinge oder auch herzvielgeliebt."

Einer von diesen Begriffen, Herzleid, wurde bereits im Jahr 1735 in Johann Heinrich Zedlers Universal-Lexicon mit den Worten "ein Leid oder Schmerz, welcher das Herz oder Gemüth betrifft, zum Unterschied von körperlichen Schmerzen" (Zedler \& von Ludewig 1735: Bd. 12: 1819-1822 ) auf eine Weise beschrieben, die den grundlegenden Gegensatz zwischen den kardiologischen und den kordiologischen Verwendungsweisen des Substantivs herausstellt. Zur Wortbedeutung gehören auch Nuancen von Kummer, Traurigkeit oder Betrübnis.

Im Grimmschen Wörterbuch (1877: 1207-1293) werden die verschiedenen Bedeutungen des Worts Herz in zwei Hauptgruppen eingeordnet. Das sieht folgendermaßen aus:

I. im eigentlichen Sinne, an Menschen und Tieren

(1) als Mittelpunkt des menschlichen Leibes,

(2) Herz oder Brust,

(3) als Sitz aller Lebenskraft,

(4) Gemütsbewegung als Sitz des Gefühls, Leidenschaft, Liebe, Hasses,

(5) Verstand, Kopf, Sitz des Verstandes, Gedanken,

(6) Sitz des Mutes, Entschlossenheit, Tatkraft.

(7) Meinung,

(8) Überlegung, selbst,

II. (1) Mittelpunkt von etwas,

(2) der Kern eines Volkes, die besten.

Daß das Herz nicht nur im deutschen Sprachraum, sondern auch in anderen Ländern als das Zentrum aller Gemütsbewegungen, Leidenschaften, Freundschaften und Emotionen gilt, läßt sich anhand von Sprichwörtern demonstrieren, die das Herz zum Gegenstand haben. Einige von den mehr als fünfhundert Redewendungen, die in einem deutschen Sprichwörterlexikon 
des 19. Jahrhunderts (Wander 1867) mit Entsprechungen in anderen europäischen Sprachen falls eine solche existiert - verzeichnet sind, werden hier wiedergegeben.

- "Auf einem traurigen Herzen steht kein fröhlicher Kopf" ; vgl. dänisch "Et sorrigfuld hierte er sielden glad" (Wander 1867: 602, Nr. 2).

- "Das Herz macht Freud und Leid"; vgl. französisch "Quine peut faire son salut par coeur ne le fera par livre" (Wander 1867: 604, Nr. 48).

- "Ein zufrieden Herz ist ein reicher Schatz; vgl. französisch "Coeur content, grand talent" (Wander 1867: 608, Nr. 162).

- "Einem frölichen Hertzen ist alles frölich, was es sihet"; vgl. lateinisch Gaudium plenum est cor serenum" (Wander 1867: 608, Nr. 166).

- "Ein frisches Herz besiegt den Schmerz"; vgl. spanisch: "Buen corazon quebranta mala ventura" (Wander 1867: 605, Nr. 89).

- "Ein unruhig Herz und ein guter Schlaf wohnen nicht unter einem Dach"; vgl. niederländisch "Een ongerust hart slaapt zelden wel" (Wander 1867: 607, Nr. 148).

Im Kontext der abendländischen Sprachen und Kulturen zeigen die Gebrauchsweisen des jeweiligen Wortes für 'Herz' viele Übereinstimmungen. Es sind in verschiedenen Sprachen immer wieder sehr ähnliche Bedeutungskonzepte, die durch Ausdrücke mit dem jeweiligen Wort für 'Herz' gebildet werden, und oft werden sogar einander lexikalisch mehr oder weniger genau entsprechende Ausdrücke in unterschiedlichen Sprachen im gleichen Sinn verstanden. Die nachstehend aufgeführten spanischen Kollokationen zeigen das in aller Deutlichkeit:

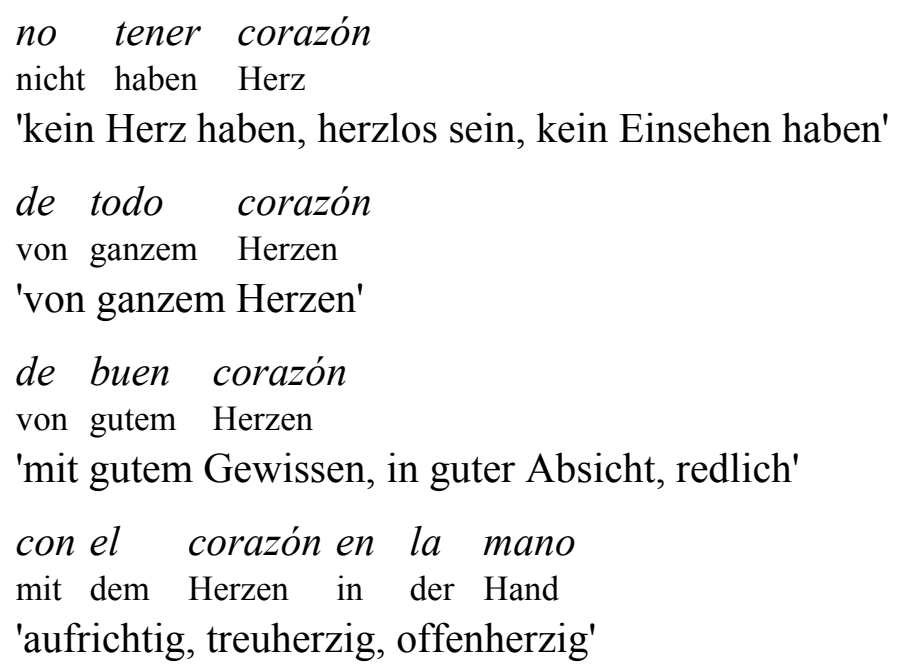

Manchmal geht die Übereinstimmung zwischen dem Spanischen und dem deutschen bis zur lexikalischen und morphologischen Gleichheit wie in den ersten beiden Beispielen. Andere 
Konzepte werden in den einzelnen Sprachen zwar idiomatisch etwas anders ausgedrückt, weisen aber dennoch signifikante Gemeinsamkeiten auf und deuten an, daß man zumindest im Umfeld der abendländischen Kulturen mit einem gewissen Maß an Homogenität zu rechnen hat.

Man geht davon aus, das Substantiv Herz - bzw. seine Entsprechungen in anderen Sprachen - und die damit gebildeten Ausdrücke seien ein wichtiges und sehr oft benutztes Mittel, um metaphorische Aussagen zu machen. Wir benutzen vermutlich häufiger Metaphern, die sich auf das Herz beziehen, als uns bewußt ist. Unser Herz spricht und hört, genau wie in der altägyptischen Literatur. Es ist nicht nur ein Organ mit bestimmten körperlichen Funktionen, sondern auch ein Teil von uns, ohne den unser Leben nicht den gleichen Sinn hätte. In vielen Ausdrücken ist überhaupt nur die metaphorische Lesart gebräuchlich und sinnvoll. So besitzt etwa die Kollokation jemand hat kein Herz normalerweise ausschließlich eine metaphorische Bedeutung, nämlich 'gefühllos' im Gegenwartsdeutschen oder 'ein Dummkopf sein' im Ägyptischen. Im folgenden Abschnitt wird dieser Gegenstand anhand einiger Beispiele etwas eingehender beleuchtet.

\subsection{Das Herz in einigen alten Sprachen}

\subsection{1 'Herz' im Indoeuropäischen und im Afroasiatischen}

Um sowohl die bisherigen Darlegungen zum Deutschen wie auch die späteren Ausführungen zur Rolle des Herzens in der ägyptischen Sprache in einen breiteren Kontext einordnen zu können und einen stärker für Generalisierungen brauchbaren Überblick über die Rolle des Herzens und die Verwendung der jeweiligen Wörter und Ausdrücke zu erhalten, werden hier Befunde aus Bereichen angeführt, die den ägyptischen Quellen chronologisch näher stehen als unsere modernen Sprachen. Man sollte nicht vergessen, wie weit die Sprache der Ägypter zeitlich von unseren heutigen Sprachen entfernt ist, und man kann es deshalb nicht von vornherein ausschließen, daß sich die Befunde womöglich ganz grundsätzlich von dem unterscheiden, was eine Analyse der gegenwärtigen Verhältnisse an Ergebnissen erbringt. Sodann müssen wir angesichts des hohen Grads an Übereinstimmungen zwischen den Verwendungsweisen in den modernen europäischen Sprachen auch damit rechnen, daß es sich hierbei um die Ergebnisse jahrhundertelanger gemeinsamer Geschichte und Kontakte handelt, die alles andere als repräsentativ sein können. Da die Übersicht sich auf afroasiatische und indoeuropäische Sprachen beschränkt, bleiben wir zwar immer noch im Rahmen eines im Weltmaßstab verhältnismäßig begrenzten Großareals, innerhalb dessen ebenfalls mit wechselseitigen Beeinflussungen in der einen oder anderen Richtung gerechnet werden muß, doch erschien eine universale Behandlung aus zweierlei Gründen nicht praktikabel. Zunächst ist für die Beschränkung die ganz simple Ursache verantwortlich, daß ich keinerlei Kompetenz in Spra- 
chen anderer Regionen besitze und mich nicht auf kaum kontrollierbare Darstellungen aus zweiter oder dritter Hand verlassen möchte. Man kann die Begrenzung jedoch insofern auch sachlich begründen, als die beiden hier behandelten Sprachzweige die mit der längsten Geschichte und mit der - vielleicht mit Ausnahme des Chinesischen - mit Abstand besten Bezeugung innerhalb der Menschheitsgeschichte darstellen und erst die Tatsache, daß wir auf Material aus einer Vielzahl unterschiedlicher Textsorten zurückgreifen können, eine wirkliche Vergleichbarkeit gewährleistet.

Die nachstehende Tabelle gibt zunächst einen exemplarischen Überblick über die Formen des Lexems für 'Herz' in einigen Sprachen der Hauptuntergruppen des Indoeuropäischen und des Afroasiatischen. ${ }^{37}$

\begin{tabular}{|c|c|}
\hline INDOEUROPÄISCH (*kerd-, kerd-en, krrd-ya-) & AFROASIATISCH (*lb-) \\
\hline ANATOLISC & ÄGYPTISCH $(* \mathrm{li}$ \\
\hline GRIECHISCH & SEMITISCH $(* 1 \mathrm{k}$ \\
\hline ROMAN & \\
\hline ARMEN & \\
\hline $\begin{array}{l}\mathrm{SCH}(* \hat{g} h r d-): \text { avestisch zərəd-, altin- } \\
\text { d- }\end{array}$ & $\begin{array}{l}\text { gggar } u l \text {, taneslemt } \\
u l\end{array}$ \\
\hline SLAVISCH: altkirchenslavisch srŭdr̃ce & KUSCHITISCH (*lb-): bedja lēb 'Bauch, Herz'; so- \\
\hline & \\
\hline $\begin{array}{l}\text { KELTISCH: altirisch cride, modernes irisch croidhe } \\
\text { 'Herz, Zentrum' }\end{array}$ & $\begin{array}{l}\text { OMOTISCH (*1bb-, *lbb-): kaffa nibbō 'Herz'; bas- } \\
\text { keto lippe 'Leib, Bauch', shinasha libbo 'Herz' }\end{array}$ \\
\hline $\begin{array}{l}\text { GERMANISCH: altenglisch heorte, modernes eng- } \\
\text { lisch heart; neuhochdeutsch Herz }\end{array}$ & $\begin{array}{l}\text { TSCHADISCH (*lb-): musgoy lib 'Leib, Bauch'; daba } \\
\text { libí 'Magen, Bauch'; Mokilko 'ùlbé 'Herz') }\end{array}$ \\
\hline
\end{tabular}

Im Anschluß werden zuerst verschiedene Verwendungsweisen und Bedeutungen des Wortes Herz in den antik bezeugten indoeuropäischen Sprachen Latein, Griechisch und Hethitisch vorgestellt, um dann auf die Situation in einigen afroasiatischen Sprachen - dem Akkadischen, dem Biblisch Hebräischen, dem Klassisch Arabischen, dem Koptischen und dem Hieroglyphisch-Ägyptischen - einzugehen. Die Gewährsleute für die Beispiele werden jeweils am Anfang genannt. Um die Abkürzungen gelegentlich erwähnter Primärquellen aufzulösen, sollten diese Werke herangezogen, beziehungsweise der besondere Abschnitt in der Bibliographie zur vorliegenden Untersuchung konsultiert werden, in dem die jeweils zitierten Ausgaben der klassischen Autoren aufgelistet werden.

\subsection{2 'Herz' im Lateinischen ${ }^{38}$}

Das Herz wird auf lateinisch cor (Genitiv cordis) genannt, und seine unterschiedlichen In-

37 Die Formen sind übernommen von Kammerzell (in Druck: Ms.-S. 43 u. 47-48).

38 Vgl. Georges (1972). 
halte lassen sich auf die folgenden Gruppen verteilen:

(a) Als körperliches Organ: si cor dolet 'wenn das Herz schmerzt' (Cato, De agricultura 157.7); corda micant regis, totoque e corpore sanguis fugit 'das Herz (Plural!) des Königs zittert und das Blut verschwindet aus dem ganzen Körper' (Plautus, Comoediae 551); cordis palpitatio 'Herzklopfen'.

(b) Als Sitz des Gedankens: tenes praecepta in corde? 'hast du etwas im Sinn?' (Plautus, Comoediae 578); der Erinnerung: quos (uersus) habere cordi et memoriae operae pretium esse ... puto 'ich glaube, es ist der Mühe wert, sie für das Herz und für die Erinnerung zu besetzen' (Aulus Gellius, Noctium Atticarum libri XX 2.29.20; 17.19.6); des Gewissens: nec cor sollicitant facta nefanda meum 'die Verabscheuungswürdigen sprechen mein Herz nicht an' (Tibull, Select elegies of Propertius 3.5.12); und der Intelligenz: hoc est non modo cor non habere, sed ne palatum quidem 'das heißt nicht nur kein Herz zu besitzen, sondern auch keinen Geschmack' (Cicero, De finibus bonorum et malorum 2.91); Musa rhetor ... multum habuit ingeni nihil cordis 'der Redner Musa hatte viel Geschick, aber keinen Verstand' (Seneca, Controversiae 10.pr.9).

(c) Mit der Bedeutung 'Seele', 'Geist': id petam id persequarque corde et animo 'das verlange ich, und danach strebe ich mit Herzen und Geist' (Plautus, Comoediae 387).

(d) Als Sitz des Willens: si fert ita corde uoluntas 'wenn der Wille sich so im Herzen verhält' (Vergil, Opera 6.675); collidens dissona corda seditio 'der Aufruhr, der die mißgestimmten Herzen zerschlägt' (Silius Italicus, Punica, II.45).

(e) Als Sitz des Charakters: scio perfidia regis corda 'ich kenne die Tücke der Herzen des Königs' (Valerius Flaccus, Argonauticon 5.290); Curia ... pellitos habuit, rustica corda 'die Kuria besaß ... vornehme Kleidung, aber bäuerliche Herzen' (Properz, Elegien 4.1.12); Dionysius nobis cordi est 'Dionysios liegt uns am Herzen' (Cicero, Epistulae ad Atticum 5.3.3.); sincerus 'herzlich'; oder der Gefühle: Antonine meo cordi dulcissime 'Antoninus, mein süßestes Herz' (Cornelius Fronto, The correspondence of Marcus Cornelius Fronto with Marcus Aurelius Antoninus, Lucius Verus, Antoninus Pius, and various friends 2, p.34 (95N)); cor timidum 'furchtsames Herz'; cor plumbeum 'gefühlloses Herz'.

(f) Als Sitz der Gefühle: z.B. cor meum als Liebeswort 'mein Liebling' (Plautus, Comoedia 367).

(g) Sonstiges: corde cupitus 'von Herzen, herzlich'; uterque utrique est cordi 'es liegt jmd. etwas am Herzen'.

Allein der Umstand, daß man verhältnismäßig häufig lateinische Kollokationen mit cor ohne weiteres mit deutschen Ausdrücken übersetzen kann, in denen das Wort Herz vorkommt, zeigt, daß es zumindest keine fundamentalen Unterschiede gegenüber der Situation im Neuhochdeutschen zu geben scheint. Eine auffällige Differenz besteht allerdings darin, daß im 
Lateinischen der Plural von cor auch dann gebraucht werden kann, wenn von einem einzelnen Individuum die Rede ist. ${ }^{39}$ Das ist im Deutschen nicht möglich.

\subsection{3 'Herz' im Griechischen ${ }^{40}$}

Im griechischen Altertum gilt das Herz als Gefühlszentrum und auch als die Seele, obwohl es in der Hierarchie der Organe nicht die erste Stelle, sondern eine eher sekundäre Position einnimmt. Bei Homer ist das Herz - wie wir später sehen werden, anders als in der ägyptischen Kultur - nicht das allwissende Wesenszentrum, läßt sich aber dennoch mit den Gefühlen identifizieren. Ähnlich findet es sich bei Plato, der dem Herzen keine besondere Bedeutung beimißt, außer der Funktion als 'Wachtposten'. Schließlich konnte das Herz von zwei Seiten betrachtet werden, entweder als inneres Organ oder als ein tieferer symbolischer Gehalt: als Ort für die Seele. Unter Berücksichtigung dieser zweiten Bedeutung identifiziert Aristoteles die Seele mit dem Steuermann, wobei das Herz als 'Zentralgelenk' das Steuerruder ist; zum Zweck des Vergleiches dieser Aussage mit ägyptischen Beispielen, verweise ich auf das Kapitel über die Metapher (siehe 3.7), in dem über die politische Schiffsmetapher gesprochen wird.

Im letzten Absatz wurde erwähnt, daß das Herz für die Griechen das Zentrum der Gefühle

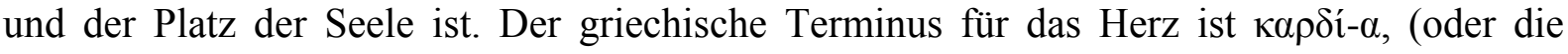
homerische Form $\kappa \rho \alpha \delta i \alpha$ ) und die unterschiedlichen Bedeutungen sind die folgenden:

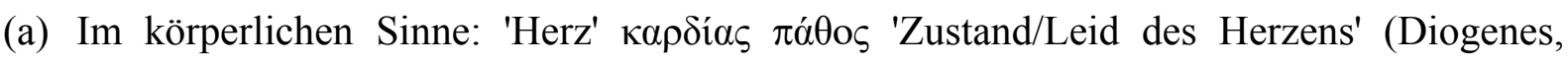
Oenoandensis fragmenta 66); 'Öffnung des Magens' (Thukydides, Historien 2.49, Hippokrates Prorretikon I.72).

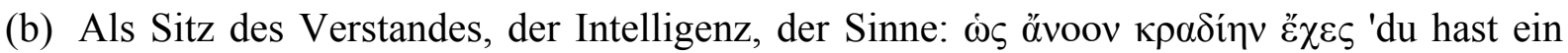

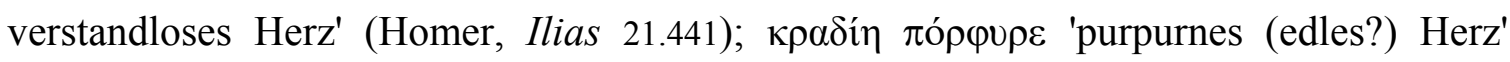

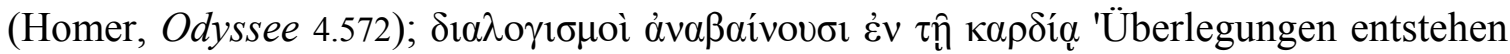
im Herzen' (Lukasevangelium 24.38). Als Bezeichnung für 'Inneres', 'Mittelpunkt'.

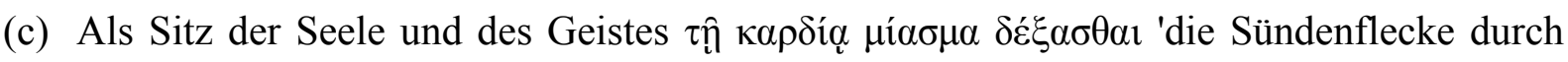
das Herz empfangen' (Basilius Caesariensis Cappadociae I.I [2.319B; M. 31.872B]).

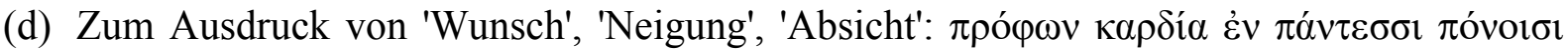

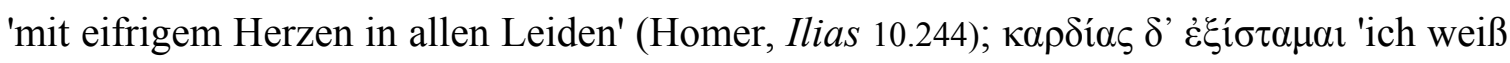

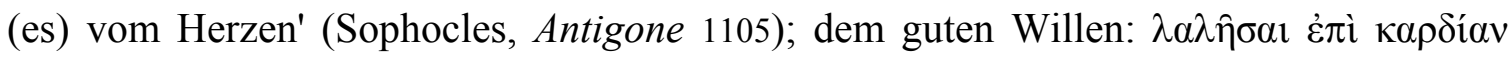

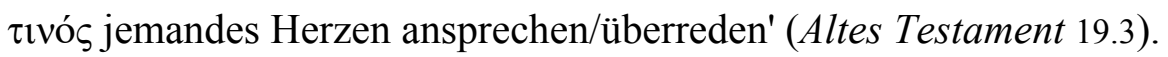

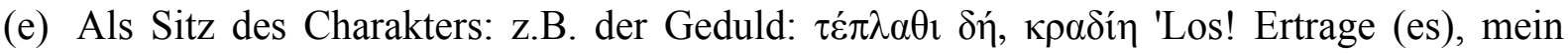

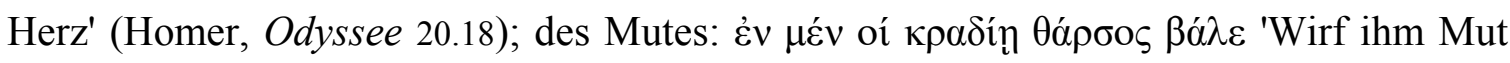

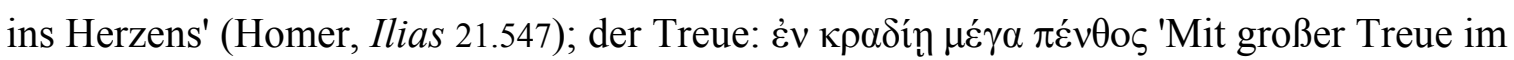

39 Siehe oben in diesem Abschnitt das zweite Beispiel unter (a).

40 Vgl. Lidell \& Scott (1996). 
Herzen' (Homer, Odyssee 17.489).

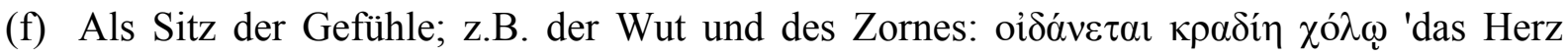

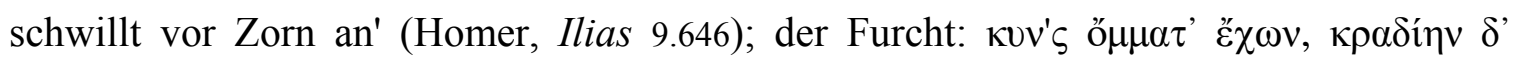

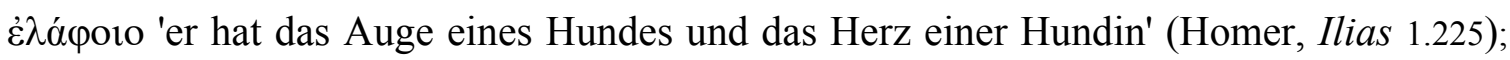

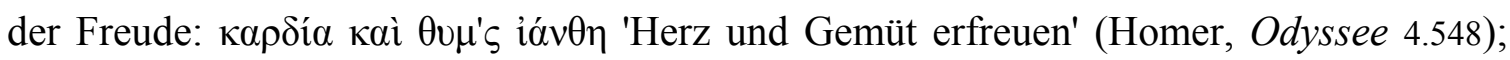

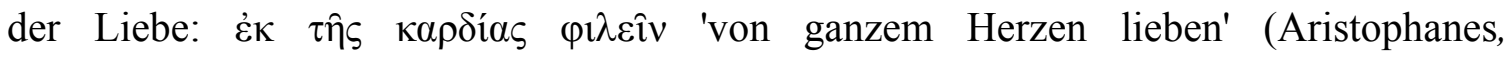
Acharnenses, Equites, Nubes, Vespas, Pacem, Aves continens 86).

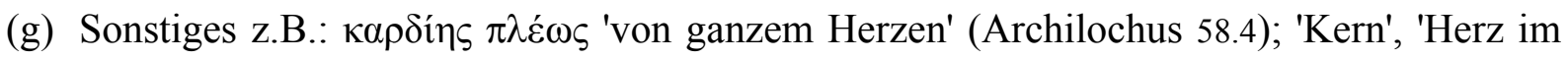

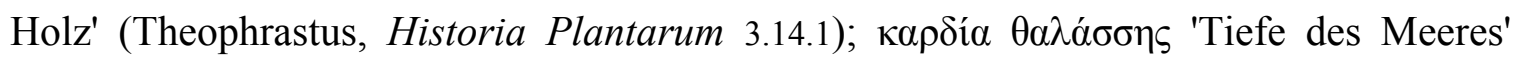

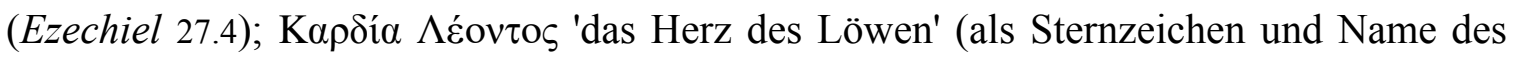
Sterns Regulus (Geminus, de Ostentis 3.5).

\subsection{4 'Herz' im Hethitischen ${ }^{41}$}

Da das Hethitische unter allen indoeuropäischen Sprachen diejenige ist, die zeitlich am nächsten zum Ägyptischen bezeugt ist, soll auch ein kurzer Blick auf die Situation in dieser anatolischen Sprache geworfen werden.

Die hethitische Form für Herz lautet im Nominativ wohl ker oder kir (Sommer 1938: 9396; Kronasser 1962: I, 123 f., 161, 340). Das Wort wird häufig bloß logographisch als ŠÀ geschrieben. Die Form ist aus gelegentlichen Schreibungen wie ki-ir-mi-it 'mein Herz' (KBo XII 18 I 11) oder ki-ir-te-it 'dein Herz' (KBo XII 18 I 9) sowie aus sprachvergleichenden Erwägungen zu erschließen.

Die Stammform im Dativ-Lokativ lautet kard-, von ihr lassen sich wohl auch die Bildungen kar-ta-aš-ma (= kartas-ma, Götze 1930: 58 I 13) und kardiiaš ableiten, die insofern bemerkenswert sind, als mit ihnen, die "wörtlich" so etwas wie 'das des Herzens bedeuten' das Konzept 'Wunsch, Wille' ausgedrückt wird (vgl. dazu weiter unten die Bemerkungen zu entsprechenden Verwendung von akkadisch $l i b b u(m)$ und ägyptisch $j b$ ).

In der nah mit dem Hethitischen verwandten anatolischen Sprache Palaisch kommt für 'Herz' der Terminus ka-a-ar-ti vor (Carruba 1972: 58).

\subsection{5 'Herz' im Akkadischen ${ }^{42}$}

Auch im Akkadischen begegnen eine Vielzahl von Verwendungsweisen des Lexems für 'Herz'. Die Termini dafür sind libbu(m), nupāru(m), șurru(m). Bei weitem am häufigsten tritt das Lexem libbu(m) auf. Die wichtigsten Verwendungsweisen lassen sich nach folgenden Gruppen klassifizieren:

(a) Im köperlichen Sinne für 'Herz' oder 'Abdomen'. Das Substantiv libbu(m) kann allgemein

41 Vgl. Tischler (1983-94).

42 Vgl. Edzard (1932-97: Bd. 4, 367-368). 
'Bauch' (im Plural auch 'Eingeweide') bedeuten, wobei es im konkreten Einzelfall nicht immer leicht ist, die exakte Bedeutung zu erschließen. Vom heutigen Kenntnisstand läßt sich nicht mit Sicherheit sagen, ob das Herz als der Motor des Blutkreislaufes erkannt war oder nicht, allerdings steht fest, daß man den Pulsschlag als Lebensäußerung identifizierte und wußte, daß sein Aufhören das Ende des Lebens anzeigte (so z.B. in Gilgamesch VIII/II 16).

(b) Mit der Bedeutung 'Gedanke' (itti libbīšu dabābu(m) 'mit seinem Herzen sprechen', d.h. 'bedenken'); 'Verstand' (tum mimma laiššu libbakâ šaniātim mimma la ubbalam "es gibt keinen Grund, sich Sorgen zu machen, dein Verstand muß nicht über eine andere Möglichkeit nachdenken"); des Bewußtseins (z.B. man sagt über eine Krankheit libbašu ēr 'sein Herz ist hell'; ihtaniț̣ašš 'bewußtlos').

(c) Als Sitz der Seele. Libbu in Zusammenhang mit kabattu (Bauch) kann sich auch auf Moralempfinden und Intellekt beziehen.

(d) Als Sitz des Vorhabens, des Wunsches: z.B. (libbaka leqâššima 'nimm sie, wenn du willst'); 'aus ganzem Herzen' (ina kul libbišu, ana gammurti libbišu); ašar libb̄̄ 'Ort des Herzens $=$ Wunsch'.

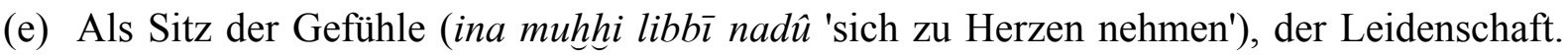
Libbu läßt sich auch insofern mit kabattu (Bauch) in Verbindung bringen, als beide Worte sowohl unterschiedliche Aspekte von Affektivität beeinhalten - 'Böses, heftige

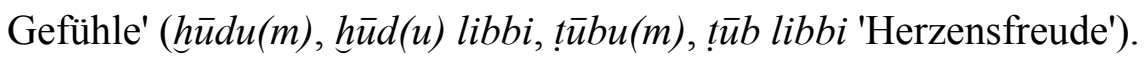

(f) Mit der Bedeutung 'Inneres' oder 'Innenseite' eines Landes, einer Region, einer Stadt (libbi āli), eines Gebäudes, des Körpers oder eines Körperteils (libbi ìni 'Innenseite der Augen'; libbi appi 'Innenseite der Nase'; ina šamāmū libbi 'im innersten Herzen').

(g) Sonstiges. Herz als Stamm einer Dattelpalme (auch Knospe und Blatt); ina libbi gamri 'aus ganzem Herzen'; nakāadu(m) 'klopfen lassen'; šaplānu(m) 'im Herzen (geheim)'; ana libbì- šadāa $u(m)$. Grammatikalisiert als Präposition mit Bedeutungen wie 'in', 'gehört zu', 'als', 'gemäß', 'unter', 'zwischen'.

Anders als in späteren Perioden, soll in den Epen und Sagen aus altbabylonischer Zeit das Herz noch nicht als das Lebenszentrum erscheinen. Die Ischtar-Epen handeln vom betrübten, gekränkten Herzen der Liebesgöttin Ischtar und vom rachsüchtigen Herz der Todesgöttin Erischkegal. Im Gilgamesch-Epos ist das Herz das empfindende Organ, mit dem der Mensch Sehnsucht verspürt, sich fürchtet, hofft und getröstet wird.

\subsection{6 'Herz' im Biblischen Hebräisch ${ }^{43}$}

Im Biblischen Hebräisch heißt das Herz לב leb-. An Einzelbedeutungen und Verwendungsweisen führt das Wörterbuch von Koehler-Baumgartner (1967-1996) folgende Gruppen auf:

43 Vgl. Koehler \& Baumgartner (1967-1996). 
(a) Als innerer Körperteil des Menschen (1Sam 25,37; 2Sam 18,14; 2Kön 9,24); eines Krokodils: 'Sein Herz ist fest wie Stein, fest wie der untere Mühlstein' (Hiob 41,16); als äußerer Körperteil von Menschen: 'auf die Brust' (Ex 28,29); 'Die Königin wird gefangen weggeführt, und ihre Jungfrauen werden seufzen wie die Tauben und auf ihre Brust schlagen' (Na 2,8); Gottes: 'Das Wort des Herrn erging an mich: Menschensohn, sag zum Fürsten von Tyrus: So spricht Gott, der Herr: Dein Herz war stolz, und du sagtest: Ich bin ein Gott, einen Wohnsitz für Götter bewohne ich mitten im Meer' (Ez 28,2); als Sitz der Lebenskraft: 'Die Elenden sollen essen, daß sie satt werden; und die nach dem HERRN fragen werden ihn preisen; euer Herz soll ewiglich leben' (Ps 22,27); Sitz einer Krankheit: 'Wohin soll man euch noch schlagen, die ihr doch weiter im Abfall verharrt? Das ganze Haupt ist krank, das ganze Herz ist matt' (Jes 1,5).

(b) Mit der Bedeutung 'Sinn' (im Allgemeinen und Ganzen), z.B. 'ihr böser Sinn' הדע לבם libbām hāa $\bar{a}$ ': 'Sie aber hörten nicht und neigten mir ihr Ohr nicht zu, sondern folgten den Eingebungen und Trieben ihres bösen Herzens' (Jer 7,24): der 'Neigung', 'Gedanken': 'Der Herr sah, daß auf der Erde die Schlechtigkeit des Menschen zunahm und daß alles Sinnen und Trachten seines Herzens immer nur böse war' (Gen 6,5); 'Der Herr sprach zu Mose: Wenn du gehst und nach Ägypten zurückkehrst, halte dir alle Wunder vor Augen, die ich in deine Hand gelegt habe, und vollbring sie vor dem Pharao! Ich will sein Herz verhärten, so daß er das Volk nicht ziehen läßt' (Ex 4,21); der Bedeutung 'Aufmerksamkeit', 'Beachtung', 'Verstand': 'Mit allem, was ihm gehörte, machte er sich auf und davon' (Gen 31,20); 'Denn diesmal will ich alle meine Plagen loslassen auf dich, deine Diener und Volk. Daran wirst du erkennen, daß mir keiner im ganzen Land gleichkommt' (Ex 9,14; vgl. auch Dtn 29,3).

(c) Mit der Bedeutung 'Wille', 'Absicht': 'Dann sagte Mose: Daran sollt ihr erkennen, daß der Herr mich gesandt hat, damit ich alle diese Taten vollbringe, und daß ich nicht aus eigenem Antrieb gehandelt habe' (Num 16,28; vgl. auch Th 3,33; 2Sam 7,27; Jes 63,4); 'einmütig': לב אחדד leb 'ähād (1Kor 12,39); 'Ja, sie halten einmütig Rat und schließen ein Bündnis gegen dich' (Ps 83,6).

(d) Als Sitz des Charakters: z.B. Mit der Bedeutung 'Entschlossenheit', 'Mut': 'David sagte zu Saul: Niemand soll wegen des Philisters den Mut sinken lassen. Dein Knecht wird hingehen und mit diesem Philister kämpfen' (1Sam 17,32).

(e) Als Sitz der Gefühlen z.B. 'zufrieden sein' ריטב ליט לב țab leb Jd 18,20); 'läßt sich wohl

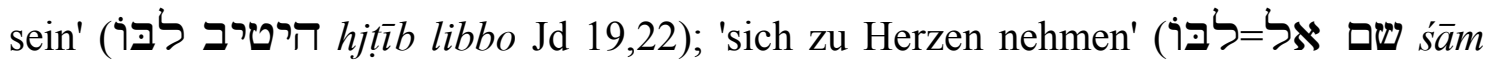
'äl-libbo 'und sagte zu ihm: Mein Herr möge mir meine Schuld nicht anrechnen; mögest du nicht an das denken, was dein Knecht sich an dem Tag zuschulden kommen ließ, als mein Herr, der König, Jerusalem verließ; der König nehme es sich nicht so zu Herzen' 2Sam 19,20); 'wird unruhig' (נפער לבר הiscar libbu 'Als das nicht nur einmal oder zweimal geschah, wurde der König von Aram beunruhigt' 2Kön 6,11). 
(f) In der allgemeinen Bedeutung 'Inneres', 'Mitte', 'Zentrum' (von Nichtlebewesen): 'Du schnaubtest vor Zorn, da türmte sich Wasser, da standen Wogen als Wall, Fluten erstarrten im Herzen des Meeres' (Ex 15,8; vgl. auch Pred 23,34).

(g) Sonstiges. Mit der Bedeutung 'Gewissen': 'Hinterher aber schlug David das Gewissen, weil er einen Zipfel von Saulus Mantel abgeschnitten hatte' (1Sam 24,6; vgl. auch 2Sam 24,10). Als Repräsentant einer Person oder seines Lebens, auch grammatikalisiert in der Funktion eines emphatischen Reflexivpronomens 'selbst': אמר אל=לבר 'ämar 'äl-libbo 'Der Herr roch den beruhigenden Duft, und der Herr sprach bei sich' (Gen 8,21), 'Sein Machthaber wird ihm selbst entstammen, sein Herrscher aus seiner Mitte hervorgehen' (Jer 30,21), 'Ich überlegte mir folgendes: Ich habe mein Wissen immerzu vergrößert, so daß ich jetzt darin jeden übertreffe, der vor mir über Jerusalem geherrscht habe. Oft konnte ich Wissen und Können beobachten' (Koh 1,16).'von ganzem Herzen': 'Dann trat Salomo in Gegenwart der ganzen Versammlung Israels vor den Altar des Herrn, breitete seine Hände zum Himmel aus und betete von ganzem Herzen' (1 Kön 8,22).

Die genannten Bedeutungen und Verwendungsweisen lassen sich in zwei große Gruppe aufteilen. Die erste besteht aus den kardiologischen Definitionen, wie es zum Beispiel in folgenden Passagen lautet:

"Als es aber Morgen geworden und die Betrunkenheit von Nabal gewichen war, sagte ihm seine Frau alles. Da erstarb sein Herz in seinem Leibe, und er ward wie ein Stein" (1Sam 25,37).

"Joab sprach: Ich kann nicht so lange bei dir verweilen. Da nahm Joab drei Stäbe in seine Hand und stieß sie Absalom ins Herz, als er noch lebend an der Eiche hing" (2Sam 18,14).

"Aber Jehu faßte den Bogen und schoß Joram zwischen die Arme, daß der Pfeil durch sein Herz fuhr und Joram in seinem Wagen zusammenbrach" (2Kön 9,24).

"Du lässest Gras wachsen für das Vieh/ und Saat zu Nutz den Menschen, daß du Brot aus der Erde hervorbringst,/ das der Wein erfreue des Menschen Herz und sein Antlitz schön werde vom Ö1/ und das Brot des Menschen Herz stärke" (Ps 104,15).

Die zweite Gruppe umfaßt Verwendungsweisen, in denen das Herz als Sitz des Verstandes und als Zentrum aller psychischen und geistlichen Attribute eines Menschen auftritt (und dann auch ganz allgemein Mit der Bedeutung 'Mitte', 'Zentrum' verwendet werden kann). Solche Erwähnungen des Herzens in der Bibel können in unseren modernen Sprachen mit Entsprechungen wie Charakter, Persönlichkeit, Wille oder Verstand gleichgesetzt werden. Diese Gebrauchsweisen illustrierte schon Robinson (1911) anhand des Alten Testaments, wenn er dem hebräischen Wort für 'Herz' folgende Bedeutungsgehalte zuwies: physisch oder figurativ ('Mitte'); Persönlichkeit, Innenleben oder Charakter (2Mo 9,14; 1Sam 16,7; 1Mo 20,5); emotio- 
nale Bewußtseinzustände, wie Rausch (1Sam 25,36), Freude oder Leid (Ri 18,20; 1Sam 1,8), Angst (1Sam 4,13), Mut und Furcht (1Mo 42,28), Liebe (2Sam 14,1); Aufmerksamkeit (2Mo 7,23), Nachdenken (5Mo 7,17), Erinnerung (5Mo 4,9), Verstand (1Kön 3,9) und Fertigkeit (2Mo 28,3); Wille oder Absicht (1Sam 2,35). Über 'Herz' im Neuen Testament schrieb Smith: ${ }^{44}$

"Es (das Herz) verliert seinen körperlichen Bezug nicht gänzlich, denn es besteht aus Fleisch (2Kor 3,3), aber es ist der Sitz des Willens (Mk 3,5), des Verstandes (Mk 2,6.8) und der Gefühle (z.B. Lk 24,32). Das heißt, daß das Herz von allen ntl. Begriffen der Bedeutung Person am nächsten kommt."

Gott und das Herz sind eng miteinander verbunden, besonders wenn Gott in das Herz und nicht bloß auf das Äußere des Menschen blickt, da das Herz als das Innerste einer Person angesehen wurde. Deswegen ist es der wichtigste Ort der Begegnung des Menschen mit Gott. Dazu steht etwa im Buch Samuel:

"Aber der HERR sprach zu Samuel: Sieh nicht an sein Aussehen und seinen hohen Wuchs; ich habe ihn verworfen. Denn nicht sieht der HERR auf das, worauf ein Mensch sieht. Ein Mensch sieht, was vor Augen ist; der HERR aber sieht das Herz an" (1Sam 16,7).

Allerdings ist das Herz nicht das einzige wichtige Organ für das Gefühl, wie es nach den bisherigen Darlegungen scheinen könnte, sondern andere Organe wie beispielsweise die Eingeweide können ebenfalls diese Funktion haben. Das Herz ist in der Bibel eines der Organe, bei dem - anders als in der griechischen Philosophie - kein Unterschied zwischen Geist und Denken gemacht wird.

\subsection{7 'Herz' im Klassischen Arabisch ${ }^{45}$}

Das Wort für Herz im Arabischen lautet لبّ lubbun und drückt insbesondere die folgenden Bedeutungsnuancen aus:

(a) 'Herz' als Körperteil.

(b) Mit der Bedeutung 'Sinn', 'Verstand'46, 'Einsicht', z.B. wāa-qālat lahā ș-ṣugrā: hadāki lī$m \bar{a}$ arā hawan ġairu macṣìyin wa-lubbun mušayyacun 'die Jüngere sagte zu ihr: eine Liebe, gegen die man sich nicht auflehnen kann, und ein verwirrter Sinn haben dich in den Zustand gebracht, den ich sehen muß' ('Umar Dìwān ibn abu Rabīc a, R. 57,4); (bisaifin) muntahabi l-lubbi lahū darbatun hadbā'u '(mit einem Schwert), das den Verstand verloren hat und das eine klaffende Wunde schlägt' (Muttanahhil 1,26). Als Sitz der Kenntniss und des Gewissens nach der $\breve{S}$ üfi-Terminologie. Im Qur'ân kommt das auch im Sinne von Herz gebrauchte Wort für 'Brust' qalb anstatt von ${ }^{c} a q l$ 'Verstand' öfter vor, z.B. 'Es ist das Herz, womit ein Mann versteht, ebenso wie er sieht mit seinen Augen und hört

\footnotetext{
44 Zitat aus Brockhaus (1988), s.v. Herz.

45 Ullmann \& Spitaler (1970 ff.: Bd. II, 77-83).

46 Seidensticker (1992: 135-137).
} 
mit seinen Ohren (Qur’ân, VII, 179, XXII, 46). Für diejenigen, die das Wort des Gottes weder verstehen noch hören, wurde gesagt: 'Es sind nicht ihre Augen, die blind sind, sondern das Herz in ihren Brüsten' (Qur'ân XXII, 46).

(c) Mit der Bedeutung 'Wunsch', 'Instinkt'. Das Herz ist der Platz für den moralischen Impuls und für den Wunsch nach der Untersuchung der Texte des Ihy $\bar{a}^{\prime}$ durch Laoust (1970: 218-221).

(d) Als Sitz der Gefühle z.B. banātu l-lubbi 'die (zarten) Regungen des Herzens', 'der Herzensgrund'; die Liebe wa-kullu muhibbin acqaba n-na'yu lubbahū sulūwa fu'ādin ġaira lubika ma yasl $\bar{u}$ 'dem lubb jedes anderen Liebenden verschafft die Trennung Trost des Herzens, nur dein $l u b b$ tröstet sich nicht' (Zuhair ('Adawi) 97 ult.).

(e) 'Inneres', 'Kern' (von Pflanzen, Früchten usw.).

(f) Sonstiges. Als der beste Teil, wesentliche Gehalt oder 'Quintessenz'. Die Formen des قلوب Palmmark, Herzblätter der Palme, Palmherz' oder قلوب Wortes im Plural lautet 'herzlich, von Herzen, Mittelpunkt, Mitte, Zentrum der Armee, innerster Teil, Kern'.

\subsection{8 'Herz' im Koptischen}

Da das Koptische außerhalb des Untersuchungsrahmens dieser Arbeit liegt, wird es an dieser Stelle erwähnt, obwohl es natürlich eigentlich eher im Zusammenhang mit dem Ägyptischen behandelt werden sollte.

Im Koptischen wurde das Herz mit den gleichen Bedeutungen wie im Ägyptischen weiter verwendet, allerdings gibt es auch einen signifikanten Unterschied, daß nämlich der Terminus $j b$ bzw. eine daraus abgeleitete Form praktisch überhaupt nicht mehr benutzt wurde ${ }^{47}$, sondern im sahidischen wie auch im bohairischen Dialekt nur noch das Wort 2HT für 'Herz' auftritt. Eine mögliche Erklärung, meiner Meinung nach, wäre das Fehlen phonetischer Schreibungen des Terminus für $j b$. Aus den ägyptischen Texten sind zahlreiche Beispiele für die Beschreibung eines Charakters zu finden, in denen nur das jeweilige Verb zusammen mit dem Logogramm vorkommt, wie etwa $t^{3}-j b$ 'Heißsporn' (W-26), wnf.t-jb 'übermütig' (W-30), w’h $h$-jb 'Zurückhaltung' (W-34, E-38), mh-jb 'Treuherziger' (W-50, W-61, W-84) und ${ }^{c} w n-j b$ 'habgierig sein' (W-46, W-49, E-69, E-72, E-78, E-79, E-82). Besonders aufschlußreich ist der Ausdruck jwty hijtj, koptisch $\mathbf{\mathbf { T }} \mathbf{2} \mathbf{2} \mathbf{H T}$, дөнт, der in der Lehre von Ani (W-137) vorkommt. Dieses Beispiel zeigt die Schreibung mit Phonogrammen; allerdings gibt es ein anderes Beispiel aus den Liebesliedern (L-18), in dem dieselbe Konstruktion für dieselbe Bedeutung

47 In dem wohl aus dem 2. Jahrhundert n. Chr. stammenden und in altkoptischer Schrift verfaßten Papyrus BM 10808 sind zwar die auf älteres $j b$ zurückgehenden Formen $\mathbf{\epsilon}, \mathbf{H B}=$ bzw. $\rangle \mathbf{B}=$ belegt (vgl. Osing 1976: 63 mit Anm. 474; 68-70 mit Anm. 536; 110 mit Anm. 878; 123-124), doch handelt es sich bei dem Text vermutlich um die zeitgenössische Wiedergabe eines mit jüngeren Interferenzen durchsetzten mittelägyptischen Textes. Deswegen sagt das Vorkommen von $j b$ in diesem Dokument kaum etwas über das Vorhandensein des Lexems in der ägyptischen Alltagssprache der Kaiserzeit aus. 
verwendet wurde, nun mit der Besonderheit, nur das Logogramm von 'Herz' zu haben. Man darf jedoch nicht nur aufgrund eines einzigen Beispieles feststellen, daß das Fehlen von der Schreibung die Erklärung dafür sein sollte. Es wäre aber eine mögliche a priori Hypothese, die man durch die Untersuchung ägyptischer, demotischer und koptischer Texte belegen oder widerlegen könnte.

Die prinzipiellen Bedeutungsgruppen des Wortes 2HT sind die folgenden:

(a) Als Teil des Körpers.

(b) 'Verstand', 'Intelligenz', und 'Organ des Denkens': saidisch 2Hт; bohairisch 2өн; Pl. sahidisch, achmimisch und lykopolitanisch $\mathbf{\epsilon} \mathbf{\epsilon}$; fayumisch $\mathbf{2} \boldsymbol{\dagger}$.

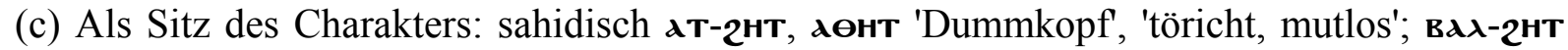
'ehrlich'; мגр-2нт 'schlau'; achmimisch пдк-2нт 'kleinmütig'; sahidisch 2нт N-Oүшт 'entschlossen'; 2HT-CNaY 'unschlüssig'; PM-N-2HT, bohairisch NEB-2HT 'intelligent';

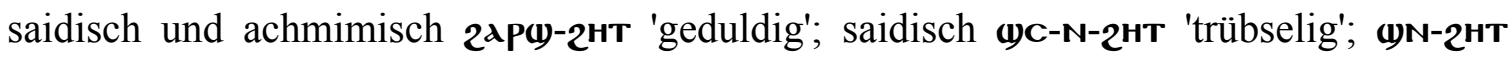
'Mitleid haben'.

(d) Als Sitz der Gefühle.

(e) Sonstiges. 'Spitze', 'Extremität', saidisch $2 \mathbf{H T}, \mathbf{2} \mathbf{T H}$; bohairisch $\mathbf{2} \mathbf{} \mathbf{H}$.

\section{4 Ägyptische Konzepte des Herzens}

\subsubsection{Gegenstand}

Im folgenden wird das Herz von unterschiedlichen Perspektiven aus betrachtet. Zunächst geht es um die ägyptischen Lexeme für 'Herz' und die kontrovers diskutierte Frage nach den genauen Denotaten der Körperteilbezeichnungen $j b, h 33 t j$ und $r^{\prime}-j b$.

Danach wird eine Zusammenfassung bestehender ägyptologischer Ansichten über die Rolle des Herzens in der ägyptischen Kultur geboten. Es wird sich zeigen, daß solche Arbeiten (z.B. Brunner 1965, Shupak 1993, Assmann 1996) häufig die entsprechende Situation im Biblisch-Hebräischen - entweder als Hintergrundfolie oder für eine direkte Kontrastierung - benutzten und darauf abzielen, durch einen Vergleich ägyptischer Texte mit einschlägigen Passagen aus der Bibel die Gemeinsamkeiten und Unterschiede zwischen den HerzKonzepten in den beiden Kulturen herauszuarbeiten.

Zum Schluß werden die gängigsten Bedeutungen und Verwendungsweisen der ägyptischen Lexeme für 'Herz' noch einmal zusammengefaßt aufgelistet.

\subsubsection{Die vorkommenden Formen}

Die in ägyptischen Texten der verschiedensten Perioden gebräuchlichen Ausdrücke für 'Herz' sind $j b$ und $h i t j$. 
Das Lexem $j b$ ist seit der frühdynastischen Epoche bezeugt ${ }^{48}$ und wurde zu allen Zeiten häufig logographisch als $\langle j b\rangle$ oder $\langle j b-1\rangle$ geschrieben. Seit dem 2. Jahrtausend wurde vor allem in Kursivtexten - auch die Graphie $\langle j b$-1-KÖRPERTEIL $\rangle$ mit zusätzlichem Klassifikator verwendet. Nur gelegentlich begegnen Schreibungen mit Phonogrammen, die explizite Angaben zur Lautgestalt machen, so beispielsweise aus der Zeit des Älteren Ägyptisch $1 \sqrt{\sigma}$

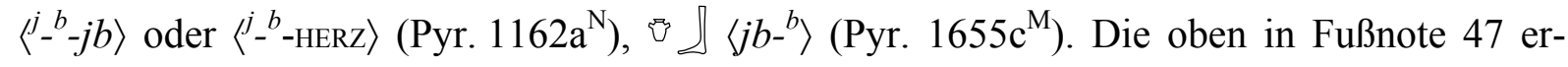
wähnten Formen in altkoptischer Schrift und der wahrscheinliche etymologische Zusammenhang von ägyptisch $j b$ und afroasiatisch *lb- deuten darauf hin, daß die Aussprache im Alten Reich wohl $/ \mathrm{jib} /<*$ lib gelautet hat.

Das konventionell als hijtj transkribierte Lexem ist seit dem Alten Reich belegt. Das Wort wird in der Regel mit dem Logogramm $\langle h\} t\rangle$, das 'Vorderseite' bedeutet, geschrieben und wird üblicherweise als maskuline Nisbe mit der Bedeutung 'das zur Vorderseite Gehörige' analysiert. Diese Interpretation basiert auf den als "Normalschreibung" geltenden Graphien

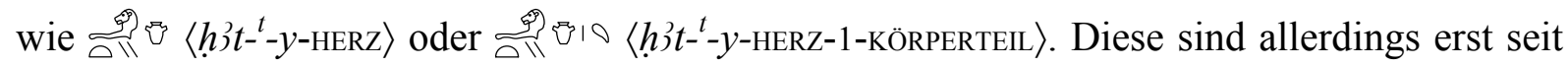
dem Mittelägyptischen belegt. Das Lexem $h 3$ itj kommt in den Pyramidentexten und in anderen Texten aus dem Alten Reich nur in Formen wie $\stackrel{p}{0}\left\langle h 3 t^{t}-\right.$ HERZ $\rangle$, $\theta\left\langle h 3 t^{t}-\right.$ HERZ $\rangle$ oder $\left\langle\right.$ hit-HERZ- $\left.^{\dagger}\right\rangle$ vor, die keine eindeutige Identifizierung als Nisbe erlauben. Da zudem nach Auskunft des Digitalen Zettelarchivs niemals Schreibungen mit $\$\left\langle\left\langle t j^{-}{ }^{j}\right\rangle\right.$ im Singular oder mit $\langle\mathrm{tjw}\rangle$ im Plural erscheinen, kann es nicht als unumstößlich gesichert gelten, daß wir es tatsächlich mit einer Nisbebildung zu tun haben. Die jüngeren Graphien mit $\triangle 1$ oder $\triangle$ siehe

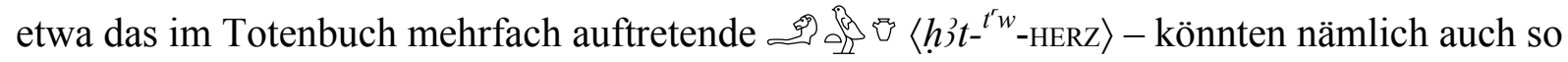
erklärt werden, daß es den Schreibern um eine unmißverständliche Kennzeichung eines im Wortauslaut gesprochenen (d.h. auch nach dem 3. Jahrtausend noch erhaltenen und nicht, wie in der Mehrzahl der Wörter, geschwundenen) Konsonanten /t/ ging. Ein weiteres Argument, das bisher überhaupt nicht diskutiert wurde, aber gegen die übliche Auffassung von $h 3 t j$ als Nisbe angeführt werden könnte, ist die Tatsache, daß es bei einem solchen Ansatz auch gewisse semantische Probleme gibt: Eine Bezeichnung des Herzen als 'das, was sich vorn befindet' ist eigentlich nicht besonders naheliegend - um so mehr, als gerade auch im Ägyptischen das Herz oft als Zentrum oder Mitte von etwas verstanden wird (vgl. etwa grammatikalisierte Ausdrücke wie $h r$-j $b$ 'inmitten'). Da eine eindeutige Entscheidung jedoch kaum möglich ist, ist in dieser Arbeit bei der Transkription durchgängig eine Art Kompromiß gewählt worden: ich umschreibe $h 3 i t j$, verzichte aber auf die Setzung eines Punkts zur Markierung einer Morphemgrenze. Die koptischen Formen wie HT erlauben sowohl eine Rekon-

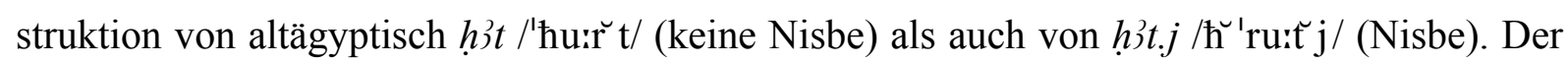

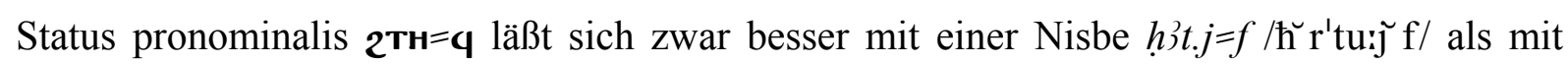

48 Kahl (1994: 501) führt als ältesten Beleg ein Dokument aus der Zeit des Königs Aha (31. oder 30. Jahrhundert v. Chr.) an. 
$h \grave{h} t=f$ verbinden, aber es kann auch nicht ohne weiteres ausgeschlossen werden, daß wir es im Älteren Ägyptisch mit einem Kontrast zwischen ḩ3t im Status absolutus und $h 3 \hat{t} t j=$ im Status pronominalis zu tun haben. ${ }^{49}$

Es wurde eben bereits erwähnt, daß $j b$ normalerweise ohne phonographische Komplementierung entweder rein logographisch oder mit dem Logogrammstrich ' auftaucht. Beide Wörter haben manchmal zusätzlich das Determinativ $\checkmark$ [FLEISCH] bzw. [KÖRPERTEIL], welches in Schreibungen von $h 3 t j$ jedoch öfter erscheint als bei $j b$. In diesem Zusammenhang wurde die Frage diskutiert, warum die Schreibung beider Worte dieses Determinativ nur unregelmäßig aufweist und weshalb es bei dem einen der beiden Wörter häufiger erscheint. Zwei mögliche Erklärungen für den Gebrauch des Determinativs stammen von Walker (1996: 150-151 und 184). Er äußerte zum einen die Ansicht, daß das Determinativ $₫$ [FLEISCH] bzw. [KÖRPERTEIL] nur als Hinweis für die bestimmte anatomische Struktur verwendet worden sei und dann überflüssig wäre. Zum anderen erklärte sich nach Walker aus der seltenen Verwendung dieses Determinativs in Verbindung mit $j b$ dessen Bedeutung als Psyche. Auf den folgenden Seiten (1996: 182) geht er davon aus:

"There are two reasons why hijty is nearly always written with the heart sign $q$; firstly, because it is the term most commonly employed to denote the physical heart (although it is not the only one) and secondly, because the heart is always the major component of the hity (but not necessarily the only one). The fact that hity denotes this discrete anatomical structure accounts for the occasional presence of the flesh sign in its writing. hity can also denote an entire anatomical region, the anatomical "field" of the hity apparently comprising the whole central compartment of the chest (the mediastinum). There can be no doubts however, that the anatomical "focus" of the hity - its true core - remains the largest and most important organ in that central compartment, the physical heart."

Generell hat man den Eindruck, daß Walker vielleicht eine etwas zu mechanistische Vorstellung über den Gebrauch der Determinative im Ägyptischen hat. Er scheint davon auszugehen, daß immer dann, wenn verschiedene Instanzen eines Lexems mit unterschiedlichen Determinativen bzw. mal mit und mal ohne Determinativ geschrieben werden, von Bedeutungskontrasten ausgegangen werden müsse. Eine solche Theorie übersieht jedoch, daß es sich bei den durch die Determinative ausgedrückten Klassifizierungen nicht um ein normativ fixiertes System von Kategorien handelt, sondern daß der Gebrauch von Determinativen sehr flexibel und ihre Setzung nicht unbedingt obligatorisch ist. Statt zu versuchen, von der Schreibung der Instanzen eines Lexems mit bzw. ohne Determinativ auf durchgängige semantische Unterschiede $\mathrm{zu}$ schließen, sollte man eher fragen, ob nicht womöglich die diachrone Verortung der jeweiligen Quellen, ihre Textsorte oder die Schriftart, in der sie abgefaßt sind, wesentlichere Kriterien darstellen. Dann könnte man etwa zu folgenden

49 Die Überlegungen zur Interpretation der Schreibungen und zur Rekonstruktion der Lautungen verdanke ich einer mündlichen Mitteilung von Frank Kammerzell. 
Beobachtungen kommen:

(1) Die Schreibung von Bezeichnungen für Teile der Anatomie mit dem Determinativ [FLEISCH] bzW. [KÖRPERTEIL] tritt in hieratischen Texten häufiger auf als in hieroglyphisch geschriebenen.

(2) In den - ausnahmslos in Kursivschrift verfaßten - medizinischen Texten zeigt sich eine deutliche Tendenz zu einer (vielleicht als fachsprachliche Besonderheit zu beschreibenden) Verwendung relativ abstrakter Determinative, die Kategorien von Oberbegriffen konstituieren.

(3) In den medizinischen Texten ist in stärkerem Maße als in anderen Textsorten damit zu rechnen, das ein Wort für 'Herz' sich in konkreter nicht-metaphorischer Weise auf ein Körperorgan bezieht.

Die Möglichkeit dialektaler Differenzierungen kann aufgrund fehlender Vorarbeiten im Rahmen dieser Arbeit nicht geleistet werden, sollte aber als weitere theoretische Möglichkeit zur Entstehung unterschiedlicher Herzbegriffe nicht außer Acht gelassen werden.

Als Konsequenz dieser Befunde wird man annehmen dürfen, daß das Vorhandensein oder das Fehlen des Determinativs ${ }^{\prime}$ kaum dazu berechtigt, einen Bedeutungsunterschied zwischen den betreffenden Formen zu postulieren.

\subsubsection{Versuche zur eindeutigen Klärung der Semantik}

Ein erst vor kurzem erschienener Versuch, die genaue Bedeutung von $j b$ und $h i j j$ herauszuarbeiten, ist im Rahmen von Walkers schon im letzten Absatz gestreifter Studie über die ägyptische Körperteilbezeichnungen (1996) unternommen worden. Der Autor geht von einem mehr oder weniger deutlichen semantischen Unterschied zwischen den beiden Termini aus, der vereinfacht so beschrieben werden kann: $j b$ bezeichne eine weniger konkrete Größe, die häufig unserem Wort 'Seele' oder 'Psyche' entspreche und sich demzufolge eher auf das kordiologische Herz beziehe, während es sich bei ḩ $3 t j$ um einen konkreteren anatomischen Begriff zur Bezeichnung des kardiologischen Herzens handeln soll (Walker 1996: 151-166). Walker beschreibt beide Begriffe wie folgt:

"ib and $h i t j$ are not two names for exactly the same entity but are the names of separate aspects of one entity, the abstract psyche dwelling within the physical heart (or medastinum)" (1996: 184).

Allerdings sind die Befunde nicht ganz so eindeutig. So führt Walker auch einige Beispiele für ḩ3tj mit der Bedeutung 'Sinn' oder 'Gefühle' an, jedoch nicht ohne abschließend darauf hinzuweisen, "...that many of the mental functions and states that are usually attributes to the ib can also be ascribed to the hỉj" (1996: 166-169). Aus den anatomischen Listen ${ }^{50}$ geht hervor, 
daß ḩ3tj mit dem Gott Khepri-Re-Atum gleichgesetzt wurde, was in Verbindung mit der Rolle des Skarabäus in den ägyptischen funerären Ritualen interessant ist. ${ }^{51}$ In diesen Listen taucht ḩ3tj seit früheren Zeiten bis zur griechisch-römischen Zeit mit anderen Körpergliedern auf, die ebenfalls mit Göttern assoziert werden.

Walker meint, $j b$ bedeute grundsätzlich 'Psyche' oder 'das Selbst' (Walker 1996: 172). Es gibt aber Fälle, in denen die Schreibung $\langle j b\rangle$ oder $\langle j b-1\rangle$ sich offensichtlich eindeutig auf das Herz als Körperteil bezieht (z.B. in den Beischriften zu Schlachtszenen). Dabei soll es sich Walkers Ansicht nach um eine verkürzte Schreibung von hỉtj handeln (Walker 1996: 169). Er weist weiter darauf hin, daß in den anatomischen Listen $j b$ nicht so häufig wie $h 3 t j$ genannt worden sei und es, wenn es überhaupt vorkomme, erst seit dem Neuen Reich in dieser Funktion belegt sei. Schließlich sei es angesichts des Aufeinanderfolgens der beiden Begriffe in manchen Texten verwunderlich, wenn sowohl hijtj als auch $j b$ das körperliche Organ Herz bezeichnen würden. Aus der Tatsache, daß $j b$ und $h j i j$ zusammen vorkommen können, hatte bereits Gardiner (1947: II 251) vermutet, daß ḩ3tj eher das körperliche Organ und $j b$ eher die Psyche darstelle. Im Endeffekt muß freilich Walker (1996: 171) einräumen, daß durchaus auch $j b$ das Herz als Körperteil bezeichnen könne, obwohl es sich in dieser Bedeutung seltener als $h i 3 t j$ belegen lasse.

Wenn $j b$ als anatomisches Organ gemeint ist, schlägt er für die Übersetzung des Wortes zwei Möglichkeiten vor (Walker 1996: 185):

(1) $j b$ wird nicht übersetzt, z.B. $m 3 s t-j b$ wird als 'kneeling of the $j b$ ' und nicht 'kneeling of the heart' übersetzt.

(2) Die uneingeschränkte Auslegung des Terminus, immer wenn eine solche möglich ist, z.B. $3 w t-j b$ wird 'joy' und nicht 'wide of heart' oder 'wide of $j b$ ' interpretiert.

Wenn es jedoch 'Seele' oder 'Psyche' bedeutet und ein Possesivpronomen aufweist, sollte man $j b$ nicht als Herz sondern mit dem Personalpronomen übersetzen, da das Herz die Person identifiziert, z.B. $n \underline{d} m j b=k$ 'dein Herz ist froh' wird 'du bist froh' übersetzt.

Allerdings kann man nicht mit Sicherheit feststellen, wann der Terminus für Herz die Psyche oder das Organ meint. Zu dieser Klärung muß der jeweilige Kontext dienen, wobei zunächst als Zwischenschritt die wörtliche Übersetzung angeboten werden sollte, und nur wenn entweder im Einzelfall eindeutig festgestellt werden kann, welche Bedeutung $j b$ oder $h 3 t j$ haben, oder sich eine konsistente Verteilung ergibt, ist die präzisere Interpretation des Terminus gerechtfertigt. Jedoch ist dieses Problem nicht so einfach zu lösen, wie es sich in Walkers Arbeit darstellt.

Die Frage nach dem Unterschied zwischen $j b$ und $h i 3 j$ und der Semantik jedes der beiden Wörter hatte schon vor der Untersuchung von Walker eine umfangreiche Forschungsliteratur hervorgebracht. Die Klärung dieser Frage ist kein unmittelbares Ziel dieser Arbeit, so daß

$51 \quad L \ddot{A}$ II, 1168. 
keine neue Lösung vorgeschlagen wird. Andererseits wäre es auch nicht angemessen, diese Diskussion ganz zu ignorieren.

Stracmans (1961: 126) versuchte, Beispiele aus dem Alten Reich zu sammeln, in denen die beiden Lexeme, denen gemeinhin der gleiche oder ein zumindest annähernd gleicher Sinn zugeschrieben wird, tatsächlich unterschiedliche Bedeutungen hätten, einmal Bauch, einmal Herz. Er griff dabei auf einen früheren Aufsatz von Hintze (1955) zurück, in dem dieser auf eine auch in anderen Sprachgemeinschaften zuweilen vorhandene Tendenz zu einer unscharfen Differenzierung zwischen Herz und Magen hingewiesen hatte, und erklärt die beiden Bedeutungen als Folge einer metaphorischen Übertragung, die eine Verwendung von $j b$ für 'Magen' und von ḩ̧ tj für 'Herz' zum Ergebnis gehabt habe.

Der Ansicht, daß sich für $j b$ und $h j$ t $j$ unterschiedliche Bedeutungen bestimmen ließen, ist auch Bernard Long (1986), der eine Studie zur Verwendung der beiden Lexeme in medizinischen Texten vorgelegt hat. Er geht davon aus, daß $j b$ vor allem ein energetisches Zentrum bezeichne, das oft der Platz von Wahrnehmung und Krankheitssymptomen sei, während ḩ3tj das Zentrum des Blutkreislaufs und die Stelle des Lebens und der Persönlichkeit repräsentiere. Überschneidungen gebe es vor allem bei metaphorischen Verwendungen. Die aus den medizinischen Texten zu ziehenden Hauptbedeutungen der beiden Wörter stellt er sich folgendermaßen vor (Abb. aus Long 1986: 488):

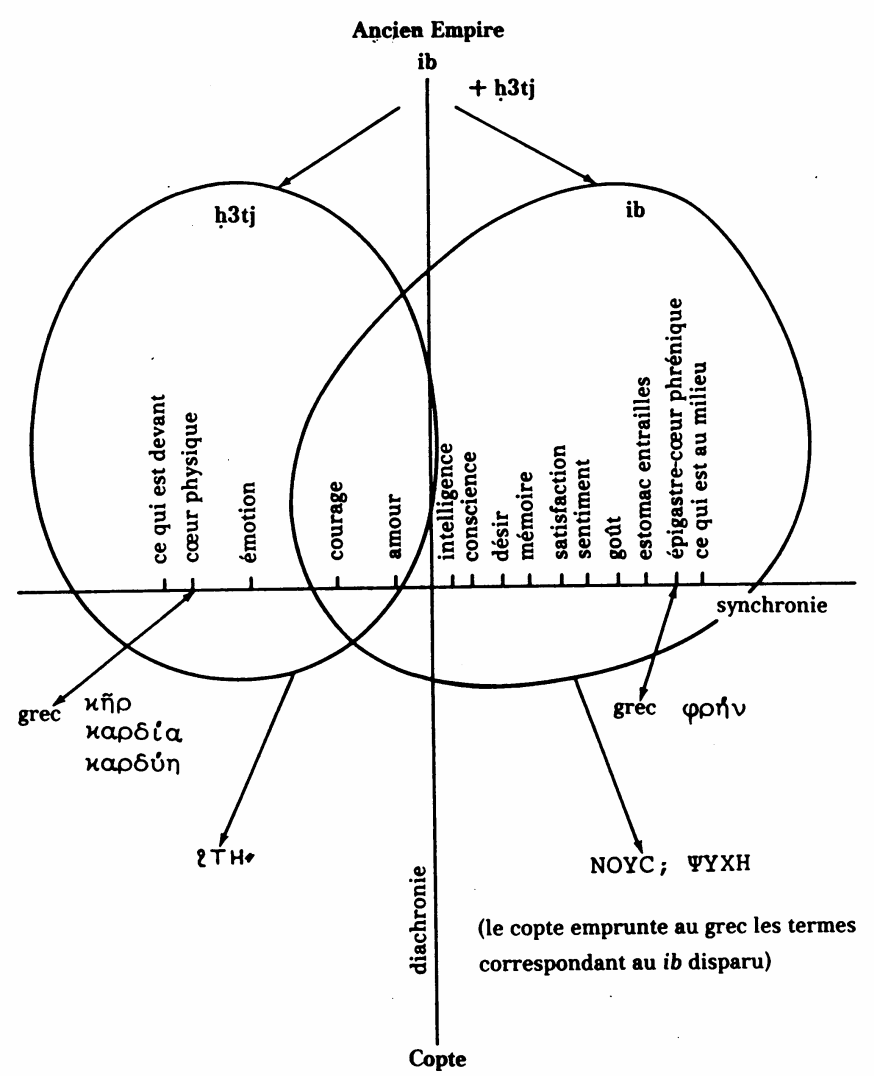


Dabei besitze $j b$ eine körperliche Bedeutung und habe mit der Verdauung zu tun. Der Unterschied zu dem weiter oben skizzierten Ansatz von Walker (1996) ist unübersehbar und manifestiert sich manchmal sogar in völlig unterschiedlichen Auslegungen ein und derselben Quelle. So hat etwa jeder der beiden Autoren jeweils eine ganz andere Meinung über die Interpretation der Passagen Papyrus Ebers 284-293 und Papyrus Hearst 50. ${ }^{52}$ Long (1986) benutzt diese Beispiele, um die Gleichsetzung von $j b$ mit dem Zwerchfell (cœur phrénique), das eine Rolle in der Verdauung spielt, zu beweisen. Im Unterschied dazu wendet sich Walker (1996: 174) gegen die Vorstellung, jb bedeute so etwas wie 'Herz' als Organ, 'Magen' oder 'Epigastrium'. Stattdessen habe das Herz eben keine anatomische Bedeutung, sondern meine 'die Person' oder 'das Selbst'.

Auch wenn diese und andere Autoren eine klare Einteilung vornehmen, bleibt festzuhalten, daß die Semantik der beiden Worte nicht ohne weiteres eindeutig geklärt werden kann und eine einfache Faustregel, wie das eine oder das andere Lexem in einem konkreten Fall zu analysieren ist, nicht gegeben werden kann. Mit der Möglichkeit einer eindeutigen Zuordnung zu Übersetzungsbegriffen sollte man besser gar nicht von vornherein rechnen, denn im Prinzip kann jedes Lexem auch metaphorisch verwendet werden, und da kaum zu erwarten ist, daß zwischen dem Gebrauch von Metaphern in unterschiedlichen Sprachen Deckungsgleichheit besteht, können gleichartige Konzepte in zwei verschiedenen Sprachen mit ähnlichen Bedeutungsfeldern angehörenden Wörtern ausgedrückt werden, ohne daß man auf eine Identität der jeweiligen Denotate schließen darf. Wenn man dann noch bedenkt, daß wir beispielsweise wenig darüber wissen, inwiefern im pharaonischen Ägypten bestimmte Phänomene (etwa Krankheitssymptome) als organisch oder als psychisch bedingt aufgefaßt wurden, wird klar, daß die Versuche fest umrissener Bedeutungszuschreibungen oft zu optimistisch sind.

Neben $j b$ und $h i t j$ gibt es noch einen weiteren Terminus, der in einem Zusammenhang mit dem Herzen steht, nämlich $r^{\prime}-j b$. In den medizinischen Texten kommt die Bezeichnung $r^{\prime}-j b$ häufiger als in anderen Textsorten vor und kann anscheinend mit 'Magen' übersetzt werden ${ }^{53}$, aber die genaue Bedeutung selbst in dieser Textsorte muß immer noch als unsicher gelten. Der Ausdruck bezeichnet wörtlich so etwas wie den 'Mund des Herzen' oder die 'Öffnung des Herzens'. Da Walker (1996: 127 ff.) meint, $j b$ sei in erster Linie mit der Psyche eines Menschen und $h 3 t j$ mit dem anatomischen Organ gleichzusetzen, stellt er die Frage, warum hier $j b$ anstatt ḩitj verwendet wurde. Er geht davon aus, daß, da der 'Mund' hier als Metapher gebraucht werde, auch das Wort 'Herz' ebenfalls metaphorische Funktion übernehme. Die von ihm vorschlagende Übersetzung ist: 'der Raum der Psyche' (the cave of the psyche), was seiner Meinung nach heißen würde: "der Raum, in dem sich das Herz (oder die Psyche) befindet, im Gegensatz zum Raum, im Innern des Herzens (oder der Psyche)" (1996: 129). Er denkt

52 Grapow \&Westendorf (1958: IV, $168 \mathrm{ff})$.

53 Wb. II 393; Grapow \&Westendorf (1961-62: VII 515); Faulkner (1962: 146); Gardiner (1947: II 251). 
über eine Verbindung zwischen Bauch und Psyche nach und vertritt schließlich die Meinung, $r^{\prime}-j b$ bezeichne also das, was eigentlich als Thorax-Struktur bezeichnet wird (Walker 1996: 128-129).

\subsection{4 Ägyptische und ägyptologische Konzepte}

Nicht nur das Herz, sondern auch andere Körperteile wie die Zunge, die Ohren oder der Mund treten in ägyptischen Textquellen in herausgehobenen Funktionen auf. Shupak (1993) teilt die Glieder gemäß ihrer Funktionen auf drei Gruppen auf:

(a) Das mit dem Kenntniserwerb verbundene Organ Ohr.

(b) Die zum Ausdruck von Informationen, Wissen und Gedanken notwendigen Organe Zunge und Mund.

(c) Die Organe, in denen Wissen und Kenntnis lokalisiert wurden, und die nach ägyptischen Vorstellungen die Vermittlung zwischen dem Inneren und dem Äußeren garantierten, nämlich der Leib und das Herz.

Diese drei Gruppen haben die Weisheiten und die Lehren als Mittelpunkt. Die Gruppen (a) und (b) existieren sowohl in der hebräischen Fassung der Bibel als auch im Ägyptischen. Shupak (1993: 276) schlägt vor, daß die zur letzten Gruppe gehörenden Körperteilkonzepte des Biblisch-Hebräischen als eine Übernahme der entsprechenden ägyptischen Vorstellungen $\mathrm{zu}$ verstehen seien, die nur an die jüdische Gottesvorstellungen angepaßt wurde. Ein passendes Beispiel dazu findet man in der biblischen Erzählung von Simson und Delila, die an die ägyptische Erzählung von den Zwei Brüdern erinnert (siehe dazu unten Beispiel E-61 in Kapitel 7). In der ägyptischen Erzählung enthüllt Bata seiner Frau, daß sein Herz auf der Blüte der Pinie liegt, und er deswegen nicht gegen andere erfolgreich kämpfen kann. Im Alten Testament fragt Delila dreimal Simson אהכחידולבךאין אקי איך תאמד "Wie kannst du nur sagen, 'Ich liebe dich', wenn doch dein Herz nicht bei mir ist", und die folgenden Verse 17 und 18 sagen וינר=לת אח=כל=לבר "Da macht er ihr sein ganzes Herz bekannt." Brunner (1954: 140) interpretierte das Herz im ersten Satz als Sitz des Geheimnisses, während der zweite Satz von der Bekanntmachung desselben spricht. Man kann wohl davon ausgehen, daß die Interpretation dieser Bibelstelle auch eine Lösung für das richtige Verständnis des ägyptischen Textes bietet. Es zeigt sich hier, daß aus dem Ägyptischen übernommene und allenfalls nach den gängigen religiösen Vorstellungen veränderten Texte oder Kollokationen in der hebräischen Bibel zuweilen auch eine Interpretationshilfe für die ägyptischen Werke sein können.

Aber nicht nur diese Verwendungsweise des Worts für das Herz wurde in die israelitische Kultur übernommen. Im Rahmen der Weisheiten und den Lehren, die die Grundprinzipien für eine harmonische Gesellschaft thematisieren, hat das Herz eine soziale Perspektive, da es nicht nur zum Individuum sondern auch zu der Gesellschaft gehört. Assmann behauptet (1996: 147), man müsse den sozialen Aspekt in der äußeren Sphäre des Lebens und Handelns 
in der Gesellschaft und den individuellen Aspekt in der inneren Sphäre körperlicher und geistiger Einheit auseinanderhalten. Was für die ägyptische Mentalität privates Leben und persönliche Ethik bedeutet, ist nach der israelitischen Meinung ein Symbol von nationaler Ethik in Bezug auf Gott ('das hörende Herz'), sowie eine Verbindung zwischen dem Gott und seinem Volk, die durch die Metapher 'Steinherz' ausgedrückt wurde.

Nach diesem kurzen Überblick über neuere ägyptologische Arbeiten zum Thema lassen sich die wichtigsten Bedeutungen und Verwendungsweisen der ägyptischen Lexeme für 'Herz' vorläufig wie folgt skizzieren:

(a) 'Herz' als Bezeichnung des Körperorgans. Über das Herz als Körperorgan und das Problem der genauen Identifizierung der Denotate der Lexeme $j b$ und $h j i j$ habe ich bereits in Abschnitt 2.4.3 gesprochen. Dem soll hier bloß noch die Randbemerkung hinzugefügt werden, daß sich die zentrale Rolle des Herzens vielleicht auch darin manifestiert, daß dieses Organ, im Gegensatz zu anderen, bei der Balsamierung Verstorbener normalerweise im Körper belassen wird $^{54}$, und daß krankhafte Zustände im Herzen lokalisiert werden. $^{55}$

(b) Als Organ des Gedankens. Das Herz kann wissen (Ani 2,14-15), denken (Urk. IV 434,8), planen (Urk. IV 1213,14), aber auch ignorant sein (Anastasi V 6,2). In Zusammenhang mit der Religion ist das Herz das Zentrum der Organe, weil der Gott die Welt nach dem Master von drei Körperaktivitäten geschaffen hat, nämlich: ${ }^{56}$

a) Die Sinne nehmen wahr.

b) Das Herz denkt und erkennt.

c) Die Zunge befiehlt es den Gliedern.

Man geht davon aus, daß das Herz eng mit der Zunge verbunden ist, da sie wiederholt, was vom Herzen erdachte wurde, wie beispielsweise in der Götterlehre (Junker 1940: 59ff. und 70ff.), in der Atum als Weltschöpfer dank des Herzes und der Zunge erscheint: "Es entstand ja jedes Gotteswort durch das, was von dem Herzen erdacht und von der Zunge befohlen wurde". ${ }^{57}$

Bei Ani (W-137) steht $j w t j j b$, das ich als 'unbedacht' im Sinn von 'gedankenlos' übersetze. Ein anderes geeignetes Beispiel stammt aus der Bibel (Hos 7,11), in dem Ephraim unbesonnen, töricht handelt, d.h. 'herzlos', weil er eine Schaukelpolitik zwischen Ägypten und Assur betreibt.

(c) 'Herz' als Bezeichnung der Seele oder des Selbsts einer Person. Zur Illustration dieser Verwendungsweise sei vorläufig auf die folgenden, später noch ausführlicher zu behandelnden Passagen aus narrativen Texten hingewiesen:

54 Vgl. dazu etwa Smith \& Dawson (1924: 146).

55 Grapow \&Westendorf (1961-62: VII s. v. jb und $h 3 t j$, ferner 1954: I, 63-72).

56 Brunner (1965: 83).

57 Junker (1940: 87). 
- 'Ich verbrachte drei Tage mutterseelenallein' (E-4) aus der Erzählung des Schiffbrüchigen,

- 'mein Herz war nicht in meinem Leib' (E-27) aus der Erzählung des Sinuhe,

- die Episode, wie das Herz auf der Blüte der Pinie liegt (E-64) aus dem Zweibrüdermärchen,

- die an das Herz gerichtete Aussage 'Du bist mein Ka, der in meinem Leib ist' aus Kapitel 30B des Totenbuches.

Daß 'Herz' für ein Individuum eintreten kann wird etwa auch dadurch deutlich, daß für den Ausdruck 'dein Herz ist bei mir' die Variante 'dein Ka ist bei mir ${ }^{58}$ existiert.

Spiegelberg (1930: 36-37) hat übrigens gezeigt, daß dieser Gebrauch auch im Koptischen noch vorkommt, vgl. beispielsweise:

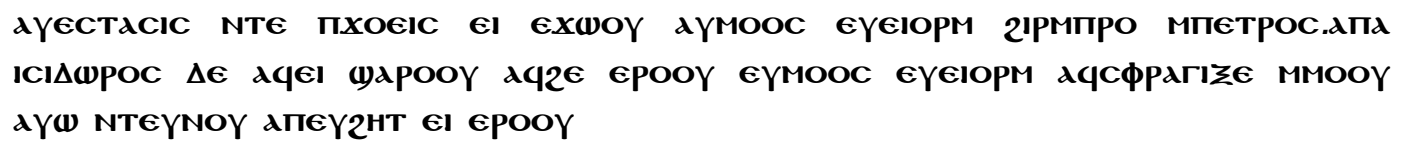

'Da kam eine Verzückung des Herrn über sie, und sie saßen da, indem sie bewußtlos (entrückt) waren an der Türe des Petros. Apa Isidoros aber kam zu ihnen und fand sie sinnenlos (?) dasitzen. Er bekreuzigte sie und sofort kam ihr Herz (wieder) zu ihnen' (Akten des Apa Isidor, siehe BIFAO 14, 1914: 146).

Wenn man auch nicht vergessen sollte, daß dieser Text von Ägyptern christlichen Glaubens verfaßt wurde, die die Seele des Menschen als zentralen Punkt ihrer Religion betrachten und diese Vorstellung möglicherweise von fremden Konzepten übernommen haben, so ist doch offensichtlich, daß diese Texte zumindest nicht in einem Gegensatz zu originär ägyptischen Konzepten standen.

Auch Shupak (1993: 298) ist der Meinung, daß in den ägyptischen Weisheitstexten, wenn man mit dem Herzen spricht, $j b$ den Sinn 'Seele' habe, da das Herz in Verbindung mit $b 3$ und $k 3$ das seelische Innere eines Menschen beschreibe. ${ }^{59}$

(d) Als Sitz des Willens (E-81; E-66). Laut Assmann ersetzt das Herz in dieser Funktion den König in den Inschriften des Alten Reiches (1996: 158).

(e) 'Herz' als Bestandteil von Kollokationen zum Ausdruck von Charakter, Gefühlen oder allgemeinen Befindenszustände einer Person. Dieser Punkt wird im folgenden Hauptkapitel intensiv kommentiert und analysiert.

(f) 'Herz' als Bezeichnung für das Innere, die Mitte oder das Zentrum von etwas. Die Lexeme für 'Herz' wurden von den Ägyptern als Bestandteil zusammengesetzter Präpositionen oder daraus abgeleiteter Ausdrücke verwendet, die oft eine Grundbedeutung wie 'inmit-

58 Urk. IV 115,3, ähnlich Urk. IV 117,13.

59 Das interpretiere ich: 'Ich spreche mit meinem Herzen' bzw. 'Ich spreche zu mir selbst'. Interessanter ist es aber, wenn das Herz gefragt wird, weil es bedeutet: 'ich frage mich selbst' oder 'Ich frage meinen Verstand' (d.h. ich überlege, etwas zu machen). 
ten, im Innern, in der Mitte' besitzen, aber auch lexikalisiert und mit spezifischeren Bedeutungen gebraucht werden können. Es gibt eine größere Anzahl derartiger Kollokationen, von denen an dieser Stelle nur einige genannt werden sollen:

- Bildungen auf der Basis von $m$ - $j b$ 'im Herzen':

$j m(. j)-j b^{\prime}$ Vertrauter, Liebling';

jm.t-j $b^{\prime}$ Gedanke, Wunsch, Begehr';

- Bildungen auf der Basis von $h r$ - jb 'am Herzen':

$h r$ - jb'inmitten';

$h r .(j)-j b$ 'Zentrum, Mitte, Mittelpunkt, Mittelteil', 'Mittlerer', 'residierend in, wohnend in, weilend in';

$h r .(j)$-jb'Körpermitte, Taille';

$m$ - hrr(j.)-jb 'in der Mitte von, inmitten';

hr.t-jb'Zentralraum, Mittelsaal'.

Assmann (1996: 143-144) hat sich im Zusammenhang mit dem Wort 'Herz' als Teil von Lokalausdrücken dahingehend geäußert, daß mit seiner Hilfe drei Stadien der Unterscheidung von Innen und Außen markiert werden, und zwar das Stadium der Indifferenz, das Stadium der Unterscheidung und zuletzt das Stadium des Hiatus zwischen Außen und Innen. Für die Geschichte ägyptischer Herzkonzepte sind die ersten zwei Gruppen dieser Entwicklung wichtiger als die dritte.

(g) Sonstiges. 'Herz' im Sinne von Sehnsucht. Bei Brunner (1965: 87) finden sich zwei Beispiele zu diesem Ausdruck, die lauten: 'Mein Herz ist heimlich fortgegangen und eilt zu dem Ort, den es kennt; es zieht nach Süden, Memphis zu sehen. Ach wenn ich doch nur ruhig dasitzen könnte und auf mein Herz warten, daß es mir berichtet, wie es in Memphis steht! Aber keine Arbeit gelingt unter meiner Hand, da mein Herz von seiner Stelle gerissen ist' und 'der Ort, wo mein Herz den ganzen Tag über weilt.' Das zuletzt genannte Beispiel beschreibt den Gemütszustand eines Mannes, der sich in der Fremde nach seinem Heimatland sehnt. In der Erzählung von den zwei Brüdern will der drei Jahre nach dem Herzen seines Bruders suchende Anubis nach Ägypten zurückkehren (E-64), in der Erzählung des Sinuhe beklagt der Held sich, weil er im Ausland lebt (E-34); ein letztes Beispiel ist die Passage aus dem Schiffbrüchigen (E-6). Das Herz gilt als Träger des Geheimnisses, als Bata sein Herz seiner Frau öffnet (E-61). Religion: Gott (Brunner 1965: 104). Durch das Herz spricht der Gott zum Menschen und der Mensch erkennt den Gott. Ein Beispiel (Brunner 1965: 95) stammt aus der Autobiographie eines Beamtern: 'Ein Gotteswort ist das Herz, das in jedem Leibe ist', 'Gott gibt es in das Herz dessen, den er liebt. Er nimmt es aber fort von dem, den er haßt' (Brunner 1965: 96); aus der Lehre des Amenenope (W-166) 'Das Herz ist die Nase Gottes'. Maat. In Zusammenhang mit der obengenannten Gruppe (c) ist das Herz das Organ, mit dem die Lehren aufgenommen und später mit Hilfe der Maat verstanden werden. Aus diesem Grund ist das Herz unbe- 
dingt nötig, um das rechte Verhalten des Menschen (Maat-gerechtes Leben) zu produzieren. Miosi (1996: 75) behauptet, das Herz sei der Ort, an dem das Individuum das MaatPrinzip findet, und daß das Herz selbst Maat enthält und deshalb göttlich ist (Miosi 1996: 76). Ordnung. Die Rebellen gegen die Ordnung (=Maat) des ägyptischen Staates werden bezeichnet als solche 'deren Herz widersetzlich ist' (Brunner 1965: 89). Umwelt und Skarabäus. Das Herz symbolisiert den Charakter und die Moral eines Mannes beim Totenurteil, deswegen findet man einen Herz-Skarabäus im Sarg als Symbol des Unschuldigen. Ein solches Objekt ist im Pyr. 1162 gemeint 'Gemacht hat sich mein Vater sein Herz, nachdem das andere ihm herausgenommen ist'. Sethe (1934: 114-115) interpretierte den Ausdruck 'sein Herz machen' als 'ihm ein Herz machen', da er ihn für ein Zeugnis für die besondere Behandlung des Herzens bei der Leichenbesorgung, die sich später in den Herzskarabäen manifestierte, hielt. Das Haus des Herzes. Im Grab des Baki (TT 298) aus der Zeit des Haremhab und Sethos I. steht: ".. daß sie (Hathor und Isis) die Herzen im Haus der Herzen und dein Herz im Haus der Herzen geben mögen, damit du deines nimmst, und auf seinen Sitz legst, ohne dich von ihm zu entfernen". Das 'Haus der Herzen' wurde auch im Totenbuch Kapitel 26 genannt; es verbindet sich mit dem körperlichen Glied, welches bei der Mumifizierung im Körper bleibt, oder mit dem seelischen Herzen, das auf der Waage der Maat gewogen wird.

\subsection{Randbemerkung: Hypothesen zur Etymologie der Wörter für 'Herz'}

Von indogermanistischer Seite wurde das indoeuropäische Lexem *kēerd- 'Herz' in einen Zusammenhang mit einer Wurzel *(s)ker-d- 'springen, fröhlich springen' gebracht (vgl. dazu Szemerényi 1970: 934) - die beispielsweise in Mittelhochdeutsch scherzen 'fröhlich springen, sich vergnügen' > Neuhochdeutsch scherzen realisiert ist. Wenn diese Zuordnung sich als richtig erwiese, würde das Herz im Indoeuropäischen ursprünglich so etwas wie 'der Springer' bedeutet haben.

Vor diesem Hintergrund könnte man überlegen, ob nicht womöglich auch im Ägyptischen eine etymologische Beziehung des Lexems i j $j b$ 'Herz' mit altägyptisch $1 \int j b(3)$ 'Tänzer' bestanden haben mag - und eventuell sogar eine Verbindung gezogen werden darf zu dem erst mittelägyptisch belegten (aber wegen der schon früheren Bezeugung des Hieroglyphen-

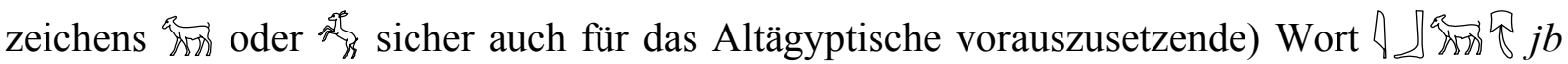
'Böckchen', das gegebenenfalls ohne viele Umstände als 'das Springende' etymologisiert werden könnte. Ein Zusammenhang zwischen $j b$ 'Herz' mit altägyptisch $\uparrow \int j b(3)$ 'Tänzer' ist in der ägyptologischen Sekundärliteratur schon wiederholt postuliert worden. ${ }^{60}$ Durch die

60 Siehe dazu zuletzt Morenz (1999: 100-101 mit Fußnote 11). 
mögliche typologische Parallele im Indoeuropäischen gewinnt der Ansatz, daß $j b$ 'Herz' einmal 'das Hüpfende' bedeutete, an Plausibilität.

\subsection{Zusammenfassung}

Es gibt mehrere Sprachen, die in einem - auf die gesamte Welt bezogen - verhältnismäßig engen historischen und geographischen Zusammenhang stehen und $\mathrm{zu}$ anderen von meinem Untersuchungsgegenstand weiter entfernten Kulturareale gehören, z.B. der chinesische Buddhismus oder die Lehre des Taoismus, die ebenso auf das Herz als Mittelpunkt des Menschen referieren. Im Buddhismus ist das Herz der Quellgrund der Gefühle, der Intelligenz und der Willensäußerung, es ist ebenfalls der Angelpunkt zwischen Mikrokosmos und Makrokosmos, 'Innen und Außen'. Um im Taoismus Tao (den göttlichen Urgrund und die rechte Bahn) zu finden, muß man ein aufrichtiges und vorbereitetes Herz haben; mit anderen Worten: das Herz ist der Platz, an dem man Gott erfährt, und nur ein 'reines Herz' oder ein 'ruhiges Herz' kann Tao kennenlernen.

Dieser Blick auf einige von Ägypten weit entfernte Kulturen beweist, daß das Herz (ungeachtet seiner körperlichen Bedeutung) immer zwei miteinander verbundene Inhalte hatte; einerseits hat es mit dem Wissen zu tun, andererseits mit den Gefühlen. Verstand und Gefühl hatten immer und haben noch eine enge Beziehung mit dem Organ, die sehr früh für einen metaphorischen Gebrauch und eine besondere Bedeutung gesorgt hat, sowohl in der Literatur und Religion als auch in der alltäglichen Sprache der unterschiedlichen Kulturen.

In der folgenden Tabelle lassen sich die Hauptbedeutungen des Wortes für 'Herz' in allen dargestellten Sprachen auf einen Blick betrachten und miteinander vergleichen.

\begin{tabular}{|l|c|c|c|c|c|c|c|c||}
\hline & Latein & Griechisch & Hethitisch & Akkadisch & Hebräisch & Arabisch & Koptisch & Ägyptisch \\
\hline Körperteil & + & + & + & + & + & + & + & + \\
\hline $\begin{array}{l}\text { Verstand, Kennt- } \\
\text { nisse, Gedanken }\end{array}$ & + & + & & + & + & + & + & + \\
\hline Seele & + & + & & + & + & & + & + \\
\hline Wunsch & + & + & + & + & + & + & + & + \\
\hline Charakter & + & + & & + & + & & + & + \\
\hline Gefühle & + & + & + & + & + & + & + & + \\
\hline $\begin{array}{l}\text { Inneres, Mittel- } \\
\text { punkt }\end{array}$ & & + & & + & + & + & + & + \\
\hline
\end{tabular}

Aus dieser Tabelle ergibt sich keine Überraschung. Die Bedeutung, oder besser gesagt, der Inhalt dieses Wortes, hat dasselbe Schema in allen der hier vorgestellten Sprachen (außer im 
nur ganz oberflächlich betrachteten Hethitischen), was bestätigt, daß das Herz schon in alten Sprachen in ähnlicher Weise metaphorisch gebraucht wurde. Interessanter ist der Vergleich einiger unterschiedlicher Bedeutungen des Wortes aus den hier gebrauchten Wörterbüchern, welche unter Sonstiges eingeordnet sind. Die Tabelle macht den Sinn einer komparatistischen Untersuchung deutlich, die unter anderem vor dem Hintergrund der Kultur, der idiomatischen Verwendung und religiöser Konzepte geführt werden könnte. Als Ergebnis dieser Untersuchung könnten eventuell Zusammenhänge zwischen unterschiedlichen Sprachen und Kontexten nachgewiesen werden.

\begin{tabular}{|c|c|c|c|c|c|c|c|c|}
\hline & Latein & Griechisch & Hethitisch & Akkadisch & Hebräisch & Arabisch & Koptisch & Ägyptisch \\
\hline \begin{tabular}{|l} 
vom Herzen, \\
herzlich; 'aus \\
ganzem Herzen'
\end{tabular} & + & + & + & + & + & & + & + \\
\hline \begin{tabular}{|l} 
es liegt jmd. \\
etwas am Herzen
\end{tabular} & + & & & & & & & + \\
\hline \begin{tabular}{|l}
$\mid$ Kern'; Herz als \\
Stamm einer \\
Dattelpalme \\
(auch Knospe \\
und Blatt) \\
\end{tabular} & & + & + & & & + & & \\
\hline |'Herz im Holz' & & + & & & & & & \\
\hline |'Tiefe des Meeres' & & + & & & & & & \\
\hline $\begin{array}{l}\text { 'das Herz des } \\
\text { Löwen' (als Ster- } \\
\text { nenamen) }\end{array}$ & & + & & & & & & \\
\hline 'klopfen lassen' & & & + & & & & & \\
\hline \begin{tabular}{|l} 
'im Herzen (ge- \\
heim)'; Geheim- \\
nisses
\end{tabular} & & & + & & & & & + \\
\hline Gewissen & & & & & + & & & + \\
\hline Selbst & & & & & + & & + & + \\
\hline Quintessenz & & & & & & + & & \\
\hline Spitze, Extremität & & & & & & + & + & + \\
\hline Sehnsucht & & & & & & & & + \\
\hline Umwelt & & & & & & & & + \\
\hline Ordnung & & & & & + & & & + (Maat) \\
\hline
\end{tabular}

Eine ausführliche Untersuchung müßte allerdings eine gewaltige Datenmenge berücksichtigen und würde den Rahmen dieser Studie sprengen. 


\title{
3. Kapitel
}

\section{DIE METAPHER}

\begin{abstract}
"Yo creí que lo que estaba viendo en aquella ciudad no era realmente lo que veía, sino que un zumbido feral había transformado unas cosas en otras, de manera que para mi las piedras en las que tropezaba eran personas petrificadas, y lo arboles que rodean la muralla eran figuras humanas con hojas, y que las aguas de las fuentes fluían asimismo de seres humanos. Hubiera asegurado que las estatuas y las demás imágenes iban a ponerse a andar, que las paredes se pondrían a hablar en cualquier momento, que los bueyes o las ovejas se disponían a emitir un presagio, y que del propio cielo, y de la esfera del sol, iba a desprenderse algún oráculo".
\end{abstract}

(El asno de oro, Apuleyo, Libro II, 1)

\subsection{Kurzer Überblick}

Über ägyptische Metaphern hat erstmals ausführlicher Grapow (1924) geschrieben, und seitdem haben sich andere Ägyptologen mit dem Thema beschäftigt, so etwa Brunner (1980), Guglielmi (1996), Goldwasser (1995). Alle diese Forscher haben ägyptische Beispiele, die entweder Metaphern oder andere "bildliche Ausdrücke" enthalten, zusammen behandelt oder schlugen eine Definition dieser Ausdrücke vor. Grapow (1924: 1-21) unterscheidet zwischen "Vergleich", der durch "wie" oder "mehr als" zwei Konzepte oder Worte in Beziehung zueinander setzt, und "Metapher", welche die vollzogene Gleichsetzung als Identifikation ausspricht. Er meint, die Aufgabe eines jeden bildlichen Ausdrucks sei, etwas Unklares zu verdeutlichen $^{61}$, andererseits führte er uns auch die Problematik einer Beschäftigung mit ägyptischen Metaphern vor Augen, die sich folgendermaßen umreißen läßt:

- Unsere Kenntnisse der ägyptischen Sprache sind zu begrenzt, und die Quellenlage ist zu fragmentarisch, um den Prozeß der Herausbildung und Verfestigung von Metaphern im Detail nachzuverfolgen oder auch nur überhaupt erkennen zu können.

- Die Unmöglichkeit das Ägyptische hören oder sprechen zu können - das heißt das Fehlen von muttersprachlichen Informanten - schränkt die Aussagemöglichkeiten auf all das ein, was in geschriebenen Texten bezeugt ist.

61 Obwohl in solche Fällen derselbe bildliche Ausdruck einen undeutlichen Sinn für uns enthält. 
- Bei der etymologischen Entwicklung und der hieroglyphischen Schreibung von Wörtern haben zwar metaphorische Prozesse mit Sicherheit eine Rolle gespielt, doch muß man besonders vorsichtig sein, wenn man Etymologie und Graphie als Hilfsmittel für die Erforschung von Metaphern benutzen will.

Die Inhalte der bildlichen Ausdrücke wurden von Grapow (1924) nach folgenden Kriterien klassifiziert:

1. nach dem "Vergleichsmittel" oder tertium comparationis, durch den das Subjekt des Vergleichs in Beziehung zu dem Vergleichstoff gesetzt ist, z.B.: Der König (Subjekt) ist wie ein Löwe (Vergleichstoff),

2. nach der Art des "verdeutlichenden Hilfsmittels", das in der Sprache verwendet werde, dessen Funktion nur eine Spielart der Grundfunktion des Vergleichs sei und das weiter in folgende Gruppen zu unterteilen sei:

2.1 Fälle von Schmuck und Übertreibung, die den Gedanken des bildlichen Ausdruckes verdeutlichen sollen (z.B.: "karneolfarbig" statt "blutig"; "küssen der Füße vom Wasser" statt, daß "sie bespült werden"),

2.2 sprichwörtliche Redensarten (z.B.: "Rechttun ist Atem für die Nase"; "wer lebt, dessen Kraut wächst");

2.3 Euphemismen, also Ersetzungen eines Wortes durch einen "besseren" Ausdruck (z.B. seien die Worte "tot sein" oder "sterben" ersetzt worden, um zu vermeiden, ihren Sinn zu deutlich zu nennen),

2.4 Verwendungen in der Namensgebung (z.B. "Löwe" aus dem Vergleich "der König ist wie ein Löwe", was zu der Metapher "der König, der Löwe" wird. Hier hat "Löwe" die Bedeutung 'König' bekommen).

Der Versuch von Grapow (1924) stellt eine erste explizite Klassifikation der "bildlichen" Ausdrücke des Ägyptischen dar. Allerdings ist Grapows Einteilung im einzelnen recht undeutlich und subjektiv, weil kein richtiges Kriterium existiert, durch das jede Gruppe definiert und somit von den anderen abgegrenzt werden kann. Die Konsequenz davon ist, daß die Metapher in jeder Gruppe auftauchen kann. Grapow definiert die Metapher als ein Substantiv, ein Verb oder einen prädikativen Ausdruck, "der in sich selbst die Übertragung enthält" (1924: 4). Seiner Meinung nach sind sowohl Metapher als auch der Vergleich das gleiche Konzept, und der einzige Unterschied zwischen ihnen sei der, daß der Vergleich das Hilfsmittel der expliziten Komparation benutze. Vielleicht kam er zu diesem Konzept durch seinen Versuch, die einzelnen Stufen in der Herausbildung von Metaphern unmittelbar in Textausschnitten zu identifizieren, beispielsweise durch den Hinweis auf mehrere Passagen, in denen jeweils ein hinsichtlich der sprachlichen Ausdrucksmittel etwas anderes Verhältnis zwischen den Begriffen 'König' und 'Stier' eine Rolle spielt (Grapow 1924: 77):

- "der Stier, der für seine Grenze kämpft" (Ramses II.),

- "er wie ein Stier sei, der auf dem Kampfplatz steht" (Ramses III.), 
- "Ramses III., der starke Stier, mit kräftigem Schenkel".

Grapow (1924) nahm diese drei Beispiele als Ausgangspunkt, ohne aber genauer zu definieren, was eine Metapher und was ein Vergleich sein solle.

Etliche Jahre später schrieb Brunner (1974) eine Zusammenfassung im Lexikon der

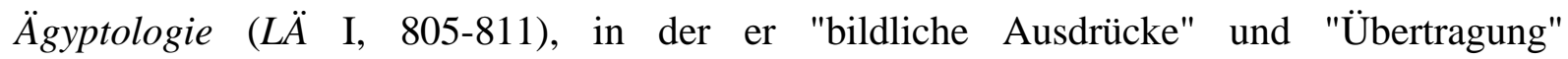
folgendermaßen definierte:

"Bildliche Ausdrücke. Verwendete Worte für etwas Vergleichbares (sei es ein konkreter oder abstrakter Name, sei es eine Eigenschaft oder auch ein Geschehen).

Übertragungen. Bildliche Ausdrücke, wenn das Bild weder dem Sprecher noch dem Hörer bewußt ist".

Der bildliche Ausdruck bestehe danach aus einem Wort (Substantiv, Verb, seltener Adjektiv), und bei seiner Analyse sollte man besonders auf die Etymologie, die Schreibung und hier insbesondere das Determinativ achten. Brunner (1974) illustriert sein mit dem Ansatz von Grapow (1924) fast identisches Konzept mit einigen Beispielen. So werde beispielsweise eine bestimmte Krone etymologisch "die Weiße" genannt, bei dieser Bezeichnung handele es sich nicht um einen bildlichen Ausdruck, sondern um eine geläufige deskriptive Benennung eines Objekt durch einen vorhandenen Ausdruck; trotz seiner Schreibung mit der Vogelhieroglyphe sei das Wort $z 3$ 'Sohn' keine Übertragung von $z 3$ 'Gans'; und schließlich sei das Determinativ mehr Reflex eines konventionell gebräuchlichen Wortbilds als ein bildlicher Ausdruck.

Solche Ausdrücke seien in der Ersten Zwischenzeit, in der Ramessidenzeit und in Biographien der Spätzeit verwendet worden. Sie sollen in Lebenslehren, Sprachdichtung, Autobiographien, medizinischer Fachsprache zur Krankheitsbeschreibung, sowie in Aussagen über tabuisierte Sphären (z.B. den sexuellen Bereich), in Aussagen über den König, über die Götter, in Mythen, Hymnen und Ritualen häufig vorkommen, hingegen in den sogenannten Märchen nicht sehr beliebt gewesen sein.

Vor kurzem schrieb Guglielmi (1996: 484) über den Gebrauch der rhetorischen Stilmittel, und in Zusammenhang mit diesem Thema über die Metapher, die bei den Tropen ("Wendungen" = verba translata, übertragene Ausdrücke, bildliche Ausdrücke) eingeordnet wird. Sie schlägt folgende Klassifikation von Tropen vor:

1. Metaphern: Eine Metapher ist nach Guglielmi (1996) ein Wort in einem Kontext, durch den es so determiniert wird, daß es etwas anders meint, als es "eigentlich" bedeutet. Sie erscheine in unterschiedlicher grammatischer Gestalt (z.B. Nominal- oder Verbalmetapher, mit prädikativen $m$ gebildete Metapher).

2. Vergleich und Gleichnis sind bildhafte Wendungen, bei der das tertium comparationis durch eine syntaktische Fügung verdeutlicht wird.

3. Metonymie, wobei das verbum proprium durch ein anders ersetzt wird, das zu ihm in einer realen Beziehung steht. 
4. Hyperbel, d.h. "Übermaß": Man ersetzt eine dem Gegenstand angemessene Bezeichnung durch einen übertreibenden Ausdruck, der den Sinn vergrößert oder verkleinert.

5. Figuren der Umschreibungen und Verschleierung:

5.1 Antonomasie ("anstelle des Namens").

5.2 Personen-Umschreibung, eine Sonderform der Periphrase durch eine bestimmte Wendung.

5.3 Euphemismus ("gut reden").

5.4 Amphibolie ("Ambigualität").

5.5 Paradoxie ("wider die Erwartung").

5.6 Ironie ("sich in Rede verstellen").

An dieser Entwicklungslinie von Grapow (1924) bis Guglielmi (1996) kann man beobachten, wie sich die Kenntnisse der Rhetorik der ägyptischen Sprache zu einer stärkeren Differenzierung zwischen dem, was eine Metapher ist, und dem, was sie nicht ist, entwickelt haben. Um diese Klassifikation mit geeigneten ägyptischen Beispiele zu verdeutlichen, verweise ich auf den Artikel Guglielmis (1996).

Es wurden hier mehrere Definitionen der Metapher vorgestellt, die eigentlich keinen großen Unterschied zueinander aufweisen. Allerdings ist es keine einfache Aufgabe, selbige zu definieren. Ganz im Gegenteil: Phänomene der Metaphorik sind seit vielen Jahrhunderten ein zentraler Gegenstand zahlreicher linguistischer und sprachphilosophischer Arbeiten (für eine Bibliographie nur der von 1970 bis in die frühen 80er Jahre erschienen Titel siehe Noppen \& Jongen 1985). An dieser Stelle wird eine knappe Skizze gegeben, die nicht mehr bezwecken soll, als einen Eindruck von der komplexen Problematik des Begriffs der Metapher zu vermitteln.

Am Ende dieses Kapitels folgen die ägyptischen Metaphern, mit denen ich versuche, ein tieferes Verständnis von Metaphern zu erreichen und gleichzeitig auf die Grenze ihrer Übersetzbarkeit hinzuweisen. Dabei soll auch beleuchtet werden, vor welchem theoretischen Hintergrund diese jeweils entstanden sind.

\subsection{Was ist eine Metapher?}

Der Ausdruck Metapher (englisch metaphor, französisch métaphore, spanisch metáfora) läßt sich über lateinisch metaphora bis auf das griechische Substantiv $\mu \varepsilon \tau \alpha \varphi \rho \rho \alpha ́$ zurückverfolgen,

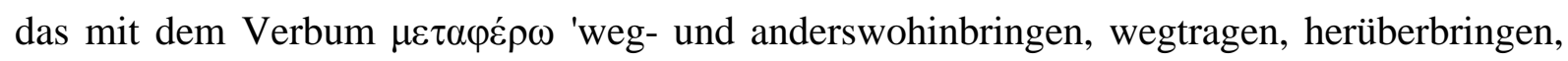
übertragen; verwechseln' zusammenhängt, und demzufolge mit 'Übertragung' widergegeben werden kann. Als alternative Eindeutschung kommt auch die Bezeichnung bildlicher Ausdruck vor. 
Allgemein versteht man Metapher als "der bildliche Ausdruck" (Wahrig, s.v. Metapher). Seit den antiken Rhetorikern, aber auch nach H. Lausbergs Definition (1976: 78) ist die metaphora (translatio; $\mu \varepsilon \tau \alpha \varphi \rho \rho \alpha ́)$ der Ersatz (immutatio) eines verbum propium durch ein Wort, dessen eigene proprie-Bedeutung mit der des ersetzten Wortes in einem Abbild-Verhältnis (similitudo) stehe. Deswegen wird die Metapher auch als abgekürzter Vergleich definiert, da der Vergleich ("der König ist wie ein Löwe") im Grunde exakt der Metapher ("der König, der Löwe") entspreche. Beispiele von Metaphern aus anderen Sprachen sind etwa:

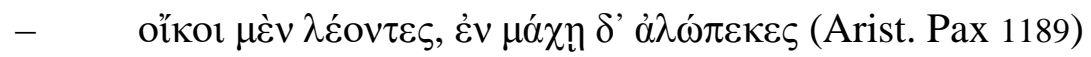

- $\quad$ domini leones, foris vulpes (Petron. 44,4)

- lion: homme hardi et courageux, renard: homme rusé

- lion: courageous person, fox: a crafty man

- $\quad$ leone: uomo forte e croaggioso, volpe: persona astutissima e maliziosa

- león: hombre audaz, imperioso y valiente, zorro, persona astuta y solapada

Nach Aristoteles setzt "die Metapher (...) eine Ähnlichkeit zweier Begriffe voraus, die eine Ersetzung des eigentlichen Wortes (verbum propium) durch ein Wort ermöglicht, das einen ähnlichen Begriff (immutatio) bezeichnet" (Metzler-Lexikon, s.v. Metapher).

Da Aristoteles als Philosoph der erste war, der auf das Phänomen Metapher eingegangen ist und sein Ansatz in der abendländischen Geistesgeschichte eine maßgebliche Rolle spielte, soll ein kurzer Blick auf die Rolle der Metapher in der Philosophie geworfen werden. Ich orientiere mich für das folgende Unterkapitel stark an dem einschlägigen Artikel im Metzler Philosophie Lexikon.

\section{3 Überblick über einige philosophische Ansätze}

Nach dem Metzler-Philosophie-Lexikon wird die Metapher als rhetorisch-poetische Redewendung betrachtet, bei der ein Ausdruck aus seinem üblichen Gebrauchsbereich unter einem bestimmten Hinblick in einem fremden Bereich übertragen wird. Sie wird auch meist als verkürzter, bildhafte Vergleich zwischen gemeinsamen Eigenschaften aufgefaßt. Die Metaphorologie (die wissenschaftliche Disziplin, die die Funktion, die Struktur und die Bedeutung der Metapher für Denken, Erkennen und Handeln in systematischer und geschichtlicher Hinsicht untersucht) unterscheidet zwischen der innovativen Metapher, die eine ganz neue Bedeutung erzeugt, und der konventionellen, aber lebendigen Metapher, sowie der toten Metapher, die zum Begriff mit eindeutiger Bedeutung erstarrt ist.

Seit Aristoteles, der über die Metapher nur in seiner Poetik und Rhetorik spricht, ist die Metapher in der Tradition bis ins 18. Jahrhundert hinein fast ausschließlich als rhetorische Figur betrachtet worden. In der nacharistotelischen Rhetorik ist die Metapher als eine der 
Tropen wahrgenommen und als Bezeichnung für solche Wortübertragungen verwendet worden, denen eine Ähnlichkeit zugrunde liegt.

In Spätantike und Mittelalter begegneten vor allem die Theologen der Metapher mit einigem Mißtrauen. So definierte sie etwa Augustinus als de re propia ad rem non propiam verbi alicuius translatio 'Übertragung irgendeines Wortes von der passenden Sache auf die nicht passende' (De mendacio, 10).

Nach Voltaire (Horace III 1, 1857: 295) sei die Metapher hingegen verdächtig, da sie Ausdruck des Affekts (passion) sei. Mit ähnlichen Verdächtigungen schreibt Friedrich Nietzsche (1920-1929: A, 6, 57) "Das Erkennen sei nur ein Arbeiten in der beliebtesten Metapher", und im 20. Jahrhundert unterstreicht Ludwig Wittgenstein die Problematik der Metapher im Zusammenhang mit dem Unsinnigkeitsverdacht gegen metaphysische Sätze (1977: §§112-115). Eine starke Gegenbewegung gegen die Skepsis an der Berechtigung von Metaphern hatte bereits im 18. Jahrhundert eingesetzt. Sie begann in Italien mit G. Vico (1816), in Frankreich mit Rosseau (1799/1800) und in Deutschland mit Hamann (siehe dazu Gründer 1958).

Seit der Begründung der linguistischen Semantik durch M. Bréal (Essai de sémantique, 1897) betrachtet die Linguistik die Metapher als linguistisches Problem, und deshalb wurde eine lebhafte Diskussion um den linguistischen Status der Metapher seit den 50er Jahren geführt, wobei die Analyse sich ins besondere auf die grammatischen Formen der Metapher richtet. In den letzten fünf Jahrzehnten - nach Freud, der eine Begegnung zwischen Metaphorik und Psychologie bewirkt hat - wird das Phänomen der Metapher auch von der psychologischen Verhaltensforschung beobachtet und als Indiz für Interaktion sozialpsychologisch interpretiert (Asch 1958: 86-94).

\subsection{Theoretische Definitionen}

Eine Möglichkeit zur Bildung einer Metapher besteht nach Ansicht mancher Wissenschaftler darin, auf der Grundlage von zwei vorhandenen Wörtern eine neue Bedeutung zu erschaffen, indem die beiden Wörter mit ihren jeweiligen Bedeutungen zu einem Wort zusammengesetzt werden. So sollte man nicht automatisch die Sprache als objektiv gegebenes Gebilde akzeptieren, sondern auf Grund einer kommunikativen Kompetenz die Sprache als ein kommunikatives Werkzeug wahrnehmen.

Wenn man über Metapher redet, kommen zwei Termini, Topic (bzw. Topik) und Vehicle (bzw. Vehikel), vor, die kurz definiert werden sollen. Topik ist die unkonventionelle Bezugnahme bei einer Metapher und Vehikel die konventionelle. Mit anderen Worten: Der Satz Das Leben ist eine Schokoladendose hat als Topik das Leben und als Vehikel eine Schokoladendose (Goatly 1998: 9). Das Topik kann ein Objekt, eine Eigenschaft, einen Prozeß, ein Konzept oder eine Beziehung enthalten, dagegen ist das Vehikel an sich kein Objekt oder Prozeß, 
sondern es wird als Bild oder Konzept wahrgenommen.

Um eine Metapher zu verwirklichen, soll es nach Goatly (1998: 113) sieben unterschiedliche Möglichkeiten geben. Gleichzeitig deutet er die Problematik einer klaren Definition der Metapher auf der Basis des Topik- und Vehikelgebrauchs an, da sich die Kriterien nicht regelmäßig und ohne Schwierigkeiten anwenden lassen. Er illustriert durch Beispiele die Art der Unkonventionalität (reference/colligation) und die vier, seiner Ansicht nach bei der Interpretation mit einzubeziehenden Elemente (vehicle/topic/part of topic/vehicle construct) (Goatly 1998: Tabelle 4.1).

So unterscheidet Goatly (1998: 116-119) zwischen drei wesentlichen Theorien, wobei als Abgrenzungskriterium die jeweiligen Interpretationsmethoden dienen:

- Als Substitutionstheorie (Substitution Theory) bezeichnete Ansätze (z.B. Black 1962: 224225, Bickerton 1969) definieren Metaphern als direkte Ersetzungen eines bestimmten "wörtlichen Ausdrucks" (literal term) durch einen anderen Ausdruck, die im Grunde rein dekorative Funktionen besäßen. Metaphern besäßen demnach eine feste Bedeutung, die sich durch die Analyse des zugrundeliegenden "wörtlichen Ausdrucks" bestimmen ließen. Goatly (1998: 116-117) verwirft derartige Ansätze - vor allem deshalb, weil sie im günstigsten Fall auf bereits konventionalisierte Metaphern (inactive metaphors) anwendbar seien, doch selbst in diesem eingeschränkten Bereich kaum den Möglichkeiten zur kreativen Verwendung selbst solcher Metaphern Rechnung tragen können.

- Die einseitige Ausrichtung auf inaktive Metaphern wird vermieden in Ansätzen, für die die Bezeichnung Interaktionstheorie (Interaction Theory) geprägt wurde (z.B. Black 1962: 230-231). Die Anhänger dieser Richtung beschreiben die Entstehung einer Metapher als Prozeß, in dem zwei verschiedenen Größen, Topik und Vehikel, von zentraler Bedeutung sind.

- Eine Weiterentwicklung der vorhergehenden Theorie ist die Spannungs- oder Kontroverstheorie (Tensional or Controversion Theory). Nach dieser Theorie ist die emotionale oder logische Spannung, die der semantische Widerspruch zustande bringt, die Hauptwirkung der Metapher (z.B. Berggren 1962; Beardsley 1967).

- Schließlich gebe es die Vergleichstheorie (Comparison Theory), nach der Vergleich und Metapher in ihrer Funktion dasselbe sein sollen (z.B. Mooij 1976). Goatly (1998) meint, die Vergleichstheorie und die Interaktionstheorie seien miteinander vereinbar, und außerdem habe die erste Theorie den Vorteil, daß sie durch die Ähnlichkeit/Analogie (Similarity/Analogy) alle Sorten der Metapher erklärt, nicht nur die Interaktivität zwischen den vergleichenden Termini.

Der Bereich des metaphorischen Ausdruckes ist nach Goatly (1998) sehr weit und durch eine Hierarchie geordnet. In einer hohen Position stehen Metapher, Polysem, Metonymie und Vergleich; hingegen befänden sich Sprichwörter, Clichés, Neologismen, Ironie, Hyperbel und Symbole in einer hierarchisch niedrigeren Position (als verschiedene Ausdrucksformen der in 
der ersten Gruppe genannten Erscheinungen). Von all diesen Größen sind die Metapher und der Vergleich für das Thema meiner Arbeit von entscheidender Bedeutung, und so muß an dieser Stelle zwischen Vergleich und Metapher unterschieden werden. Ricoeur bemerkt dazu (1994: 25):

"The grammatical analysis of simile confirms its dependent status with regard to metaphor in general. They differ only by the presence or absence of a specific term of comparison: the particle like or as in all the quotations. (...) Rather, simile is a metaphor developed further; the simile says "this is like that", whereas the metaphor says "this is that". Hence, to the extent that simile is a developed metaphor, all metaphor, not just proportional metaphor, is implicit comparison or simile."

Die Ansicht, nach der man von einem Unterschied zwischen Metapher und Vergleich auszugehen habe, ist schon von den klassischen Autoren vertreten worden und wird auch heutzutage für gültig gehalten. Für Aristoteles hatte die Metapher eine festere Bedeutung als der Vergleich von zwei Wörtern, und für Quintilian ist sie wichtiger, weil sie die beiden Wörter, die verglichen werden, ersetzt.

Aktuell setzen sich mit theoretischen und methodischen Fragen zur Metapher verschiedene Disziplinen auseinander, insbesondere Literaturwissenschaft, Linguistik (vor allem die stärker an Pragmatik und Kognitionsforschung interessierten Richtungen) und Philosophie (v.a. Rhetorik- und Sprachphilosophie). In der Literaturwissenschaft konzentriert sich die Forschung vor allem auf die Rolle von Metaphern in literarischen Texten. Das Ergebnis solcher, meist recht spezieller Untersuchungen ist allerdings in erster Linie von Relevanz für die Literaturtheorie, weniger für eine allgemeine Theorie der Metapher. Die Philosophie bringt sowohl die Rolle der Metapher als auch ihre Definition ein; die Linguistik erklärt den linguistischen Mechanismus der Metapher und die Verbindung zwischen wörtlicher und bildlicher Sprache; und letztlich betont die Pragmatik den Wert des Kontextes und die außersprachlichen Kenntnisse.

Zusammenfassend läßt sich sagen,

- daß eine Metapher aus (mindestens) zwei Worten besteht,

- und daß man nicht nur die Erkenntnisse von Philologie oder Linguistik berücksichtigen, sondern auch die anderer Fächer beachten sollte, um Metapher in allen ihren Aspekten richtig zu verstehen.

\subsection{Vorschläge zur Klassifikation von Metaphern}

Wenn wir von warmen, kalten, satten oder schreienden Farben sprechen, oder von hellen oder dunklen Tönen, wie könnte dieses Phänomen eines speziellen Gebrauchs der entsprechenden Adjektive allgemein bezeichnet werden? In den besagten Formulierungen kann man die Adjektive als Bezeichnungen für akustische und visuelle Phänomene verstehen; 
aber kann man sie auch als Metapher verstehen? Die Bedeutung der einzelnen Ausdrücke hat zweifellos einen semantischen Hintergrund, der nicht ganz von der "Standardbedeutung" der Lexeme loszulösen ist. Daher wäre es wohl nicht richtig, von einer absoluten Größe Metapher zu sprechen - zumal es im Deutschen für die genannten Fälle keine andere, "nichtmetaphorische" Möglichkeit gibt, dasselbe auszudrücken.

Man muß davon ausgehen, daß für eine Klassifikation der Metapher verschiedene Kriterien relevant sein können. Nicht zuletzt deswegen hat es im Laufe der Zeit eine unüberschaubare Fülle von Forschungsansätzen gegeben, von denen hier bloß einige vorgestellt werden, um einen groben Überblick zu geben.

Bereits bei Aristoteles findet sich ein Klassifizierungsvorschlag, bei dem ein System unterschiedlicher Kriterien von Bedeutung ist (Poetik, 21). Demnach könne man Metaphern nach folgenden Merkmalen auseinanderhalten:

- nach formalen Kriterien (der Art der ersetzten Wortart bzw. "von der Gattung auf die Art"),

- nach syntaktischen Kriterien (der Anzahl der Wörter des ersetzten Ausdrucks bzw. "von der Art auf die Gattung"),

- nach modalen Kriterien (ästhetischen Kriterien bzw. "von der Art auf die Art"),

- nach der Häufigkeit ihres Auftretens in einem bestimmten Zeitraum oder in Texten einer bestimmten Person bzw. gemäß der Analogie.

Der römische Grammatiker und Rhetoriker Quintilian klassifizierte die Metapher nach dem semantischen Kriterium von Belebtheit und Unbelebtheit und stellte vier Gruppe einander gegenüber:

- etwas Belebtes wird für etwas Unbelebtes gesetzt,

- etwas Unbelebtes wird für etwas Unbelebtes gesetzt,

- etwas Belebtes wird für etwas Belebtes gesetzt,

- etwas Unbelebtes wird für etwas Belebtes gesetzt.

Erstaunlicherweise sind auch in der Moderne noch Klassifizierungen von Metaphern im Gebrauch, die solchen antiken Ansätzen sehr ähnlich sehen. Dazu zählt etwa der Vorschlag von Kurz (1982: 21-22), der folgende auf der jeweiligen Art der prädikativen Grundstruktur basierende Klassifikation anbietet:

- Syntaktisch: Mein Gedicht ist mein Messer,

- Attributive Metaphern: schwarze Milch der Frühe,

- Kompositionsmetaphern: Wahllokomotive,

- Appositionsmetaphern: Und dein Schweigen, ein Stein, und

- Genitivmetaphern: Mehr noch als der Zahn der Zeit nagt am Kölner Dom der Zahn der Chemie 
Eine andere Klassifikation wird von Pisarska (1989: 103-109) vorgeschlagen, welche sie in vier Gruppen ordnet: Begriffsmetaphern, Verzierungsmetaphern, neue Metaphern und gebräuchliche (oder: konventionalisierte) Metaphern.

- Begriffsmetaphern sind für sie echte Metaphern und kommen vorrangig in Texten vor, die mit einen besonderen ästhetischen, künstlerischem, symbolischen oder kognitiven Wert verbunden sind.

- Verzierungsmetaphern kommen nach Pisarska (1989) in allen Textsorten vor, spielen eine primäre dekorative Rolle und haben somit eine "Hilfsfunktion".

- Neue und gebräuchliche Metapher sind diejenigen, die entweder noch nicht oder schon länger geschrieben wurden oder eine mündliche Tradition haben oder nicht haben. Das Problem dabei ist, eine klare Grenze zwischen neu und konventionell zu ziehen - vor allem aufgrund der Kurzlebigkeit der gesprochenen Sprache und der Unmöglichkeit, alle schriftlichen Quellen zu überprüfen. Zudem wurden viele gebräuchliche Metaphern auch lexikalisiert und sind damit im Grunde nicht länger als Metaphern zu beschreiben.

Sowohl für die Begriffsmetaphern als auch für die gebräuchlichen Metaphern gilt:

- Sie sind so etwas wie geistige Abkürzungen oder stilistische Abweichungen.

- Sie nützen normalerweise kollektiv vertraute kulturelle Konzepte, können aber auch in privaten imaginären Felder auftreten.

- Konventionalisierte Metaphern gehören als feste Bestandteile mit zum lexikalischen Inventar der jeweiligen Sprache.

Man kann feststellen, daß die Klassifikation für die Metapher im allgemeinen von den jeweils angewendeten Kriterien abhängt. Die Wahl eines oder mehrerer Kriterien bedingt eine Untergliederung des Phänomens Metapher in unterschiedliche Gruppen. Mit anderen Worte: es gibt mindestens so viele Metapherklassifikationen wie Kriterien dafür. Als Zusammenfassung des hier vorgestellten Überblicks über die in der Vergangenheit vorgeschlagenen Klassifikationen füge ich eine Tabelle mit allen Arten von Metaphern und den jeweiligen Klassifizierungskriterien ein.

\begin{tabular}{||c|c|c|c||}
\hline \hline FORMAL & GEBRAUCHSSPRACHE & DIACHRONE DIMENSION & NACH DER ART DES VERGLICHENEN \\
\hline "syntaktisch" & Ästhetik & neue Metapher & Belebtes-Belebtes \\
attributiv & Kunst & gebräuchliche Metapher & Unbelebtes-Unbelebtes \\
Komposition & Symbol & & Belebtes-Unbelebtes \\
Apposition & Kognitiv & & Unbelebtes-Belebtes \\
Genitiv & Dekorativ & & \\
\hline
\end{tabular}




\section{6 Übersetzungsprobleme}

Wie Ricoeur (1994: 79) schreibt, verhält es sich so, daß "To translate is to invent an identical constellation, in which each word is influenced by all the others and, bit by bit, profits from its relation to the whole language." Deswegen müsse man die Bedeutung eines Wortes im Grunde erraten, wobei zusätzlich damit zu rechnen sei, daß es einen nicht eindeutig bestimmbaren Grad an Instabilität der Bedeutung für jedes Wort gebe. Ein Wort mit einer metaphorischen Bedeutung ohne Erklärung gebrauchtes Wort habe dabei als Funktion die semantische Identität des Terminus zu erhalten. Allerdings sei es sehr schwer, die Funktion eines Worts exakt einzuschätzen, da sich die Bedeutung in einem konkreten Gebrauchsfall immer im Spannungsfeld zwischen der allgemeinen Semantik einer lexikalischen Größe und der Semantik des Satzes bewege. Da bei metaphorischem Gebrauch der Unterschied zwischen der allgemeinen lexikalischen Bedeutung und der Bedeutung in der konkreten Aussage erheblich sein kann (und kaum systematisch vorhersagbar ist), gilt für manche Semantiker die Metapher als ein (beabsichtigter) Verstoß gegen die semantischen Regeln einer Sprache und als Ausdrucks, der vom "normalen" Sprachgebrauch abweicht. Andere schlagen vor, Metaphern sollten grundsätzlich auch durch semantische Regeln erklärt werden, was eine Zunahme der Komplexität des semantischen Regelsystems zur Folge haben müßte.

Es wurde bereits ausgeführt, daß die Metapher aufgrund der unterschiedlichen Ansätze zu einer Definition und Klassifikation kein unkomplizierter Gegenstand ist. Diese Situation verschärft sich noch, wenn man es mit Metaphern in einer fremden Sprache oder in mehreren Sprachen zu tun hat, weil verschiedene Einzelsprachen (aber verschiedene Sprachstufen, Dialekte, Soziolekte usw. einer einzigen Sprache) in Hinblick auf ihren Metapherngebrauch mehr oder weniger anisomorph sind.

Für die Übersetzung der Metapher gibt es auch eine bestimmte Terminologie, die hier kurz vorgestellt wird. In Bezug auf die Terminologie sprach Richards (1936) in seiner Studie über "tenor" und "vehicle", die später Newmark (1981: 75 ff.) kritisierte. Er argumentiert gegen die Meinung Richards mit den Begriffen Metapher/Objekt/Bild/Sinn. Für die Erklärung benutzt er das folgende Beispiel: "a sunny smile", the metaphor is "sunny", the object is "smile", the image (vehicle) is the "sun", the sense (tenor) is "cheerful", "happy", "bright", "warm". Damit entfernt er sich von Richards Terminologie aufgrund eines deutlichen Unterschiedes zwischen dem Ausdruck und seinen Bestandteilen.

Eine interessante Arbeit wurde von Dagut (1976) verfaßt, der sich mit Metaphern im Hebräischen beschäftigte und auf die Möglichkeiten ihrer Übersetzung ins Englische einging. Seiner Meinung nach könnten die Metaphern jeweils Wort für Wort übersetzt werden "owing to the existence of universally shared fields of imaginary and structures of imagination" (Dagut 1976: 28). Er unterscheidet zwischen zwei Gruppen:

1. den echten Metaphern, die weiter in drei Untergruppen aufgeteilt werden, nämlich: 
1.1 in Metaphern aus literarischen Texten, Zeitungen und mündlicher Tradition, die heutzutage schon vergessen sind,

1.2 in semantische Erschaffung,

1.3 in Ausdrücke, die Teil des stabilisierten (lexikalisch-)semantischen Inventars der Sprache geworden sind, und

2. den Formen von Bedeutungserweiterungen, die teils sehr eng an die ursprüngliche Bedeutung anschließen, aber auch erheblich davon abweichen können.

Newmark setzt sich mit dieser Einteilung von Dagut (1976) auseinander und spricht sich gegen einen Unterschied zwischen "echter" und erzählender Art von Metaphern aus. Seinerseits schlägt er fünf Gruppen von Metaphern vor (Newmark 1981: 84 ff.):

1. Tote Metaphern (! Die Bezeichnung ist selbst eine Metapher!) als diejenigen, die aus einem Fremdwort stammen;

2. Clichésmetaphern als solche, die zwischen Toten Metaphern und Stamm-Metaphern anzusiedeln seien. Sie könnten zwei Mustern folgen, nämlich erstens einen Komplex aus einem übertragen gebrauchtem Adjektiv (figurative adjective) und einem wörtlich $\mathrm{zu}$ verstehenden Nomen darstellen (z.B. sweet dreams) und zweitens aus einem figurativ zu verstehenden Verb und einem ebenfalls nicht "wörtlich" aufzufassenden Nomen bestehen (z.B.: leave no stone unturned);

3. Stammmetaphern, die kulturelle, universale und subjektive Aspekte haben;

4. Moderne Metaphern, die auf der Basis von einem Neologismus gebildet werden;

5. Ursprüngliche Metaphern, die den "echten" Metaphern nach dem Ansatz von Dagut (1976) entsprächen.

Newmark (1981) geht davon aus, daß bei der Übersetzung dieser fünf Gruppen sieben mögliche Verfahrensweisen angewendet werden könnten:

1. Wenn die Häufigkeit des Vehikels in den zwei Sprachen vergleichbar ist, könne man das gleiche Bild im übersetzungssprachlichen Text wiedergeben;

2. Das Bild des ausgangssprachlichen Texts wird durch ein normales Bild im zielsprachlichen Text ersetzt;

3. Übersetzung durch einen Vergleich;

4. Gebrauch eines Vergleichs mit einer zusätzlichen expliziten Erklärung des Sinns;

5. Die Umwandlung der Metapher zum Sinn;

6. Die Streichung eines überflüssigen oder ungünstigen Ausdruckes;

7. Die Metapher vom ursprünglichen Text wird in Verbindung mit dem Sinn im Übersetzungstext wiedererzeugt.

Es gibt noch eine weitere Klassifikation, die interessante Beobachtungen bietet, die von van den Broeck (1981: 76). Dieser Autor schlägt die folgenden Kriterien vor: die Kategorie, der Gebrauch und die Funktion der Metapher im Zusammenhang mit der Übersetzung. Damit unterscheidet er zwischen "schöpferischen Metaphern" und "dekorativen Metaphern". Die 
erste Gruppe könne wörtlich interpretiert werden; außerdem habe sie auch eine tiefe Verbindung zwischen tenor und vehicle. Sie komme vorrangig in Gedichten, kreativer Prosa und allgemeiner kreativer Literatur vor. Hingegen würden die dekorativen Metaphern vor allem in fiktionaler Literatur, in Zeitungstexten und in alltagssprachlicher Rede benutzt. Der Gebrauch von Metaphern hänge sowohl von der Sprache als auch von der Kultur ab. Zum Übersetzen möchte van den Broeck (1981) je nach Situation drei Strategien angewendet wissen:

1. Bei der sensu stricto Übersetzung sollen der Tenor und das Vehikel der ursprünglichen Sprache in den Übersetzungstext übertragen werden.

2. Das Vehikel der ursprünglichen Sprache solle durch ein anderes Vehikel der Übersetzungssprache ersetzt werden, wenn der Tenor in beiden Sprachen ähnlich ist.

3. Unter Umständen komme nur eine Paraphrase, d.h. die Wiedergabe eines ursprünglichen Ausdruckes als nicht-metaphorischer Ausdruck im übersetzungssprachlichen Text, infrage.

In den voranstehenden Abschnitten wurden die Meinungen von drei Autoren über die Frage der Übersetzung von Metaphern zusammengefaßt. Schon die Existenz einer ganzen Anzahl von Untersuchungen, die sich mit diesem Gegenstand beschäftigen, zeigt, daß wir es offenbar mit einer komplizierten Angelegenheit zu tun haben und eine eindeutige Entscheidung kaum zu fällen ist. Wie soll man also eine Metapher übersetzen? Vielleicht ist es eine kurze, aber klare Anwort dafür, was Mason (1982: 149) als Zusammenfassung von Dagut (1976) schrieb:

"each occurrence of metaphor for translation must be treated in isolation; each of its components must be dealt with in the light of its cultural connotations before a translation of the whole can take place, and account must also be taken of the textual context in which the metaphor is used".

Einerseits braucht man, um eine Metapher zu übersetzen, wegen der genannten Schwierigkeiten ein gewisses Maß an Kreativität; andererseits ist ein genaues Verständnis dessen, was ausgesagt ist, erforderlich, weil Metaphern häufig nicht direkt übersetzbar sind.

Man muß realistisch denken und akzeptieren, daß gewisse Informations- oder Konnotationsverluste bei einer Übersetzung von Metaphern unvermeidlich sind - umso mehr, wenn wir es mit dem Spezialfall einer nur schriftlich überlieferten Sprache, für die es keine muttersprachlichen Informanten gibt, zu tun haben. Dies resultiert nach der in Kapitel 3.4 erwähnten Interaktionstheorie vor allem aus dem Umstand, daß eine Metapher in dem konkreten Kontext eines Texts semantisch unmotiviert erscheinen kann, denn wir können nicht davon ausgehen, daß die Motive für die Schöpfung einer bestimmten Metapher für uns in allen Fällen nachvollziehbar bzw. rekonstruierbar sind. Auch wenn bilinguale Wörterbücher Informationen über den möglichen metaphorischen Gebrauch bestimmter Lexeme enthalten (was nicht immer der Fall ist), kann es schwierig sein, in einem bestimmten Einzelfall den Sinn einer Metapher zu erkennen. Dann stellt sich die Frage, wie es machbar 
ist, eine Metapher so in eine andere Sprache zu übersetzen, daß beim Leser der Übersetzung die gleichen Konnotationen wie beim Rezipienten des ursprünglichen Texts hervorgerufen werden. Daß man dazu gründliche Kenntnisse der Kultur, aus der der Text entstammt, braucht, versteht sich von selbst und dürfte jedem bewußt sein. Weniger im Blick scheinen jedoch viele Übersetzer von Texten aus alten Sprachen zu haben, daß umfassende lexikographische Kenntnisse im Bereich der Zielsprache, in die übersetzt worden soll, genauso wichtig sind, um adäquate Metaphern bilden und Formulierungsfehler vermeiden zu können. Daß man trotz eines Bewußtseins für diese Problematik und eines intensiven Bemühens, dem Rechnung zu tragen, nicht selten an seine Grenzen stoßen wird, läßt sich aber nicht vermeiden.

\subsection{Individuum, Kontext und Kultur}

Der Kontext spielt eine wichtige Rolle, wenn man davon ausgeht, die Metapher habe eine kommunikative Funktion, mit der man ihre Bedeutung besser verstehen kann.

Das Metapherproblem wurde auch in Hinblick auf diachrone Aspekte untersucht (Köhler 1975). Man habe seiner begründeten Ansicht nach davon auszugehen, daß die Bedeutung einer Metapher und ihr Gebrauch historischen Veränderungen unterworfen sein können. Außerdem müsse man die selbstreflexiven Sprachformen beachten, die die Kommunikationsströme innerhalb einer Sprachgemeinschaft gewährleisten und den einzelnen Sprechern erlauben, ihre geistige Individualität in differenzierten Formen auszudrücken. Daraus können natürlich wiederum insofern neue Probleme erwachsen, als die verschiedenen Denkweisen der Individuen Schwierigkeiten beim Verstehen einer Metapher darstellen. Der Grund dafür ist die Unmöglichkeit, die kognitiven und kommunikativen Intentionen einer einzelnen Person zuverlässig zu rekonstruieren.

Ein Grundprinzip aller Sprachen ist die symbolische Transformation von Wirklichkeitserfahrungen und dem Verhältnis des Individuums und der Gemeinschaft zur Welt in sprachliche Zeichen mit Hilfe von Kategorisierungsprozessen. Das geschieht durch einzelne Zeichen oder Zeichenkombinationen, die nach jeweils wechselnden Kriterien und Zielsetzungen interpretiert werden.

Schon vor langer Zeit schrieb der Sprachphilosoph Richards (1936: 99ff.) über die Metapher und behauptete, die Bildung von Metaphern sei nicht nur ein stilistisches Ornament, sondern müsse auch als grundlegende Tätigkeit verstanden werden, die jeder Sprecher in seinen Gedanken und seiner Redeweise benutzt. Zur Identifizierung und Interpretation einer Metapher sollte man den Standpunkt der Sprechenden einnehmen, das heißt, sich am Bewußtsein der Sprechenden und ihrer Sprache orientieren. Gerade, wenn eine Metapher lexikalisiert wird, spiele der außersprachliche Kontext eine wichtige Rolle. So gebe es zum 
Beispiel politische Metaphern, die von der Antike bis heute auf eine sehr ähnliche Weise gebraucht würden und mit den Größen Organismus, Familie und Schiff zu tun haben. Die Metapher des Schiffes werde insbesondere in Krisenzeiten benutzt, im Sinne der Ordnung und Einheit gegen die Gefahr des Untergangs: "Wir sitzen alle in einem Boot, und wenn jemand sich nicht an die festen Positionen und Hierarchien von oben nach unten hält, bringt er alle in Gefahr," ist eine häufig verwendete Metapher, die darauf abzielt, Kritik an den herrschenden Verhältnissen und an unpopulären Maßnahmen der jeweils herrschenden Gruppe zu diskreditieren. Eine in eine ähnliche Richtung zielende Variante ist die Krankheitsmetapher, welche die Korruption und angebliche Unordnung einer Gesellschaft anprangert. Als extremes, seinerzeit aktuelles Beispiel dazu nannte Richards die antisemitische Rhetorik des Nationalsozialismus, in der "die Juden" unter anderem als "Pest" oder "Krebsgeschwür" identifiziert wurden. Es dürfte nur wenige andere Metaphern geben, an denen das manipulative Potential, das Metapherngebrauch unter Umständen auch haben kann, deutlicher erkennbar ist als an der Krankheitsmetapher.

Der Kontext ist sehr wichtig und man muß berücksichtigen, daß er auch von Sprecher und Hörer, von Schreiber und Leser, von der Situation und vom betreffenden Gegenstand abhängt. Wenn es darum geht, ob man einen Satz wörtlich oder metaphorisch verstehen soll, und man eine Entscheidung für eine der beiden Möglichkeiten treffen muß, ist es in erster Linie der außersprachliche Kontext, der uns helfen kann.

Ein wörtliches Verstehen einer Metapher ohne ihre eigentliche Bedeutung zu erkennen, würde zu einem völlig falschen Verständnis einer metaphorischen Aussage führen, weil sich dieses Verstehen auf ihre wörtliche Bedeutung und nicht die dahinter verborgene Übertragung bezieht. Wie kann man eine Metapher also richtig interpretieren?

Beim wörtlichen Sprachgebrauch geht der Empfänger einer metaphorischen Aussage von der Existenz einer ursprünglichen Grundbedeutung für diese Metapher aus, er identifiziert die wörtliche mit der etymologischen Bedeutung, indem er die Aussage Wort für Wort untersucht. Wird die Aussage in ihren Kontext gestellt, gewinnt die Bedeutung einen situationsabhängigen Bezug und wird letztlich nicht mehr als Eigenschaft des syntaktischsemantischen Satzes, sondern als Eigenschaft einer Äußerung wahrgenommen. Darauf muß der Empfänger erwägen, ob die kommunikative Situation, die der Aussage zugrunde liegt, eine metaphorische Bedeutung derselben zuläßt. Während dieses Prozesses "aktualisieren wir auf der Suche nach Sinn nicht nur die lexikalische Bedeutung des Ausdrucks, sondern auch einen diffusen, daher suggestiven Komplex von implizierten Vorstellungen, Ansichten, Wertungen und affektiven Besetzungen" (Kurz 1982:21-22).

Der Versuch, dem metaphorischen Sprachgebrauch den wörtlichen gegenüberzustellen, erinnert an die Probleme des aristotelischen Ansatzes. Aristoteles meinte, die Schwierigkeit dabei sei, sowohl den wörtlichen als auch den metaphorischen Begriff richtig zu verstehen, und darüber hinaus sollen beiden Ausdrücke dieselbe Bedeutung haben. 
Kultur und Kontext sind, wie schon mehrfach betont, entscheidend, um eine Metapher korrekt verstehen zu können. Allerdings darf man auch nicht vergessen, daß das Individuum zumindest potentiell die Fähigkeit hat, eine Metapher zu erschaffen. Deswegen geht man davon aus, diese Begabung sei universal. Andererseits hat jedes Individuum eine besondere Persönlichkeit, und trotzdem benutzt jede Person innerhalb einer Sprechergemeinschaft dieselbe Sprache. Unter diesen Umständen erscheint es vernünftig anzunehmen, der normale Gebrauch einer Sprache sei für alle diejenigen verstehbar, die diese Sprache beherrschen, während ein metaphorischer Ausdruck nur für diejenigen verständlich wäre, die dieselben Kenntnisse, denselben Wissenshintergrund, dieselben Ansichten, Haltungen, Glaubenvorstellungen usw. haben.

Womöglich kann die Befähigung, Metaphern zu schaffen, bei einzelnen Sprechern sehr unterschiedlich entwickelt sein. Für Mayenova (1979) ist es auch aus diesem Grund wichtig, die noch lebendigen von den toten Metaphern, die poetische von der wissenschaftlichen Sprache und die sprachliche (bzw. wörtliche) von der rhetorischen/poetischen Metapher zu unterscheiden. Ein Hilfsmittel dafür ist die Wahrnehmung der grundlegenden menschlichen Erfahrungen, die sich auf die Verwandtschaft, Gemeinschaft, das Ritual, die Arbeit, die Instuitionen, Wertvorstellung etc. beziehen, und die nach Lakoffs und Johnsons Meinung (1980) die metaphorische Darstellung von Erfahrungen einer spezifischen Kultur sind, wodurch sich gleichzeitig eine Kultur von anderen unterscheidet. Deshalb gebe es solche Metaphern, deren Übersetzung in eine andere Sprache nicht direkt möglich ist. Es ist allerdings einfach zu erklären, welche man übernehmen kann: die Nachkommen der ursprünglichen Metapher, die aus derselben Kulturlandschaft kommen. (z.B. Griechenland, römische Mythologie, religiöser Glauben).

Zum Schluß zitiere ich Pisarska (1989: 115) als Zusammenfassung:

"Similarly, metaphor in translation should be considered at two levels - at the level of language and at the level of the value of metaphor for the whole work. In other words, metaphors which combines metaphorical, cognitive, conceptual, creative, intellectual artistic, symbolic, and functional elements and, as the last point, its linguistic character."

\subsection{Metaphern in der ägyptischen Literatur}

In den vorausgehenden Abschnitten wurde dargestellt, wie man "moderne" Metaphern übersetzen und mit welchen Problemen man dabei konfrontiert sein kann. Wenn entsprechende Überlegungen bei der Beschäftigung mit der ägyptischen Literatur gemacht werden sollen, tauchen mehrere Schwierigkeiten auf.

Natürlich könnte man versuchen, auch ägyptische Metaphern nach einer der zuvor in Kapitel 3.5 genannten Klassifikationen zu ordnen. Gemäß der erwähnten Klassifikation von 
Kurz fände man beispielsweise attributive Metaphern wie "ein hitziges Herz" (W-15) bei Ptahhotep oder Kompositionsmetaphern wie "der Großherzige" (W-14). Eine mechanisch Aufteilung auf die für andere Sprachen nach grammatischen Kriterien vorgeschlagenen Typen erscheint allerdings nicht besonders fruchtbar (siehe dazu unten in diesem Unterkapitel sowie in Abschnitt 5.3).

Man kann nicht sicher entscheiden, ob es tatsächlich Metaphern mit einer rein dekorativen Funktion in ägyptischen Texten gibt. Manche Metaphern in ägyptischen Texten können nicht rein dekorative Elemente sein, weil ihnen eine erklärende Funktion beigefügt ist (z.B. W-81: "Ein Mann, den kann man nicht verdrehen, solange das Herz sein Türwächter ist"; W-79: "Dring in die Schriften ein und gib sie in dein Herz, damit sich alles, was du sagst, erfolgreich realisiert"), und in anderen Fällen sind unsere Kenntnisse nicht ausreichend, um zu entscheiden, ob wir es tatsächlich mit dem überflüssigen Gebrauch eines Wortes mit einer metaphorischen Absicht zu tun haben. Ebenso ist es sehr schwer abzugrenzen, ob es sich um eine Cliché-, Begriffs-, Neu- oder Gebrauchsmetapher handelt, da die überlieferten Texte nur einen verschwindend geringen Ausschnitt dessen, was die ägyptische Sprache war, darstellen und es kaum möglich ist zu sagen, wie stark ein bestimmter Metapherngebrauch in der lebendigen Sprache der jeweiligen Epoche verbreitet und konventionalisiert gewesen sein mag.

Es ist übrigens nicht so, daß - aus der heutigen Perspektive betrachtet - alle ägyptischen Metaphern tote Metaphern wären. Im Gegenteil, es ist nicht schwer, aktuelle Metaphern, die ähnliche Bedeutungen wie die ägyptischen Metaphern haben, zu finden. So existieren beispielsweise in der ägyptischen Literatur Metaphern mit dem Vehikel 'Schiff' (bzw. 'Teil eines Schiffs'), die nicht nur ohne weiteres von modernen Lesern verstanden werden, sondern fast in derselben Form auch in unserer Sprache auftreten könnten. Ein einschlägiges Beispiel ist die folgende Passage aus der Erzählung des Beredten Bauern (Parkinson 1991: B1 298):

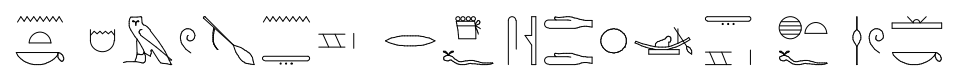
ntk hmw
$n-t^{3} \quad r-\underline{d} r=f s q d d$
t) $h f t \quad w d=k$

Du bist das Steuerruder des ganzen Landes, das Land fährt gemäß deines Befehles.

In der Lehre des Amenenope steht (W-164): "Sei gewichtig durch deinen Charakter, mache dein Herz standfest und sei nicht der Steuermann deiner Zunge. Die Zunge eines Mannes ist das Steuerruder eines Schiffs, und derer Allherr ist sein Lotse".

Die Metapher für Krankheit, die sich auch auf die Politik oder den Feind bezieht, steht oft in den Texten, wie z.B. bei Ptahhotep (W-22):

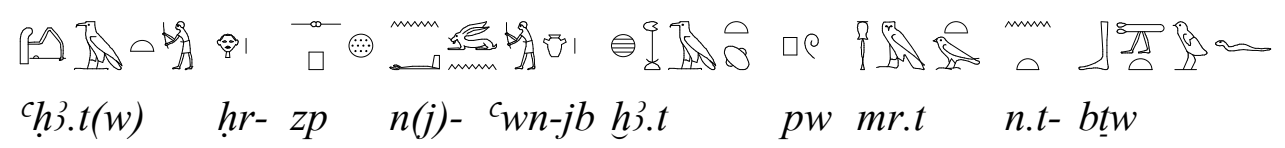


Hüte dich vor (jedem) Anflug von Habgier. Das ist etwas Krankhaftes und ein unheilbares Übel. ${ }^{62}$

Das Herz ist anscheinend ein besonders für die Bildung von Metaphern prädestiniertes Wort, weil es in vielen Sprachgemeinschaften eine besondere Rolle in metaphorischen Schöpfungen gespielt hat.

Zuvor wurde über die Übersetzungsprobleme einer Metapher gesprochen. Aber im Zusammenhang mit den ägyptischen Texten verschärft sich das Problem, da es oft nicht bloß um die Nuancen der genauen Auslegung eines metaphorischen Ausdruckes geht, sondern darum, überhaupt herauszubekommen, wie die entsprechende Stelle, handele es sich um eine Metapher oder auch nicht, zu interpretieren ist.

Abschließend kann man sagen, daß ägyptische Metaphern nur in eindeutigen Fällen verstehbar sind, und zwar in solchen, in denen sowohl die Grammatik als auch der Sinn und die Semantik nicht sehr problematisch sind, z.B. bei Ptahhotep (W-32) "Leben, Wohlbefinden und Gesundheit eines Menschen sind sein Herzenswunsch". ${ }^{63}$

Allerdings gib es mehrere Möglichkeiten, die Metapher kontextabhängig zu übersetzen, und deshalb hätte dieser Ausdruck aufgrund der kleinen Nuancen unterschiedliche Bedeutungen. Und genau das ist es, was man mit einem Vergleich des Textes in Verbindung mit dem Kontext neu erfinden kann. Allerdings werden im Verlauf dieser Arbeit in Bezugnahme auf das Thema nur solche Metaphern widergegeben, welche Gefühle ausdrücken.

Probleme bereiten hierbei Ausdrücke, die sehr schwierig zu übersetzen sind. Im diesem Falle sollte man entweder eine Vermutung über deren Bedeutung anstellen oder versuchen, sie zu paraphrasieren, z.B. $m h-j b$ "das Herz füllen" wird als "vertrauen" übersetzt; es kann aber auch eine andere mögliche Bedeutung haben, wie "naiv" (siehe Kapitel 5.2.2), und diese Nuance findet man nur durch den Kontext heraus.

Gibt es eindeutige grammatische Kriterien, um eine Metapher in einem ägyptischen Text zu erkennen? Zuvor wurde gesagt, daß eine Vergleichs-Metapher eine Art von Metapher ist (Goatly 1998: 116-119). Vergleiche werden in den ägyptischen Texten durch die Präposition $r$ gebildet, wie z.B. bei Merikare (Helck 1977: § IXP)

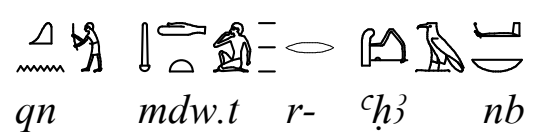

"Die Rede ist effektiver als jeder Kampf."

Allerdings tritt dieselbe Konstruktion natürlich auch in Aussagen auf, die überhaupt nicht metaphorisch zu verstehen sind.

62 Junge (2003: 196) übersetzt: "Sie ist eine schmerzhafte Krankheit, der man aus dem Weg gehen sollte".

63 Zur Richtigkeit dieser Aussage siehe Kapitel 8.4.2 Die übersetzungssprachliche Wiedergabe der Lexeme für 'Herz'. 
Äußerungen, die man mit Sicherheit als Fälle von Metapherngebrauch interpretieren wird, können im Ägyptischen beispielsweise die Gestalt eines Satzes mit Verbum haben, als Nominalsatz mit oder ohne Demostrativpronomen $p w$, oder als Adverbialsatz mit der Präposition $m$ - 'in (der Rolle von)' auftreten:

Urk III 20, Pianchi 54

hmw $p w$ jb

'Das Herz ist das Steuer'

Merikare (Helck 1977: § IX)

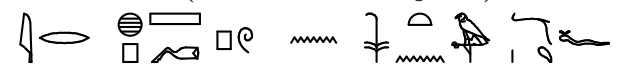

jr hpš́ $\quad p w n \quad n s w \quad n \underline{d} s=f$

"Denn die Kraft eines Königs ist seine Zunge."

Merikare (Helck 1977: § XXXV)

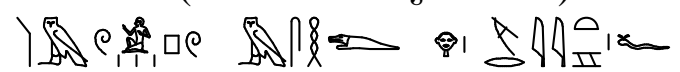

c3m.w pw msh hr mry.t=f

"Die Asiaten sind das Krokodil auf seinem Ufer."

W-130: 'Sorge dafür, daß dein Herz so wie ein mächtiger Damm wird, wenn die Flut an seiner Seite stark ist'.

Amenemope (Budge 1923: XXIV,8)

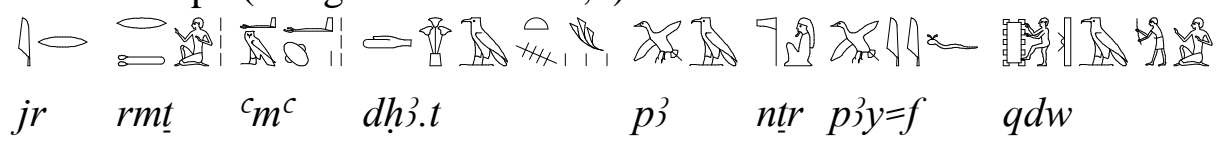

"Der Mensch ist Lehm und Stroh, sein Gott ist der Schöpfer."

Allerdings ist jede grammatikalische Form möglich, um eine Metapher zu bilden, immer wenn Topik und Vehikel im Satz stehen, d.h. ein Satz wie "ich bin dein Vater" kann als Nominalsatz konstruiert werden, und trotzdem keine Metapher sein; andererseits wenn "dein Vater" als ein Gott zu interpretieren ist, stellt der Satz eine Metapher dar. Es muß also festgehalten werden: ein eindeutiges grammatisches Indiz zur Identifizierung von Metaphern gibt es im Ägyptischen nicht.

Leider sind die Beispiele von Metaphern über Gefühle entgegen der zunächst von mir gehegten Erwartungen nicht zahlreich. Es gibt allerdings viele Ausdrücke, deren Sinn man metaphorisch interpretieren kann. Wenn das Herz sich mit seinem Träger oder mit einer anderen Bedeutung (Wunsch, Gedanke, Erinnerung etc.) identifiziert, werden diese Begriffe hier aufgenommen, außerdem muß man einerseits unterscheiden, ob das Herz eine echte Metapher 
oder einer metaphorischer Ausdruck ist, andererseits ob es einen metaphorischen Sinn hat. Das ist machbar dank des Kontextes, jedoch nicht immer verständlich. Dieser Prozeß kann mit dem folgenden Schema skizziert werden:

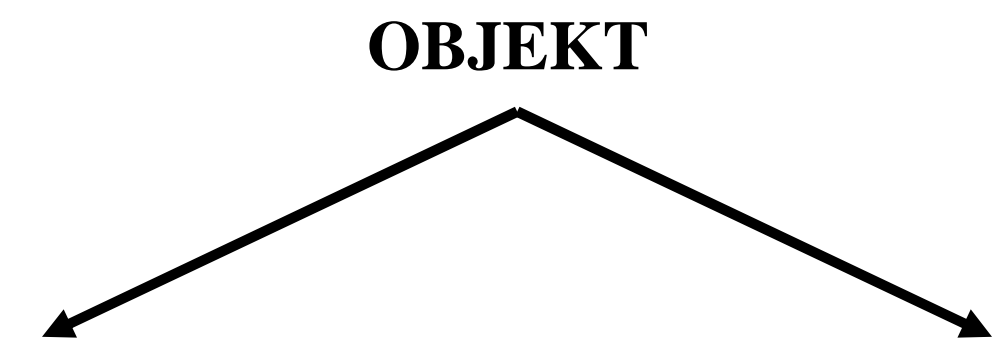

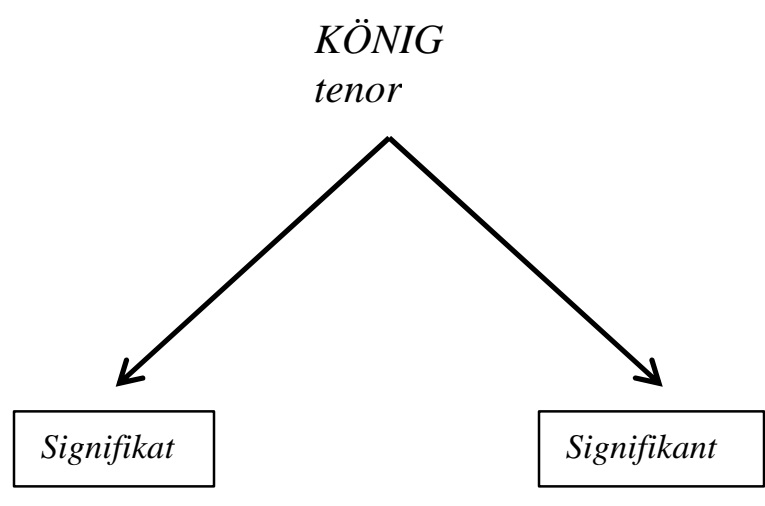

kœniç

belebt lœ:v?
human
adult
Königreich
mächtig Metapherbereich
mutig

\section{LÖWE}

vehicle

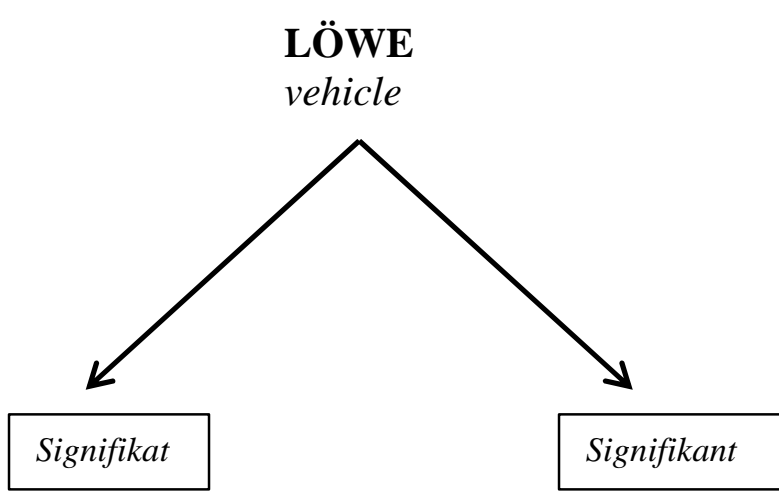

fürchtet

Tier

adult

Tierreich

mächtig

mutig

Der König ist ein Löwe = Der König ist mutig

Der König ist mächtig 
Im Zusammenhang mit Metaphern soll auch die Frage nach metaphorischen Prozessen in der ägyptischen Schrift kurz angeschnitten werden, obwohl Schrift kein spezieller Gegenstand dieser Untersuchung ist. Der Unterschied zwischen unseren modernen Schriften und der ägyptischen ist, daß in den gängigen Buchstabenschriften normalerweise keine bildlichen Zeichen vorkommen. In den modernen Kulturen begegnen allerdings auf Schritt und Tritt konventionalisierte Systeme bildhafter Zeichen mit ganz speziellen Funktionen, z.B.: Die Figuren und Farben von Fußgängerampeln, Beschilderungen nach der Straßenverkehrsordnung, ikonische Zeichen im öffentlichen Raum (z.B. ein Finger auf dem Mund, der "Ruhe" bedeutet), zwei einander überschneidende Kreise im Fernsehen ("Dolby Sound"), welche alltäglich benutzt werden. Dieses System wurde aus dem sprachlichen System durch eine Abstraktion entwickelt, die wir entziffern können. In Ägypten geschah nach Ansicht einiger Forscher(innen) der umgekehrte Prozeß, indem die Ägypter den metaphorischen Inhalt eines Wortes hätten benutzen können, um bestimmte Zeichen ihres Schriftsystems zu kreieren. Ausführlich mit dem Gegenstand der Metaphern in der ägyptischen Hieroglyphenschrift hat sich Goldwasser (1995 und 2002) auseinandergesetzt. Die wichtige Rolle, die sie metaphorischen Prozessen zuschreibt, wird aus dem folgenden Zitat deutlich;

"The newly invented tools of thought, which we have names icons, pictorial metaphors, and phonetic metaphors are clearly represented and exemplified. Metaphor reigns over reality: from the icons to phonetic metaphors via other forms of metaphor, the world is represented as a conceptual cosmos, and reality is subject to human cognitive faculties." (Goldwasser 1995: 25)

Ihr Ansatz geht dahin, zu beweisen, daß die Hieroglyphen Gemeinsamkeiten mit dem Wortkonzept der modernen Semiotik haben, da die Hieroglyphen sowohl den Signifikanten als auch das Signifikat beinhalten und in komplexe Bezeichnungsrelationen der Art Signifikanten, Signifikat, Bild, Konzept und Kontext eintreten, die den entsprechenden Verhältnissen gesprochensprachlicher Zeichen entsprechen. Das wird von der Autorin anhand zahlreicher Beispiele illustriert. Sie meint (Goldwasser 1995: 52), die Hieroglyphenschrift sei ein schriftliches System, welches die sechs von Jakobson (1987) vorgeschlagenen kommunikativen Funktionen antreibt, und zwar:

- Die refentielle Funktion betont das bildliche Wesen, wenn die ikonographische Information nicht abzulegen ist, d.h. die meisten der Determinative tragen zur refentiellen Information bei.

- Die emotive Funktion läßt nicht das Wort phonetischerweise objektiv ausdrücken, weil der Schreiber seine emotionale und persönliche Haltung im Wort beiträgt.

- In der conativen Funktion spielt eine wichtige Rolle der metaphorische Sinn der Schrift, weil der Leser lieber ein Dolmetscher als ein unberührter Leser ist.

- Die phatische Funktion drückt sich durch das einseitige Zeichen aus, welches vom Leser zur Entziffert der Schrift benutzt wird. 
- In der metalinguistischen Funktion wurde das Determinativ sowohl als eine metalinguistische Erklärung als auch als ein Hilfsmittel überschüssiger Information wahrgenommen.

- Die poetische Funktion ist die ästhetische Funktion der Sprache, wobei das bildliche gebrauchte Mittel eine wichtige Rolle spielt (graphic rhetoric nach Derrida).

Zum Schluß dieses Blickes über die Hieroglyphen und ihr "metaphorisches" Entstehen soll Derrida (1976: 90) zitiert werden, der schreibt:

"As pictogram, a presentation of the thing may find itself endowed with a phonetic value. This does not efface the "pictographic" reference which, moreover, has never been simply "realistic". The signifier is broken or constellated into a system: it refers at once, and at least, to a thing and a sound. The thing is itself a collection of things or a chain of differences "in spaces"; the sound, which is also inscribed within a chain, may be a word; the inscription is then ideogrammaticals or synthetic, it cannot be decomposed; but the sound may also be an atomic element itself entering into the composition: we are dealing then with a script apparently pictographic and in fact phonetico-analytical in the same way as the alphabet."

Nach dieser kurzen Abschweifung zur Metaphorik der Hieroglyphenschrift wird im nächsten Kapitel das eigentliche Thema "Metaphern" wieder aufgenommen. 


\section{Kapitel}

\section{DIE EMOTIONEN}

LXXIII

Had I no eyes but ears, my ears would love That inward beauty and invisible; Or were I deaf, thy outward parts would move Each part in me that were but sensible:

Though neither eyes nor ears, to hear nor see, Yet should I be in love by touching thee.

\section{LXXIV}

Say, that the sense of feeling were bereft me, And that I could not see, nor hear, nor touch, Yet would my love to thee be still as much;

For from the stillitory of thy face excelling

Comes breath perfumed that breedeth love by smelling.

(W. Shakespeare, Venus and Adonis, 433-444)

\subsection{Gegenstand und Wortbedeutung}

Im Folgenden wird eine zusammenfassende Darstellung unterschiedlicher Ansätze zur Definition des Konzepts der Emotion präsentiert. Um eine generell tragfähige Definition des Begriffs der Emotion zu liefern, wäre eigentlich eine intensive Auseinandersetzung mit psychologischen, neurologischen und philosophischen Ansätzen erforderlich. Das ist im Rahmen dieser Arbeit, die von ihrer Ausrichtung her nicht unbedingt psychologisch, medizinisch oder philosophisch ist, jedoch nicht durchzuführen. Auch wenn mein Ziel nicht eine theoretischallgemeine Klärung des Begriffs ist, erscheint eine zumindest oberflächliche Kenntnis gängiger Konzepte über Gefühle unverzichtbar, um über Gefühlsmetaphern sprechen zu können. Aus diesem Grund werden hier in aller Knappheit sowohl einige Vorschläge zur Definition des Terminus 'Emotion' angeschnitten wie auch Untersuchungen vorgestellt, die sich mit kognitiven Prozessen und der Versprachlichung von Emotionskonzepten in unterschiedlichen Kulturen auseinandersetzen.

Im Englischen bedeutet emotion "a strong mental or instinctive feeling such as love or fear; emotional intensity or sensibility", während als Bedeutung für feelings "a particular emotional reaction; a physical sensation" angesetzt wird. ${ }^{64}$ Young (1947: 51) präzisiert die Definition der Emotion als "an acute disturbance of an individual, psychological in origin, involving behaviour, conscious experience, and visceral functioning".

64 Siehe The Concise Oxford Dictionary (s.v. emotion; feeling). 
Im Spanischen werden emoción als "alteración del ánimo intensa y pasajera, agradable o penosa, que va acompañada de cierta conmoción somática" und sentimiento als "estado afectivo del ánimo producido por causas que lo impresionan vivamente" beschrieben. ${ }^{65}$

Die Encyclopadia universalis der französischen Sprache erklärt den Begriff émotion folgendermaßen: "A l'émotion correspond aussi une hypertonicité à toute action. Une réaction tonique mesurée est un prélude à toute action. Dans ce cas, elle est localisée. Dans l'émotion, au contraire, elle est diffuse, généralisée. Elle paralyse l'action ou elle se résout en tremblement et en explosions motrices violentes plus ou moins adaptées à la situation. Cette hypertonicité se retrouve aussi dans toutes les émotions et on passe facilement dur ire aux larmes." ${ }^{66}$

Gefühl wird im Grimmschen Wörterbuch auf mehrfache Weise umschrieben: "(1) als Subst[stantiv] zu fühlen, tastend prüfen, (2) empfinden, d.h. sinnlich empfinden, (3) Gefühl der Seele, des Herzens, (4) inneres Gefühl des Körpers, (5) in Plural Empfindungen und Gedanken"67, und zu Gemüt heißt es, das sei "ursprünglich, wie der Mut unser inneres überhaupt im Unterschied vom Körper oder Leib, daher Leib und Gemüt u.ä. wie Leib und Seele". ${ }^{6}$

In der deutschen Sprache gibt es kein autochthones Wort, welches zwischen mental und physisch unterscheidet. Emotion bzw. emoción wird auf deutsch als Gemütsbewegung und feelings bzw. sentimiento als Gefühl wiedergegeben.

Aufwallung und Gemütserschütterung wurden vor einigen Jahrzehnten für den Ausdruck Emotion, was ursprünglich Aufwühlung bedeutete, gebraucht (Strasser 1956: 181), so daß man zwischen Gefühlen der Liebe, der Verehrung oder der Mutlosigkeit einerseits und den Aufwallungen des Zorns, der Begeisterung, der Rührung oder der Freude andererseits unterscheiden konnte. Allerdings wird man derartige Verwendungsweisen kaum im normalen Sprachgebrauch vorfinden, da sie vorzugsweise in literarischen Texten oder in Äußerungen von Sprechern mit einer Tendenz zu fremdwortvermeidendem Purismus auftreten.

Zwei Gesichtspunkte spielen bei den Versuchen zur Definition des Ausdrucks Emotion eine besondere Rolle:

(1) Emotion wird weniger als Ergebnis eines Ereignisses oder einer Handlung denn vielmehr als Unterkategorie eines Zustands aufgefaßt.

(2) Zustände, die mit dem Begriff Emotion bezeichnet werden können, sind psychisch-gefühlsmäßige.

Eine Aussage wie "Emotionen sind gefühlsmäßige Zustände" kann man vorläufig als allgemeine Definition des Begriffs Emotion akzeptieren, was sich im Deutschen z.B. in den Begriffen "etwas im Gefühl haben" bzw. "ein Gefühl haben" ausdrücken läßt. Wie eine spezifische Emotion verstanden, erfahren und sprachlich wiedergegeben wird, kann von unter-

65 Siehe Diccionario de la Lengua Española (s.v. emoción; sentiemento).

66 Siehe Encyclopédie universale (s.v. émotion).

67 Das Grimmsche Wörterbuch, Bd. IV 1897 (2167-2186).

68 Das Grimmsche Wörterbuch, Bd. IV 1897 (3293-3327). 
schiedlichen Faktoren abhängen. Dabei mag etwa von Bedeutung sein, ob es in einem konkreten Fall um ein Individuum oder um eine Gemeinschaft mehrerer oder vieler Individuen geht. Gemäß solcher entweder auf das Individuum oder auf die Gemeinschaft zielender Kriterien wird in den folgenden Abschnitten ein Überblick über unterschiedliche Ansätze zur Emotionsforschung geliefert. Die Beschreibung von Emotionen unter gesellschaftlichen Aspekten ist ein Gegenstand der Ethnologie bzw. Anthropologie (im angelsächsischen Sinne) und zielt darauf $a b$, die spezifischen Emotionen einer Gemeinschaft zu verstehen, während die Rolle der Emotionen für ein Individuum mit zu den Forschungsgegenständen der Kognitionswissenschaft (neben anderen Disziplinen wie beispielsweise der Psychologie) zählt. Zuerst wird über Definitionen und Theorien zu Struktur und Funktion der Emotion gesprochen, um dann mit knappen Ausführungen zu anthropologischen Ansätzen und Vorstellungen über den Kognitionsprozeß fortzufahren.

\subsection{Definitionsansätze}

Kleinginna \& Kleinginna (1981) sammelten in ihrer Arbeit über Theorien und Versuche zur Definition von Emotion vor allem die im Laufe der letzten einhundert Jahre in englischsprachigen Arbeiten gelieferten Ansätze zur Emotionsforschung. Abhängig davon, welches Kriterium in den einzelnen Untersuchungen hervorgehoben wurde bzw. welchen Komponenten von Emotionen in den theoretischen Betrachtungen und Definitionen eine besondere Relevanz zugeschrieben wurde, entwickelten sie elf Kategorien, denen sie die in ihrer Untersuchung erfaßten Veröffentlichungen zuordneten. Danach ist von folgenden Richtungen auszugehen:

(1) Die am häufigsten in der Literatur vertretenden Ansätze sind die affektiven Definitionen. In ihnen spielen die Gefühle der Erregung und/oder der Lust/Unlust eine besondere Rolle. Als maßgebliche Vertreter gelten Hebb (1966) und Buck (1976).

(2) Psychophysiologische Definitionen verweisen insbesondere auf die Abhängigkeit der Emotionen von physiologischen Mechanismen und wurden beispielsweise von Cannon (1928) und Pribram (1970) vorgeschlagen.

(3) Die Vertreter der kognitiven Definitionen, zu denen etwa Schachter (1970) und Mandler (1984) gehören, heben die Wahrnehmungs- und Denkaspekte hervor.

(4) Situative Definitionen sind solche, in denen die Rolle von externen Faktoren bei der Auslösung emotionaler Reaktionen akzentuiert werden. Als wichtigster Vertreter wird Strasser (1970) genannt.

(5) Von den Anhängern der expressiven Definitionen wird die zentrale Bedeutung der emotionalen Ausdrucksreaktionen herausgehoben. In diesen Zusammenhang werden etwa Darwin (1872/1965), Clynes (1977) und Wallon (1949) gestellt. 
(6) In disruptiven Definitionen werden die desorganisierenden oder dysfunktionalen Effekte von Emotionen als besonders bedeutsam unterstrichen. Solche Ansätze wurden beispielsweise von Young (1943) und von Wickens \& Meyer (1961) vorgelegt.

(7) Adaptive Definitionen betonen die bedürfnissichernden und funktionalen Effekte von Emotionen. Einschlägige Arbeiten sind die von Carr (1929), Rado (1969) und Buck (1984).

(8) Motivationale Definitionen schenken in besonderem Maße der Beziehung zwischen Motivation und Emotion Beachtung. Zu den Repräsentanten dieser Gruppe gehören Arnold (1960) und Tomkins (1970).

(9) Als syndromische Definitionen werden diejenigen bezeichnet, in denen die verschiedenen Emotionskomponenten als zu einer Reaktionseinheit integriert angesehen werden. Diese Richtung ist von Lazarus (1975), Resenzein (1983) und Scherer (1984) entwickelt worden.

(10) In restriktiven Definitionen wird eine Emotionsbestimmung primär durch die Abgrenzung gegenüber anderen psychischen Erscheinungsformen vorgenommen. Als wohl wichtigster Vertreter gilt Freud (1915/1940), doch auch bei Ewert (1970) findet sich noch ein derartiger Ansatz.

(11) Schließlich werden Arbeiten, in denen der Wert des Emotionskonzepts überhaupt in Frage gestellt wird - z.B. Meyer (1933), Duffy (1941), Stein \& Rosen (1974) - unter der Überschrift der skeptischen Definitionen zusammengefaßt.

In den letzten Jahrzehnten wurde der von Kleingimma \& Kleingimma (1981) vorgelegte Katalog um eine weitere Gruppe ergänzt:

(12) Dabei handelt es sich um den sozial-konstruktivistischen Ansatz, nach dem Emotionen in erster Linie als sozial vermittelte Konstrukte angesehen werden. Die wichtigsten Vertreter sind Averill (1980), Hochschild (1983), Vowinckle (1983) und Harré (1986).

Obwohl die unterschiedlichen Definitionsweisen als konkurrierende Ansätze zu verstehen sind, ist es für die Zielsetzung der vorliegenden Untersuchung weder erforderlich noch praktikabel, eine Auswahl zu treffen oder sich etwa gar für einen einzigen als "den definitiven" zu entscheiden. Mit der eben gegebenen Auflistung soll vielmehr lediglich auf mögliche Untersuchungsperspektiven, die auch für die Analyse des ägyptischen Materials nützlich sein könnten, hingewiesen werden.

Zwei weitere Aspekte haben sich bei den Versuchen zur Definition von Emotionen ebenfalls als relevant erwiesen, nämlich die Struktur und die Funktion derselben. Die Beschreibung von Aufbau und Phänomenologie emotionaler Reaktionen ist wichtig, um die strukturellen Eigenschaften von Emotionen zu klären. Nach dem sogenannten Reaktionsprinzip wurden von Mandler, Mandler \& Uviller (1958) sensible Personen als solche definiert, die eine stärkere Reaktivität als weniger sensible zeigen. Zusätzlich führten Buck, Miller \& Caul (1974) 
noch den Unterschied zwischen "verinnerlichenden" Personen - solchen, die auf eine stark physiologische Weise und nur schwach expressiv reagieren - und "externalisierenden" Personen - das sind solche, die sich stärker ausdrücken und in physiologischer Hinsicht eher schwach reagieren - hinzu.

Battacchi (1997: 21) hat eine Synthese der Theorien über emotionale Reaktionen vorgelegt und unterscheidet dabei:

(1) Physiologische Reaktionen. Der Körper reagiert auf ein Ereignis mit der Aktivierung des autonomen sowie des endokrinen Nerven- und des Immunsystems. Das ist ein Prozeß, welcher einer empfindenden Person passiert und welcher beobachtet und wahrgenommen werden kann (z.B. Erröten, Zittern der Stimme, Hitze- oder Kälteempfindungen).

(2) Tonische Haltungsreaktionen: ${ }^{69}$ Der ganze Körper wird entweder entspannt oder angespannt.

(3) Instrumentelle motorische Reaktionen: ${ }^{70}$ Die betreffende Person reagiert mit Handlungen wie etwa Beißen, Schlagen oder Fliehen.

(4) Expressive motorische Reaktionen: ${ }^{71}$ Mimik, Gestik, Vokalisationen, paralinguistische Indizien (z.B. Sprechpausen, Sprechgeschwindigkeit, Lautstärke).

(5) Expressive sprachliche Reaktionen: Darunter werden besondere Varianten in der Rede einer von einer Emotion betroffenen Person verstanden.

(6) Subjektive Erfahrungskomponenten: Sie sind die Empfindungen oder Gefühle einer Person, die nur von ihr selbst beschrieben werden können. Die Untersuchung dieser Komponente wurde unter vier Hauptgesichtspunkten vorgenommen. Eine Rolle spielen demnach:

- die hedonistische Qualität (angenehme und unangenehme Emotionen) ${ }^{72}$,

- die Aufmerksamkeitsausrichtung (die Emotionen führen zu einer Fokussierung bestimmter Informationen) ${ }^{73}$,

- die Intentionalität (eine emotionale Erfahrung ist immer eine Erfahrungsform von etwas, z.B. Furcht ist immer Furcht vor etwas) ${ }^{74}$ und

- das Bewußtsein (gemäß eines subjektiven oder prä-objektiven Selbstbewußtseins). ${ }^{75}$

An Funktionen von Emotionen lassen sich den Forschungen der einschlägigen Autoren insbesondere folgende entnehmen:

(1) die Handlungssteuerungsfunktion, z.B. die Auslösung instrumenteller Handlungen, die Vorbereitung des Organismus auf einen Notfall, auf eine kritische Situation, sowie die

69 Wallon (1949).

70 Arnold (1960); Fridja (1986).

71 Tischer (1993).

72 Scherer (1984); Fridja (1986); Campos \& Barret (1989).

73 Izard (1977); Tomkins (1980).

74 Brentano (1874); Sartre (1939).

75 Lewis (1992); Bolton (1982). 
Bereitschaft zur und die Vorbereitung auf die Handlung (Arnold 1960; Fridja 1986; Buck 1984 und 1986).

(2) Die Mitteilungsfunktion, d.h. die Kommunikation mit der Umwelt über den Zustand des Organismus. Das wird durch die emotionalen Ausdrücke realisiert, die einerseits motorische und instrumentelle Reaktionen und andererseits tonische Haltungsreaktionen enthalten.

(3) Die Innere Signalisierung gemäß der Erfahrungs- oder Gefühlsdimension der Person. Durch diese Funktion wird ein Organismus über seinen Zustand, welcher sich auf die Bedürfnisse, Wünsche, Ziele und Erwartungen bezieht, informiert (Schere 1984; Dahl 1979; Fridja 1986; Oatley \& Johnson-Laird 1987; Oatley 1992).

(4) Die Darstellungsfunktion, in der die Kognition (die ich im Folgenden darstellen werde) eine wichtige Rolle spielt, da die Person sich eine kognitive Repräsentation einer Situation vorstellt. In dieser Funktion ist die Gefühlskomponente wichtig, weil sie die Situation wahrnimmt und beurteilt, wobei die emotionalen Ausdrücke auch ausgeübt werden (Brentano 1874; Guillame 1937; Battacchi 1988; Buck 1984 und 1986).

Ein letzter Vorschlag für die Definition der Emotion, den ich im Hinblick auf die Zielsetzung dieser Arbeit für erwähnenswert halte, stammt aus einer Arbeit Izards (1969; 1972; vgl. auch Izard, Dougherty, Bloxom \& Kotsch 1974). Izard gründete seine Überlegungen auf die neutrale und expressive Ebene der Emotionen und erstellte die Differential Emotion Scale (DES). Diese Skala nimmt an, daß es getrennte und diskrete Emotionen gibt und daß jede von ihnen meßbare Erfahrungen und motivierende Eigenschaften hat.

Er benennt drei Hauptkonzepte: Emotion, Stimmung und Emotionseigenheit haben für die weiter unten erfolgende Bearbeitung der ägyptischen Texte eine besondere Relevanz und können an dieser Stelle wie folgt zusammengefaßt werden:

- Emotion ist als flüchtiges und kurz andauerndes Reaktionssyndrom zu verstehen. ${ }^{76}$

- Stimmung läßt sich als eine zeitliche Dimension beschreiben, welche Stunden, Tage oder in besonderen Fällen auch noch länger andauern kann, und nicht intentional abläuft. Sie bezieht sich auf ein für die betreffende Person eindrucksvolles Ereignis und drückt nicht unbedingt einen Charakter aus. ${ }^{77}$

- Emotionseigenheiten oder emotionale Dispositionen sind die Größen, die eine bestimmte emotionale Reaktion in Abhängigkeit von der individuellen Neigung oder Veranlagung einer individuellen Person determinieren. ${ }^{78}$

76 Battacchi (1987: 28); vgl. Ewert (1983), siehe Kapitel 5.4 Das Herz in Ausdrücken zur Bezeichnung von Emotionen.

77 Ewert (1983); Berner (1988).

78 Ewert (1983); Berner (1988). 


\title{
4.3 Anthropologische Konzepte über den kulturspezifischen Charakter von Emotionen
}

Die englische Sprache versteht emotion in einem objektiven Sinn (Birch 1995) und feeling in einem eher subjektiven Sinn (Gaylin 1979). Deswegen spricht man unter anthropologischen Gesichtspunkten meisten über emotions anstatt über feelings, weil emotion eine soziale und kulturelle Komponente enthält. In diesem Zusammenhang kann auf eine schon ältere Studie von Strasser (1956) verwiesen werden, der dazu ausführte:

\begin{abstract}
"Das Wort Stimmung wird ferner nicht ausschließlich auf das eigene ego und dessen $\mathrm{Zu}-$ stände bezogen. Man spricht von einer Abend-, einer Morgenstimmung, einer stimmungsvollen Landschaft, einer religiösen, einer revolutionären, einer Inflation-, einer Panikstimmung usw.(...) Tatsächlich ist das, was in der Stimmung erfaßt wird, immer eine überpersönliche Ganzheit: Die Natur, die Landschaft, die Gesellschaft, kurzum <die Welt>. Es ist auch bezeichnend, daß Stimmungen im sprachlichen Ausdruck mit Vorliebe in einer unpersönlichen Form zum Ausdruck gebracht werden: Es reut mich, es schmerzt mich, es freut mich, es ekelt mir, es schwindelt mir, sagt man" (1956: 115).
\end{abstract}

Ortony (1988: 175) schlägt vor, daß wir von einer Theorie ausgehen sollen, nach der Emotionen auf universalen kulturellen Prinzipien basieren und erlernt wurden. Auf der Grundlage einer solchen Theorie wird behauptet, daß die unterschiedlichen Arten und Ausprägungen von Emotionen in einer bestimmten Kultur davon abhängen, wie die Mitglieder der betreffenden Gemeinschaft ihre Welt erfahren. Man geht davon aus, daß emotionale Zustände kulturbestimmt sind, weil die Äußerungen, Auswirkungen und Bewertungen anscheinend gleicher Emotionen in unterschiedlichen Kulturen nicht zwangsläufig auf dieselbe Weise geschehen müssen. ${ }^{79}$ Shweder (1991: 10) vertritt ebenfalls die unter Anthropologen und Ethnologen gängige Forschungsmeinung, nach der kognitive Bedeutungen und insbesondere die Bedeutungen von Emotionen in verschiedenen Kulturen unterschiedlich sein können. Desgleichen dürfte es sich bei den Konzepten, die von einem Individuum benutzt werden, um über seine emotionalen Erfahrungen zu sprechen, um kulturspezifische Modelle handeln. Solche Beobachtungen über den kulturspezifischen Charakter von Emotionen ziehen fast zwangsläufig weitere Hypothesen über die Variabilität von Emotionskonzepten nach sich: ${ }^{80}$

(1) Es ist davon auszugehen, daß die innerhalb einer Gesellschaft als prototypisch zu beschreibenden Emotionen sich im Laufe der Zeit verändern können.

(2) Miteinander konkurrierende und einander ergänzende Prototypen von Emotionen können durchaus gleichzeitig innerhalb einer Gesellschaft existieren.

Einige illustrative Beispiele zum kulturspezifischen Charakter von Emotionen, die sich in der neueren Literatur finden, sind im folgenden zusammengestellt:

79 Kövecses (2000: 187).

80 Kövecses (2000: 173). 
- Das Gefühl von ANGST soll bei "den" Eskimo als eine typische Erfahrung der Kindheit gelten und im Erwachsenenleben keine Rolle mehr spielen. Im Gegensatz dazu sei für die Ilongot, eine malayo-polynesische Sprechergemeinschaft auf Nueva Vizcaya (Philippinen), das Gefühl von ANGST eine generelle Bedrohung, welche unter Umständen sogar bis hin zur Zerstörung der Gemeinschaft führen könne. Und für nordamerikanische Industriearbeiter schließlich sei ANGSTgefühl in erster Linie ein Mittel, das zur Vorsicht mahne, mit dem Angst letztendlich überwunden und mehr Erfahrung gesammelt werden könne. ${ }^{81}$

- In Zulu-Kulturen soll ÄRGER eine positive Seite enthalten, weil er eine intensive Aktivität enthält. Deswegen sei dort eine öfter ihrem ÄRGER Ausdruck verleihende Person höher angesehen, weil sie aktiver ist als eine ruhige Person (Taylos and Mbense 1988).

- Einerseits sei ANGST als eine weniger zentrale Emotion im Indonesischen als im Englischen zu verstehen. Andererseits sollen TRAURIGKEIT und VERWIRRUNG im Indonesischen zentralere Emotionen sein als im Englischen. ${ }^{82}$

- In Japan spiele die kontrollierte Beherrschung körperlicher Reaktionen eine besonders hohe soziale Rolle. Als Folge davon werde heftige körperliche Bewegung kaum benutzt, um eine einzigartige Individualität zu demonstrieren, sondern sie diene vielmehr dazu, sich dem Gefühl zwischenkörperlicher Gemeinschaftlichkeit hinzugeben (Frever 2000: 231). Dieses als erstrebenswert geltende Gemeinschaftsgefühl innerhalb sozialer Gruppen werde durch säkulare Entgrenzungsstrategien erreicht und in der Arbeitswelt von Unternehmen oft gezielt als Bestandteil ihrer Personalpolitik eingesetzt. Japantypische Phänomene wie Karaoke oder andere gemeinsame Vergnügungen nach der Arbeitszeit, bei denen die sonst zu beobachtende Kontrolle oder gar Unterdrückung von emotionalen Regungen ausgeschaltet zu sein scheint, seien Mittel zur Stärkung des Gemeinschaftsgefühls und der engeren Bindung an die Gruppe.

- Die heutzutage immer weiter als romantisches Konzept verbreitete Emotion der LIEBE sei noch in viktorianischer Zeit stärker mit männlicher Freundschaft identifiziert worden, wie aus den damaligen Briefen und Journalen hervorgehe (Stearns 1994: 81-82).

- Lachen und Lächeln sollen in China, sofern es um Männer geht, eng mit Vorstellungen von Status, Ehre und SCHAM zusammenhängen. Chinesische Frauen hingegen würden auf eine andere Weise lachen. Sie kichern, wenn sie sich unter Frauen oder in Gegenwart eines Mannes befinden, besonders wenn erotische Elemente eine Rolle spielen. Sie lachen nie laut, auch nicht über ihren eigenen Mann und stoßen angeblich kein kaltes oder verächtliches Lachen aus. ${ }^{83}$ Sie können jedoch aus SCHAM und VERLEGENHEIT lachen und dür-

81 Shweder (1991: 245).

82 Heider (1991: 11).

83 Dieser Begriff ist auf den kommenden Seiten erklärt, siehe unter Glückliches und ähnliches. 
fen nur harmloses und vergnügtes Lachen von sich geben, ebenso wie Männer, wenn sie betrunken sind (Eberhard 1977: 33).

- Beim Weinen ist es in der europäischen Kultur normal, daß die Frauen und Kinder wegen eines unglückliches Gefühles laut weinen, während die Männer sich traditionell eher ohne oder allenfalls mit lautlosen Tränen ausdrücken. In China unterscheidet sich die Reaktion der Männer unwesentlich von der der Europäer, während die Frauen und Kindern ihre TRAUER durch Verziehen des Mundes mit tränenlosem Geheul zum Ausdruck bringen (Eberhard 1977: 14). Es gibt Fälle, in denen es gemäß eines bestimmten Protokolls überhaupt nicht als opportun gilt, zu weinen. So wird beispielsweise von den Mitgliedern der spanischen oder der britischen Königsfamilie erwartet, daß sie ihre persönlichen Gefühle bei öffentlichen Anlässen weitestgehend unterdrücken. In China ist es im Gegensatz dazu passend und wird geradezu erwartet, daß hochgestellte Personen Tränen vergießen (Eberhard 1977: 19).

Wie zuverlässig solche doch recht oberflächlichen und pauschalisierenden Beschreibungen im konkreten Einzelfall auch sein mögen, mag dahingestellt bleiben. Die Beispiele genügen jedoch, um zu zeigen, daß in verschiedenen Kulturen unterschiedliche Umgangsweisen mit Emotion(en) im allgemeinen und eine unterschiedliche Bedeutsamkeit von spezifischen Emotionen zu beobachten sind. Die sichtbaren Äußerungen von Emotionen haben nicht unbedingt etwas mit individuellen Empfindungen zu tun, sondern können sozial geformt - unter Umständen auch überformt - sein, wie sie im konkreten Einzelfall vordergründig nicht erkennbare persönliche Motivationen oder auch Tendenzen zur individuellen Selbstdarstellung widerspiegeln mögen (vgl. dazu etwa Battacchi 1997: 79).

\subsection{Emotion und Kognition}

Das Thema Emotion-Kognition löste am Anfang der achtziger Jahre eine Debatte aus, die hauptsächlich von Zajonc und Lazaurs geführt und vorangetrieben wurde. Die Diskussion entstand aufgrund des semantischen Begriffes der "Kognition". Für Zajonc (1980, 1984) sind Emotion und Kognition Systeme, die eine eigene Struktur aufweisen und teilweise voneinander unabhängig sind. Für Lazarus $(1982,1984)$ sind Emotionen die Folge kognitiver Prozesse (postkognitive Phänomene) und somit als ihr Produkt zu verstehen.

Mit Kognition und Emotion und ihrer Verbindung hat sich eine Vielzahl Autoren bereits vor und auch nach den oben Genannten beschäftigt. Je nach den dabei gesetzten Schwerpunkten und Perspektivsetzungen gibt es eine Fülle unterschiedlicher Theorien und Meinungen, von denen hier nur einige Erwähnung finden können.

Nach der psychoevolutionären Emotionstheorie von Plutchik (1984) soll es eine funktionelle Komplementarität von Kognitionen und Emotionen geben. Dabei hätten sich das kogni- 
tive und das emotionale System in der Evolution des Gehirns parallel als mehr oder weniger eigenständige Größen entwickelt.

Das von Lantermann (1983) propagierte Handlungskontrollsystem ${ }^{84}$ enthält einerseits ein kognitives Kontroll- und andererseits ein Emotionalsystem. Danach sollen sich Emotion und Kognition insofern gegenseitig beeinflussen, als das kognitive Handeln emotionale Prozesse verändere und diese ihrerseits dem Handelnden kognitive Handlungen und Verhaltensweisen diktieren.

In Arbeiten, die sich dem Gegenstand unter psychologischen Gesichtspunkten näherten, spielte bis vor kurzem die Theorie der zerebralen Hemisphärenspezialisierung eine wichtige Rolle. Gemäß dieser Theorie sollte die rechte Hirnhälfte für die Verarbeitung emotionaler und spatialer Stimuli zuständig sein, während die linke Hirnhälfte sich durch sprachliche und logisch-assoziative Fähigkeiten auszeichne. Gainotti (1988) hat jedoch demonstriert, daß zumindest die positiven Emotionen beidseitig "repräsentiert" werden, da sie durch die linke Hemisphäre vermittelt werden. Neuropsychologische Forschungen bekunden einerseits, daß sowohl emotionale als auch kognitive Prozesse von zerebralen Strukturen abhängig seien ${ }^{85}$, während psychophysiologische Forschungen andererseits postulieren, daß für die nachhaltige Beeinflussung des emotionalen Erlebens bestimmte Substanzen auf Gedächtnisprozesse wirken. ${ }^{86}$ Die frühere Meinung, daß Kognition und Emotionen sich unter neuropsychologischen Gesichtspunkten grundsätzlich voneinander unterscheiden sollen, läßt sich heutzutage wohl nicht mehr aufrechterhalten. ${ }^{87}$

Die Diskussionen über diese Frage führten zu einer lebhaften Debatte, als deren Konsequenz die internationale Zeitschrift Cognition and Emotion gegründet wurde. Der Stand der Dinge, wie er sich kurz vor der Jahrtausendwende präsentierte, wird im folgenden zusammengefaßt: ${ }^{88}$

Man unterscheidet zwischen drei Phasen der Beteiligung kognitiver Prozesse an Emotionen:

(1) In der ersten Phase findet ein kognitiver Prozeß statt, durch den die Situation erkannt wird. Automatisch löst sich eine emotionale Reaktion aus. Das Erkennen kann zwei Intensitätsgrade enthalten, nämlich: niedrig (z.B. Wahrnehmung des Gleichgewichtsverlustes im Falle der Furcht) und hoch (z.B. im Falle des Schamgefühls).

(2) Die zweite Phase ist die Wahrnehmung des inneren Zustandes, der physiognomischen Wahrnehmung, der Aufmerksamkeitsfokussierung und des prä-objektiven Selbstbewußtseins.

84 Vgl. dazu auch Leontjev (1979).

85 Mishkin \& Appenzeller (1987); Olton, Becker \& Handelmann (1979).

86 Gray (1990).

87 Canavan \& Sartory (1990).

88 Bacchatti (1997: 42-51). 
(3) Die letzte Phase erfaßt das Identifizieren von Emotion, das bewußte Nachdenken über den emotionalen Zustand und seine situationalen Auslöser. Das wird Die-EmotionenDenken oder Die-Emotionen-Repräsentieren benannt.

\subsection{Vorschläge zur Klassifikation von Emotionen}

Oben wurden einige allgemeine Konzepte von Emotion vorgestellt. Im folgenden wird über konkrete Emotionen sowie über mögliche Klassifikationen von Emotionen gesprochen. Dazu werden einige Beispiele angeführt.

$\mathrm{Zu}$ den am häufigsten von Psychologen und Soziologen untersuchten Gefühle gehören LIEBE, ZORN, FURCHT, SCHAM, SCHULD, SCHMERZ, TRAUER und EIFERSUCHT. Im Gegensatz dazu wurden STOLZ, HOFFNUNG, NEID, MISSGUNST, EINSAMKEIT, DANKBARKEIT oder HASS vergleichsweise wenig beachtet.

Im letzten Abschnitt wurde gezeigt, daß über das Konzept der Emotion in den letzten Jahrzehnten intensiv diskutiert wurde. Gleiches gilt für deren Klassifikation. Abgesehen von Stellungnahmen zur Frage der Intensität von Emotionen und der Bedeutung einzelner Emotionen, wird in der einschlägigen Literatur vor allem der Frage nachgegangen, wie viele Emotionen zu unterscheiden seien. Damasio (1994: 150) arbeitete für den Terminus Gefühl (feelings) drei untergeordnete Typen heraus:

(1) Gefühle, die angeboren und universal sind, z.B. FREUDE, ANGST, TRAURIGKEIT, WUT, EKEL.

(2) Varianten der als grundlegend charakterisierten Gefühle, welche subtilere Unterschiede konstituieren und nach Damasio zwar ebenfalls universal, aber nicht angeboren sein sollen, z.B. EUPHORIE und EXTASE als Varianten von GLÜCK, MELANCHOLIE und SEHNSUCHT als Varianten von TRAURIGKEIT.

(3) Hintergrundsgefühle, die sich mit der Stimmung in Verbindung bringen lassen.

Wittgenstein (1953) unterscheidet zwischen Emotionen, die bloß Sekunden oder Minuten andauern, Gemütsbewegungen (wie DEPRESSION, TRAUER, FREUDE) und Gemütsdispositionen (z.B. LIEBE und HASS).

Anhand der Kriterien Zeit (vergangen, gegenwärtig, zukünftig), Qualität (gut, schlecht) sowie Art der Beziehung zum kognitiven Kontext (subjektiv oder objektiv) schlägt Wierzbicka (1999: 49-122) eine Klassifikation vor, mit der beispielsweise folgende Gruppen von Emotionen beschrieben werden können:

- Glückliche Ereignisse (good events) und die damit verbundenen guten Gefühle (good feelings), die insofern in verschiedenen zeitlichen Relationen zum Augenblick des Gefühls stehen können, als sie Vergangenes, Gegenwärtiges oder Zukünftiges betreffen können. Demnach unterscheidet Wierzbicka: 
- Glückliches im generellen, also Ereignisse, die sich als [gut, zeitneutral, objektiv] charakterisieren lassen,

- Glückliches für "mich" (d.h. die jeweils betroffene Person), was als [gut, zeitneutral, subjektiv] beschreibbar ist,

- Glückliches in einem Moment, der bereits geschehen ist, also etwas, was [gut, vergangen, subjektiv] ist,

- Glückliches für "mich" in einem Moment, der bereits geschehen ist, demnach etwas, was als [gut, vergangen, subjektiv] zu beschreiben ist, und

- Glückliches, das dauerhafte Wirksamkeit besitzt.

$\mathrm{Zu}$ diesen Ereignissen gehören solche Gefühle wie FREUDE, GLÜCK, ZUFRIEDENHEIT, VERGNÜGEN, LUST, ERLEICHTERUNG, AUFREGUNG, HOFFNUNG.

- Unangenehme Ereignisse (bad events), die nur etwas Gegenwärtiges oder bereits Vergangenes betreffen, und die dazugehörigen schlechten Gefühle wie etwa TRAURIGKEIT, UNGLÜCK, KUMMER, VERZWEIFLUNG, ENTTÄUSCHUNG, FRUSTRATION.

- Etwas Schlimmes, das in Zukunft passieren kann, mit den zugehörenden Gefühlen wie FURCHT, ANGST HABEN VOR, SCHRECKEN, VOLL ANGST SEIN, STARR VOR ANGST SEIN, PANIK, BEKLEMMUNG, BEFÜRCHTUNG, NERVOSITÄT, SORGE.

- Ich will nicht, daß das passiert, wie z.B. WUT, EMPÖRUNG, ZORN, WÜTEND, SCHRECKHAFT SEIN, SCHOCKIERT SEIN.

- Über andere Leute wie z.B.: NEID, EIFERSUCHT, MITLEID, MITGEFÜHL, SCHADENFREUDE, DANKBARKEIT, BEWUNDERUNG, ZUFRIEDENHEIT.

- Über uns selbst wie z.B.: ZUFRIEDENHEIT, SELBSTMITLEID, SCHAM, PEINLICHKEIT, REUE, SCHULD, STOLZ.

Alle diese Klassifikationen lassen sich in ein Diagramm umsetzen, welches eine korrelative Beziehung zweier Parameter darstellt. Einer der beiden Parameter ist die Zeit (Vergangenheit, Gegenwart, Zukunft), während der zweite sich auf den Grad der Involviertheit der betreffenden Person (Nähe, Gleichgültigkeit, Ferne) bezieht. Durch dieses Diagramm können die Emotionen beispielsweise so beschrieben werden: 


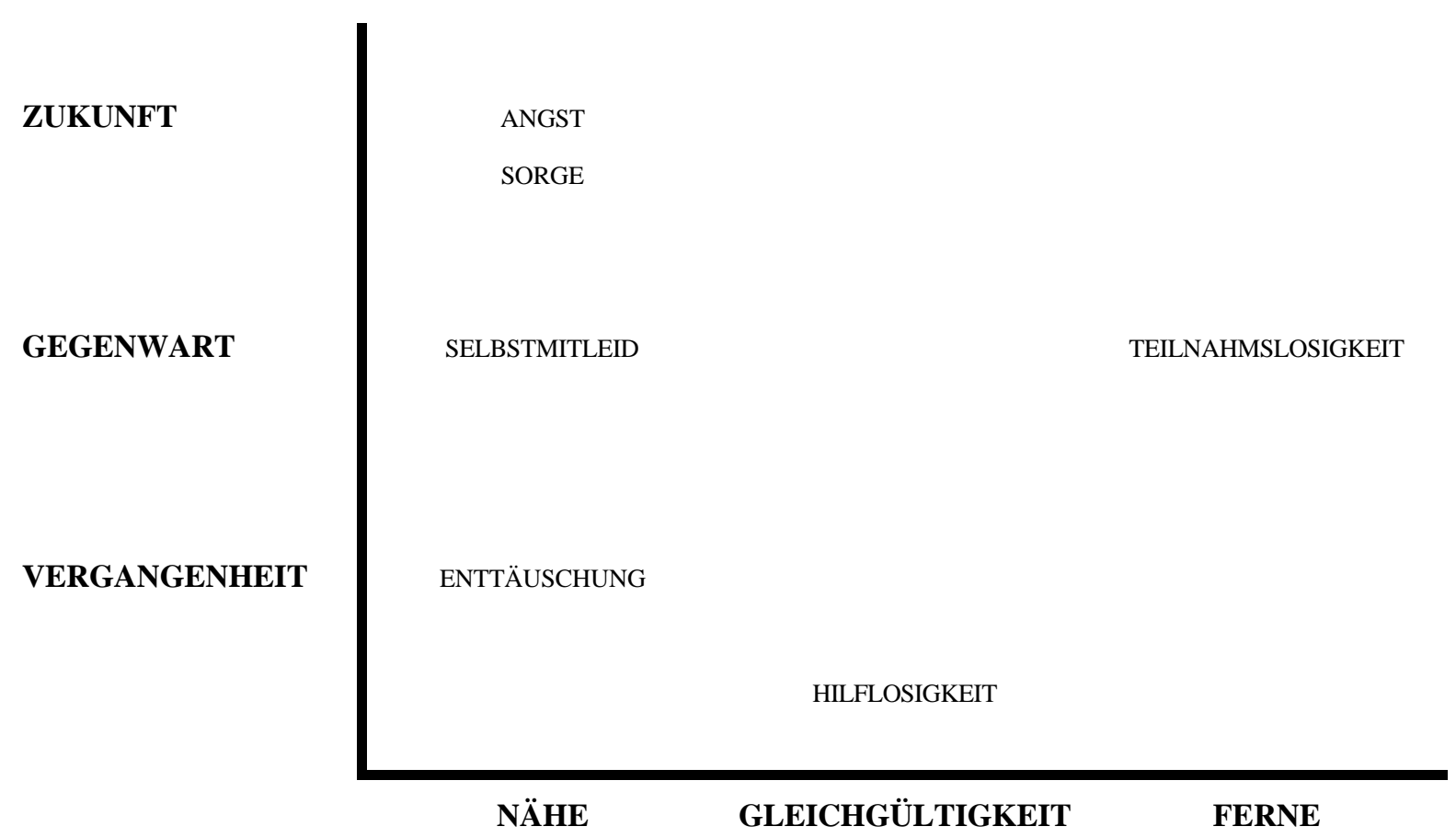

Die letzte zu erwähnende Klassifikation stammt aus der Arbeit Taylors (1996: 57-73), in der die Moralität als Kriterium eine Rolle spielt. Anhand dieses Kriteriums differenziert er zwischen zwei Arten von Emotionen:

(1) REUE, wobei der Täter eine moralische Verantwortung trägt.

(2) SCHULD und SCHAM, in denen das Subjekt eine passive Rolle spielt.

Die dargestellten Klassifikationen der Emotionen sind das Ergebnis der Rekapitulation einiger zu diesem Thema publizierter Forschungsansätze. Im Anschluß werden einige konkrete Beispiele von Emotionen behandelt, die zur Klärung dere Bedeutungen beitragen können.

\subsection{Beispiele für Emotionen und Reaktionen auf Emotionen}

\subsubsection{ANGST}

Nach den Gesichtspunkten Zustand und Eigenschaft wurde ANGST von Spielberger (1972) definiert als ein temporärer emotionaler Zustand, der instabil sei, da er weder zeitlich noch hinsichtlich seiner Intensität eindeutig zu bestimmen ist.

Es wurde gezeigt, daß eine Emotion aus einer Situation entsteht und, daß diese Reaktion auch in unterschiedlicher Art und Weise ausgedrückt wird. Ein Beispiel dafür ist der Ausdruck Angst im Deutschen, welcher zwei Bedeutungen enthält, die semantisch nicht eindeutig zu unterscheiden sind, nämlich: ANGST und FURCHT, z.B.

- Er hatte Angst vor der Prüfung $=$ Er fürchtete sich vor der Prüfung

- Er hatte Angst vor dem Hund = Er fürchtete sich vor dem Hund 
Was afraid im Englischen bedeutet, kann man im Deutschen interpretieren als Angst vor etwas Konkretem, und fear als Angst vor etwas Unbekanntem. Im Duden wird ANGST als ein Gefühlszustand definiert. Nach dem Gebrauch von afraid in der englischen Sprache könnte man es als einen Zustand verstehen und fear als ein Gefühl.

Wierzbicka (1999: 123ff.) erklärt den Fall der Angst in der deutschen Sprache. Ihren Vorschlag gebe ich in der Form einer Tabelle wieder:

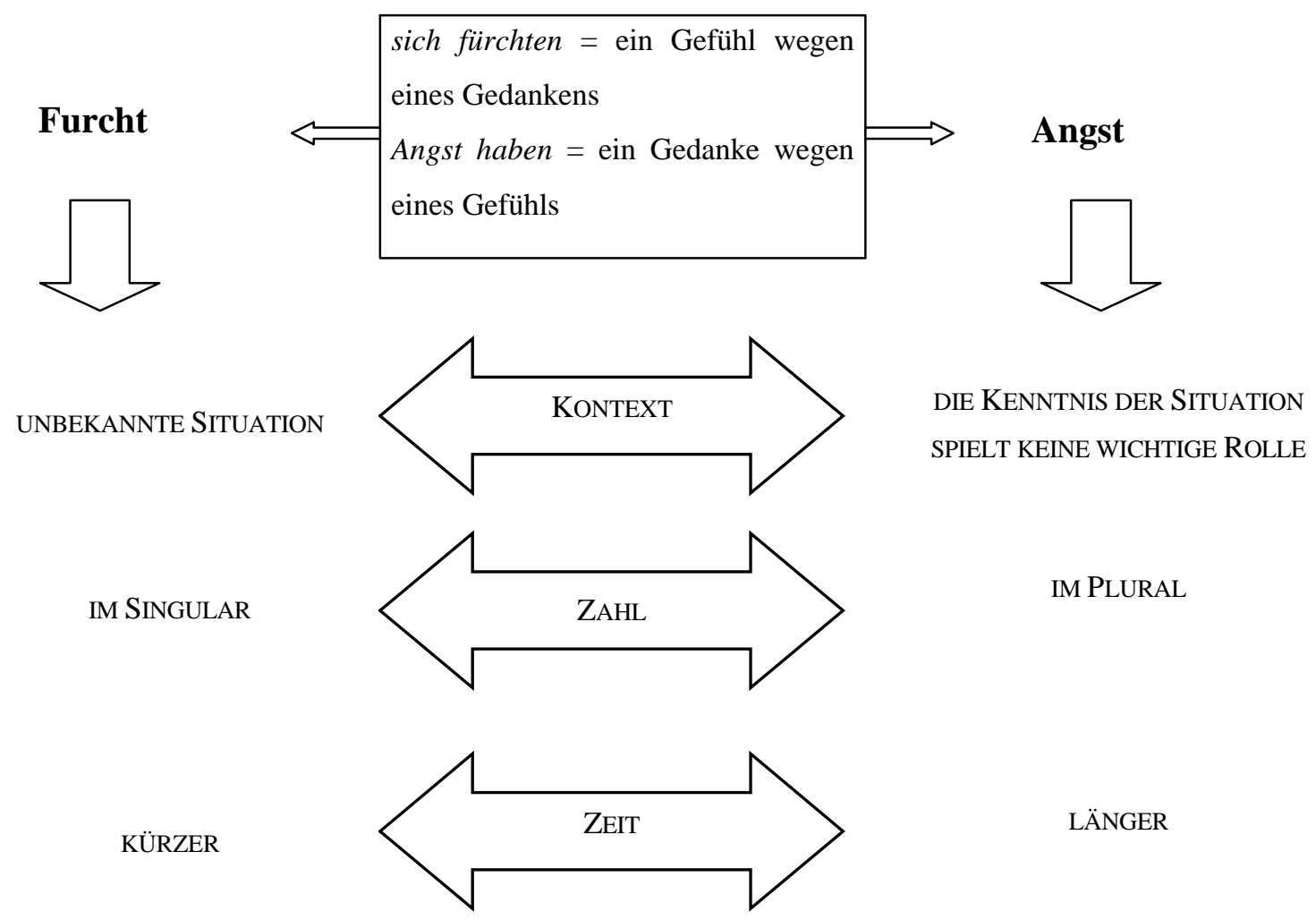

\subsubsection{GLÜCKSZUSTAND}

HEITERKEIT und GLÜCK verstand Strasser (1956: 239) als relativ lang anhaltende Gemütszustände im Gegensatz zur eher kurzfristigen Emotion FREUDE. Die FREUDE ist seiner Ansicht nach die Antwort des Gemüts auf die beginnende Vollendung des Glückszustandes. Zufriedenheit wäre ein friedliches Dasein eines Mannes, der beispielsweise in einer bestimmen Situation mit den sozialen, politischen, ökonomischen Gegebenheiten in Einklang lebt (Strasser 1956: 244). Der Glückliche wäre nach Rousseaus Meinung ${ }^{89}$ einer, der sich ebenso wie seine Seele in einem dauerhaften Zustand befindet, in dem beide Zeit haben, um sich zu sammeln und zu ruhen. Bei diesem Zustand werden sowohl die Vergangenheit sowie die Zukunft nicht wahrgenommen.

89 Zitat bei Strasser (1956: 244). 
In Bezug auf den inneren Zustand ist der Genuß etwas Intimes, "wobei man etwas besitzt, was man nicht jedermann mitteilen will" (Strasser 1956: 232). Dieser Besitz impliziert eine Intimität, in der der Besitzende sich isoliert, um froh werden zu können. All dieses Handeln bildet den Genuß (idem.).

Lachen ist auch ein Teil dieser Emotion. Man kann lachen, wenn man zufrieden, glücklich usw. ist. Man kann aber auch lachen und kein gutes Gefühl dabei haben. Es gibt formelles Lachen, welches leer von Emotion ist. Eine Person lacht oder lächelt als Höflichkeitsform, oder als Anerkennung einer Tat oder Worte, wie z.B. ein Minister oder Kaiser auch ohne jede Spur von Aggressivität lachen können. Es wird auch im alkoholischen Zustand gelacht. All diese Formen des Lachens und Lächelns sind keine echten Ausdrücke eines Gefühls, sondern eine künstliche Form.

Mit Gefühl kann man herzlich lachen, wenn etwas lustig aussieht oder wenn jemand zufrieden ist. Man kann auch kichern, was nicht unbedingt mit einem guten Gefühl in Verbindung stehen muß, sondern auch Schadenfreude andeuten kann.

Als letztes Beispiel wird verächtliches Lachen genannt, bei dem ein Gefühl implizit ist. Das wird im Chinesischen als "kalt lachen" (leng-hsiao) wiedergegeben, welches kaum als eigentliches Lachen verstanden wird (Eberhard 1977: 31-32).

\subsubsection{UNGLÜCK}

Beim Weinen, Jammern und Lamentieren ist normalerweise ein unglückliches Gefühl dabei. Man kann beim Tod einer geliebten Person, bei Schreck, Angst, Kummer und körperlichem oder seelischem Schmerz weinen oder ein jammerndes Geheul ausdrücken. In China drücken Frauen und Kinder ein Unglücksgefühl mit tränenlosem Geheul aus, während die Männer durch lautlose Tränen dasselbe bekunden. ${ }^{90}$ All diese Fälle dienen dazu, ein Gefühl auszuschütten und um sich zu beruhigen. Manchmal kann man in der Öffentlichkeit weinen, um jemanden zu beeinflussen, wobei es nicht um ein Gefühl, sondern um eine Absicht oder ein Ziel geht.

\subsubsection{SCHAM und SCHANDE}

Jemand schämt sich wegen etwas oder wegen jemandem, nachdem diese Person in eine peinliche Situation gebracht wurde. Das Gefühl dabei kann entweder ein gutes oder ein schlechtes sein, d.h. wenn jemand gefragt oder bekanntgemacht wurde, wird die Person ins Zentrum der Aufmerksamkeit gestellt. Das kann ein SCHAMgefühl als Ergebnis produzieren, welches frei von moralischen Vorstellungen ist. Andererseits schämt sich eine Person wegen einer als unmoralisch geltenden Tat oder Äußerung. Bis zum Anfang des letzten Jahrhunderts schämten Frauen sich aufgrund der vorherrschenden Moralvorstellungen öfter als die Männer. In

90 Siehe oben unter 4.3 Anthropologische Konzepte über den kulturspezifischen Charakter von Emotionen. 
Spanien wurden die Frauen gemäß der katholischen und traditionellen Erziehung relativ schnell mit den Eigenschaftsworten "schandhaft" oder "unverschämt" durch die Gemeinschaft charakterisiert und aufgrund etwaiger von der gesellschaftlichen Norme abweichenden Handlungen kritisiert. Die Konsequenz war es, daß diese Frauen unter dem sozialen Druck litten und in extremen Fällen umziehen mußten. In China waren SCHAM und SCHANDE ebenfalls die wesentlichen Grundlagen des moralischen Verhaltens. Die Frauen hatten weniger Freiheiten als die Männer. Wie in Spanien kommen Beschreibungen von sich schämenden Frauen in Texten bei weitem häufiger vor als solche von Männern. In beiden Kulturen, obwohl sie sehr unterschiedlich sind, schämten sich Frauen, wenn Erotisches zur Sprache kam oder wenn ihre "Ehre" verletzt wurde, wobei das sexuelle Tabu in beiden Kulturen zu finden ist.

Bei Männern ist es eine Frage der "Ehre". Wenn ein Mann seinen Status in der Gesellschaft oder seine Ehre verlor, hat er ein Schamgefühl, welches ihn auch unglücklich macht. Dieser Fall wurde in Spanien mit der dauerhaften patriarchalisch gehaltenen Position eines Mannes sowohl in der Gesellschaft als auch im Innern der Familie verbunden, die auch Prestige für den Mann bedeutete. Der Verlust dieser Position ist ein Grund, um sich zu schämen. In China wird dieser Ehrverlust als "das Gesicht verlieren" bezeichnet, wenn der Mann selbst oder einer seiner Verwandten sich nicht so verhält, wie es von ihm aufgrund seiner sozialen Stellung erwartet wird (Ho 1976).

Es ist festzustellen, daß SCHAM und SCHANDE eine wichtige Beziehung mit der Gesellschaft haben. Diese Idee wird auf den kommenden Seiten mit den ägyptischen Texten in Verbindung gebracht.

\subsubsection{HOFFNUNG Und VERTRAUEN}

Wenn jemand Hoffnung hat, befindet er sich in einem Zustand, welcher als ein emotionaler bezeichnet werden kann, d.h. Unruhe oder Begierde. Allerdings ist die Hoffnung in unserer europäischen Kultur nicht als Emotionen wahrzunehmen. Averill (1996: 24ff.) richtete Fragen über "Hoffnung" an zu verschiedenen Kulturen gehörende Leute. Die Antworten der gefragten Personen, die aus den Vereinigen Staaten, Australien, Puerto Rico, Japan, Korea, Indonesien, Malaysia und Sri Lanka stammen, lassen sich unter folgenden Ergebnissen zusammenfassen:

Für Amerikaner, Japaner und Australier ist HOFFNUNG ein Gefühl. Insbesondere Amerikaner sehen die HOFFNUNG als einen vorübergehenden Zustand an.

Für Koreaner, Indonesier, Malaien und die Bewohner Sri Lankas ist HOFFNUNG dagegen kein Gefühl. Die Koreaner interpretieren HOFFNUNG beispielsweise als einen dauerhaften Bestandteil des Charakters. 
Ähnliches gilt für das VERTRAUEN. Meyers Großes Conversations-Lexicon für die gebildeten Stände aus dem Jahr 1852 führt für 'Vertrauen' zwei unterschiedliche Bedeutungen an: ${ }^{91}$

(1) Vertrauen "im Allgemeinen", was der Psychologie überantwortet wird.

(2) Vertrauen "auf Gott", was in den Zuständigkeitsbereich der Moral fällt.

Die Frage dabei ist, ob VERTRAUEN tatsächlich ein Gefühl ist oder vielleicht doch eher als eine Haltung bezeichnet werden muß. Es ist eindeutig, daß VERTRAUEN ein Empfindungszustand ist, welcher sowohl körperliche Veränderungen hervorrufen kann wie auch expressive Gesten, die zu einem kulturellen Code gehören und mit einer bestimmten Bedeutung versehen werden. Allerdings ist VERTRAUEN keine spontane Aktion, sondern wird in einem längeren Wahrnehmungs- und Sozialisationsprozeß hergestellt. Unter psychologischen Geschichtspunkten wird VERTRAUEN als eine Gefühlshaltung angesprochen, wobei die lange Dauer der Vertrauensbildung und die kognitiven Anteile der Entstehung des Vertrauens besonders hervorgehoben werden (Frevert 2000: 183).

\subsection{Sprache $^{92}$}

\subsubsection{Sprachgebrauch}

Der Gebrauch der Sprache ist wichtig, um die Emotionen zu verstehen, da ein Mensch durch sie seine Gefühle ausdrückt. Deswegen muß zunächst auf die Sprache und ihre Funktionen im Hinblick auf die Emotionen im individuellen oder gemeinschaftlichen Gebrauch eingegangen werden.

Die Gesellschaft spielt eine wichtige Rolle beim sprachlichen Ausdruck von Emotionen. Die Theorie der sozialen Konstruktion von Emotionen (Averill 1980, Harré 1986) beinhaltet, daß die soziale Umwelt einen wichtigen Beitrag zur Entfaltung und Formung von Emotionen darstellt. Unterschiedliche Kulturen können verschiedene Emotionen als wichtige und sozialisationswürdige Wertvorstellungen haben. Der Gebrauch von Emotionswörtern muß unter verschiedenen Bedingungen nicht unbedingt nur Emotionen ausdrücken (Harré 1986). Das ist etwa der Fall bei körperlicher emotionsspezifischer Erregung, externen Gegenständen, Situationskonstellationen oder Moralordnungen (z.B. lokal üblichen Verpflichtungen, Regeln, Zwängen, Bewertungskonventionen oder Geboten). Wenn jedoch ein Wort von einem Mitglied einer Kultur- bzw. Sprachgemeinschaft benutzt wird, können unter demselben Emotionswort unterschiedliche Bedeutungsstrukturen verstanden werden, da die Emotionsbezeichnung unter Umständen von Person zu Person strukturell und funktional anders zu charakterisieren ist (Battacchi 1997: 82).

91 Vgl. Frevert (2000: 185).

$92 \mathrm{Im}$ Kapitel 6.1 über die ägyptischen Liebeslieder wird die Art der Dialoge in Bezug auf die ägyptischen Texte vorgestellt. 
Nur durch eine intensive Untersuchung der Sprachspiele, der Lebensform (z.B. Ort, Zeit und Begleitumstände), der Texte und der Sprecherpersönlichkeit (z.B. Absicht der Person) ist es möglich, emotive Bedeutungen erschöpfend zu entdecken und emotionale Aussagen zu enthüllen, welche sich als strategische Mittel mit Selbstdarstellungstendenzen zusammenfügen lassen (Lorenzer 1976; Paul 1989). Für die Analytiker von Sprachinhalten (Hölzer, Scheytt \& Kächele 1992; ${ }^{93}$ Gottschalk 1995) kann Sprache "Emotionen" bedeuten, da unter bestimmten Bedingungen die inhaltliche Ebene des verbalen Verhaltens den emotionalen $\mathrm{Zu}$ stand und auch die emotionalen Veranlagungen des Sprechers ausdrücken kann.

\subsubsection{Funktionen der Sprache}

Unter Sprachfunktion versteht man im allgemeinen die Aufgabe oder den Zweck einer sprachlichen Äußerung oder der Sprache an sich. Nach der aristotelischen Vorstellung, die Sprache bildet die Welt $a b$, schlug Bühler (1934) drei Hauptfunktionen des Sprachzeichens vor:

(1) die symbolische Funktion (Darstellungsfunktion), in der die Zeichen der Sprache oder ihr Lautgebilde zur Darstellung von Gegenstände und Sachverhalten fungieren,

(2) die Symptomfunktion, mit der der innere Zustand des Sprechens ausgedrückt wird, und

(3) die Signalfunktion, die sich an einen Hörer wendet.

Auf den Arbeiten von Jakobson (1960) und Halliday (1975) beruhend, werden hier knapp die wichtigsten Sprachfunktionen dargestellt:

- Die referentielle (informative/repräsentative) Funktion gemäß der Darstellungsfunktion von Bühler, in der die Sprache Dinge und Sachverhalte mitteilt.

- Die konative (regulatorische) Leistung der Sprache entspricht der Signalfunktion von Bühler, in der der Sprecher durch seine Äußerung andere Personen nach eigenen Wünschen und Bedürfnissen steuert.

- Die emotive (Personal) Sprachfunktion, mit der der Sprecher seine Persönlichkeit und seine Emotionen ausdrückt.

- Die phatische (interaktionale) Sprachleistung entspricht dem von Malinowski geprägten Begriff der phatic communion, wonach das Sprachziel bzw. die Lautäußerungen eine soziale Beziehungen zu schaffen und zu festigen hat (vgl. Hörmann 1977).

- Die poetische (imaginative) Funktion, welche sich einerseits auf die Benutzung der Sprache für ästhetische Zwecke bezieht, und anderseits zur Schaffung von Traum, Spiel und Fiktion dient.

93 Von diesen drei Autoren wurde der Affektive Diktionär Ulm veröffentlicht. Das Wörterbuch besteht aus acht Emotionskategorien, denen als "gefühlshaft" beurteilte Adjektive bzw. Substantive eines Textes zugeordnet werden. 
- Die metalinguistiche Funktion, in der die Sprache zum Objekt ihrer selbst wird, um etwas Gesagtes zu interpretieren.

- Die instrumentelle Funktion, mit der eigene materielle Wünsche befriedigt werden.

- Die heuristische Funktion, durch die die Umwelt analysiert und verstanden wird.

- Die textuale Funktion, mit der sinnvolle Texte z.B. Dialoge zu bilden sind.

\subsubsection{Universal human concepts}

Nach der Untersuchung der Emotionen in unterschiedlichen Kulturen und Sprachen läßt sich feststellen, daß die Gefühle gleich oder sehr ähnlich sind. Kövecses (2000: 142-146) überprüfte den Fall der Angst in vier unterschiedlichen Sprachen, nämlich japanisch, chinesisch, ungarisch und englisch. Es ergaben sich erstaunlich viele Übereinstimmungen, die sich seiner Meinung nach auf eine basic structure zurückführen lassen. Das erklärt er wie folgt:

- Einige dieser Übereinstimmungen sind zufällig, da das Verständnis der Angst bei diesen Völkern ähnlich ist.

- Eine Übertragung einer basic structure, d.h. eine basic structure entsteht als "Volksverstand" und wird von anderen Kulturen übernommen.

- Eine universell menschliche Konzeptualisation d.h. die basic structure ist das Ergebnis einer menschlichen Konzeptualisation, welche durch die universellen Eigenschaften des menschlichen Körpers beeinflußt wird.

Allerdings findet man für dasselbe Gefühl von einer Sprache zu anderen entweder kleine Nuancen eines Ausdruckes oder kein passendes Äquivalent. Osgood (1964: 171 ff.) schlägt vor, daß bestimmte Konnotationen universal sind, wie die allgemeine Dimensionen der Entwicklung (gut oder schlecht), der Tätigkeit (schnell oder langsam) und der Macht (stark und schwach). Wierzbicka (1972: 17 ff.) fügt hinzu, daß die Bedeutung der Emotionen aus einer ursprünglichen universalen Semantik kommt. Man sollte aber ihrer Meinung nach nicht annehmen, daß Emotionswörter in bestimmten Sprachen, z.B. Englisch, universal sind (1995: 20). Sie nennt die folgenden Sorten der ursprünglichen Semantik der englischen Sprache:

[substantives]
[determiners]
[mental predicates]
[speech]
[action, events, movement]
[existence, life]
[evaluators]
[descriptors]
[space]

- I, YOU, SOMEONE, SOMETHING, PEOPLE

- THIS, THE SAME, OTHER, ONE, TWO, SOME, MUCH/MANY, ALL

- KNOW, WANT, THINK, FEEL, SEE, HEAR

- SAY

- DO, HAPPEN, MOVE

- THERE IS, LIVE

- GOOD, BAD

- BIG, SMALL

- WHERE, SIDE, INSIDE, FAR, NEAR, UNDER, ABOVE, HERE 


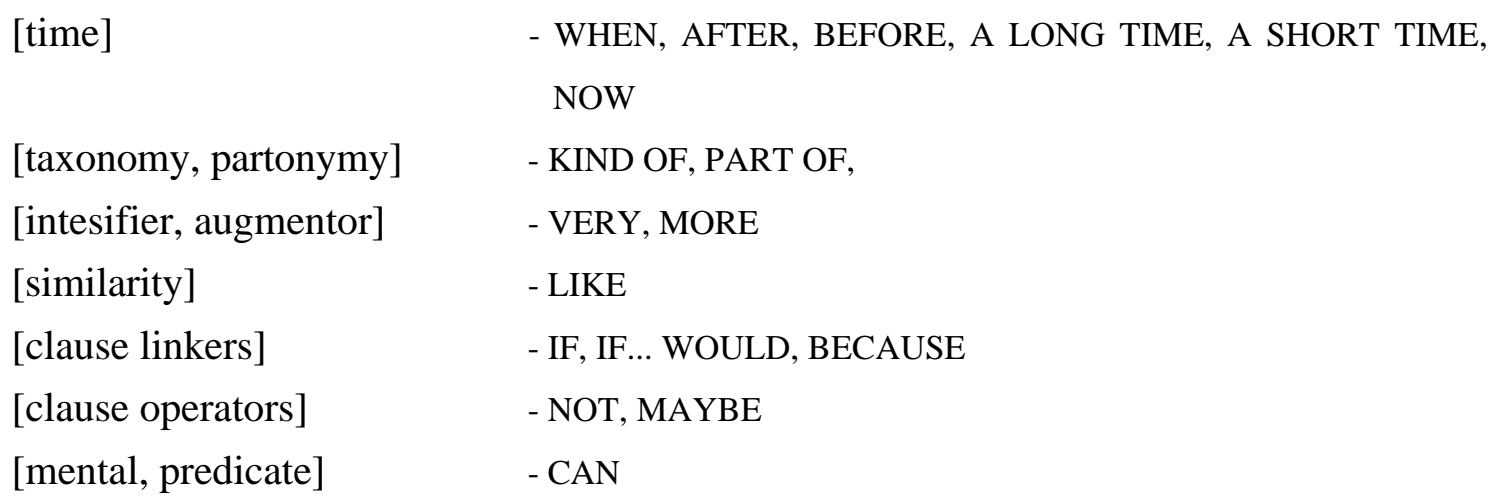

Zum Schluß bilde ich ein Diagramm ab, in dem die oben erwähnten human concepts, Zeit, Kultur und Sprache zusammen dargestellt werden. Human Concepts sind die Basis oder der Hintergrund in allen Sprachen und Kulturen, die zu dem Menschen gehören. Da der Mensch sich innerhalb einer Gesellschaft befindet, welche auch eine kulturelle und sprachliche Entwicklung enthält, wurden sowohl das Individuum als auch die Gesellschaft gegenseitig beeinflußt. Die Gefühle werden jeweils als ein persönlicher und sozialer Teil des Individuums und der Gesellschaft wahrgenommen. Obwohl die human concepts nach Wierzbickas Meinung universal sein können, beinhalten sie in jeder Kultur und in jeder Sprache Unterschiede, welche ihre Eigenarten einbringen. Diese Unterschiede ergeben sich aus der spezifischen Entwicklung jeder Kultur. 


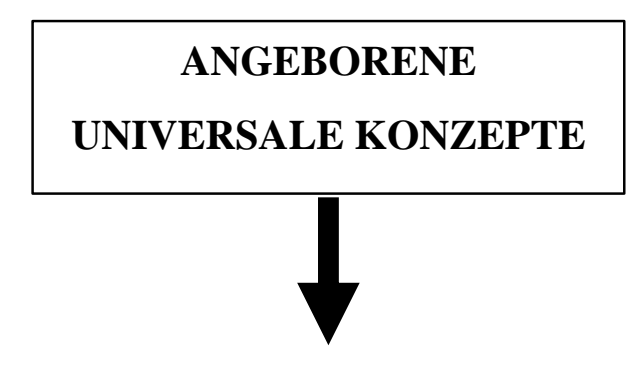

\section{ZEIT}
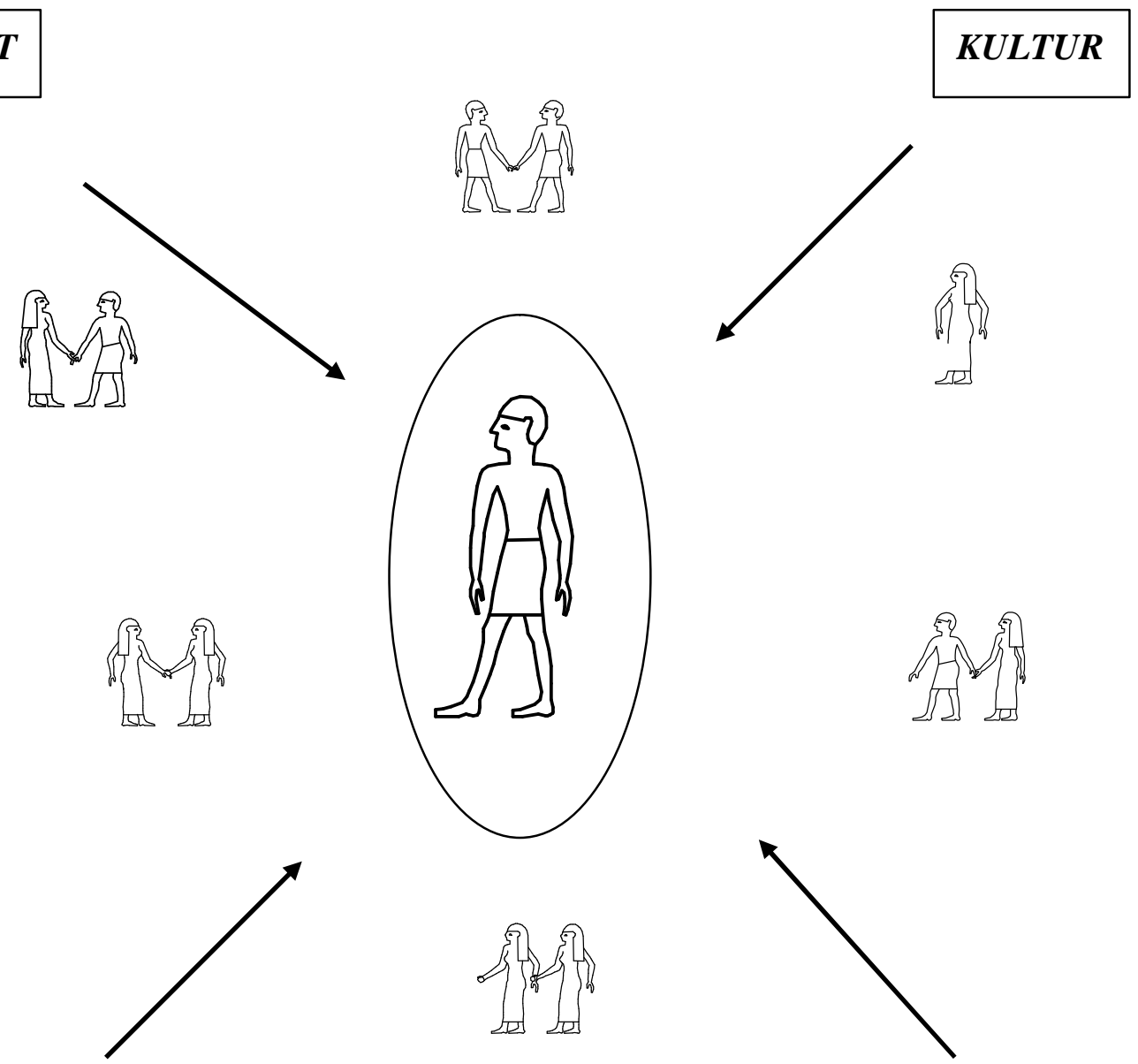

ROLLE

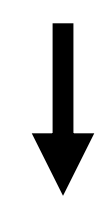

SPRACHE

INDIVIDUELLE

(einzelsprachliche) GEFÜHLE

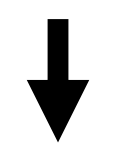

SPRACHLICHE AUSDRÜCKE VON GEFÜHLEN

(Metaphern, Emotionsbegriffe etc.) 


\subsection{Emotionen und Metaphern}

Die obigen Ausführungen dienen dazu, die mit Emotionen zusammenhängenden Metaphern von Emotionen besser zu verstehen. Auf den kommenden Seiten werden die Ausdrücke vorgestellt, die im Grunde genommen eine Metapher bilden. In der Literatur sind es die Dichter, die am häufigsten mit der Metapher arbeiten. Sie kombinieren auf allgemein verständliche Weise, um künstlerische Sprachbilder zu schaffen. Sie können Metaphern, die alltagssprachlich sind, und neue Ausdrucksweisen entstehen lassen. Die immer wieder verwendeten poetischen Metaphern könnten gemäß der gemeinsamen Basis identisch sein. Die neu erschaffenen Ausdrücke entstehen eigentlich aus dem ausgeweiteten Normalgebrauch einer konzeptuellen Metapher, die zum Allgemeingut einer Sprachgemeinschaft gehört. Lakoff \& Turner (1989) erklären das wie folgt:

"The basic metaphors are not creations of poets; rather, it is the masterful way in which poets extend, compose, and compress them that we find poetic. Poetic compression accounts in part for the effort required to comprehend rich poetry, even when all the metaphors in it are basic metaphors" (S. 54f.).

Um die Basismetapher von Gefühlen besser zu verstehen, erklärt Schermer (1988: 85) mit Hilfe der Psychologie bzw. des Rationalitätsgesichtspunkts, daß Emotionen oft einseitig als Störungen des normalen Denk- und Verhaltensablaufs aufgefaßt wurden. Die heftigen Emotionen können unsere wohlgeordneten Funktionen lahmlegen.

Die Bildung einer Metapher ist ein "Prozeß", welcher sich mit der Psyche und dem Körper eines Menschen in Verbindung bringen läßt. Die Organisation unseres Nervensystems ist der Grund, um Emotionen mit dem Herz-Kreislauf-System oder dem Magen-Darm-System zu verbinden. Das geschieht, da im Menschen, wenn er sich in einem Zustand emotionaler Erregung befindet, miteinander verbundene Organe aktiviert werden. Dies hat eine Veränderung im Herz-Kreislaufsystem und im Magen-Daum-Bereich zur Folge. Weber (1995: 66) bildet dafür eine metonymische Übertragung z.B. "Er hatte Schaum vor dem Mund" = Er war wütend.

Zudem läßt sich noch hinzufügen, daß die zentrale Bedeutung solcher Metaphern nach Lakoff \& Turner (1989: 85) einen Standort einnimmt, der z.B. ${ }^{94}$ die sich auf das Konzept "Depression" beziehenden Zustände im Englischen, Deutschen und Spanischen folgendermaßen ausgedrückt:

- "getting through a depression"; "having sunk into a depression"; "getting out of a depression"; "going from one depression to the next".

- "versunken sein in einer Depression"; "herauskommen aus einer Depression".

• "caer en una depresión"; "estar sumergido en una depresión"; "salir de una depresión".

94 Die spanischen und deutschen Beispiele sind von der Autorin hinzugefügt worden. 
Dadurch kann festgestellt werden, daß die physiologischen Effekte von zentraler Bedeutung für die Bildung von Metaphern sind. Dabei spielen die verbundenen Empfindungen von Wärme und Kälte eine Rolle. Mit Kälte lassen sich im allgemeinen negative Gefühle verbinden wie auch mit dem Bereich "Lähmung" im Fall der Traurigkeit. Im Gegensatz dazu werden positiven Gefühle durch Wärme-Metaphern ausgedrückt. Beides kann in folgender Tabelle zusammenfaßt werden:

\begin{tabular}{||l|c|c||}
\hline \hline & WARM & KALT \\
\hline POSITIV & $\begin{array}{c}\text { Liebe } \\
\text { Freude }\end{array}$ & \\
\hline NEGATIV & Wut & Trauer \\
\hline
\end{tabular}

Gemäß des körperlichen Konzeptes lassen sich die unterschiedlichen Theorien in fünf Hauptgruppen zusammenfassen:

(1) Die Theorie, welche die Emotion als eine Störungsform der Aufregung, d.h. körperliche Störung oder Unruhe versteht. Diese Gruppe schließt die psychoanalytischen Theorien von Emotionen sowie die Verhaltenstheorien (Young 1943) ein. Das hauptsächliche Thema dieser Theorien zur Fokussierung ist "Jemand ist beunruhigt" und "Jemand erfährt die körperlichen Effekte der Aufregung".

(2) Die Motivationstheorien, in der die organisierten und funktionierenden Eigenschaften der Emotionen betont werden, wobei die Emotionen eine Art von Kraft oder Schwung sind, welche die Person zur Reaktion antreiben (Plutchik 1980). Eine Abwandlung dieser Theorie versteht (Leeper 1970) die Emotion als einen Zustand, welcher auf einer bestimmten Weise der Stimuli der Umgebung antwortet.

(3) Die Theorien, in denen die Emotion als eine physikalische Empfindung beschrieben wird (James 1890; Schachter 1971). Das metaphorische Konzept dieser Theorie lautet: "Emotionaler Effekt bedeutet physikalischen Kontakt" und "Emotion ist eine innere Empfindung".

(4) Die biologische Evolution-Theorie (Darwin 1872/1965), in der die Emotionen als gemeinsame zu Menschen und Tieren gehörenden instinktiven Reaktionen zu verstehen sind.

(5) Die kognitiven Theorien, in der die Emotionen als eine irrationale Form des Urteils zu betrachten sind. Die irrationalen Urteile können sich zu einem intuitiven Urteil (Arnold 1960), magischen Transformationen der Welt (Sartre 1948) und einem Schätz-Urteil (Solomon 1976) entwickeln. 


\subsection{Beispiele}

\subsubsection{WuT}

Oben wurde gezeigt, wie die Konzepte "warm" und "kalt" benutzt werden, um Metaphern auszubilden. Diese Idee wird von Weber (1995) in Zusammenhang mit ihrer Untersuchung über Körper und über Metapher benutzt, um das Verständnis für eine Emotion zu erzeugen. Im Fall der Wut versteht sie die zentrale Metapher als "Wut ist die Wärme einer Flüssigkeit in einem Behälter" und geht davon aus:

Der Körper ist ein Behälter für die Emotionen + Wut ist die Wärme einer Flüssigkeit $=$ Wut ist die Wärme einer Flüssigkeit in einem Behälter (1995: 52, vgl. Kövecses 2000: 22). Die Basis für ihre Theorie stammt aus den folgenden Bereichen:

\begin{tabular}{||l|l|l|l||}
\hline \hline METAPHER & Wut ist Wärme & $\begin{array}{l}\text { Wut ist die Wärme einer Flüssig- } \\
\text { keit }\end{array}$ & $\begin{array}{l}\text { Wut ist Feuer (Wärme eines } \\
\text { Feststoffes) }\end{array}$ \\
\hline QUELLENBEREICH & Wärme, Erwärmung & Erwärmung einer Flüssigkeit & Feuer \\
\hline ZIELBEREICH & Wut & Wut & Wut \\
\hline MOTIVATION & & Wärme, innerer Druck & Wärme, Rötung \\
\hline
\end{tabular}

Das Gefühl "Wut" untersucht sie in der französischen Sprache nach fünf Quellenbereichskriterien, nämlich "Hitze einer Flüssigkeit in einem Behälter", "Feuer", "Krankheit", "Kampf", "Gefährliches Tier", mit den folgenden Ergebnissen (1995: 65-70):

- "Hitze einer Flüssigkeit in einem Behälter" beruht auf dem Konzept "der Körper ist ein Behälter für Gefühle" und wird hier kombiniert mit dem für Wut spezifischen physiologischen Effekt der Erhöhung der Körpertemperatur.

- "Feuer" beruht auf dem physiologischen Effekt der Erhöhung der Körpertemperatur.

- "Krankheit" steht in direkter Verbindung zu "Gefühle = Krankheit", ist also eine direkte Übernahme des Konzepts für Gefühl.

- "Kampf" beruht auf dem Quellenbereich "Gefühle sind Feinde".

• "Gefährliches Tier" beruht ebenfalls auf dem Quellenbereich "Gefühle sind Feinde".

\subsubsection{TRAUER}

Dieses Gefühl wird im Wahrings Deutsches Wörterbuch sowie im Brockhaus Lexikon nur durch Schmerz erklärt. Im Micro Robert ${ }^{95}$ wird "tristesse" durch "douleur morale" charakterisiert. Man geht davon aus, daß Trauer psychologisch mit Schmerzen identifiziert wird. ${ }^{96}$ Als andere psychologische Effekte von Trauer könnte man folgende erwähnen (Weber 1995: 71):

- Schmerz,

- Passivität, 
- verminderter Blut- und Muskeldruck,

- blasse Gesichtsfarbe,

- flache Atmung.

Im Vergleich haben Wut und Trauer psychologische Reaktionen, die auf physiologische Effekte hinauslaufen. Um diese voneinander zu unterscheiden ist festzuhalten, daß mit Wut "Wärme" assoziiert wird und im Gegensatz dazu die Trauer mit "Kälte" verbunden ist.

Im Folgendem werden die physiologischen Effekte anderer Emotionen dargestellt, um schließlich eine Tabelle mit den ableitbaren wichtigsten Konzeptionen von Emotion erstellen zu können. Diese Konzeptionen sind wichtig, um Metaphern zu verstehen und zu schaffen.

\subsubsection{ANGST}

Oben (4.3.1) wurde dieses Gefühl in Bezug auf unterschiedliche Sprachen definiert. Im Folgenden lassen sich die phsysiologischen Effekte von Angst zusammenfassen (Weber 1995: 77):

- erhöhte Sinneswahrnehmung,

- geöffneter Mund,

- Bewegungslosigkeit,

- Atemlosigkeit,

- zusammengekrümmte Körperhaltung,

- erhöhte Pulsfrequenz,

- Blässe,

- Schwitzen,

- Aufrichten der Körperhaare,

- Zittern,

- trockener Mund,

- rauhe Stimme.

Dieses Gefühl wird auch als "Flüssigkeit in einem Behälter" oder als "Gegner" verstanden. Dies läßt sich erklären, da die Person mit der Angst in einer Situation, welche überwunden werden muß, konfrontiert wird. Diese Überwindung kann man sich als einen Kampf vorstellen, um sie zu überstehen.

\subsubsection{FREUDE}

Dieses positives Gefühl läßt sich durch Ausdrücke der Zufriedenheit charakterisieren, die auf einem physiologischen Niveau durch die folgenden Effekte übertragen werden können (Weber 1995: 82):

- unmotivierte Bewegungen (Schütteln, Zusammenzucken),

- lautes Lachen,

- glänzende, evtl. tränende Augen, 
- unregelmäßige Atmung,

- roter Kopf.

Bei diesem Gefühl befindet man sich in einem Zustand, welcher mit den metaphorischen Ausdrücken "nach oben, hoch", "glänzen" und "entzücken" assoziiert wird.

\subsubsection{LIEBE}

Im Fall der Liebe sollte man nicht über "physiologische Effekte" sprechen. Der Grund für diese Behauptung basiert auf der von einer verliebten Person nicht wahrgenommenen Situation. Diese Effekte werden im Grunde genommen von anderen Personen wahrgenommen wie z.B. (Weber 1995: 87):

- Lächeln,

- glitzernde Augen.

Liebe gehört zu einem der am meistens metaphorisierten Gefühlskonzepte. Interessant dabei ist das Konzept, in dem die Person oder ein geliebtes Objekt als "Besitz" verstanden wird. Das läßt sich durch das Vereinigungs-Konzept erklären, d.h. zwei Teile komplementieren und vereinigen sich, wenn sie einander lieben. Diese Idee stammt von Plato und wird als traditionelles Konzept der Liebe bis in die Moderne verwendet (Fuller 1843).

\subsubsection{HASS}

Wenn man zwei Gefühle in Verbindung bringen möchte, sind Haß und Wut eine gutes Beispiel dafür. Von beiden sind die Effekte sehr ähnlich, und man geht davon aus, daß diese Effekte von beiden Gefühlen verglichen werden können (Weber 1995: 92):

- Herzklopfen,

- erhöhter Blutdruck,

- gerötetes Gesicht,

- unregelmäßige Atmung,

- aufrechte Körperhaltung,

- verkniffener Mund mit zusammengebissenen Zähnen,

- erhobene Fäuste,

- Zittern,

- gesträubte Haare.

\subsubsection{SCHAM}

Es ist interessant, daß dieses Gefühl nach Rusells Meinung (1955) in Amerika als "nicht angezogen" (having no clothes on) zu verstehen ist. Oben wurde erwähnt, daß dieses Gefühl in China als "der Verlust des Gesichtes" zu identifizieren ist. In beiden Fälle fehlt oder verliert man etwas, was wichtig für jede Kultur ist. Im Fall der Amerikaner fehlt die Kleidung d.h. sie 
sind nackt, und in China fehlt das Gesicht, d.h. sie haben keine angesehene Position mehr in den Augen der Umwelt.

Die psychologischen Effekte sind die folgenden (Weber 1995: 96):

- gerötetes Gesicht,

- Herzklopfen,

- Zittern,

- Erröten,

- rauhe Stimme.

\subsubsection{Zusammenfassung}

Die vorgestellten Beispiel "physiologischer Effekte" lassen sich tabellarisch übersichtlich wie folgt darstellen:

\begin{tabular}{||l|c|c|c|c|c|c|c||}
\hline & WUT & TRAUER & ANGST & FREUDE & LIEBE & HASS & SCHANDE \\
\hline POSITIV & & & & $\bullet$ & $\bullet$ & & \\
\hline NEGATIV & $\bullet$ & $\bullet$ & $\bullet$ & & & $\bullet$ & $\bullet$ \\
\hline WARM & $\bullet$ & & & $\bullet$ & & $\bullet$ & \\
\hline KALT & & $\bullet$ & & & & & $\bullet$ \\
\hline VERBLIC̈NDERUNG VERÄNDERUNG DER HAUT & $\bullet$ & $\bullet$ & $\bullet$ & & & $\bullet$ & $\bullet$ \\
\hline VERÄNDERUNG DER HALTUNG & & & $\bullet$ & $\bullet$ & & & $\bullet$ \\
\hline HERZKLOPFEN & $\bullet$ & & & & & $\bullet$ & $\bullet$ \\
\hline VERÄNDERUNG DER ATMUNG & $\bullet$ & $\bullet$ & & & & $\bullet$ & \\
\hline
\end{tabular}

\subsection{Kriterien}

Mit dem Fall der Wut wurde eine Bildmetapher eingeführt nämlich "der Behälter". Es gibt allerdings andere Metaphern, mit denen die Gefühle analysiert werden können. Das ist es, was in die folgenden Gruppen dargestellt wird.

(1) Der menschliche Körper definiert sich als Behälter durch seine Innen- und Äußenseite. Dies darf man als universales Konzept annehmen, da viele Kulturen die Gefühle als Ereignis im Inneren des Körpers wahrnehmen (Kövecses 2000: 37). Zum Beispiel sagen die Tahitianer "Ein wütender Mann ist wie eine Flasche, wenn er sich gefüllt hat, fängt er an sich zu ergießen" (Solomon 1984: 238). Im Wolof, einer afrikanische Sprache, die im Senegal und in Gambia gesprochen wird, gibt es das Wort bax (kochen), welches mit dem metaphorischen Sinn "sehr wütend sein" wiedergegeben wird (Munro 1991). 
(2) Naturelle und physikalische Kraft. Mit dem ersten Konzept z.B. dem Wind, Sturm oder der Flut sind viele Gefühle verbunden (stürmisch sein, überwältigt sein, durch den Wind sein). Die physikalische Kraft kann unterschiedliche Formen haben z.B. Anziehung(skraft); abrupt physikaler Kontakt zwischen Körper. Außer der Schande halten alle Konzepte der Emotionen diese körperliche Kraft ein.

(3) Krankheit. Normalerweise wird dieses Konzept mit einem negativen Aspekt wahrgenommen, z.B. Angst, Leidenschaft, (unglückliche) Liebe, Schande und Traurigkeit. ${ }^{97}$

(4) Feuer bei Ärger, Wut, (romantische) Liebe und Schande. Es ist aber nicht zu erwarten bei Freude, Traurigkeit.

(5) "Warm-Kalt", "Hell-Dunkel", "Oben-Unten", "Vitalität- Fehlen von Vitalität". All diese Konzepte finden sich nur bei Freude und Traurigkeit.

Diese fünf Kategorien können in zwei Hauptgruppen geordnet werden, nämlich positive und negative Gefühle. Unter dem positiven Aspekt lassen sich all diejenigen Emotionen gruppieren, die mit dem metaphorischen Sinn "hoch" und "warm" verstanden werden. Im Gegensatz dazu werden unter dem negativen Aspekt die Gefühle, die mit "unter", "kalt" und "unschätzbar" zu verstehen sind, gesammelt.

\subsection{Ein ägyptisches Emotionswörterbuch}

Es wurden auf den vorherigen Seiten einige Theorien von Emotionen, die vorgeschlagenen Klassifikationen von Emotionen und ihre Konzepte in unterschiedlichen Kulturen und Sprachen eingeführt. Emotionen wurden traditionellerweise als fünf Gruppen der sogenannten basic emotions klassifiziert, nämlich als Freude, Trauer, Haß, Angst und Liebe (Shaver, Schwartz, Kirson \& O'Connor 1987; Fehr \& Russel 1984; Fridja, Markan, Sato \& Wiers 1995).

Die Ägypter hatten ihrerseits einen zahlreichen Wortschatz, mit dem sie über Emotionen sprechen konnten. Im Anschluß wird ein ägyptisches Emotionswörterbuch präsentiert, in dem die Emotionen in mehr als die traditionellen fünf Basigruppen (Freude, Trauer, Haßen, Angst und Liebe) geordnet werden. Die erste Gruppe beinhaltet angenehme Gefühle wie froh und zufrieden; die zweite bildet deren Gegensatz d.h. Trauer usw. In die dritte Gruppe gehören die ärgerlichen Gefühle; die vierte Gruppe besteht aus der Angst; die fünfte wird durch die Sorge gebildet; während die sechste die Liebe enthält und die siebte die Milde und Ruhe.

Die Gruppe V, VII, VIII, IX und X gehören nicht zu dieser traditionellen Klassifikation der basic Emotion.

97 In den Kapitel 6 und 7 werden Beispiele aus den ägyptischen Texten angeführt, in denen die Gefühle mit solchen Sinn beschrieben werden. 
Die von mir vorgenommene Einteilung beruht auf der Ansicht, daß sowohl "Sorge" wie "Milde oder Ruhe" einen positiven Hintergrund haben können, aus dem sich ein gutes Gefühl ergeben kann. Dieses Gefühl soll aber nicht unbedingt als Freude oder hohe Stimmung bezeichnet werden. "Sorge" kann einen Hintergrund haben, welcher einen aufgeregten und unruhigen Zustand herstellt (siehe dazu E-32 im Kapitel 7.3).

Die Gruppen VIII und IX werden mit Bezeichnungen belegt, deren Bedeutung keine Emotion an sich enthalten. Allerdings können sie als eine Ableitung von einer körperlichen Grundbedeutung interpretieren werden, um eine Emotion widerzugeben. Als Beispiel wird das Wort $j 3 w j$ angeführt, dessen Bedeutung "alt werden" ein physisches Ergebnis impliziert. Dieses könnte als metaphorischer Gebrauch verstanden und benutzt werden, um einen emotionalen Zustand auszudrücken.

Die Gruppe X beinhaltet Begriffe, deren Bedeutung nicht klar widergegeben werden kann. Je nachdem, ob ein positives oder negatives Verständnis von ihnen vorausgesetzt wird, lassen sie sich eventuell mit einer Emotion in Verbindung bringen, da die Emotionen generell mit einer positiven oder negativen Eigenschaft identifiziert werden können.

Jede dieser Gruppen verfügt neben der Tabelle, in der alle unter der jeweiligen Überschrift zusammengefaßten Begriffe ähnlicher Bedeutung aufgeführt werden, über eine weitere, in der das Herz mit einer ähnlichen Bedeutung fokusiert wird. Die Tabelle wurden in vier Spalten geteilt:

Spalte I: Das ägyptische Wort

Spalte II: Die Bedeutung des Wortes gemäß des Wörterbuches von Erman/Grapow

Spalte III: Das Zitat des Wortes im Wörterbuch

Spalte IV: Das Determinativ des Wortes

Spalte V: Die Datierung des Wortes

Für die Zusammenstellung der drei ersten Spalten wurden im Grunde genommen keine Kriterien verwendet, abgesehen von der Bedeutung des Wortes, gemäß der sie zur dieser Gruppe gehören. Allerdings galten zwei Kriterien für die zwei folgenden Spalten.

Die Entwicklung eines emotionalen Ausdruckes verändert sich im Laufe der Zeit, wie oben im Fall der Liebe oder Schande im letzten Jahrhundert gezeigt werden konnte. Nach diesem Kriterium wurde die Datierung der Entstehung des Wortes mit dieser Bedeutung spezifiziert.

In den folgenden Kapiteln werde ich nicht alle Wörter (ca. 450) überprüfen, sondern nur diese, die in einem bestimmte Kontext, nämlich Weisheiten-, Erzählung- und Liebesliedertexten, vorkommen. 


\begin{tabular}{|c|c|c|c|c|c|c|c|c|c|}
\hline $\begin{array}{c}\text { GRUPPE } \\
\text { I }\end{array}$ & $\begin{array}{c}\text { GRUPPE } \\
\text { II }\end{array}$ & $\begin{array}{c}\text { GRUPPE } \\
\text { III }\end{array}$ & $\begin{array}{c}\text { GRUPPEI } \\
\text { IV }\end{array}$ & $\begin{array}{c}\text { GRUPPE } \\
\mathrm{V}\end{array}$ & $\begin{array}{c}\text { GRUPPE } \\
\text { VI }\end{array}$ & $\begin{array}{c}\text { GRUPPE } \\
\text { VII }\end{array}$ & $\begin{array}{c}\text { GRUPPE } \\
\text { VIII }\end{array}$ & $\begin{array}{c}\text { GRUPPE } \\
\text { IX }\end{array}$ & $\begin{array}{c}\text { GRUPPE } \\
X\end{array}$ \\
\hline Freude & Trauer & Haßen & Angst & Sorge & Liebe & Milde & \multirow[t]{2}{*}{$\begin{array}{l}\text { gutes } \\
\text { Gefühl }\end{array}$} & \multirow{2}{*}{$\begin{array}{l}\text { schlechtes } \\
\text { Gefühl }\end{array}$} & Zustände \\
\hline Herz & Herz & Herz & Herz & Herz & Herz & Herz & & & $\begin{array}{l}\text { positiven } \\
\text { negativen }\end{array}$ \\
\hline Zufrieden & \multirow[t]{2}{*}{ Jammern } & Böse & & & & \multirow[t]{2}{*}{ ruhig sein } & & & \\
\hline Herz & & Herz & & & & & & & \\
\hline Glücklich & $\begin{array}{l}\text { Benach- } \\
\text { teiligt }\end{array}$ & $\begin{array}{l}\text { Aggressiv } \\
\text { Herz }\end{array}$ & & & & & & & \\
\hline & & Herz & & & & & & & \\
\hline $\begin{array}{l}\text { Freund- } \\
\text { lichkeit }\end{array}$ & Mutlos & brennen & & & & & & & \\
\hline Herz & Herz & Herz & & & & & & & \\
\hline \multirow[t]{2}{*}{$\begin{array}{l}\text { angeneh- } \\
\text { men sein }\end{array}$} & matt sein & $\begin{array}{l}\text { ärgerlich } \\
\text { sein }\end{array}$ & & & & & & & \\
\hline & Herz & Herz & & & & & & & \\
\hline & \multirow[t]{2}{*}{ Scheu } & mutig & & & & & & & \\
\hline & & Herz & & & & & & & \\
\hline
\end{tabular}




\section{GRUPPE I}

\section{FREUDE}

\subsection{GENERELL}

\begin{tabular}{|c|c|c|c|c|}
\hline $3 w j$ & erfreuen & $\mathrm{Wb}$ I 4,5-6 & $\omega$ (D.18) & $\mathrm{Gr}$ \\
\hline $3 b j$ & sich freuen (mit m: über) & Wb I 7,4 & 2 & Nä; Gr \\
\hline $3 h$ & es freut sich über, es geht ihm gut & Wb I 14,20-24 & $\begin{array}{l}\varnothing \\
w \\
\end{array}$ & $?$ \\
\hline 3h $n f$ & er freut sich über (mit $m, h r, n$ ) & Wb I 14,22-24 & $\varnothing$ & $?$ \\
\hline$j^{c j} j-j b$ & erfreut werden & Wb I 39,10 & $\mathrm{~mm}$ & seit D.18 \\
\hline$j w 3$ & sich freuen & $\mathrm{Wb}$ I 49,12 & $\frac{1}{4 x}$ & N.R. \\
\hline$\overline{j s ̌ w t}$ & jauchzen & $\mathrm{Wb}$ II 455,5 & 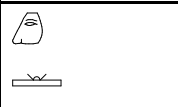 & belegt seit D.18 \\
\hline$\overline{c_{n}\left(c_{j n}\right)}$ & freundlich, heiter, erfreulich & Wb I 190,8 & $\infty$ & seit Lit M.R. \\
\hline$w 3 b$ & erfreulich für in $w 3 b h r j b$ & $\mathrm{~Wb}$ I 250,13 & ih & A.R. \\
\hline$\overline{w n f}$ & sich freuen, freuen sein & Wb I 319,11-19 & 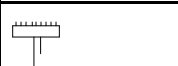 & Gr und N.R. \\
\hline wisj & sich freuen & Wb I 261,5-6 & 20 & $\begin{array}{l}\text { belegt A.R.-D. } \\
\text { 18, Sait }\end{array}$ \\
\hline wihj & sich freuen (von Herz und Nase) & Wb I 259,8-9 & $\sqrt{10}$ & $\mathrm{Gr}$ \\
\hline wihh & sich freuen über einen Ort & Wb I 259,14-15 & $\varnothing$ & Pyr; M.R. \\
\hline$b n b n$ & sich erfreuen an & Wb I 459,18 & $\varnothing$ & D. 19 \\
\hline bnhm & jauchzen & $\mathrm{Wb}$ I 463,19 & D & $\mathrm{Gr}$ \\
\hline bnhm & jauchzen & Wb I 463,19 & S & $\mathrm{Gr}$ \\
\hline$\overline{f t f t}$ & springen vom lebhaften klopfen des Herzens & $\mathrm{Wb}$ I 581,6 & $\wedge$ & $\begin{array}{l}\text { belegt Med, } \\
\text { N.R. }\end{array}$ \\
\hline$m f k$ & sich freuen, erfreuen & Wb II 58,3-5 & 0 & $\mathrm{Gr}$ \\
\hline$m s h 3$ & sich freuen, erfreuen & Wb II 147,6-13 & is & belegt $\mathrm{Gr}$ \\
\hline$m q d$ & sich freuen, in Freude & $\mathrm{Wb} \mathrm{V} 77,9-11$ & $\omega$ & belegt $\mathrm{Gr}$ \\
\hline$m n \underline{h}$ & sich freuen an & Wb II 87,7 & $\begin{array}{l}\varnothing \\
8\end{array}$ & altes Wort \\
\hline$m h \underline{b} b$ & in festlicher Stimmung, fröhlich & $\mathrm{Wb}$ II 58,13-21 & $\otimes$ & seit M.R. \\
\hline$m n h$ & frohlocken & Wb II 84,1 & $\frac{6}{2}$ & $\mathrm{Gr}$ \\
\hline$m n \underline{h}$ & Staunen (freuen) & Wb II 87,7 & $\begin{array}{l}\varnothing \\
0\end{array}$ & altes Wort \\
\hline$m n \check{s}$ & im Geg. zu fröhlich & Wb II 89,11 & 进 & Lit. M.R. \\
\hline$m k$ & Festfreude & Wb II $162,8-9$ & $\otimes$ & belegt $\mathrm{Gr}$ \\
\hline
\end{tabular}




\begin{tabular}{|c|c|c|c|c|}
\hline$n h m$ & jubeln & Wb II 297,12 & 0 & Pyr, D.18 \\
\hline$n \underline{d} m$ ršs $w t$ & fröhlich & Wb II 379,21 & I & N.R. \\
\hline$n w h$ & vergnügt sein & Wb II 224,6 & $=0$ & $\begin{array}{l}\text { belegt seit D. } \\
22 \text {, oft Gr }\end{array}$ \\
\hline$n m^{c} m^{c}$ & jauchzen & Wb II 267,3 & $\varnothing$ & $\mathrm{Gr}$ \\
\hline$n h m$ & jubeln, jauchzen & Wb II 285,7-14 & 2 & belegt seit Pyr \\
\hline njm & sich freuen & Wb II 203,6 & $\varnothing$ & D.18 \\
\hline$r n n$ & jubeln & Wb II 435,9 & $\sum^{2}$ & M.R., N.R. \\
\hline$r \check{s} w$ & froh sein & Wb II 454,1-12 & $\sum_{1}$ & belegt seit M.R. \\
\hline jšwt & in Freude etw. tun & $\begin{array}{l}\text { Wb II } 454,18 \text { bis } \\
455,15\end{array}$ & 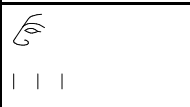 & seit D.18 \\
\hline$\overline{r s ̌ r} r \check{s}$ & sich freuen & Wb II 456,1-4 u. 6 & 同 & $\begin{array}{l}\text { belegt seit ende } \\
\text { M.R. }\end{array}$ \\
\hline$\overline{h r w}$ & froh sein & Wb II 496,7;12;16 & $w$ & belegt seit Pyr \\
\hline$h r w$ & erfreulich & Wb II 497,17-18 & $w$ & seit Pyr \\
\hline$h j$ & jauchzen (siehe bei $h j$ ) & Wb II 483,1-11 & 2 & seit M.R. \\
\hline$\overline{h 3 j}$ & jauchzen (siehe bei $h j$ ) & Wb II 475 & 2 & seit M.R. \\
\hline$h n w$ & jubeln, jauchzen & Wb II 493,15-20 & 禺 & seit Pyr \\
\hline$h t \underline{t}$ & jubeln, jauchzen & Wb II 504,7-8 & 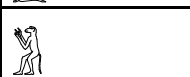 & seit D.18 \\
\hline$h j^{c}$ & jubeln, sich freuen & $\begin{array}{l}\text { Wb III } 40,2 \text { bis } \\
41,1-2\end{array}$ & is & seit Pyr \\
\hline$h b j$ & Festlich sein & Wb III 60,12 & $\varnothing$ & Pyr, N.R, D.19 \\
\hline hpg & vergnügt sein & \begin{tabular}{|l} 
Wb III 71,6 \\
\end{tabular} & \& & \begin{tabular}{|l|} 
Gr \\
\end{tabular} \\
\hline$h$ hlkn & jubeln, sich freuen & $\begin{array}{l}\text { Wb III } 178,7 \text { bis } \\
179,3\end{array}$ & $\begin{array}{l}\text { seit D.18 迆 } \\
\text { H u.ä }\end{array}$ & seit Pyr \\
\hline ḥngg & jauchzen, sich laut freuen & Wb III 121,7-9 & 2 & $\mathrm{Gr}$ \\
\hline$\overline{h z j}$ & jubeln & Wb III 159,16 & $\Lambda$ & seit M.R. \\
\hline$h r$ & jubeln & Wb III 128,3 & 9 & seit D.18 \\
\hline$h \underline{d} \underline{d}$ & sich an Licht freuen & Wb III 215,4 & 0 & belegt seit N.R. \\
\hline$h^{c c} w t$ & in Freude sein & Wb III 41,3-9 & $\begin{array}{l}w \\
\mathbb{N} \\
w \\
w\end{array}$ & seit Pyr \\
\hline$h \dot{h} g$ & froh sein & Wb III 34,18-20 & 2 & M.R., Nä, Gr \\
\hline$h j g\} g$ & froh sein & Wb III 35,2-3 & $w$ & Ritual \\
\hline hִtp & froh sein & Wb III 193,29 & $\varnothing$ & seit Pyr, Nä \\
\hline$h b j$ & vergnügt sein & Wb III 250,11 & 这 & $\mathrm{Gr}$ \\
\hline hnt & sich freuen & Wb III 308,19 & 同 & M.R. \\
\hline
\end{tabular}




\begin{tabular}{|c|c|c|c|c|}
\hline$\overline{h h n t \check{s}}$ & sich freuen & $\begin{array}{l}\text { Wb III } 311,11-18 \\
\text { u. } 312,1-5\end{array}$ & $\approx$ & seit D.18, oft Gr \\
\hline hsffw & sich freuen & Wb III 337,7 & $\Lambda$ & seit Pyr \\
\hline hnnm & froh sein, erfreuen & Wb III 292,10-14 & A & M.R., N.R. \\
\hline hhntš & in Freude sein & Wb III 312,8-11 & $\begin{array}{l}a \\
w\end{array}$ & N.R., oft Gr \\
\hline$\underline{h} n m$ & voll Freude sein & Wb III 378,26 & $\varnothing$ & belegt seit Pyr \\
\hline$z^{3}-t^{3}$ & jauchzen & Wb III 416,9 & $\varnothing$ & $\mathrm{Sp}, \mathrm{Gr}$ \\
\hline$z 3 b$ & erfreuen & Wb III 421,3 & और & seit M.R. \\
\hline$z f n$ & erfreuen, froh sein, sich freuen, froh machen & Wb III 443,6-11 & S & $\mathrm{Gr}$ \\
\hline$s z b \underline{t}$ & jmd. zum Lachen bringen & Wb IV 274,1 & 28 & belegt Lit. M.R. \\
\hline snhmhm & jauchzen & Wb IV 168,7 & 2 & belegt $\mathrm{Gr}$ \\
\hline shnts & froh machen, erfreuen & $\begin{array}{l}\text { Wb IV 256,17 bis } \\
257,1\end{array}$ & $\begin{array}{l}\text { A } \\
\text { 9m }\end{array}$ & belegt $\mathrm{Gr}$ \\
\hline$s h^{c c}$ & froh machen, erfreuen & Wb IV 211,5-10 & \begin{tabular}{|l} 
Les \\
If
\end{tabular} & seit N.R., oft Gr \\
\hline sḥd & froh machen, erfreuen & Wb IV 225,18-20 & 0 & seit Pyr \\
\hline $\operatorname{shb}$ & Ägypten in festliche Stimmung versetzen & Wb IV 213,14 & $w$ & N.R.; Gr \\
\hline$s z b \underline{t}$ & jmd. zum Lachen bringen & Wb IV 274,1 & Qf & Lit M.R. \\
\hline$s b \underline{t}$ & lachen & Wb III 434,5-10 & 9 & seit Pyr \\
\hline$s b j$ & lachen & Wb IV 89,4 & Q & D.19 \\
\hline$s \underline{d} 3 j-h r r$ & sich vergnügen & $\begin{array}{l}\text { Wb IV } 378 \text { bis } \\
379,13\end{array}$ & $\varnothing$ oder $\mathbb{2}$ & belegt seit M.R. \\
\hline$s r q$ & erfreuen & Wb IV 202,3 & 8 & D. $18, \mathrm{Gr}$ \\
\hline stfn & erfreuen & Wb IV 343,1 & 同 & belegt Gr \\
\hline s3wj & jmd. erfreuen & Wb IV 17,8-9 & $w$ & $\mathrm{Gr}$ \\
\hline$s g^{3}$ & staunen (freuen) & Wb IV 320,5-6 & $\mathbb{S}^{2}$ & belegt N.R.; Sp \\
\hline$s g 3 w t$ & staunen (freuen) & Wb IV 320,9 & $\infty$ & belegt Totb. \\
\hline$s n \underline{d m}$ & jmd. erfreuen & Wb IV 186,1 & & belegt seit Pyr \\
\hline swih & Nase u.ä mit Duft erfreuen & Wb IV 63,19 & 80 & belegt $\mathrm{Gr}$ \\
\hline sih & erfreuen & Wb IV 23,13 u. 15 & $w$ & $\mathrm{Gr}$ \\
\hline$s b n r$ & erfreuen & Wb IV 90,6 & 8 & $\mathrm{Gr}$ \\
\hline$\check{s} s p$ & Freude empfangen, sich freuen & Wb IV 532,16 & in & belegt seit Pyr \\
\hline$\check{s} m s$ & fröhlich sein, erfreuen & Wb IV 483,11-14 & $\Lambda$ & seit M.R. \\
\hline $\begin{array}{l}q b \\
q b b\end{array}$ & befriedigt wird & $\mathrm{Wb} \mathrm{V} 23,9-10$ & $\xi £$ & belegt seit Pyr \\
\hline th & sich an ihm erfreuen & $\mathrm{Wb} V 325,9$ & $=\underbrace{}_{1}$ & belegt $\mathrm{Gr}$ \\
\hline
\end{tabular}




\begin{tabular}{|c|c|c|c|c|}
\hline $\begin{array}{l}t f n \\
t f n n\end{array}$ & sich freuen & Wb V 299,8-16 & $\therefore$ & belegt $\mathrm{Gr}$ \\
\hline tpnpn & sich freuen & $\mathrm{Wb}$ V 364,8 & $\varnothing$ & belegt M.R. \\
\hline$\underline{t h n n n}$ & sich freuen & Wb V 395,2 & (s) & belegt Pyr \\
\hline$\underline{t h h h}$ & sich freuen, jauchzen, jubeln & $\mathrm{Wb}$ V 395,5-7 & & belegt seit D.18 \\
\hline$t h w$ & sich freuen, Freude & Wb V 389,5-6 & Did & belegt D.18 \\
\hline trworw & sich an etw freuen & Wb V 387,4 & $\varnothing$ & belegt seit Pyr \\
\hline$\underline{t h h n}$ & heiter, froh sein & Wb V 392,12-16 & $\frac{y_{3}}{100}$ & belegt seit Pyr \\
\hline$\underline{t} 3 j$ & jubeln anstimmen & $\mathrm{Wb}$ V 346,20 & 21 & Nä \\
\hline thhḥw.t & jauchzen, Jubel, Freude, in Jubel sein & $\begin{array}{l}\text { Wb V 395,8 bis } \\
396,1\end{array}$ & D? & belegt seit M.R. \\
\hline$d m$ & beim Nennen des Namens des Königs jubeln & $\mathrm{Wb} \mathrm{V} \mathrm{449,17}$ & Q & $\begin{array}{l}\text { belegt seit Ende } \\
\text { A.R. }\end{array}$ \\
\hline$\underline{d} j j-h r$ & sich vergnügen & Wb V 514,10-12 & & seit D.18 \\
\hline
\end{tabular}

\subsection{AUSDRÜCKE MIT EINEM LEXEM FÜR 'HERZ'}

\begin{tabular}{|c|c|c|c|c|}
\hline $3 w j-j b$ & fröhlich machen, erfreuen & $\mathrm{Wb}$ I 4,9 & 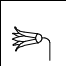 & $\mathrm{Gr}$ \\
\hline $3 w j-j b$ & fröhlich sein, fröhlich & $\mathrm{Wb} \mathrm{I} 4,7$ & 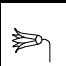 & $\mathrm{Gr}$ \\
\hline $3 m s-j b$ & sich freuen & Wb I 11,7 & 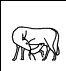 & M.R.; Gr \\
\hline$w \underline{d} ; j b$ & froh & Wb I 400,9-10 & $\omega$ & seit Pyr \\
\hline$w \underline{t z} j b$ & frohlocken & Wb I 383,12-13 & 4 & D. 19,20 \\
\hline wị jb & "das Herz neigen zu.." & Wb I 256,14 & w & seit Lit M.R. \\
\hline$p \underline{d}$ & $\begin{array}{l}\text { vom Herzen, sich freuen (mit n- wegen) } \\
\text { ähnlich wie } 3 w-i b\end{array}$ & Wb I 568,4 & $\leadsto$ & $?$ \\
\hline$p h 3-i b$ & heiter, fröhlich, Frohsinn & Wb I 542,17-18 & $\omega$ & D. $18, \mathrm{Gr}$ \\
\hline$n h n h$ hn & vom Herzen, sich freuen & Wb II 312,11 & $\varnothing$ & Pyr \\
\hline$n h \underline{r} r \underline{h r}$ & sein Herz freut sich beim Nahen jds. & Wb II 299, 1 & $\varnothing$ & Pyr, D.19, Gr \\
\hline$n \underline{d} m$ jb & fröhlich, freundlich zu jdm. & Wb II 379,15-16 & w & N.R. \\
\hline$n j w j w$ & vom Herzen, fröhlich sein & Wb II 203,4 & $\varnothing$ & D. 18 \\
\hline$n \underline{d} m \mathrm{jb}$ & vom Herzen, sich freuen, fröhlich sein & Wb II 380,7-14 & $\omega$ & seit M.R. \\
\hline$r h \underline{r h h}$ & vom frohen Herzen & Wb II 442,3 & A & Gr \\
\hline$r b n b n$ & vom Herzen, sich freuen & Wb II 414,4 & س & D. 19 \\
\hline
\end{tabular}




\begin{tabular}{|c|c|c|c|c|}
\hline$\overline{m h b}$ & in festlicher Stimmung, fröhlich & $\mathrm{Wb}$ II 58,18 & $\nabla$ & seit M.R. \\
\hline$h k n$ & das Herz erfreuen mit etw & Wb III 178,6 & $\begin{array}{l}\text { seit D.18 } \\
\text { u.ä } \\
\text { u }\end{array}$ & seit Pyr \\
\hline hrrḥr & sich freuen & Wb III 150,8 & $\hat{g}$ & $\mathrm{Gr}$ \\
\hline hijg & froh sein & Wb III 34,19 & 2 & M.R., NÄ, Gr \\
\hline$h \underline{d}$ & froh & Wb III 207,26 & 0 & $\mathrm{Gr}$ \\
\hline ḩnťs & sich freuen & Wb III 312,2-5 & 同 & seit D.18, oft Gr \\
\hline ḩntšs & in Freude sein & $\mathrm{Wb}$ III 312,10 & 国 & N.R., oft Gr \\
\hline hnnt-jb & das Herz ist froh & Wb III 309,1-2 & $\varnothing$ & Pyr \\
\hline$\underline{h n m-j b}$ & das Herz erfreuen & Wb III 379,17 & $\varnothing$ & Sait, Gr \\
\hline$z f n$ & das Herz froh machen & $\mathrm{Wb}$ III 443,10 & $\mathbb{N}^{2}$ & $\mathrm{Gr}$ \\
\hline$s^{c} n h$ & $\begin{array}{l}\text { das Herz, die Herzen beleben, erfreuen, sich } \\
\text { erheitern }\end{array}$ & Wb IV 47,12 & $\varnothing$ & seit Pyr \\
\hline$s 3 w j$ & das Herz jmds. erfreuen & Wb IV 17,5-7 & $w$ & Pyr, Gr \\
\hline$s 3 b$ & das Herz seinem Herrn erfreut & Wb III 421,6 & 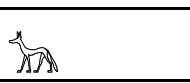 & D.18 \\
\hline$s 3 b$ & das Herz erfreuen & Wb IV 17,12 & 2 & $\mathrm{Gr}$ \\
\hline sih & das Herz erfreuen & Wb IV 22,14 & $w$ & $\mathrm{Gr}$ \\
\hline smn & das Herz fest machen & Wb IV 132,24 & ש & belegt seit Pyr \\
\hline snhihin & (das Herz) erfreuen & Wb IV 169,9 & $\varnothing$ & belegt A.R. \\
\hline$s n f r$ & das Herz erfreuen & Wb IV 163,12 & $\varnothing$ & seit A.R. \\
\hline $\begin{array}{l}\text { swih } \\
\text { swrh }\end{array}$ & das Herz erfreuen & Wb IV 63,20 & 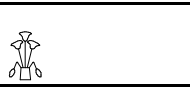 & belegt $\mathrm{Gr}$ \\
\hline$s n \underline{d m}$ & das Herz erfreuen & Wb IV 186,12-17 & $w$ & $\mathrm{Gr}$ \\
\hline$s n^{c C}$ & vom Herzen erfreuen & Wb IV 156,16 & seit D.18 固等 & Lit M.R., Totb. \\
\hline snf & vom Herzen: es erfreuen & Wb IV 162,10 & $\frac{\bar{Z}}{V^{2}}$ & $\mathrm{Gr}$ \\
\hline$s w \underline{d})$ & das Herz jmds. erfreuen & Wb IV 80,1 & $w$ & $\mathrm{Gr}$ \\
\hline swnf & das Herz froh machen & Wb IV 69,10 & $\beta$ & belegt $\mathrm{Gr}$ \\
\hline$s r \check{s} w$ & das Herz froh machen & Wb IV 201,15 & 同 & belegt Nä \\
\hline$s h^{c c}$ & das Herz jmds froh machen & Wb IV 211,5-6 & Les & seit N.R, oft Gr \\
\hline shntš & das Herz jmds. froh machen, erfreuen & Wb IV 256,18 & in & belegt $\mathrm{Gr}$ \\
\hline$s n b$ & vom Herzen sich freuen, froh sein & Wb IV 158,15 & $\varnothing$ & belegt seit Pyr \\
\hline snp & vom Herzen, froh sein & Wb IV 162,2 & W & belegt $\mathrm{Gr}$ \\
\hline
\end{tabular}




\begin{tabular}{|c|c|c|c|c|}
\hline šsp & das Herz empfindet Freude, was ihn erfreut & Wb IV 533,1-4 & $\longleftarrow$ & belegt seit Pyr \\
\hline $\begin{array}{l}t f n \\
t f n n\end{array}$ & sich freuen, Herzensfroh & Wb V 299,12-13 & $\Leftrightarrow$ & belegt $\mathrm{Gr}$ \\
\hline then & heiter, froh sein & Wb V 392,14 & & belegt seit $\mathrm{Pyr}$ \\
\hline
\end{tabular}

\section{ZUFRIEDEN}

\subsection{GENERELL}

\begin{tabular}{|c|c|c|c|c|}
\hline htp & zufrieden sein & $\begin{array}{l}\text { Wb III } 188,3 \text { bis } \\
189,10 \text { u. } 191,27 \\
\text { u. } 192,5 \text { u. } 9 \\
\end{array}$ & $\varnothing$ & seit Pyr \\
\hline shrj & zufrieden sein & Wb IV 208,1-5 & & seit M.R. \\
\hline $\operatorname{shtp}$ & zufrieden stellen & $\begin{array}{l}\text { Wb IV } 221,10 \text { bis } \\
222,20\end{array}$ & 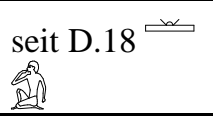 & belegt seit Pyr \\
\hline tp.t-r\} & Ausspruch jdms., mit dem man zufrieden ist & Wb V 287,15 & $\varnothing$ & belegt seit M.R. \\
\hline$t p-r\}$ & Worte, mit ihnen zufrieden sein & Wb V 287,7 & seit D.19 \& & belegt seit A.R. \\
\hline
\end{tabular}

\subsection{AUSDRÜCKE MIT EINEM LEXEM FÜR 'HERZ'}

\begin{tabular}{|l|l|l|l|l||}
\hline shtp & zufrieden stellen das Herz jmds. & $\begin{array}{l}\text { Wb IV 221,16 u. } \\
18\end{array}$ & $\begin{array}{l}\text { seit D.18 } \\
\text { oder } \mathbb{N}^{2}\end{array}$ & belegt seit Pyr \\
\hline
\end{tabular}

\section{GLÜCKLICH}

\begin{tabular}{||l|l|l|l|l||}
\hline \hline$m^{c} r$ & glücklich & Wb II 48,10 & $w$ & belegt seit A.R. \\
\hline$h t p$ & glücklich & Wb III 193,29 & $\varnothing$ & seit Pyr, Nä \\
\hline$s b q$ & glücklich, trefflich & Wb IV 94,9 & $\ldots$ & belegt seit Pyr \\
\hline$s m^{c} r$ & jmdn. glücklich preisen & Wb IV 131,3-4 & $\varnothing$ & Gr \\
\hline
\end{tabular}

\section{FREUNDLICHKEIT}

\subsection{GENERELL}

\begin{tabular}{||l|l|l|l|l||}
\hline \hline w3h & $\begin{array}{l}\text { freundlich sein; geneigt sein etwas zu tun; so } \\
\text { freundlich sein und ... tun; als gute Ei- } \\
\text { genschaft }\end{array}$ & Wb I 256,15-18 & alt \\
\hline$m s b b$ & freundlich sein zu jdm. & Wb II 143,13 & Wb IV 274,3 & belegt D.18, Gr \\
\hline$s z f$ & freundlich stimmen & Wb IV 86,18-21 & Lit M.R. \\
\hline$s b 3 q$ & heiter stimmen, beglücken, freundlich & belegt seit Pyr \\
\hline
\end{tabular}




\begin{tabular}{||l|l|l|l|l||}
\hline \hline sjm 3 & jmd. freundlich stimmen & Wb IV 37,7-9 & & $\begin{array}{l}\text { belegt seit M.R., } \\
\text { Gr }\end{array}$ \\
\hline$q b, q b b$ & vom erfreulichen Zustand eines Landes & Wb V 24,4 & $\pi$ & belegt seit M.R. \\
\hline$\underline{d} 3 . t$ & mit freundlicher Hand & Wb V 516,5 & $\varsigma$ & M.R. \\
\hline
\end{tabular}

\subsection{AUSDRÜCKE MIT EINEM LEXEM FÜR 'HERZ'}

\begin{tabular}{|c|c|c|c|c|}
\hline$p \underline{h} r-i b$ & freundlich als Eigenschaftswort & Wb I 545,2 & $\Lambda$ & seit D.18 \\
\hline$m h^{3}$ & das Herz freundlich stimmen & Wb II 130,15 & $\Delta$ & N.R. \\
\hline $\operatorname{sjm} 3$ & das Herz freundlich machen & Wb IV 37,8 & $w$ & D.18, Gr \\
\hline$\overline{s j m 3}$ & freundlich sein (vom den Herzen) & Wb IV 401,4 & $\sqrt{60}$ & belegt $\mathrm{Sp}$ \\
\hline
\end{tabular}

\section{ANGENEHMEN SEIN}

\begin{tabular}{||l|l|l|l|l||}
\hline$\check{s} p s$ & jmd. angenehm sein = von ihm begnadet sein & Wb IV 447,24 & & Seit D.19 \\
\hline$\check{s} z p$ & $\begin{array}{l}\text { angenehm sein für.. "Personen, die dem } \\
\text { Namen teuer sind" }\end{array}$ & Wb IV 534,1 & & Sargt \\
\hline$m n h$ hr jb & angenehm sein & Wb II 86,5 u. 8-9 & 8 & M.R., D.18 \\
\hline
\end{tabular}

\section{SONSTIGES}

\subsection{GENERELL}

\begin{tabular}{|c|c|c|c|c|}
\hline$n h \mathrm{ht}$ & siegreich sein & Wb II 314,13 & 斿 & A.R., D20 \\
\hline $\begin{array}{l}\hat{i} f j \\
q f\end{array}$ & erstaunt sein & $\mathrm{Wb} \mathrm{V} 11,13$ & $\begin{array}{l}2 \\
28 \\
28\end{array}$ & belegt Nä \\
\hline$g 3 g 3 w$ & staunen über & Wb V 157,4-6 & 20 & belegt seit D.18 \\
\hline 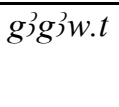 & in Erstaunen & Wb V 157,7 & $\begin{array}{l}\infty \\
11\end{array}$ & $\begin{array}{l}\text { belegt seit } \\
\text { D.18, Sp }\end{array}$ \\
\hline
\end{tabular}

\subsection{AUSDRÜCKE MIT EINEM LEXEM FÜR 'HERZ'}

\begin{tabular}{|c|c|c|c|c|}
\hline$b 3 q$ & Stolz vom Herzen, es stolz machen & Wb I 425,17 & 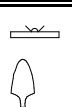 & $\begin{array}{l}\text { belegt Pyr, } \\
\text { Med-Gr }\end{array}$ \\
\hline$\overline{s^{c 3}}$ & Stolz vom Herzen, es stolz machen & Wb IV 42,24 & & belegt seit M.R. \\
\hline shmh & sich belustigen & $\begin{array}{l}\text { Wb IV 252,10 } \\
\text { bis } 253,5\end{array}$ & $\begin{array}{l}\varnothing \\
\frac{2}{2} \\
\frac{2}{5}\end{array}$ & belegt Pyr-Saït \\
\hline$\underline{t} z$ & erheben & Wb V 399,2 & $-\infty$ & $\mathrm{Sp}$ \\
\hline$t z j$ & erheben & $\mathrm{Wb} \mathrm{V} \mathrm{406,4}$ & 4 & seit Lit M.R. \\
\hline
\end{tabular}




\section{GRUPPE II}

\section{TRAURIG}

1.1 GENERELL

\begin{tabular}{|c|c|c|c|c|}
\hline$m r$ & sehr traurig & Wb II 95,12 & 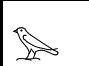 & $\mathrm{Gr}$ \\
\hline $\begin{array}{l}m \check{s}^{c}-h r- \\
m w\end{array}$ & treu sein & Wb II 156,11 & $\mathcal{L}$ & D.22 \\
\hline$m g$ 3.t & traurig & Wb II 164,10 & 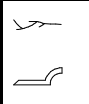 & Lit M.R., Sp \\
\hline$m r$ & sehr traurig, von traurigen Worten & Wb II 95, 2 u. 15 & 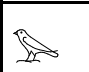 & Gr, Nä \\
\hline$n h r h r$ & traurig sein & Wb II 313,1 & $\varnothing$ & Pyr \\
\hline$n h p$ & trauern um jmd & Wb II 284,17 & & M.R., N.R. \\
\hline$n q m$ & traurig sein & Wb II $344,4-5$ & 20 & Zaub Nä \\
\hline$n q b$ & traurig & Wb II 344,1 & De & $\begin{array}{l}\text { späte } \\
\text { Schreibung für } \\
\text { nqm }\end{array}$ \\
\hline jrj $m r$ & klagen, trauern & Wb II 96,5 & 2 & belegt seit Med \\
\hline$\overline{h t b}$ & trauern & Wb III 183,3 & E & Lit Sp \\
\hline$h b$ & trauern um jmd & Wb III 61,14 & H & Lit M.R. \\
\hline$h m s j$ & traurig & Wb III 97,7 & 篮 & belegt seit Pyr \\
\hline$\underline{h} s t j$ & traurig werden & $\mathrm{Wb}$ III 400,15 & 领 & $\mathrm{Gr}$ \\
\hline snm & traurig sein, Trauer & Wb IV 165,4-9 & 20 & $\begin{array}{l}\text { Lit M.R. und } \\
\text { oft Gr }\end{array}$ \\
\hline snqb & trauern & Wb IV 175,4 & $5 \pi ?$ & Lit M.R. \\
\hline$g 3 s$ & trauern & $\mathrm{Wb}$ V 156,1 & $\pi$ & belegt Nä \\
\hline gjs.t & die Trauernde & Wb V 157,1 & $\pi i$ & belegt $\mathrm{Gr}$ \\
\hline$t p-m 3 s . t$ & Trauer, traurig & $\mathrm{Wb} V 285,6-7$ & $\int$ & belegt seit M.R. \\
\hline$\underline{d m^{c}}$ & von Zustand der Trauer & $\mathrm{Wb}$ V 574,12 & 2 & $\begin{array}{l}\text { belegt N.R. } \\
\text { (Zaub.) } \\
\end{array}$ \\
\hline
\end{tabular}

\subsection{AUSDRÜCKE MIT EINEM LEXEM FÜR 'HERZ'}

\begin{tabular}{|c|c|c|c|c|}
\hline$h w^{3}$ & sich grämen & Wb III 50,16 & $\infty$ & Nä \\
\hline$g m . w$ & das Herz in Schwäche ist, d.h. traurig & Wb V 169,16 & $\sum_{0}^{20}$ & belegt seit M.R. \\
\hline$d h r$ & betrüben & $\mathrm{Wb} \mathrm{V} \mathrm{483,2-4}$ & $\sum \approx$ & Med., Nä \\
\hline$\underline{d} w$ & betrübt sein & $\mathrm{Wb}$ V 547,4 & 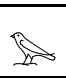 & Wetscar, Nä \\
\hline$\underline{d w} \cdot t$ & traurig werden & $\mathrm{Wb}$ V 548,16 & $\Leftrightarrow$ & Westcar, Nä \\
\hline$\underline{d} w$ & traurig werden & $\mathrm{Wb}$ V 549,20 & Dos & belegt seit D.18 \\
\hline
\end{tabular}




\begin{tabular}{|l|l|l|l|l|}
\hline \hline$\underline{d w} \cdot t-j b$ & Traurigkeit & Wb V 549,23 & belegt N.R., Gr \\
\hline
\end{tabular}

\section{JAMMERN}

\begin{tabular}{||l|l|l|l|l||}
\hline $\begin{array}{l}r m j, r m w, \\
r m j . t\end{array}$ & weinen & $\begin{array}{l}\text { Wb II 416 bis } \\
417,17\end{array}$ & belegt seit Pyr \\
\hline$h w t$ & jammern, klagen & Wb II 485,2-3 & Seg & Königsgr, Gr \\
\hline
\end{tabular}

\section{BENACHTEILIGT}

\begin{tabular}{||l|l|l|l|l}
\hline \hline$q b$ & sich demütigen & Wb V 22,3 & belegt N.R. \\
\hline
\end{tabular}

\section{MUTLOS}

4.1 GENERELL

\begin{tabular}{|l|l|l|l|l||}
\hline \hline hnrg & entmutigt sein & Wb III 115,6 & Nä \\
\hline
\end{tabular}

\subsection{AUSDRÜCKE MIT EINEM LEXEM FÜR 'HERZ'}

\begin{tabular}{||l|l|l|l|l||}
\hline wsth & vom Herzen, unverzagt & Wb I 368,1 & $\wedge$ & belegt seit M.R. \\
\hline$\underline{h t m}$ & mutlos werden & Wb III 198,1 & D.20 \\
\hline$s \underline{d}$ & zerbrochenen Herzen = mutlos & Wb IV 374,22 & $\times$ & belegt seit Pyr \\
\hline$s \underline{h m}$ & $\begin{array}{l}\text { das Herz des Feindes mutlos werden las- } \\
\text { sen }\end{array}$ & Wb IV 215,5 & $\mathbb{\Lambda}$ & Pyr, Gr \\
\hline
\end{tabular}

\section{MATT SEIN}

\begin{tabular}{||l|l|l|l|l||}
\hline$\underline{h}{ }^{\prime} d$ & matt, gleichgültig & Wb III 236,12 & belegt D.21, Sp \\
\hline$\underline{h} z j$ & matt, schlaff werden & Wb III 399,7 & & N.R \\
\hline
\end{tabular}

\section{SCHEU}

\begin{tabular}{||l|l|l|l|l||}
\hline$\underline{t} m$ & sich schämen, bereuen & Wb V 367,4 & belegt Nä \\
\hline
\end{tabular}




\section{GRUPPE III}

\section{HASSEN}

1.1 GENERELL

\begin{tabular}{||l|l|l|l|l||}
\hline$m s \underline{d j}$ & hassen & Wb II 154,1-9 & alt \\
\hline$\underline{h} b d$ & hassen & Wb III 257,10 & M.R., N.R. \\
\hline$s f 3, s f 3 t$ & hassen, Haß & Wb IV 114,6-7 & Lit M.R. \\
\hline$s f 3$, & hassen) Verbum & Wb IV 114,8 & Lit M.R. \\
\hline$\underline{d} w . t$ & hassen das Böse vermeiden & Wb V 548,3-4 & belegt seit Pyr \\
\hline$\underline{d} w$ & hassen, das Böse meiden & Wb V 549,7 & belegt seit D.18 \\
\hline
\end{tabular}

\subsection{AUSDRÜCKE MIT EINEM LEXEM FÜR 'HERZ'}

\begin{tabular}{|l|l|l|l|l||}
\hline$t^{3}$ & heiß sein, vom Herzen & Wb V 229,5 & $\begin{array}{l}\text { Med, belegt seit } \\
\text { A.R. }\end{array}$ \\
\hline
\end{tabular}

\section{BÖSE}

2.1 GENERELL

\begin{tabular}{|c|c|c|c|c|}
\hline bjn & Böse & Wb I 443,6 & $N$ & $\begin{array}{l}\text { belegt seit Ende } \\
\text { A.R. }\end{array}$ \\
\hline$m r t$ & böses tun gegen jmd. & Wb II 96,12 & 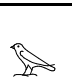 & $\begin{array}{l}\text { Pyr, Königsgr, } \\
\text { Zaub. N.R. }\end{array}$ \\
\hline$m r . t$ & Böses, Schlimmer & Wb II 96,12 & $\Rightarrow$ & $\begin{array}{l}\text { Pyr, Königsgr, } \\
\text { Zaub. N.R. }\end{array}$ \\
\hline$m t j$ & Böse & $\begin{array}{l}\text { Wb II } 169,9 \text { u. } 15 \\
(m n t j=m t j)\end{array}$ & $2 \Rightarrow$ & belegt $\mathrm{Gr}$ \\
\hline$m d s$ & Böse wütet & Wb II 183,9 & $\otimes$ & Nä (Zaub), Gr \\
\hline$\overline{n s ̌}$ & wütend sein & Wb II 337,10 & $E$ & $\begin{array}{l}\text { späte Schreibung } \\
\text { für } n \check{s} n\end{array}$ \\
\hline$\overline{n s ̌ n j}$ & wütend sein & $\begin{array}{l}\text { Wb II 340,11 bis } \\
341,22\end{array}$ & 45 & belegt seit Pyr \\
\hline ḩrst & Wutgerötet sein (von den Augen) & Wb III $151,1-2$ & $\circ$ & belegt $\mathrm{Gr}$ \\
\hline$\overline{h^{c} r}$ & wütend sein & Wb III 244,2-6 & 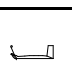 & seit D.18 \\
\hline hiswt & rasen, in Verzückung sein & Wb III 226,9 & 题 & belegt Nä \\
\hline$\underline{h} z j$ & bösartig & Wb III 399,19 & 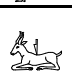 & $\mathrm{Gr}$ \\
\hline qnd & wütend sein; werden zürnen & $\begin{array}{l}\text { Wb V 56,16 bis } \\
57,16\end{array}$ & ind & seit M.R. \\
\hline$q s n$ & böser Zustand & $\mathrm{Wb}$ V 70,8 & $\Leftrightarrow$ & belegt seit Pyr \\
\hline$\overline{d \check{s} r}$ & mit rotem Gesicht, wütend & $\mathrm{Wb}$ V 490,4-5 & $\Leftrightarrow$ & $\mathrm{Sp}, \mathrm{Gr}$ \\
\hline$d n d n$ & der Zorn, das Wütend & $\begin{array}{l}\text { Wb V 471,1 bis } \\
472,5\end{array}$ & 4 & belegt seit D.18 \\
\hline
\end{tabular}




\begin{tabular}{|c|c|c|c|c|}
\hline$d h r$ & von Aussprüchen die nicht bitter sind & $\mathrm{Wb}$ V 482,20 & $\Leftrightarrow$ & belegt seit Med \\
\hline$\underline{d n d}$ & zornig sein, wütend & Wb V 579,6-7 & & $\begin{array}{l}\text { belegt seit Pyr, } \\
\text { M.R., D.18 }\end{array}$ \\
\hline$\underline{d n d}$ & der Zorn, das Wütend & $\mathrm{Wb}$ V 579,1-5 & 4 & $\begin{array}{l}\text { belegt seit Pyr- } \\
\text { D. } 18\end{array}$ \\
\hline
\end{tabular}

\subsection{AUSDRÜCKE MIT EINEM LEXEM FÜR 'HERZ'}

\begin{tabular}{||l|l|l|l|l||}
\hline$\check{s} w$ & das Herz vom Böses frei machen & Wb IV 428,2 & Gr \\
\hline$q m 3 \dot{m}$ & Böses, Feindseliges ausüben & Wb V 35,19 & & belegt seit Pyr \\
\hline$d \check{s} r$ & mit rotem Herzen, wütend & Wb V 490,6 & seit M.R. \\
\hline$\underline{d} n d$ & zornmütig & Wb V 579,7 & \multicolumn{2}{c}{ M.R., D.18 } \\
\hline
\end{tabular}

\section{AGRESSIV}

3.1. GENERELL

\begin{tabular}{||l|l|l|l|l||}
\hline$\underline{h} 3 k$ & feindlich sein gegen & Wb III 363,12 & $\varnothing$ & Königsgr \\
\hline
\end{tabular}

\subsection{AUSDRÜCKE MIT EINEM LEXEM FÜR 'HERZ'}

\begin{tabular}{||l|l|l|l|l||}
\hline \hline$m d s$ & gewalttätig sein & Wb II 183,3 u. 8 & & $\begin{array}{l}\text { belegt seit M.R., } \\
\text { oft Gr }\end{array}$ \\
\hline$s z w n$ & bestrafen & Wb IV 273,15 & belegt seit M.R. \\
\hline šnt-ib & streiten in der Verbindung & Wb IV 519,8 & Lit. M.R \\
\hline
\end{tabular}

\section{BRENNEN}

4.1 GENERELL

\begin{tabular}{|c|c|c|c|c|}
\hline$\check{s} m, \check{s} m m$ & Hitzige & Wb IV 469,1-8 & $A_{\infty}$ & $\begin{array}{l}\text { Nä (zaub.), Gr., } \\
\text { Sp }\end{array}$ \\
\hline$\overline{t 3}$ & heiß, entzündet & Wb V 229,4 & A & $\begin{array}{l}\text { Med, belegt sein } \\
\text { A.R. }\end{array}$ \\
\hline
\end{tabular}

\subsection{AUSDRÜCKE MIT EINEM LEXEM FÜR 'HERZ'}

\begin{tabular}{|l|l|l|l|l||}
\hline míh & $\begin{array}{l}\text { die Herzen der Feinde brennen = sich } \\
\text { haben Angst }\end{array}$ & Wb II 31,11 & D.18 \\
\hline
\end{tabular}

\section{5. ÄRGERLICH}

\subsection{GENERELL}

\begin{tabular}{||l|l|l|l|l||}
\hline \hline$b \check{s} \underline{t} w$ & sich empören & Wb I 479,6 & Lit M.R., D.19 \\
\hline$m n$ & ärgerlich sein für & Wb II 67,3 & Sp \\
\hline
\end{tabular}




\begin{tabular}{|c|c|c|c|c|}
\hline$m s \underline{d} j$ & unzufrieden sein mit jdm, jdn. schelten & Wb II 154,2 & 92 & D.18, Äth \\
\hline$h p t$ & ärgerlich (siehe bei $\check{s} p t$ ) & Wb III 270 & DOS & ? \\
\hline $\begin{array}{l}h \underline{h d n} \\
h \underline{d} \underline{d} n n\end{array}$ & unwillig sein & Wb III $214,4-6$ u. 8 & & Nä \\
\hline$s f n w, s f n\}$ & ärgerlich & Wb IV 115,4-6 & $\infty$ & Lit M.R, D.18 \\
\hline shnnd & sich ärgern über & Wb IV 257,2 & Df & belegt Nä (D.21) \\
\hline $\bar{s} n t j$ & ärgerlich & Wb IV 518,11 & 政 & belegt Nä, Sp \\
\hline $\bar{s} p t, \underline{h p t}$ & ärgerlich sein, unzufrieden sein, verärgert & Wb IV 453,10-16 & $\sum_{0 \rightarrow}$ & $\begin{array}{l}\text { belegt seit Pyr, } \\
\text { Gr }\end{array}$ \\
\hline$\check{s} p t, \underline{h p t}$ & Ärger & Wb IV 454,1-12 & $\alpha \Leftrightarrow$ & $\begin{array}{l}\text { belegt Totb., oft } \\
\text { Gr }\end{array}$ \\
\hline
\end{tabular}

\subsection{AUSDRÜCKE MIT EINEM LEXEM FÜR 'HERZ'}

\begin{tabular}{||l|l|l|l|l||}
\hline \hline$\underline{h} w^{3}$ & verdrießlich sein & Wb III 50,16 & $\varnothing$ & Nä \\
\hline$s \check{s} n$ & vom Herzen (Arger) & Wb IV 294,3 & $\varnothing$ & D.18, Gr \\
\hline$s \underline{h} \underline{d} n$ & (das Herz jmds) ärgerlich machen & Wb IV 228,8 & & Lit M.R. \\
\hline$\check{s} p t, \underline{h} p t$ & Ärger ist im Herzen & Wb IV 454,2-4 & $\begin{array}{l}\text { belegt Totb., oft } \\
\text { Gr }\end{array}$ \\
\hline
\end{tabular}

\section{MUTIG}

\subsection{GENERELL}

\begin{tabular}{||l|l|l|l|l||}
\hline \hline$h z j$ & mutig sein & Wb III 159,9 & $\wedge$ & D.18, Sp \\
\hline shm & kühn & Wb IV 246,15-17 & $\smile$ & M.R, D.18 \\
\hline
\end{tabular}

\subsection{AUSDRÜCKE MIT EINEM LEXEM FÜR 'HERZ'}

\begin{tabular}{|c|c|c|c|c|}
\hline$n h t$ & mutig sein & Wb II 314,16-17 & bs & A.R., D20 \\
\hline$h z j$ & mutig sein & Wb III 159,9 & $\wedge$ & D. $18, \mathrm{Sp}$ \\
\hline smn & ermuntern, ermutigen & $\mathrm{Wb}$ IV 132,25 & $w$ & belegt seit Pyr \\
\hline$s w \underline{d}\}$ & das Herz jmds mutig machen & Wb IV 80,2 & $\omega$ & $\mathrm{Gr}$ \\
\hline$t p h-j b$ & mutig & Wb V 296,13 & 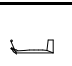 & belegt $\mathrm{Gr}$ \\
\hline
\end{tabular}




\section{SONSTIGES}

\begin{tabular}{||l|l|l|l|l||}
\hline \hline$b q$ & widerspenstig & Wb I 479,11 & $\varkappa$ & belegt D.18 u. Sp \\
\hline$p r j j b$ & ungeduldig & Wb I 524,17 & N & N.R. \\
\hline
\end{tabular}




\section{GRUPPE IV}

1. ANGST

1.1 GENERELL

\begin{tabular}{||l|l|l|l|l||}
\hline$n r j$ & erschrecken, schaudern & Wb II 277,4-7 & Pyr \\
\hline$r w j$ & schrecken & Wb II 406,4 & seit Lit M.R. \\
\hline$h r j . t$ & Schrecken & Wb III 148,3-12 & belegt Totb., \\
N.R.
\end{tabular}

\subsection{AUSDRÜCKE MIT EINEM LEXEM FÜR 'HERZ'}

\begin{tabular}{|c|c|c|c|c|}
\hline$p z h$ & $\begin{array}{l}\text { vom Herzen, das aus Angst in } \\
\text { Verwirrung gerät }\end{array}$ & Wb I 550,17 & $\wedge$ & Lit M.R. \\
\hline$m 3 \underline{h}$ & Angst haben um jmd. & Wb II 31,9-10 & A & Lit M.R. \\
\hline$s \underline{d}$ & $\begin{array}{l}\text { die Herzen zerbrochenen = tödlich er- } \\
\text { schrecken, }\end{array}$ & Wb IV 374,20 & $\underset{\square}{\longleftarrow}$ & belegt seit Pyr \\
\hline$t p-t f j$ & aus Unruhe, aus Angst & Wb V 298,7 & 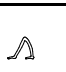 & belegt Nä \\
\hline
\end{tabular}

\section{SICH FÜRCHTEN}

2.1 GENERELL

\begin{tabular}{|c|c|c|c|c|}
\hline snd & Furcht haben vor & $\begin{array}{l}\text { Wb IV 182,2 bis } \\
183,1\end{array}$ & 2 & belegt seit Pyr \\
\hline$\check{s} \tilde{s} \tilde{s} f t$ & sich vor ihm fürchten & Wb IV 460,13-14 & $\pi^{2}$ & $\begin{array}{l}\text { belegt Pyr, M.R.- } \\
\text { ende N.R., oft Gr }\end{array}$ \\
\hline$\check{s p}$ & $\begin{array}{l}\text { die Furcht vor jdm. macht einen blind, } \\
\text { übertragen }\end{array}$ & $\mathrm{Wb}$ IV 443,11 & $\infty$ & Lit M.R., D.18 \\
\hline$q m 3$ & Schrecken, Furcht & Wb V 35,15-19 & & belegt seit Pyr \\
\hline$\underline{d d f}$ & Zeichen der Furcht & $\mathrm{Wb}$ V 634,5-6 & $\Rightarrow$ & $\begin{array}{l}\text { belegt Lit M.R., } \\
\text { Sp }\end{array}$ \\
\hline
\end{tabular}


2.2 AUSDRÜCKE MIT EINEM LEXEM FÜR 'HERZ'

\begin{tabular}{||l|l|l|l|l||}
\hline \hline$s h \check{s} n$ & in Furcht versetzen & Wb IV 174,6 & Belegt Gr. \\
\hline$s h$ & in Furcht versetzen & Wb IV 205,19 & - & belegt Lit M.R. \\
\hline
\end{tabular}




\section{GRUPPE V}

\section{SORGE}

1.1 GENERELL

\begin{tabular}{|c|c|c|c|c|}
\hline$m h$ & bekümmert sein, sich Sorge machen & $\begin{array}{l}\text { Wb II } 120,13 \text { u. } 15- \\
16\end{array}$ & $x^{28}$ & seit M.R., Äth \\
\hline$n \underline{d} s \underline{h r}$ & sich um etwas sorgend kümmern & Wb II 371,14 & س山 & belegt seit Pyr \\
\hline$n w j$ & sorgen für, für sich selbst sorgen & Wb II 220,5-14 & 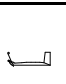 & $\begin{array}{l}\text { belegt seit Lit } \\
\text { M.R }\end{array}$ \\
\hline ḩmt & sich nicht kümmern um & Wb III 285,7 & 92 & N.R. \\
\hline sihj & Sorgen für, für sich selbst sorgen & Wb IV 22,6 & $\Leftrightarrow$ & $\mathrm{Nä}$ \\
\hline$s^{3}$ & $\begin{array}{l}\text { sich kümmern um, das Herz hinter etw. } \\
\text { setzen }\end{array}$ & Wb IV 10,21-23 & $\varnothing$ & belegt seit Pyr \\
\hline$\check{s} n n$ & Kummer & Wb IV 515,5-9 & हs & $\mathrm{Gr}$ \\
\hline
\end{tabular}

1.2 AUSDRÜCKE MIT EINEM LEXEM FÜR 'HERZ'

\begin{tabular}{|c|c|c|c|c|}
\hline$m \hat{3} \underline{h}$ & Sorge tragen & Wb II 31,10 & $A_{0}$ & $\mathrm{Gr}$ \\
\hline $\begin{array}{l}\text { rdj hijtj.f } \\
m s j\end{array}$ & $\begin{array}{l}\text { sein Herz hinter etw geben }=\text { sich sorgen } \\
\text { um }\end{array}$ & Wb III 27,17 & $\varnothing$ & belegt seit Pyr \\
\hline$\overline{s 3}$ & $\begin{array}{l}\text { sich kümmern um, das Herz hinter etw. } \\
\text { setzen }\end{array}$ & Wb IV 10,21-23 & $\varnothing$ & belegt seit Pyr \\
\hline$q s n$ & seelisch vom Herzen, bekümmert, bestürzt & $\mathrm{Wb}$ V 69,10 & Nos & belegt seit Pyr \\
\hline
\end{tabular}




\section{GRUPPE VI}

\section{LIEBE}

Wb II 98 bis 104,14

2⿺ 


\section{MILDE}

GRUPPE VII

1.1 GENERELL

\begin{tabular}{|c|c|c|c|c|}
\hline$n \underline{\underline{d}-h r t}$ & Anteil nehmen (an jdm.) & "Wb II 373,19 & 28 & Nä \\
\hline$\overline{n^{c}}$ & Mitleid haben, Mitleid & Wb II 206,4-5 & $20 x$ & $\begin{array}{l}\text { belegt D.19, } \\
\text { D.20, Gr }\end{array}$ \\
\hline$z f n$ & milde sein & Wb III 443,2-4 & a & seit M.R. \\
\hline$\overline{z f}$ & sanftmütig sein, milde & Wb III 442,3 & 2 & seit M.R. \\
\hline$h t p$ & gnädig sein & Wb III 189,11-18 & $\varnothing$ & seit Pyr \\
\hline
\end{tabular}

1.2 AUSDRÜCKE MIT EINEM LEXEM FÜR 'HERZ'

\begin{tabular}{|l|l|l|l|l||}
\hline \hline$z 3 w$ & mitleidig & Wb III 419,9 & $\times$ & Gr \\
\hline
\end{tabular}

\section{RUHIG SEIN}

\begin{tabular}{|c|c|c|c|c|}
\hline$m d n$ & ruhig sein & Wb II 182,8 & $\begin{array}{l}0 \\
w \\
w\end{array}$ & belegt Nä \\
\hline$\overline{s \check{s} p}$ & ruhig, unbesorgt & Wb IV 284,3 & R & $\begin{array}{l}\text { Lit. M.R., } \\
\text { Westcar, Saït }\end{array}$ \\
\hline$s g r$ & $\begin{array}{l}\text { Klagenden beruhigen, das klein Kind } \\
\text { beruhigen }\end{array}$ & Wb IV 323,8-9 & 2 & belegt seit A.R. \\
\hline sgrh & $\begin{array}{l}\text { Klagenden beruhigen, das klein Kind } \\
\text { beruhigen }\end{array}$ & Wb IV 324,7-12 & $=0$ & belegt seit M.R. \\
\hline $\begin{array}{l}q b \\
q b b\end{array}$ & ruhig & $\mathrm{Wb}$ V 23,4-17 & 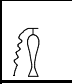 & belegt seit Pyr \\
\hline$g r$ & ruhig & $\mathrm{Wb}$ V 180,6-7 & in & belegt N.R. \\
\hline$t \check{s}$ & friedfertig sein & Wb V 329,16 & 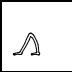 & belegt Sp \\
\hline
\end{tabular}




\section{GUTES GEFÜHL}

GRUPPE VIII

1.1 GENERELL

\begin{tabular}{|c|c|c|c|c|}
\hline$j 3 w j$ & alt sein & Wb I 28,8 & if & belegt seit A.R. \\
\hline${ }^{c} \underline{d}$ & wohlbehalten sein & Wb I 237,11 & $\omega$ & seit M.R. \\
\hline$c_{n \underline{h}}$ & lebendig sein & Wb I 194,13-16 & $\varnothing$ & seit Pyr \\
\hline$m 3 w j$ & verjüngen & Wb II 26,4 & $\omega$ & $?$ \\
\hline$n \underline{d} m$ & sich wohl befinden & Wb II 380,4 & $\varnothing$ & Med \\
\hline$r w \underline{d}$ & sich wohl befinden & Wb II 411,14 & 89 & belegt seit Pyr \\
\hline rnpj & sich verjüngen & $\begin{array}{l}\text { Wb II } 432,11 \text { bis } \\
434,8\end{array}$ & $£$ & seit Pyr \\
\hline$h w n$ & sich verjüngen & Wb III 54,3-10 & 38 & seit Pyr \\
\hline jrj hwwn & sich verjüngen & Wb III 54,14 & 38 & seit D.21 \\
\hline 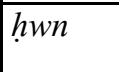 & verjüngen & Wb III 54 & Q & $\mathrm{Gr}$ \\
\hline$\underline{h r d}$ & sich verjüngen & Wb III 398,13-17 & 38 & seit D.19 \\
\hline$\overline{s i j}$ & satt werden, sich sättigen & $\begin{array}{l}\text { Wb IV } 15,1 \text { u. } 12 \text { u. } \\
16\end{array}$ & $2^{2}$ & Seit D.18 \\
\hline$s n h$ & verjüngen & Wb IV 169,7 & $\mathscr{Q}$ & belegt Pyr; Gr \\
\hline srnp & verjüngen & Wb IV 198 & 9 & $\mathrm{Gr}, \mathrm{Sp}$ \\
\hline$s n h \underline{h}$ & verjüngen & Wb IV 170,2-3 & 38 & belegt seit N.R. \\
\hline sḥwn & verjüngen & Wb IV 213 & 2 & $\mathrm{Gr}$ \\
\hline shhrd & verjüngen & Wb IV 271,4-8 & $\begin{array}{l}38 \\
40\end{array}$ & belegt seit D.19 \\
\hline snh & sich verjüngen & Wb IV 169,7 & ? & $\mathrm{Gr}$ \\
\hline$s \underline{h} r d$ & sich verjüngen & Wb IV 271,4-6 & 38 & $\mathrm{Gr}$ \\
\hline$s n b$ & sich wohl befinden & Wb IV 158,9-13 & $\begin{array}{l}\varnothing \\
w \\
\end{array}$ & Nä \\
\hline$s \underline{d} \hat{d} s$ & in Wohlstand sein & Wb IV 380,6 & 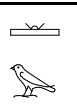 & $\begin{array}{l}\text { belegt seit Lit. } \\
\text { M.R. }\end{array}$ \\
\hline$\check{s} n . w$ & sich verjüngen & Wb IV 491,12 & $\Longleftarrow$ & seit D.18 \\
\hline
\end{tabular}

\subsection{AUSDRÜCKE MIT EINEM LEXEM FÜR 'HERZ'}

\begin{tabular}{||l|l|l|l|l||}
\hline \hline$w m t$ & dick sein (vom Herzen) & Wb I 306,12 & $w$ & N.R. \\
\hline$p g 3 i b$ & offenherzig & Wb I 562,5 & $\times$ & M.R. \\
\hline
\end{tabular}


1. SCHLECHTES GEFÜHL

\section{GRUPPE IX}

\subsection{GENERELL}

\begin{tabular}{|c|c|c|c|c|}
\hline$c_{m d}$ & $\begin{array}{l}\text { matt sein (vom Herzen und von den Glie- } \\
\text { dern) }\end{array}$ & Wb I 187,6-7 & $2 \Rightarrow$ & Med \\
\hline$w^{c} j$ & allein sein & Wb I $277,1-14$ & - & Pyr, D.18, N.R. \\
\hline fjw & sich ekeln & Wb I 576,3 & $\varnothing$ & Pyr \\
\hline$\overline{f t}$ & überdrüssig & Wb I 580,9-10 & 0 & belegt Med, Nä \\
\hline$m r$ & krank sein (seelisch) & Wb II 95,5-7 & $\Leftrightarrow$ & belegt seit Pyr \\
\hline$m r$ & krank sein (von Schrecken, Wut) & Wb II 95,9-10 & $2 B$ & belegt seit Pyr \\
\hline$n n j$ & müde sein & Wb II 275,2-8 & 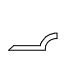 & belegt seit M.R. \\
\hline$h w r w$ & schwach sein, elend sein & $\mathrm{Wb}$ III 55,9 bis 56,2 & 2 & belegt M.R.-Gr \\
\hline$s f$ & elend sein & Wb IV 113,17 & 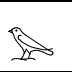 & D.21 \\
\hline$s w g 3$ & töricht sein, töricht & Wb IV 76,8 & $\begin{array}{l}30 \\
28 \\
28\end{array}$ & belegt Nä \\
\hline$\check{s} m 3\}$ & elend sein & Wb IV 471,13 & Es & belegt M.R. \\
\hline$k n j$ & verdrossen sein & $\mathrm{Wb}$ V 131,11-12 & $\begin{array}{l}\sum^{5} \\
0 \\
0 \\
0\end{array}$ & belegt seit M.R. \\
\hline$g b j$ & elend sein schwach sein & $\mathrm{Wb}$ V 161,8-10 & $E \Rightarrow$ & belegt Nä \\
\hline gnn & schwach sein & $\begin{array}{l}\text { Wb V } 174 \text { bis } \\
175,17\end{array}$ & 曷 & belegt seit A.R. \\
\hline ginh & matt sein & Wb V 155,8-10 & $\mathrm{N}^{2}$ & $\begin{array}{l}\text { belegt seit Totb. } \\
\text { N.R. }\end{array}$ \\
\hline thth & verwirren, verworren sein & $\mathrm{Wb} \mathrm{V} \mathrm{328,10}$ & 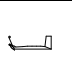 & belegt seit M.R. \\
\hline
\end{tabular}

1.2 AUSDRÜCKE MIT EINEM LEXEM FÜR 'HERZ'

\begin{tabular}{|c|c|c|c|c|}
\hline $\begin{array}{l}j w . t j \\
b ; g g . f\end{array}$ & vom Herzen, das matt schlägt & $\mathrm{Wb}$ I 431,10 & 2 & $\mathrm{Sp}$ \\
\hline$w r \underline{d} j b$ & das Herz wird müde & Wb I 338,4-6 & 禺 & seit Pyr, D.18 \\
\hline$\overline{f t}$ & vom Herzen, überdrüssig & Wb I 580,11-12 & De & belegt Med, Nä \\
\hline$m 3 s$ & klein sein & $\mathrm{Wb}$ II 32,3 & S & belegt Med \\
\hline$m h j$ & vergeßlich sein & Wb II 113,7 & $2 \Rightarrow$ & $\begin{array}{l}\text { belegt M.R.-Sp } \\
\text { (nicht Gr) }\end{array}$ \\
\hline$m h$ & vergeßlich sein & Wb II 122,11 & O & Med \\
\hline$\overline{h n s}$ & engherzig(ignorant) (im Gegs. zu wsh-ib) & Wb III 116,16 & $2 \Rightarrow$ & $\begin{array}{l}\text { belegt Med-Ende } \\
\text { N.R. }\end{array}$ \\
\hline
\end{tabular}




\begin{tabular}{||l|l|l|l|l||}
\hline \hline$t m$ & vergeßlich sein & Wb V 301,10 & Lit M.R. \\
\hline$\underline{t t f}$ & das Herz verwirren & Wb V 412,9-10 & $\AA$ & Nä, Gr \\
\hline
\end{tabular}


1. POSITIVE

\section{GRUPPE X}

1.1 GENERELL

\begin{tabular}{|c|c|c|c|c|}
\hline $3 \mathrm{~h}$ & heilig sein & "Wb I 13,7 & 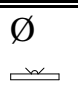 & seit Pyr \\
\hline$\overline{n f r}$ & vom guten Zustand jds. & Wb II 254,22 & $\varnothing$ & seit A.R. \\
\hline$n h z j$ & wach sein & Wb II 287,7 & $20 x$ & N.R., Sp \\
\hline$s \mathrm{~h} m$ & imstande sein etw zu tun & Wb IV 247,17 & $\varnothing$ & seit Pyr \\
\hline$s m^{c} r$ & Charakter jmds, Art gut machen & Wb IV 131,1-2 & $\varnothing$ & D.22; Gr. \\
\hline$s 3 q$ & gute Eigenschaft & Wb IV 26,3 & $s=0$ & M.R. \\
\hline$\check{S} S$ & vom guten Zustand von Personen & Wb IV 542,5 & $\begin{array}{ll}2 \\
1\end{array}$ & häufig Nä. \\
\hline$\check{s} b j$ & gute Eigenschaft & $\mathrm{Wb}$ IV 436,14 & $w$ & belegt seit D.18 \\
\hline grg & als gute Eigenschaft & Wb V 188,7 & $\stackrel{\rightleftarrows}{\rightleftarrows}$ & belegt seit M.R. \\
\hline grḥ & gewöhnlich, als gute Eigenschaft & $\mathrm{Wb}$ V 183,2 & $\underset{\omega}{w}$ & $\mathrm{Gr}$ \\
\hline$\overline{g w 3}$ & $\begin{array}{l}\text { als guter Zustand von Personen, die im } \\
\text { Sonneschiff fahren }\end{array}$ & Wb V 159,15 & 品 & Pyr \\
\hline
\end{tabular}

\subsection{AUSDRÜCKE MIT EINEM LEXEM FÜR 'HERZ'}

\begin{tabular}{|c|c|c|c|c|}
\hline$\overline{m r}$ & Mitleid haben Mittleid & "Wb II 95,13-14 & हs & belegt seit Pyr \\
\hline hnn & das Herz ist geneigt zu... & Wb II 495,3 & $\square$ & $\mathrm{Nä}$ \\
\hline snk & eine Eigenschaft (mit Bezug auf das Herz) & Wb IV 175,6 & (2) & belegt Pyr \\
\hline$k j 3$ & $\begin{array}{l}\text { als gute Eigenschaft der Schatzmeister, } \\
\text { sparsam }\end{array}$ & $\mathrm{Wb} \mathrm{V} 120,10$ & Di & belegt seit M.R. \\
\hline grh & gewöhnlich, als gute Eigenschaft & $\mathrm{Wb}$ V 183,1 & $\underset{w}{w}$ & D. 18 \\
\hline grg & als gute Eigenschaft & Wb V 188,6 & $\stackrel{\Gamma}{\rightleftarrows}$ & belegt seit M.R. \\
\hline$\underline{t} \underline{3}$ & als gute Eigenschaft des Menschen & Wb V 342,9 & ש & belegt D.18 \\
\hline
\end{tabular}

\section{NEGATIVE}

\subsection{GENERELL}

\begin{tabular}{||l|l|l|l|l||}
\hline \hline$j d$ & elend sein (miserable) & Wb I 35,9 & belegt N.R.-Gr \\
\hline wsh & weit sein & Wb I 364,15 & $\square$ & seit Pyr \\
\hline
\end{tabular}




\begin{tabular}{|c|c|c|c|c|}
\hline w3sj & schwach sein, elend sein & Wb I 261,6 & Es & $\begin{array}{l}\text { belegt A.R.-D18, } \\
\text { Sait }\end{array}$ \\
\hline bnd & übel daran sein & Wb I 464,14 & in & belegt Nä \\
\hline$f k$ & bedrückt sein & Wb I 580,3 & is & D18 \\
\hline$\overline{n h l}$ & vom schlechter Laune & Wb II 290,13 & $\infty$ & belegt seit Med \\
\hline ḩsmn & schlechter Zustand & Wb III 163,26 & $\Leftrightarrow$ & Lit M.R. \\
\hline hish & schlechte Eigenschaft & Wb III 233,8 & $\stackrel{\wedge}{A}$ & M.R. \\
\hline znnj & trübe gestimmt sein & Wb III 461,1 & $E$ & belegt $\mathrm{Sp}, \mathrm{Gr}$ \\
\hline$\check{s} w$ & in unordentlichen Zustand & $\mathrm{Wb}$ IV 427,17 & $\Leftrightarrow$ & belegt seit Pyr \\
\hline$g 3 w$ & schlechte Eigenschaft eines Menschen & $\mathrm{Wb}$ V 153,14 & $\Leftrightarrow$ & belegt Nä \\
\hline$\underline{d n w d}$ & schlechter Seelenzustand & Wb V 576,1 & 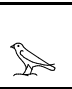 & $\begin{array}{l}\text { belegt Med, Lit } \\
\text { M.R. }\end{array}$ \\
\hline$\underline{d r j}$ & in unklarem Zustand hängt & Wb V 600,1 & $\Leftrightarrow$ & $\begin{array}{l}\text { belegt Lit M.R., } \\
\text { D.18 (Zaub.) }\end{array}$ \\
\hline
\end{tabular}

\subsection{AUSDRÜCKE MIT EINEM LEXEM FÜR 'HERZ'}

\begin{tabular}{|c|c|c|c|c|}
\hline$w \check{s}$ & hilflos & Wb I 368,15 & $\sum$ & Lit M.R. \\
\hline$f n$ & schwach sein, auch bildlich vom Herzen & Wb I 576,12 & Es & $\begin{array}{l}\text { belegt M.R., } \\
\text { N.R. }\end{array}$ \\
\hline$n h$ h.t.t & krankhafter Zustand des Herzens & Wb II 291,4 & is & Med \\
\hline $\begin{array}{l}\text { ḩmj } \\
h m m\end{array}$ & unwissend, ungelehrt & Wb III 280,3 & $=\infty$ & Nä u. Gr \\
\hline$q 3 q^{3}$ & $\begin{array}{l}\text { schlechte Eigenschaft des Herzens als Sitz } \\
\text { des Geistigen }\end{array}$ & $\mathrm{Wb} \mathrm{V} 14,2$ & D & belegt M.R. \\
\hline$k f 3$ & als schlechte Eigenschaft, knauserig & $\mathrm{Wb}$ V 120,11 & DS & belegt seit M.R. \\
\hline$\underline{d} w$ & es ist jdm unangenehmen & Wb V 547,6 & $\exists$ & Alt \\
\hline$\underline{d} \underline{d} \underline{d} s$ & schlechter Zustand & $\mathrm{Wb}$ V 618,2 & $\sum \Rightarrow$ & belegt Nä \\
\hline
\end{tabular}





\title{
5. Kapitel
}

\section{DAS HERZ IN DEN LEHREN}

\begin{abstract}
"Dies ist das Selbst in meinem Herzen, kleiner als ein Reiskorn, kleiner als ein Haferkorn, kleiner als ein Senfsamen, kleiner als ein Hirsekorn, $<\mathrm{ja}$, noch $>$ kleiner als der Kern eines Hirsekorns. Dies ist das Selbst in meinem Herzen, tiefer als die Erde, weiter als der Luftraum, höher als der Himmel, größer als die Welten des Diesseits. Allen Taten in sich begreifend, jeden Wunsch, jede Stimmung, jede Regung des Gefühls, die ganze Welt umfassend, sprachlos, blicklos, so ist das Selbst in meinem Herzen; dieses ist die Wirklichkeit. In diese werde ich eingehen. Wer so glaubt, der hat keine Zweifel mehr".
\end{abstract}

(Chandogya-Upanisad III, 14,3-4, zitiert nach Agarwala \& Moebus 1996: 142)

\section{1 Überblick}

Grund und Antrieb dafür, daß der Mensch ein 'hörender' - das heißt gehorsamer - Schüler sein und die Anweisungen der Lehren verinnerlichen soll, ist hauptsächlich der Umstand, daß ihm auf diese Weise ein erfolgreiches Leben zu führen ermöglicht werde. Die Lehren verfolgen die Zielsetzung, daß sowohl die Gesellschaft als Ganzes wie auch der Mensch individuell in Harmonie und Ordnung lebe und dadurch Chaos und Regellosigkeit in den zwischenmenschlichen Beziehungen vermieden werde. ${ }^{98}$ Der Mensch bewegt sich zwangsläufig ständig in einem bestimmten sozialen Umfeld - sei es Familie, Sippe, Dorf, Stadt oder Kollegenschaft -, weswegen sein Verhalten in und zu all diesen Gruppen im Mittelpunkt der Aufmerksamkeit steht. Assmann erklärt die zwei Dimensionen menschlichen Verhaltens, die soziale und die individuelle, mit Blick auf das Herz als

den sozialen Aspekt in der äußeren Sphäre des Lebens und Handelns in der Gesellschaft, und den individuellen Aspekt in der inneren Sphäre körperlicher und geistiger Einheit. In der individuellen Sphäre ist der Idealzustand voller Lebendigkeit erreicht, wenn das Herz (a) "lebendig" oder "wach", und (b) "auf seinem Platz" ist. Daher muß das Herz (a) stimuliert, aufgeweckt, belebt, und (b) be- und gefestigt werden. Die entsprechenden Gegenzustände sind (a) das "müde Herz" bzw. Herzensmüdigkeit, eine Bezeichnung des Todeszustands, und (b) das losgelöste oder abwesende Herz. (Assmann 1996: 147)

Man muß zunächst einmal zwischen zwei, relativ einfach voneinander abzugrenzenden Hauptverwendungsweisen des Wortes Herz unterscheiden, nämlich derjenigen, mit der man

98 Deshalb spielt in diesen Texten das Konzept der Maat eine außerordentlich wichtige Rolle (siehe dazu grundlegend Assmann 1996; 1990). 
auf das Herz als körperliches Organ referiert, und der, bei der das Herz als Bestandteil von Ausdrücken für Charaktereigenschaften, den Verstand oder die Emotionen einer Person benutzt wird. Eine anderes Kriterium, mit dem verschiedene Gebrauchsweisen der Termini $j b$ bzw. hỉj 'Herz' klassifiziert werden können, ist die jeweilige grammatische Funktion, in der das entsprechende Wort in einer konkreten Äußerung auftritt. Im Ägyptischen kann es gleichermaßen in der Funktion des Objekts wie auch als Subjekt aktiver Sätze erscheinen, also sowohl Patiens als auch Agens oder Experiencer sein. Wenn das Herz als Subjekt einer Tätigkeit verwendet wird, so ist damit mehr oder weniger deutlich impliziert, daß es wie eine Person handelt, es kann mit Experiencer-Verben wie $f t$ 'sich ekeln' (W-142) oder $h n$ 'zu etwas neigen' (W-148; W-149; W-40) stehen, aber auch Agens von Verben wie rmj 'weinen' (W-4), hhjj 'suchen' (W-65) oder wšb 'antworten' (W-66; W-69) sein. In derartigen Ausdrücken liegt ein prosopopäischer ${ }^{99}$ Gebrauch des Worts vor. In anderen Beispielen ist das Herz als Objekt bzw. Patiens zu analysieren, an dem jemand Handlungen vornimmt: man kann 'das Herz glätten' (W-17; W-18: $s n^{c}$ ), 'das Herz erheben' (W-25: $q^{3} j$ ) oder 'das Herz zum Kämpfen schikken' (W-57: $h 3 b r$ - ' $h$ '). Eine weitere gängige semantische Rolle erscheint in Formulierungen wie 'was es im Herzen gibt', in denen das Herz als Ort oder Platz für oder von etwas verstanden werden kann: So kann man etwa 'aggressiv in seinem Herz sein' (W-8: $3 d j b=k$, "eigentlich" 'wütend in Bezug auf dein Herz'), 'Böses auf dem Herzen haben' (W-10: bjn.t hr $r$ - jb), 'den Gott in Herz geben' (W-80: $r \underline{d} j$ nt $t r m-j b$ ) oder 'sich eine Lehre zu Herzen nehmen' (W167: $r \underline{d} j s b 3 . y t m-j b)$.

Man muß davon ausgehen, daß das Herz nicht allein ein körperliches Organ ist, in dem sich der Verstand, die Gefühle und der Charakter einer Person befinden, sondern daß es auch als ein Bindeglied aufgefaßt werden kann, durch das zwischen der menschlichen und der göttlichen Sphäre vermittelt wird. Im Folgenden werden die verschiedenen Verwendungsweisen des Begriffs, soweit sie in den Weisheitstexten vorkommen, anhand entsprechender Beispiele illustriert.

\subsection{Zum Verwendungsumfang von $j b$ und $h 3 t j$ in den Lehren}

\subsubsection{Das Herz als Verstand}

In ägyptischen Weisheitstexten wird das Herz oft schlechthin mit dem Auffassungsvermögen identifiziert, da es als das Mittel angesehen wird, wodurch die Lehren und die Maat erfahren werden (vgl. dazu Brunner 1965: 82 und 1988: 23; Shupak 1993; Assmann 1979). In den Texten werden Anweisungen gegeben, was zu tun und was zu unterlassen sei, um ein Leben als rechtschaffener Mann und angesehenes Mitglied der Gesellschaft zu führen. Adressaten

99 Prosopopöie oder Personifikation ist ein Stilmittel, das in der Einführung konkretere Dinge sowie abstrakter und kollektiver Begriffe als redender und handelnder Personen besteht (Lausberg 1976: 140). 
der Lehren sind männliche Mitglieder der sozialen Eliten, in einigen Fälle ist eine Lehre sogar - sei es tatsächlich oder literarisch fingiert - direkt an einen Herrscher adressiert. In solchen Zusammenhängen wird nicht selten explizit auf das Konzept der Maat bzw. Gerechtigkeit ${ }^{100}$ verwiesen und eine enge Beziehung zum Herzen hergestellt: 'die Lehren (bzw. die Schriften) sind zu Herzen genommen' (W-105: $r \underline{d} j \mathrm{j}-j b$ ), jemand 'handelt Maat-gerecht, wenn sein Herz gemäß seiner Bestimmung funktioniert' (W-35: jrj $\left.m 3^{c} . t j r . n j b r-n m t . t=f\right)$, und 'das Herz kann die Wahrheit nicht aufnehmen' (W-71: ̌̌zp jb $\left.m 3^{3} . t\right)$.

Das ägyptische Wort $j b$ 'Herz' erscheint auch in Kontexten, in denen man es als Organ des Verstands (W-100: $b n h h^{3} t j=k m$ - $\underline{h} . t=k$ 'du bist nicht bei Verstand'; vgl. auch W-101) oder der Erinnerung (W-4: jb mh.w'das Herz ist vergeßlich') analysieren kann. In einem solchen Sinne ist es etwa $\mathrm{zu}$ interpretieren, wenn in Verbindung mit dem Herz vom 'Klugwerden' (W-152: $r \underline{d j} c_{r q}$ ) die Rede ist oder ein 'Herz mit Wissen' (W-68: jb m-rh ) erwähnt wird. Ein maatgerechtes Herz vermag die spontanen Gefühle und Triebe zu unterdrücken und soll in der Lage sein, sein individuelles Selbst mit dem Allgemeinen und Sozialen in Einklang zu bringen (Assmann 1996: 161). In den am Ende dieser Arbeit gesammelten Abschnitten aus den Weisheitstexten ist nicht immer mit aller Deutlichkeit ausgedrückt, wenn es um den Verstand geht. Nur die Beispiele W-100 (bn ḩ3tj=k $m$ - $\underline{h} . t=k$ 'denn du bist nicht bei Verstand') und W-101 ( $\underline{d} d=j m-j b=j$ 'Ich sprach zu mir selbst') belegen unmittelbar den metonymischen Gebrauch des Herzens mit der Bedeutung 'Verstand'. In den übrigen Passagen ist ein solcher Sinn lediglich impliziert. In diesen Zusammenhang könnten etwa die Textabschnitte W-35 (jr.n jb=fr$n m t . t=f$ 'das Herz funktioniert gemäß seiner Bestimmung'), W-53 ( $m$ fh $j b=k \underline{h} r$ - $\underline{d} d . t=j-n=k$ 'löse dein Herz nicht von dem, was ich sagen werde') und W-42 (twt $j b=f-h n^{c}=j$ 'das Herz meines Ba gleicht dem meinigen') gehören. Es wurde oben bereits erwähnt, daß in den Lehren das Konzept der Maat oder das "maatisierte Herz" (Assmann 1996: 161) bedeutungsvoll für ein harmonisches Zusammenleben ist. Die Wahrnehmung dieser mustergültigen Lebensform wird durch das Herz geleistet. Im Beispiel W-42 wird das Herz eines Mannes mit dem Herzen seines $\mathrm{Ba}^{101}$ verglichen, und wenn das Herz des Ba mit dem des Mannes gleichzusetzen ist, wird auch der Ba erfolgreich. Das Beispiel mit der Formulierung 'das Herz lösen' (W-53) gehört infolge der Textsequenz "hören - nicht ignorieren - nicht das Herz lösen" ebenfalls in diese Kategorie und ist als 'vergessen, der Aufmerksamkeit entgehen lassen' zu interpretieren. $^{102}$

100 "Maat, ein kompakter Begriff, den wir im Deutschen mit einer Vierheit von Wahrheit, Gerechtigkeit, Ordnung und Sinn umschreiben müssen (..)" (Assmann 1988: 98; vgl. auch Assmann 1990).

101 Zum Konzept des Ba siehe $L \ddot{A}$ I, 589-590 (Zabkar, s.v. Ba).

102 Brunner übersetzt es als 'hören - mißachten - wende dein Herz nicht ab' (1988: 188). 


\subsubsection{Das Herz und die Persönlichkeit}

Inhalt und mutmaßliche Funktion der Lehren hängen in hohen Maße von ihrem Adressatenkreis ab, bei dem es sich in vielen Fällen um Personen aus der Gruppe der Beamten gehandelt haben wird. Das vordringlichste Ziel der Lehren ist es, einen idealen Menschen heranzubilden. Assmann (1996: 145) schlägt drei Gattungen vor, in denen es besonders um die Persönlichkeit und Integrität einer Person geht, nämlich Hymnen, Verklärungen und Flüche. Unter diesen sind insbesondere die Verklärungen geeignet, die Persönlichkeit eines Menschen genauer: die eines Verstorbenen - zu beschreiben. In den entsprechenden Charakterisierungen spielt das Herz eine besondere Rolle (vgl. Brunner 1988: 23-25; Assmann 1996: 143-155). Dabei werden eine ganze Reihe von mit dem Wort 'Herz' gebildeten Begriffen gebraucht, die den Charakter einer Person beschreiben und sich auch in den Lehren finden lassen. Hierher gehören beispielsweise Ausdrücke wie der 'Streitsüchtige' (W-81: hnnn-jb), der 'Treuherzige' (W-84: $m h$-jb), der 'Ungestüme' (W-56: $3 s-j b$ ) oder die 'Habgier' (W-22: ‘wn-jb). In solchen Beispielen kann das Herz in unterschiedlichen grammatischen Funktionen auftreten:

- Es kann als Ort in Erscheinung treten, in dem der Charakter lokalisiert wird, beispielsweise in Kollokationen wie 'wütend in Bezug auf das Herz' (W-8: $3 d j b$ ) oder 'vorwurfsvoll im Herzen sein' (W-6: $\underline{t} j b$ ). Obwohl in keinem der Beispiele eine Präposition vor dem Lexem $j b$ auftritt, handelt es sich um explizite Ortsangaben, da wir es mit Konstruktionen aus einem Adjektivverb mit "bestimmendem Substantiv" (also einem Nominaladverb) zu tun haben.

- Es kann als zweiter Bestandteil eines Kompositums mit einem weiteren Substantiv kombiniert werden und die Funktion des Possessors haben, z.B. 'Kummer des Herzens' (W-21: h3.t-jb). Diese Verwendungsweise ist von der folgenden nicht immer ohne weiteres zu unterscheiden.

- Es kann als Subjekt zu einem Verb im Infinitiv (oder in einer anderen flektierten Form) treten, z.B. 'Habgier', wörtlich 'Gierigsein des Herzens' (W-22: $\left.{ }^{c} w n-j b\right)$.

- Es kann als Objekt an eine Verbalform treten, z.B. in 'das Herz waschen' (W-16: $\left.j^{c} j j b\right)$, 'das Herz abwenden' (W-54: stinj jb).

- Es kann als "bestimmendes Substantiv" mit einem Partizip verbunden sein und etwa in Ausdrücken wie 'Zorniger' - 'einer, mit wütendem Herz' (W-82: $d n d n-j b)$ - oder 'Treuherzige' - 'einer, das Herz füllt' (W-84: $m h$-j $b$ ) - auftreten.

Einschlägigen ägyptischen Texten ist zu entnehmen, daß man davon ausging, daß das Herz und der Charakter einer Person miteinander verbunden seien.

\subsubsection{Das Herz und Emotionen}

Das Herz kann auch als der zentrale Punkt für Emotionen oder gute wie schlechte Gefühle aufgefaßt werden. Die in solchen Fällen gebrauchten sprachlichen Mittel sind die gleichen wie die, die im Zusammenhang mit den Ausdrücken für den Charakter begegneten: 
- Der Begriff für das Herz kann in Kombination mit einem Verb auftreten und als sein Objekt dienen, wie z.B. in 'das Herz erfreuen' (W-23: $s 3 w$ jb) oder 'sich Gedanken machen um' (W-88: $r \underline{d j} j$ jb $m-s\}$ "das Herz hinter jemanden legen").

- Es kann als Subjekt fungieren, z.B. in 'das Herz ist süß' (W-143D: $n \underline{d} m$ jb), oder 'die Herzen sind traurig' (W-70: hijtj.(w) snm.w).

- Es kann als Possessor an einem Infinitiv stehen und zur Bildung von Ausdrücken wie 'Entspannung' (W-72: snd $m$ - jb) oder 'Glücksgefühl' (W-98: $n f r . t-j b)$ dienen.

- Es wird als Ort verstanden, an dem ein Zustand lokalisiert wird oder von dem eine Handlung ausgeht, wie 'Leiden vom Herzen vertreiben' (W-68: $d r m n . t n$ - jb), 'am Herzen leiden' (W-67: znnj $h r-j b$ ), 'aus (ganzem) Herzen opfern' (W-106: wdn m- jb mry=k).

Eine ausführlichere Behandlung von mit $j b$ oder $h 3$ jtj gebildeten Emotionsausdrücken erfolgt weiter unten in Abschnitt 5.4.

\subsubsection{Das Herz als handelnde Person}

Von besonderem Interesse sind die Ausdrücke, in denen das Herz als Person handelt wie 'das Herz schläft' (W-4: $s \underline{d} r j b$ ), 'das Herz verurteilt jemanden' (W-19 und W-20: jb hrr-wjn ), 'das Herz ekelt sich' (W-142: ft jb), 'das Herz schweigt' (W-143: ḩ3tj gr.w), oder 'das Herz spricht (W-103: $\underline{d} d$ ), und es kann 'antworten' (W-69: wšb) und 'erklären' (W-69: wḥ ). In allen diesen Fällen wäre zu bedenken, ob es sich um eine Metapher oder einen metaphorischen Gebrauch des Herzens handelt. Meiner Meinung nach liegt hier weder eine Metapher noch ein metaphorischer Gebrauch des Terminus vor, sondern ein metonymischer Gebrauch für die jeweilige Person, so daß etwa 'das/mein Herz ist müde' soviel wie 'ich bin müde' bedeutet und mit 'das Herz ekelt sich' die Aussage 'jemand ekelt sich' gemeint ist. Walker (1996: 171-172) schlägt ähnliches vor, wendet diese Übersetzung aber nur auf die Stellen an, in denen das Herz als Seele zu verstehen ist. Mein Vorschlag wäre es, diese Art der Übersetzung auf all die Stellen zu übertragen, in denen das Herz als Person handelt und deren körperlichen und menschlichen Fähigkeiten übernimmt. Es ist außerdem zu berücksichtigen, daß zuweilen ${ }^{103}$ eine Verbindung aus $j b$ bzw. ḩitj und einem suffigierten Personalpronomen auf eine Weise verwendet wird, in der dieser Verbindung fast eine pronominale Funktion zukommt. Mit anderen Worten: die Kodierung des Subjekts geschieht - vor allem bei Experiencer-Verben nicht direkt, sondern durch einen Ausdruck für 'Herz' mit Possessor; man sagt nicht 'jemand fühlt ...', sondern 'jemandes Herz fühlt ...'. Ein Beispiel aus dem hier diskutierten Teilkorpus ist etwa 'halte dein Herz zurück' (W-34: w’̧h jb) anstelle von 'halte dich zurück'. Mit Bezug auf dieses Phänomen spricht Assmann (1996: 148) von einer "Dissoziation von Herz und

103 Die Beispiele W-28 und W-58, in denen das Herz in der Funktion eines Objektes auftritt, sind zur Bestätigung dieser Übersetzung nicht geeignet. Der Grund dafür ist es, daß das Herz nicht zur angesprochenen Person, sondern zu einer anderen Person gehört. 
Selbst, dem redenden Ich", und es existieren Beispiele - etwa Passagen aus den Klagen des Chacheperreseneb, in denen der Protagonist mit seinem Herzen spricht und das Herz ihm antwortet (W-66: $\underline{d} d=j$ st $w s ̌ b \quad n=j j b=j$ 'damit ich es sagen und mein Herz mir antworten könnte'; W-69: jmj $j b=j m d w=j-n=k w s ̌ b=k-n=j \underline{t} z . w=j$ 'Komm, mein Herz, daß ich zu dir spreche und du mir meine Aussprüche beantwortest'), oder eine Äußerung 'solange du schläfst, wacht über dich nur dein Herz' (W-95: $s \underline{d} r=k z 3 w-n=k j b=k$ ) -, die Assmanns Auffassung tatsächlich gerechtfertigt erscheinen lassen. Vergleichbares kommt freilich nicht nur in den Lehren vor, sondern wird gelegentlich auch in anderen Textsorten verwendet, um Liebeskrankheit, das Motiv des Schlafens und der Mattigkeit oder die Sehnsucht infolge räumlicher Entfernung auszudrücken, und man sollte die von Assmann vorgeschlagene psychologisierenden Erklärung auf keinen Fall verallgemeinern. Dafür ist die indirekte Kodierung von Experiencern durch eine Körperteilbezeichnung und einen Possessorausdruck ein viel zu gängiges Phänomen in dem linguistischen Großareal, zu dem das Ägyptische gehört. Wenn solche Konstruktionen grammatikalisiert sind, haben die Sprecher ebensowenig eine Wahlmöglichkeit wie etwa bei der Verwendung des Verbs $s \underline{d} m$ 'hören', bei dem der Urheber des Gehörten üblicherweise auch nicht direkt als Objekt kodiert wird, sondern als Possessor an hrw 'Stimme, Geräusch' tritt. Der Umstand, daß in einem solchen Fall wohl niemand von einer "Dissoziation von Stimme und Selbst" sprechen würde, mahnt zur Vorsicht vor einer Generalisierung von Assmanns Hypothese.

\subsubsection{Das Herz als 'Wunsch', 'Meinung' und 'Seele'}

Man geht davon aus und trägt dem in der Übersetzungspraxis Rechnung, daß die Lexeme für 'Herz' (insbesondere $j b$ ) auch als Hilfsmittel dafür dienen können, um in metonymischem Gebrauch Konzepte zu kodieren, die eine andere Bedeutung haben. Es wurde oben erwähnt, daß der 'Verstand' nicht mittels eines speziellen Lexems bezeichnet wird, sondern das Wort für 'Herz' diese Bedeutung mit ausdrücken kann (vgl. W-100: ḩ3tj $m$ - h. .t 'bei Verstand sein'). Ähnliches läßt sich auch für die Bedeutungskonzepte 'Wunsch, Bedürfnis' (vgl. W-86: šms $j b=f$ 'seiner Laune folgen'; W-153: ḩ3tj 'Bedürfnis'), 'Absicht' (W-74: $k f j$ j $j b=f$ 'seine Absicht enthüllen') feststellen.

\subsubsection{Das Herz als Körperorgan}

Das Herz als anatomischer Begriffe kommt nicht nur in den medizinischen Papyri, sondern auch in anderen Textsorten vor, dort allerdings nicht in größerer Anzahl. Ob wir auch für die Lehren von einer derartigen Verwendung von $j b$ bzw. hijtj auszugehen haben, muß erst noch geklärt werden. Das Problem liegt in der Interpretation des jeweiligen Worts für 'Herz', das in spezifischen Kontexten mit unterschiedlichen Bedeutungen wiedergegeben werden kann.

Im Beispiel W-3 beschreibt Ptahhotep seinen Zustand, als er alt wird ( $p h t j h r-3 q$ wrd $j b=j$ 'Die Kräfte sind im Schwinden begriffen, weil mein Herz müde ist'). Wenn man annimmt, daß 
das Wort ph.tj als 'Stärke' in Bezug auf den Körper zu verstehen ist ${ }^{104}$, so wäre es vernünftig zu denken, daß das alternde Herz als körperliches Organ 'müde' oder 'matt' (wro $\underline{d})$ ist. Dann besäße das Herz nicht mehr die Stärke von früher, und als Konsequenz wären die Kräfte verschwunden. ${ }^{105}$

Man könnte womöglich geneigt sein, in Beispiel W-29 ( $m$ - $h t-\underline{h} \underline{\underline{d}}=f j b=f$ 'nachdem er sein Herz zermürbt hat') das Herz als körperliches Organ zu interpretieren. Dann müßte man allerdings annehmen, daß die in dem Text genannte Person, die die ganze Nacht lang Widerstand gegen sexuelle Annäherungsversuche seitens des Adressaten der Lehre leistet, sich als Folge des Bedrängtwerdens eine Herzerkrankung zugezogen hätte, nämlich $h \underline{d}$, das heißt 'krank, zermürbt $^{106}$, im körperlichen Sinne geworden wäre. Wenn man zur Stütze einer solchen Auffassung auch immerhin darauf hinweisen könnte, daß in der direkten Umgebung eine Form des Verbs $q b b$ 'kühl sein'107 erscheint, das in Bezug auf den Körper oder auf erkrankte Körperteile eine Bedeutung wie 'gelindert werden' haben kann. Allerdings ist es ganz unwahrscheinlich, daß der Verfasser der Lehre des Ptahhotep nahelegen wollte, unwillkommene Annäherungsversuche könnten eine Herzerkrankung zur Folge haben. Da das Verb $q b b$ bei Bezug auf eine Person auch die Bedeutung 'ruhig, leidenschaftslos' ${ }^{108}$ besitzt, bietet sich auch hier eine nicht-körperliche Interpretation an: das Herz ist als Zentrum des Gefühls zu verstehen, das infolge des unerwünscht Drängens seiten des Mannes (seelischen) Schaden erlitten hat, nämlich 'zermürbt' wurde.

Im Papyrus Ramesseum II kommt eine Diagnose für die Schmerzen vor, die im Herzen entstanden sind (W-58: whd.w hpr.w m- jb). Das kann man so verstehen, daß das Herz in Zusammenhang mit den Schmerzen als körperliches Organ zu interpretieren ist. Allerdings hat es in Verbindung mit der ganzen Passage eine andere Bedeutung. Es geht um den Spruch für den Fremden, in dem ein Verhalten beschrieben wird, bei dem diese 'Schmerzen im Herzen' metaphorisch und nicht körperlich zu interpretieren wären.

Beispiel W-96 spricht davon, daß das Herz begann, dem Zustand seines Besitzers zu folgen $\left(\check{s}^{3}{ }^{c} . n h 3 t j=j \check{s} m s q d=j\right.$ ) und enthält die Beschreibung des Überganges zwischen wachem und schlafendem Zustand, wobei das Herz - wenn es denn im organischen Sinne zu verstehen wäre - eine bestimmte Körperfunktion ausdrücken müßte. Die Stelle könnte man jedoch auch anders interpretieren, und zwar so, daß die Person sich beruhigte und müde war, und ihr Herz oder Verstand ebenso einschlief. Dann wäre auch hier das Herz nicht als körperliches Organ zu verstehen.

$104 \mathrm{~Wb}$ II 539,9 .

105 Junge (2003: 173) übersetzt "- nun schwindet auch die Liebeskraft, da mein Mut müde geworden ist".

$106 \mathrm{~Wb}$ III $213,15$.

$107 \mathrm{~Wb}$ V 22,9.

$108 \mathrm{~Wb} \mathrm{~V} \mathrm{23,4.}$ 


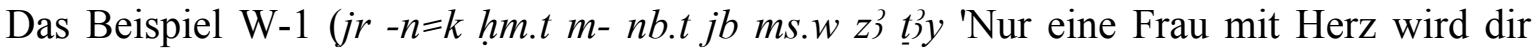
Kinder und einen männlichen Nachkommen verschaffen') ist für unsere Frage von Relevanz, da das Wort für Herz auch hier auf unterschiedlichem Weise interpretiert werden könnte. Helmut Brunner (1988: 102) übersetzt hm.t m- nb.t- $j b$ als "wackere Frau", während Miriam Lichtheim (1975: 58) die Formulierung "a hearty wife" gewählt hat und in einer Fußnote erklärt als "a woman who is 'mistress of (her) heart"'. Als Synonyme zu dem deutschen Adjektiv wacker führt der Thesaurus (Duden 2001: 1765, s.v. wacker) eines aktuellen Textverarbeitungsprogramms Lexeme wie, rechtschaffen, ehrlich, anständig, redlich, treu, aufrecht, ehrbar, charakterfest; tüchtig, mutig, topfer an, und als Alternativen zu englisch hearty werden unter anderem warm and friendly, cheerful, enthusiastic sowie strong and healthy, lively, robust, sound, strong, good oder fit angeboten. Man kann vermuten, daß sowohl Lichtheim als auch Brunner Bedeutungen wie 'tüchtig, mutig, tapfer, aufrecht' im Sinn hatten. Man könnte zwar alternativ erwägen, ob etwa an der betreffenden Stelle ein aufrichtiges Herz impliziert und ausgesagt ist, daß sich der Adressat der Unterweisung eine Frau suchen solle, die dem gesellschaftlichen Ideal von Aufrichtigkeit, Charakterstärke und Ehrbarkeit entspricht. Allerdings käme einer solchen Bedingung wohl auch nach ägyptischem biologischem Kenntnisstand keine Bedeutung zu, um einen männlichen Nachkommen auf die Welt zu bringen. Daher ist es wahrscheinlich, daß in der Hordjedef-Passage (zumindest auch) die körperliche Konstitution der Frau angesprochen wird. Dennoch ist nicht vom Herz im engeren organischen, kardiologischen Sinn die Rede. Denn es bedarf zum Gebären eines männlichen Nachkommens nicht speziell einer Mutter mit einem besonders starken Herzen. Das Herz sollte daher an der betreffenden Stelle in erster Linie als Zentrum der Person interpretiert werden, in dem sich alle Eigenschaften eines Menschen konzentrieren, nämlich Verstand, Gesundheit und Seele. Das, was mit der Kollokation wohl gemeint ist, erinnert an die Bedeutung des deutschen Worts herzhaft. Wenn auch letzteres gemeinhin kaum als Prädikat für eine Person verwendet wird, so treffen die oben aufgelisteten Synonyme anständig, rechtschaffen bzw. tüchtig, tapfer ziemlich genau den Sinn, den der ägyptische Ausdruck in der hier diskutierten Passage hat.

Als Resultat kann festgehalten werden, daß die Ausdrücke für das Herz in den Weisheitstexten kaum jemals im organischen Sinne verwendet werden. Sämtliche Beispiele, die auf den ersten Blick eine kardiologische Interpretation zu ermöglichen scheinen, lassen sich überzeugender im kordiologischen Sinne analysieren.

\subsubsection{Das Herz als Platz und Ort}

Es wurde bereits erwähnt, daß sowohl die Emotionen wie auch die Charaktereigenschaften eines Menschen im Herzen lokalisiert werden (vgl. dazu die bereits mehrfach erwähnten Beispiele W-6: $m$ t $3 j b=k-r=f$ 'Sei nicht einmal in deinem Herzen vorwurfsvoll gegen ihn' und W8: $m 3 d j b=k-r=f$ 'Sei nicht einmal innerlich wütend auf ihn'). Als etwas, was in ägyptischen 
Äußerungen als im Herzen angesiedelt bezeichnet wurde, gelten jedoch nicht nur Emotionen und Merkmale des Charakters, sondern man findet 'im Herz' auch Abstrakta wie Rede, die 'perfekt auf dem Herzen' oder besser 'ganz im Sinne von jemandem' sein soll (W-11: $\underline{d} d . t=k r-$ $n f r h r-j b$; W-104: $w n-n=f n f r . w h r-j b n(j)-n t \underline{r}$ 'wenn einem Armen Gutes widerfährt, ist das ganz im Sinne Gottes'), wie 'etwas Böses', das man 'im Sinn' (W-10: bjn.t hr - jb) haben kann, oder Konkreta - z.B. das 'Geschrei der Sünde' (W-78: hrrw- jzft) - und körperliche Zustände wie 'Schmerzen' (W-58: whd). Außerdem soll man auch nach Maßgabe der Weisheitstexte 'sich die Lehren zu Herzen nehmen' (W-167, W-139 und W-105: r $\underline{d j} m$ - $j b$ ), die eine wichtige Rolle spielen, um ein richtig ausgebildeter Mensch zu werden. 'In das Herz' können schließlich auch Gott oder der König 'gegeben werden', so daß sie jemandem 'am Herzen liegen' (W80: $d j=j n t r=j m-j b=j n z w m-h i j t j=j$ ) und 'in den Herzen verehrt werden' (W-75: snsn $m-j b . w)$. Außerdem kann man 'sich auf seinem Herz niederlassen' (W-68: shnj $h r-j b=f$ ), was soviel heißt wie 'sich auf sein Herz stützen' oder 'sich auf sein Herz verlassen'. Kollokationen wie diese sind möglich, da das Herz offensichtlich als Mittelpunkt eines Individuums verstanden wurde, in dem sich Gefühle, Schmerzen, Personen, Gottheiten, Abstraktes oder Konkretes befinden können. So entsteht ein konkretes Bild des Herzens, durch das Ausdrücke wie 'was in den Herzen ist' (W-75: jmj-ḩ3tj.w) je nach dem Kontext als 'Verstand', 'Gedanken' oder 'Wunsch' interpretiert werden können. ${ }^{109}$

\subsection{Das Herz in Metaphern}

Das Herz wird nicht selten als Tenor benutzt, um Metaphern zu bilden. Innerhalb des in diesem Kapitel behandelten Korpus lassen sich entsprechende Verwendungsweisen in der Lehre des Ptahhotep (W-32), der Lehre des Ani (W-141), der Lehre der Amunnacht (W-130), der Lehre der Amenemope (W-155; W-159; W-161; W-166; W-163) und auf der Schultafel aus Abydos (W-103) finden. In diesem Abschnitt werden einige einschlägige Stellen, die in etlichen Fällen auch schon von anderen Ägyptologen diskutiert wurden, präsentiert und insbesondere mit einem Blick auf ihre sprachliche und rhetorische Form analysiert.

In dem als W-32 zitierten Beispiel aus der Lehre des Ptahhotep lautet die durch einen zweigliedrigen Nominalsatz ausgedrückte Metapher 'Leben, Heil und Gesundheit eines Menschen sind sein Herz' ( ${ }^{c} n \underline{h} w \underline{d}$ ) $s n b n(j)-z(j) j b=f$ ). Die in dieser Metapher enthaltene Idee reflektiert nach Ansicht etlicher Autoren einen Determinismus, welcher durch das Herz bestimmt wird, da das Herz als eine Größe aufgefaßt wird, die verantwortlich für das Leben eines Menschen ist (Lichtheim 1973: I 80,68; Brunner 1988: 440; Fecht 1965: 129-130). Fecht sieht hinter dieser Metapher im Zusammenhang mit dem vorausgehenden Satz die 
Vorstellung, 'von Gott geliebt zu sein' (1965: 129), da das Herz eines Mannes über Hören und Nichthören bestimmt und nur ein Hörender von Gott geliebt werde. Vordergründiger, aber kaum weniger plausibel könnte man den Sinn der Metapher auch wiedergeben als "Leben, Heil und Gesundheit sind das wichtigste für einen Menschen" oder - wenn man an die in Abschnitt 5.2. diskutierten Verwendungsweisen von $j b$ im Sinne von 'Wunsch, Bedürfnis' denkt - sogar übersetzen: "Leben, Heil und Gesundheit eines Menschen sind das, was er sich am meisten wünscht".

In der Lehre des Ani findet man die Metapher 'das Herz ist ihr Türwächter' (W-141: ḩ̉tj $p 3 y=s j r y-{ }^{c}$ ) $)$. Quack segmentiert die Stelle anders als in der hier wiedergegebenen Übersetzung und schlägt vor: "Tief ist das Feld eines Mannes, man kann es nicht umkreisen. Das Herz ist sein Torwächter" (1994: 135), für die Interpretation der Metapher ändert das allerdings nichts. Diese Metapher könnte man als einen metonymischen Gebrauch des Wortes 'Gewissen' verstehen, welches durch das Wort 'Herz' wiedergegeben würde. Darüber hinaus sind Tenor und Vehikel identifizierbar, wobei der an erster Stelle genannte Begriff eine abstrakte Idee enthält, nämlich das Herz oder das Gewissen. Das Vehikel ist der Türwächter, dem die konkrete Funktion des Bewachens obliegt.

In den Lehre des Amunnacht kommt eine Metapher vor, in der das Herz mit einem Damm gleichgesetzt wird (W-130: jmj h $p r j b=k m j$ dnj.t 'sorge dafür, daß dein Herz wie ein Damm wird'). Grapow (1924: 62-63) bezieht das Bild auf einen König oder einen hohen Beamter, der als Beschützer angesehen wird. Diese Interpretation beruht auf der Funktion eines Deiches, welcher die Felder vor dem Wasser schützt. In eben diesem Sinn wird zum Beispiel auch Ramses II. als der 'Uferdamm für Theben' genannt. ${ }^{110}$ Posener (1955: 66) versteht den Sinn der Metapher als Schutz, der dem Druck der Bewegung standhält. In Zusammenhang mit dem Kontext schlägt er zwei mögliche Interpretationen der Passage vor: Wenn die Metapher sich mit dem vorherigen Satz zusammenbringen ließe, würde der Damm eine Tugend symbolisieren, welche ein Mann haben sollte, um kompetent und zu jeder Arbeit in der Lage zu sein. ${ }^{111}$ Wenn die Metapher hingegen enger mit dem folgenden Satz zusammenhängt, hätte die Stelle eine andere Bedeutung, nämlich "Rüste dich, meine Ratschläge festzuhalten, wie der Damm das Wasser zurückhält"112 oder "Wie ein Damm der Bewegung standhält, so halte du die Versuchungen fern, die dich von meinen Worte trennen könnten". ${ }^{113}$

Die Lehre des Amenenope enthält mehr Metaphern als die oben besprochenen Texte, was insofern nicht verwundert, als der Text deutlich länger ist als die bisher vorgestellten. Bei dem ersten Beispiel (W-155) handelt sich um eine Passage, in der mehrere Metaphern mit

110 Siehe pTurin Cat. 1892+1893+1886 = CGT 54031 (Pleyte \& Rossi 1869-76: 20,1,7), zitiert bei Grapow (1924: 63, n.1).

111 Siehe Posener (1955: 66): "homme compétent dans n'importe quel travail".

112 "Apprête-toi à retenir mes conseils comme la digue retient l'eau" (Parker, Zitat bei Posener 1955: 66).

113 "Comme une digue résiste aux flots, résiste aux tentations qui pourraient te détacher de ma parole". 
dem Körper verbunden werden. Zuerst wird der 'Kasten des Leibes' ( $h n w n(j)$ - $\underline{h} . t)$ durch einen metonymischen Gebrauch als 'Sitz des Herzens ${ }^{\prime 14}$ bestimmt. Der metaphorische Sinn dieser Stelle wird durch 'das Schloß am Herzen' ( $\left.p n^{c} j . t\right)$ ausgedrückt, wobei die Metapher sich eigentlich auf die Lehre bezieht, welche gelernt werden soll. Interessant ist die Vorstellung vom Herzen als eine Art Gebäude oder Behältnis, das einen Verschluß hat. Andere Vorschläge zur Übersetzung des Wortes $p n^{c} j . t$ erwähnt Shirun-Grumach (1994: 26), nämlich "Schloß", "Riegel", "Schlüssel", "Schwelle" oder "Türpfosten", wovon ihrer Ansicht nach "Pfosten" die treffendste Übersetzung darstellt. Sie begründet ihre Entscheidung mit dem in weiteren Verlauf des Textes vorkommenden Wort $n^{c}$ j.t "Landepflock". Daß allerdings ein im weiteren Verlauf des Text auftauchendes, $p n^{c} j . t$ lautlich nahestehendes und möglicherweise auf es bezogenes Lexem $n^{c}$ j.t direkte Auskunft über die lexikalische Bedeutung von $p n^{c} j . t$ geben soll, erscheint fraglich. Den Sinn dieser Metaphern erklärt Couyer (1961: 399 f.) als "die Bewahrung der Maximen im Gedächtnis, zum Zwecke des Umsetzens in die Praxis". Konkreter ist Shirun-Grumachs Interpretation, die den Pfosten als eine Stütze des Herzens interpretiert (1994: 28).

In einem weiteren Beispiel wird das Herz mit einem Lot identifiziert (W-163: hms $p$ 3- $j^{c} n$ $r-g s-t 3-m h 3 y . t j w$ p $y=f j b m-t h)$, was auf Thot und die Waage-Ikonographie zum Kapitel 125 des Totenbuches anspielt. ${ }^{115}$ Der Text gibt im Grunde das wieder, was man in der Vignette dieses Kapitel sehen kann: Der Gott Anubis beobachtet das Lot und der sitzende Gott Thot verkündigt das Ergebnis. In Beispiel W-163 scheint $j b$ allerdings nicht als die Personifikation eines Mannes angesehen werden zu können, der während des Jenseitsgerichts beurteilt wird $^{116}$, da es danach aussieht, als sei nicht vom Herz des Verstorbenen die Rede, und $j b$ sich in diesem Fall auch nicht als zu Beurteilendes (d.h. als Gewicht) in einer der Waagschalen zu befinden scheint, sondern als Indikator des Ergebnisses des Wiegeprozesses erwähnt wird. Man mag demnach zunächst an folgende Interpretation denken: 'Der Pavian hockt neben der Waage, und sein Herz dient als Lot', was freier etwa mit "Der Pavian sitzt neben der Waage, und sein Herz gibt den Ausschlag' wiedergegeben werden könnte. Freilich ist die Stelle komplizierter als auf den ersten Blick anzunehmen. Das, was eben gerade als Übersetzung angeboten wurde, sollte nämlich auch im Neuägyptischen nicht mit dem Ausdruck $p 3 y=f j b$, sondern mit $j b=f$ gebildet werden. Denn bei dem 'Herz' handelt es sich um einen unveräußerlichen Besitz, und der pronominale Possessor eines solchen Substantivs wird bis ins Koptische nicht mit am Possessivpräfix, sondern als Suffixpronomen am Substantiv bezeichnet. Zumindest symbolisch und ikonographisch losgelöst von seinem Besitzer ist in der Totengerichtsszene allenfalls das Herz des Verstorbenen. Daher wäre zu erwägen, ob sich

114 Wb II 492,2, siehe auch Shirun-Grumach (1972: 26).

115 Vgl. Hermann (1954: 106-115).

116 Siehe dazu etwa Bonnet (1971: 334-341). 
das Pronomen der dritten Person in $p^{3} y=f j b$ womöglich gar nicht auf den Pavian bezieht, sondern doch auf den Verstorbenen. Dann müßte man annehmen, daß entweder der Verfasser der Lehre des Amenemope keine genaue Kenntnis der Bestandteile einer Waage (bzw. ihren Benennungen) besaß oder die Textüberlieferung nicht in Ordnung ist. Beide Vermutungen sind von einer solchen Art, daß man sie meines Erachtens besser nicht ohne zwingenden Grund und ungeprüft akzeptieren sollte. Besser ist es vielleicht, in dieser Metapher von einem metonymischen Gebrauch von $j b$ im Sinne von 'Ansicht, Meinung, Ermessen, Standpunkt' auszugehen. Bei einer solchen abstrakteren Bedeutung wäre $j b$ weniger unabänderlich mit seinem Besitzer verbunden. Man könnte nicht nur sinnvoll übersetzen "Der Pavian hockt neben der Waage, und seine Ansicht gibt den Ausschlag', sondern hätte gleichzeitig sogar möglicherweise ein diagnostisches grammatisches Kriterium für den metonymischen Gebrauch von $j b$ gefunden.

Ähnliche Elemente sind auch in einer Metapher aus einer der Klagen des Beredten Oasenbewohners zu finden, wo es in Beispiel E-13 heißt 'deine Zunge ist das Lot, dein Herz ist das Gewicht, und deine Lippen sind ihre Balken' (th $p w n s=k d b n$ pw jb=k rmn.w=f $p w$ sp.t=ky)'. Hermann (1954: 107-109) erklärt die Stelle als einen Verweis auf das menschliche Handeln, das ausgeglichen sein soll und damit einer im Lot befindlichen Waage gleiche. Es wird außerdem davon ausgegangen, daß die Idee des Totengerichts in der Metapher aus E-13 präsent sei. Tatsächlich hat das aber nicht unmittelbar etwas mit der Form der Metapher zu tun, sondern man sollte sich besser auf die Aussage beschränken, daß dieselbe Metapher auch im Zusammenhang mit dem Jenseitsgericht gebraucht wird: Was die Zunge sagt, soll das komplementieren, was das Herz enthält. Eine falsche Rede der Zunge würde das Gleichgewicht stören und der Person während des Totengerichts schaden; die Lippen sind metaphorisch als Balken der Waage genannt, während das Herz für das Gleichgewicht der Waage verantwortlich ist. 'Arme', 'Zunge' und 'Herz' lassen sich darüber hinaus auch metonymisch für 'Taten', 'Rede' und 'Gefühle' verstehen, so daß Parkinsons (1997: 81) Interpretation des Ganzen als Beschreibung eines idealen Großen durchaus angemessen erscheint. Was das Herz repräsentiert ist das, was in der oben kommentierten Metapher W-163 erklärt wurde. 


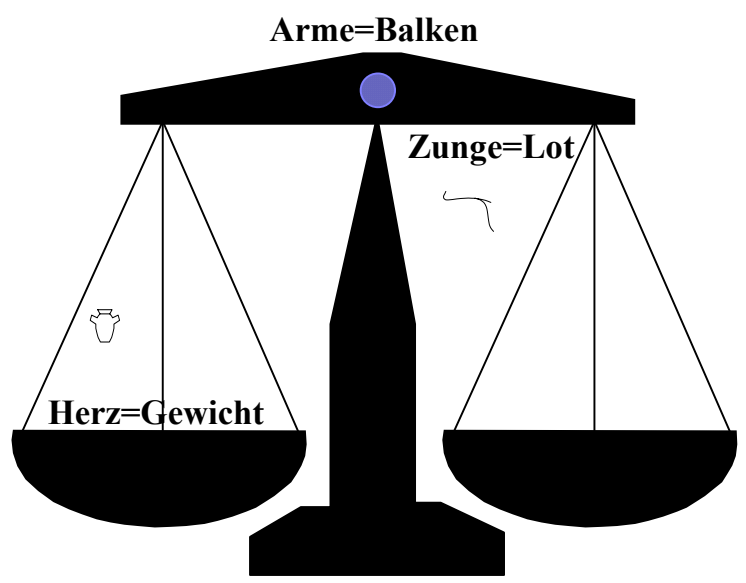

Im Beispiel W-166 (jr ḩ’tj n(j)- rmt fnd $n(j)$ - ntrr) wird das Herz eines Mannes mit der Nase des Gottes identifiziert. Eine gewisse Schwierigkeit bei der Deutung dieser Stelle entsteht durch eine andere auf der Turiner Dublette enthaltene Version, die $f q^{3} n(j)$ - ntrr 'das Geschenk des Gottes' statt fnd $n(j)$ - ntr schreibt. Shirun-Grumach bringt diesen Ausdruck mit einem anderen aus derselben Lehre in Verbindung ${ }^{117}$, um die Lesung 'Nase' zu beweisen (1994: 153). Assmann (1996: 172, Anm. 39) stimmt mit der Meinung Shirun-Grumachs überein und fügt hinzu, daß die Lesung 'Gabe', anstatt 'Nase' keinen Sinn mache, da im Kontext einer Lehre alles als Gabe des Gottes zu verstehen sei. Faulkner, Wente \& Simpson (1972: 262) schlagen als Übersetzung 'Schnabel' vor, was durch eine Übertragung auf den menschlichen Körper als 'Nase' wiederzugeben ist, wie Lange (1925: 119) bereits vor ihnen bemerkte. Nur Posener (1966: 61-62) und später Lichtheim (1976: 160) halten an der Bedeutung 'Gabe' auf der Grundlage der Turiner Schreibtafel fest. In dieser Arbeit wird der Übersetzungsvorschlag Poseners und Lichtheims nicht übernommen, stattdessen schließe ich mich der Meinung der anderen Autoren an. Die Interpretation dieser Metapher durch Shirun-Grumach geht dahin, in ihr eine Warnung vor indiskreter Rede zu sehen. In Verbindung mit der Stelle 17,7-8 desselben Texts deutet sie die Passage in einem religiösen $\operatorname{Sinn}^{118}$ und stellt fest, daß "die Integrität des Schreibers als eines in jeder Lebenslage seinem Gotte Verpflichteten" (1972: 155) zu betonen sei. Wenn die Nase des Gottes nicht vernachlässigt werden darf und "der Finger des Schreibers der Schnabel des Ibis ist", so heiße das, daß der Gott aus dem Schreiber wirkt, und man dem nicht unrecht tun dürfe. Die Erklärung von Assmann (1996: 171-172) sieht einen pessimistischeren Hintergrund und beruht auf dem in derselben Lehre beschriebenen Motiv einer hoffnungslosen Situation in einer Welt, der man nicht mehr vertrauen könne. In einer solchen Situation sei Gott das einzige, woran man sich halten könne, und müsse demzufolge "ins Herz gesetzt" werden. Assmann erinnert weiter daran, daß der Mensch von Gott auch "eingeatmet" werde, was bereits in den Pyramidentexten ausgedrückt ist, wenn der tote König

117 In 17,7-8 steht "Der Schnabel des Ibis ist der Finger des Schreibers".

118 Die gemeinte Gottheit ist ibisgestaltig. 
die Lotosblüte an der Nase des Re zu sein wünscht, und auch in einem Sargtext erscheint, in dem Maat in die Nase des Vestorbenen gegeben werden soll. ${ }^{119}$ Assmann schließt daraus, daß "das Herz und der Gott dieselbe Luft menschlicher Gerechtigkeit atmen" (1996: 172).

Auf einer Schultafel aus Abydos ${ }^{120}$ findet man möglicherweise eine Metapher, die lautet 'die Hände des Herzens' (W-103: ' ${ }^{c} w j$ - $h{ }^{3} t j=k$ ). Die Textpassage ist interessant, da sie womöglich nicht nur eine Metapher enthält, sondern auch, weil sie eine Vorstellung des Herzens bildet, die nicht typisch für die Weisheitstexte ist. Im Zuge seiner Bearbeitung der Tafel interpretierte van de Walle (1963: 118-123) das Wort ḩ3tj in dieser Metapher als "Vergnügen". Zudem wies er auf die Originalität des Ausdrucks 'Hände des Herzens' hin und erklärte ihn mit einem Verweis auf Papyrus Sallier I,5 ${ }^{121}$, wo eine ähnliche Kollokation vorkomme, obwohl die spezifische Formulierung in diesem Text einen Bruch mit den traditionellen Formen darstelle. Eine der Übersetzung van de Walles entsprechende Interpretation von 'Herz' als "Vergnügen" schlägt auch Brunner (1988: 398) vor. Das ist meiner Meinung nach nicht angemessen. Wenn das Wort 'Herz' hier metonymisch für 'Vergnügen' gebraucht wäre, würde eine merkwürdige Metapher gebildet, nämlich 'die Hände des Vergnügens', die man mit einem übertragenen Sinn als 'sich von seiner Leidenschaft fortreißen lassen' verstehen könnte. In Hannigs Wörterbuch (1995: 582, 30) steht "seiner eigenen Laune nachgeben"; 'Laune' kann hier aber nicht die treffende Übersetzung sein, da dieser Begriff zwar einen negativen Sinn enthalten kann, jedoch nicht zwangsläufig eine unkluge Handlung provozieren muß. Es wurde weiter oben ausgeführt, daß das Herz in den Lehren eine zentrale Rolle als positive Größe spielt, wenn es mit dem Verstand gleichzusetzen ist, und als das Organ verstanden wird, durch das gelernt und ein erfolgreiches Leben erreicht wird und das in besonderem Maße mit der Gerechtigkeit verbunden ist. An der vorliegenden Textstelle ist nun auffällig, daß der Schreiber gerade nicht auf sein Herz vertrauen soll, um unüberlegte Handlungen zu vermeiden. Das kann eigentlich nur bedeuten, daß der in den Weisheitstexten meistens übliche Sinn des Wortes hier nicht vorliegt, 'Herz' also nicht für 'Verstand', sondern für etwas anderes steht. Am wahrscheinlichsten ist eine Interpretation, die davon ausgeht, daß das Herz in Beispiel W-103 mit den Gefühlen verbunden ist und die Aussage intendiert wird, daß sich eine Person dann, wenn sie gemäß ihres Gefühls handelt und womöglich böse, ärgerlich oder unkontrolliert ist (vgl. W-8: $m 3 d j b=k$ 'Sei nicht einmal innerlich wütend auf ihn' und W-82: $d n d n$ jb 'eines Jähzorniges'), töricht benehmen könnte. Im Gegensatz zu vielen anderen Bei-

119 "Küsse (oder atme) deine Tochter Maat, gib sie an deine Nasse" Shirun-Grumach (1985: 176).

120 Die Datierung dieser Tafel auf Grund der spezifischen Formen einiger Determinative ist nicht sicher. Nach

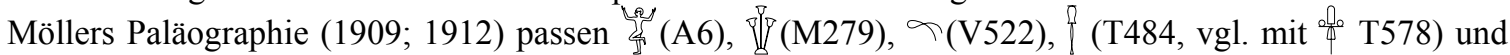

(V510) eher zu einem Ansatz in die Phase des Späthieratischen. Deswegen wird hier die Stelle analysiert aber mit der Anmerkung ihrer fragwürdigen Datierung.

121 "On dit que tu abandonnes les écrits et que tu te dissipes dans les plaisirs"; "Ne laisse pas ton coeur se dissiper dans les plaisirs" und "Ne livre pas ton coeur aux plaisirs" (van de Walle: 1963: 123). 
spielen aus den Weisheitstexten wird das Herz in dieser Passage also nicht mit dem Verstand, sondern im Gegenteil mit dem Un-Verstand identifiziert, der sich mit Emotionen oder unkontrollierten Wünschen in Verbindung bringen läßt. Setzt man voraus, daß das Herz der Ort ist, wo sich die Emotionen und subjektiven Absichten einer Person befinden, so wäre es für die Deutung dieser Stelle naheliegend zu denken, daß das Herz als 'Unkontrolliertes' oder 'Unbedachtes' zu interpretieren ist. Die Folge eines in diesem Zustand befindlichen Herzens wäre eine unüberlegte Handlung.

Eine ganz andere Möglichkeit zur Interpretation des Beispiels W-103 besteht darin, $h r^{-}{ }^{c}$.wj als grammatikalisierten Ausdruck aufzufassen. Eine komplexe Präposition $h r^{-}{ }^{c}(. w j)$ ist mehrfach bezeugt, kann die Bedeutung '(jemandem) unter(geben) ${ }^{122}$ haben oder auch ohne Komplement (d.h. als Adverb) in der Bedeutung 'sogleich' ${ }^{123}$ auftreten. Liest man anstelle von $m$-jr $h^{3}{ }^{c}=k h r-{ }^{c} \cdot w j-h{ }^{3} t j=k$ 'verlasse dich nicht auf die Hände deines Herzens' vielmehr $m-j r \quad h{ }^{3}=k$ $h r^{-}{ }^{c} . w j-h 3 j t j=k$ 'verlasse dich nicht auf dein Herz', so läge überhaupt keine Metapher vor. Da in der Sekundärliteratur allgemein von der Existenz der Formulierung 'Hände des Herzens' ausgegangen wird und es nur schwer zu beweisen ist, daß eine solche Metapher nicht existierte, wird der Ausdruck hier weiter berücksichtigt, aber als zweifelhaft gekennzeichnet.

Nach den Ausführungen zum mutmaßlichen Sinn dieser Metaphern soll im Folgenden ein Versuch unternommen werden, sie mittels der in Kapitel 3 vorgestellten Klassifizierungskriterien zu Gruppen zusammenzufassen, um auf diese Weise womöglich weitere Einblicke in die Besonderheiten des ägyptischen Metapherngebrauchs zu gewinnen. Zur Erinnerung werden die Metaphern aus den Weisheitstexten, um die es hier gehen soll, noch einmal zusammen aufgelistet:

- W-32: ${ }^{c} n \underline{h} w \underline{d}$ s snb $n(j)-z(j) j b=f^{\prime}$ Leben, Wohlbefinden und Gesundheit sind sein Herz(enswunsch)',

- W-141: h3tj p3y=s jry-C3 'das Herz ist ihr Torwächter',

- W-130: jmj hpr jb=k mj dnj.t 'sorge dafür, daß dein Herz wie ein Damm wird',

- W-155: $p n^{c} j . t m-j b=k$ 'das Schloß an deinem Herz',

- W-163: $p^{3} y=f j b m-t h$ 'sein Herz dient als Lot',

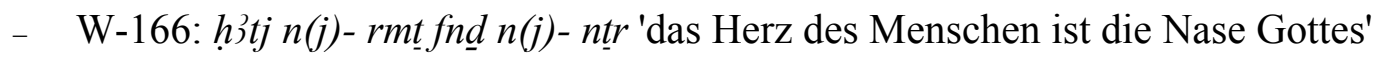

- W-103: '. wj- ḩ3tj=k'Hände deines Herzens' (?),

- E-13: $d b n p w j b=k$ 'dein Herz ist das Gewicht'.

Dabei zeigt sich, daß keineswegs alle der früher oder später von den verschiedenen Autoren vorgeschlagenen und in Kapitel 3 vorgestellten Einteilungsprinzipien für eine Analyse des ägyptischen Materials anwendbar oder sinnvoll sind. Insbesondere solche Kriterien wie neu// 
gebraucht oder Begriffsmetapher//Verzierungsmetapher (siehe dazu Pisarska 1989: 103-109 und vgl. oben Kapitel 3.5.) sind in Ermangelung der für eine Zuordnung notwendigen Detailinformationen über den ägyptischen Sprachgebrauch kaum zu verwenden.

Auch die Quintiliansche Klassifizierung, bei der die Belebtheit oder Unbelebtheit von Tenor und Vehikel eine Rolle spielen, leistet für die hier verfolgte Fragestellung wenig und wirft eher Schwierigkeiten auf. Bevor man unsere Beispiele nach Quintilians Prinzipien klassifizieren kann, müßte man zunächst grundsätzlich die nicht unbedingt triviale Frage klären, ob man das Herz als etwas Belebtes der als etwas Unbelebtes ansehen möchte. Ist das geschehen vielleicht in dem Sinne, daß man dem Herz als integralem Bestandteil von belebten Wesen ebenfalls das Merkmal [belebt] zuspricht -, so könnte man zu folgendem Ergebnis kommen:

\begin{tabular}{||c|l||}
\hline ART DER METAPHER & \multicolumn{1}{|c||}{ BEISPIELE } \\
\hline Belebtes für 'Herz' & W-141 ('Torwächter') \\
& W-166 ('Nase') \\
& W-103 ('Hände') \\
\hline Unbelebtes für 'Herz' & W-32 ('Leben, Heil und Gesundheit') \\
& W-130 ('Damm') \\
& W-155 ('Schloß') \\
& W-163 ('Lot') \\
& E-13 ('Gewicht') \\
\hline
\end{tabular}

Mehr als die Aussage, daß in Metaphern aus ägyptischen Weisheitstexten sowohl Belebtes wie auch Unbelebtes für 'Herz' gesetzt werden konnte, haben wir dadurch nicht gewonnen. Daß in W-166 die Körperteilbezeichnung 'Nase' - und in W-103 womöglich auch 'Hände' steht, beides Substantive, die dieselben Zuordnungsprobleme aufwerfen wie die Wörter für 'Herz', zeigt die Grenzen einer solchen Art der Metaphernklassifikation.

Nach der auf der jeweiligen prädikativen Struktur beruhenden Klassifikation von Kurz (1982: 21-22) müßte man in formaler Hinsicht vor allem zwischen durch den einen Satz ausgedrückten Metaphern (syntaktische Metaphern) und als Possessionsausdrücke realisierten (Kompositionsmetaphern und Genitivmetaphern) unterscheiden. Danach würden die vorgestellten Beispiele folgende Gruppen bilden: 


\begin{tabular}{||l|l||}
\hline FORM DER METAPHER & \multicolumn{1}{|c|}{ BEISPIELE } \\
\hline syntaktische Metaphern & $\begin{array}{l}\text { W-32; W-141; W-130; W-166; W-163 } \\
\text { E-13 }\end{array}$ \\
\hline Attributive Metaphern & W-155 \\
\hline Kompositionsmetaphern & W-98, W-103 \\
\hline Appositionsmetaphern & $\varnothing$ \\
\hline Genitivmetaphern & $\varnothing$ \\
\hline
\end{tabular}

Syntaktische Metaphern können im Ägyptischen in Form eines Nominalsatzes konstruiert werden (z.B. W-141: hỉj p 3y=s jry-c3 'das Herz ist ihr Torwächter'), allerdings ist das nicht die einzige Möglichkeit. Daneben begegnen als Adverbialsätze gebaute Metaphern - z.B. W-163: $p^{3} y=f j b m-d h$ 'sein Herz dient als Gewicht' (mit dem sogenannten $m$ of predication); W-130: jmj h hpr jb=k mj dnj.t 'sorge dafür, daß dein Herz wie ein Damm wird'. Als Metaphern dienende Possessionsausdrücke können einerseits durch eine Konstruktverbindung, den soge-

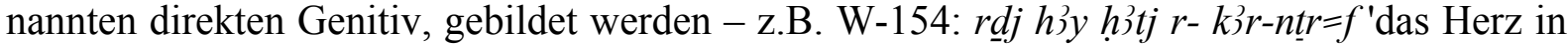
seinen Gottesschrein eintreten lassen ${ }^{\prime 24}$ - und andererseits im sogenannten indirekten Genitiv, einer Verbindung zweier Substantive mittels des Determinativpronomens $n(j)$ stehen. Letztere, die sich syntaktisch am ehesten mit den anhand des Deutschen entwickelten Genitivmetaphern gleichsetzen lassen, sind in den Weisheitstexten nicht belegt.

Grapow (1924) bietet in seiner Arbeit über die bildlichen Ausdrücke im Ägyptischen keine allgemeine Klassifikation für Metaphern, sondern gliedert seine Untersuchung nach den Vehikeln, mit denen eine Metapher konstruiert wird, und bietet vor allem zahlreiche Ausdrücke als Beispielmaterial. Charakteristikum seiner Arbeit ist es, daß die am häufigsten für die Ausbildung einer Metapher verwendeten Typen von Vehikeln zusammenfassend dargestellt werden. In der folgenden Tabelle werden die Metaphern unserer Beispiele auf eine der Grapowschen Klassifikation entsprechenden Weise geordnet:

\begin{tabular}{||l|l||}
\hline \multicolumn{1}{|c||}{ VEHIKEL DER METAPHER } & \multicolumn{1}{|c||}{ BEISPIELE } \\
\hline Person & W-141 ('Torwächter') \\
\hline Körperteil & W-166 ('Nase'); W-103 ('Hände') \\
\hline Sache & W-130 ('Damm'); W-154 ('Gottesschrein); W-155 ('Tor'); W-163 ('Lot') \\
& E-13 ('Gewicht') \\
\hline Abstraktes & W-103 ('Leben, Heil und Gesundheit') \\
\hline
\end{tabular}

$124 \mathrm{Da}$ wir hier tatsächlich eine Konstruktverbindung $k 3 r$-ntr- hijtj 'Gotteskapelle des Herzens' voraussetzen dürfen, geht daraus hervor, daß in dem neuägyptisch abgefaßten Text der pronominale Possessor durch ein Suffixpronomen am Substantiv $(k 3 r-n t r=f)$ ausgedrückt wird und nicht etwa durch den einem "indirekten Genitiv" entsprechenden Ausdruck aus Possessivartikel und Substantiv ( $p 3 y=f k 3 r-n t r)$, der im Jüngeren Ägyptisch - außerhalb von Inalienablia - das Normale darstellt (vgl. dazu Junge 1996: 62-66, Kammerzell 2000: 100-107). 
Faßt man die Resultate einer Klassifizierung nach Art der von Grapow (1924) vorgenommenen und einer an Kurz (1982) angelehnte Sortierung nach grammatischen Gesichtspunkten zusammen, so ergibt sich vorläufig folgender Befund:

\begin{tabular}{||l|c|c|c|c||}
\hline \multirow{2}{*}{} & \multicolumn{2}{|c|}{ BELEBTES } & \multicolumn{2}{c||}{ UNBELEBTES } \\
\cline { 2 - 5 } & PERSON & KÖRPERTEIL & SACHE & ABSTRAKTES \\
\hline syntaktische Metaphern & W-141 & W-166 & W-130 & W-32 \\
& & & W-163 & \\
\hline attributive Metaphern & & & E-13 & \\
\hline Kompositionsmetaphern & & & W-155 & \\
\hline
\end{tabular}

Besonders aussagekräftig ist das nicht. Insbesondere die Kategorie "syntaktische Metaphern" ist angesichts der unterschiedlichen Bildungsmöglichkeiten im Ägyptischen viel zu unscharf. Da es aber andererseits nicht sinnvoll erscheint, die wenigen Einzelbeispiele aus den Lehren auf fast ebensoviele Klassen zu verteilen, soll eine detaillierte Behandlung zunächst aufgeschoben werden und erst im letzten Kapitel für sämtliche in dieser Arbeit berücksichtigten Teilkorpora zusammen erfolgen.

\subsection{Das Herz in Ausdrücken zur Bezeichnung von Emotionen}

Eine Reihe von Beispielen, in denen Begriffe wie 'zufrieden sein', 'froh sein' oder 'traurig sein' vorkommen (z.B. W-28: sḥdn jb 'das Herz schädigen' oder 'die Stimmung verderben'; W-70: h3 3 j.(w) snm.w 'die Herzen sind traurig' und $j b h r$ 'das Herz ist zufrieden'; W-51: $h r j b$ 'das Herz ist zufrieden' oder 'das Herz ist gleichgültig'; E-77: $j b$ 3tp 'das Herz ist beladen'), lassen eindeutig erkennen, daß wir es dabei mit Emotionen zu tun haben.

Im Kapitel über Emotionen wurde dargestellt, daß drei Konzepte - nämlich Emotionserfahrung, Emotionszustand (oder Stimmung) und Emotionsdisposition - für die Analyse der einschlägigen Ausdrücke relevant sein können. Die Unterschiede ergeben sich insbesondere aus der zeitlichen Dimension: Emotionserfahrung wird als nur kurz andauerndes Ereignis definiert, Emotionszustand bezieht sich auf einen Zeitraum, der normalerweise Stunden oder Tage anhält, und Emotionsdisposition ist als dauerhaftere Eigenschaft einer Person aufzufassen. Versucht man, die Gesamtheit der mit Emotionen (im weiteren Sinne) zusammenhängenden Ausdrücke aus den Weisheitstexten danach zu klassifizieren, stellt sich rasch heraus, daß dies nicht einfach ist. Während zuweilen durch den Kontext oder bestimmte grammatische Merkmale (z.B. Temporalausdrücke) deutlich gemacht sein kann, ob an der entsprechenden Stelle von einer punktuellen Emotionserfahrung, einer begrenzte Zeit andauern- 
den Stimmung oder einer dauerhaften Eigenschaft die Rede ist, gibt es andere Beispiele, in denen nicht ohne weiteres eine klare Entscheidung gefällt werden kann. Dieser Unsicherheit wird hier dadurch begegnet, daß insgesamt sechs verschiedene Klassen angesetzt werden. Neben den drei Hauptgruppen, die die einigermaßen sicher entweder als Emotionserfahrung, als Emotionszustand oder aber als Emotionsdisposition zu identifizierenden Ausdrücke enthalten, gibt es eine Klasse von Kollokationen, bei denen zwar ausgeschlossen werden kann, daß sie emotionale Disposition oder Charaktereigenschaften bezeichnen, jedoch nicht klar zwischen Emotionserfahrung oder Emotionszustand unterschieden werden kann. Desweiteren lassen sich einige Beispiele klar als nicht kurzfristige Ereignisse analysieren und zu einer Gruppe Emotionszustand oder Emotionsdisposition zusammenfassen. Die sechste Kategorie bilden nicht zuzuordnende Fälle.

Daß keine eindeutige Klassifizierung möglich ist, hängt vermutlich nicht nur mit den zweifellos vorhandenen - Unzulänglichkeiten in unserer Beherrschung des Ägyptischen zusammen, sondern auch damit, daß eine klare Trennung keine direkte Entsprechung in der Sprache aufweist. Ein und derselbe Ausdruck kann sich je nach konkretem Kontext ohne weiteres auf verschiedene Ereignistypen beziehen. So ist das Kompositum ' $w n$ - $j b$ 'Habgier' zwar sicherlich eher als Zustand oder sogar als Charaktereigenschaft zu klassifizieren, doch wenn - wie beispielsweise in der Passage W-22 - von einem 'Anflug von Habgier' $(z p n(j)$ $\left.c_{w n-j b}\right)$ die Rede ist, liegt eindeutig eine Emotionserfahrung vor. Die nachstehende Tabelle soll nicht nur einen Gesamtüberblick über die in den Weisheitstexten vorkommenden Emotionsausdrücke geben, sondern auch als erste Grundlage für die im weiteren Verlauf dieser Arbeit durchzuführende Analyse darstellen, die darauf abzielt, etwaige Zusammenhänge zwischen spezifischen grammatischen Ausdrucksmitteln und speziellen Bedeutungen herauszuarbeiten.

\begin{tabular}{|c|c|}
\hline EREIGNISKLASSE & BEISPIELE \\
\hline EMOTIONSERFAHRUNG & 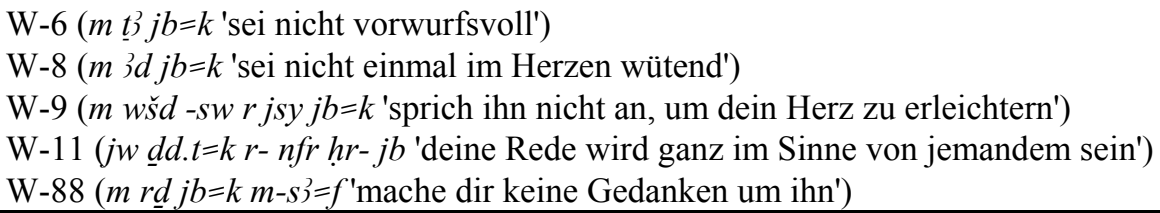 \\
\hline $\begin{array}{l}\text { EMOTIONSERFAHRUNG } \\
\text { ODER EMOTIONSZUSTAND }\end{array}$ & 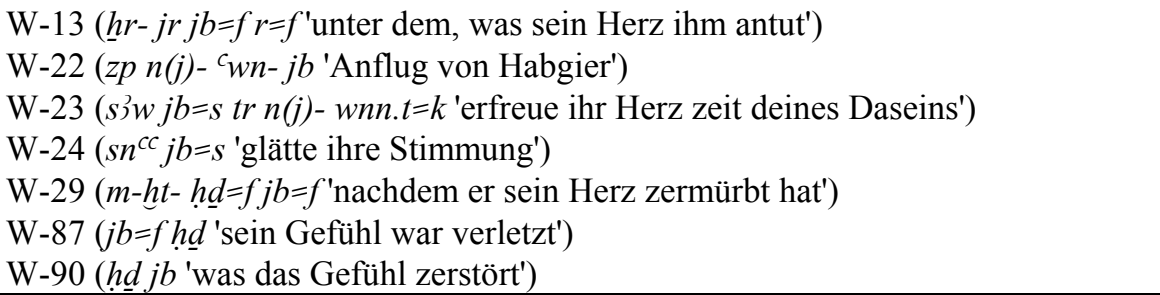 \\
\hline
\end{tabular}




\begin{tabular}{|c|c|}
\hline EREIGNISKLASSE & BEISPIELE \\
\hline EMOTIONSZUSTAND & 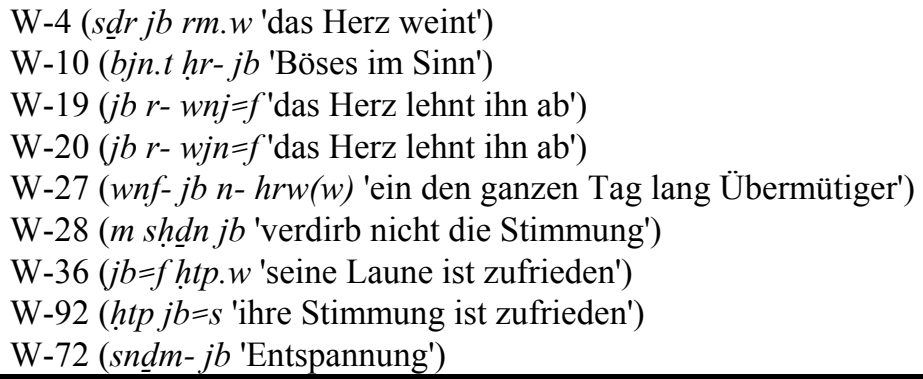 \\
\hline $\begin{array}{l}\text { EMOTIONSZUSTAND ODER } \\
\text { EMOTIONSDISPOSITION }\end{array}$ & $\begin{array}{l}\mathrm{W}-21(\check{s} w=k m-h \grave{h} . t-j b \text { 'du wirst frei von Herzenskummer sein') } \\
\mathrm{W}-30 \text { (wnf.t- } j b \text { eine'Übermütige') }\end{array}$ \\
\hline EMOTIONSDISPOSITION & 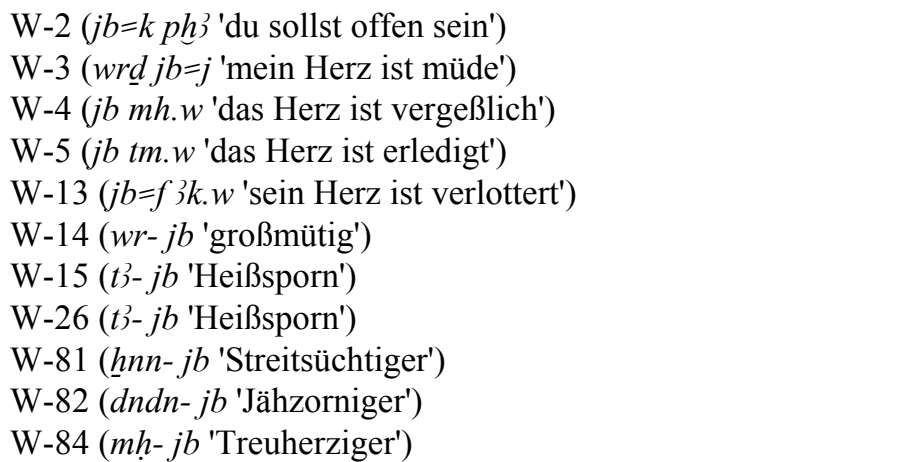 \\
\hline
\end{tabular}

Man findet andere Ausdrücke, die wie Emotionsausdrücke gebildet sind, aber wohl kein richtiges Gefühl bezeichnen. Das ist etwa der Fall bei den Erwähnungen von Handlungen in W134 und W-106, die 'in/aus geliebtem Herzen' ( $m$ - jb mr.w) durchgeführt werden sollen. In beiden Fällen ist wohl nicht von Emotionen die Rede, sondern als Übersetzung bieten sich vielleicht Formulierungen wie 'von ganzem Herzen', 'inbrünstig' oder einfach 'eifrig' an (W134: snmh $-n=k m-j b m r . w$ 'bete aus dem geliebten Herz' > 'bete von ganzem Herzen'; W-106: $w d n-n=f m-j b m r . y=k$ 'opfere ihm aus dem Herz, das du liebst' > 'opfere ihm aus ganzem Herzen'). Ähnlich bestellt dürfte es um den Ausdruck $m$ - $m s d d$ - hỉ tj 'während das Herz haßt' in Beispiel W-144 realisiert wird. All diese Ausdrücke enthalten ein positives oder negatives Gefühl an sich, allerdings drücken sie nicht aus, wie die genannte Person sich fühlt, sondern wie sie sich benehmen und auf welche Art und Weise sie handeln soll.

Es gibt weitere Beispiele, die noch interessanter sind, da sie direkt oder indirekt den impliziten Zustand eines Gefühles ausdrücken. Das ist der Fall in den Beispielen W-158, W-160, W-166, W-67 und W-68, die im folgenden genauer analysiert werden.

Zur Lehre des Amenenope gehören die ersten drei Beispiele, die sich mit der Rede oder der Handlung beim Sprechen in Verbindung bringen lassen.

Das Beispiel W-158 enthält auch eine Metapher, in der die Rede mit dem Wind identifiziert ist ( $\check{s} r s m d y m-\underline{d r t y}-\underline{h d} j b r-\underline{t} \hat{\jmath} w)$. Es handelt sich um eine Person, die sich in einem 
emotionalen Zustand befindet, so daß ihre Rede schneller ist als der Wind. ${ }^{125}$ Das Wort had, dessen Determinativ [HAusSPERLing sog. SCHLEChter Vogel] etwas Negatives darstellt, wird als Verb in Zusammenhang mit dem Herzen ${ }^{126}$ als "jmds. Herz kränken" wiedergegeben und mit dieser Bedeutung von Brunner (1988: 215) übersetzt. Allerdings ist die Hauptbedeutung des Wortes "schädigen"127, die von Shirun-Grumach (1972: 72) übernommen und später durch "ärgerlich" ersetzt wird (1991: 235). Meiner Meinung nach geht es in dem Beispiel W158 sowie W-160 um ein negatives Gefühl, welches eine schlechte Handlung provoziert. Im ersten Beispiel (W-158) ist es die schnelle Rede und im zweiten (W-160) die Begrüßung eines Feindes mit einer unrechtmäßigen Absicht. Diese Metapher ist interessant, da sie nach dem Kriterium "natürliche Kraft" ${ }^{128}$ klassifiziert werden kann. Der Wind ist eines von mehreren Vehikeln, um eine Emotion auszudrücken. Bei der Lehre des Amenenope befindet sich die Person in einer bedrohlichen Situation, auf die sie mit der schnellen Rede reagiert, die wie "der Wind des Gewässers" ist.

Im Beispiel W-160 ( $m-j r$ wšd.tw $m-p 3 y=k$ šmn $g n s=k m t w=k$ h $\underline{d} j b=k \underline{d} d s=k$ 'Grüße deinen Feind nicht, indem du Unrecht hast (tust) und kränke dein eigenes Herz nicht') befindet sich die Person in einem Zustand, in dem sie Unrecht tun, und ihr Herz kränken könnte, und deswegen sollte sie in diesem Gemütszustand niemanden begrüßen. In diesem Fall tritt eine Situation auf, in der es besser ist, nicht zu sprechen. Man geht davon aus, daß in beiden Fällen eine Kränkung einer Person durch die Rede möglich ist, wahrscheinlich weil diese Person sich durch unrechte oder unbedachte Äußerungen blamiert. Es wurde ausgeführt, daß ein Mensch zu einer Gesellschaft gehört und wie er sich inmitten dieser sozialen Beziehung benehmen soll. ${ }^{129}$ Das Schamgefühl spielt eine wichtige Rolle in Bezug auf die Verbindung zwischen der Gesellschaft und einem Mann, da es um eine Frage der Ehre geht. Man geht davon aus, daß ein Mann, wenn er sich selbst durch eine schlechte Tat schädigt, sein Prestige oder seine Position verlieren kann.

In Beispiel W-166 (m-dr.t jn.tw $r^{c}=k m-b w-r^{c}-t m h i j t j=k j k n w$ 'Laß nicht zu, daß man deine Rede nach außen weiterträgt, damit dein Herz nicht verbittert wird') kommt das Gefühl der Kränkung wieder im Zusammenhang mit der Rede vor. In diesem Fall mahnt Amenenope, die Worte eines anderen Beamten nicht preiszugeben, um Indiskretion zu vermeiden, damit das Herz nicht gekränkt wird. Shirun-Grumach bringt dies mit der oben genannten Stelle zusammen, indem sie davon ausgeht, daß die Indiskretion das Herz verärgert (1972: 155). Das Wort $j k n w^{130}$ wird als "schlechte Eigenschaft von Herz und Zunge" wiedergegeben, wobei die

125 Vgl. Ani 7,8-9.

126 Wb III 213,15.

$127 \mathrm{~Wb}$ III 212.

128 Siehe Kapitel 4.10 (2).

129 Siehe Kapitel 4.3, Antropologosiche Konzepte über den kulturspezifischen Charaktervon Emotionen.

$130 \mathrm{~Wb}$ I $140,4-5$ 
Übersetzung Shirun-Grumachs eine Konkretisierung dieser allgemein gefaßten Bedeutung darstellt. Sie bringt diese Stelle mit einer anderen in Verbindung, in der gesagt wurde, daß derjenige, der ein gekränktes Herz hat, eine saure Zunge besitzt. Meiner Meinung ist diese Stelle mit dem Beispiel W-158 und dem W-160 in Verbindung zu bringen, wobei Indiskretion als gesellschaftlich unerwünschte Handlung zu beschreiben ist, deren Ergebnis ein schädliches Gefühl ist. Aus diesem Grund wird vorgeschlagen, daß das Wort $j k n w$ in diesem Text als "sich kränken" wiederzugeben ist. Die dieser Textpassage folgende Metapher "das Herz eines Menschen ist die Nase des Gottes" wurde bereits auf den vorherigen Seiten kommentiert, so daß hier nur auf sie verwiesen wird. ${ }^{131}$

Zusammenfassend wird davon ausgegangen, daß sich ein Mann durch seine Rede oder seine Indiskretion blamieren kann und als Konsequenz sich selbst kränkt (W-160 und W166). Man kann ebenso seinen gekränkten emotionalen Zustand durch die eigene Rede (W158) verschlimmern. In beiden Fällen ist es zu bemerken, daß die Rede eines Mannes eine relevante negative Rolle für das Schamgefühl spielt.

In den Klagen des Chacheperreseneb (W-67: ${ }^{c}(w) . t=j$ znnj $=j h r-j b=j$ whd $s w h i p h . . t=j-h r=f$ 'Meine Glieder waren beladen, ich litt an meinem Herzen. Es ist schmerzlich, darüber den Mantel des Schweigens zu decken') wird eine chaotische Situation beschrieben. Chacheperreseneb beklagt sich über diese Situation und äußert seine Gefühle, unter denen sowohl sein Körper als auch seine Seele leiden. Durch diese Situation gerät er in einen schmerzlichen Zustand, welcher durch die Akzeptanz dieser chaotische Lebensumstände vermieden werden könnte. Diesen körperlichen und seelischen Zustand könnte man als das Gefühl "trauern" oder "betrübt sein" verstehen, welches durch seelische oder körperliche Schmerzen definiert werden kann. ${ }^{132}$

In der nächsten Textpassage (W-68: $k 3 j r y=j s h n y-h r=f 3 t p=j s w m-m d w . t n . t-m 3 j d r=j-n=f$ $m n(. t)=j$ 'Dann könnte ich mich untätig auf es stützen, es mit Klagen über das Elend beladen und so schließlich mein Leid auf seine Kosten vertreiben') wird beschrieben, wie Chacheperreseneb es sich vorstellt, sein Leid durch das Herz auszuschütteln. Zuerst würde er sich auf seinem Herzen ausruhen, wobei ein ermüdender Zustand impliziert werden kann. Dann wird Chacheperreseneb sein Herz mit den Klagen des Elends beladen, d.h. das Herz wird wieder durch eine Rede unter Druck gesetzt. Zum Schluß wird er das Leid vom Herzen entfernen. Das Wort $m n$ hat als Hauptbedeutung ${ }^{133}$ "Leiden" oder "kranke Stelle". ${ }^{134}$ In dieser Passage bezeichnet der Begriff allerdings nicht etwas Körperliches, sondern etwas Seelisches. Aufgrund der Untersuchung über die Emotionen im Kapitel 4 kann eine Nuance für den Sinn dieses Wortes angeboten werden, nämlich 'Angst', 'Schande' oder 'Leiden'.

131 Siehe Kapitel 5.3 Das Herz in Metaphern.

132 Siehe Kapitel 4.9.2 Trauer.

$133 \mathrm{~Wb}$ II 67.

134 Wb II 67,14. 
Das letzte Beispiel stammt aus der Prophezeiung des Nefertij (W-63: hn [n(j)-] mdw.t ḥr$j b m j$ - h.t $n(n)$ whd. $n=t w p r n(j)-r^{\prime}$ 'Die Sprichwörter werden auf das Herz treffen wie Feuer. Man kann den Maulhelden nicht mehr ertragen'), in der wieder eine chaotische Situation beschrieben wird. Erneut spielt die Rede eine wichtige Rolle. In diesem Fall wird es durch eine Metapher ausgedrückt, die sich indirekt auf das Herz bezieht. Die Sprichwörter werden mit dem Feuer identifiziert, die das Herz treffen und es heiß werden lassen. Im Kapitel über die Emotionen wurde gezeigt, wie das Gefühl 'wütend sein' mit einem warmen und negativen Sinn identifiziert werden kann. Dieser Metapher wäre als "Die Sprichwörter werden die getroffene Person wütend machen" zu interpretieren, so daß "nicht mehr ertragen werden kann, was aus dem Mund kommt". Man kann es aber auch in dem Sinn verstehen, daß das Herz verbrannt bzw. verletzt wird. Nach dieser Deutung lassen sich die Schmerzen wie im Fall W-67 mit einem Gefühl der Trauer in Verbindung bringen. ${ }^{135}$ Aufgrund dieser Schmerzen kann man nicht mehr ertragen, was gesprochen wird.

Die dargelegte Untersuchung läßt sich in einer Tabelle mit dem folgenden Ergebnis rekapitulieren:

\begin{tabular}{||l|l|l|l|l|l||}
\hline \hline BEISPIEL & \multicolumn{1}{|c|}{ EMOTION } & ASPEKT & AUSDRUCKSMODUS & \multicolumn{1}{|c||}{ REAKTION } & \multicolumn{1}{c||}{ METAPHER } \\
\hline W-158 & sich kränken & negativ & Rede & schnelle Rede & Wind \\
\hline W-160 & sich kränken & negativ & Grüßen & & \\
\hline W-166 & sich kränken & negativ & indiskreter Ausspruch & geschädigt werden & Nase \\
\hline W-67 & trauern & negativ & sprechen & schmerzen & \\
W-68 & leiden & negativ & & seelisch-krank & \\
\hline W-63 & $\begin{array}{l}\text { wütend/traurig } \\
\text { sein }\end{array}$ & negativ & Sprichwörter & heiß/krank werden & Feuer \\
\hline
\end{tabular}

Die Beispiele W-158, W-166 und W-63 enthalten eine Metapher an sich, obwohl im Beispiel W-166 keine richtige Verbindung zwischen der Emotion und der Metapher zu finden ist. Die Metaphern lassen sich folgendermaßen in einer Tabelle zusammenfassen:

\begin{tabular}{||l|l|l|l||}
\hline & KRITERIUM & TENOR & VEHIKEL \\
\hline W-158 & Natürliche Kraft & Rede & Wind \\
\hline W-166 & Körper & Herz & Nase \\
\hline W-63 & Naturkraft & Sprichwörter & Feuer \\
\hline \hline
\end{tabular}

Von allen kommentierten Beispielen für Emotionen enthalten nur die drei oben dargestellten eine Metapher. Es ist zu bemerken, daß das einzige Beispiel, in dem eine Metapher des Herzens vorkommt, keine richtige Verbindung mit dem implizierten Gefühl, nämlich 'sich 
schädigen' hat. Es ist ebenfalls der einzige Fall, in dem das Kriterium nicht aus einer Naturkraft besteht, sondern aus dem Körper. Die Rede und die Sprichwörter haben jeweils einen negativen Sinn, während das Herz als die Nase des Gottes an sich keinen negativen Sinn enthält. Man geht davon aus, daß die Rede für die negativen Gefühle eine besondere Rolle spielt, sei es wegen der Form des Ausdruckes (schnell, unrecht), oder sei es wegen ihres Informationsgehaltes (indiskrete Handlung) .

\subsection{Ein Vorschlag zur Klassifikation}

Als Ergebnis läßt sich aus der Sammlung einschlägiger Passagen der Weisheitstexte der Gebrauch der Lexeme für 'Herz' nach ihrer jeweiligen Verwendung und Bedeutung in unterschiedliche Gruppen klassifizieren. Da es jedoch nicht immer einfach ist, die richtige Bedeutung zu treffen, ist es unumgänglich, einige Ausdrücke in unterschiedliche Gruppen einzuordnen. Es ist ebenso möglich, daß ein Ausdruck infolge seiner grammatischen Funktion und seines Sinnes in mehreren Gruppen vorkommt.

GRUPPE 1

Das Herz als Subjekt (handelt als Person)

\begin{tabular}{|l|l||}
\hline das Herz ist müde & W-3 \\
\hline das Herz schläft & W-4 \\
\hline das Herz weint & W-4 \\
\hline das Herz ist vergeßlich; vergißt & W-4; \\
& E-14 \\
\hline das Herz erinnert sich (nicht mehr) an etwas & W-4; W-5 \\
& E-14 \\
\hline das Herz ist erledigt & W-5 \\
\hline das Herz ist gierig & E-11; E-13; E-20 \\
\hline das gierige Herz zerstört etwas & E-13 \\
\hline das Herz verurteilt jemanden & W-19; W-20 \\
\hline das Herz neigt zu etwas & W-40; W-148; W-149 \\
\hline das Herz regt sich & W-61 \\
\hline das Herz sorgt sich um etwas & W-62 \\
\hline das Herz sucht & W-65 \\
\hline das Herz antwortet & W-66; W-69 \\
\hline das Herz erklärt & W-69 \\
\hline das Herz weist ab & W-70 \\
\hline das Herz kann die Wahrheit nicht aufnehmen & W-71 \\
\hline das Herz ist verletzt & W-87 \\
\hline das Herz zerstört & W-90 \\
\hline das Herz ist schwach & W-91 \\
\hline das Herz setzt sich auf etwas & W-92 \\
\hline das Herz wacht & W-95 \\
\hline das Herz kommt nicht über etwas hinweg & W-97 \\
\hline das Herz sagt etwas & W-103 \\
\hline das Herz ekelt sich & W-125* W-142 \\
\hline & \\
\hline
\end{tabular}




\begin{tabular}{||l|l||}
\hline das Herz schweigt & $\mathrm{W}-143^{*}$ \\
\hline das Herz wendet sich ab & $\mathrm{W}-145^{*}$ \\
\hline das Herz tritt in seinen Gottesschrein ein & $\mathrm{W}-154^{*}$ \\
\hline
\end{tabular}

\section{GRUPPE 2}

Das Herz als Objekt

\begin{tabular}{||l|l||}
\hline jmd wäscht das Herz & W-9; W-16; W-59 \\
E-15
\end{tabular}

\section{GRUPPE 3}

Das Herz als Körper

\begin{tabular}{||l|l||}
\hline \hline Kinder verschaffen & W-1? \\
\hline das Herz ist müde & W-3 \\
\hline Antlitz & W-29?* \\
\hline das Herz zermürben & W-29? \\
\hline Schmerzen im Herzen & W-58? \\
\hline schlafen & W-96?* \\
\hline
\end{tabular}

136 "Geduldig sein" nach Gardiner (1923: 16), Lichtheim (1975: 178) und Parkinson (1997: 68). 'Wohlgesinnt' paßt nach meiner Meinung nach besser zu dieser Stelle.

137 Siehe Kapitel. 7.5 Andere Gebrauchsweisen des Begriffs 'Herz'. 
GRUPPE 4

Das Herz für den Ausdruck des Charakters

\begin{tabular}{|c|c|}
\hline vorwurfsvoll sein & W-6 \\
\hline wütend sein & $\mathrm{W}-8$ \\
\hline das Herz ist gierig & E-11; E-13; E-20 \\
\hline Herz $=$ Charakter & W-12 \\
\hline der Großherzige & $\mathrm{W}-14$ \\
\hline das Herz ist leicht & E-15 \\
\hline schnell im Herzen sein & E-15 \\
\hline frei von Kummer & $\mathrm{W}-21$ \\
\hline $\begin{array}{l}\text { Habgier; Habgieriges Herz; von gierigem Herzen sein; das } \\
\text { Herz ist habgierig }\end{array}$ & $\begin{array}{l}\text { W-22; W-46; W-49 } \\
\text { E-10; E-12; E-19; E-20; E-23 }\end{array}$ \\
\hline heißes Herz (Heißsporn) & $\mathrm{W}-26$ \\
\hline der Übermütige & $\mathrm{W}-30$ \\
\hline das Herz macht jdn & $\mathrm{W}-31$ \\
\hline das Herz zurückhalten; Zurückhaltung, zurückhalten sein & $\begin{array}{l}\text { W-34; W-55; W-79; W-112; W-115; } \\
\text { W-188 }\end{array}$ \\
\hline der Treuherzige; Vertrauen & W-38; W-50; W-84 \\
\hline tadellos & $\mathrm{W}-53$ \\
\hline der Ungestüme & $\mathrm{W}-56$ \\
\hline taub für das Herz sein & $\mathrm{W}-60$ \\
\hline $\begin{array}{l}\text { das Herz ist nachlässig (das Herz sorgt sich nur um sich } \\
\text { selbst) }\end{array}$ & $\mathrm{W}-62$ \\
\hline der Übelgesinnte & W-64 \\
\hline aufbrausendes Herz & $\mathrm{W}-73$ \\
\hline einnehmend sein & $\mathrm{W}-76$ \\
\hline der Streitsüchtige & W-81 \\
\hline klug sein & W-122 \\
\hline das Herz ist groß ${ }^{138}$ & $\mathrm{~W}-131^{*}$ \\
\hline bedächtig sein & W-132 \\
\hline entspann sein $\left({ }^{\circ}\right.$ süß $\left.\operatorname{sein}^{\circ}\right)$ & $\mathrm{W}-143^{*}$ \\
\hline ein hervorragendes Herz haben & $\mathrm{W}-151^{*}$ \\
\hline begriffsstutziges Herz & $\mathrm{W}-152^{*}$ \\
\hline das Herz ist angenehm & W-157 \\
\hline $\begin{array}{l}\text { gewichtig im Herzen sein (gewichtig durch den Charakter } \\
\text { sein) }\end{array}$ & W-164* \\
\hline
\end{tabular}

\section{GRUPPE 5}

Das Herz als Verstand und Erinnerung

\begin{tabular}{||l|l||}
\hline das Herz ist vergeßlich und erinnert sich nicht an etwas & $\mathrm{W}-4 ;{ }^{139} \mathrm{~W}-5$ \\
\hline Verstand & $\mathrm{W}-15 ; \mathrm{W}-58 ; \mathrm{W}-100^{*} ; \mathrm{W}-108^{*} ;$ \\
& $\mathrm{W}-120 ; \mathrm{W}-129 * ; \mathrm{W}-135 ; \mathrm{W}-147^{*} ;$ \\
$\mathrm{W}-148 ; \mathrm{W}-149$
\end{tabular}

138 'integrierte Person' (Assmann 1996: 149).

139 Siehe Burkard (1988: 19-30). 


\begin{tabular}{||l|l||}
\hline \hline das Herz such etwas & W-65 \\
\hline Herz mit Wissen & W-68 \\
\hline das Herz kann die Wahrheit nicht aufnehmen & W-71 \\
\hline das Herz begann, dem Schlaf zu folgen & W-96* \\
\hline im Herzen bedächtig sein & W-132 \\
\hline das Herz erfährt & W-133* \\
\hline sich unbedacht verhalten & W-137* \\
\hline das Herz hat zu schweigen & W-143* \\
\hline das Herz einsetzen, etwas zu erklären & W-155* \\
\hline der Verstand von der Zunge trennen & W-161* \\
\hline das Herz standfest machen & W-164* \\
\hline
\end{tabular}

\section{GRUPPE 6}

Herz $=$ Wunsch, Bedürfnis

W-15; W-32; W-76; W-153*

GRUPPE 7

Herz $=$ Absicht

W-74; W-140

GRUPPE 8

Herz $=$ Seele

W-9; W-16; W-109*

GRUPPE 9

Stimmung, Laune, Disposition

W-7; W-17; W-18; W-24; W-28;

W-36; W-86; W-92; W-121*;

W-129; W-138; W-146*; W-148;

W-157*; W-158

GRUPPE 10

Herz $=$ Meinung

W-33; W-105; W-111; W-116;

W-156

GRUPPE 11

Das Herz als Ort

\begin{tabular}{||l|l||}
\hline vorwurfsvoll im Herzen sein & W-6 \\
\hline wütend in Bezug auf das Herzen sein & W-8 \\
\hline etwas ist im Herzen begehrenswert & E-8 \\
\hline Böses auf dem Herzen & W-10 \\
\hline Schönes auf dem Herzen & W-11; W-104 \\
\hline leicht auf dem Herzen sein & E-12 \\
\hline im Herzen schnell sein & E-15 \\
\hline was im Herzen ist & E-17; E-18 \\
\hline sich auf das Herz stützen & W-49 \\
\hline dem Herzen nahestehen & W-56 \\
\hline Schmerzen im Herzen & W-58 \\
\hline \hline
\end{tabular}




\begin{tabular}{||l|l|}
\hline sich untätig auf das Herz stützen & W-68 \\
\hline verehren im Herzen & W-75 \\
\hline Kinder, die dem Herzen nachstehen & W-77 \\
\hline das Geschrei der Sünde ist laut auf dem Herzen & W-78 \\
\hline Gott und König am Herzen liegen & W-80* \\
\hline im Herzen sein & W-75*; W-99* \\
\hline $\begin{array}{l}\text { die Schriften ins Herzen geben (die Schriften sich zu Her- } \\
\text { zen nehmen) }\end{array}$ & W-105; W-139 \\
\hline laste schwer auf dem Herzen (bedächtig sein) & W-132 \\
\hline im Herzen des Gottes & W-156 \\
\hline $\begin{array}{l}\text { die Lehre ins Herzen geben (die Lehre sich zu Herzen } \\
\text { nehmen) }\end{array}$ & W-167 \\
\hline
\end{tabular}

GRUPPE 12

Das Herz für den Ausdruck eines Zustandes

\begin{tabular}{||l|l||}
\hline Entspannung & W-72; W-96 \\
\hline herzzerreißend (Gefährden des Herzens) & W-44 \\
\hline $\begin{array}{l}\text { das Herz ist leer/trocken (das Herz des Haustands ist rui- } \\
\text { niert) }\end{array}$ & W-45 \\
\hline das Herz ist im Körper verdorben & W-162 \\
\hline
\end{tabular}

GRUPPE 13

Das Herz und das Gefühl

\begin{tabular}{||l|l||}
\hline wütend sein & W-8 \\
\hline sich erfreuen; das Herz erfreuen & W-23; W-36; W-119; W-149* \\
\hline das Herz verderben & W-28 \\
\hline das Herz legen (zurückhaltend sein) & W-39 \\
\hline das Herz regt sich ${ }^{140}$ & W-61 \\
\hline sich sorgen um & W-62 \\
\hline etwas trifft auf das Herz & W-63 \\
\hline starkes Herz & W-67 \\
\hline am Herzen leiden & W-67 \\
\hline Leiden vom Herzen vertreiben & W-68 \\
\hline das Herz ist traurig & W-70* \\
\hline wütendes Herz & W-82 \\
\hline liebendes Herz & W-106 \\
\hline weinen entsprechend dem Herzen & W-138 \\
\hline zufrieden; zufriedenes Herz & W-36; W-51; W-92; W-149 \\
\hline entspann sein $\left({ }^{\circ}\right.$ süß sein $\left.{ }^{\circ}\right)$ & W-143* \\
\hline das Herz haßt & W-144* \\
\hline das Herz beruhigen & W-148 \\
\hline das Herz kränken & W-148; W-158; W-160; W-166 \\
\hline das Herz wird verbittert & W-166* \\
\hline \hline
\end{tabular}

140 Der Ausdruck bezieht sich nicht direkt auf eine Emotion. Meiner Meinung nach läßt er sich aber mit dem nächsten Satz in Verbindung bringen, der eine Emotion enthält, nämlich "das Land beweinen". 
GRUPPE 14

Die Metapher des Herzens

\begin{tabular}{||l|l||}
\hline das Herz $=$ das Gewicht & E-13 \\
\hline Leben, Wohlbefinden und Gesundheit = Herz & W-32 \\
\hline die Hände des Herzen & W-103* \\
\hline das Herz = Damm & W-130 \\
\hline das Herz = Torwächter & W-141* \\
\hline Schloß am Herzen & W-155 \\
\hline Herz = Lot & W-163 \\
\hline Herz $=$ Nase des Gottes & W-166 \\
\hline
\end{tabular}

GRUPPE 15

Sonstiges

\begin{tabular}{|l|l}
\hline das Herz ist bei jemandem & W-102*
\end{tabular}

\begin{tabular}{|l|l|}
\hline Klumpigwerden der Herzen & W-159* \\
\hline
\end{tabular} 


\subsection{Textbeispiele}

\section{Die Lehre des Djedefhor (Helck 1984)}

Quelle: $\quad$ Ostrakon München 3400

Datierung: $\quad$ Mittleres Reich ${ }^{141}$

Textausgaben: $\quad$ Brunner-Traut (1940: 3-9), Helck (1984).

Übersetzungen: $\quad$ Posener (1966: 45-65), Lichtheim (1975: 58-59), Brunner (1988: 101-103), Roccati (1994: 25-27), Burkard \& Thissen (2003: 81-82).

W-1 I, 4-5

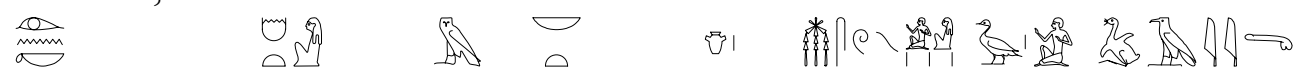

jr $\quad-n=k \quad h m . t \quad m-\quad n b . t \quad j b \quad m s . w \quad z^{3} \quad \underline{t} 3 y$

FUT. PRÄP.-2sm SBST.-FEM. PRÄP. SBST.-FEM. SBST. SBST.-PL. SBST. ADJ.

(...) Nur eine Frau mit Herz wird dir Kinder und einen männlichen Nachkommen verschaffen.

W-2 VII, 5

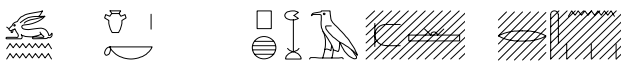

wnn $j b=k \quad$ phi $\quad-r=s n$

FUT. SBST.-2sm STAT.:3sm PRÄP.-3pc

Dein Herz soll ihnen gegenüber offen sein.

141 Gnirs (1996: 207-208); Quirke (1996: 393 u. 399); Brunner-Traut (1940: 3) datiert es in die Ramessidenzeit. 


\section{Die Lehre des Ptahhotep (Zába 1956)}

Quelle: $\quad$ Papyrus Prisse

Datierung: $\quad$ Späte XI/frühe XII. Dynastie ${ }^{142}$

Textausgaben: Jéquier (1911), Dévaud (1916), Žaba (1956), Sethe (1924).

Übersetzungen: Gunn (1912: 41-64), Erman (1923: 86-99), Lexa (1928), Bissing (1955: 45-51), Lichtheim (1975: I, 61-82), Foster (1977), Lalouette (1984: 235-250), Brunner (1988: 104-132), Burkard (1988: 19-30), Burkard (1991: 195-221), Hornung (1990: 63-77), Foster (1992: 53-55), Roccati (1994: 33-53), Vernus (1996: 119140), Fischer-Elfert (1997: 20-23), Parkinson (1997: 246-271), Kurth (1999), Junge (2003: 172-205), Burkard, \& Thissen (2003: 88-98).

\section{W-3 P12}

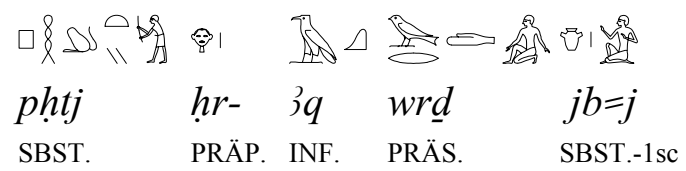

Die Kräfte sind im Schwinden begriffen, weil mein Herz müde ist.

W-4 L2, 15-16

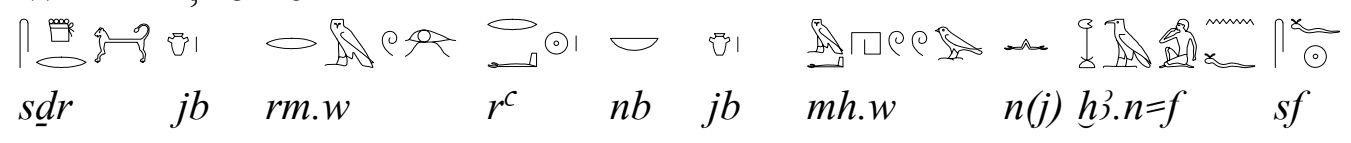

PRÄS. SBST. STAT.-3sm SBST.INDEF. SBST. STAT.-3sm NEG. VB.-PRÄT.-3sm SBST.

Das Herz schläft und weint jeden Tag. Das Herz ist vergeßlich und erinnert sich nicht an das Gestern. ${ }^{143}$

W-5 P10 und P16

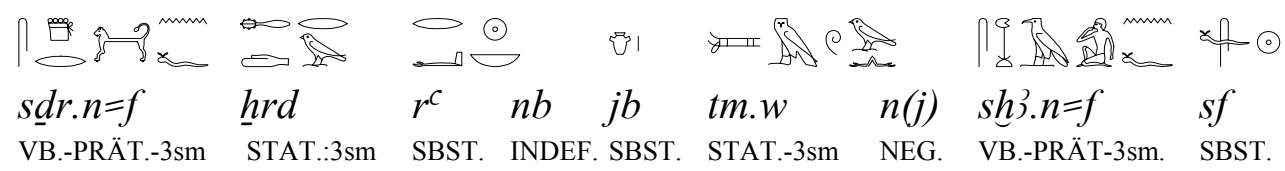

(Wieder) zum Kind geworden, hat er jeden Tag verschlafen. Das Herz ist erledigt und kann sich nicht an das Gestern erinnern.

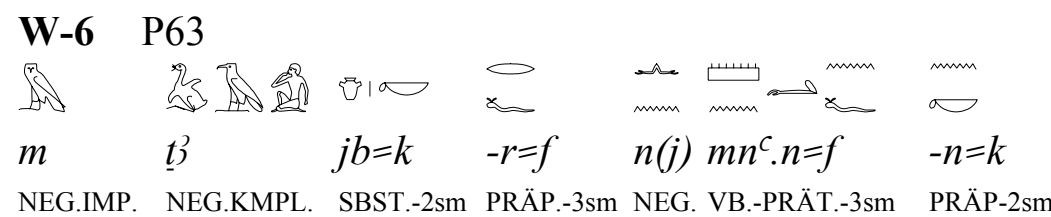

Sei nicht einmal in deinem Herzen vorwurfsvoll gegen ihn, wenn er sich nicht schon mit dir gestritten hat.

142 Für die Datierung siehe Erman (1927: 24-25); Žaba (1956: 7-8); Burkard (1991: 195); Parkinson (1997: 246); Blumenthal (1996: 107); Gnirs (1996: 207); Lichtheim (1996: 244 Anm. 3); Quirke (1996: 380;384;387-389); Eichler (2001: 97-107): Junge (2003: 12-14).

143 Über das Alter und Ptahhotep siehe Burkard (1988: 19-30). 
W-7 P67

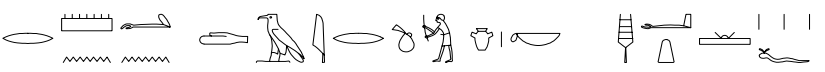

rmn.n $\quad d i r \quad j b=k \quad c h^{c}=f$

VB.-PRÄT. INF. SBST.-2sm SBST.-3sm

Kontrolle deiner Stimmung hat seine Resourcen aufgewogen. $\left({ }^{\circ}\right.$ deines Herzens $\left.{ }^{\circ}\right)$

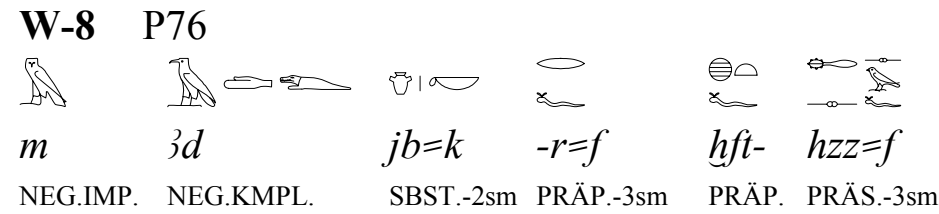

Sei nicht einmal innerlich wütend auf ihn, wenn er schwach ist. (' wütend in Bezug auf dein $\left.H e r z^{\circ}\right)$

W-9 P78-79

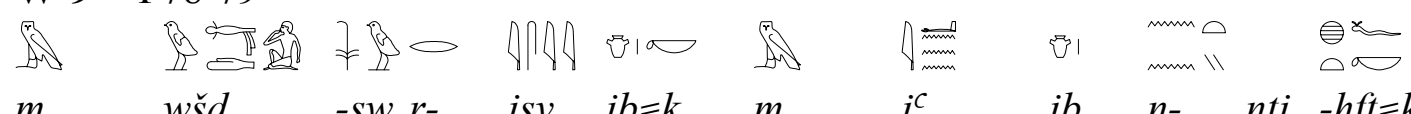
$m \quad w \check{s} \underline{d} \quad-s w r-\quad j s y \quad j b=k \quad m \quad j \quad j^{c} \quad j b \quad n-\quad n t j-h f t=k$

NEG.IMP. NEG.KMPL. 3sm PRÄP. INF. SBST.-2sm NEG.IMP. NEG.KMPL. SBST. PRÄP. REL. PRÄP.-

$2 \mathrm{sm}$

Sprich ihn nicht an, um dein Herz zu erleichtern. Vermeide, dir bei einem, der dein Kontrahent ist, (etwas) von der Seele zu reden. $\left({ }^{\circ} \operatorname{Herz}^{\circ} /{ }^{\circ}\right.$ das $\operatorname{Herz}$ zu waschen $\left.{ }^{\circ}\right)$

W-10 P127

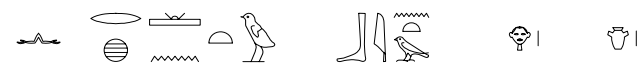

$n(j) r h . n=t w \quad$ bjn.t $\quad h r-\quad j b$

NEG. VB.-PRÄT.-3imp NPA.-FEM. PRÄP. SBST.

Man kann nicht wissen, ob Böses im Schild geführt wird. ( ${ }^{\circ}$ auf dem Herzen ist ${ }^{\circ}$ )

W-11 P130

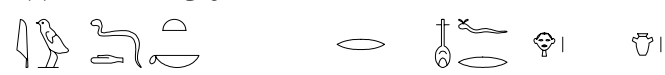

$j w \quad$ dd.t $=k \quad r-\quad n f r \quad h r-\quad j b$

TOP. RLTVF.-FEM.-2sm PRÄP. INF. PRÄP. SBST.

(Sprich nicht zu ihm, ehe er das Wort ergreift, und) deine Rede wird ganz in (seinem) Sinne sein. ( ${ }^{\circ}$ schön auf dem Herzen ${ }^{\circ}$ )

W-12 P243-244

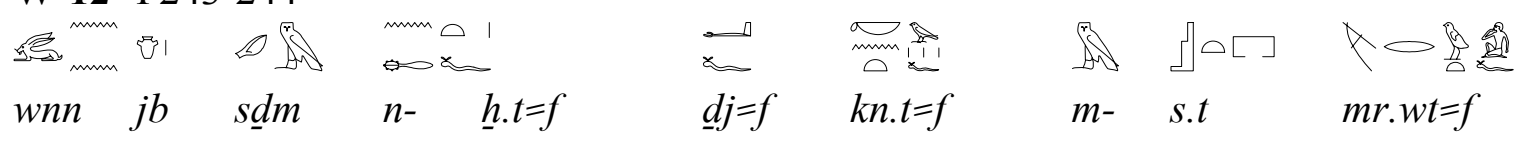

PRÄS. SBST. STAT.:3sm PRÄP. SBST.-FEM.-3sm PRÄS.-3sm SBST.-FEM.-3sm PRÄP. SBST.-FEM. VB.-DPP.-3sm Ist das Herz (von jemandem) seinem Körper hörig, dann führt es dazu, daß Verachtung für ihn an die Stelle (früherer) Sympathie für ihn tritt (in direktem Ausschlu $\beta$ steht $W-13$ ). 
W-13 P245-246

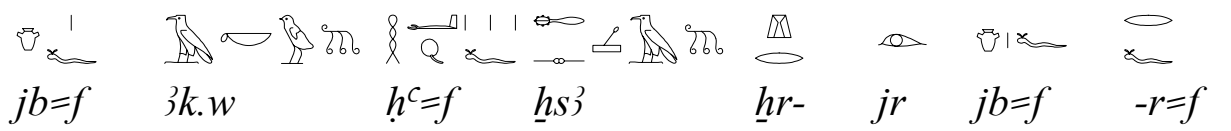

SBST.-3sm STAT.-3sm SBST.-3sm STAT.:3sm RLTVF. RLTVF.SBST.-3sm PRÄP.-3sm

(voran geht $W$-12) Ist das Herz verkommen, so ist auch sein Körper verwahrlost unter (der Last dessen,) was sein Herz ihm angetan hat (es folgt $W$-14).

\section{W-14 P247-248}

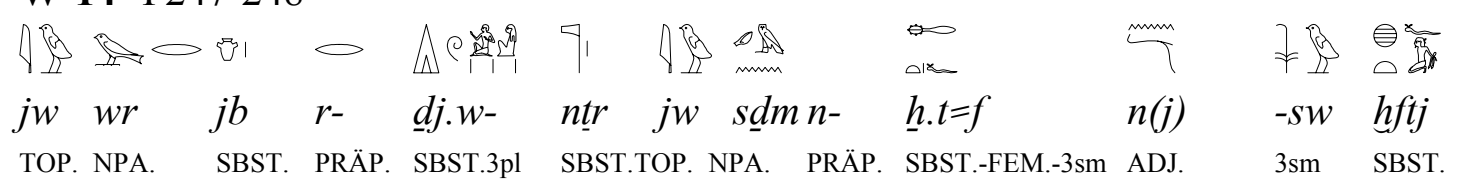

Der Großherzige reiht sich ein unter die Gottesgeschenke, wer aber auf seinen Bauch hört, der gehört dem Feind.

W-15 P243-248 (L2)

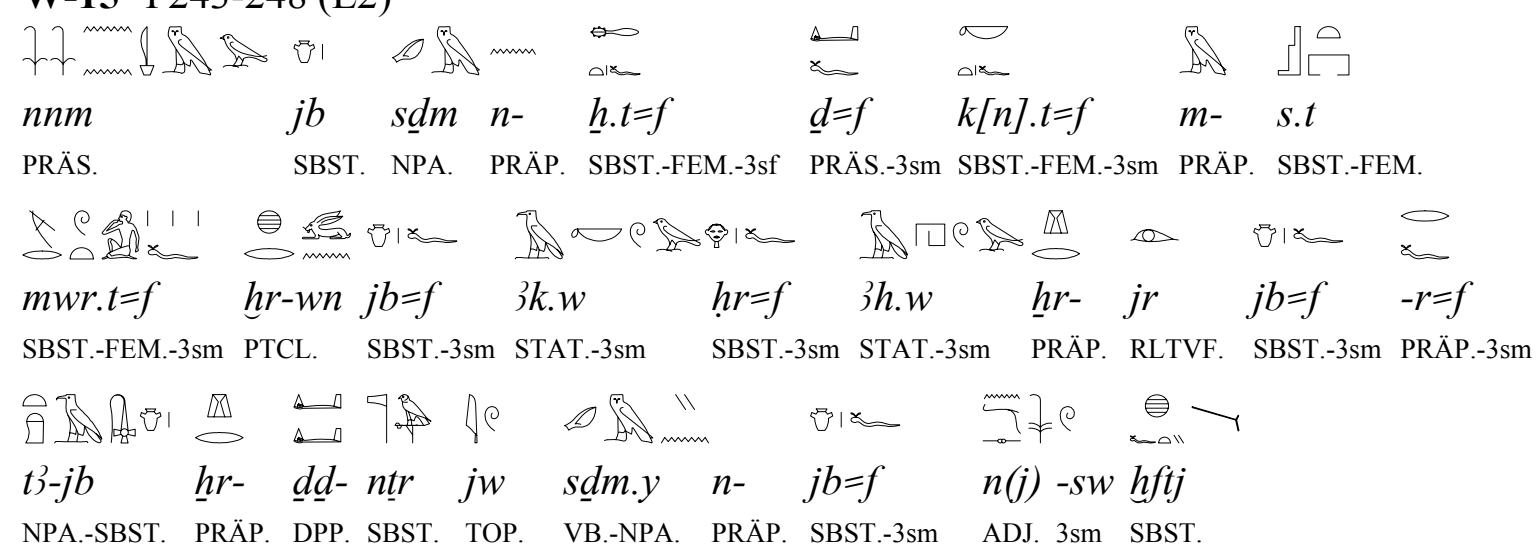

Der Verstand von jemandem, der auf seinen Körper hört, geht in die Irre, ruft Verachtung für ihn anstelle seiner früheren Beliebtheit hervor. Sein Herz ist verkommen und sein Gesicht schmerzverzerrt unter (der Last dessen,) was sein Herz ihm angetan hat. Der Heißsporn steht unter dem, den Gott gibt. Wer seinem Wünschen hörig ist, gehört zum Feind. $\left({ }^{\circ} \mathrm{Herz}^{\circ} /{ }^{\circ} \mathrm{der}\right.$ mit heißem $\mathrm{Herz}^{\circ} /{ }^{\circ} \mathrm{Herz}^{\circ}$ /)

W-16 P264-268

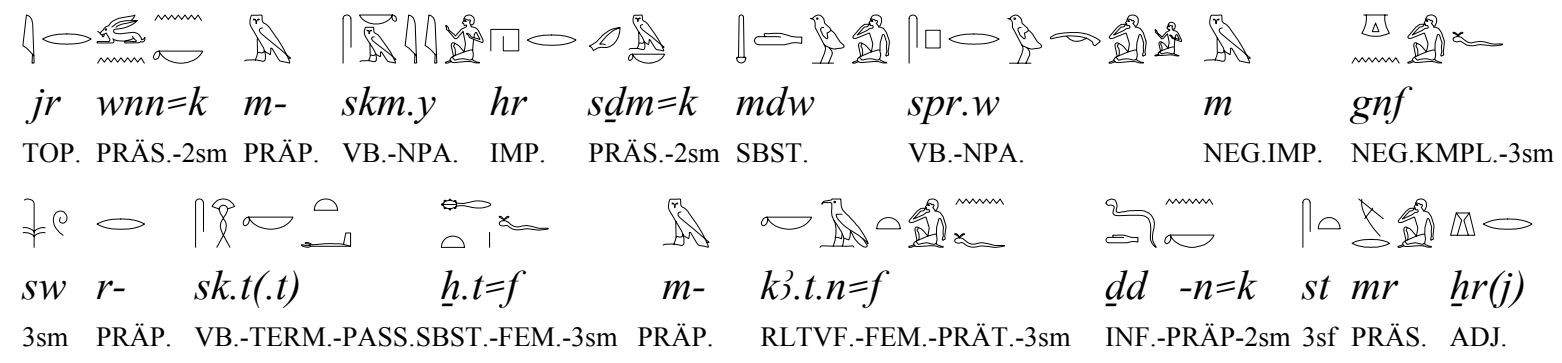




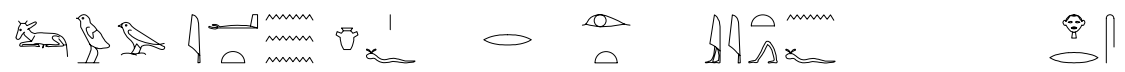

$$
\begin{aligned}
& \text { jw } \quad j^{c} . t \quad j b=f \quad r-\quad j r . t \quad j j . t . n=f \quad-h r=s \\
& \text { NPA. } \quad \text { VB.-INF. SBST.-3sm PRÄP. VB.-INF. RLTVF.-FEM.-PRÄT.-3sf PRÄP.-3sm }
\end{aligned}
$$

Wenn du Vorgesetzter bist, sei geduldig, während du anhörst, was der Bittsteller sagt. Weise ihn nicht zurück, ehe sein Bauch ausgefegt worden ist von dem, was er dir zu sagen gedachte. Denn einer, der eine schlimme Last trägt, will sich lieber (etwas) von der Seele reden als das zu tun, weswegen er (eigentlich) gekommen ist. ( ${ }^{\circ}$ sein Herz waschen $\left.{ }^{\circ}\right)$

W-17 P272 (L2)

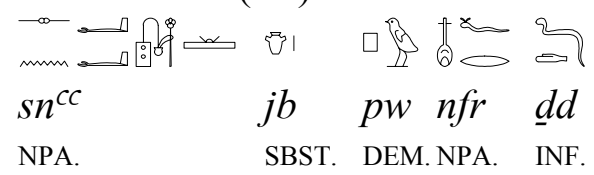

Wer gut im Reden ist, kann die Stimmung glätten. $\left({ }^{\circ}\right.$ das $\left.\operatorname{Herz}^{\circ}\right)$

W-18 P275-276

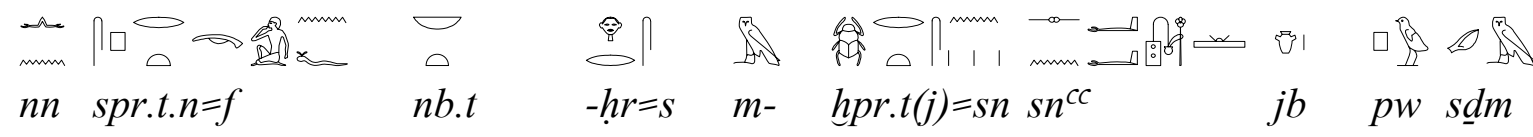

NEG. RLTVF.-FEM.-PRÄT.-3sm INDEF.-FEM. PRÄP.-3sf PRÄP. VB.-FPA.-3pl. INF.

20

$n f r$

ADV.

Nicht alles, worum er gebeten hat, muß auch realisiert werden, gut Zuhören ist genug, um die

Stimmung zu glätten. $\left({ }^{\circ}\right.$ das $\left.\operatorname{Herz}^{\circ}\right)$

W-19 P292-293

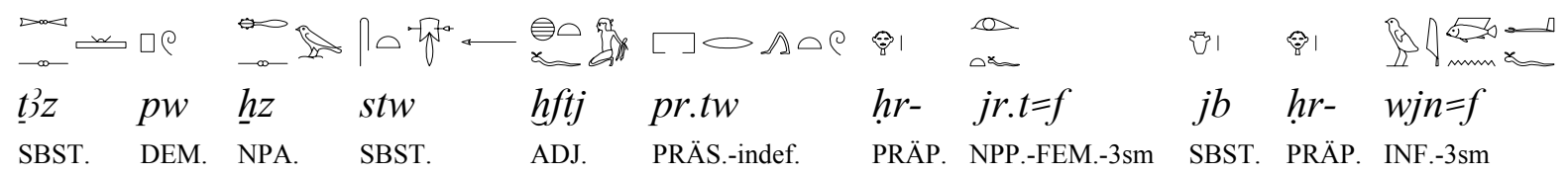

Der Pfeil des inneren Schweinehunds ist ein übles Problem, und selbst wenn jemand mit dem, was er angestellt hat, davonkommt, verurteilt ihn das (eigene) Herz.

W-20 P292-293 (L2)

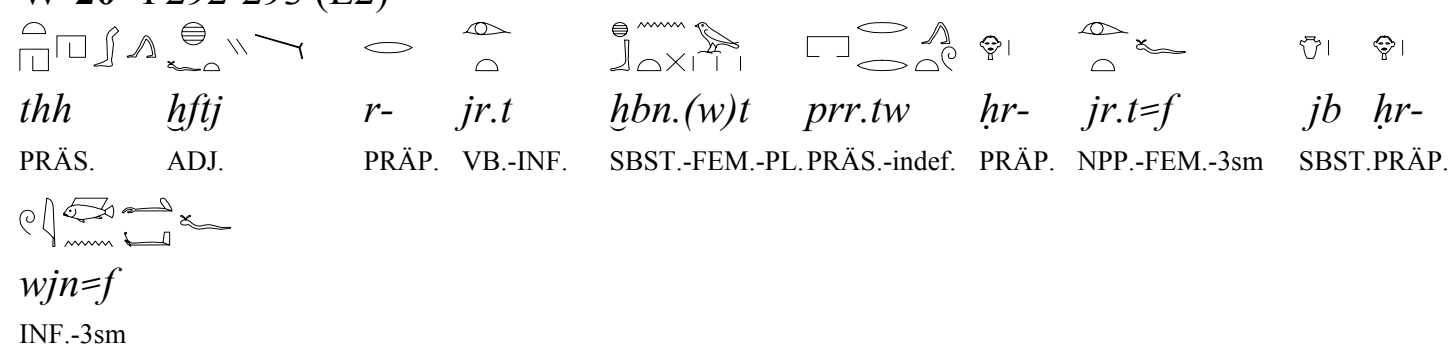

Wenn der innere Schweinehund dazu verführt, Verfehlungen zu begehen, und man mit dem, was man angestellt hat, davonkommt, so verurteilt einen doch das (eigene) Herz. 
W-21 P295

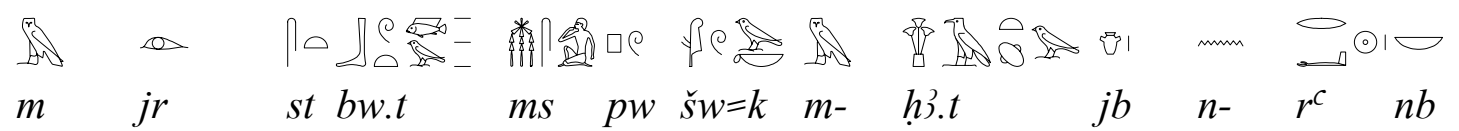
NEG.IMP.NEG.KMPL. 3sf SBST.-FEM.PTCL. DEM. FUT.-2sm PRÄP. SBST.-FEM. SBST. PRÄP. SBST. INDEF. Tue das nicht. Das ist doch böse. Du wirst frei von Kummer des Herzens für alle Tage sein.

W-22 P301

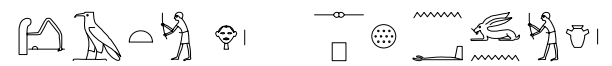

chj t(w) hr- zp n(j)- ${ }^{c_{w n}}$ wn $\mathrm{j} b$

IMP. 2sm PRÄP. SBST. DET. INF.-SBST.

Hüte dich vor (jedem) Anflug von Habgier.

W-23 P329

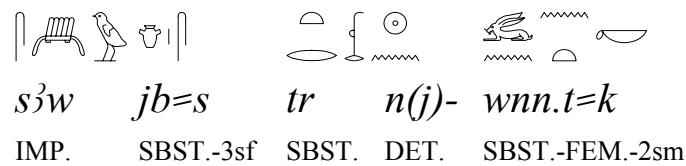

Erfreue ihr Herz zeit deines Daseins.

W-24 P333-335 (L1)

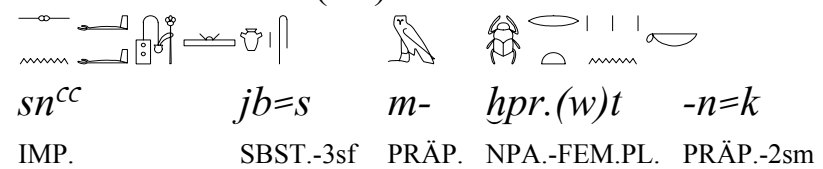

Besänftige ihre Laune mittels dessen, was dir zuteil geworden ist. ( ${ }^{\circ}$ glätte ihr $\mathrm{Herz}^{\circ}$ )

W-25 P374

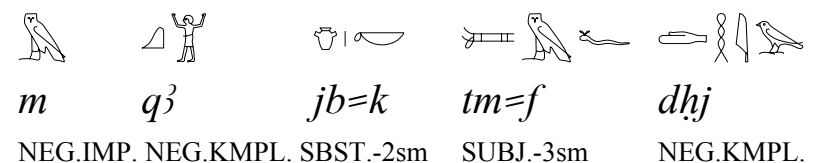

Vermeide hochmütig zu sein, um nicht erniedrigt zu werden. ( ${ }^{\circ}$ sei nicht hoch in Bezug auf dein $\mathrm{Herz}^{\circ}$ )

W-26 P378

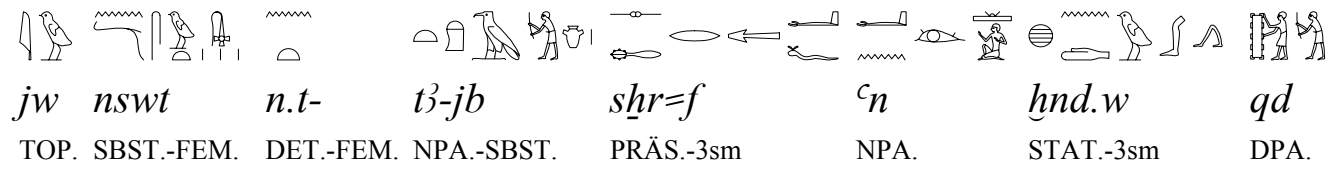

isming

$m \underline{t} n=f$

SBST.-3sm

Die Flamme eines Heißsporns, die provoziert sogar den Gutmütigsten, so daß er beleidigt ist, und sein Weg ist verbaut. ('eines mit heißem Herzen ${ }^{\circ}$ ) 
W-27 P382-383

$\begin{array}{lllllllll} & \end{array}$

Einer, der den ganzen Tag lang übermütig ist, dem kann das Haus nicht richtig geordnet sein. ( ${ }^{\circ}$ einer, der froh in Bezug auf das Herz ist für den Tag $^{\circ}$ )

W-28 P389

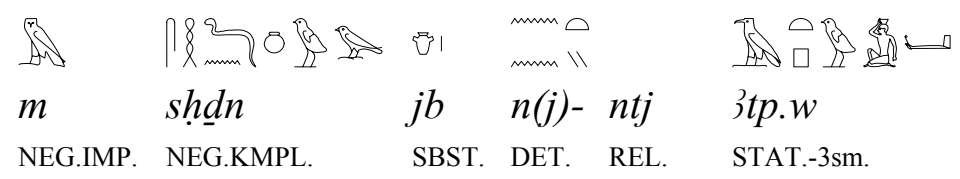

Verdirb nicht die Stimmung eines, der eine Bürde trägt. ( ${ }^{\circ}$ schädige nicht das $\operatorname{Herz}^{\circ}$ )

W-29 P457-462

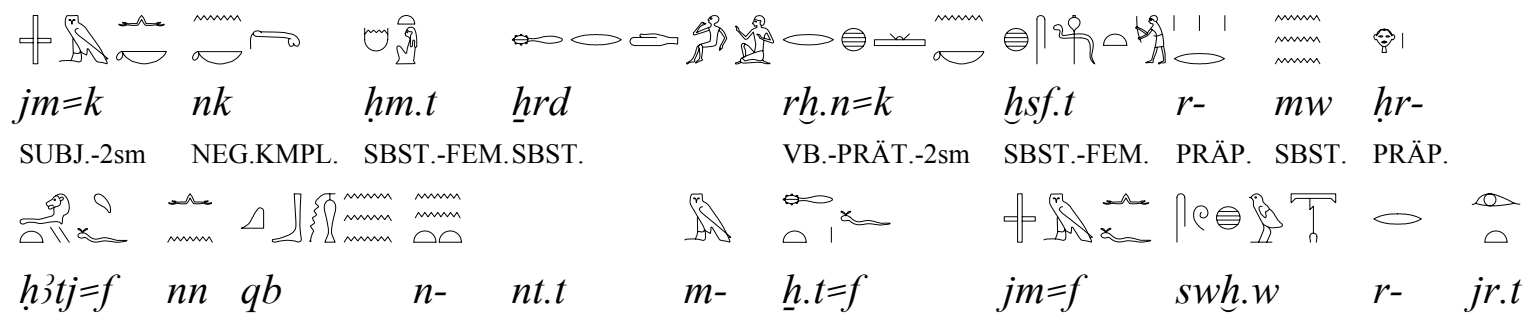
SBST.-3sm NEG. SBST. PRÄP. RLTVF.-FEM. PRÄP. SBST.-FEM.-3sm SUBJ.-3sm NEG.KMPL. PRÄP. VB.-INF.

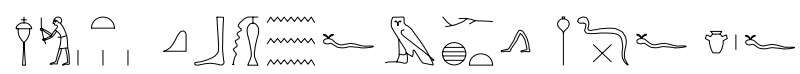

hssf.t $\quad q b=f \quad m-h \underline{t}-\quad \underline{h d}=f \quad j b=f$

SBST.-FEM.FUT.-3sm PRÄP. PRÄS.-3sm SBST.-3sm

Du sollst nicht eine Frau oder eine Knaben begatten, wenn du Widerstand gegen das Wasser auf seinem/ihrem Antlitz erkennst, ohne daß es Linderung gibt für das, was in ihm/ihr vorgeht. Es soll nicht dazu kommen, daß er/sie die ganze Nacht lang Widerstand leistet und sich erst dann beruhigt, wenn er/sie sein/ihr Herz zermürbt hat. $\left({ }^{\circ} \mathrm{Herz}^{\circ}\right)$

W-30 P499-500

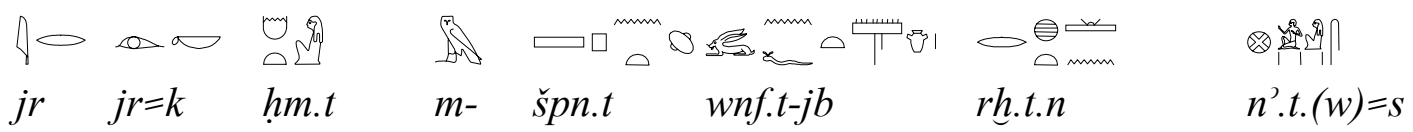

PRÄP. SUBJ.-2sm SBST.-FEM. PRÄP. NPA.-FEM. NPA.-FEM.SBST. RLTVF.-FEM.-PRÄT. SBST.-FEM.-ADJVR.-PL.-3sf

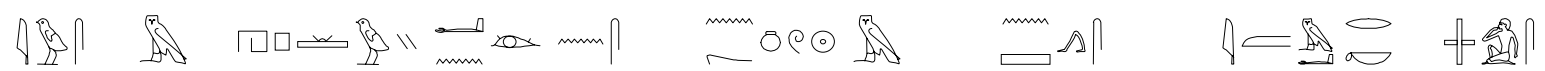

$j w=s \quad m-h p . w j \quad c_{n} \quad-n=s \quad n w \quad m \quad n \check{s}=s \quad$ jmj $r k \quad w m=s$ TOP.-3sf PRÄP. SBST.-du NPA. PRÄP.-3sf $\quad$ SBST. NEG.IMP. NEG.KMPL.-3sf IMP. PRTCL. SUBJ.-3sf

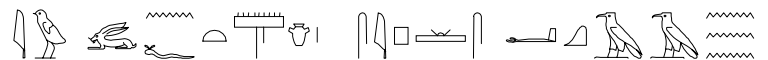

jw wnf.t-jb sjp=s ${ }^{c} q 33$

TOP. SBST.-FEM.SBST. PRÄS.-3sf SBST.

Wenn du es mit einer Frau zu tun hast, die mal verdrießlich ist und dann wieder übermütig, von der aber ihre Mitmenschen wissen, daß sie in (dem Rahmen der) beiden Gesetze ist, so 
daß es ihr beizeiten wieder schön ergehen wird, dann verstoße sie nicht, sondern sorge dafür, daß sie ißt. Denn eine Übermütige kontrolliert den richtigen Wasserstand. ( ${ }^{\circ}$ froh in Bezug auf das Herz ${ }^{\circ} /{ }^{\circ}$ eine, die froh in Bezug auf das Herz ist ${ }^{\circ}$ )

W-31 P550

A m m

jn $\quad j b \quad s . h p r \quad n b=f \quad m-\quad s \underline{d m} \quad m-\quad t m \quad s \underline{d m}$

PTCL. SBST. KAUS.-NPA. SBST.-3sm. PRÄP. NPA. PRÄP. NPA. NEG.KMPL.

Es ist das Herz, das seinen Besitzer entweder zu einem, der zuhört, oder zu einem, der nicht zuhört, macht (Es folgt W32).

W-32 P552

f 9 ?

$\left.{ }^{c} n \underline{h} \quad w \underline{d}\right] \quad s n b \quad n(j)-z(j) \quad j b=f$

SBST. SBST. SBST. DET. SBST. SBST.-3sm

Leben, Wohlbefinden und Gesundheit eines Menschen sind sein Herzenswunsch (Schließt direkt an W31 an). $\left({ }^{\circ} \mathrm{Herz}^{\circ}\right)$

W-33 P618

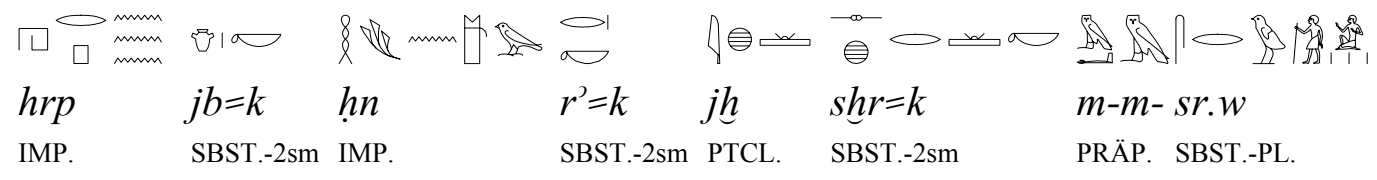

Unterdrücke deine Meinung und kontrolliere deinen Mund, damit dein Betragen im Kreis der Würdenträger (angemessen) ist. $\left({ }^{\circ} \mathrm{Herz}^{\circ}\right)$

W-34 P624

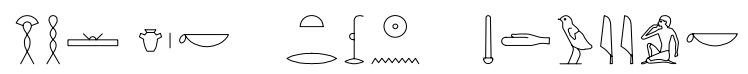

wih $j b=k \quad$ tr $\quad n(j)-m d w y=k$

IMP. SBST.-2sm SBST. DET. FUT.-2sm

Halte dich zurück, wann immer du sprechen willst. ('lege dein Herz hin ${ }^{\circ}$ )

W-35 P636

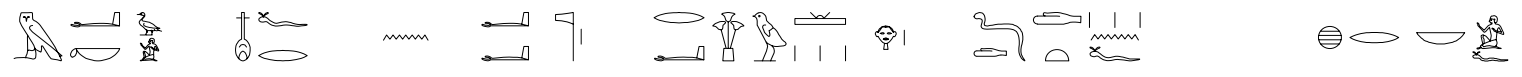
$m k \quad z) \quad n f r \quad n-\quad \underline{d d} n t r \quad r d \quad h j w \quad h r-\quad \underline{d} d d . t \quad-n=f \quad h r-\quad n b=f$ PTCL. SBST. STAT.:3sm PRÄP. DPP. SBST. NPA. SBST. PRÄP. VB.-NPP.-FEM. PRÄP.-3sm PRÄP. SBST.-3sm 


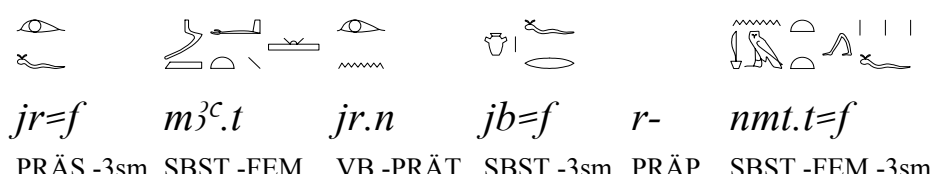

Ein Sohn, der gut ist dank dem, was Gott bewirkt, gibt mehr als ihm von seinem Herrn aufgetragen wird, und er handelt Maat-gerecht, wenn sein Herz gemäß seiner Bestimmung funktioniert. 


\section{Die Lehre für Kagemni (Gardiner 1946)}

Quelle:

Datierung: Papyrus Prisse I/2

Textausgaben: XI./XII. Dynastie ${ }^{144}$

Übersetzungen:

Jéquier (1911: Pl. I), Gardiner (1946: 71-74), Sethe (1924: 42-43).

Gunn (1912: 62-64), Erman (1923: 99-100), von Bissing (1955: 52-53), Barns (1972: 159-166), Lichtheim, (1975: I, 59-60), Brunner (1988: 133-136), Morschauser (1994: 177-185), Roccati (1994: 29-31), Sánchez Ródriguez (1996: 97-110), Burkard, \& Thissen (2003: 83-84).

W-36 3-9

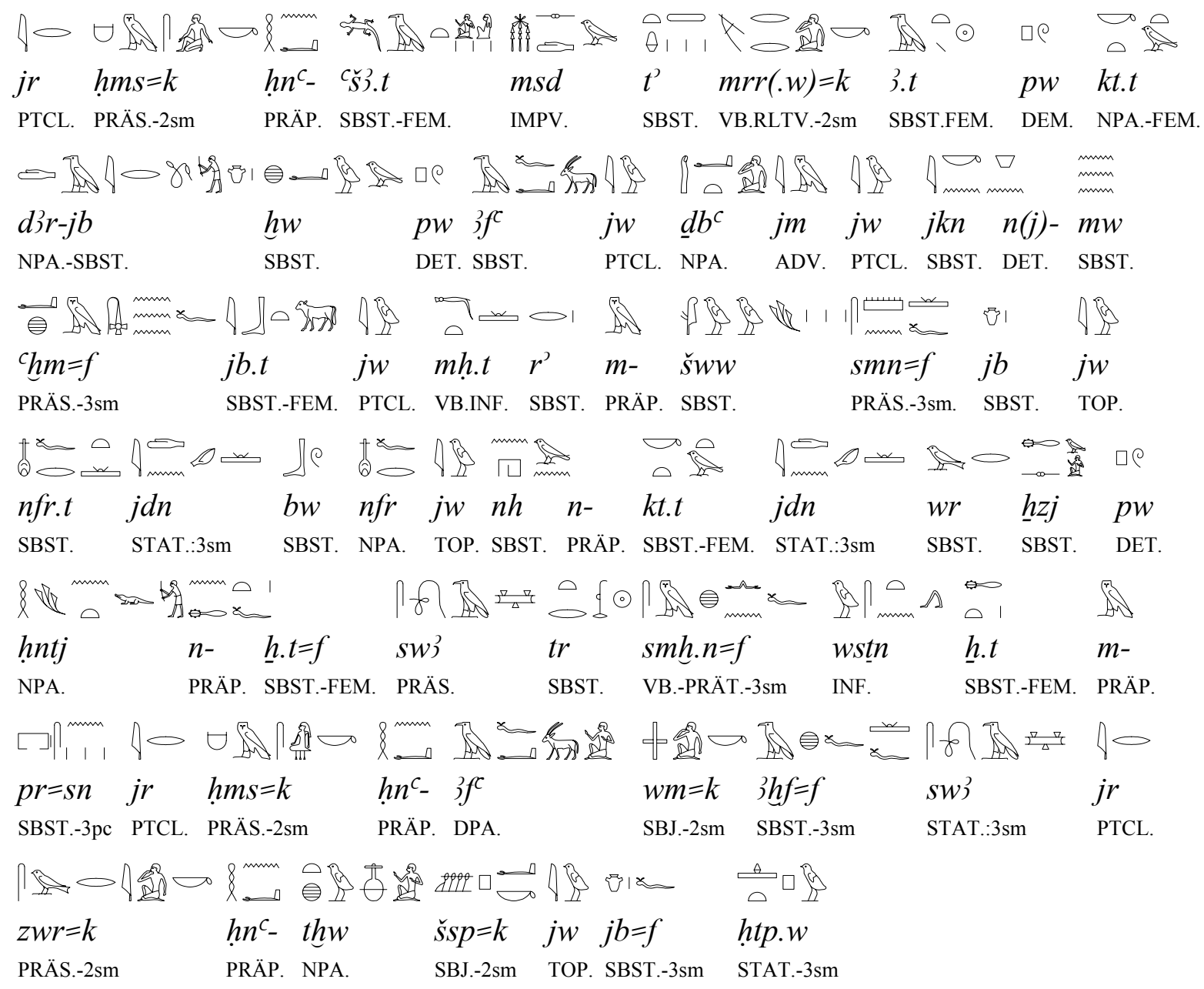

Wenn du mit der Menge zusammensitzt, dann lehne die Speise, die du (besonders) magst, ab. Das ist nur ein kurzer Augenblick der Selbstbeherrschung. Gier ist eine Sünde, und auf sie wird es mit dem Finger gezeigt. Ein Napf Wasser löscht den Durst. Ein Bissen von Kraut stärkt die Kondition. Ein gutes Ding ersetzt das Beste, und ein bißchen einer Kleinheit ersetzt das Große. Ein Elender ist der, dessen Körper gierig ist. Die Zeit vergeht und er vergaß, in ihrem Haus den Bauch zu kontrollieren. Wenn du mit einem Gefräßigen zusammensitzt, dann iß du erst, wenn sein Appetit vorbei ist. Wenn du mit einem Trunkenbold trinkst, dann lange $\mathrm{zu}$, und seine Laune ist zufriedengestellt. ( ${ }^{\circ}$ das Herz bezwingen ${ }^{\circ} /{ }^{\circ}$ das $\operatorname{Herz}{ }^{\circ} /{ }^{\circ}$ das Herz ${ }^{\circ}$ )

144 Jéquier (1911: 5); Erman (1927: 53); Brunner (1988: 133); Blumenthal (1996: 107); Gnirs (1996: 207); Lichtheim (1996: 244); Quirke (1996: 269;380;384 u. 387). 


\section{Autobiographie des Mentuhotep}

Quelle: $\quad$ Stele des Mentuhotep

Datierung: $\quad$ XI. ${ }^{145} /$ XII. ${ }^{146}$ Dynastie

Textausgabe: $\quad$ Goedicke (1962: 25-35).

Übersetzung: $\quad$ Schenkel (1964: 6-12), Brunner (1988: 370-373).

\section{W-37 2}

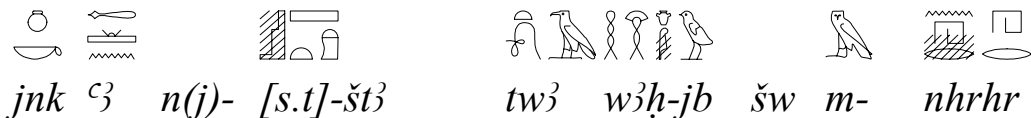

1sc ADJ. DET. SBST.-FEM.-SBST. SBST. NPA.-SBST.NPA. PRÄP. SBST.

Ich war der Leiter der Stätte-des-Mysteriums, einer, der Halt gab, immer zurückhaltend und frei von Launenhaftigkeit war. ( ${ }^{\circ}$ einer, der das Herz hinzulegen pflegte ${ }^{\circ}$ )

W-38 4

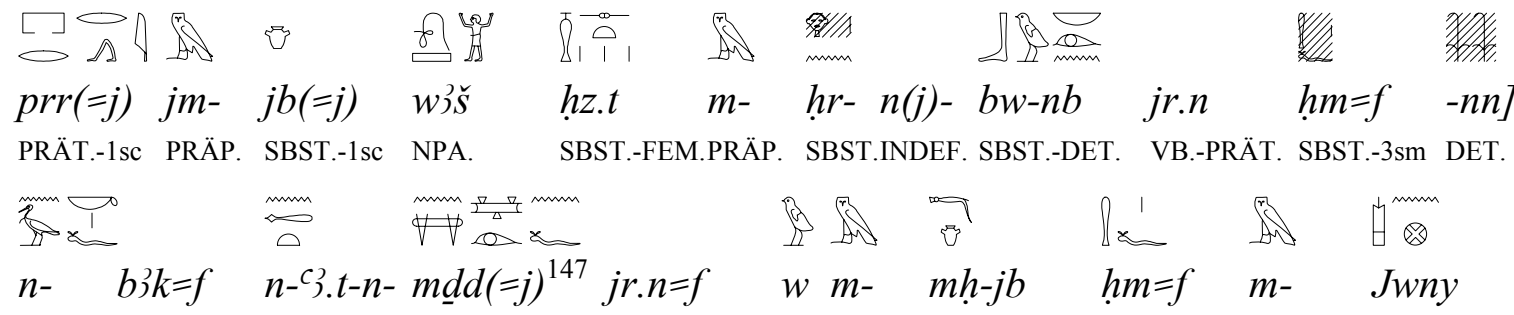

PRÄP. SBST.-3sm PRÄP. SBST.-1sc VB.-PRÄT.-3sm 1sc PRÄP. DPA.-SBST. SBST.-3sm PRÄP. TOPON.

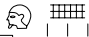

$\operatorname{tp.t(.j)~sp3.t=f}$

ADJ. $\quad$ SBST.-FEM.PL.-3sm

Wenn ich dort ausging, war meine Brust vor Stolz geschwellt von der Wertschätzung, (die sich) auf dem Gesicht von Jedermann (abzeichnete). Seine Majestät tat das für einen seiner Diener wegen meiner besonderen Sorgfalt. Er machte mich zur Vertrauensperson Seiner Majestät in Armant und zum Obersten seiner Provinz. $\left({ }^{\circ}\right.$ mein Herz ${ }^{\circ} /{ }^{\circ}$ zu dem, der das Herz Seiner Majestät füllt ${ }^{\circ}$ )

W-39 11

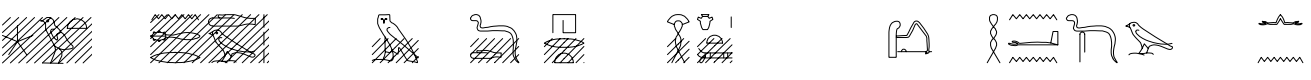

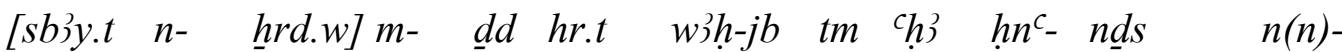
SBST.-FEM.PRÄP. SBST.-PL.PRÄP. DPP. VB.-INF. INF.-SBST. NEG. INF. PRÄP. SBST. NEG.

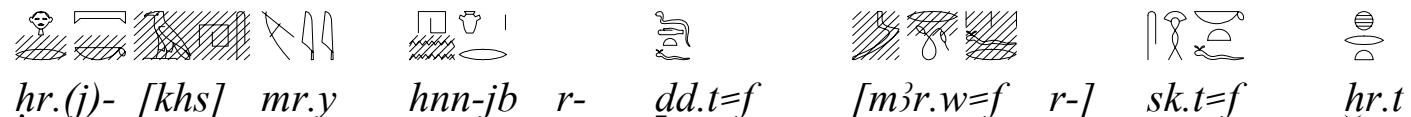
ADJ. SBST. STAT.-3sm. INF.-SBST. PRÄP. VB.-TERM.-3sm SBST.-PL.-3sm PRÄP. VB.-TERM.-3smSBST.-FEM.

145 Goedicke (1962: 27).

146 Schenkel (1964: 6-7).

147 Das von Goedicke mtn gelesene Wort ist nicht deutlich zu erkennen. Meine Meinung nach erscheint es als eine freie Stelle über dem Verb jrj wie ich im Text transkribiere. 


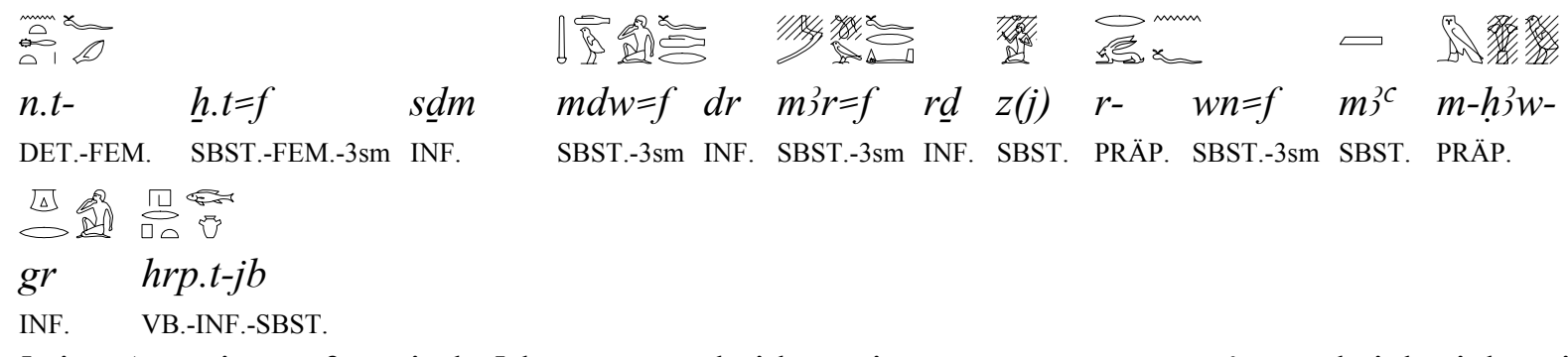

[Eine Anweisung für Kinder] lautet: Bescheiden sein, zurückhaltend sein, und sich nicht mit einem Kleineren streiten - denn ein Höherer, der sich gemein verhält, ist nicht beliebt. Zuwendung zeigen, bis er seine Probleme erzählt hat und losgeworden ist, was ihm auf der Seele brennt ${ }^{148}$, seine Aussage anhören und sein Problem beseitigen, damit der Mann wieder in einen schicklichen Zustand versetzt wird, und außerdem: aufhören, die Meinung zu unterdrücken. $\left({ }^{\circ}\right.$ das Herz legen ${ }^{\circ} /{ }^{\circ}$ das $\operatorname{Herz} z u w e n d e n^{\circ} /{ }^{\circ}$ das $\left.\operatorname{Herz}^{\circ}\right)$

W-40 14

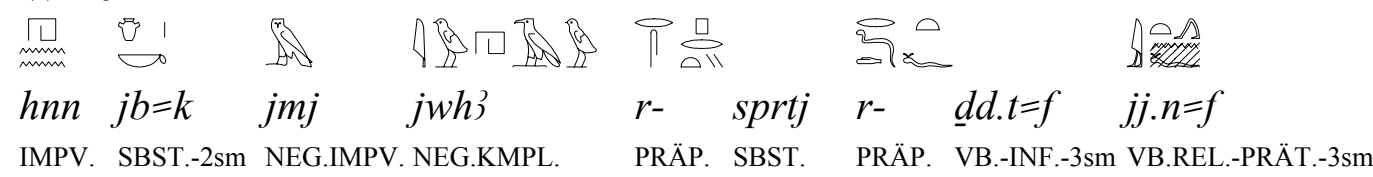

Zeige Zuwendung und sei nicht deprimiert ${ }^{149}$ gegenüber einem Bittsteller, ehe er erzählt hat weswegen er gekommen ist. $\left({ }^{\circ}\right.$ neige dein $\left.\mathrm{Herz}^{\circ}\right)$

$148{ }^{\circ}$ und den Zustand seines Leibs ausgekehrt hat ${ }^{\circ}$.

149 Die Übersetzung beruht auf der Hypothese, daß wir es mit einer Schreibung des Verbums $3 h$ bzw. $j h$ 'traurig sein' zu tun haben. Die Bearbeiter lesen: "Sei nicht voreingenommen gegen einen Bittsteller, bis er ausgesprochen hat, weswegen er gekommen ist" (Brunner 1988: 372) bzw. "Do not be prejudiced against a petitioner, until he has said what he came for" (Goedicke 1962: 27). 


\title{
Gespräch eines Mannes mit seinem Ba (Barta 1969)
}

Quelle:

Datierung:

Textausgaben:

Berlin 3024

\author{
XII. Dynastie ${ }^{150}$
}

Erman, (1896), Barta (1969).

Erman (1923: 122-130), Golénischeff (1952: 155-157), Wilson (1969: 405-407),

von Bissing (1955: 124-128), Lichtheim (1975: I, 161-169), Parkinson (1997: 151165), Burkard, \& Thissen (2003: 149-152).

W-41 (Lebensmüder 33)

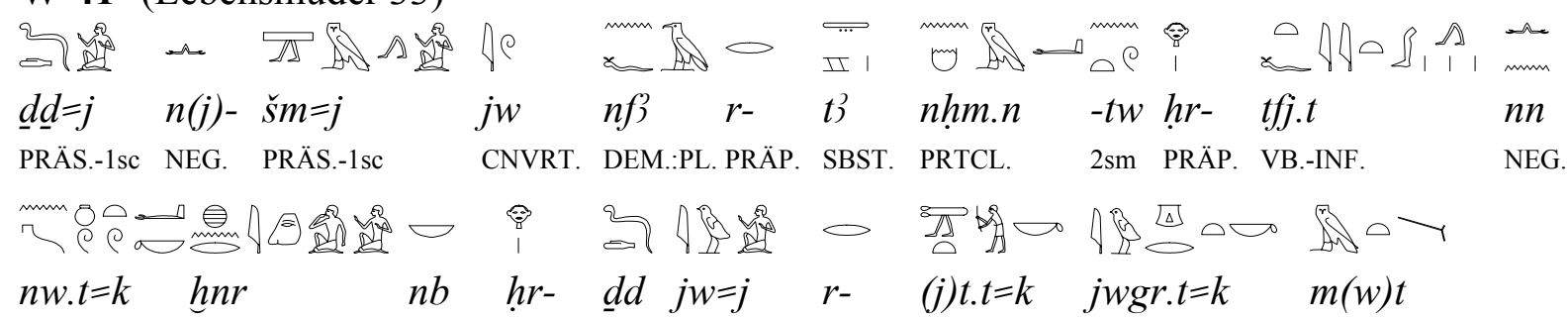

VB.-INF.-2sm SBST.

INDEF. PRÄP. INF. TOP.-1sc PRÄP. VB.-INF.-2sm SBST.-FEM.-2sm INF.

\begin{tabular}{|c|c|c|c|c|c|c|c|c|}
\hline$\sum_{r n=k}^{\infty}$ & $\begin{array}{l}f_{\ominus}^{m m} \\
c_{n h}\end{array}$ & $\begin{array}{l}\int \square \\
s . t\end{array}$ & $x_{n f 3}^{m}$ & $\begin{array}{l}\operatorname{mun}^{-} \\
n . t-\end{array}$ & 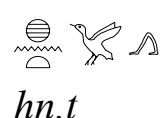 & 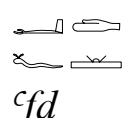 & $\begin{array}{c}\min ^{-} \\
n . t-\end{array}$ & $\begin{array}{l}\mathcal{Y} \\
1 \\
j b\end{array}$ \\
\hline & & s.t & $n f 3$ & n.t- & hnn.t & ${ }^{c} \mathrm{~d}$ & h.t- & $J b$ \\
\hline
\end{tabular}

SBST.-2sm INF. SBST.-FEM. DEM.-FEM. DET.-FEM. SBST.-FEM. SBST. DET.-FEM. SBST. SBST.

म

pw jmn.t

DEM. SBST.-FEM.

Und ich erwiderte: Ich bin nicht dahingehen. Das Drüben gehört zur Welt. Doch du bist dabei, auszuweichen, ohne dir um dich Sorgen zu machen, obwohl sogar jeder Sträfling sagt „Ich werde dich erwischen." Deine Ruhestätte ${ }^{151}$ ist der Tod, dein Name ist das Leben. Das Drüben ist eine Stätte zum Niederlassen und das Endziel des Herzens. Der Westen ist eine Heimstatt. ${ }^{152}$

150 Barta (1969: 9); Lichthteim (1996: 252); Blumenthal (1996: 131); Quirke (1996: 387); Loprieno (1996: 409).

151 Die in den Bearbeitungen von Lichtheim (1973: 165) und Parkinson (1997: 156) gleichermaßen vorausgesetzte Lesung $j w-g r . t=k m(w) t(. t j)$ mit Trennung des suffigierten Pronomens $=k$ von $j w$ durch die Partikel gr.t ist ungrammatisch (in den seltenen Fällen von $j w-g r . t+$ Pronomen steht eines der autonomen Reihe, siehe Gardiner 1957: $\S \S 66,255$ und 468,3, und vgl. DZA Nr. 30663220 ff.). Die Übersetzungen wären allenfalls zu rechtfertigen, wenn man annähme, daß es sich um einen intendierten Normverstoß des Verfassers handele, der auf ein Wortspiel mit jgr.t bzw. jwgr.t 'Ruhestätte, Nekropole, Unterwelt' abzielte. Das Sprachspiel läßt sich im Deutschen nicht nachbilden und ist etwa so, als würde man den Satz du bist tot durch $B D U$ ist tot ersetzen, weil $B D U$ 'deine Ruhestätte' bedeuten könnte (Diese Hinweis verdanke ich Frank Kammerzell).

152 "I said: 'I will not go as long as this is neglected. Surely, if you run away, you will not be cared for. Every criminal says: 'I shall seize you.' Though you are dead, your name lives. Yonder is the place of rest, the heart's goal. The West is a dwelling place, (...)'" (Lichtheim 1973: 165); "I said, 'So I haven't passed away yet, but that's not the point! Indeed, you are leaping away - and you will be uncared for, with every desperado saying, "I will seize you!" Now, when you are dead, but with your name still living, that place is an alighting place, attractive to the heart. The West, an [inescapable] voyage, is harbour. (...)" (Parkinson 1997: 156). 
W-42 39

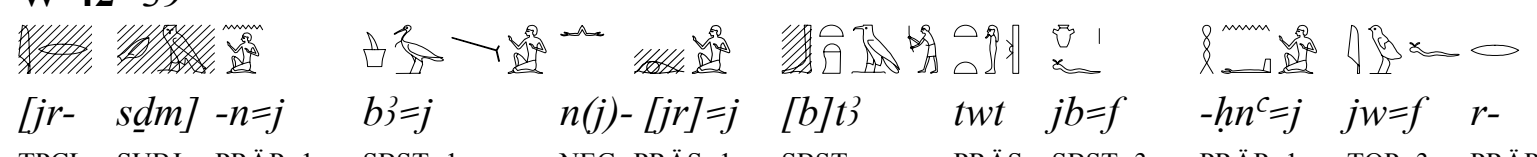

TPCL. SUBJ. PRÄP.-1sc SBST.-1sc NEG. PRÄS.-1sc. SBST.

PRÄS. SBST.-3sm PRÄP.-1sc TOP.-3sm PRÄP.

Dis 2

SBST.-3sm

[Wenn] mein Ba auf mich [hört], ich keine Verfehlung [begangen habe] ${ }^{153}$ und sein Charakter meinem ${ }^{154}$ gleicht, dann wird er erfolgreich sein. ${ }^{155}\left({ }^{\circ} \mathrm{Herz}^{\circ}\right)$

$\mathrm{W}-\mathbf{4 3} 52$

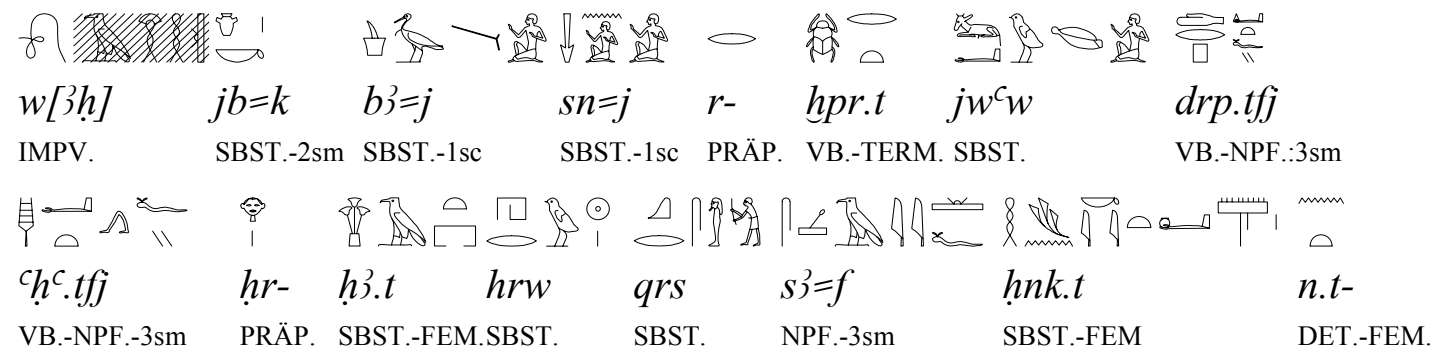

on 0

$\underline{h r} \cdot t-n \underline{t} r$

PRÄP.-FEM-SBST.

Sei zurückhaltend, du mein Ba und Bruder, bis es einen Erben gibt, der opfern wird und am Tag der Beisetzung am Grab stehen wird. Der wird die Schlafstätte der Nekropole zur Genüge haben ausstatten. ${ }^{156}$ ('lege dein Herz hin $\left.{ }^{\circ}\right)^{157}$

W-44 (Lebensmüder 56)

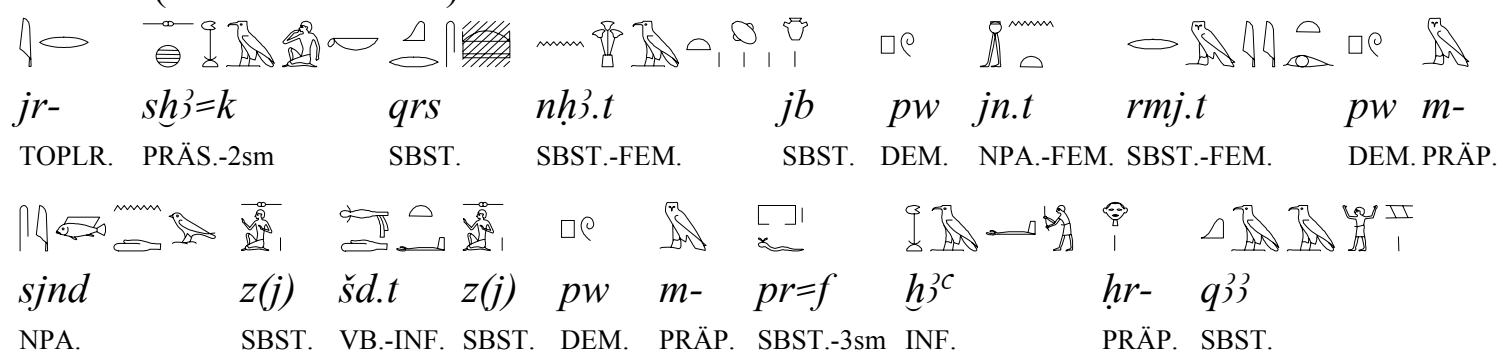

153 Die gängigen (in der übernächsten Fußnote zitierten) Übersetzungen basieren auf einer Ergänzung von $j w[t j$ $b] t 3$ anstelle von $n(j)-[j r]=j[b] t$. Sie unterschlagen das Suffixpronomen der ersten Person (bzw. interpretieren es als ungewöhnliches Determinativ von $j w t j$ und tragen vor allem nicht dem Umstand Rechnung, da $\beta$ die angesetzte Konstruktion einen Possessor an $b t 3$ verlangte.

$154{ }^{\circ}$ mir $^{\circ}$.

155 "If my $b a$ listens to me ${ }^{\lceil}$without malice $\rceil$, its heart in accord with me, it shall be happy" (Lichtheim 1973: 165); "If my soul listens to me, without wrongdoing, with his heart inaccordance with mine, he will prosper." (Parkinson 1997: 156).

$156{ }^{\circ}$ sättigt ${ }^{\circ}$.

157 "Be patient, my $b a$, my brother, until my heir comes, one who will make offerings, who will stand at the tomb on the day of burial, having prepared the bier of the graveyard" (Lichtheim 1973: 165); "Be patient, my soul, my brother, untiel an heir exists who will make offerings of food, and will wait at the grave on the day of burial, and make ready a bed of the necropolis" (Parkinson 1997: 156). 
Wenn du an das Begräbnis zurückdenkst: das war herzzerreißend, das war etwas, was Tränen und Trauer bei einem Mann ${ }^{158}$ hervorrief, das bedeutete, einen Mann aus seinem Zuhause herauszureißen und auf einem Berg auszusetzen. ${ }^{159}$ ( ${ }^{\circ}$ Gefährden des Herzens ${ }^{\circ}$ )

W-45 (Lebensmüder 80)

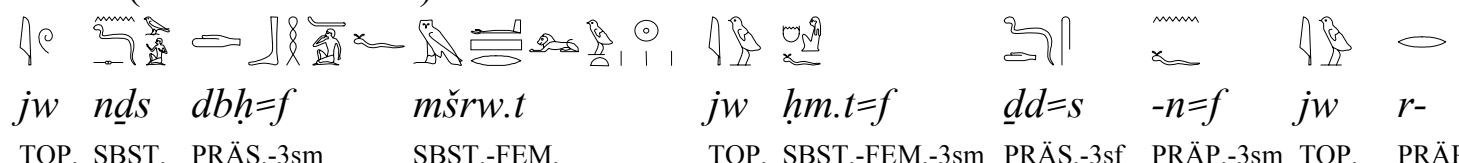

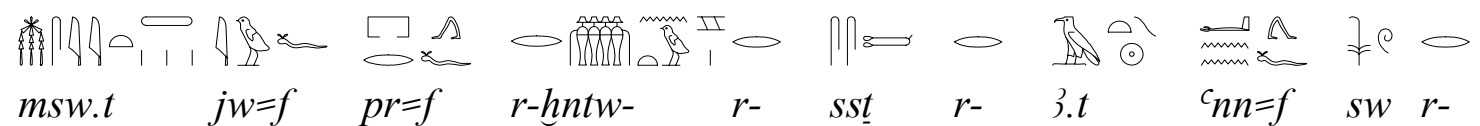

SBST.-FEM. KB.PI.-3sm STAT.-3sf PRÄP. PRÄP. INF. PRÄP. SBST.-FEM.PRÄS.-3sm 3sm PRÄP.

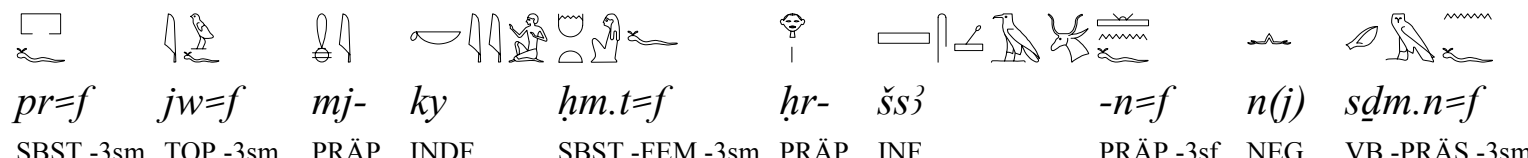

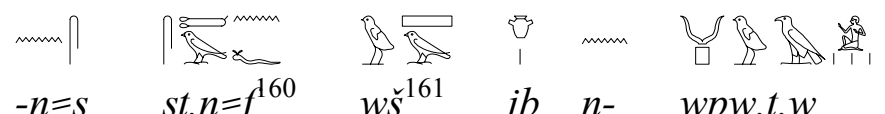

PRÄP.-3sf VB.-PRÄT.-3sm PRÄS. SBST.PRÄP. SBST.-FEM.-ADJRV.:PL.

Ein Bauer verlangt nach dem Abendessen. Seine Frau erwidert: „Es dauert noch bis zum Nachtmahl.", und da geht er noch einmal nach draußen, um bis zu dem Zeitpunkt ... zu lassen $^{162}$. Als er sich nach Hause zurück begibt, da ist er wie ein anderer Mensch. Seine Frau versucht sich mit ihm auszusprechen, aber er hört nicht auf sie, denn er hat ... ${ }^{163}$, und die Atmosphäre des Hausstands ist ruiniert. ${ }^{164}$ ( ${ }^{\circ}$ das Herz $^{\circ}$ )

$158{ }^{\circ}$ das war Tränen Hervorbringen sowie Traurigkeit eines Mannes ${ }^{\circ}$.

159 "If you think of burial, it is heartbreak. It is the gift of tears by aggrieving a man. It is taking a man from his house, castng (him) on high ground" (Lichtheim 1973: 165); "'If you call burial to mind, it is heartbreak; it is bringing the gift of tears, causing a man misery; it is taking a man away from his house, and throwing him on the high ground. (...)" (Parkinson 1997: 156-157).

$160 \mathrm{~Wb}$ IV 350,15.

161 Im Wörterbuch der Medizinischen Texte findet man wš (VII 1,222) und wšr (VII 1,224), die am wahrscheinlichsten das selbe Wort sind. Über die Umschreibung siehe Kammerzell, Einführung Hannigs Wörterbuch (1995). Im Erman/Grapows Wörterbuch werden die beiden Worte auch miteinande vergliechen (I,368 und 374). Was in dieser Stelle beschrieben wird, ist ein neuer krankhafter Zustand des Herzens, wobei die Person nicht mehr fähig ist, um normal zu denken und zu handeln.

162 Seiner (in der übernächsten Anmerkung wiedergegebenen) Übersetzung nach zu urteilen, scheint Parkinson

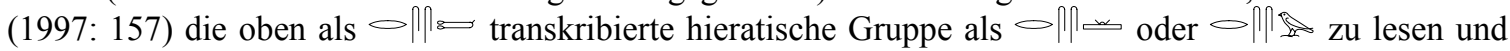
mit dem Kauastiv sjzj 'erleichtern' identifizieren zu wollen. Das ist aus mehreren Gründen problematisch: der Infinitiv terzinfirmer Kausative zeigt normalerweise eine Endung - $t$, und der Anlautkonsonant von Wurzeln Iae-j fällt bei der Bildung eines Kausativstamms (anders als das $w$-von Verben Iae-w) nicht aus.

163 Bei der hier stehenden Verbalform st. $n=f$ könnte es sich um eine Bildung auf der Grundlage der im Kausativ sst realisierten Wurzel unbekannter Bedeutung handeln.

164 "A man asked for an early meal. His wife said: 'It is for supper.' He went outdoors to ... a while. When he came back to the house, he was like another (person). His wife beseeches him and he does not listen to her. He ... heedless of the household." (Lichtheim 1973: 166); "A commoner asks for dinner. His wife says to him, 'It's for supper-time.' He goes outside to relieve himself for a moment. He is like another man as he turns back to his house, and though his wife pleads with him, he does not hear her, after he has relieved himself, and the household is in distraught" (Parkinson 1997: 157). 
W-46 (Lebensmüder 104)

\begin{tabular}{|c|c|c|c|c|c|c|c|c|c|}
\hline 勻通 & man & $f \circ$ & 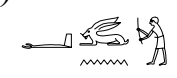 & $\begin{array}{lll}3 & 1 \\
1 & 1 & 1\end{array}$ & 酮， & 8 & $\frac{\pi}{\Delta}$ & $\frac{\theta_{0}}{111}$ & 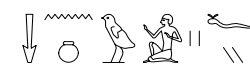 \\
\hline$=i$ & $n-m$ & $m j n$ & $c_{w n}$ & $j b . w$ & $z(j) n b$ & $h r-$ & jt.t.t & jh.t & $s n w=f$ \\
\hline PRÄS.-1sc & PRÄP.-INTERR & R. ADV. & NPA. & SBST.-1 & L.SBST.INDE & PRÄP & VB.-INF & SBST & M.SBST. $-3 \mathrm{sm}$ \\
\hline
\end{tabular}

Mit wem kann ich heute sprechen? Die Herzen sind habgierig, und jedermann ist dabei, sich das Eigentum seines Mitmenschens unter den Nagel zu reißen.

W-47 (Lebensmüder 113)

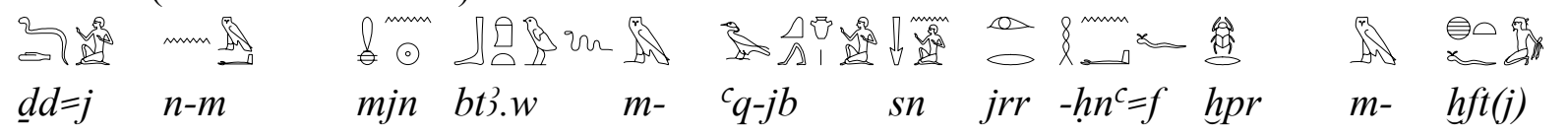
PRÄS.-1sc PRÄP.-INTERR. ADV. VB.-NPA. PRÄP. NPA.-SBST. SBST. DPP. PRÄP.-3sm STAT.:3sm PRÄP. SBST.

Mit wem kann ich heute sprechen? Der Schurke ist (plötzlich) ein Vertrauter, und der Bruder, mit dem man immer gemeinsam zu Gang war, ist zum Gegenspieler geworden. ( ${ }^{\circ}$ einer, der das Herz betritt ${ }^{\circ}$ )

W-48 (Lebensmüder 116)

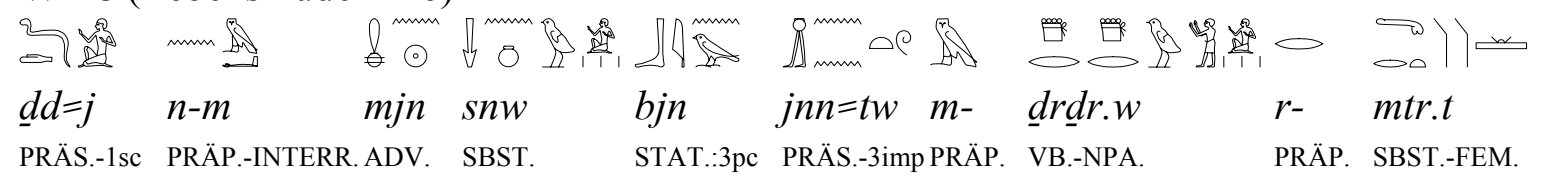

$\min _{\triangle} \quad \mathrm{G}$

n.t- $\quad j b$

DET.-FEM. SBST.

Mit wem kann ich heute sprechen? Die Brüder sind gemein, und zwecks Leumundszeugnis muß man auf Fremde zurückgreifen. ${ }^{165}$ ('Bezeugung des Herzens ${ }^{\circ}$ )

W-49 (Lebensmüder 120)

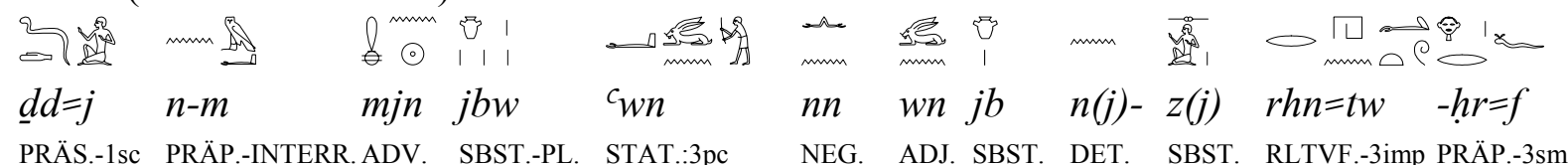
Mit wem kann ich heute sprechen? Die Herzen sind habgierig, und es gibt kein Herz einer Person, auf das man sich stützen kann.

W-50 (Lebensmüder 123)

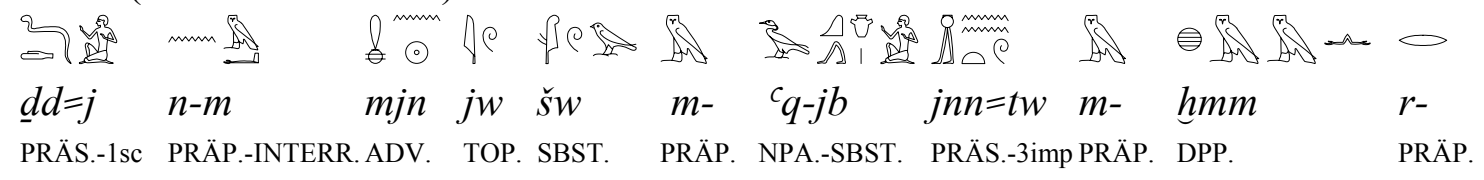

165 "To whom shall I speak today? Brothers are mean, one goes to strangers for affection" (Lichtheim 1973: 167); "Who can I talk today? For Brothers are bad, and one turns to strangers for honesty" (Parkinson 1997: $159)$. 


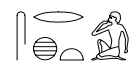

srh.t

VB.-INF.

Mit wem kann ich heute sprechen? Es herrscht Mangel an Vertrauten, und man muß auf einen Unbekannten zurückgreifen, wenn man sich jemandem anvertrauen will. ${ }^{166}$ ( ${ }^{\circ}$ einem, der das Herz betritt ${ }^{\circ}$ )

W-51 (Lebensmüder 23)

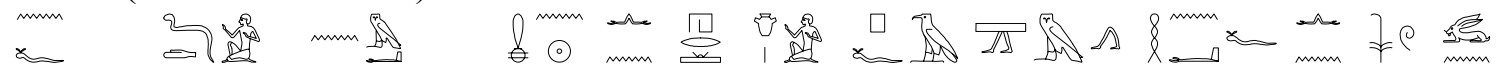
$-n=f \quad \underline{d} d=j \quad n-m \quad$ mjn $n n h r \quad j b \quad p f 3 \quad \check{s} m \quad-h n^{c}=f \quad n n \quad s w \quad w n$ PRÄP.-3sm PRÄ.S-1sc PRÄP.-INTERR. ADV. NEG. ADJ. SBST. DEM. NPA. PRÄP.-3sm NEG. 2sm STAT.:3sm

Mit wem kann ich heute sprechen? Es gibt keinen, dessen Herz zufrieden wäre, und derjenige, mit dem man einst konform ging, der existiert nicht mehr.

W-52 (Lebensmüde 23)

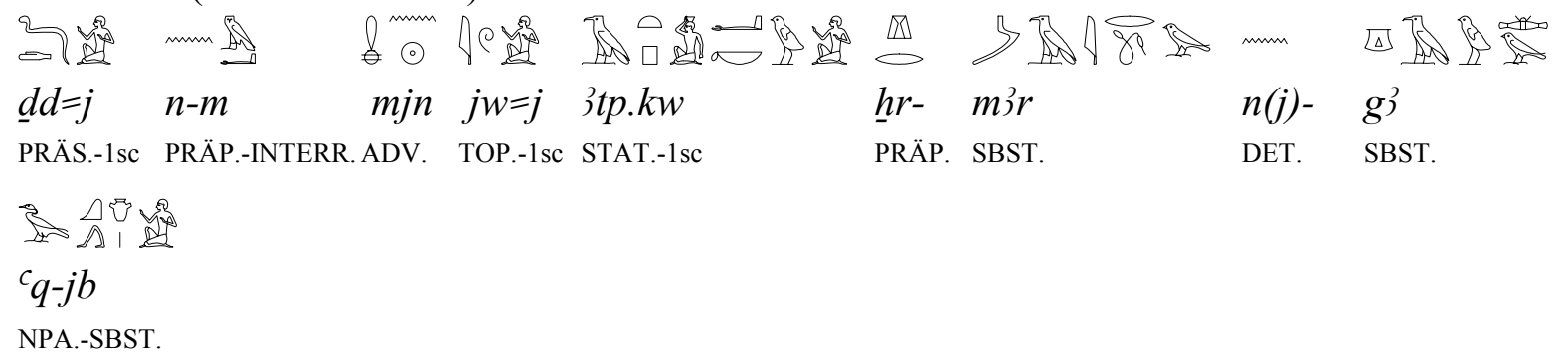

Mit wem kann ich heute sprechen? Mangels eines Vertrauten bin ich vor Kummer niedergedrückt. ( ${ }^{\circ}$ eines, der das Herz betritt ${ }^{\circ}$ ) 


\section{Die Lehre eines Mannes für seinen Sohn (Helck 1984)}

Quelle: $\quad$ Papyrus BM 10258

Datierung: $\quad$ XII. Dynastie/Zweite Zwischenzeit ${ }^{167}$

Textausgaben: $\quad$ Kitchen (1969: 189-208), Helck (1984).

Übersetzungen: Helck (1984), Brunner (1988: 185-192), Roccati (1994: 97-103), Burkard \& Thissen (2003: 171-172).

W-53 I 1-6 (pBM 10258)

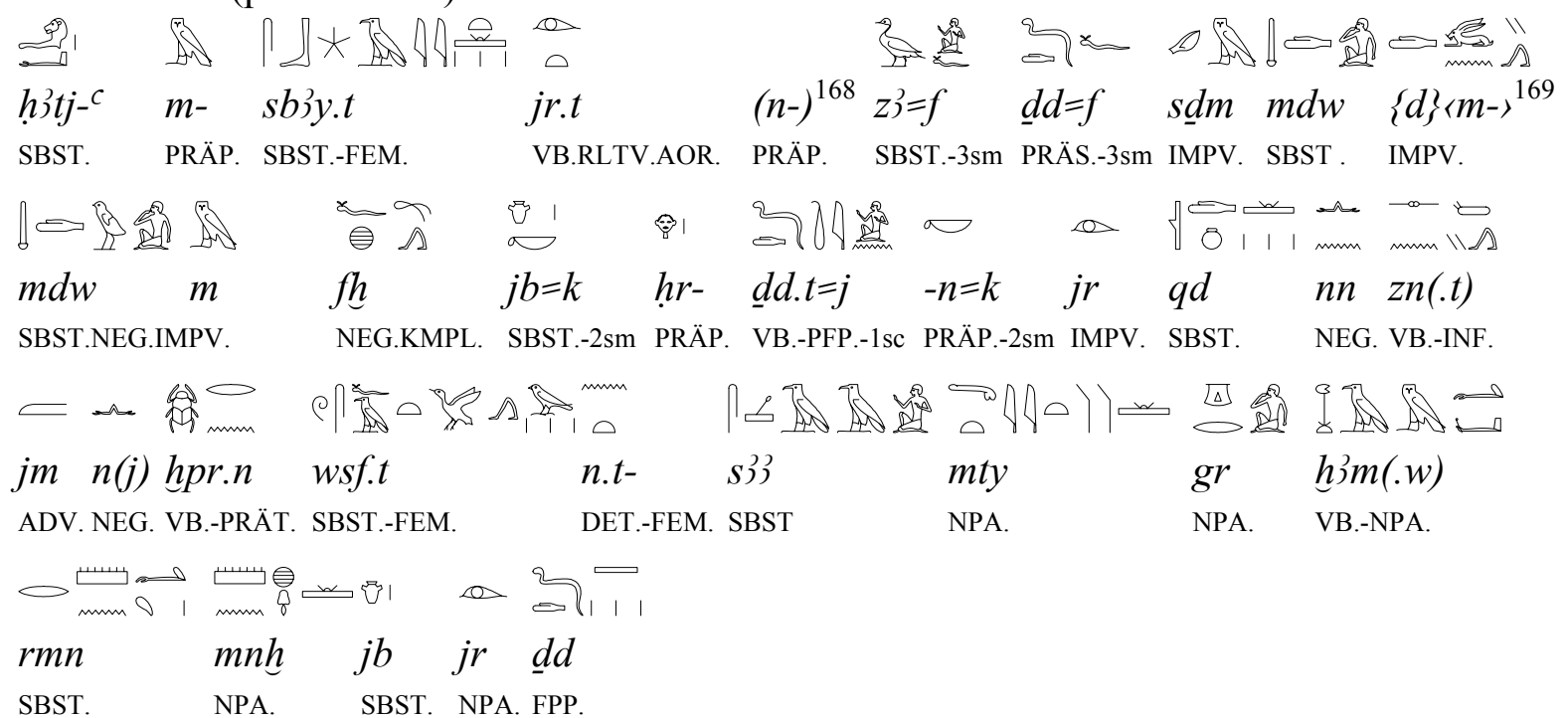

Anfang der Lehre die <ein Mann für $>^{170}$ seinen Sohn verfaßt hat; er sagt: Höre die Rede, ignoriere die Worte nicht, löse dein Herz nicht von dem, was ich dir sagen werde. Handle genauso ohne davon abzuweichen. Der Weise hat keine Muße. Wer schweigt und die Schulter beugt ist zuverlässig. Ein Herz welches tut, was (hier) gesagt wird, ist tadellos

W-54 II 6-7 ODeM 1266+ergänzt mit CG 95,3

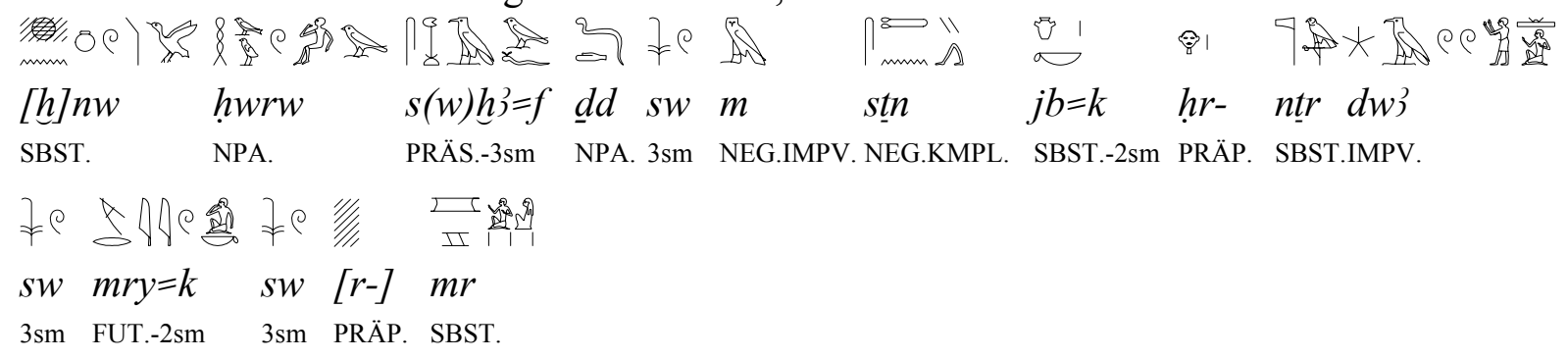

Vulgäre Rede schadet bloß dem, der sie sagt. Wende dein Herz nicht von Gott ab, sondern preise ihn. Du sollst ihn mehr lieben als die Angehörigen.

167 Kitchen (1969: 197-198); Helck (1984: 25); Lichtheim (1996: 251); Quirke (1996: 386).

168 In den anderen Version steth pr.t. $n-z(j)$.

169 Korrigiert mit der Version M94, siehe Helck (1984: 32).

170 In allen anderen Versionen steht jr.t.n $z(j)$, aus diesem Grund wird es hier auch in der Übersetzung eingefügt. 
W-55 XIV, 3 M16+DEM 1398

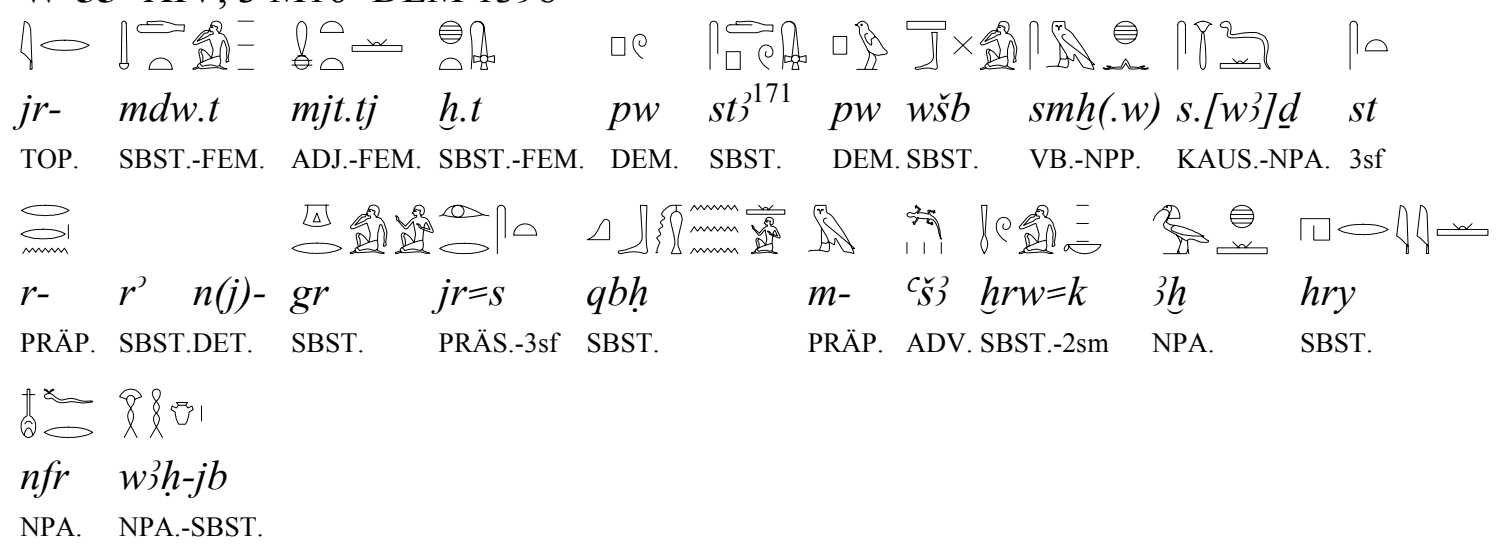

Die Rede, die ist so etwas wie eine Flamme. Eine unbedachte Antwort ist ein Schadenfeuer. Sie ist erfrischender als der Mund eines Schweigsamen, denn sie sorgt für die Abkühlung deiner Geschwätzigkeit. Freundlichkeit ist effizient, und Zurückhaltung ist perfekt. $\left({ }^{\circ}\right.$ Hinlegen des Herzens $\left.{ }^{\circ}\right)$

W-56 XV, 1-4 M16

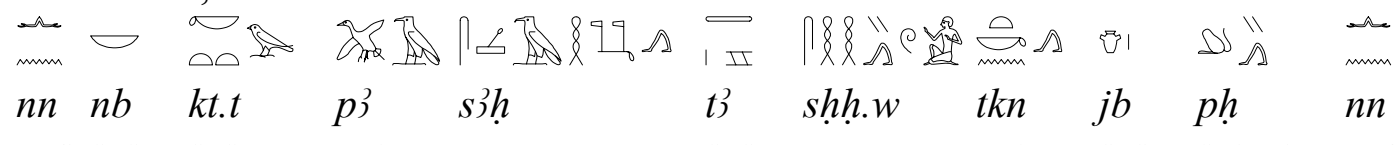

NEG. SBST. SBST.-FEM.NPA. INF. SBST. VB.-DPP. NPA. SBST. STAT.3sm NEG.

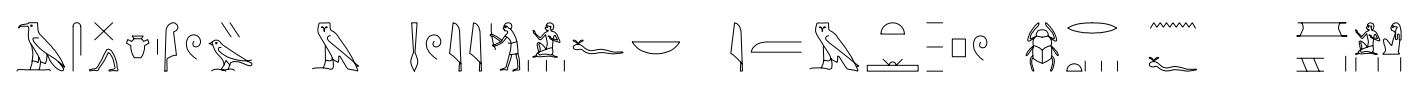

is $s b \quad \check{s} w . y \quad m-\quad h r . y=f \quad n b \quad j m 3 . t \quad$ pw hpr $\quad n=f \quad m r . w$

NPA.-SBST.STAT.-3sm PRÄP. SBST.-PL:-3sm SBST. SBST.-FEM. DEM.VB.-NPA. PRÄP.-3sm SBST.-PL.

Unmöglich, daß ein Kleinkarierter schon jemals Land gesehen hätte; wer immer auf der Suche ist und wer dem Herzen nahesteht, der ist angekommen.

Unmöglich, daß ein Ungestümer keine Feinde hat; nur wer Liebenswürdigkeit besitzt, dem bildet sich eine Anhängerschaft. ( ${ }^{\circ}$ einer mit hetzendem Herz ${ }^{\circ}$ )

W-57 XVIII, 1 Mo+BIM+ODEM 1231

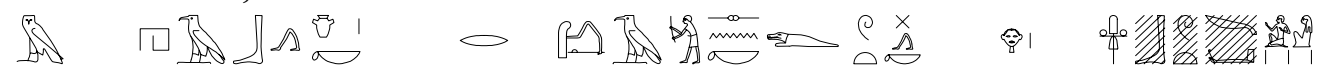

$m \quad h 3 b \quad j b=k \quad r-\quad{ }^{\prime} h 3 \quad s n k-t w \quad s w 3=k \quad h r-\quad 3[b . w t]$

NEG.IMP.NEG.KMPL. SBST.-3sm PRÄP. INF. IMP.-2sm PRÄS.-2sm PRÄP. SBST.-FEM.PL.

Schick dein Herz nicht in den Kampf. Sei auf der Hut, wenn du bei einer Sippe vorbeigehst.

171 Korrigiert durch P. Illahun, vgl. Müller, Hieratisch, S. 393, siehe Helck (1984: S. 64, Anm.). 


\section{Sprüche des Papyrus Ramesseum II}

Datierung: $\quad$ Spätes Mittleres Reich ${ }^{172}$

Textausgabe: $\quad$ Barns (1956: 11-14, Tafeln 7-9).

Übersetzung: $\quad$ Brunner (1988: 193-195), Morenz (1997: 65-70), Burkard, \& Thissen (2003: 199).

W-58 III, recto 3

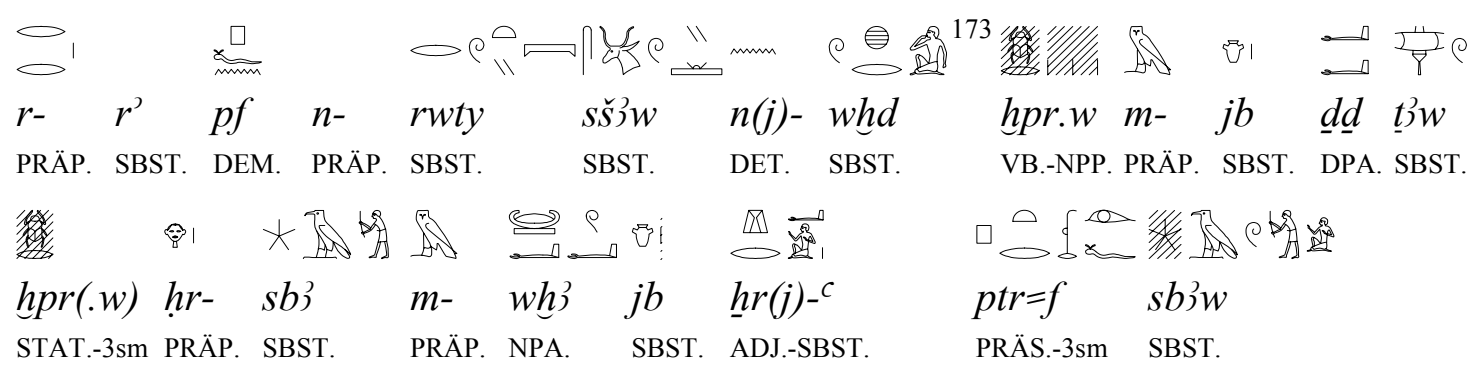

$\mathrm{Zu}$ jenem Spruch für den Außenstehenden und der Diagnose für die Schmerzen, die im Herzen entstanden sind: Wer erlaubt, daß im Unterricht Freiräume entstehen ${ }^{174}$, der verleiht dem Verstand des Untergebenen Flügel, wenn er den Lehrer sieht. ('öst das Herz des Untergebenen $^{\circ}$ )

\section{W-59 IV 4}

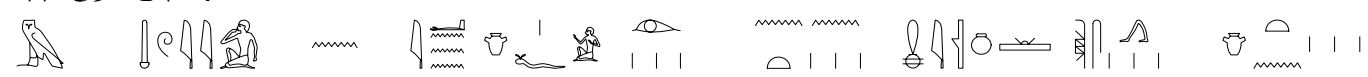
$m \quad m d w y \quad n-\quad j^{c} \quad j b=f \quad j r . w \quad-n=\underline{t n} \quad m j-q d-\quad \check{s} m s . w \quad j b=\underline{t} n$ NEG.IMP.NEG.KMPL. PRÄP. NPA. SBST.-3sm IMP.-PL. PRÄP.-2pc PRÄP. IMPV-PL. SBST.-2pc Sprich nicht (bloß) zu jemandem, der sich (etwas) von der Seele redet. Handelt entsprechend und folgt eurem Herzen. $\left({ }^{\circ} \mathrm{der} \operatorname{sein} \mathrm{Herz}\right.$ wäscht ${ }^{\circ}$ )

W-60 Verso II,4

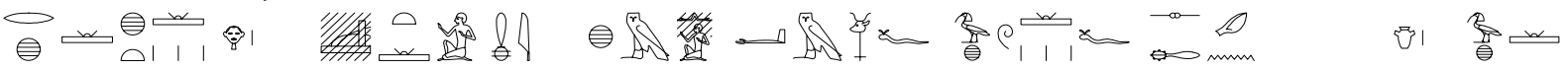

$$
\begin{aligned}
& r h-(j) h . t \quad h r-\quad s h . t \quad m j-\quad h m \quad c_{m=f} \quad 3 h w=f \quad z h n \quad n-\quad j b \quad 3 h \\
& \text { NPA.-SBST.-FEM.PRÄP. VB.-INF. PRÄP. NPA. PRÄS.-3sm SBST.-PL.-3sm STAT.3ssm PRÄP. SBST.NPA. }
\end{aligned}
$$

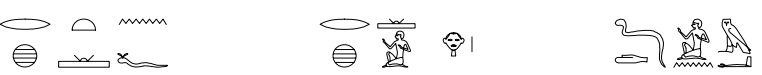

$$
\begin{aligned}
& \text { rh.t.n=f rh } \quad \text { hr }-(\underline{d} d) \quad \underline{d} d=j \quad n-m \\
& \text { RLTVF.-FEM.-PRÄT.-3sm NPA. PRÄP.(INF.) FUT.-1sc PRÄP.-INTERR. }
\end{aligned}
$$

Der Gelehrte auf der Jagd (nach Wissen) ist wie ein Ignorant, wenn er seine Kenntnisse verschluckt und taub ist für das Herz. Nützlich ist nur das, was er kennengelernt hat. Der Weise sagt: Mit wem soll ich sprechen? 


\section{Die Prophezeiung des Nfr.tj}

Quelle: $\quad$ Papyrus Petersburg 1116B

Datierung: $\quad$ XII. Dynastie ${ }^{175} /$ XVIII. Dynastie ${ }^{176}$

Textausgabe: Helck (1970).

Übersetzungen: $\quad$ Wilson (1969: 444-446), Helck (1970), Barta (1971: 35-45), Lichtheim (1975: I, 139-144), Kammerzell (1986: 102-110).

W-61 III a-g (Pet)

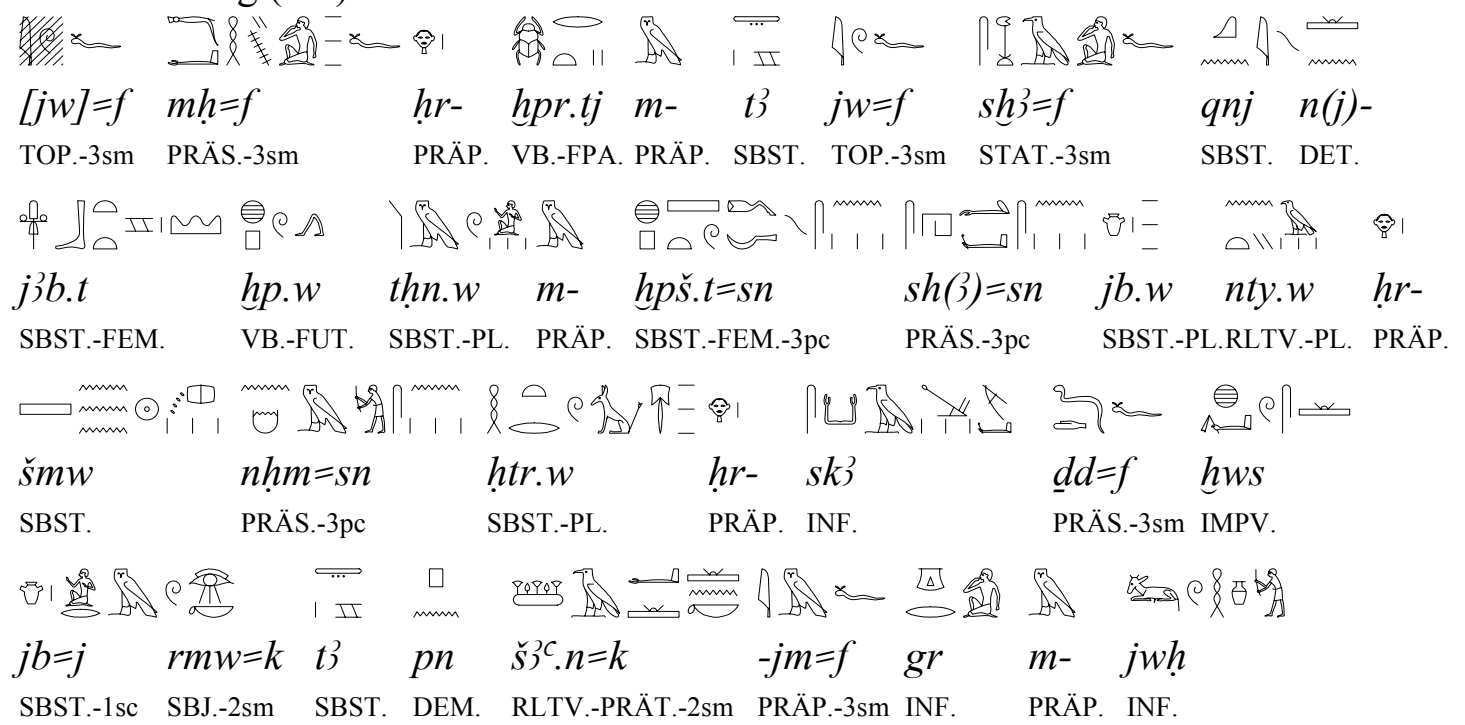

Er machte sich Sorgen wegen das, was im Land geschehen wird und dachte an den Schaden des Ostens, wenn die Asiaten mit ihrem Schwert einfallen, wobei sie die Herzen derer, die mit dem Ernten beschäftigt sind, in Unruhe versetzen ${ }^{177}$ und die Gespanne beim Pflügen rauben würden. Er sagte: Rege dich, mein Herz, daß du dieses Land beweinst, in dem du (zu leben $)^{178}$ begannst, Schweigen ist bloß Verdrängung. ${ }^{179}$

W-62 IX a-f (Pet)

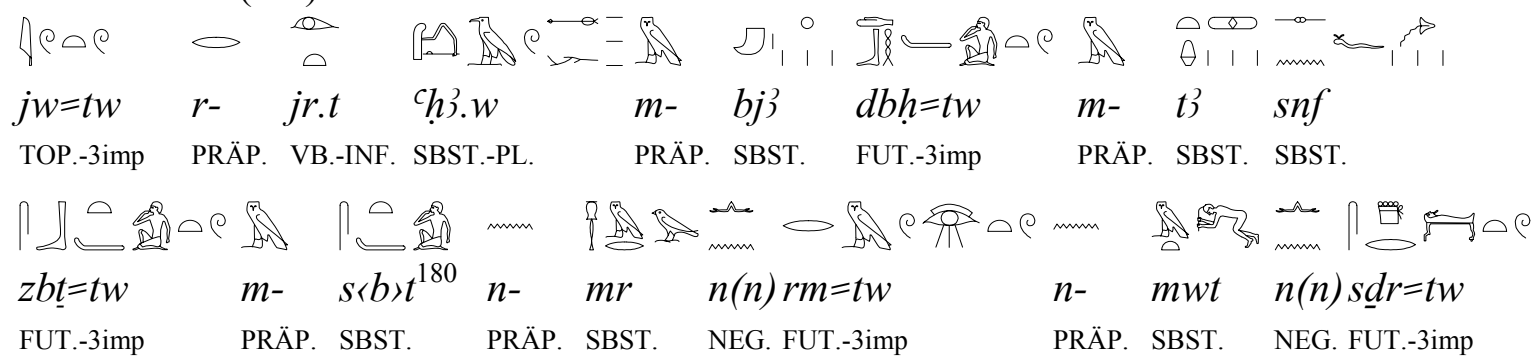

175 Helck (1970: 1); Blumenthal (1996: 131).

176 Lichtheim (1975: 139); Baines (1996: 160, Anm. 17); Quirke (1996: 388 u. 392).

177 Wb. IV 205,19. Andere Lesungsvorschläge: shd (Kammerzell 1989: 105) bzw. Korrektur mit DeM 1187 zu dhm (?), siehe Helck (1970: 18 Anm. d).

178 Für diesen Sinn siehe Kammerzell (1989: 105, Anm. XXX).

179 "Hu says: 'Stir, my heart, and beweep this land, in wich you began, for silence is what overwhelms!" (Parkinson 1997: 135).

180 Für die Ergänzung siehe Helck (1970: 36 Anm. b). 


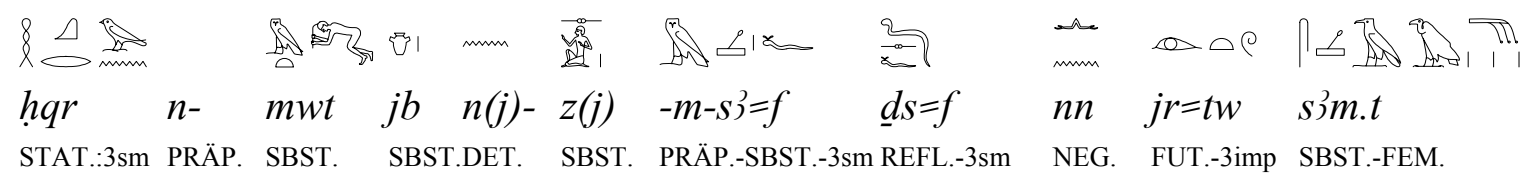

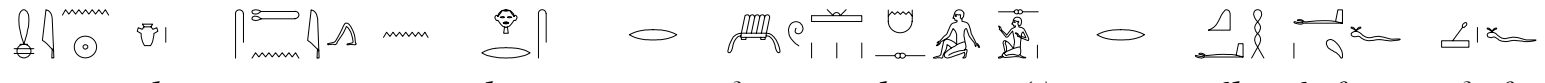

$\left.m j n \quad j b \quad s \underline{n} n \quad n-\quad h r=s \quad r-\quad 3 w \quad h m s \quad z(j) \quad r-\quad q^{c} h \quad c=f \quad s\right\}=f$

ADV. SBST. STAT.:3sm PRÄP. SBST.-3sf PRÄP. SBST. FUT. SBST. PRÄP. INF. SBST.-3sm SBST.-3sm

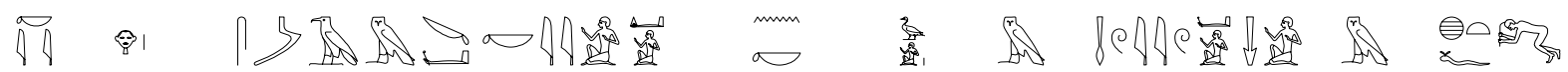

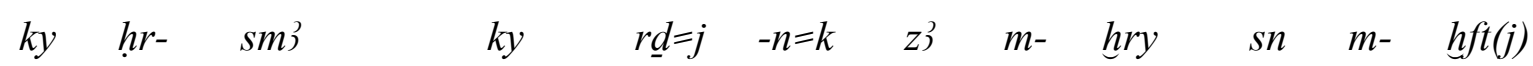

INDF. PRÄP. INF. INDF. FUT.-1sc PRÄP.-2sm SBST. PRÄP. SBST. SBST. PRÄP. SBST.

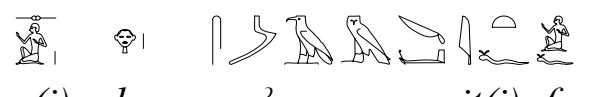

$z(j) \quad h r-\operatorname{sm} 3 \quad j t(j)=f$

SBST. PRÄP. INF. SBST.-3sm

Man wird Waffen aus Kupfer anfertigen und Brot um Blut erbitten. Man wird über das Leid lauthals lachen, sogar den Tod nicht mehr beweinen, und wegen eines Todesfalls nicht einmal mehr fasten. Denn das Herz eines Mannes sorgt sich nur noch um sich selbst. Man wird heutzutage keine Trauerfrisur mehr machen, da das Herz ganz davon abgekommen ist. Ein Mann wird sich hinsetzen, um seinen Arm und seine Rüchen zu beugen, während einer den anderen tötet. Ich werde dir einen Sohn als Feind, einen Bruder als Gegner und einen (normalen) Mann, der seinen Vater tötet, zeigen. ${ }^{181}$

W-63 XIa-c (Pet)

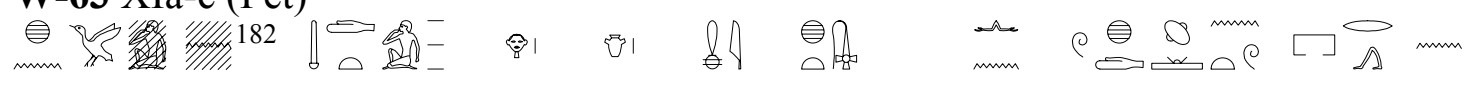

hnn [n(j)-] mdw.t hr- jb mj- h.t $n(n)$ whd.n=tw $p r \quad n(j)-$

SBST. DET. SBST.-FEM.PL. PRÄP. SBST. PRÄP. SBST.-FEM. NEG. VB.-PRÄT.-3imp NPA. DET.

○盗

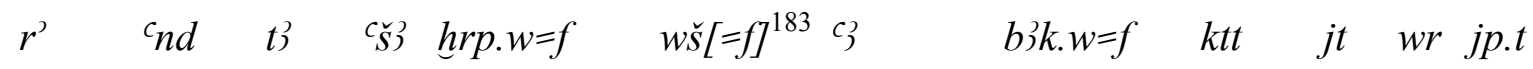

SBST. NPA. SBST. NPA. SBST.-PL.-3sm ADJ.-3sm ADJ. SBST.-PL.-3sm NPA. SBST.NPA. SBST.-FEM.

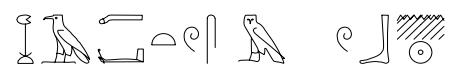

h3.tw $=s \quad m-\quad w b n$

PRÄS.-PASS.-3sf PRÄP. INF.

Die Sprichwörter werden auf das Herz treffen wie Feuer. Man kann den Maulhelden ${ }^{184}$ nicht mehr ertragen. Das Land ist dürftig, aber seine Besitzer sind viele. Es ist kahl, aber seine

181 "Men will make arrows of copper, will crave blood for bread, will laug aloud at distress. None will weep over death, none will wake fasting for death, each man's heart is for himself. Mourning is not done today, hearts have quite abandoned it. A man sits with his back turned, while one slays another. I show you the son as enemy, the brother as foe, a man slaying his fahter" (Lichtheim 1973: 142); "Arms will be made out of copper; bread will be asked for with blood; a sick man will be laughed at out loud; death will not be wept at; the night will not be spent fasting for death, for a man's heart is concerned only with himself. Mourning will not be done today, for the heart has turned away from it entirely. A man will sit and bow his back while one person is killing another. I shall show you a son as a foe, a brother as an enemy, a man killing his own father" (Parkinson 1997: 137).

182 Sowohl das Determinativ als auch das Kennzeichen des Genitivs $n$ lassen sich durch die andere Versionen ergänzen werden, siehe Helck (1970: 42).

183 Ergänzung durch die Version auf dem Ostrakon Gardiner 331 (Gardiner-Černý 1957: pl. 106, 2). 
Abgaben sind hoch. Der (Ertrag an) Gerste ist gering, aber das Maß ist groß, und man befüllt es überquellend. ${ }^{185}$

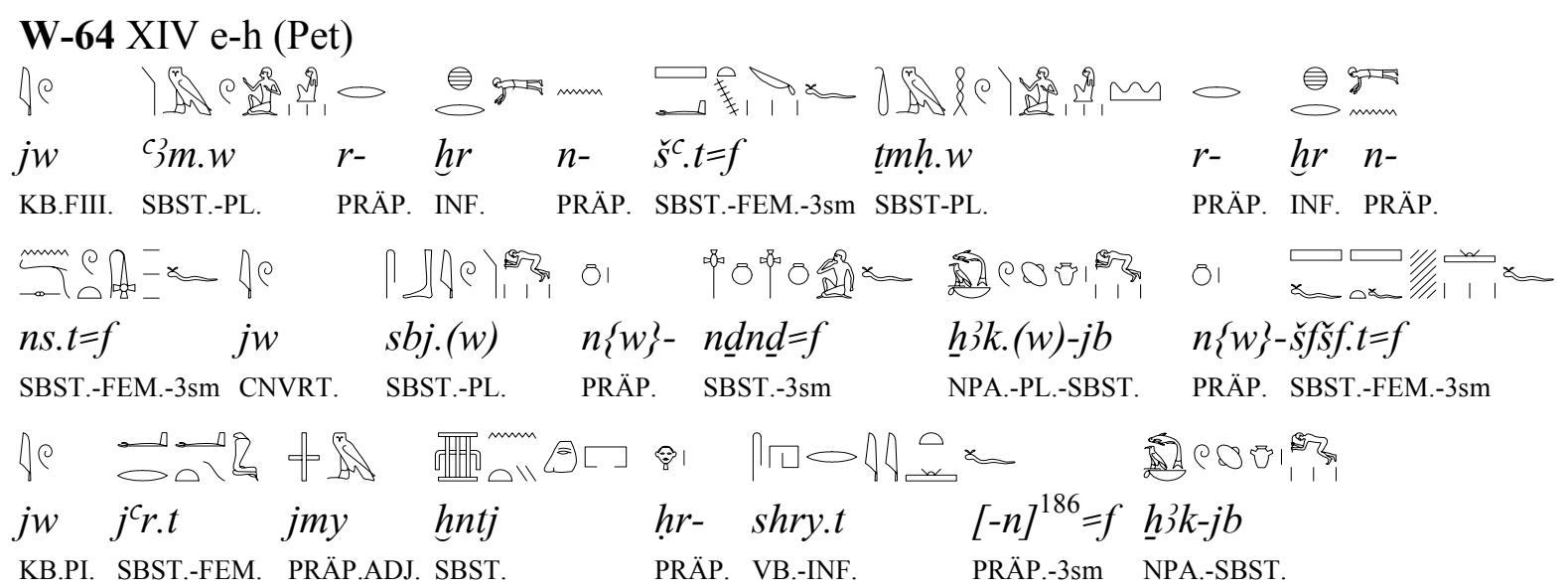

Die Asiaten werden seinem ${ }^{187}$ Schrecken anheimfallen, die Libyer werden seiner Flamme anheimfallen, die Rebellen seinem Verhör, die Übelgesinnten seiner Autorität. Der Uräus, der sich an seiner Stirn befindet, beruhigt (für) ihn die Übelgesinnten. ${ }^{188}$

184 Die meisten Übersetzungen lesen $p r n-r^{\text {? }}$ und sehen darin ein Partizipialsyntagma, das "was aus dem Mund kommt" bedeuten soll (siehe die folgende Fußnote). Dabei wird allerdings nicht nur übersehen, daß man hierfür im Mittelägyptischen einen feminine Form erwarten soll und daß 'hervorgehen aus' die Präposition m- verlangt, sondern auch die Hieroglyphe A1 unterschlagen. Die hier vorgeschlagene Analyse basiert darauf, daß eine Anspielung an die Kollokation $\operatorname{pr}^{-}{ }^{c}(w)$ 'energisch, tüchtig; Held' vorliegen könnte.

185 "Speech falls on the heart like fire, one cannot endure the word of mouth. The land is shrunk-its rulers are many, it is bare-its taxes are great; the grain is low-the measure is large, it is measured to overflowing" (Lichtheim 1973: 142); "To the heart, spoken words seem like fire; what comes from the mouth cannot be endured. Shrunk is the land-many its controllers. It is bare-its taxes are great. Little is the grain-large is the measure, and it is poured out in rising amounts" (Parkinson 1997: 137-138).

186 Siehe Anmerkung Kammerzell (1982: 110).

187 Der Sohn eines (ehrenhaften) Mannes.

188 "Asiatics will fall to his sword, Libyans will fall to his flame, rebels to his wrath, traitors to his might, as the serpent on his brow subdues the rebels for him" (Lichtheim 1973: 143); "Asiatics will fall to his slaughtering, and Libyans will fall to his flame. Rebels belong to his rage, and malcontents to his awesomeness. The uraeus which is on his forehead now quietens the malcontents for him" (Parkinson 1997: 139). 


\section{Die Klagen des Chacheperreseneb (Gardiner 1969)}

Quellen: $\quad$ Papyrus Leiden 344 Recto $=$ BM 5645

Datierung: $\quad$ XVII./XVIII. Dynastie ${ }^{189}$

Textausgaben: Gardiner (1969), Parkinson (1997: 55-58).

Übersetzungen: $\quad$ Simpson (1972: 230-234), Bissing (1955: 122-123), Lichtheim (1975; I, 145-149),

Ockinga (1983: 88-95), Brunner (1988: 378-383), Hornung (1990: 101), Parkinson (1997: 144-150), Burkard \& Thissen (2003: 131-137).

W-65 Par. 1, recto I

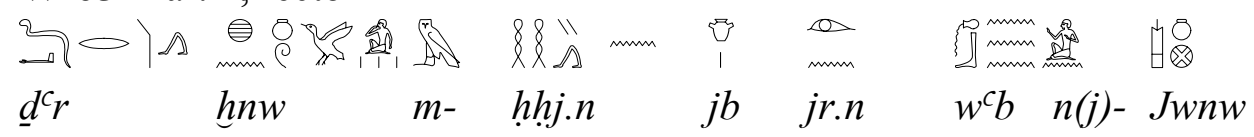

SBST. $\quad$ SBST.-PL. PRÄP. RLTVF.-PRÄT. SBST. REL.-PRÄT.SBST. DET. TOPON.

Die Suche des Ausspruches durch das, was das Herz suchte, ist es, was der $w^{c} b$-Priester von Heliopolis machte.

W-66 Par. 2, recto 7
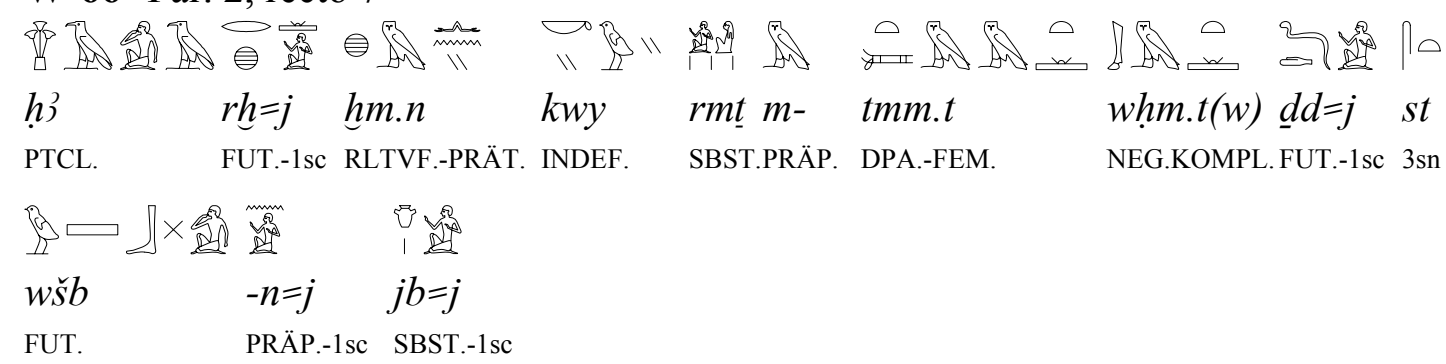

Ach, wüßte ich doch, was andere nicht wissen - von dem, was nicht berichtet wurde, damit ich es sagen und mein Herz mir antworten könnte.

W-67 Par.3, recto 12

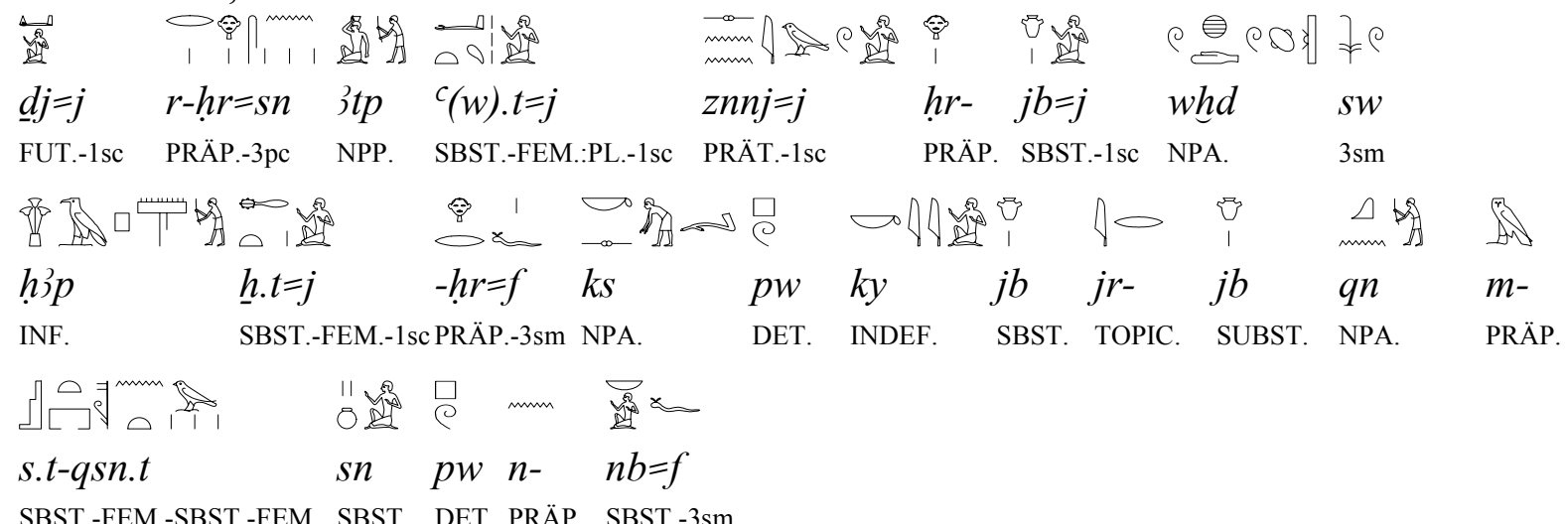

Ich werde über sie sprechen. Meine Glieder waren beladen, ich litt an meinem Herzen. Es ist schmerzlich, darüber den Mantel des Schweigens zu decken. Das heißt, ein anderes Herz wäre gebeugt. Ein Herz, das auch in einer bösen Situation stark ist, ist der Genosse seines Herrn. 
W-68 Par.3, recto 13

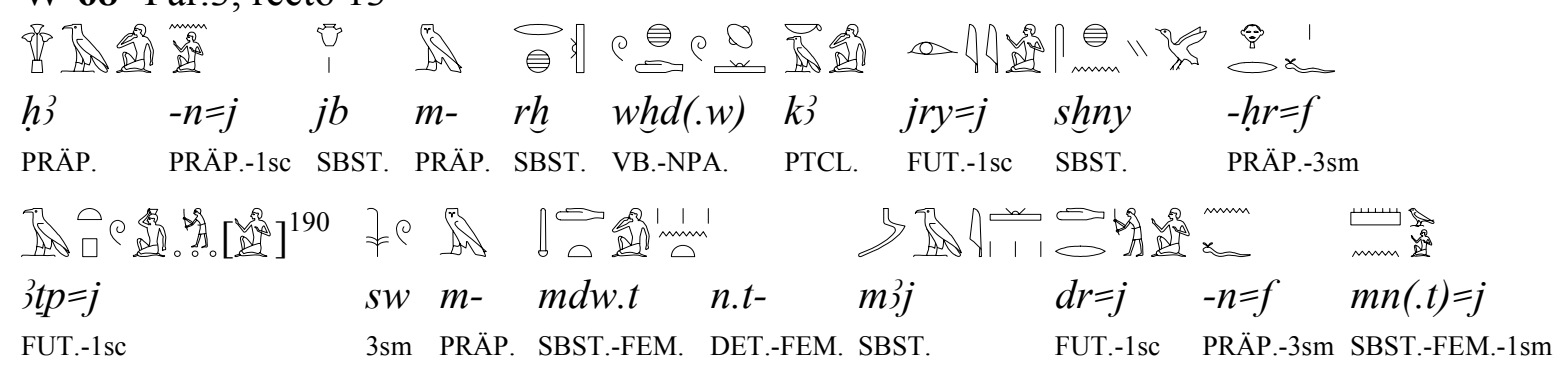

Ach, hätte ich ein Herz mit Wissen, welches ertragen kann. Dann könnte ich mich untätig auf es stützen, es mit Klagen über das Elend beladen und so schließlich mein Leid auf seine Kosten vertrieben.

W-69 Par. 4, verso 1

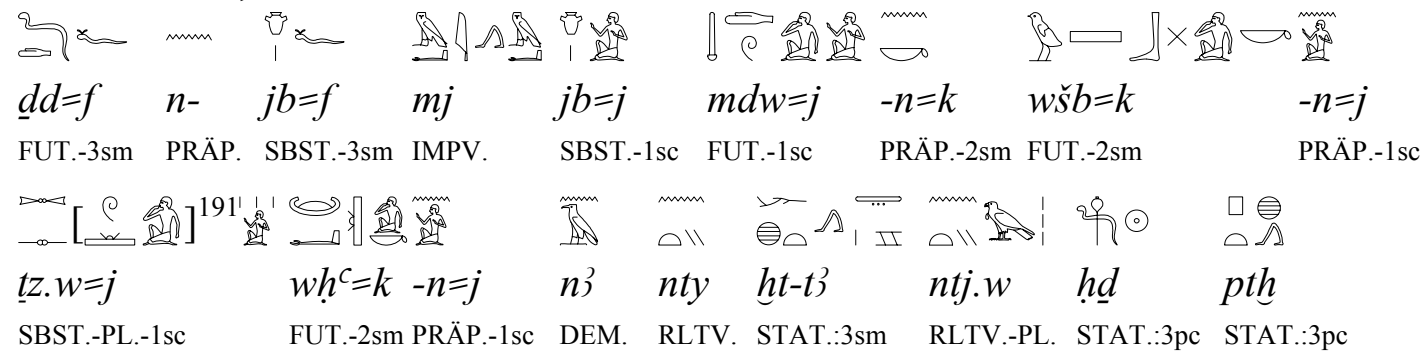

Möge er zu seinem Herzen reden: komm, mein Herz, daß ich zu dir spreche und du mir meine Aussprüche beantwortest und mir erklärst, was im Land vorgeht und warum die, die früher heiter waren, jetzt niedergeschlagen sind.

W-70 Par. 4, verso 2-3

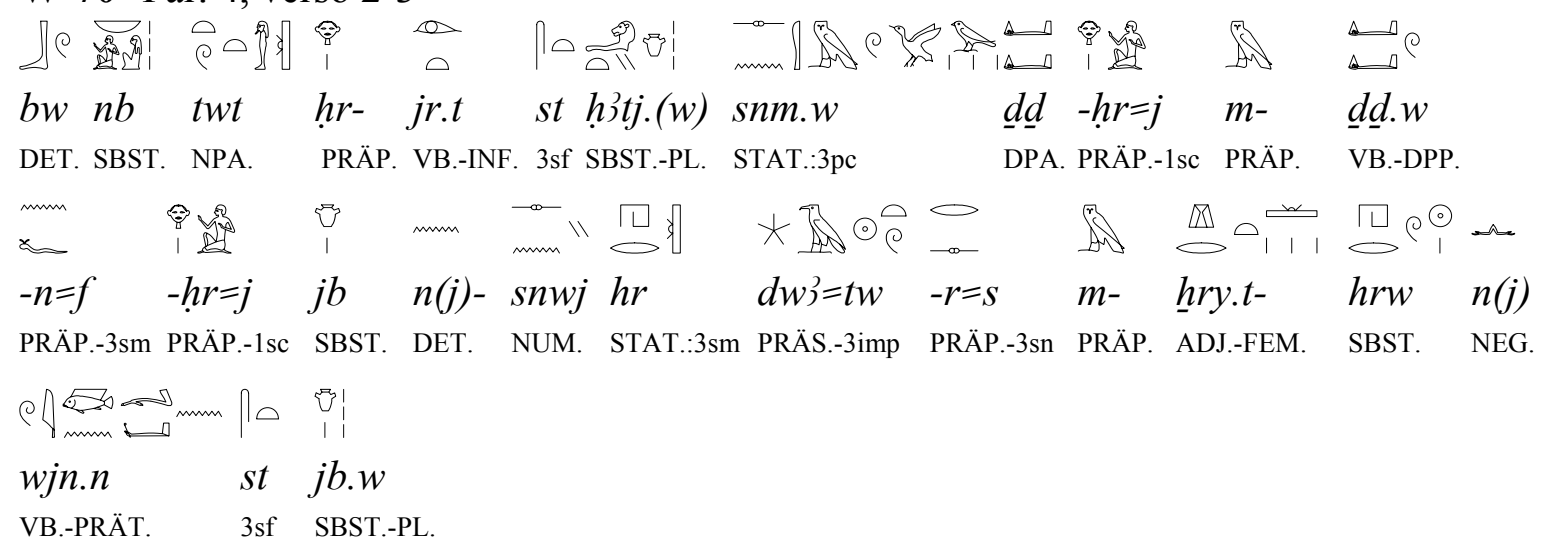

All mögliche Leute machen es (das Böses) und die Herzen sind traurig. Einer, der meinetwegen gewöhnlich gibt, wird einer, dem meinetwegen gegeben wird und das Herz von beiden ist zufrieden. Man fängt damit täglich morgens an und die Herzen weisen es nicht ab.

190 Ergänzung nach Gardiner (1960: 105).

191 Ergänzung nach Gardiner (1960: 105). 
W-71 Par. 4, verso 4

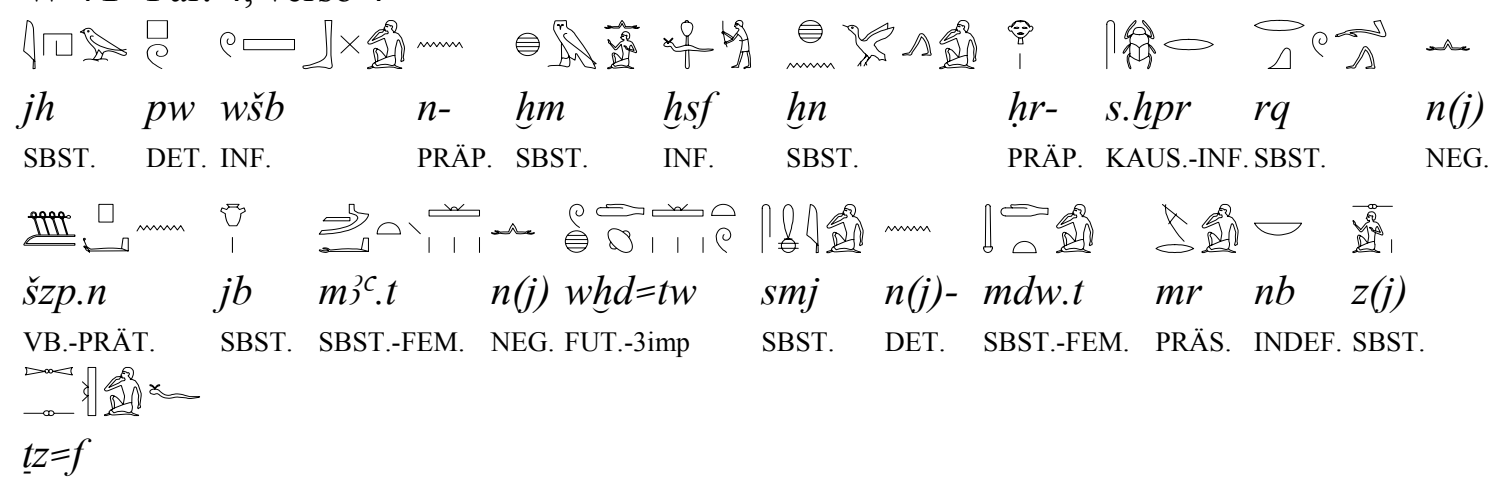

Es ist die deprimierend, einem Unwissenden zu antworten und eine Rede wegen dem, der Feindseligkeit erschafft, abzulehnen. Das Herz kann die Wahrheit nicht aufnehmen und man kann die Mitteilung nicht ertragen, da jeder Mann nur seinen Spruch liebt. 


\title{
Die Lehre des Cheti (Helck 1970)
}

Quellen: $\quad$ Papyrus Sallier II, Papyrus Anastasi VII

Datierung:

Textausgaben:

Übersetzungen:

\author{
XVIII. Dyanstie ${ }^{192}$ \\ Budge (1923: Pl. 65-73), Brunner (1944), Helck (1970). \\ Bissing (1955: 57-60), Wilson (1969: 432-434), Lichtheim (1975: I, 184-192), \\ Burkard (1977), Brunner (1988: 155-168), Hoch (1991/1992: 88-100), Guglielmi \\ (1994: 44-72), Roccati (1994: 79-87), Parkinson (1997: 273-286), Burkard \& \\ Thissen (2003: 163-169).
}

W-72 XVIe (Louv)

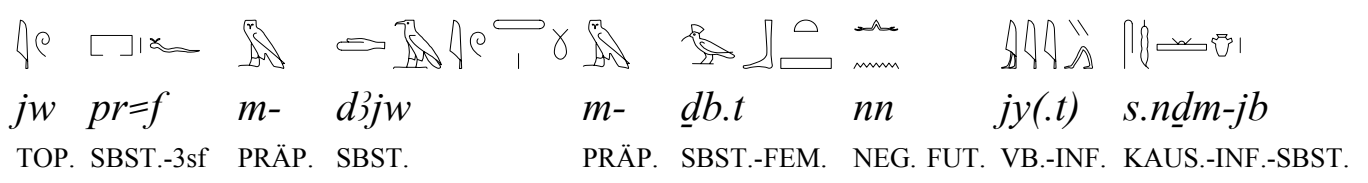

Seine Unterkunft mag aus Leinwand oder aus Ziegeln bestehen, aber es wird keine Entspannung aufkommen. ( ${ }^{\circ}$ Angenehmmachen des Herzens ${ }^{\circ}$ )

XXa-c (s.II) und XXVIIIb (s.II). Das einzige Beispiel steht in Papyrus Sallier an gleicher Stelle, diese Quelle gilt jedoch als einer der schlechtesten Textzeugen. Weder die Grammatik noch der Sinn sind verständlich, und für eine weiter Ausweitung in Rahmen der Fragestellung vorliegender Arbeit auszuwerten. Es wird hier dennoch erwähnt, falls der Leser den Text selbst überprüfen möchte.

XXIIIc-Dem 1013. Das Adverb $3 s w$ hat das Zeichen $j b$ als Determinativ. Es ist das einzige Beispiel hierfür. Anders als in der Lehre für Ani (W-77) und der Lehre für Amunnacht (W92) kommen das Wort $j b$ und das Adverb 3sw, aber nicht als Determinativ vor. Außerdem sehen beide Wörter auf Hieratisch nicht ähnlich aus, und bei Ermann \& Grapow kommt diese Schreibung ebenfalls nicht vor. Meiner Meinung nach handelt es sich bei diesem Beispiel um einen Schreibfehler.

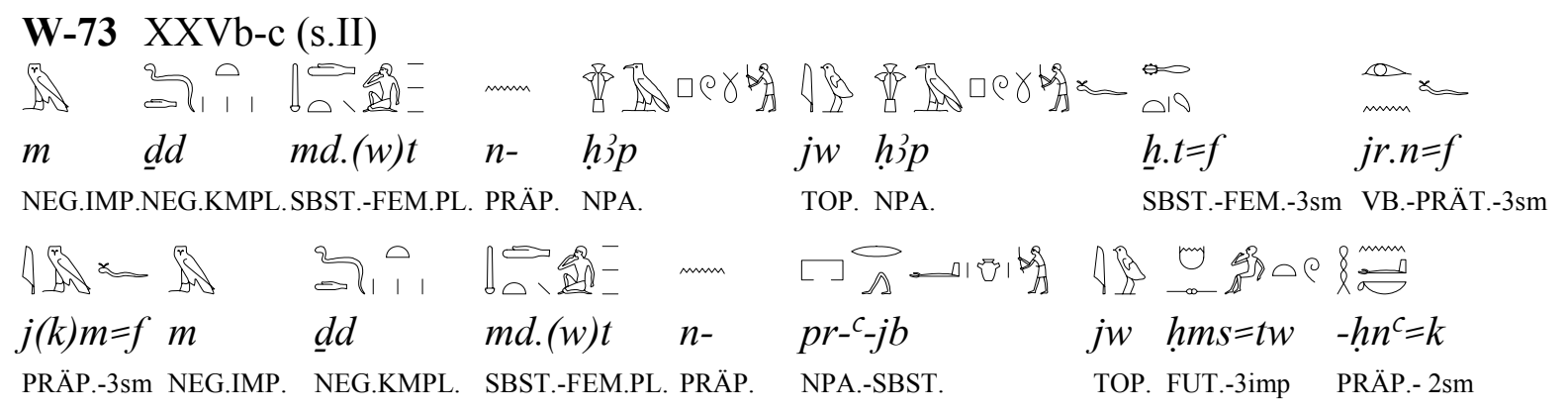

192 Helck (1970: 1); Lichtheim (1975: 185); Burkard (1977: 8); Schenkel (1996: 28); Baines (1996: 160, Anm. 17 u. 166); Quirke (1996: 269 u. 388); Loprieno (1996: 406); Parkinson (1997: 274). 
$\prod_{-\infty}^{\infty} \underset{\rho \infty}{\infty}$

ksm:w

STAT.-3sm

Verrate keine Dinge an einen Heimlichtuer. Denn wer seinen Leib versteckt, hat dadurch einen Schutzschild geschaffen. Und verrate auch keine Dinge an einen mit aufbrausendem Charakter. Sonst wird man aufmüpfig mit dir zusammenhocken. $\left({ }^{\circ}\right.$ Herzen $\left.^{\circ}\right)$

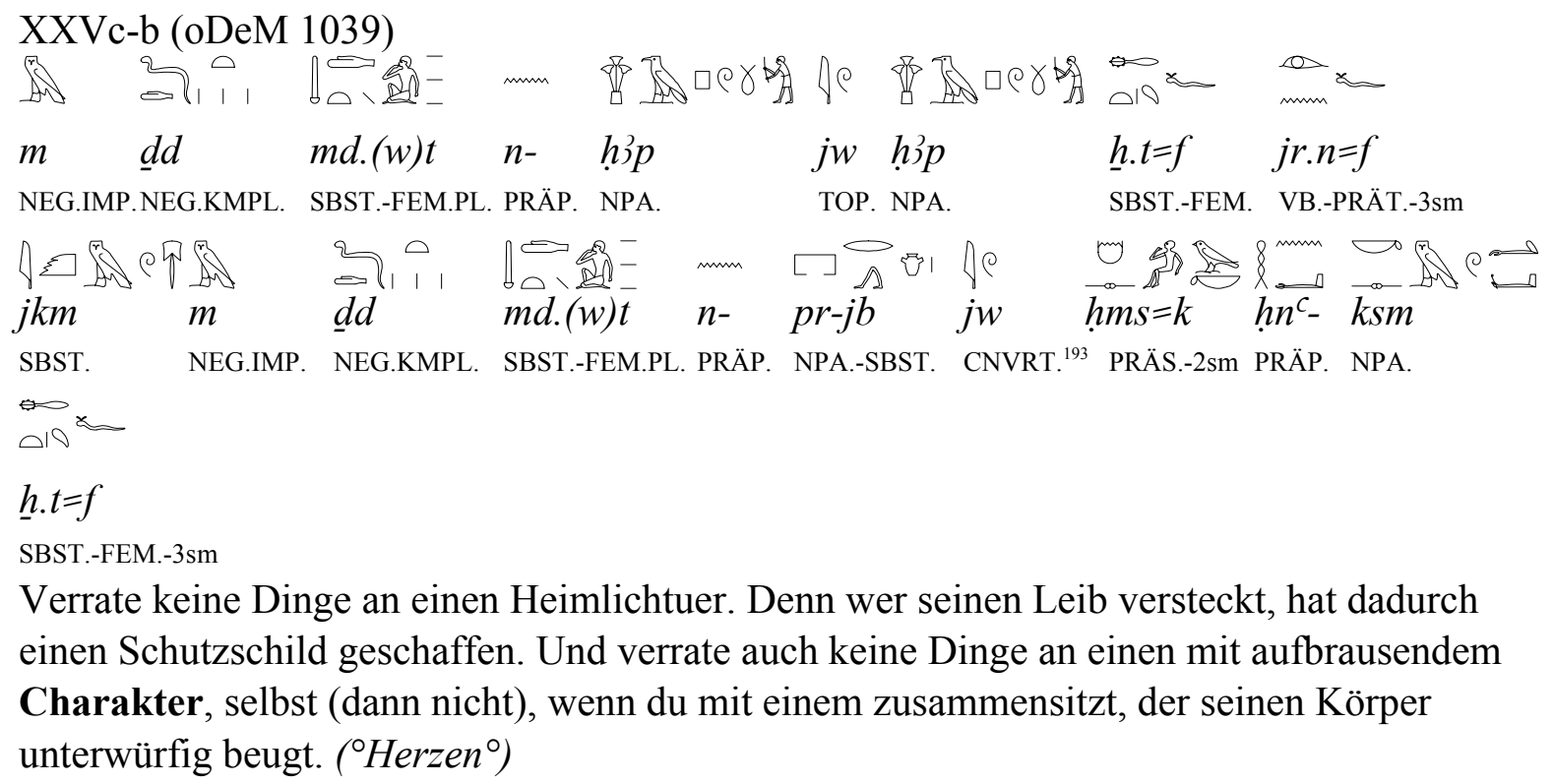

XXVIId. $J b$ hat nichts mit Gefühlen oder Menschen zu tun, sondern mit dem Namen einer Person.

W-74 XXIXc (s.II)

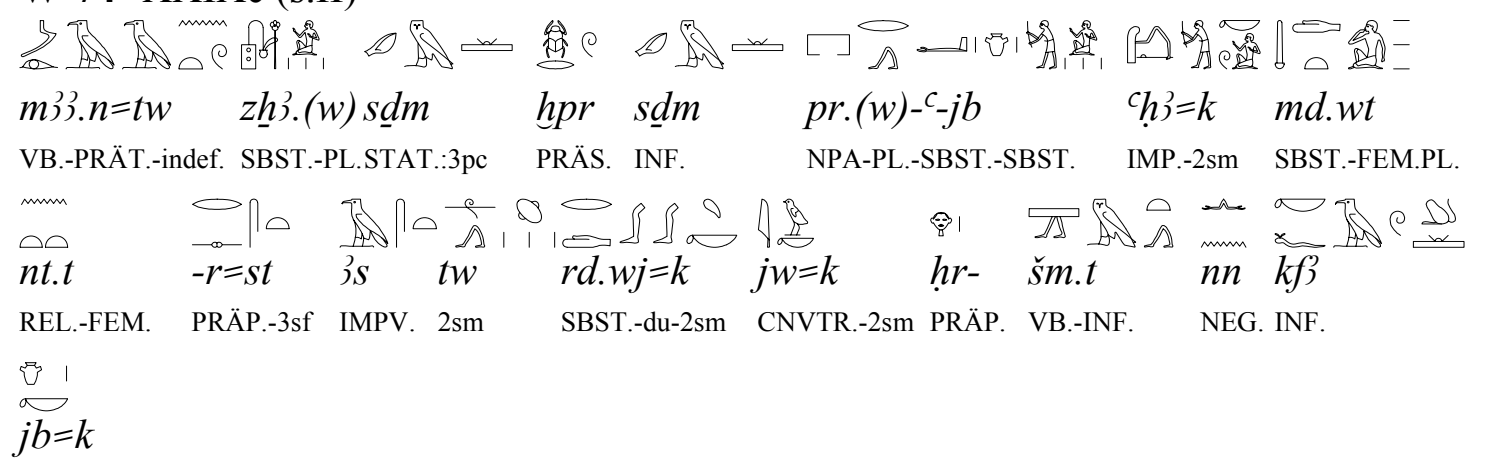

SBST.-2sm

Man hat immer schon darauf geachtet, daß Schreiber gehorsam sind. Denn nur Gehorsam schafft Tüchtige. Hüte dich vor Behauptungen, die das bestreiten. Treibe deine Füße an, wenn du wo hingehst, ohne deine Absicht zu enthüllen ( ${ }^{\circ}$ dein Herz ${ }^{\circ}$ ) 


\section{Die Loyalistische Lehre}

Quellen:

Datierung:

Stele des Sehetepibre /Tablette Carnavon II Cairo JE 43261/Papyrus Louvre E. 4864

Textausgaben:

XVIII. Dynastie ${ }^{194}$

Übersetzungen: $\quad$ Simpson (1972: 198-200), Lichtheim (1975: I, 128-129), Roccati (1994: 89-95), Parkinson (1997: 235-245), Burkard \& Thissen (2003: 174-177).

$\mathbf{W}-75 \S 2,5(\mathrm{St})$

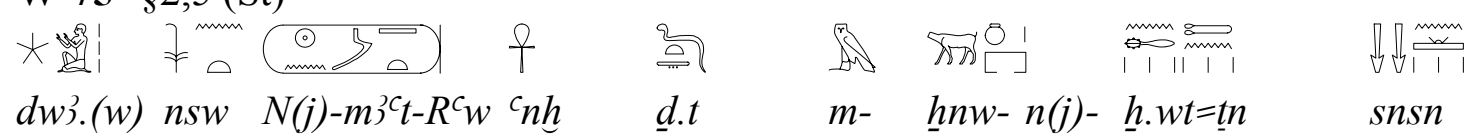

IMPV-PL. SBST. PROP. STAT.3sm SBST.-FEM. PRÄP. SBST. DET. SBST.-FEM.PL.-2pc.IMPV.

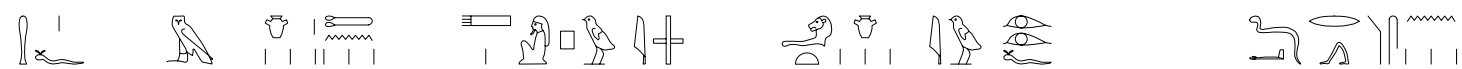

$h m=f \quad m-\quad j b . w=t \underline{t n} \quad s j 3 \quad p w \quad j m j-\quad$ hijtj.w $\quad j w \quad j r . t(j)=f \quad \underline{d}^{c} r=s n$

SBST.-3sm PRÄP. SBST.-PL.-2pc. SBST. DEM. ADJ. SBST.-PL. TOP. SBST.-FEM.-du-3sm PRÄS.-3pc

$\infty$

h.t $\quad$ nb.t

SBST.-FEM.INDEF.-FEM.

Lobet dem König Nj-Maat-Re, damit er ewig im Innern eurer Leiber lebe. Verehrt Seine Majestät in euren Herzen. Denn er ist es, der erkennt, was in den Herzen ist. Und seine Augen untersuchen jeden Leib.

W-76 $§ p, 3(\mathrm{PL})$

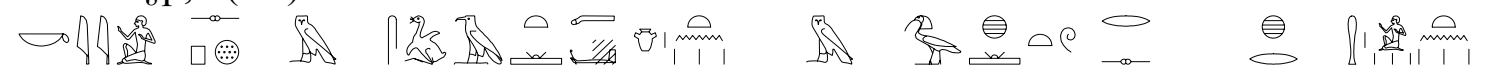

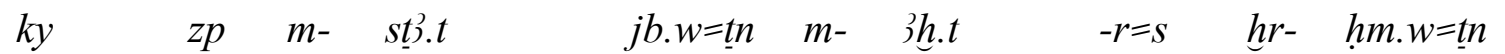

KNTR.PRON. SBST. PRÄP. NPA.-FEM. SBST.-PL.-2pcPRÄP. NPA.-FEM PRÄP.-3sf PRÄP. SBST.-PL.-2pc

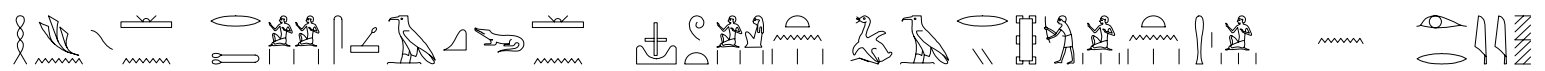

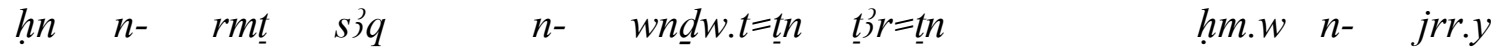

IMPV. PRÄP. SBST. IMPV. PRÄP. SBST.-FEM.-2pc SBST.-2pc SBST.PL.PRÄP. VB.-NPP.

Eine andere Möglichkeit, eure Herzen für sich einnehmend sein zu lassen, ist gegenüber euren Dienern noch effektiver als das: Seid fürsorglich zu den Menschen und verhaltet euch verbindlich gegenüber euren Leuten, damit ihr euch Diener sichert für das, was zu tun ist.

W-77 $§ 12,8$ (TC und PL)

\begin{tabular}{|c|c|c|c|c|c|c|c|c|c|c|}
\hline$n h ̣ b$ & b’k.w & $r-\underline{d}) . w t-$ & $\check{s} m^{c}$ & $p w$ & $h r-$ & $j b$ & n.t- & $n t r$ & $n(j)$ & $z p . n$ \\
\hline IMPY & SBS & PRÄP. & SBST. & DEM. & RÄP. & BST. & DET.-FEM. & ST. & IE & VP $P P$ \\
\hline
\end{tabular}




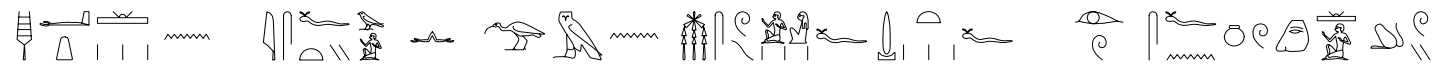

$$
\begin{aligned}
& c^{c} h^{c} . w \quad n(j)-j s f t y \quad n(j) g m . n \quad \text { ms.w=f } \quad \underline{d} \cdot . t=f \quad \text { jr } \quad \text { sfnw } \quad \text { phwwy } \\
& \text { SBST.PL. DET. SBST. NEG. VB.-PRÄT. } \quad \text { SBST.-PL.-3sm SBST.-FEM.-3sf FUT. NPA. SBST. }
\end{aligned}
$$

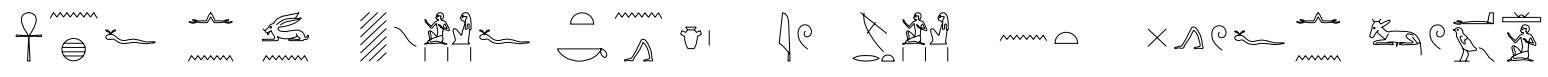

$$
\begin{aligned}
& { }^{c} n h=f \quad \text { nn } \quad w n \quad[m s] . w=f \quad t k n .(w) j b \quad j w \quad m r . t \quad n . t-\quad s w 3=f \quad n n \quad j w^{c} w \\
& \text { SBST.-3sm NEG. PRÄT. SBST.-PL.-3sm NPA-PL. SBST. TOP. SBST.-FEM.DET.-FEM. NPA.-3sm NEG. SBST. }
\end{aligned}
$$

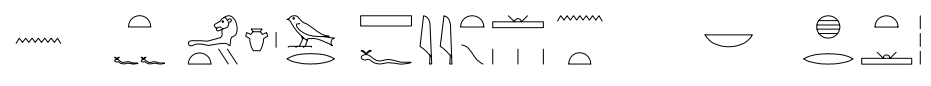

$$
\begin{aligned}
& \text { n- } \quad \text { tff } \quad h 3 t j \quad w r \text { sffyt n.t- } n b \quad \text { hr.t }
\end{aligned}
$$

Wer die Steuern nach Maßgabe des Getreide(ertrags) festsetzt, der ist nach dem Dafürhalten Gottes ein $<\ldots .>$. Die Reichtum eines Sünders kann unmöglich überdauern, und seine Kinder können nicht einmal einen Rest davon finden. Wer sich unrechtmäßig benimmt, führt das Ende seines Lebens herbei und wird keine Kinder haben, die dem Herzen nahestehen. Die Dienerschaft $<$ liebt $>$ einen, der über sich hinauswächst. ${ }^{195}$ Hingegen gibt es keinen Erben für jemanden, den das Herz abstößt. Groß ist das Prestige von jemandem, der seine Stimmung beherrscht. ( ${ }^{\circ}$ auf dem $\operatorname{Herz}^{\circ}$ )

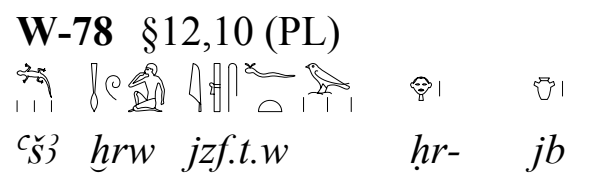

NPA. SBST. SBST.-FEM.ADJ. PRÄP. SBST.

Das Geschrei der Sünde schlägt laut auf das Gemüt. ( ${ }^{\circ}$ ist laut auf dem Herzen ${ }^{\circ}$ )

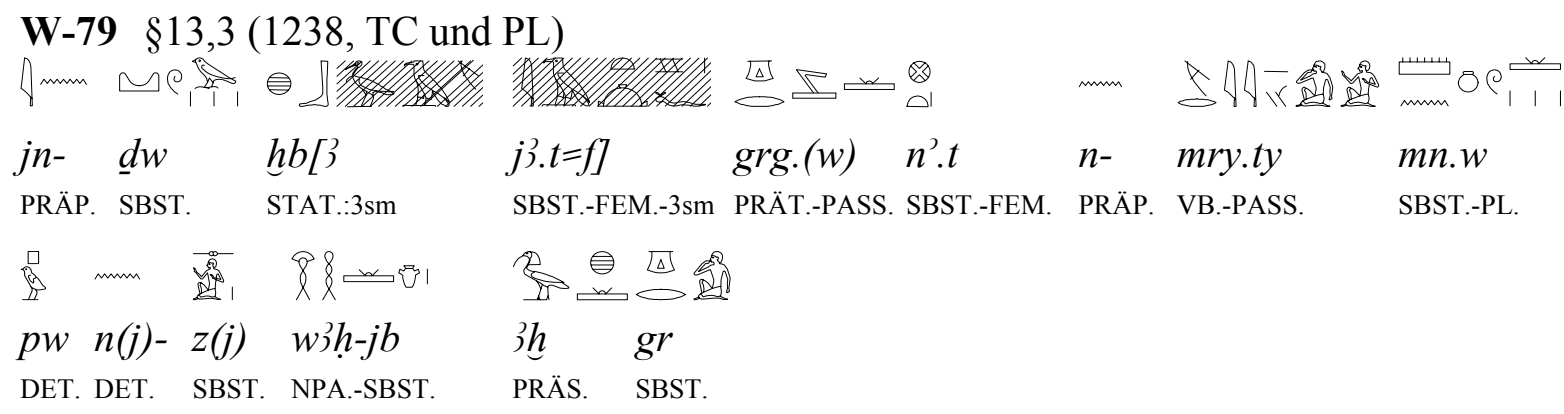

195 Das Verständnis dieser Passage ist außerordentlich problematisch. Was in der Fassung TC steht, sieht aus wie eine unvollständige Äußerung 'Die Dienerschaft eines, der über sich hinauswächst $<$... >', während man in PL eigentlich 'Die Liebe zu einem, der über (sich) hinauswächst <...>' lesen müßte. Die von Parkinson (1997: 241) angebotene Übersetzung "Serfs belong to the man who passes over himself" setzt nicht nur eine Emendation von $n t(j)$ zu $n$ - voraus, sondern wirft auch noch weitere Schwierigkeiten auf: Zwar gibt es im Mittelägyptischen gelegentlich Adverbialsätze, der Prädikatskern die Präposition $n$ - bildet, doch handelt es sich dabei keineswegs um Aussagen der Bedeutung ' $\mathrm{X}$ gehört $\mathrm{Y}$ ' (das müßte vielmehr $n j-X Y$ lauten), sondern um Sätze, die ' $\mathrm{X}$ ist für Y bestimmt' bedeuten (vgl. Gardiner 1957: § 114). Sodann ist in Parkinsons Interpretation *jw $m r . t n-\{t\} s w\}=f^{*}$ das suffigierte Personalpronomen $=f$ als direktes Objekt eines aktiven Partizips aufgefaßt, was als ungrammatisch gelten muß. Retten ließ sich der Ansatz allenfalls, wenn $s w^{3}=f$ als Relativform aufgefaßt würde, dann hieß es 'Die Dienstboten sind für den bestimmt, der ihn überholt'. 
Der Böse verwüstet seine eigene Heimstätte, während einem Beliebten schon eine Stadt gegründet wurde. Das, was bleibend an einen Menschen erinnert, ist Zurückhaltung; Schweigen ist effizient, .... $\left({ }^{\circ}\right.$ Hinlegen des Herzens $\left.{ }^{\circ}\right)$ 
Aus der Autobiographie des dritten Gottesvaters des Amun, namens Nefer

Datierung: $\quad$ XVIII. Dynastie ${ }^{196}$

Textausgaben: Gaballa (1970: Tafeln XXIV-XXV).

Übersetzungen: $\quad$ Gaballa (1970: 49-54); Bradboury (1986: 73-95), Brunner (1988: 392).

W-80 1

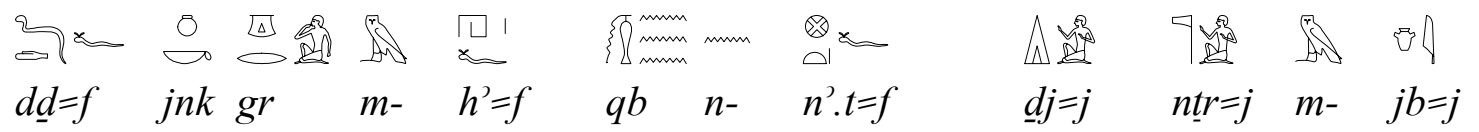

PRÄT.-3sm 1sc SBST. PRÄP. SBST.-3sm SBST. PRÄP. SBST.--FEM.-3sm PRÄT.-1sc SBST.-1sc PRÄP. SBST.-1sc

$\neq$ man

$n z w \quad m-\quad h 3 t j=j$

SBST. PRÄP. SBST.-1sc

(...) er sagt: Ich war ein im eigenen Hof Schweigsamer und der Ruhigste seiner Stadt, und mein Gott stand bei mir ebenso im Mittelpunkt, wie mir der König am Herzen lag. ( ${ }^{\circ}$ und ich gab meinen Gott in mein Herz und den König in mein Herz ${ }^{\circ}$ ) 
Die Lehre für Merikare (Helck 1977)

Quellen: $\quad$ Papyrus Leningrad = Papyrus Petrograd 1116A = St-Pétersbourg No. 1.

Datierung: $\quad$ XVII./XIX Dynastie ${ }^{197}$

Textausgaben: $\quad$ Helck (1977), Quack (1992).

Übersetzungen: $\quad$ Bissing (1955: 54-56), Klaembt (1969: 157-171), Lichtheim 1975: I, 97-109), Helck (1977), Blumenthal (1980: 5-41), Lalouette (1984: 50-57), Quack (1992: 1684), Foster (1992: 3-4), Roccati (1994: 55-71), Parkinson (1997: 212-234), Brunner (1988: 137-154), Burkard \& Thissen (2003: 98-103).

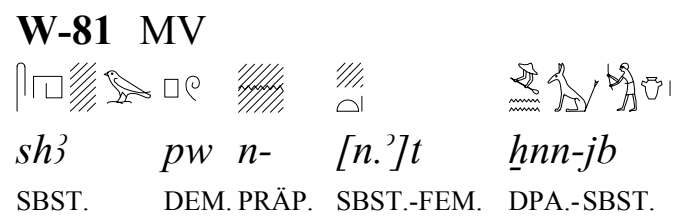

Ein Störenfried für eine Stadt ist der Streitsüchtige. $\left({ }^{\circ}\right.$ der mit streitbarem $\mathrm{Herz}^{\circ}$ )

W-82 PVIII

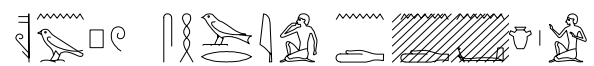

qns $p w$ shwr $\quad n(j)-d[n d n]-j b$

NPA. DEM. SBST. DET. DPA.-SBST.

Übel ist der Fluch eines Jähzornigen. ( ${ }^{\circ}$ eines mit wütendem $\mathrm{Herz}^{\circ}$ )

W-83 PXI

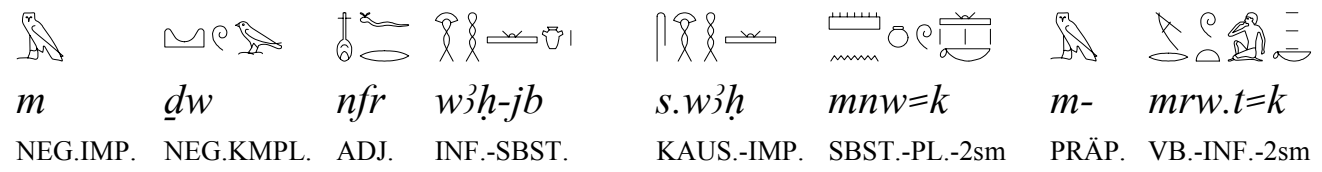

Sei nicht böse, Zurückhaltung ist gut. Lasse die Erinnerung an dich fortbestehen durch deine Beliebtheit. $\left({ }^{\circ}\right.$ Hinlegen des Herzens $\left.{ }^{\circ}\right)$

W-84 PXII

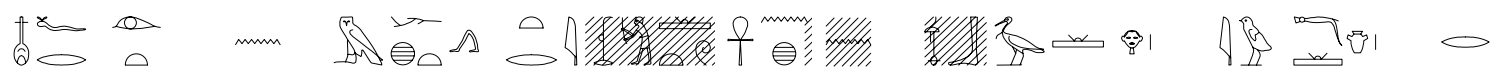
$n f r \quad j r . t \quad n-\quad m-h t \quad$ trj.tw $\quad{ }_{n} n h \quad n(j)-w b 3-\quad h r \quad j w \quad m h-j b \quad r-$ NPA. VB.-INF. PRÄP. SBST. VB.-imp. $\quad$ SBST. DET. NPA. SBST. TOP. NPA.SBST. PRÄP.

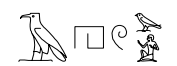

$3 h w$

NPA.

Gut für die Zukunft ist es, zu handeln, denn man respektiert das Leben dessen, der ein offenes Gesicht hat. Der Treuherzige jedoch wird zum Leidenden. $\left({ }^{\circ}\right.$ der das Herz füllt $\left.{ }^{\circ}\right)$

197 Blumenthal (1980: 40-41) mit sekundäre Bibliographie dazu; idem (1996: 128); Baines (1996: 160); Lichtheim (1996: 247); Quirke (1996: 388); Parkinson (1997: 212). 
W-85 PXIX

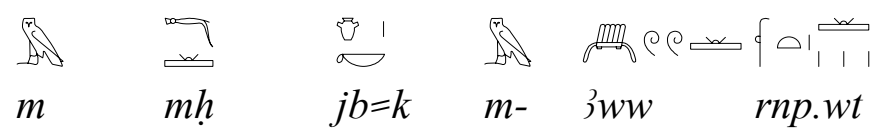

NEG.IMP. NEG.KMPL. SBST.-2sm PRÄP. SBST. SBST.-FEM.PL.

Vertraue nicht auf die Länge der Jahre.

\section{W-86 PXXI}

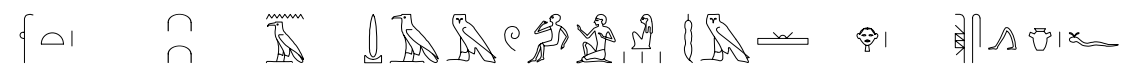

rnp.t $\underline{d} w . t j n\} \quad \underline{d} 3 m w \quad n \underline{d m} \quad$ hr- $\quad \check{s} m s j b=f$

SBST.-FEM.NUM. DEM. SBST. STAT.:3sm PRÄP. INF. SBST.-3sm

Zwanzig Jahre lang ist die Jugend fröhlich der eigenen Laune gefolgt. ( ${ }^{\circ}$ ihrem Herzen $^{\circ}$ )

\section{W-87 PXXXI}

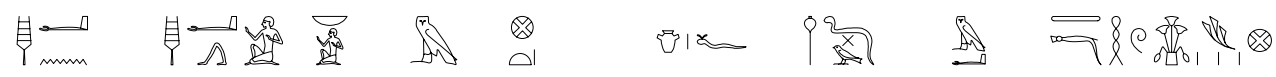

$c^{c} . n \quad c h c^{c} \quad n b \quad m-\quad n^{\prime} . t \quad j b=f \quad h \underline{d} \quad m-c_{-} \quad T 3-m h w$

VB.-PRÄT. NPA. SBST. PRÄP. SBST.-FEM.SBST.-3sm STAT.3sm PRÄP. TOPON.

Einer stand auf, ein Herr in einer Stadt, dessen Gefühl verletzt war durch Unterägypten. $\left({ }^{\circ} \mathrm{Herz}^{\circ}\right)$

\section{W-88 PXXXV}

\begin{tabular}{|c|c|c|c|}
\hline Nov & -0 & 81 & b \\
\hline & $r \underline{d}$ & $j b=k$ & $-m-s\}=$ \\
\hline
\end{tabular}

Mach dir keine Gedanken um ihn. ('lege dein Herz nicht hinter ihn ${ }^{\circ}$ )

W-89 PXXXVII

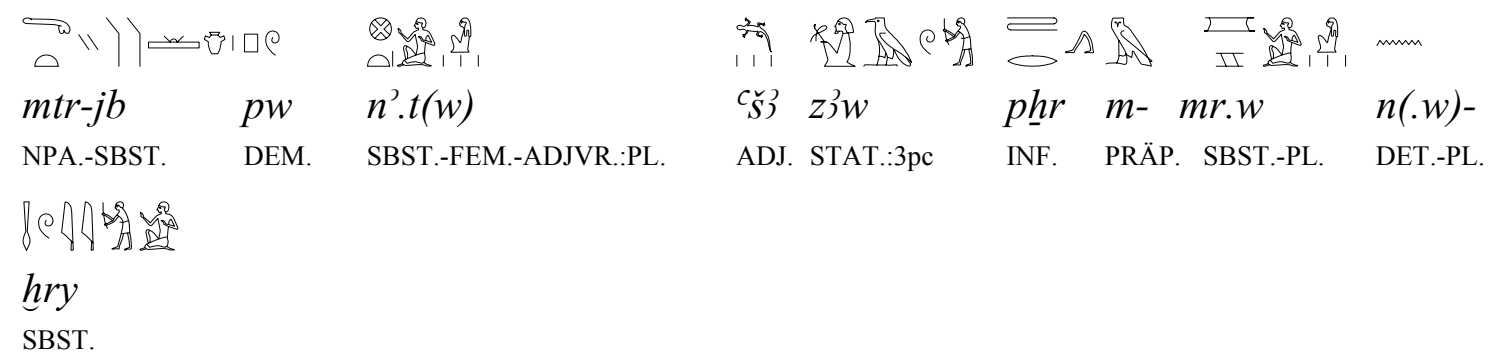

Aufrichtigen Herzens sind die Stadt und ihre Bewohner, wenn sie sich vor dem Umgang mit den Angehörigen des Feinds hüten.

\section{W-90 CXXXVIII}

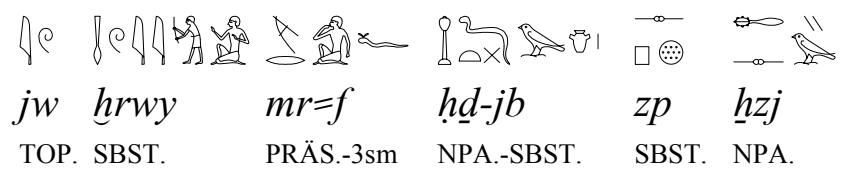

Der Feind mag das, was das Herz zerstört, und den Frevel. 
W-91 PXL

\begin{tabular}{|c|c|c|c|c|c|}
\hline 2 & $\infty_{-\infty} \mathbb{N}^{\prime \prime}$ & Wl & N & & $-1 / 1 / 11$ \\
\hline$\underline{d d}$ & $p w$ & $j b$ & $m$ & $f h$ & ${ }^{c} \cdot w j=k$ \\
\hline
\end{tabular}

NEG.IMP. NEG.KMPL. NPA. DEM. SBST. NEG.IMP. NEG.KMPL. SBST.-du.-2sm

Sage nicht "Das Herz ist schwach", und laß nicht locker mit den Händen.

W-92 PXLIV

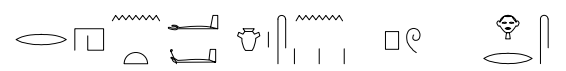

rhn.t $\quad j b=s n \quad p w \quad-h r=s$

RLTVF.-FEM. SBST.-3pc DEM. PRÄP.-3sf

Das ist, worauf ihr Herz sich stützt.

\section{MXLIV}

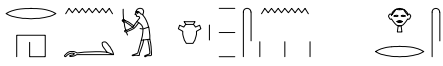

$r h n \quad j b .(w)=s n \quad-h r=s$

RLTVF. $\quad$ SBST.-PL.-3pc PRÄP.-3sf

Denn ihre Herzen stützen sich darauf.

\section{CXLIV}

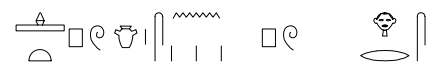

$h t p \quad j b=s \quad p w \quad-h r=s$

NPA. SBST.-3pc DEM. PRÄP.-3sf

Das bedeutet, ihre Stimmung ist damit zufrieden. $\left({ }^{\circ} \mathrm{ihr} \mathrm{Herz}^{\circ}\right)$

W-93 PXLIV

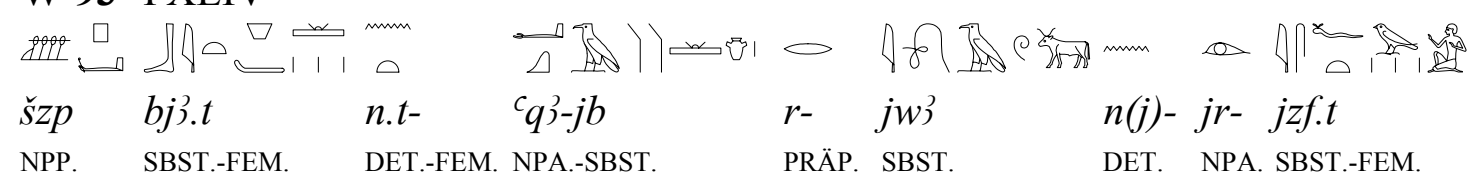

Das Opferbrot eines mit aufrichtigem Herzen wird eher akzeptiert als das Rind eine Sünders.

Das Herz kommt bei PXLVI aber mit der Bedeutung lebendig vor. Gott hat den Himmel, und die Erde und die Luft... den Menschheit gegeben, damit die Menschen leben können. 


\section{Die Lehre des Königs Amenemhet}

Quelle: $\quad$ Papyrus Sallier I verso und recto 2.

Datierung: $\quad$ XVIII./XIX. Dynastie ${ }^{198}$

Textausgabe: Helck (1969).

Übersetzungen: $\quad$ Erman (1923: 106-109), Lichtheim (1975: I, 135-139), Blumental (1984: 85-107), Goedicke (1988), Roccati (1994: 73-78), Parkinson (1997: 203-211), Burkard \& Thissen (2003: 104-109).

W-94 IIb (MiII)

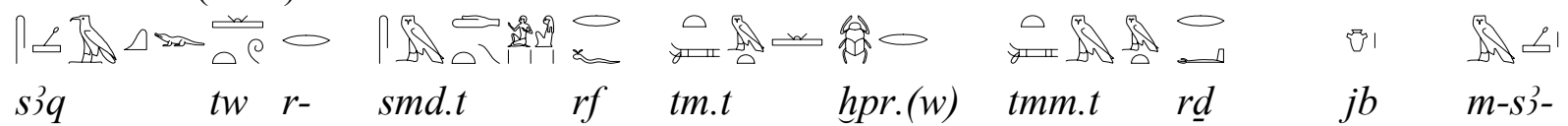
IMP. 2 sm PRÄP. SBST.-FEM. PTCL. NPA.-FEM. NEG.KMPL. DPP.-FEM. NEG.KMPL. SBST. PRÄP.

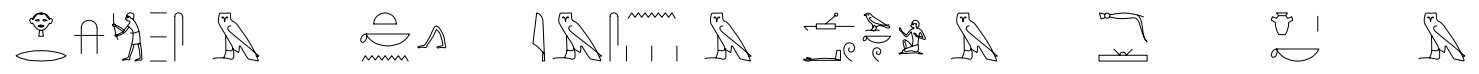
$h r .(w)=s \quad m \quad t k n \quad-j m=s n \quad m-\quad w^{c}=k \quad m \quad m h \quad j b=k \quad m-$ SBST.-PL.-3sf NEG.IMP. NEG.KMPL. PRÄP.-3pc PRÄP PRÄS.-2sm NEG.IMP. NEG.KMPL. SBST.-2sm PRÄP.

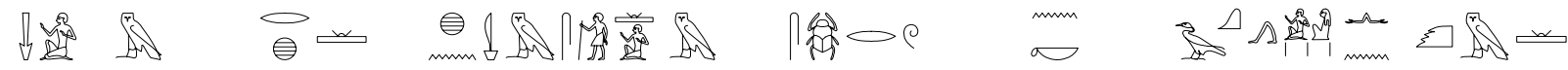
$\begin{array}{lllllllll}\text { sn } & m & \text { hh } & \mathrm{hnm} & \text { s.hpr.w } & -n=k & { }^{c} q . w & n n & \mathrm{~km}\end{array}$

SBST. NEG.IMP. NEG.KMPL. SBST. NEG.IMP.KAUS.-NEG.KMPL. PRÄP.-2sm SBST.-PL. NEG. INF.

$\ell_{11}^{\infty}$

jry

ADJ.

Nimm dich in acht vor Hilfspersonal, das nichts geworden ist und um dessen Bereitwilligkeit man sich keine Gedanken macht. Komm ihnen nicht zu nahe, wenn du allein bist. Vertraue keinem Bruder, kenne keinen Freund und schaffe dir keine Vertrauten. Das führt zu nichts. ('hinter dessen Bereitschaft man das Herz nicht legt ${ }^{\circ} /{ }^{\circ}$ fülle nicht dein Herz mit einem Bruder $^{\circ}$ )

W-95 IIIa (MiII)

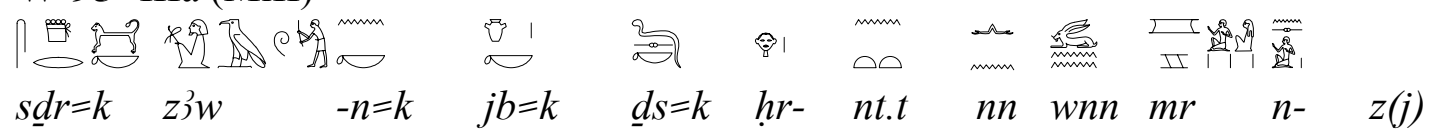

PRÄS.-2sm PRÄS. PRÄP.-2sm SBST.:2sm SUF.-2sm PRÄP. CMPLR. NEG. FUT. SBST. PRÄP. SBST.

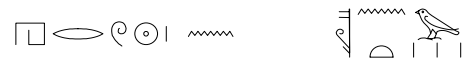

$h r w(w) \quad n(. t) \quad$ qsn.t

SBST. DET.-FEM. SBST.-FEM.

Solange du schläfst, wacht für dich nur dein Herz, denn es wird für keinen Menschen Anhänger am Tag des Unheils geben.

198 Helck (1969: 1); Lichtheim (1975: 136); Blumenthal (1996: 131); Baines (1996: 160, Anm. 17); Quirke (1996: 272 u. 388). 
W-96 VIb (MiII)

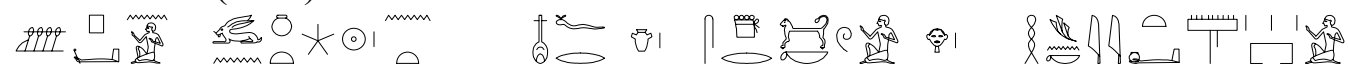

$\check{s} s p . n=j \quad$ wnw.t $\quad$ n.t- $\quad n f r \quad j b \quad s \underline{d} r . k w \quad h r-\quad h n k .(w) t=j$

VB.-PRÄT.-1sc SBST.-FEM. DET.-FEM. INF. SBST.STAT.-1sc PRÄP. SBST.-FEM.PL.-1sc

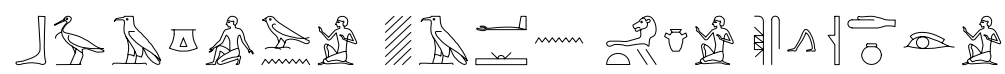

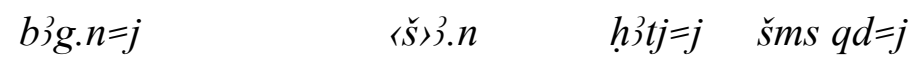

VB.-PRÄT.-1sc VB.-PRÄT. SBST.-1sc INF. SBST.-1sc

Ich genoß eine Stunde der Entspannung, während ich auf meiner Bettstatt lag. Ich wurde müde, und mein Herz begann, mir in den Schlaf zu folgen. ( ${ }^{\circ}$ das Gutseins des Herzens ${ }^{\circ}$ )

W-97 VIIIe (MiII)

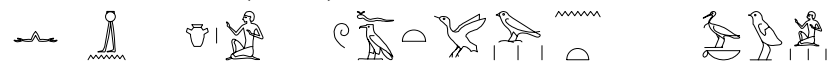

$n(j)$ jn $j b=j \quad$ wsf.t $\quad$ n.t bjk.w

NEG. PRÄT. SBST.-1sc SBST.-FEM. DET.-FEM. SBST.-PL.

Mein Herz konnte nicht über die Unzuverlässigkeit der Diener hinwegkommen.

W-98 XIVe (MiII)

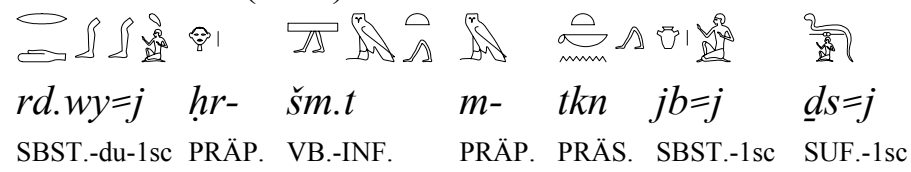

XIVf(DM 1103)

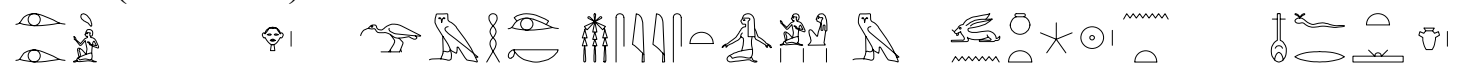

$j r .(t j)=j \quad h r-g m h=k \quad m s y \quad m-\quad$ wnw.t $\quad$ n.t- $\quad$ nfr.t- $j b$

SBST.-FEM.du-1sc PRÄP. INF.-2sm NPP. PRÄP. SBST.-FEM. DET.-FEM. ADJ.-FEM. SBST.

$\mathrm{XIVg}(\mathrm{DM} 1103)$

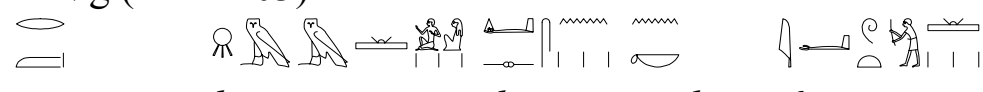

$r$ - gs hnmm.t $\quad \underline{d j}=s n \quad-n=k \quad j^{c} w . t$

PRÄP. SBST. SBST.-FEM. PRÄS.-3pc PRÄP.-2sm SBST.-FEM.

Meine Füße gehen davon, während bloß mein Herz mir nahe ist. Meine Augen erblicken dich, der Du geboren wurdest in einer Stunde des Glücksgefühls, neben dem Sonnenvolk, das dich preist. $\left({ }^{\circ}\right.$ Gutsein des Herzens ${ }^{\circ}$ )

W-99 XVb (s.II)

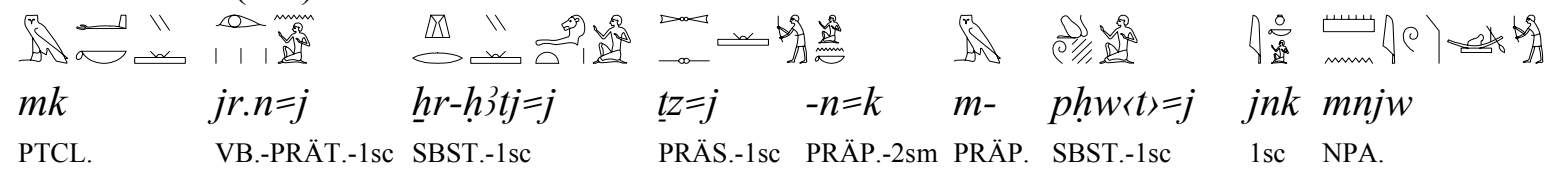




\begin{tabular}{|c|c|c|c|}
\hline mmm & mnn & N & 赵 \\
\hline$n t . y w$ & nty & $m-$ & $j b=k$ \\
\hline PRÄP. REL.-PL. & REL. & PRÄP & SBST.-2sm \\
\hline
\end{tabular}

Sieh doch, ich habe meinen früheren Zustand (wieder) hergestellt, und ich knüpfe für dich an meinem Ende an. Ich bin es, der für die Seienden steuert und in deinem Herzen ist.

$\mathrm{XVb}(\mathrm{DM} 12004)$

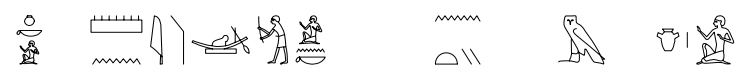

jnk $m n j \quad-n=k \quad$ nty $\quad m-j b=j$

1sc NPA. PRÄP.-2sm REL. PRÄP. SBST.-1sc

Ich bin einer, der für dich lenkt, der du in meinem Herzen bist. 


\section{Brief des Menna an seinen Sohn Paj-jrj}

Quelle: $\quad$ Ostrakon Oriental Institute 12074

Datierung: Ramessidenzeit ${ }^{199}$

Textausgabe: Foster (1984).

Übersetzungen: $\quad$ Goedicke (1987: 63-80), Brunner (1988: 399-402), Guglielmi (1983: 147-166), Foster (1984: 56-58).

\section{W-100 20-21}

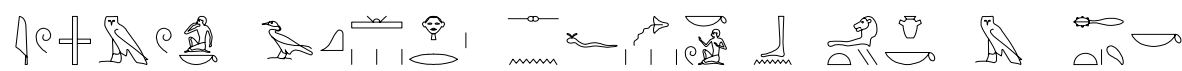 \\ jw $\quad w m=k \quad{ }^{c} q \quad$ hr- $\quad s n f=k \quad$ bn $h i j t j=k \quad m-\quad \underline{h} . t=k$}

PTCL. PRÄT.-2sm SBST. PRÄP. SBST.-2sm NEG. SBST.-2sm PRÄP. SBST.-FEM.-2sm

Du ißt mit deinem Blut vermischtes Brot, denn du bist nicht bei Verstand. ( ${ }^{\circ}$ denn dein Herz ist nicht in deinem Körper ${ }^{\circ}$ )

\section{W-101 26-27}

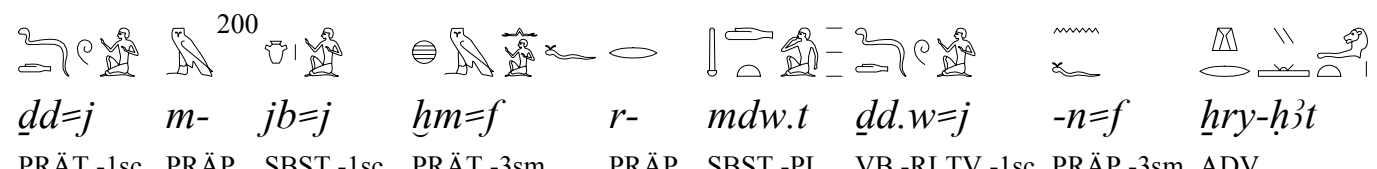

PRÄT.-1sc PRÄP. SBST.-1sc PRÄT.-3sm PRÄP. SBST.-PL. VB.-RLTV.-1sc PRÄP.-3sm ADV.

Ich sprach zu mir selbst: Er hat überhaupt nicht auf die Worte geachtet, die ich vorher gesagt habe. ( ${ }^{\circ}$ in meinem $\operatorname{Herz}^{\circ}$ )

\section{W-102 64-69}

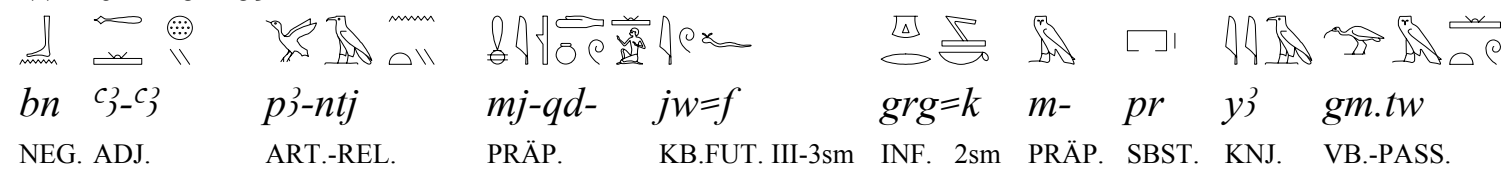

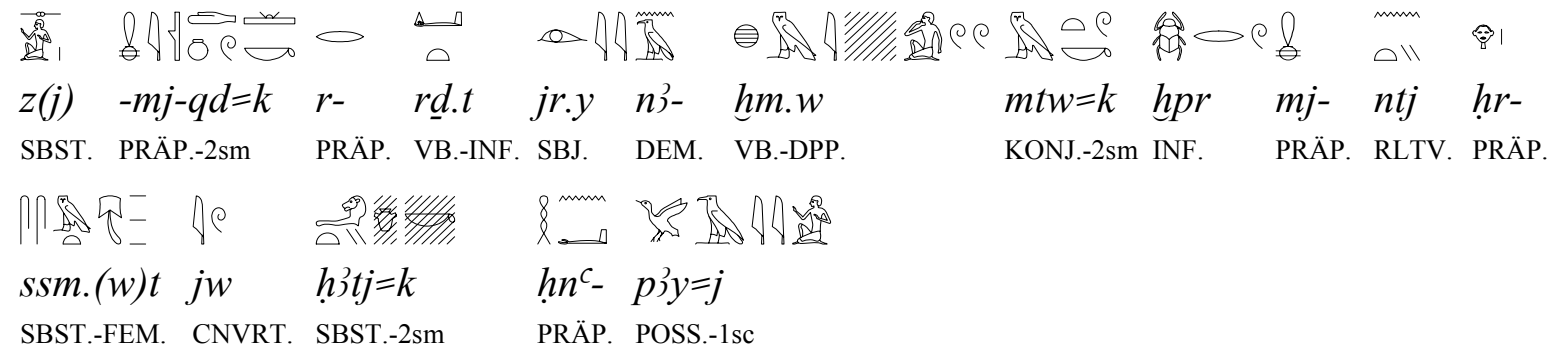

Wer genauso ist, ist unmöglich bedeutend, aber er wird dich in einem Haus unterbringen. Und dann wird man jemanden von deiner Wesensart finden, um dafür zu sorgen, daß die Ignoranten aktiv werden und du wie einer auf dem Pferd bist, während dein Herz bei dem meinigen ist! 


\section{Von einer Schultafel}

Datierung: $\quad$ Spätere Ramenssidenzeit ${ }^{201}$

Textausgabe: $\quad$ Van de Walle (1963: 118-123).

Übersetzung: $\quad$ Brunner (1988: 398).

\section{W-103}

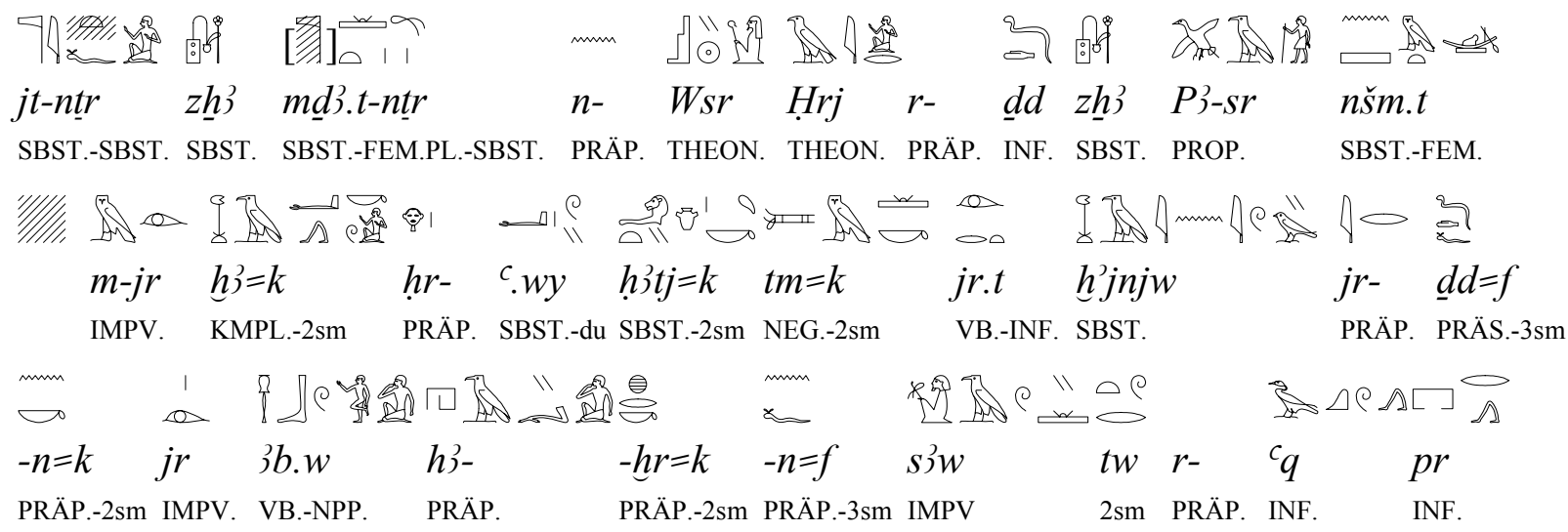

Der Gottesvater und Gottesbuchschreiber des Osiris Hori spricht (zu) Paser, dem Schreiber der Neschemetbarke: Mach dich nicht abhängig von deinem Gefühl, damit du vermeidest, Dummes zu tun. Wenn es dir sagt: "Tu was du willst!"202, dann mußt du erwidern: "Hüte dich davor, mal in die eine und mal in die andere Richtung zu streben". ${ }^{203}$ ( ${ }^{\circ}$ eg dich nicht in die Hände deines Herzens ${ }^{\circ}$ ) 


\section{Die Lehre des Papyrus Chester Beatty IV}

Quellen:

Datierung:

BM 10684

Textausgaben:

Spätere XIX. Dynastie ${ }^{204}$

Übersetzungen:

Gardiner (1935: II, P1. 8-22).

Wilson (1969: 431-432), Lichtheim (1976: II, 175-178), Brunner (1988: 218-230).

W-104 Verso II, 2

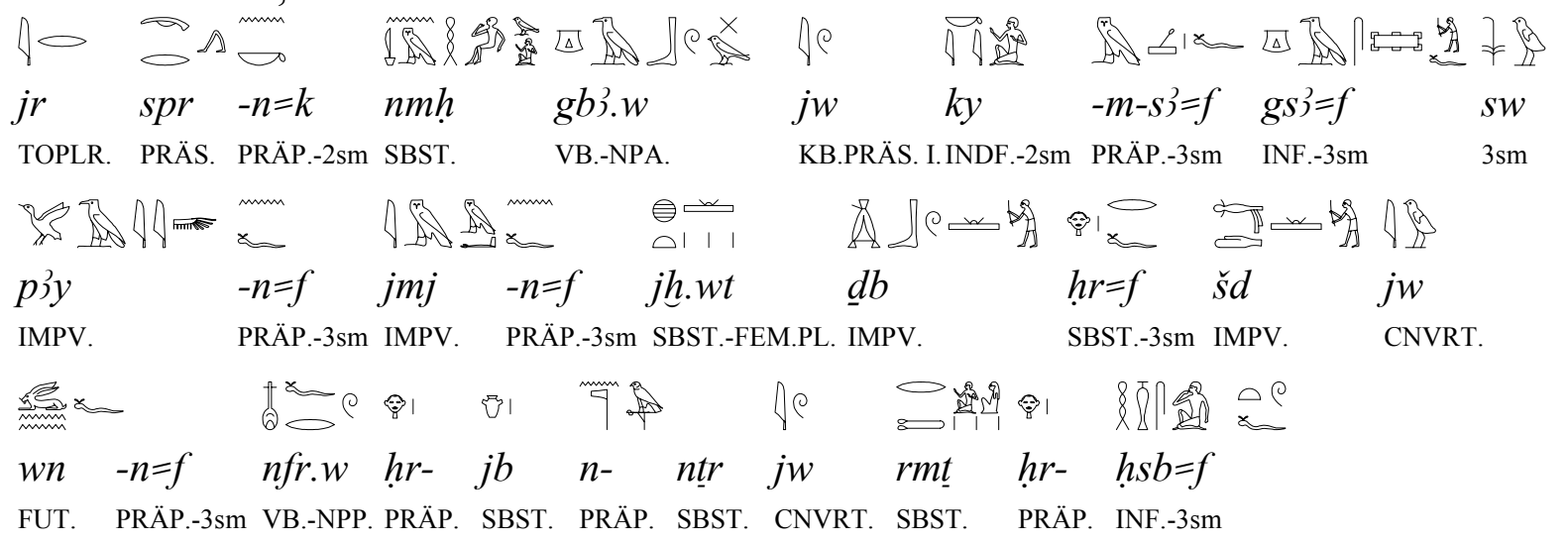

Wenn ein Bedürftiger, der verschuldet ist, weil ein anderer hinter ihm her ist und ihn betrügt, so daß er schließlich geflohen ist, sich an dich wendet, dann gibt ihm etwas und zahle um seinetwillen, damit er erlöst ist. Wenn ihm Gutes widerfährt, ist das ganz im Sinne Gottes. Und die Leute werden es anerkennen. ( ${ }^{\circ}$ auf dem Herzen ${ }^{\circ}$ )

W-105 Verso II, 13

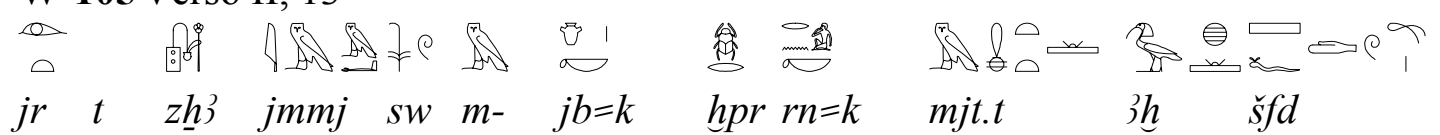

IMP. 2 sm SBST. IMPV. 3sm PRÄP. SBST.-2sm FUT. SBST.-2sm SBST.-FEM. ADJ. SBST.

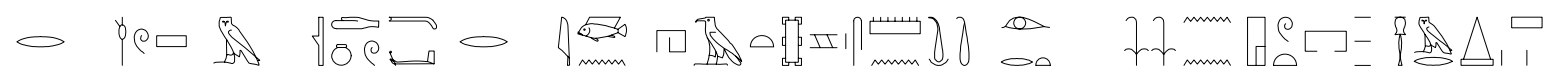

$r-\quad w \underline{d} \quad m-\quad q d . t \quad r-\quad j n r$ hi.t $\quad$ smn.tj jr.t $n n$ ḩw.t $m r$

PRÄP. SBST. PRÄP. SBST.-FEM.PRÄP. SBST. SBST.-FEM. VB.-PASS. VB.-INF. DET. SBST.-FEM.SBST.

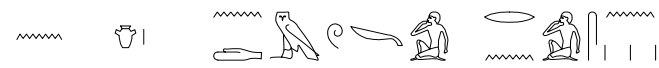

$n-\quad j b \quad n-\quad d m \quad r n=s n$

PRÄP. SBST. PRÄP. RLTV.PRÄS. SBST.-3pc

Schreibe auch ${ }^{205}$ und nimm es dir zu Herzen, damit du dir genauso einen Namen machst. Ein Schriftrolle ist besser als eine Stele in musterhafter Ausführung oder als eine massive Kapellenwand. Das zu tun (ist gleichbedeutend mit) Tempeln oder Gräbern nach Meinung dessen, der ihren Namen nennt. ('gib es in dein Herz ${ }^{\circ}{ }^{\circ}$ für das Herz ${ }^{\circ}$ )

W-106 Verso IV, 11

$\begin{array}{lllllllll} & \end{array}$

204 Gardiner (1935: I, S. 28).

$205{ }^{\circ}$ tu schreiben ${ }^{\circ}$. 


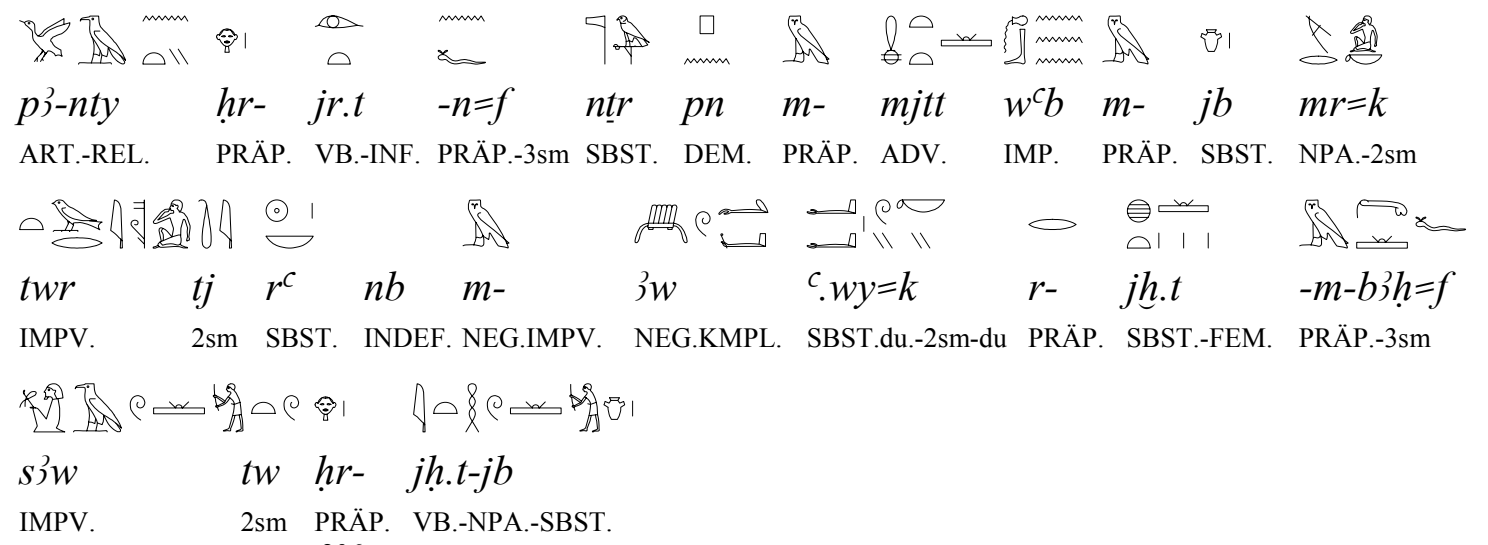

Opfere dem Gott $^{206}$ aus ganzem Herzen, damit er dir die Versorgung zugesteht, die er normalerweise gewährt. Die Menschen lieben denjenigen, der für Gott ${ }^{207}$ tätig ist, und er selbst $^{208}$ ebenso. Halte dich mit Eifer sauber und sei allzeit ordentlich. Streck deine Finger nicht nach dem Besitz vor ihm aus. Hüte dich davor, das Herz einzuschüchtern. ( ${ }^{\circ}$ aus dem Herz, das du liebst ${ }^{\circ} /{ }^{\circ}$ aus dem Herz, das du liebst ${ }^{\circ}$ )

W-107 Verso VI, 8

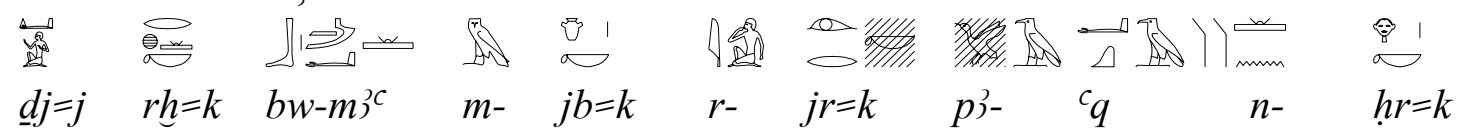

FUT.-1sc SBJ.-2sm SBST.-SBST. PRÄP. SBST.-2sm PRÄP. PRÄS.-2sm ART. PRÄS. PRÄP. SBST.-2sm

Ich will dafür sorgen, daß du Rechtschaffenheit in deinem Herzen erkennst, so daß du das tun kannst, was deiner Ansicht nach richtig ist. 


\section{Die satirische Streitschrift des Papyrus Anastasi}

Quellen:

Datierung:

Textausgabe:

Papyrus Anastasi I

Ramessidenzeit ${ }^{209}$

Übersetzungen:

Fischer-Elfert (1986: 94).

Fischer-Elfert (1986), Brunner (1988: 396-397), Wente (1992: 217-218).

W-108 An. I 1,1

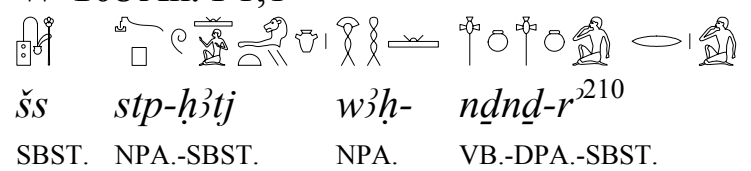

Der Schreiber mit überragendem Verstand und mit überlegtem Ratschlag. $\left({ }^{\circ} \mathrm{Herz}^{\circ}\right.$ )

W-109 An. I 1,4-1,5

\begin{tabular}{|c|c|c|c|c|c|c|c|c|c|}
\hline$\therefore c$ & $\lambda_{0}$ & 임 & $21^{2}$ & $\underset{\infty}{\infty}$ & $\cap \_\mathbb{R}$ & 0 & $\left.\frac{3}{2}-1\right] 2$ & RAd & $\otimes \prod_{1}^{m}$ \\
\hline$s t p$ & jp & & $\underline{d} . t=f$ & $c_{r q}$ & şr.t & & $s b 3 q$ & hijtj & $-h r=s\{n\}$ \\
\hline NPA. & NPA. & PRÄP. & SBST.-FEM.-3sm & NPA. & SBST.-FEM. & & NPA. & SBST. & PRÄP.-3sf \\
\hline & & $\neq$ & 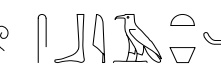 & & & (1) & $v_{-}^{-}$ & 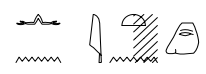 & en \\
\hline$S^{3}$ & & $s v$ & $s b 3 . t=f$ & & mrytj & $m$ & $j b . w$ & $n n \quad j t n=f$ & \\
\hline NPA. & & $3 \mathrm{st}$ & n SBST.-FEM.-3s & & SBST. & Ä. & SBST.-PL. & NFG. SBST - $3 \mathrm{~s}$ & \\
\hline
\end{tabular}

Einer, der auswählen kann, und sein Selbst kontrolliert ${ }^{211}$, einer mit klugem Verstand, der durch ihn die Seele erleuchtet, einer, der sich <infolge $>$ seiner Erziehung zusammenreißen kann, ein in den Herzen Beliebter, der keinen Konkurrenten hat. $\left({ }^{\circ} \mathrm{Herz}^{\circ}\right)$

W-110 An. I 1,7-1,8

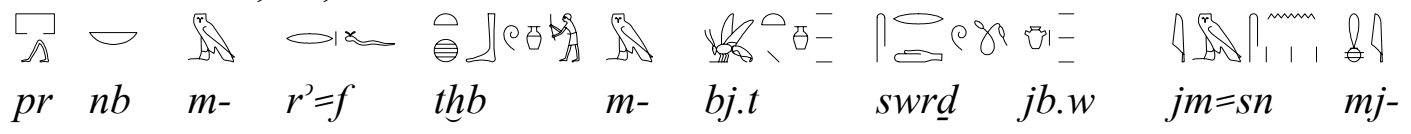

NPP. INDEF. PRÄP. SBST.-3sm STAT.:3sm PRÄP. SBST.-FEM. FUT.PASS SBST.-PL. PRÄP.-3pc PRÄP.

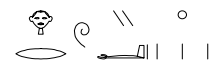

$h r j(. t)_{-}{ }^{c}$

SBST.-FEM.-SBST.

Alles, was aus seinem Mund strömt wird, ist in Honig getaucht, so daß die Herzen dadurch gefestigt werden wie durch einen Heiltrank.

W-111 An. I 2,3-2,5

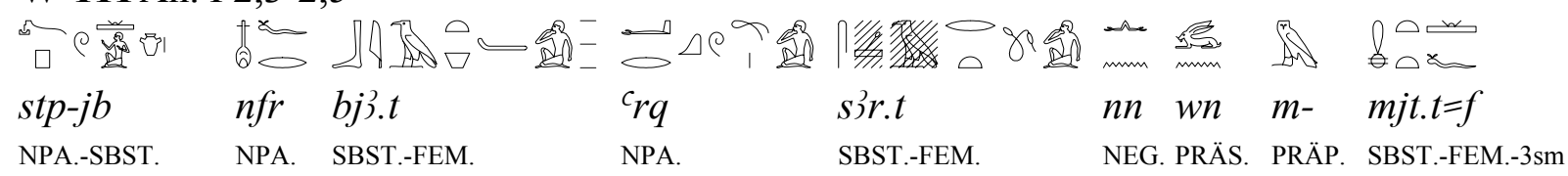

209 Brunner (1982: 676).

210 Für die Lesung siehe Fischer-Elfert (1986: 13).

211 Die Stelle ist nicht unproblematisch und ist verschieden interpretiert worden. Hannig (1995: 662, s.v. s3q) scheint von folgender Lesung ausgegangen: $s i q s w\{s\}\langle h r\rangle b j 3 . t=f$ 'der sich seines Chrakters wegen beherrst'. Hingegen ist im Wörterbuch der ägyptsichen Sprache ein Lemma sbj.3.t 'Lachen' verzeichnet (Wb IV 89,5), woraus auf folgende Lesart geschlossen werden darf: $s 3 q s w\langle r\rangle s b j 3 . t=f$ 'der sich vor seinem Lachen in acht nimmt'. Siehe auch Fischer-Elfert (1986: 20 ff.). 


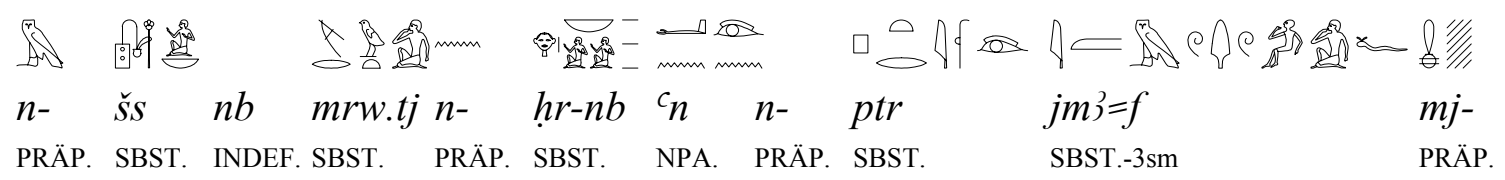

Alov- $\begin{array}{ll}- \\ -\end{array}$

jh.w $\quad h r-\quad j b \quad n-\quad k j . w$

SBST.-PL. PRÄP. SBST. PRÄP. SBST.-PL.

Der, der an der Seele ausgewählt ist, am Charakter perfekt ist und am Verstand klug ist, der unter allen Schreibern nicht seinesgleichen hat. Beliebt von allen Leute, schön anzusehen, dessen angenehmen Wesen nach Meinung der Leute wie süße Früchte ist. $\left({ }^{\circ} \mathrm{Herz}^{\circ}\right.$ / ${ }^{\circ}$ Herzen $^{\circ}$ ).

W-112 An. I 2,6

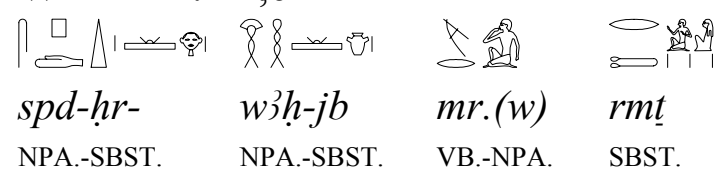

Einer, der aufmerksam und zurückhaltend ist, einer, den die Leute lieben. $\left({ }^{\circ}\right.$ das Herz hinlegen ${ }^{\circ}$ )

W-113 An. I 2,7-2,8

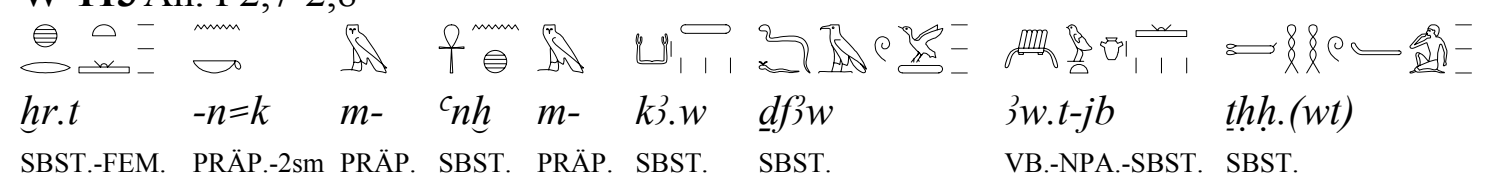

$\begin{array}{lll}\text { STAT.:3pc } & \text { PRÄP. } & \text { SBST.-SBST.-FEM.-2sm }\end{array}$

Bedarf von dir an Leben an Nahrung und an Speisen. Freude und Jauchzen sind auf sich in deinem Weg vereinigt.

W-114 An. I 5,7-5,8

\begin{tabular}{|c|c|c|c|c|c|c|c|c|c|c|}
\hline $8 \& \underset{0}{\infty}$ & 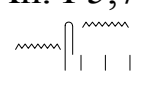 & 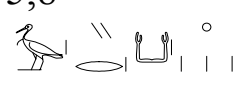 & 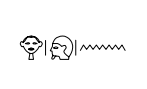 & 迹 & thi. & $2 e_{-}^{-}$ & WIIII, & क्ष & $\underbrace{E}_{0}$ & $f e_{1}^{m}, 1$ \\
\hline wi $h=k$ & $-n=s n$ & brk & $h r-t p-n$ & $z(j)$ & $n b$ & $\underline{d} d=w$ & $-n=k$ & smn & $j b=k$ & $j w=n$ \\
\hline IMPV.-2sm & PRÄP.-3pc & SBST. & PRÄP. & SBST. & INDEF. & FUT.-3pc & PRÄP.-2sm & IMPV. & SBST.-2sm & KB.FUT.III-2pc \\
\hline$\infty$ & $\square \Longrightarrow$ & & & & & & & & & \\
\hline$r-$ & $h d=f$ & & & & & & & & & \\
\hline RÄP. & INF.-3sm & & & & & & & & & \\
\hline
\end{tabular}

Liege ihnen Opfer für jeden einzelnen Mann hin. Sie werden dir sagen: Mach dein Herz standfest und wir (die Schreiber) werden ihn (Hori) bekämpfen.

W-115 An. I 6,3

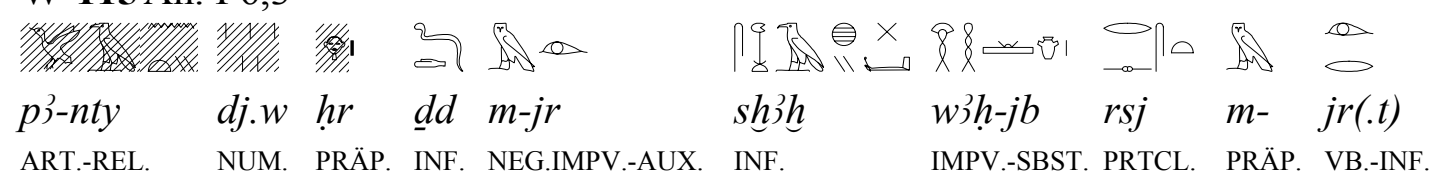




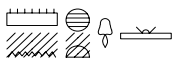

mnh.t

SBST.-FEM.

Der fünfte (Schreiber) sagte: Sei nicht vorschnell, sondern halte dich lieber zurück, wenn du das Richtige tust. $\left({ }^{\circ}\right.$ das Herz hinlegen $\left.{ }^{\circ}\right)$

W-116 An. I 8,6-8,7

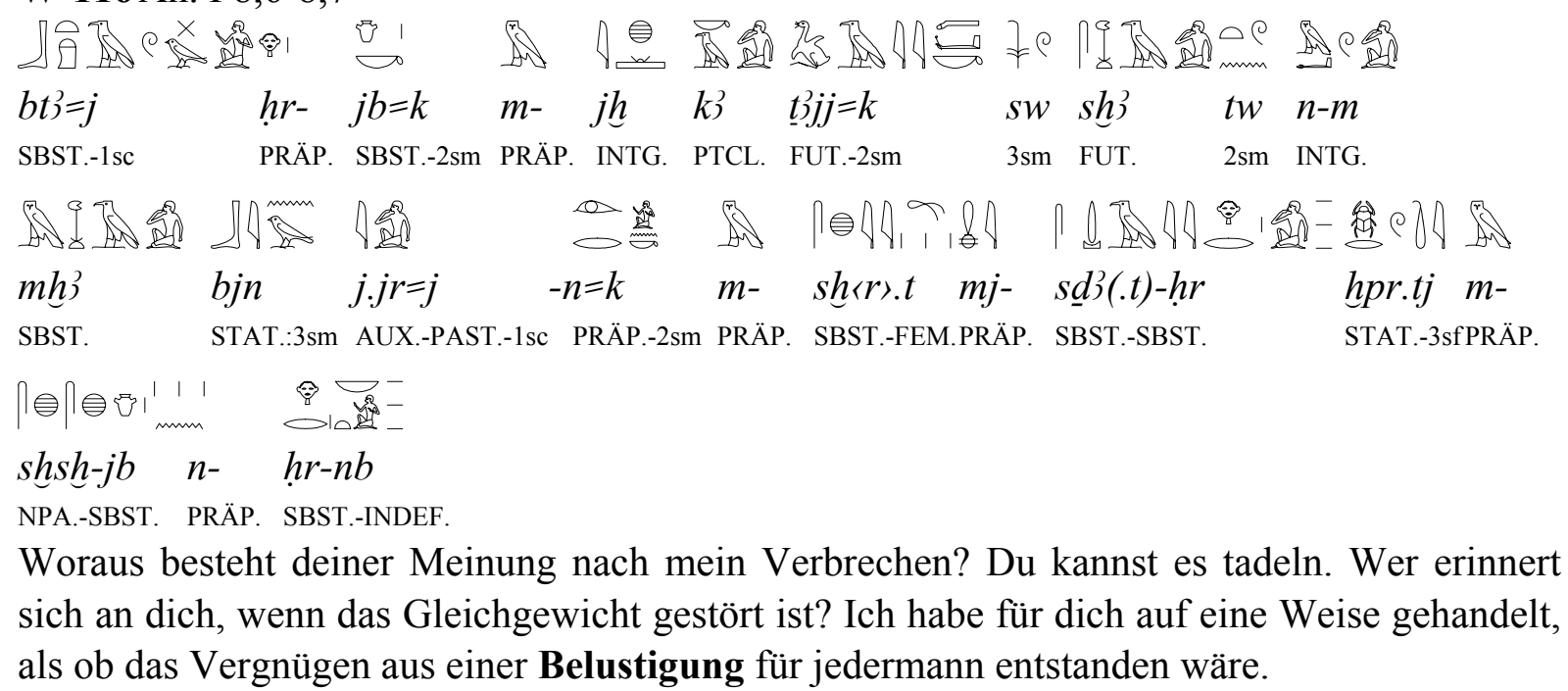

W-117 An. I, 11, 2-3

\begin{tabular}{|c|c|c|c|c|c|c|}
\hline$n t k$ & $s \check{S}$ & 533 & $m-h$ h.t $-j r y \cdot w=f$ & $s b 3 y . t$ & {$[\check{s} f d w]$} & ht.tj \\
\hline $2 \mathrm{sm}$ & SBST. & NPA. & SBST.-PL.-3sm & SBST.-FEM. & SBST.-PL. & STAT.-3sf \\
\hline
\end{tabular}

$\underset{\zeta}{0}$

$j b=k$

SBST.-2sm

Du bist ein Schreiber, der, was seinen Verstand betrifft, an der Spitze seiner Kollegen steht. Die Lehre der Bücher ist in deinem Herzen eingraviert.

W-118 An. I 14,5

$\begin{array}{llll}m h=w & j b=w & -j m=k & r-\underline{d} r=w \\ \text { FUT.-3pc } & \text { SBST.-3pc } & \text { PRÄP.-2sm } & \text { PRÄP.-SBST.-3pc }\end{array}$

Sie werden dir völlig vertrauen. $\left({ }^{\circ}\right.$ ihre Herzen erfüllen sich mit dir $\left.{ }^{\circ}\right)$

W-119 An. I 15,1-15,2

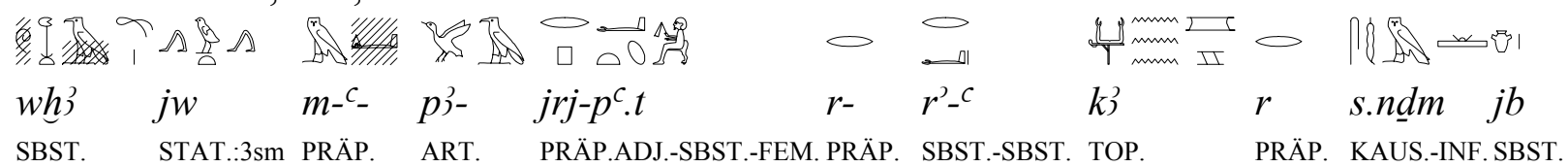


min

n- $\quad H r-n b w$

PRÄP. THEON.-ADJ.

Ein amtliches Schreiben vom Fürst ist bis nach Ka gekommen, um das Herz des Goldhorus zu erfreuen.

W-120 An. I 15,8-16,2

PRTCL.FUT.-2sm
$m k \quad$ FUT.-1sc SUBJ.

Siehe doch, wenn du gehst, lasse ich dein Herz sich freuen. Ich [...] am Anfang wie du. Fangen wir einen Kampf zusammen an. Denn mein Verstand ist verständig und meine Finger gehorchen, denn sie sind kundig, selbst wenn du mich in die Irre schickst. $\left({ }^{\circ}\right.$ mein $\operatorname{Herz}^{\circ}$ )

W-121 An. I 17,1,17,2

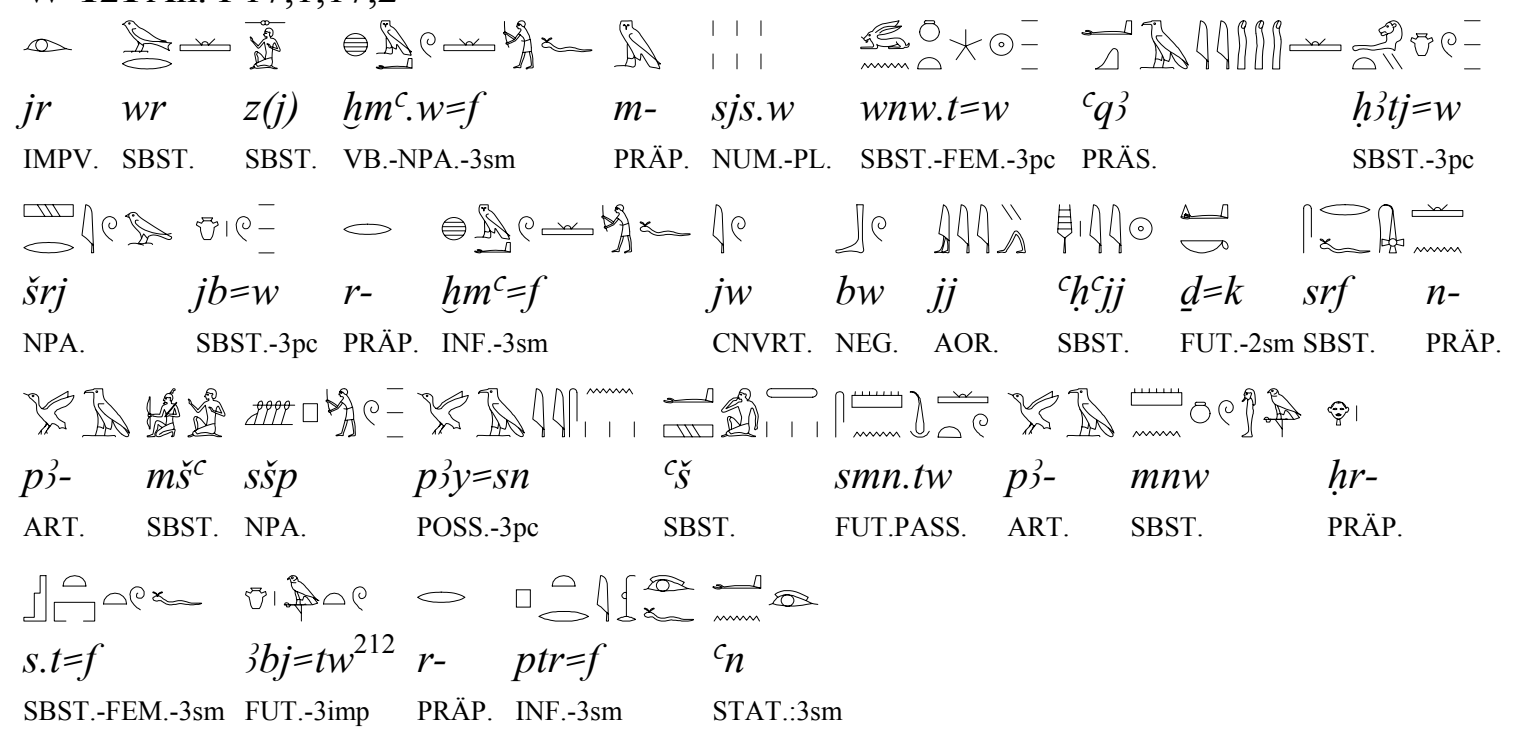

Rechne die Zahl der Männer, die ihn (scil. den Sand) in sechs Stunden wegräumen können, wenn ihre Disposition richtig ist. Ihre Motivation wird aber weniger, ihn abzureißen, wenn das Mittagessen nicht kommt. Dann sollst du der Truppe, die ihr Mahlzeit annimmt, Leidenschaft einflösen, so daß das Denkmal auf seinem Platz festgestellt wird, denn man wünscht es schön zu sehen. $\left({ }^{\circ}\right.$ deren Herzen ${ }^{\circ}{ }^{\circ}$ ihr Herzen $^{\circ}$ ) 
W-122 An. I 17,2

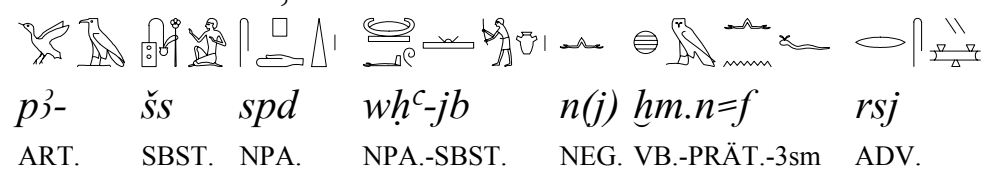

Der tüchtige und kluge Schreiber, der ist niemals ignorant.

W-123 An. I 23,1-23,2

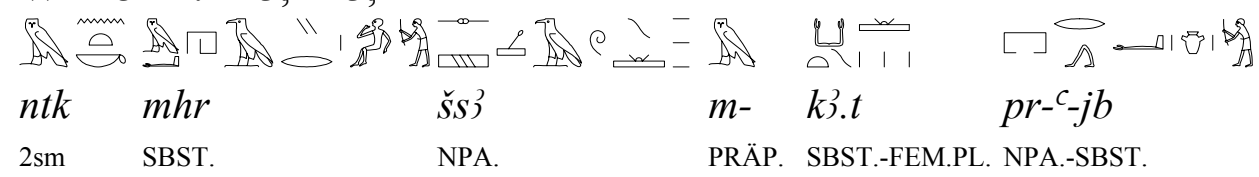

$\mathrm{Du}$ bist ein Logistikoffizier, der sich mit drängenden Aufgaben auskennt $\left({ }^{\circ}\right.$ Arbeiten aufbrausenden Herzen ${ }^{\circ}$ ).

W-124 An. I 23,8

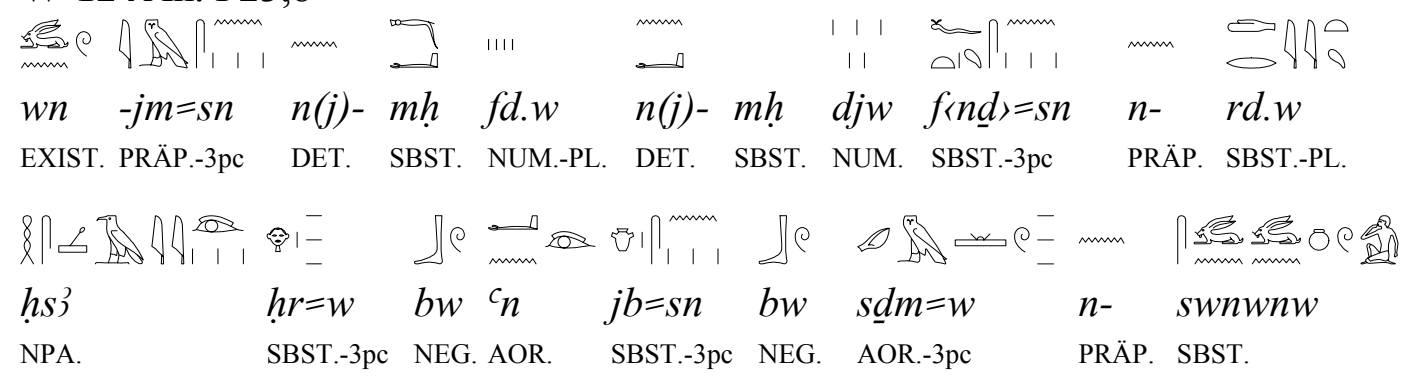

Es gibt unter ihnen (scil. den Beduinen) welche von vier Ellen und sogar welche von fünf Ellen. Ihre Nase reicht bis zu den Füßen, ihre Gesichter sind brutal, ihr Charakter ist alles andere als freundlich, und sie hören nicht auf Schmeicheleien. ( ${ }^{\circ} \mathrm{Ihr} \mathrm{Herz}{ }^{\circ}$ )

W-125 An. I 24,7-24,8

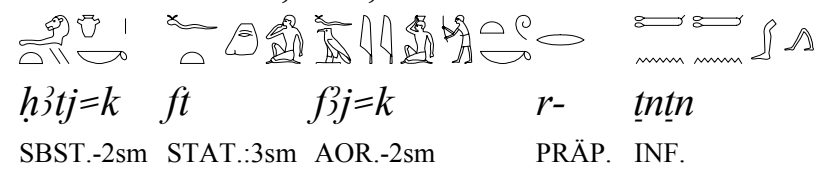

Dein Herz ekelt sich, wenn du zu Fuß gehst.

W-126 An. I 26,9

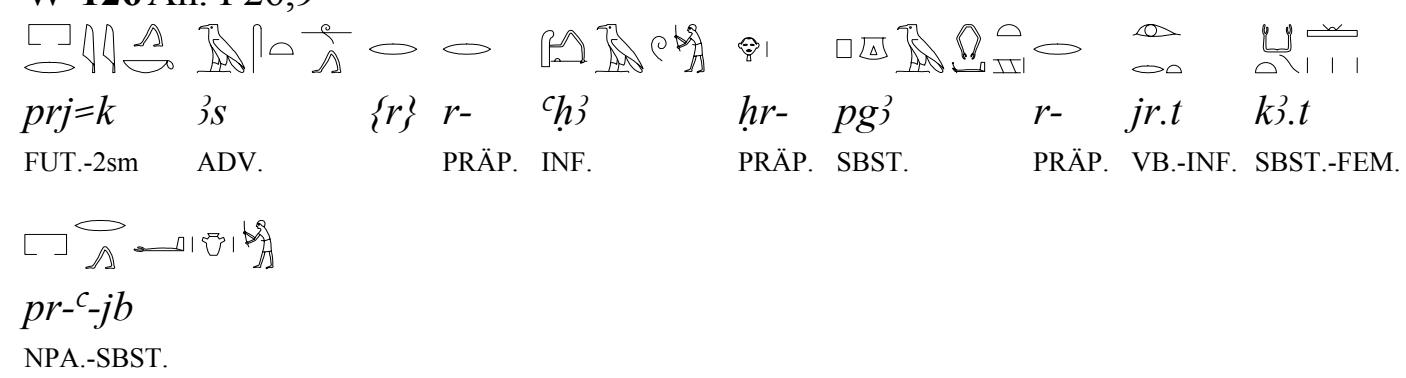

Du wirst schnell herauskommen, um auf dem Kampfplatz zu kämpfen und die drängenden Aufgaben zu machen. ( ${ }^{\circ}$ Arbeiten aufbrausenden Herzens ${ }^{\circ}$ ) 
W-127 An. I 28,1

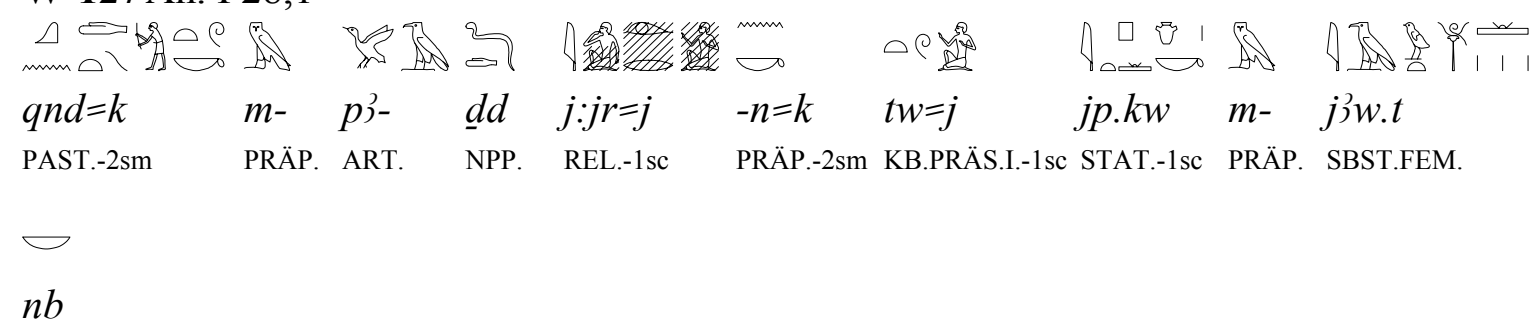

INDEF.

Du warst wütend über das, was ich dir gesagt hatte: Ich bin verständig in jedem Amt.

W-128 An. I 28,2

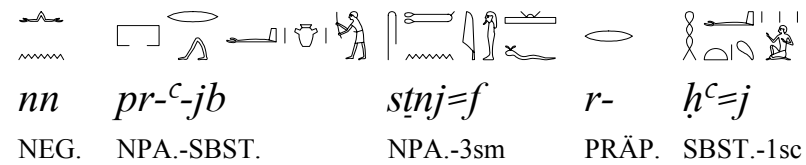

Es gibt keinen aufbrausenden Charakter, der mit mir verglichen werden kann. $\left({ }^{\circ} \mathrm{Herz}^{\circ}\right)$

W-129 An. I 28,4-28,5

$\begin{array}{lllll}h n n=t w & d n s & h 3 t j=k & j b=k & s m n \\ \text { IMPV.-2sm } & \text { FUT. } & \text { SBST.-2sm } & \text { SBST.-2sm } & \text { STAT.3sm }\end{array}$

Verlasse dich darauf, daß dein Verstand gewichtig sei, (wenn) deine Stimmung befestigt ist. $\left({ }^{\circ} \mathrm{Herz}^{\circ} /{ }^{\circ} \mathrm{Herz}^{\circ}\right)$ 


\section{Die Lehre des Amunnacht}

Quelle: $\quad$ Ostrakon British Museum 41541

Datierung: $\quad$ XX./XXI. Dynastie ${ }^{213}$

Textausgabe: $\quad$ Posener, (1955: 61-72).

Übersetzungen: $\quad$ Simpson (1972: 341), Brunner (1988: 231-233), Roccati (1994: 143-144).

\section{W-130 O.B.M. 4}

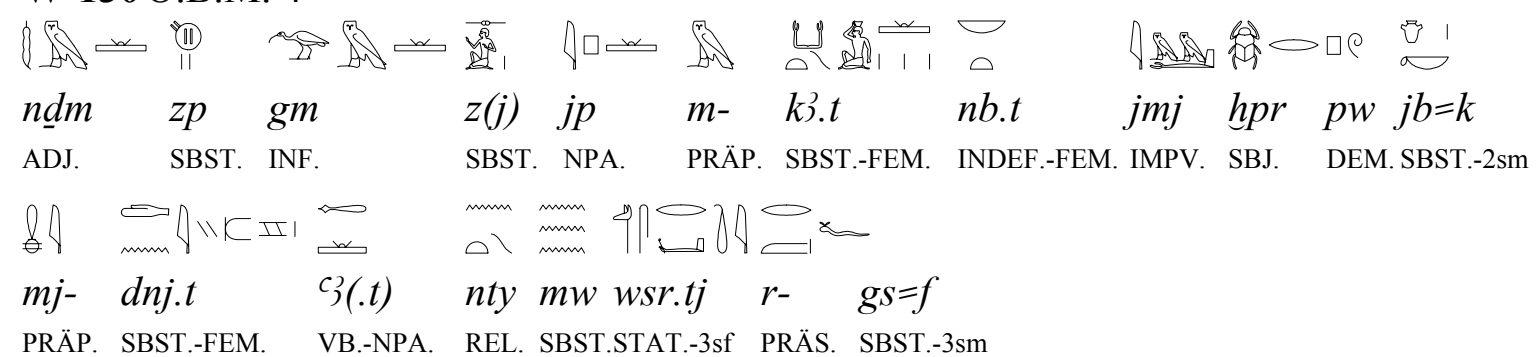

Es ist geil ${ }^{214}$, jemanden zu finden, der jeder Aufgabe gewachsen ${ }^{215}$ ist. Sorge dafür, daß dein Herz so wie ein mächtiger Damm wird, wenn die Flut an seiner Seite stark ist.

W-131 O.B.M. 10

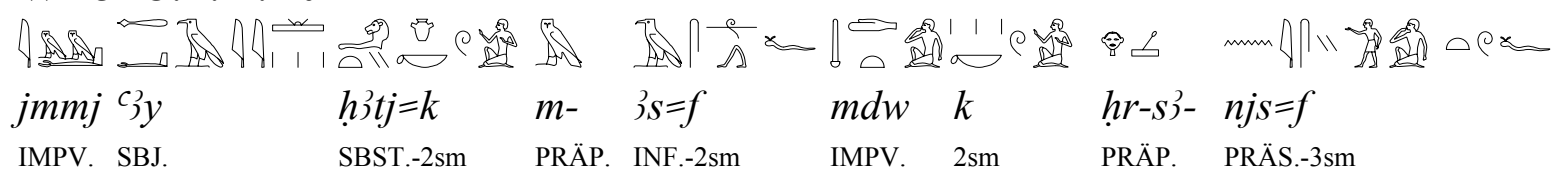

Trage Sorge, daß dein Herz groß ist. Treib es nicht zur Eile an und sprich erst, nachdem es angerufen wurde.

213 Posener (1955: 68); Bains (1996: 167); Quirke (1996: 392).

214 Die Wiedergabe von $n \underline{d} \underline{m} n \underline{d} \underline{\underline{d}} m$ mit dem erst in jüngster Zeit (nach mehreren Jahrhunderten) auch wieder ohne sexuelle Konnotation verwendeten Wort geil ist angemessen, da das ägyptische Lexem vor allem für 'sich geschlechtlich vergnügen' verwendet wurde.

$215{ }^{\circ}$ verständig in jeder Arbeit ${ }^{\circ}$. 


\section{Die Lehre des Ani (Quack 1994)}

Quelle: $\quad$ Papyrus Kairo CG 58042 (früher Papyrus Boulaq 4)

Datierung: XXI. Dynastie ${ }^{216}$

Textausgaben: $\quad$ Mariette (1871: Pl. 15-28), Suys (1935), Quack (1994).

Übersetzungen: $\quad$ Erman (1923: 234-242), Suy (1935), Brunner (1963: 103-120), Wilson (1969: 420421), Lichtheim (1976: II, 135-146), Lalouette (1984: 250-260), Brunner (1988: 196-214), Quack (1994: 82-147), Roccati (1994: 107-124), Fischer-Elfert (1997: 18-30).

W-132 B 15,6-7

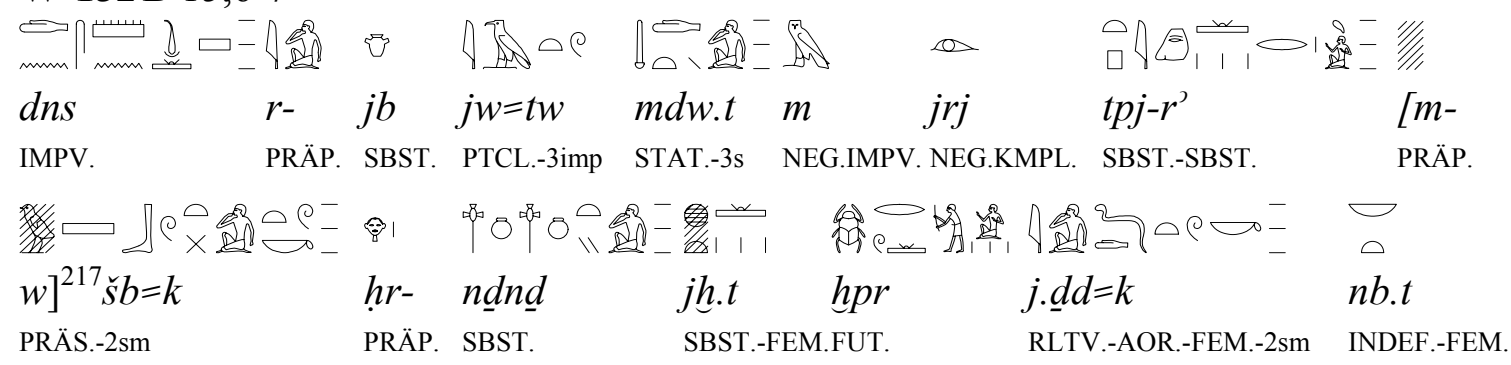

mm

mnh

STAT.:3sm

Sei ganz bedächtig, wenn man spricht. Gibt keine Stellungnahme ab, [bevor] du auf eine Anfrage reagierst, damit alles, was du sagst, mustergültig wird. (\%laste schwer auf dem Herzen $^{\circ}$ )

W-133 B 15,14-15

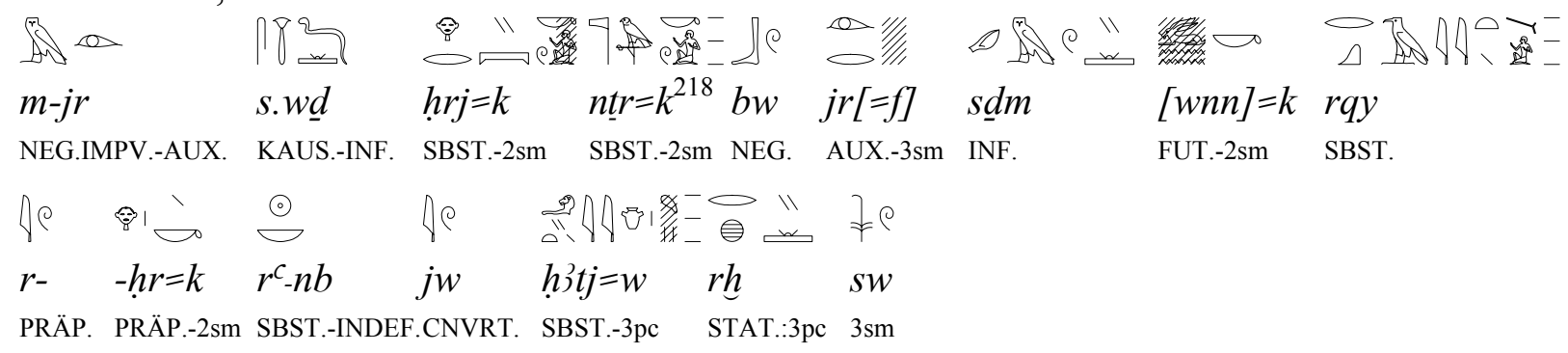

Beklage dich nicht über deinen Vorgesetzten oder deinen Gott, denn er wird nicht (darauf) hören. Du wirst ihm dauerhaft als Feind gelten, wenn ihre Herzen es erfahren.

216 Lichtheim (1976: 135); Quack (1994: 7); Quirke (1996: 389).

217 Nach Quack Ergänzung (1994: 86).

218 Quack liest (n) nt tr deinem Gott, S. 88, das ist aber kein Dativ sondern Akkusativ, wobei seine Lektur überflüßig ist. 
W-134 B 17,2-3

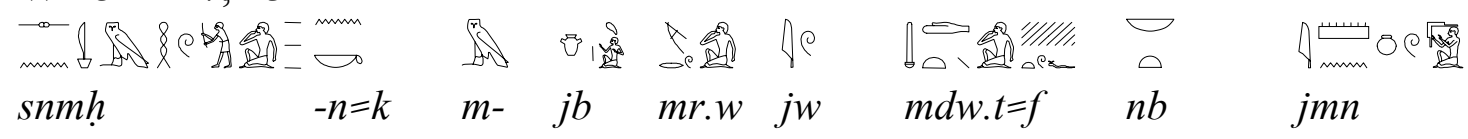

IMPV. PRÄP.-2sm PRÄP. SBST.VB.-NPA. CNVRT. SBST.-FEM.-3sf INDEF.-FEM. STAT.:3pc

Bete du von ganzem Herzen, auch wenn alle seine Worte verborgen sind. ( ${ }^{\circ}$ aus liebendem $\operatorname{Herz}^{\circ}$ )

W-135 B18,4-5

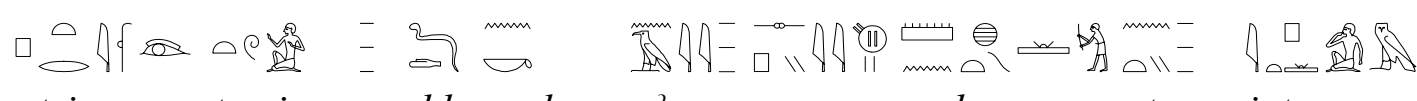
ptrj tw $=j \quad \underline{d} d-n=k \quad n j y \quad z p \cdot y \quad m n h \quad$ nty jpt mPTCL. KB.PRÄS.I.-1sc INF. PRÄP.2sm DEM. SBST. NPA. RLTVF. PRÄS. PRÄP.

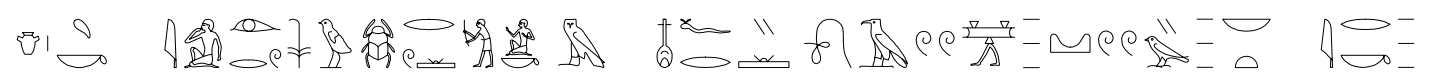
$j b=k \quad j: j r r \quad s w \quad h p r . w=k \quad m-\quad n f r \quad$ w $\quad \underline{d} \quad \underline{w} \quad n b \quad-j r=k$ SBST.-2sm IMPV. 3sm PRÄS.-2sm PRÄP. NPA. SBST. SBST. INDEF. PRÄP.-2sm $\mathrm{Pa}$ auf, ich erzähle dir diese Beispiele von Vortrefflichkeit, die von deinem Verstand richtig $\mathrm{zu}$ beurteilen sind. Eifere dem nach, damit du zu einem vorbildlichen Menschen wirst und sich alles Üble von dir fern hält. ( ${ }^{\circ}$ deinem Herzen $\left.{ }^{\circ}\right)$

W-136 B 19,4-5

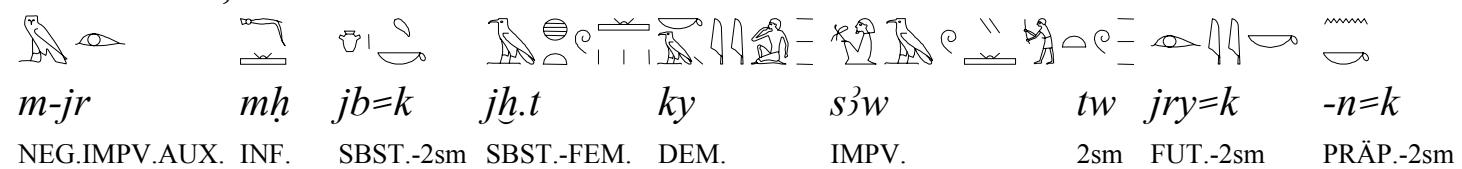

Verlasse dich nicht (auf) den Besitz eines anderen und bewahre das, was du für dich erarbeitet hast. (' ${ }^{\circ}$ ülle nicht dein Herz (mit) ${ }^{\circ}$ )

W-137B 19,10

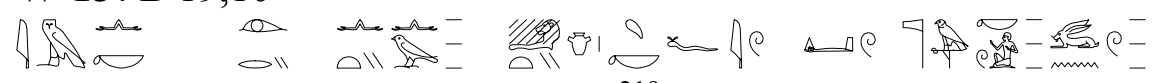
$j m j=k \quad$ jry $\quad$ njwty $\quad h i t j\{k\}^{219}=f \quad j w \quad \underline{d j} \quad n t r=k \quad$ wnw.t NEG.IMPV.-2sm SBJ. NEG.RLTVF. SBST.-3sm TOP. PRÄT. SBST.-2sm SBST.-FEM.

Du sollst dich nicht unbedacht verhalten, da doch Gott geschenkt hat, was es gibt. ${ }^{220}$ ('nicht einer sein, der kein Herz hat ${ }^{\circ}$ )

219 Für die Erklärung siehe Quack (1994: 105, Anm. 72) mit sekundärer Literatur dazu.

220 "Do not be a mindless person, then your god will give you wealth." (Lichtheim 1976: 139); "Stell dich nicht töricht an, wenn dein Gott Vermögen gegeben hat" (Quack 1994: 105). 
W-138 B 20,2-3

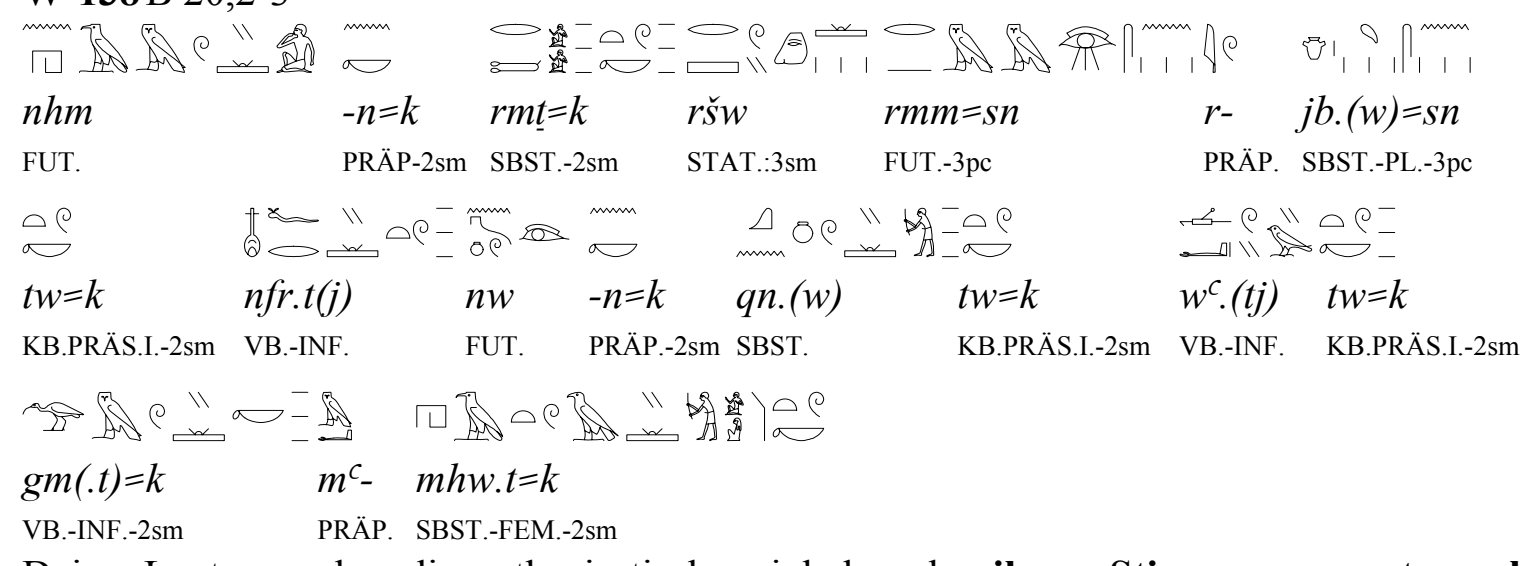

Deine Leute werden dir enthusiastisch zujubeln oder ihren Stimmungen entsprechend weinen. Geht es dir gut, werden die Tüchtigen nach dir sehen. Bist du allein, findest du dich bei deinen Angehörigen wieder. ${ }^{221}$ ( ${ }^{\circ}$ nach ihren Herzen ${ }^{\circ}$ )

W-139 B 20,4-5

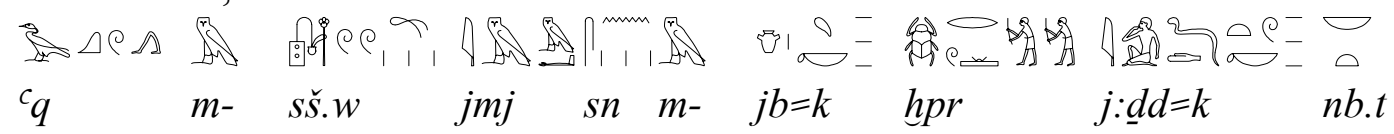

IMPV. PRÄP. SBST.-PL. IMPV. 3pc PRÄP. SBST.-2sm FUT. RLTV.PRÄS.-2sm INDEF.-FEM.

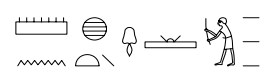

mnh.tj

STAT.-2sf

Vertiefe dich in die Schriften und nimm sie dir zu Herzen, damit sich alles, was du sagst

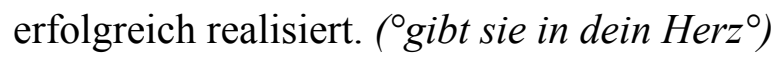

W-140 B20,7-8

$$
\begin{aligned}
& \text { A }
\end{aligned}
$$

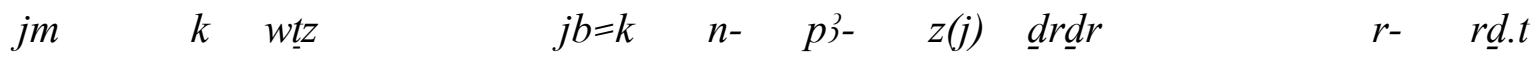

$$
\begin{aligned}
& \text { NEG.IMPV. 2sm NEG.KMPL. } \quad \text { SBST.-2sm PRÄP. ART. SBST. NPA. PRÄP. VB.-INF. }
\end{aligned}
$$

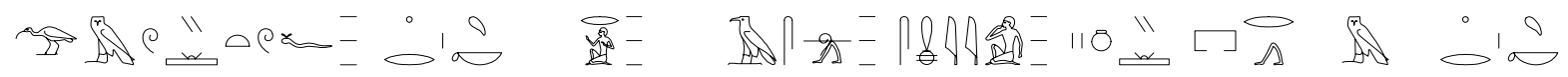

$$
\begin{aligned}
& g m=f \quad r^{\prime} \cdot(w)=k \quad\{r=j\}^{222} \quad 3 s . w \quad s m j \quad \text { sn.wy } \operatorname{pr}(. w) \quad m-\quad r^{\prime}=k \\
& \text { SBJ.-3sm SBST.-PL.-2sm NPA.-3pc SBST. NUM.-du. NPA.-3sm PRÄP. SBST.-2sm }
\end{aligned}
$$

Verrate deine Ansicht nicht einem Fremden, (um zu vermeiden) daß er etwa in die Lage versetzt wäre, vorschnelle Äußerungen von dir und unschlüssiges Gerede zu entdecken, sobald sie aus deinem Mund kommen. $\left({ }^{\circ}\right.$ dein $\left.\operatorname{Herz}{ }^{\circ}\right)$

221 "Your people will hail you when you are joyful, they will weep freely ${ }^{\lceil}\langle$when you are sad $\rangle$; when your are happy the brave look to you, when you are lonely you find your relations" (Lichtheim 1976: 140); "Deine Leute werden dir in Freude zujubeln, sie werden in ihrem Herzen weinen. dir geht es gut? - Dann werden viele auf dich sehen. Du bist allein? - du wirst deine Sippe finden" (Quack 1994: 107).

222 Es ist nicht zu lesen, siehe Quack (1994: 107, Anm. 81) 
W-141 D $5,3^{223}$

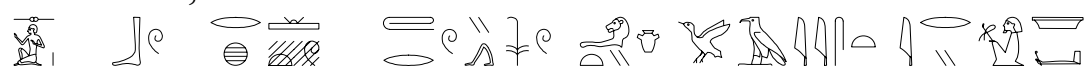

$z(j) \quad b w \quad$ rh.tw $\quad p h r \quad s w$ hijtj $p 3 y=s^{224} \quad$ jry- ${ }^{2} 3$

SBST. NEG. PAST.-indef INF. 3sm SBST. POSS.-3sf SBST.-SBST.

Einen Mann, den kann man nicht verdrehen, solange das Herz ihr Torwächter ist.

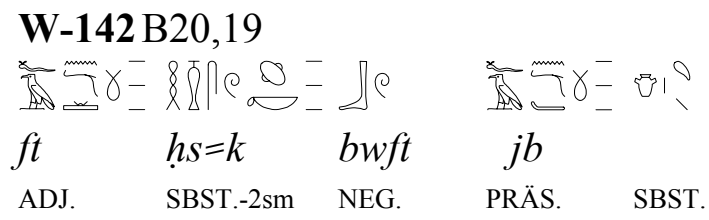

Dein Kot ist ekelerregend, aber das Herz ekelt sich nicht.

W-143 B21, 19-20

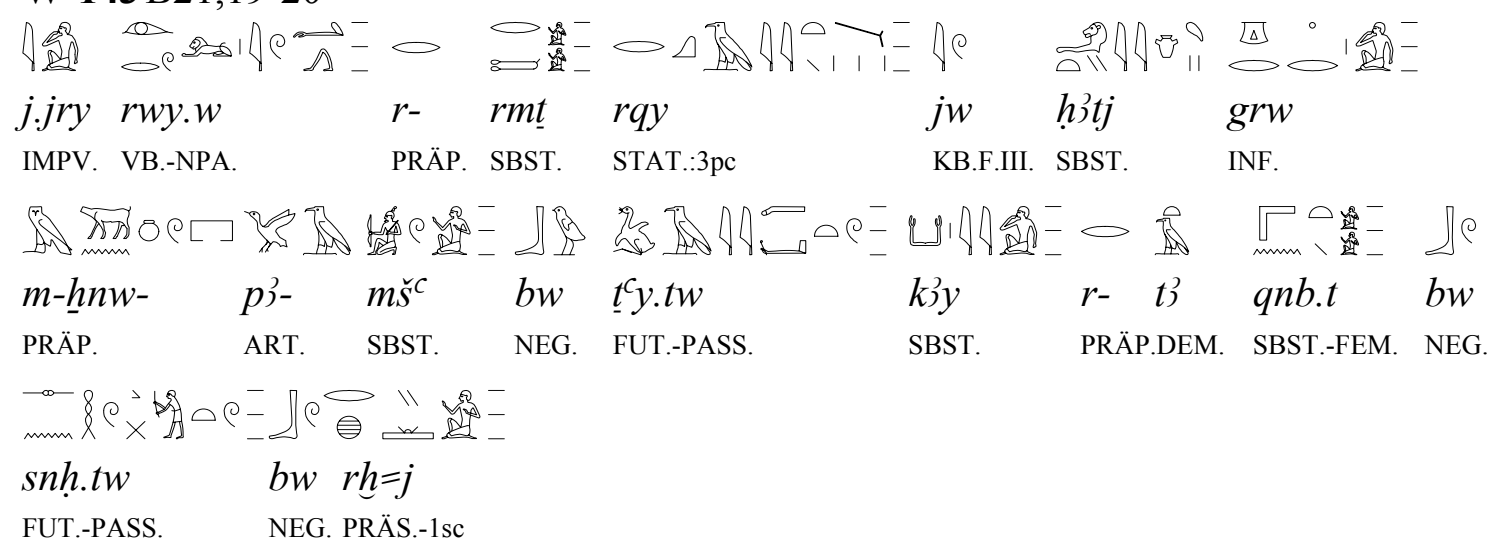

Entferne dich von Leuten, die randalieren. Das Herz hat zu schweigen inmitten des Pöbels. Gedanken können nicht vor Gericht geschleppt werden, einen Ich-weiß-nicht-wer kann man nicht verhaften.

\section{D8,7}

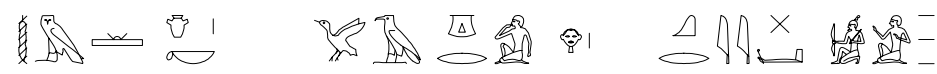

$n \underline{d} m \quad j b=k \quad p 3-\quad g r \quad h r-q r y \quad m \check{s}^{c}$

NPA. SBST.-2sm ART. NPA. PRÄP. INF. SBST.

Du bist entspannt, oh du, der du beim Herannahen des Pöbels schweigst. ( ${ }^{\circ}$ dein Herz ist sü $\beta^{\circ}$ )

223 Segmentierung anders als bei Quack, bis vorher ... tiefer als ein tiefer Brunnen (auf) dem Feld

224 Das feminine Possessivpronomen bezieht sich auf das im Satz vorher vorkommende Wort sh.t. 


\section{G1,3}

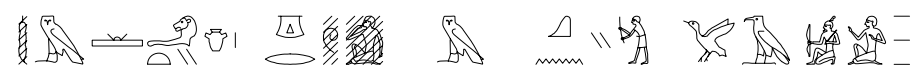

$n \underline{d} m-\underline{h}$ jtj $\quad g r \quad m-\quad q n y \quad p$ ) $\quad m \check{s}^{c}$

NPA.-SBST. STAT.:3sm PRÄP. SBST. ART. SBST.

Entspannt ist derjenige, der in der Umgebung des Pöbels schweigt. ( ${ }^{\circ}$ sü $\beta$ ist das Herz dessen $^{\circ}$ )

\section{W-144 D8,1-2}

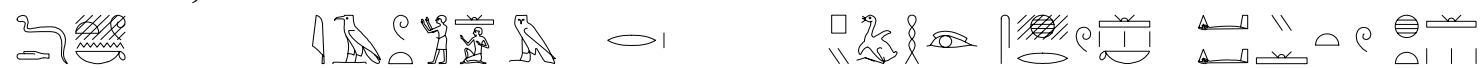

$$
\begin{aligned}
& \underline{d d}[. t w]-n=k \quad j 3 w . t \quad m-\quad r^{\prime} \quad[\ldots]^{225} p \underline{j}{ }^{3} \quad s h r . w=k \quad[\underline{d} \underline{d} . t w]^{226} \quad j h . t \\
& \text { FUT.-indef PRÄP.-2sm SBST.-FEM. PRÄP. SBST. INF. SBST.-PL-2sm PRAS.-indef SBST.-FEM. }
\end{aligned}
$$

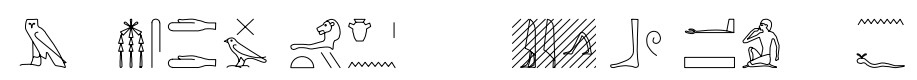

$$
\begin{aligned}
& m-\quad m s \underline{d} \underline{d} \quad h i t j \quad n-\quad[j y] \quad b w \quad c \breve{s}(. w) \quad-n=f
\end{aligned}
$$

PRÄP. DPP. $\quad$ SBST. PRÄP. NPA. NEG. PRÄT.PASS. PRÄP.-3sm

Man wird dir mit dem Mund "Willkommen!" sagen, [selbst wenn] man dein Verhalten verachtet. Doch man gibt einem, der ungerufen kommt, nur widerwillig etwas. ( ${ }^{\circ}$ während das Herz $\left.h a \beta t^{\circ}\right)$

W-145 B22,2-3

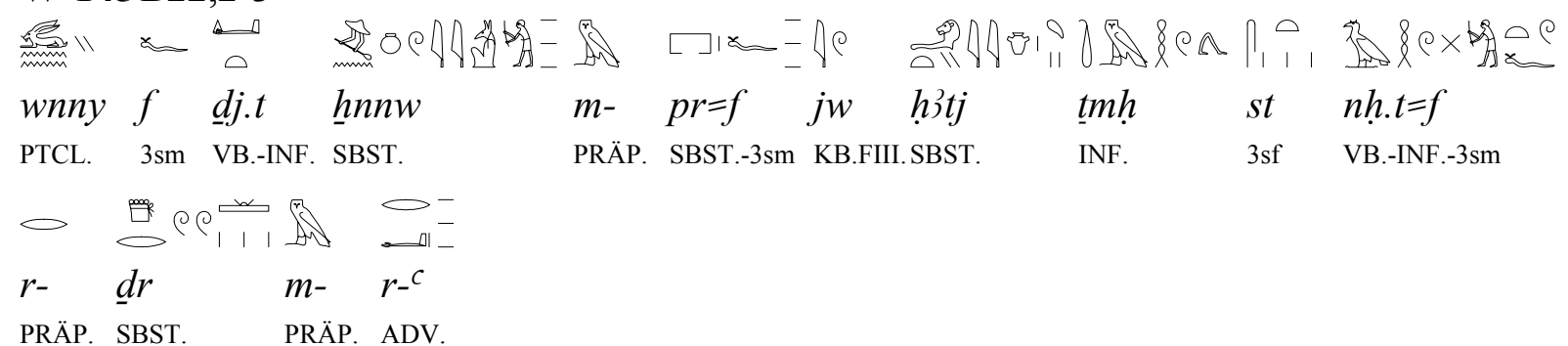

Wenn er zuläßt, daß in seinem Haushalt Chaos herrscht, wird das Herz sich davon abwenden, und er wird schließlich ein Ende herbeiflehen.

\section{W-146B22,6}

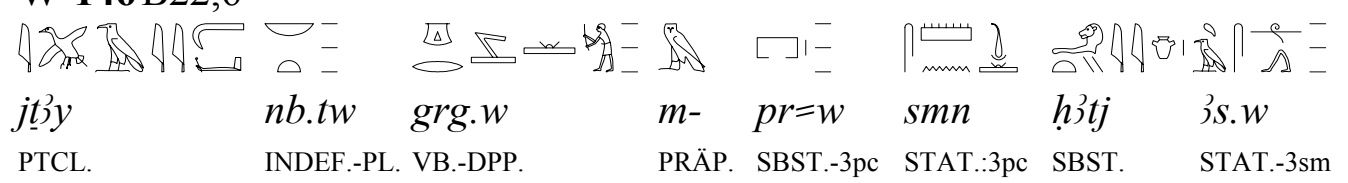

Alle Männer, die gerüstet sind in ihrem Haushalt, richten die Stimmung rasend schnell auf. $^{227}$ ( ${ }^{\circ}$ befestigen das Herz, indem sie eilen ${ }^{\circ}$ )

225 Für die Korrektur siehe Quack (1994: 320, Anm. b-c).

226 Ergänzung durch Version B.

227 "Every man who founds a household should hold back the nasty heart." (Lichtheim 1976: 143); "Ein jeder, der im Hausstand begründet ist, halt inne das hastige Herz!" (Quack 1994: 117). 


\section{W-147 B22,6}

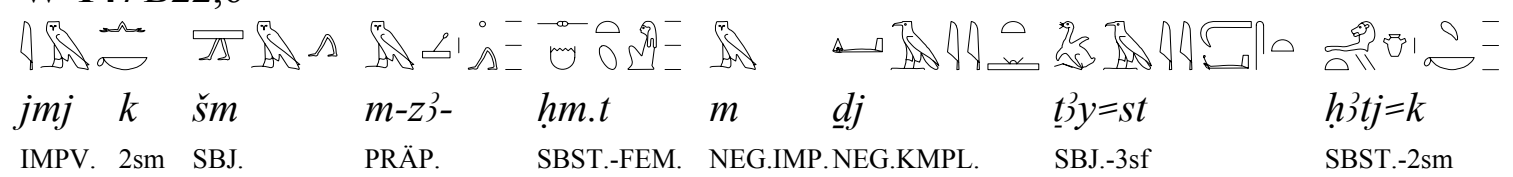

Lauf einer Frau nicht hinterher und laß sie dir nicht den Verstand rauben. ${ }^{228}$ ( ${ }^{\circ}$ icht dein $\operatorname{Herz}^{\circ}$ )

\section{W-148 B22,6}

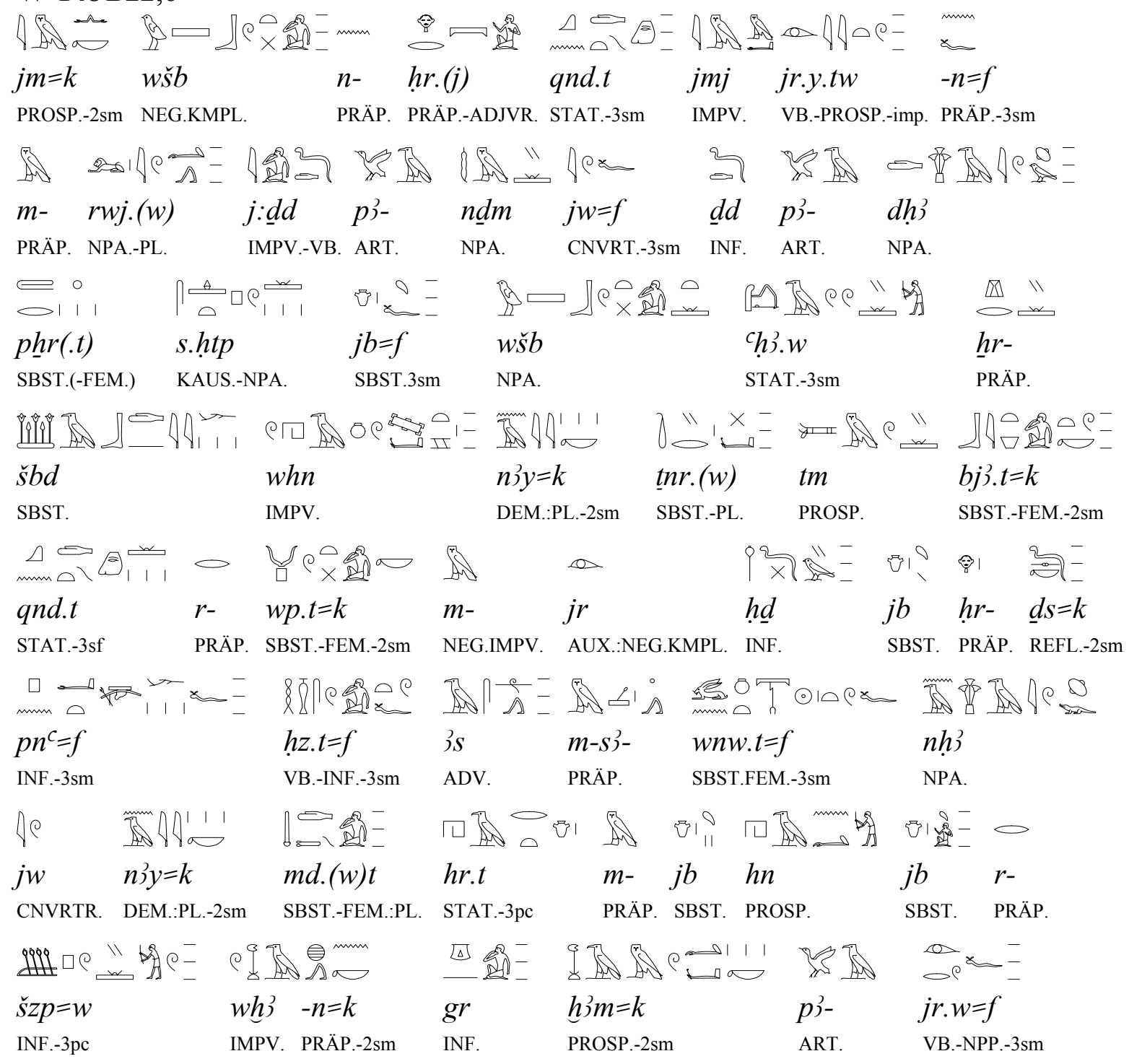

Du sollst einem Vorgesetzten nicht widersprechen, wenn er wütend ist. Sorge dafür, daß man beschwichtigend auf ihn einwirkt. ${ }^{229}$ Sag nur Angenehmes, auch wenn er Bitteres sagt - ein Patentrezept, das seine Laune verbessert. Wer streitsüchtig reagiert, landet unter dem

228 "Do not go after a woman, let her not steal your heart." (Lichtheim 1976: 143); "Gehe nicht hinter der Frau her, laß sie nicht deine Einstellung tadeln" (Quack 1994: 117).

$229{ }^{\circ}$ Veranlasse, daß man handelt für ihn als welche, die für das Aufhören sorgen ${ }^{\circ}$. 
Knüppel. Reiß (alle) deine Kräfte zusammen, damit dein Temperament nicht zorniger ist als deine Entscheidung(sfähigkeit). Kränke nicht die Stimmung aus persönlichen Gründen. Drehe ihn um, damit er rasch wieder günstig gestimmt ist, wenn die Phase seiner üblen Laune vorüber ist. Wirken deine Bemerkungen erst einmal beruhigend auf die Stimmung, wird der Verstand dazu neigen, sie zu akzeptieren. Versuche zu schweigen und beuge dich dem, was er tut. ${ }^{230}$ ( ${ }^{\circ}$ sein Herz beruhigt ${ }^{\circ} /{ }^{\circ}$ das Herz wegen deiner selbst ${ }^{\circ} /{ }^{\circ}$ das Herz ${ }^{\circ} /{ }^{\circ}$ das Herz ${ }^{\circ}$ )

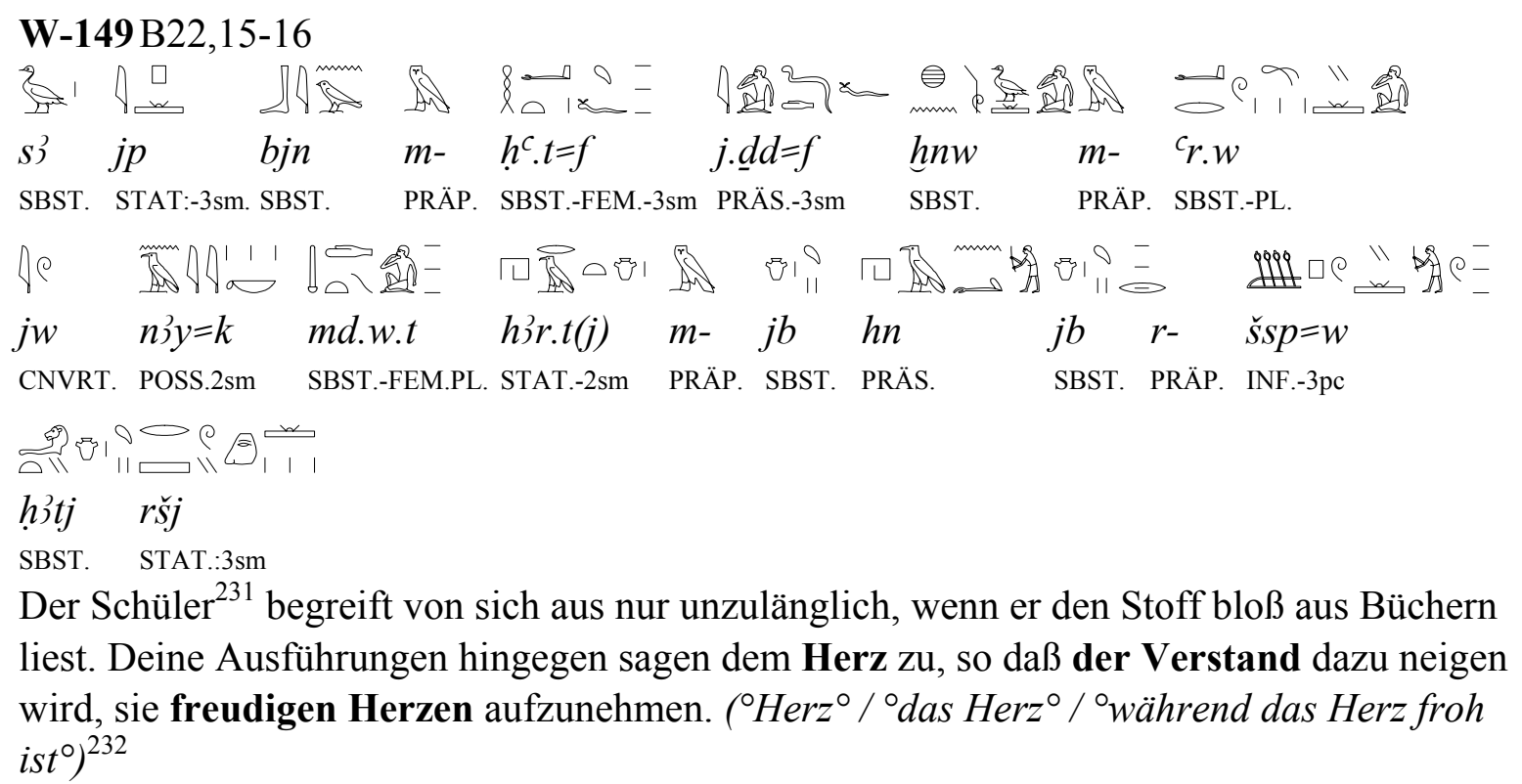

W-150 B22, 18-19

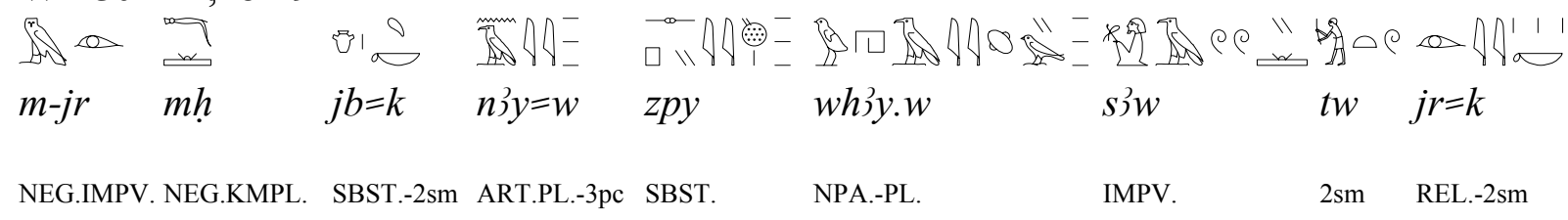

230 "Do not talk back to an angry superior, let him have his way; speak sweetly when he speaks sourly, it's the remedy that calms the heart, Fighting answers carry sticks, and your strength collapses; ...... Do not vex your heart. He will return to praise you soon, when his hour of rage has passed. If your words please the heart, the heart tends to accept them; choose silence for yourself, submit to what he does." (Lichtheim 1976: 143); "Antworte einem zornigen Vorgesetzten nicht! Laß durch Ausweichen für ihn handeln! Sag das Angenehme, wenn er das Bittere sagt. Das ist ein Heilmittel, das sein Herz besänftigt. Eine kämpffersiche Antwort verfällt dem Sotck. bezwinge deinen Groll, damit dein zorniges Verhalten dich nicht veurteil. Gräme dich nicht persönlich. Er wird dich rasch wieder loben nach seiner groben Stunde. Wenn deine Worte im Herzen erfreulich sind, ist das Herz geneigt, sie anzunehmen. Erwähl dir das Scheigen, beuge dich dem, was er tut" (Quack 1994: 118-119).

$231^{\circ} \mathrm{Der}$ Sohn ${ }^{\circ}$.

232 "The son, he understands little when re recites the words in the books. But when your words please the heart, the heart tends to accept them with joy." (Lichtheim 1976: 144); "Der Sohn dagegen denkt schlecht. Nur aus der Schriftrolle sagt er Sprüche" (Quack 1994: 121). 


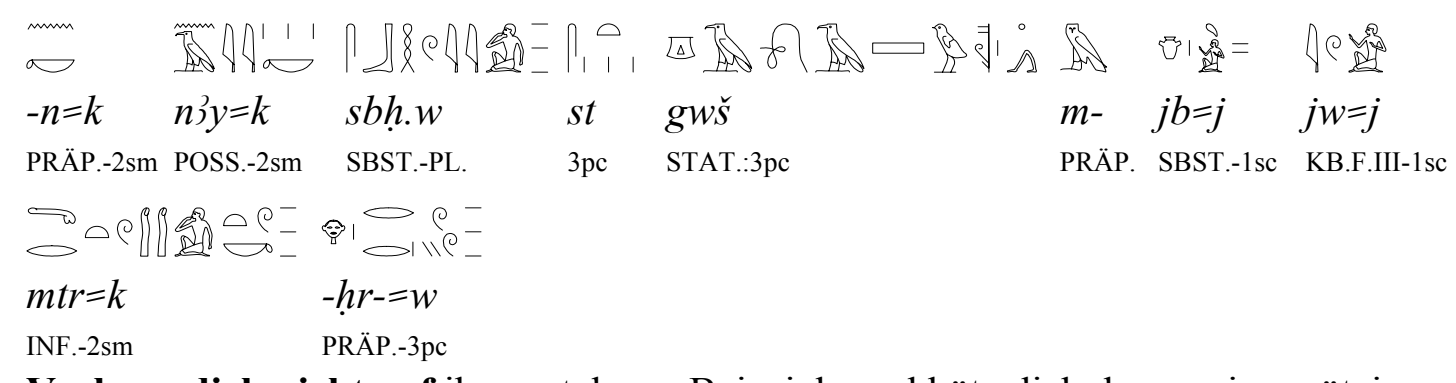

Verlasse dich nicht auf ihre nutzlosen Beispiele und hüte dich davor, eigennützig zu handeln. Dein Gejammere ist meiner Meinung nach verkehrt. Ich werde dich darüber ins rechte Licht setzen. ('fülle nicht dein Herz (mit) ${ }^{\circ}{ }^{\circ}$ in meinem Herzen ${ }^{\circ}$ )

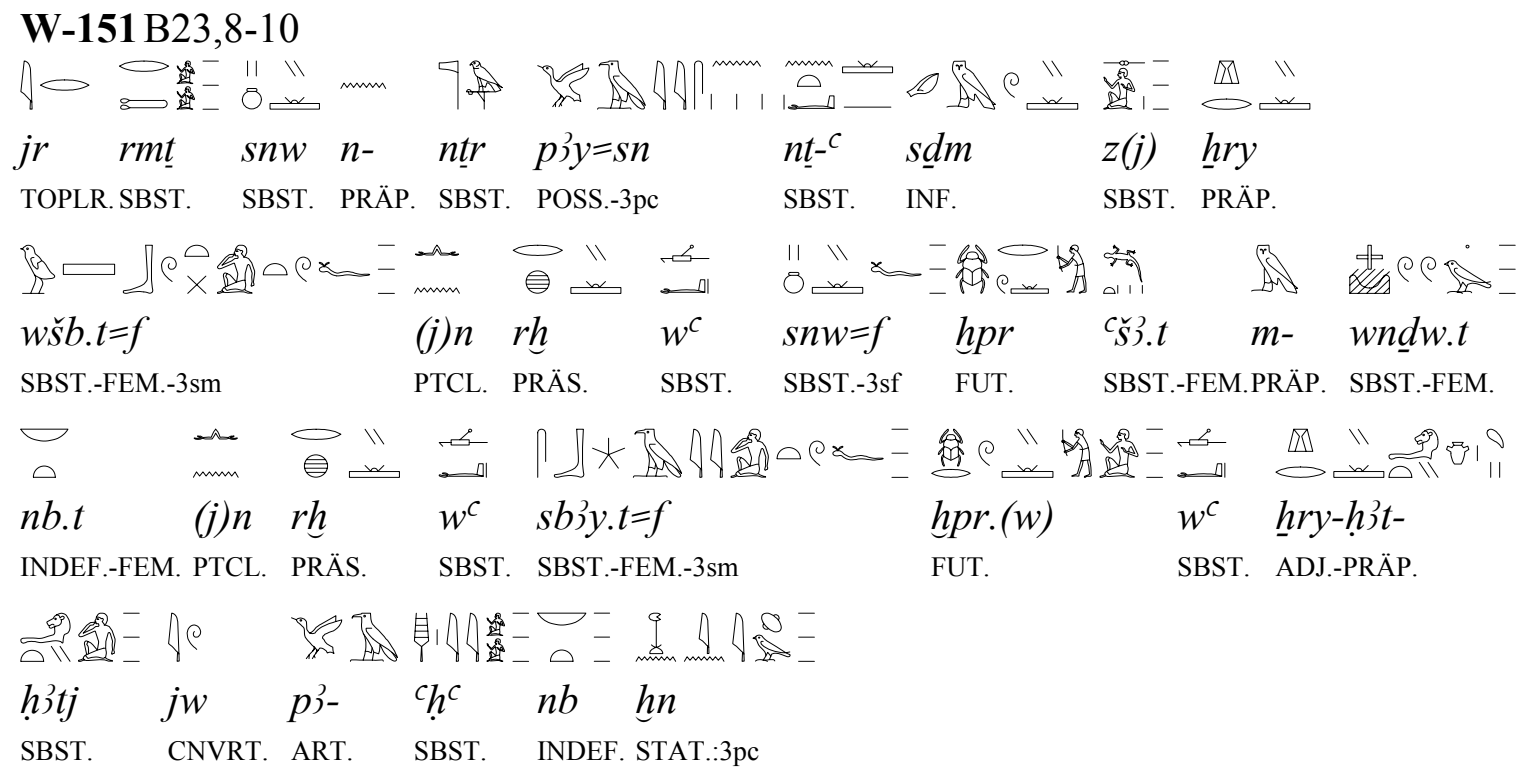

Denn ein Mensch ist der Genosse des Gottes und ihre Tradition ist es, die Meinung eines Mannes zu hören. Kennt einer seine Genossen? Die Menge entsteht in jeder Art. Kennt einer seine Lehre? Einer, der ein hervorragendes Herz hat, entsteht, während die ganze Menschenmenge töricht ist.

W-152 B23, 14-15

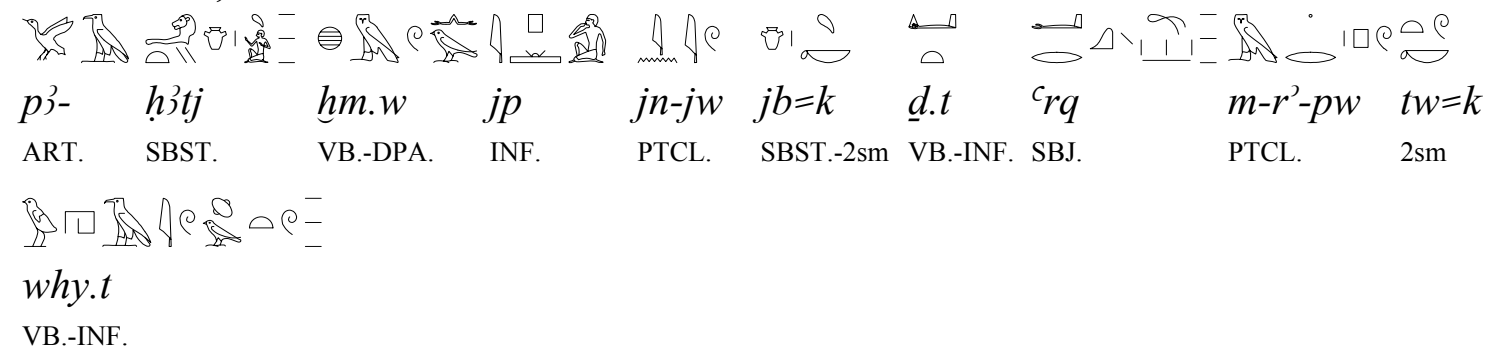

Du begriffsstutziges Herz, ist dein Streben (darauf gerichtet), uns klüger zu machen, oder bist du ein Versager? $\left({ }^{\circ} \mathrm{Herz}^{\circ}\right)$ 


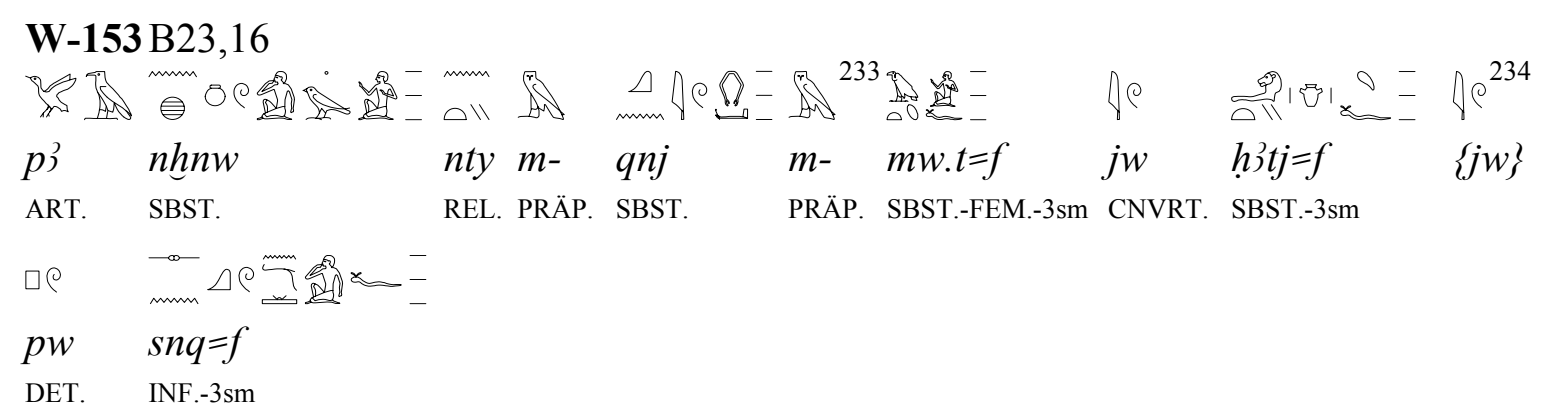

Das Kind, das sich in den Armen seiner Mutter befindet, dessen einziges Bedürfnis ist es, gesäugt zu werden. $\left({ }^{\circ} \mathrm{Herz}^{\circ}\right)$ 


\title{
Die Lehre des Amenemope
}

Quelle:

Datierung:

BM 10474

Textausgaben:

Übersetzungen:

\author{
XXVI. Dynastie ${ }^{235}$
}

Budge (1923: 41-51; P1. 1-14), Lange (1925).

Shirun-Grumach (1972), Shirun-Grumach (1991: 222-250), Lichtheim (1976: II, 146-163), Simpson (1972: 241-265), Brunner (1988: 234-256), Roccati (1994: 123-141).

W-154 c. I, 9

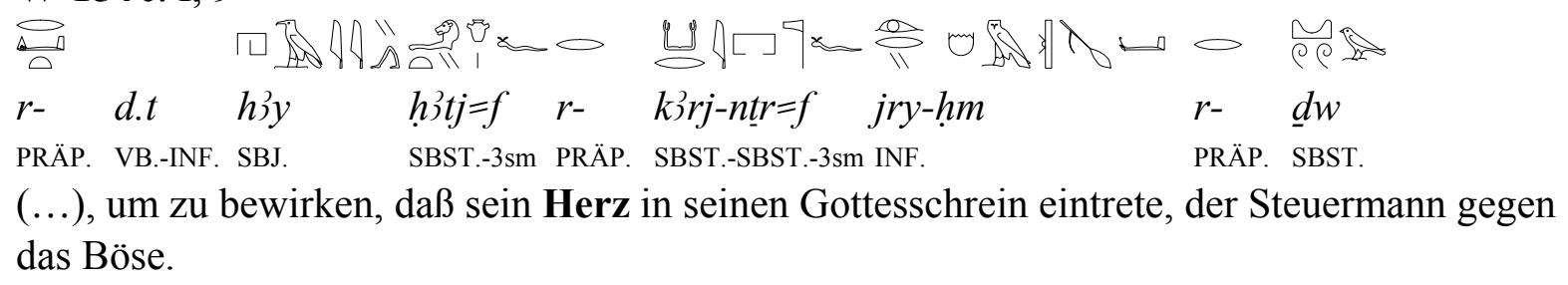

W-155c. III, 9

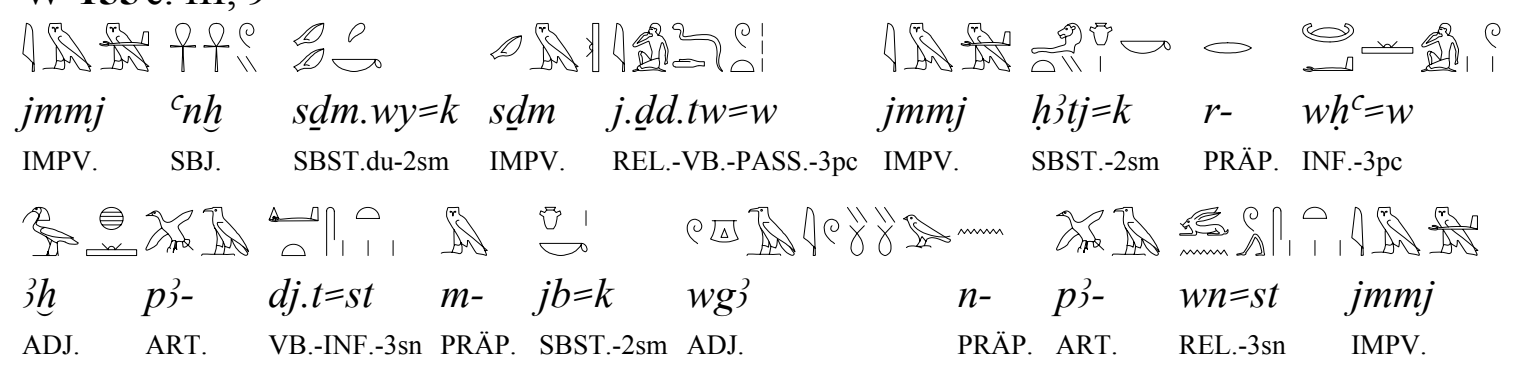

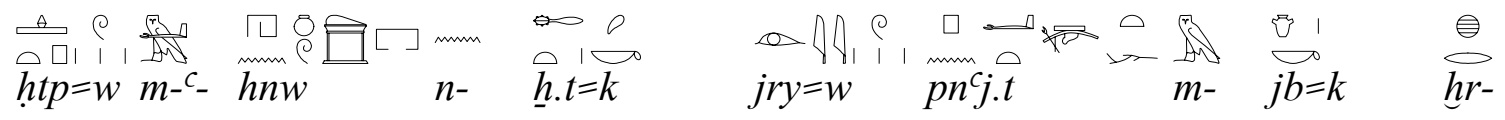
SBJ.-3pc PRÄP. SBST. PRÄP. SBST.-FEM.-2sm FUT.-3pc SBST.-FEM. PRÄP. SBSTS.-2sm PRÄP.

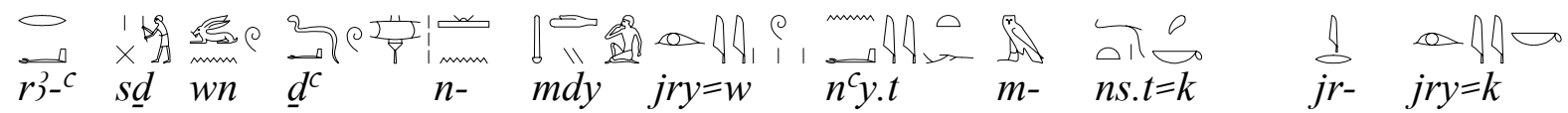
SBST. INF. FUT. SBST. PRÄP. SBST. FUT.-3pc SBST.-FEM. PRÄP. SBST.-FEM.-2sm TOPLR.PRÄT.-2sm

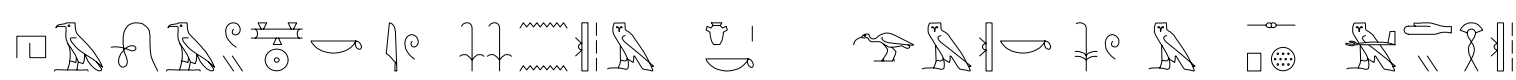

$h 3 w=k \quad j w \quad n n \quad m-\quad j b=k \quad g m=k \quad s w \quad m-\quad z p \quad m^{c} r y$

SBST.-2sm TOP. DEM. PRÄP. SBST.-2sm FUT.-2sm 3sm PRÄP. SBST. NPA.

r D w

$\left.g m=k \quad m d w=j \quad m-\quad w \underline{d} 3 \quad n-\quad c_{n \underline{h}} \quad w \underline{d}\right\} \quad h^{c} . t=k \quad h r y-t p-t 3$

FUT.-2sm SBST.-2sc PRÄP. SBST. PRÄP. SBST. FUT. SBST.-FEM.-2sm PRÄP. SBST.

Sorge dafür, daß deine Ohren quicklebendig sind und höre dir an, was man sagt. Setze dein Herz ein, es ${ }^{236}$ zu erklären. Es ist segensreich, es $^{237}$ dir zu Herzen zu nehmen, und wehe

235 Shirun-Grumach (1991: 222); Lichthteim (1976: 147); Quirke (1996: 389).

$236{ }^{\circ} \operatorname{sie}^{\circ}$ (scil. 'die Worte').

$237{ }^{\circ}$ sie $^{\circ}$. 
dem, der darüber hinwegsieht! Sorge dafür, daß die Unterweisungen ${ }^{238}$ im Kasten deines Leibes ruhen und auch als Schloß an deinem Herzen dienen. Sollte es einen Sturm der Worte geben, werden sie als Pflock an deiner Zunge dienen. Wenn du dir dies dein ganzes Leben lang zu Herzen nimmst ${ }^{239}$, wirst du feststellen, daß es ein erfolgversprechendes Vorbild ist, und entdecken, daß meine Worte ein Vorratsspeicher für das Leben sind, so daß es deinem Körper auf Erden wohlergeht. ( ${ }^{\circ}$ es in dein Herz zu geben ${ }^{\circ} /{ }^{\circ}$ in deinem Herzen ${ }^{\circ} /{ }^{\circ}$ diese in deinem Herzen sind ${ }^{\circ}$ )

W-156c. V, 9

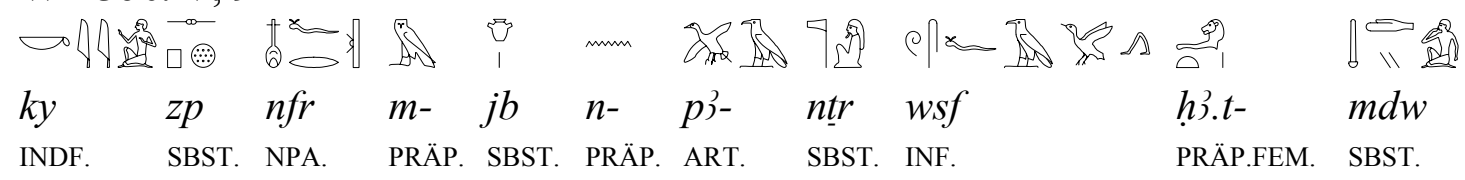

Ein anderer Fall: Gut ist es nach Meinung Gottes, vor dem Sprechen abzuwarten. ( ${ }^{\mathrm{im}} \mathrm{Her}-$ $\left.z e n^{\circ}\right)$

W-157 c. IX, 9

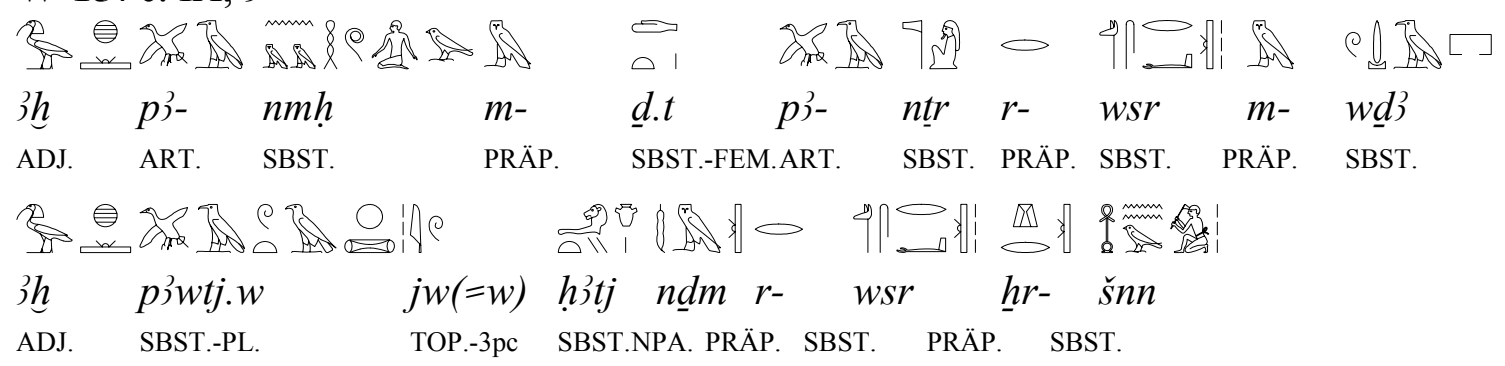

Armut aus der Hand Gottes ist besser als Reichtümer im Magazin. Gebäck in entspannter Stimmung ist besser als Reichtum mit Kummer. ( ${ }^{\circ}$ während das Herz angenehm ist ${ }^{\circ}$ )

W-158 c. XII, 1

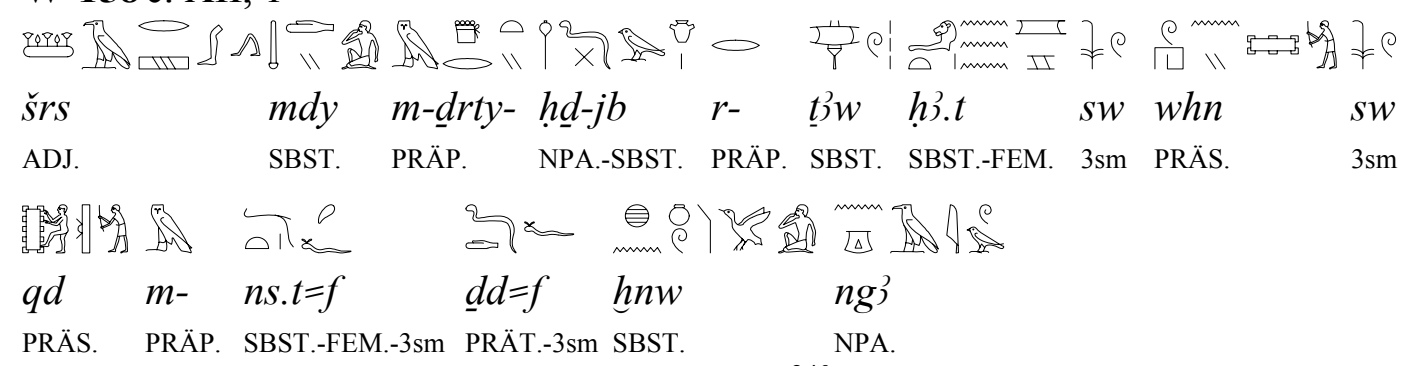

Schneller als die Böen des Mündungsbereichs ${ }^{240}$ ist die Rede, wenn das Herz gekränkt ist.

238 sie $^{\circ}$.

$239{ }^{\circ}$ Wenn du deine Lebenszeit verbringst, während diese in deinem Herz sind ${ }^{\circ}$.

240 Die Übersetzung basiert auf der Überlegung, daß ḩ3.t hier anstelle von $r^{\prime}-h$ 3.t steht. 
W-159c. XII, 13

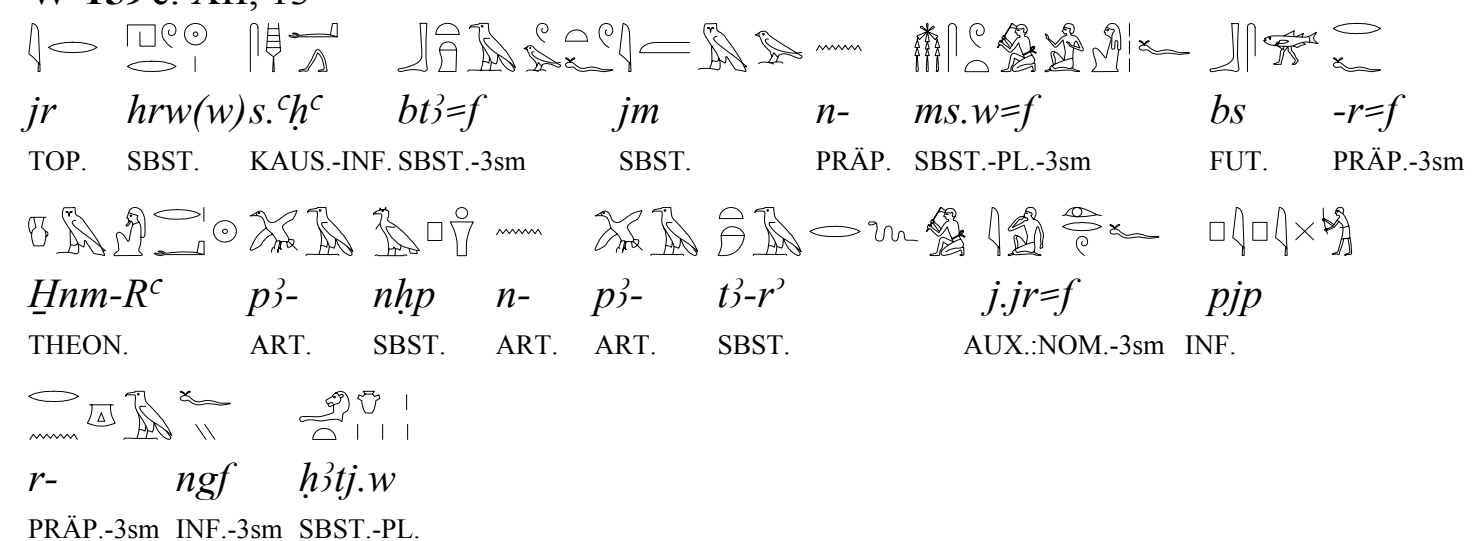

PRÄP.-3sm INF.-3sm SBST.-PL.

An dem Tag nun, da seine Verfehlung aktenkundig wird und Jammer über seine Kinder kommt $^{241}$, da wird auch Chnum-Re an ihn herantreten, der Töpfer. Der Heißmäulige ist es, der kneten wird, bis zum Klumpigwerden der Herzen. ${ }^{242}$

W-160 c. XIII, 10

\begin{tabular}{|c|c|c|c|c|c|c|}
\hline$m-j r$ & $w \check{s} \underline{d} . t w$ & $m-$ & $p 3 y=k$ & $\check{s} m m$ & $g n s=k$ & $m t w=k \underline{h} \underline{d}$ \\
\hline NEG.IMPV. & NEG.KMPL. & PRÄP. & POSS.-2sm & SBST. & PRÄS.-2sm & KNJ.-2sm IMPV. \\
\hline$\underset{0}{G 1}$ & 3 & & & & & \\
\hline$j b=k$ & $\underline{d} s=k$ & & & & & \\
\hline
\end{tabular}

Grüße deinen Feind nicht, indem du Unrecht hast (tust) und kränke dein eigenes Herz nicht.

W-161 c. XIII, 17

\begin{tabular}{|c|c|c|c|c|c|c|c|c|}
\hline Sis & $\square \cos (\mathrm{A})$ & $\frac{0}{\Delta l 1} \vec{b}$ & $\infty$ & alle & 舟舟 & $\eta \ominus \rho \|_{1}^{\ominus}$ & $\varpi$ & 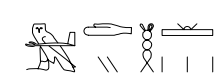 \\
\hline & $p s \check{s}$ & $h^{2}+i-l$ & $r-$ & $n s . t=k$ & $h p r$ & $s h r . w=k$ & $n b$ & $m^{c} r . w$ \\
\hline G.IMPV & I. NEG.KMPL. & SBST.-2sm & PRÄP. & SBST.-FEM.-2sm & FUT. & SBST.-PL.-2sm & INDEF & $\mathrm{VB}$ \\
\hline
\end{tabular}

Trenne deinen Verstand nicht von deiner Zunge, damit sich alle deine Pläne mit Erfolg realisieren.

$241{ }^{\circ}$ was den Tag der Aufstellung seines Verbrechens und des Jammers für seine Kinder betrifft ${ }^{\circ}$.

242 "Der Tag, der seine Sünde feststellt: wehe seinen Kindern. Möge doch Chnum eintreten, möge doch Chnum eintreten, der Töpfer des Heißmäuligen. Er ${ }^{[\text {sic] }}$ knetet ja seinen Mangel am Herzen (zurecht)." (Shirun-Grumach 1991: 235-236); "The day he is charged with his crime is misfortune for his children. If only Khnum came to him, the potter to the heated man, so as to knead the ${ }^{\lceil}$faulty $^{\top}$ heart." (Lichtheim 1976: 154). 
W-162 c. XIV, 9

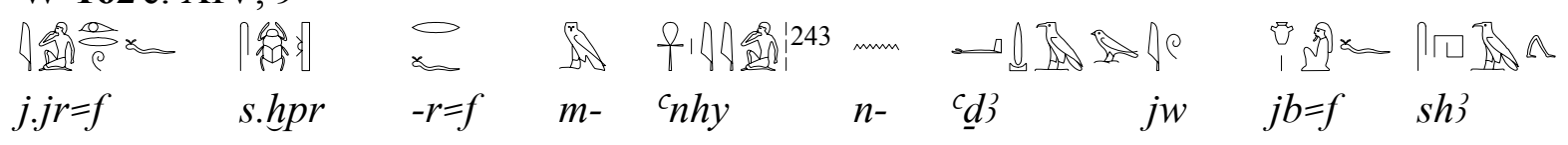

AUX.:NOM.-3sm KAUS.-INF. PRÄP.-3sm PRÄP. SBST. PRÄP. SBST. CNVRT. SBST.-3sm STAT.:3sm

in $\infty$

$m-\quad \underline{h} . t=f$

PRÄP. SBST.-FEM.-3sm

Er (der Abhängige) läßt durch den Eid des Unrechtes entstehen, wenn sein Herz in seinem Körper verdorben ist.

W-163 c. XVII, 22

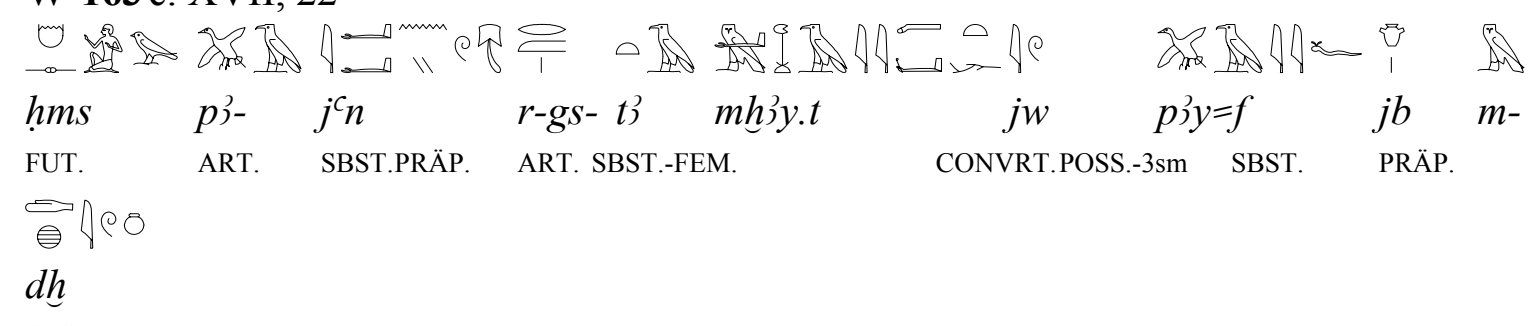

SBST.

Der Pavian hockt neben der Waage, und sein Herz dient als Lot.

W-164 c. XX, 3

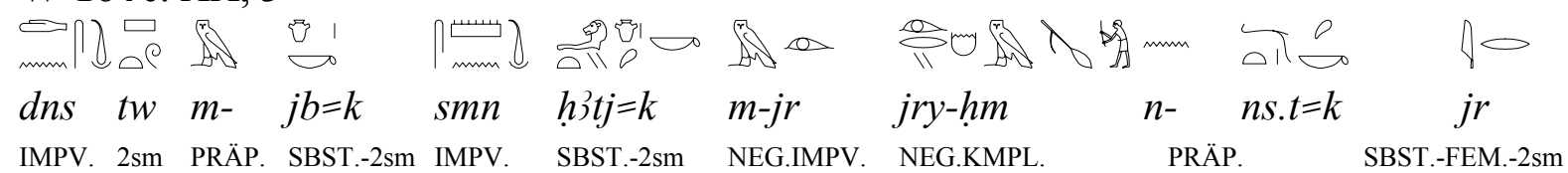
TPCLR.

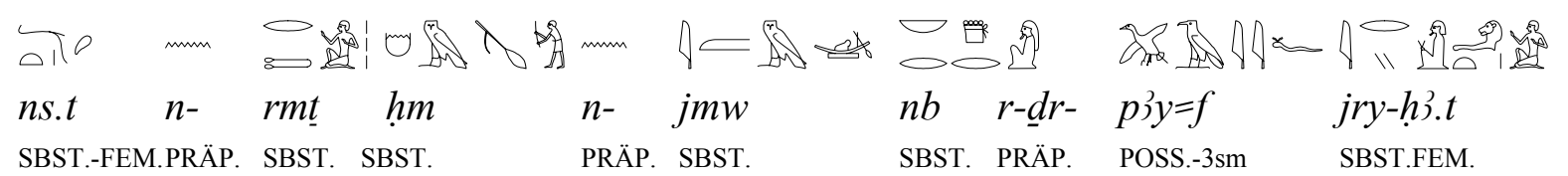

Sei gewichtig durch deinen Charakter, mache dein Herz standfest und sei nicht der Steuermann deiner Zunge. Die Zunge eines Menschen ist das Steuerruder eines Schiffs, und der Allherr ist sein Lotse.

W-165 c. XXII, 13

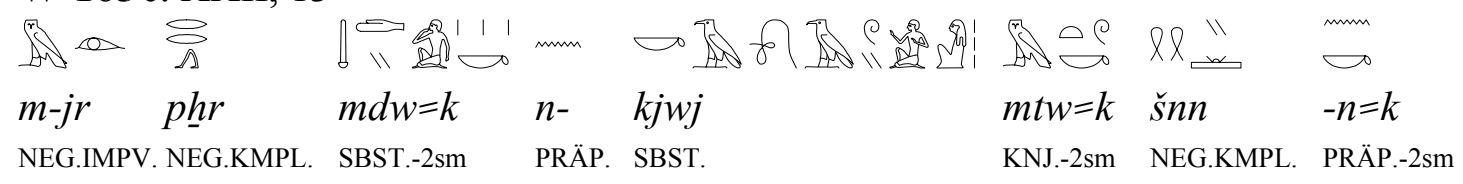

243 Lektur nach Schirun-Grumach (1972). 


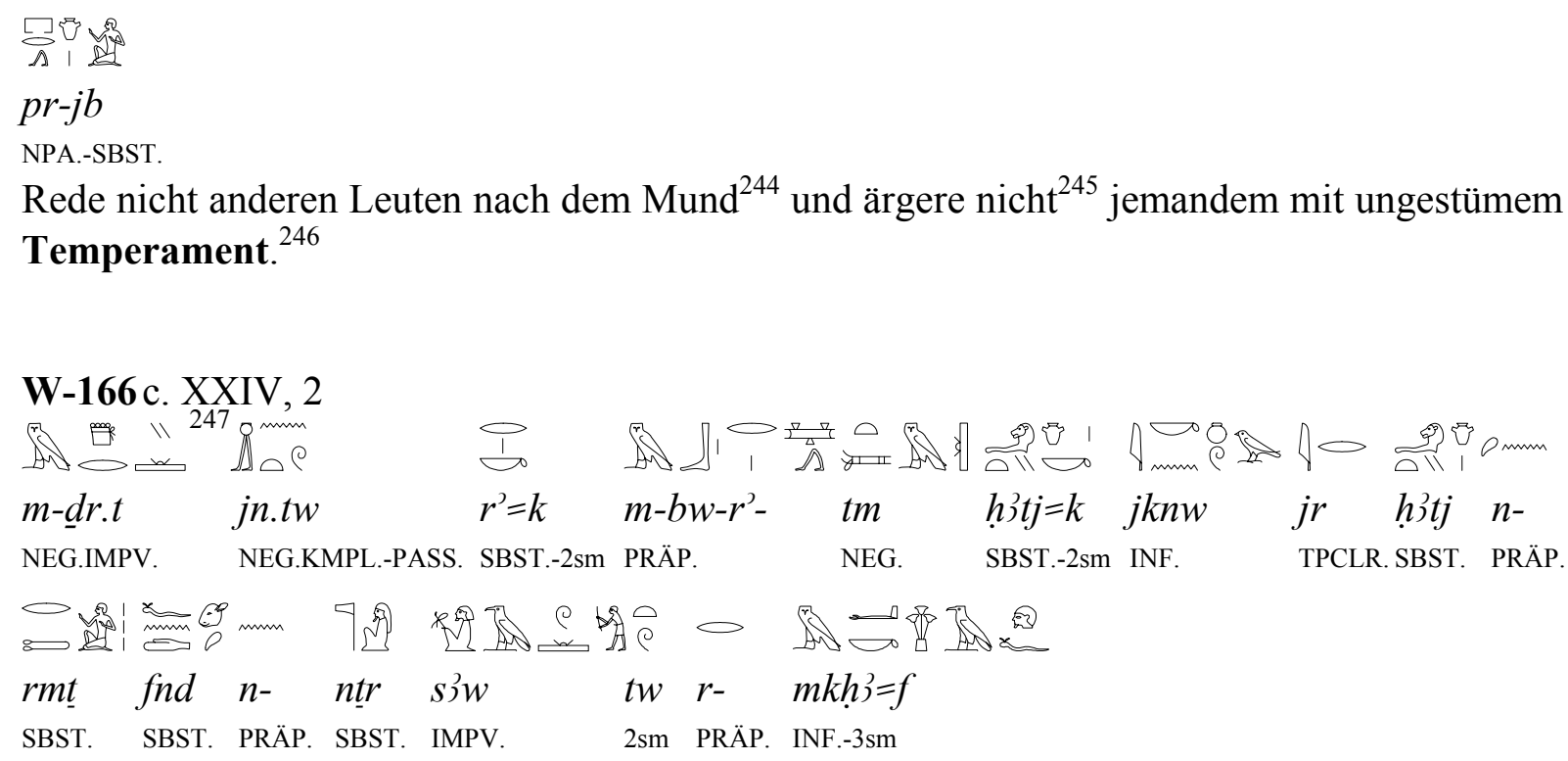

Laß nicht zu, daß man deine Rede nach außen weiterträgt, damit dein Herz nicht verbittert wird. Das Herz eines Menschen ist die Nase Gottes. Hüte dich, es zu vernachlässigen.

W-167 c. XXVII, 13

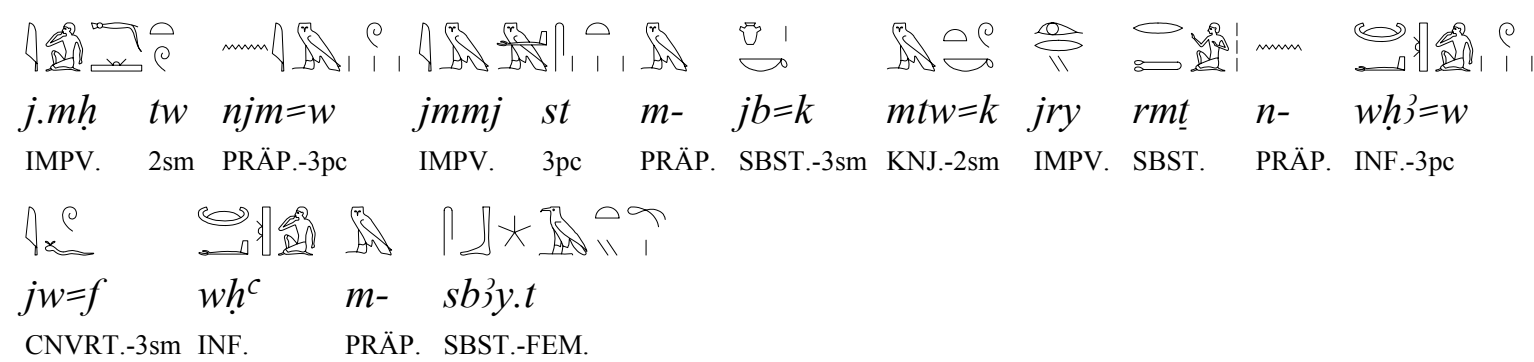

Verleibe dir diese dreißig Kapitel ein $^{248}$, nimm sie dir zu Herzen und sei ein Mann, der sie dadurch veranschaulicht, daß er im Unterricht aufklärt. ${ }^{249}$ ( ${ }^{\circ}$ gib sie in dein Herz $^{\circ}$ )

$244{ }^{\circ}$ wende deine Rede nicht um zu den anderen ${ }^{\circ}$.

$245{ }^{\circ}$ schmähe nicht für dich ${ }^{\circ}$.

246 "Laß nicht deine Rede heraumgehen bei den Leuten, und verbrüdere dich nicht mit dem Unbeherrschten" (Shirun-Grumach 1991: 245); "Broadcast not your words to others, nor join with one who bares his heart" (Lichtheim 1976: 159).

247 Über die Form der Schreibung sehen Posener (1966:61) und vgl. Grumach (1972: 153).

248 fülle dich an mit ihnen ${ }^{\circ}$.

249 "Erfülle dich mit ihnen / gib sie in dein Herz; werde en Mann, der sie erklären kann. Er wird sie als Lehrer erklären." (Shirun-Grumach 1991: 250); "Be filled with them, put them in your heart, and bevome a man who expounds them, one who expounds as a teacher." (Lichtheim 1976: 162). 


\title{
6. Kapitel
}

\section{DAS HERZ IN DEN LIEBESLIEDERN}

\author{
"La poesía es el sentimiento; \\ pero el sentimiento no es más que un efecto, \\ $\mathrm{y}$ todos los efectos proceden de una causa \\ más o menos conocida. \\ ¿Cual lo será? \\ ¿Cual podrá serlo de este divino arranque de \\ entusiasmo, de esta vaga y melancólica aspiració \\ del alma, que se traduce al lenguaje de los hombres \\ por medio de sus más suaves armonías sino el amor? \\ Si; el amor es el manantial perenne de toda poesía, \\ el origen fecundo de todo lo grande, \\ el principio eterno de todo lo bello; \\ y digo el amor porque la religión, \\ nuestra religión sobre todo, \\ es un de todo lo grande, \\ el principio eterno de todo lo bello; \\ y digo el amor porque la religión, \\ nuestra religión \\ sobre todo, es un amor también, \\ es el amor más puro, más hermoso, \\ el único infinito que se conoce, \\ y solo a estos dos astros \\ de la inteligencia. \\ El amor es la causa del sentimiento; \\ pero... ¿qué es el amor?".
}

(Segunda carta a una mujer, G. A. Béquer)

\subsection{Die ägyptischen Liebeslieder}

$\mathrm{Zu}$ Beginn der 19. Dynastie und bis in die zweite Hälfte der 20. Dynastie blühte die ägyptische Liebespoesie. Über ihre Vergangenheit und ihre mögliche ältere Entstehung gibt es unterschiedliche Meinungen. Eine schon in älterer Zeit entstandene, doch verlorene Liebesdichtung hielten Erman (1923: 303), Gardiner (1957: 24) und Hermann (1959: 1 und 9-35) für möglich, während Pieper (1929: 68) dies ablehnte. In jüngster Zeit ist von Fox (1985: 183) und Vernus (1992: 16) die Meinung vertreten worden, daß Liebeslieder durchaus vor der Mitte der 18. Dynastie entstanden sein könnte. ${ }^{250}$

Hermann schlägt die Existenz von drei wesentlichen chronologischen Phasen innerhalb der 18. Dynastie vor, nämlich die Regierungszeit der Hatschepsut (1959: 37-48), die Jahrzehnte 
der Thutmosiden (1959: 48-54) und die Herrschaft Amenophis III. und IV. (1959: 54-64). Zur Zeit Hatschepsuts habe seiner Ansicht nach eine mit "Gefühlswerten geladene Atmosphäre" geherrscht, die in dieser Form vorher nicht existiert und in der Amarnazeit ihre vollständige Ausprägung erreicht hätte. Die öffentlich gezeigten (in der Kunst dargestellten) Zuneigungsbekundungen des Königs gegenüber der Königin, die freilich auch schon unter Amenophis III. vorkamen, und die Darstellungen intimer Szenen des königlichen Familienlebens unter Amenophis IV. böten eine neue gefühlvolle Konzeption des Lebens an. Diese Äußerung von Gefühlen ist nach Hermann (1945: 62) ein Teil des Programms der Amarna-Ideologie, obwohl entsprechende Ausdrucksformen auch unter den Nachfolgern des Achenaton zu finden sind. Die "Revolution" in der Kunst fand auch in den Darstellungen der Gräber aus der 19. und 20. Dynastie ihren Niederschlag. ${ }^{251}$

Die Literatur der Amarnazeit läßt sich mit der ramessidischen Literatur in Verbindung bringen, wie Fox (1985: 184) detailliert ausführt "the naturalism, the fluidity of expression, the interest in varieties of emotions, and the fascination with the particularity of the moment". $\mathrm{Da}$ nicht nur die Kunst sondern auch die Religion und Literatur sich wandelten, bestätigt die Bedeutung dieser Zeit für die ägyptische Kulturgeschichte. Eine der gesprochenen Sprache nahe (das bedeutet: näher als zuvor) stehende Varietät des Ägyptischen wurde zum geschriebenen Neuägyptisch der Ramessidenzeit und der 21. Dynastie und mit mehr oder weniger deutlichen Bezügen auf die mittelägyptische Literatursprache auch für die Abfassung der Literatur dieser Epoche verwendet. ${ }^{252}$ Die Literatur des späten Neuen Reichs umfaßt außer den aus der älteren Epoche bereits bekannten Textsorten Erzählung und Lehre insbesondere eine größere Anzahl von Liebesgedichten. ${ }^{253}$

Die Sprache der Liebeslieder, unterscheidet sich von den der neuägyptischen Erzählungen dadurch, daß sie ein höheres Maß an poetischer Formung aufweist, mehr eigentlich mittelägyptische Merkmale besitzt und wohl auch stärker von der Alltagssprache abweicht. ${ }^{254}$ Mit Ausnahme der kürzeren Texte auf Ostraka bestehen die Liebeslieder aus zumeist drei, sieben oder acht Gedichten, einige auch mit Refrain. Fox (1985: 200-202) bezeichnet diese Art der Komposition als "Anthologie", was nach Meinung Guglielmis (1996) unpassend sei. Sie tritt dafür ein, daß wir es mit einer Form von mehr oder minder ausgeprägten Zyklen zu tun hätten (Guglielmi 1996: 342).

Inhaltlich sind die Liebeslieder durch die Anwesenheit eines Erzählers charakterisiert, der nicht Abstraktes oder Symbolisches über die Liebe mitteilt, sondern über eine leidenschaftliche und realistische Liebe spricht und sowohl die Gefühle des Geliebten als auch der Geliebten ausdrückt. ${ }^{255}$ Deswegen wird die Sprache der Liebeslieder erfolgreich in Ausdrücke

251 Wilson (1956: 261).

252 Erman (1933), Černy \& Groll (1975), Junge (1999), Silvermann (1991: 301-314), Baines (1996: 157-174).

253 Baines (1996: 166).

254 Groll (1975-76: 237-246 und 1992: 229-234).

255 Die Thematik der Liebespoesie kann auch durch andere Sorten von Texten beeinflußt werden, wie beispielsweise die Erzählungen Verwunschener Prinz, Wahrheit und Lüge, Horus und Seth oder Zwei 
umgesetzt, die ein Gefühl enthalten und den Zustand der geliebten Person beschreiben, wie z.B. im Blumenlied (L-11: $\underline{d} r-s \underline{d} r=(j)-h n^{c}=k \underline{t} z . n=k j b=j$ 'seit ich mit dir geschlafen habe, und du meine Stimmung gehoben hast').

Aber nicht nur der Erzähler spricht über das Thema. Die Liebenden halten sehr oft Monologe, durch die sie ihren Zustand und ihre Gefühle äußern. ${ }^{256}$ Fox (1985: 259-261) und Mathieu (1996: 144) stellen in ihren Arbeiten über die Liebespoesie fest, daß in diesen Monologen der Geliebte (bzw. "Bruder") nicht direkt zur Geliebten (bzw. "Schwester") oder umgekehrt spricht, sondern zum Herzen des anwesenden oder abwesenden Gegenübers (im Beispiel L-14 spricht nur die "Schwester" und im Beispiel L-16 nur der "Bruder"). Diese Monologe sind als Gedanken zu interpretieren, die direkt oder indirekt an das Herz (L-20: $h \mathrm{~m}$ tw $j b=j r$-jqr 'du bist völlig unwissend, mein Herz', L-21: jfd $s w j b=j$ js $\underline{d} r-s h i=j$ mrw.t=k 'er, mein Herz, ist eilig fliehend, seit ich an deine Liebe denke', L-22: j:jr=k hhn hrr-jh 'wieso handelst du töricht?') gerichtet sind und durch die zweite (L-11) oder die dritte Person (L-9) formuliert würden. Diese Art des Monologs ließe sich als innerer Monolog bezeichnen.

Es gibt aber auch andere Monologe, nämlich die äußeren, in denen sich eine Person an eine andere richtet. Diese Art des Monologs wird nur von Frauen gehalten, die ihren Geliebten ansprechen (L-3: ${ }^{c} h^{c} . k(w)-m d j=k r-r^{\prime} n-J t j w j \underline{t}=k h j t j=j r-J w n w$ 'Ich stehe mit dir an der Mündung des Itjw-Kanals. Du hast mein Herz nach Heliopolis mitgenommen', L-4: $s n m r j=j$ $j b<=j>m-s\}-m r w . t=k$ qm3.t.n=k $n b$ 'Mein geliebter "Bruder", ich sorge mich um deine Liebe und um alles, was du geschaffen hast', L-11: $t w=j m$ - $q n j=k$ 'Ich bin in deiner Umarmung'). ${ }^{257}$ Hingegen sind die Dialoge zwischen den Geliebten in der ägyptischen Poesie im Gegensatz zu Werken der modernen Literatur nicht zahlreich. Trotzdem kann man eine Art DoppelMonolog finden, in dem beide zu der anderen Person sprechen, ohne jedoch direkten Kontakt miteinander zu haben. Nach der Meinung von Fox (1985: 264) existiert diese Art des Monologs, da die ägyptischen Dichter den echten Dialog nicht als Notwendigkeit für ein interaktives Porträt der Liebe betrachtet hätten. Das beste Beispiel dafür seien die Sieben Stanzen, in denen der Geliebte sowie die Geliebte innere Monologe halten, die an den Partner adressiert sind.

\subsection{Die Liebe}

\subsubsection{Die glückliche Liebe}

Dieses Gefühl und seine Reaktionen wurden auf den vorherigen Seiten dargestellt. Ein interessantes Konzept bildet die Vorstellung von der Geliebten oder dem Geliebten als "Besitz". In den Liebesliedern wird dieses Konzept sehr deutlich. Der Gebrauch des possessiven Pronomens, sei die "Schwester" gemeint oder der "Bruder", ist ein klares Zeichen für dieses Kon-

Brüder (Mathieu 1996: 146-149 und 220-222).

256 Vernus (1992: 23), Guglielmi (1996: 343).

257 Eine Ausnahme stellt das Beispiel L-32 dar, siehe Fox (1985: 261). 
zept (L-2: $p 3 y=j \underline{t} \underline{3} n-w n \check{s}$ 'mein junger Wolfschakal', L-4: $s n m r j=j$ 'Mein geliebter "Bruder"'). Die Geliebten brauchen einander, um weiter leben zu können (L-6: hnnm.t fnd $=k w^{c} . t j n$ j- $n t y$ $h r-s .{ }^{C} n h j b=j$ 'Allein der Geruch deiner Nasse ist das, was mich am Leben erhält', L-7: $p$ 3- thnn $n-[.] n-.s n b=k n-p 3-j b=j h r-w h 3=k$ 'das Trefen $[\ldots]^{258}$ für deine Gesundheit ist das, weswegen das Herz dich sucht') und nicht unter der Leidenschaft zu leiden (L-9: $\underline{d j}=j$ t3 $m r w . t$ $n-s n=j m-h{ }^{\prime} . t=j w^{c} . k w h r-n t j-n=f^{\prime}$ ich habe meinem "Bruder" die Liebe als meinen (ganzen) Besitz geschenkt, und jetzt bin ich wegen dem, was nun ihm gehört, allein'). Die Tatsache, daß die Geliebten sich als "Schwester" oder "Bruder" bezeichnen, verdeutlicht ihre tiefe emotionale Verbundenheit, die im diesem Fall nicht auf gleiche familiäre Wurzeln zurückzuführen ist, sondern auf Liebe basiert. Durch die Verwendung der Ausdrücke ergibt sich, daß einer zum anderen gehört.

Da die beiden miteinander verbunden sind, wird der Partner bei der Abwesenheit der geliebten Person melancholisch. Aber wenn sie zusammen sind, sind beide glücklich. Gemäß diesen zwei Situationen entstehen Gefühle oder Zustände, die positiv oder negativ sein können.

Die Konsequenz der Zweisamkeit sind positive Gefühle, die durch 'entspannt' (L-8: $n \underline{d} m$ $m$ - h. 3.w), 'das Herz in Jubel ausbrechen lassen' (L-14: jry thh hw.t) und 'das Herz jauchzt' (L-29: ${ }^{c} \underline{d}^{c} \underline{d}$ ) ausgedrückt werden. Die Liebe kann auch der Grund sein, um jemanden zu beleben, z.B. wenn der Geruch der Nase des Geliebten das Herz belebt (L-6: hnnm.t fnd $\underline{h}=k w^{c}$.tj $n$ ? $n t y$ hr$s .{ }^{c} n h j b=j$ ), die Liebe der "Schwester" den Geliebten stark sein läßt (L-28: ${ }^{3} y=s$ mrw.t $j: \underline{d} \underline{d}$ $r w \underline{d}=j$ ) oder das Herz am Leben durch die Nachrichten der Geliebten erhalten wird (L-26: $p$;${ }^{c} q$ pr $n-n j y=s w p w t j . w p 3-n t j s .{ }^{{ }} n h j b=j$ 'das Eintreten und Hinausgehen ihrer Gesandten ist es, was mich am Leben erhält'). Daß nur dieses Gefühl der Liebe die Person auch in einen guten Zustand versetzen kann, ohne daß der Partner anwesend sein muß, belegen folgende Textpassagen, in denen die Liebe bejubelt wird (L-5: $j w=j h r-m s b b \underline{h} r-m r w . t=\langle k\rangle)$ oder das Herz erhoben wird (L-11: $t s . n=k j b=j$ ). In all diesen Beispielen ist die Liebe der Grund dafür, gesund und lebendig zu bleiben, ungeachtet ob die Geliebten zusammen oder getrennt sind.

Bei der glücklichen Liebe hat man das Gefühl, daß die Seele als Zeichen des Glücks nach oben steigt, z.B. wenn das Herz erhoben wird (L-11: $\underline{t} . . n=k j b=j$ ). Abgeleitet von diesem Zustand entsteht eine innerliche Unruhe, in der 'das Herz springt' (L-24: $t f$ ), 'im Innern aufsteht' (L-6: ' $h^{c} m-\underline{h} n w$ ), 'nach dem Geliebter sucht' (L-7: whỉ), 'keine Ruhe gibt' und 'einen Boten ausschicken' (L-9: $b w$ gr; h3̉b wp.t), 'bereit ist, die Botschaft des Geliebtes zu hören' (L-14: $j b=f m$ - $h r . t n-s \underline{d} m=w)$ oder davon fliegt, wenn es an die Liebe der/s Geliebte/s denkt (L-21:

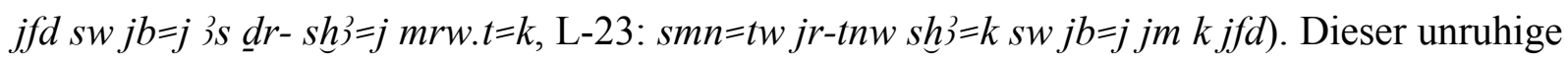
Zustand ist eine normale Reaktion der Freude auf die Liebe, da man aufgeregt ist. 


\subsubsection{Liebeskummer ${ }^{259}$}

Viele Menschen werden im Laufe ihres Lebens einmal oder mehrmals das Opfer von Liebeskummer. Normalerweise würde man in einem solchen Fall von einer epidemischen Erkrankung sprechen. Aber merkwürdigerweise wird diese teilweise schlimme psychische Ausnahmesituation in der Medizin kaum zur Kenntnis genommen. Dabei sind die Folgen von echtem Liebeskummer teilweise dramatisch, bis hin zu schweren körperlichen Erkrankungen oder sogar Selbstmord. Außerdem wird in den Medien immer wieder von Fällen berichtet, in denen Betroffene nicht nur sich selber, sondern die ganze Familie einschließlich der Kinder getötet haben.

Es sei angemerkt, daß all das, was über Liebeskummer gesagt wird, in vergleichbarer Form auch für andere Formen von Verlusten, wie z.B. den Tod von Freunden oder Verwandten, gilt.

\section{Ursachen}

Die Ursachen von Liebeskummer sind in der Regel eindeutig und wohl den meisten Menschen bekannt. Liebeskummer kann heterosexuelle Menschen genauso treffen wie homosexuelle, alte wie junge, reiche und arme.

Aber Liebeskummer muß nicht immer nur durch Verlust oder Trennung entstehen. Es gibt auch viele Fälle, in denen sich ein Mensch in einen anderen verliebt, ohne daß es zu irgendeiner Art von Beziehung gekommen ist. Hin und wieder weiß der oder die Betroffene nicht einmal von den Gefühlen des anderen. Derartiges Liebesleid kann bis hin zum Stalking führen und eindeutig zwanghafte Züge annehmen und damit behandlungsbedürftig werden.

Dieses Gefühl der Liebe, oder wie immer man es auch nennen mag, ist oft so stark, daß es jedes rationales Handeln überdeckt und für Außenstehende zu unbegreiflichem Verhalten, wie übertriebener Hingabe, Selbstaufgabe, Opferbereitschaft u.ä. führt. Wird dieses Gefühl dann doch erwidert, ist es oft mit ungeheurem Glücksgefühlen, innerer und äußerer Zufriedenheit sowie großer Ausgeglichenheit verbunden. Oft ist die Liebe zu einem anderen Mensch für Dritte unbegreiflich, da sie oft Bildungsschranken, soziale Schranken, Alter und Vermögen völlig ignoriert.

Liebe kann dem Mensch aber, neben den vielen positiven Aspekten dieses Gefühls, auch regelrecht zerstören. Dann kann man von krankhafter Liebe sprechen. Meist ist Liebe außerdem mit intensiver Sexualität gepaart. Entzieht der eine Partner dem anderen seine Liebe, so wird der Verlassene fast immer von Liebeskummer betroffen.

\section{Symptome}

Die Reaktion der Menschen auf den Verlust der Liebe eines Mitmenschen oder der auf eine von vornherein unerfüllte Sehnsucht ist sehr verschieden und kann von leichten Formen mit relativ kurzer Dauer bis hin zu langer und schwerster Verzweiflung reichen. In seltenen Fällen 
kommen Menschen lebenslang, vor allem in höherem Alter, nicht über den Verlust des Liebes- und Lebenspartners hinweg.

Ein Mensch, der unter Liebeskummer leidet, zeigt erhebliche bis massive Leistungseinbrüche:

- Das Interesse an anderen Menschen wird oft extrem gering.

- Appetitlosigkeit ist oft die Folge.

- Keine Aktivitäten können die betroffene Person noch erfreuen. Die meisten betroffenen Menschen ziehen sich auf sich bzw. in sich selbst zurück und meiden jeden Kontakt, selbst zu nahestehenden Menschen. Die Welt erscheint grau, öde und leer.

- Gewichtsabnahme ist oft die Folge.

- Schlaflosigkeit bis hin zu ganz durchwachten Nächten und generelle Zukunftsängste.

- Nicht selten werden dadurch Depressionen ausgelöst, oder es entsteht ein depressionsähnliches Verhalten.

- In seltenen Fällen werden Neurosen, wie z.B. Herzneurosen, beobachtet, die unbedingt behandlungsbedürftig sind.

Alle diese, vielen modernen Menschen aus eignen Erfahrungen bzw. Wahrnehmungen vertrauten Symptomen lassen sich ebenso in den ägyptischen Liebesliedern beobachten. Wenn der Geliebte abwesend ist, "stirbt" die Geliebte (L-7: jw $=j \underline{h r} r \underline{d} d d n-j b=j m-\underline{h} . t=k m-n$ j- nh.t [..] $p^{3} y=j C_{3} m-p 3-g r h t w=j m j-n t y m-p 3 y=j(j)$ s.t 'ich sage zu meinem Herzen: "Beherrsche dich mit diesem Wunsch [...] [gib mir] meinen Großen in dieser Nacht oder ich bin wie eine, die sich in seinem Grab befindet"); wenn der Geliebte das Herz seiner Partnerin betört, wird sie krank (L-17: $s n h r-s-t 3 h \underline{j} j b=j m-\underline{h} r w=f \underline{d} j=f \underline{t} 3 y-n=j \underline{h} 3 y . t$ 'mein Geliebter betört mein Herz mit seiner Stimme. Er veranlaßt, daß die Krankheit mich ergreift'), so daß sogar die Ärzte nichts dagegen tun können (L-25: jr- jw -n=j n3-wr-swn.w bw hr (w)j phr.wt=sn 'wenn die wichtigsten Ärzte zu mir kommen, können ihre Heilmittel mich nicht beruhigen') und der Geliebte ihretwegen unzufrieden wird (L-33: $n n h t p j b=j-h r=s$ ).

Man geht davon aus, daß das Herz als "Prinzip" des Lebens zu verstehen sei. Das heißt, daß man wegen der Liebe sowohl krank werden wie auch am Leben erhalten werden kann. Im Zusammenhang mit den vorgestellte Kriterien für die Gefühlsmetaphern ${ }^{260}$ sind die Nummern 3 und 5, nämlich das Krankheitskriterium und "Oben-Unten"- und "Vitalitäts-Fälle der Vitalität"- Kriterium übertragbar auf die Liebeslieder.

Im Kapitel über die Emotionen wurde gesagt, daß sich mit Krankheit normalerweise negative Gefühle wie Trauer im Allgemeinen, Leidenschaft oder unglückliche Liebe in Zusammenhang bringen lassen. ${ }^{261}$ Aus diesem Grund kann das im Beispiel L-17 zum Ausdruck gebrachte Gefühl, das durch die Lüge des Geliebten gegenüber seiner Partnerin hervorgerufen und metaphorisch als "Krankheit" erwähnt wird, als "Leid" interpretiert werden (sn ḥr-s.t3̣h $j b=j m-\underline{h} r w=f \underline{d} j=f \underline{t} 3 y-n=j \underline{h} 3 j . t$ 'Der Brüder betört mein Herz mit seiner Stimme. Er veranlaßt, 
daß das Leid mich ergreift'). Mit Sicherheit wurde diese Form der Beschreibung gewählt, um den seelischen Zustand der Betroffenen darzustellen. Dieselbe Erklärung läßt sich auch auf Beispiel L-25 anwenden, in dem der Geliebte seit sieben Tagen seine Geliebte nicht mehr gesehen hat und deswegen krank wird, ohne daß es ein Heilmittel gebe, das ihn gesunden ließe (jr- jw - n=j nj-wr-swn.w bw hr (w)j phr.wt=sn). Es handelt sich hier nicht um eine körperliche Krankheit, sondern um eine seelische, die somit nicht von dem Vorlesepriester diagnostiziert werden kann.

Die Beschreibungen dieser Zustände läßt sich als "Liebeskummer" identifizieren. Heutzutage wird er psychologisch behandelt, was zur Zeit der alten Ägyptern wohl eher nicht vorstellbar war. Deswegen wurden solche Zustände als physische Krankheiten wahrgenommen und von Ärzte behandeln, logischerweise ohne Erfolg (z.B. L-6, L-9, L-17, L-25, L-26).

\subsubsection{Besondere Zustände in Zusammenhang mit der Liebe}

Interessant ist das Kontrastpaar 'warm'//'kalt', welches normalerweise mit Freude und Trauer verbunden ist. Auf dem Ostrakon 304 (L-32) kommt der Ausdruck qb.w 'es wurde kühl' vor und beschreibt, was geschehen sein soll, als die Geliebte den Geliebten ansah. Das ist das einzige Beispiel, in dem dieses Kriterium eine Rolle spielt. Die Textpassage läßt zwei unterschiedliche Interpretationen zu. Einerseits könnte vorausgesetzt sein, daß der Geliebte innerlich verbrennt und erst durch den Blick, den die Frau ihm zuteil werden läßt, 'kühler', 'beruhigt' oder 'erfrischt' wird. Auf diese Weise übersetzt Fox (1985: 81) ${ }^{262}$, obwohl die Stativform $q b . w$ keine Personalendung der ersten Person besitzt und sich auch weder an dieser noch an einer anderen Stelle des Texts ein expliziter Hinweis dafür findet, daß die sprechende Person aus Liebe "entbrannt" wäre. Die Übersetzung von Fox (1985:81) basiert auf einer der gängigen Bedeutungen des Wortes $q b b .^{263}$ Eine andere Möglichkeit wäre die Interpretation der Passage als unpersönlicher Satz 'es wurde kühl'. Zum besseren Verständnis der Aussage sollte Bezug auf den Kontext des Individuums genommen werden, da 'kühl' und 'Kälte' in Zusammenhang mit Gefühlen heutzutage - zumindest in Europa - meistens etwas Unerfreuliches oder Trauriges beschreibt. ${ }^{264}$ Im Gegensatz dazu werden 'kühl' und 'Kälte' in Ägypten (vielleicht nicht zuletzt aufgrund der dort herrschenden Temperaturen) mit etwas Angenehmen assoziiert. Für die Textpassage bedeutet dies, daß der Geliebte durch den Blick der "Schwester" in einen angenehmen Zustand versetzt wird, der auch als 'erfrischend' umschrieben werden kann. ${ }^{265}$ Die Eigenschaft 'kühl sein' wird also nicht der Person, sondern der Situation zugeschrieben.

262 "... when she looks at me, (I) am refreshed".

$263 \mathrm{~Wb} \mathrm{~V} \mathrm{23,4-13.}$

264 Als mögliche Entsprechungen zu kühl führt ein Thesaurusprogramm für das Deutsche an: gefühllos, abgestumpft, gefühlsarm, beherrscht, gefühlskalt, kalt, gemütsarm, eisig, gleichgültig, erfrischend, leidenschaftslos, frisch, lieblos, unempfindlich, desinteressiert, frigid, interesselos, reserviert, stumpf.

265 Siehe Kapitel 7.3 Das Herz und die Gefühle. 
Eine häufig in der modernen Literatur vorkommende Bezeichnung ist das Herz "stehlen",

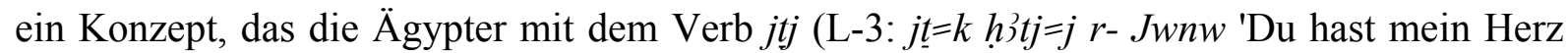
nach Heliopolis mitgenommen', L-16: jt $=s j b=j m$ - hp. $t=s$ 'sie raubte meinen Verstand ( ${ }^{\circ}$ mein Herz $^{\circ}$ ) mit ihrer Umarmung' und L-24: $m r w . t=f h r-j t . t j b n$ - hnd $n b h r-w 3 . t$ 'seine Liebe raubt den Verstand einer jeder Person, die auf den Weg vorübergeht') und $j \underline{t}$ ) (L-30: [jw jnk] j.t $\underline{\text { 3 }}$ $h j t j=s$ '[ich bin es], der ihr Herz nehmen wird' und L-32: $n t s j: t 3 j b=j$ 'Oh sie ist es, die mein Herz nahm') ausdrückten. In Zusammenhang mit dem oben vorgestellten Konzept von der Verbindung zwischen den Geliebten wird der Inhalt des Ausdruckes so interpretiert, daß das Herz der Person nicht mehr zu sich selbst gehört, sondern zu dem Geliebten. Das Herz wird metaphorisch von dem Geliebten in eine andere Stadt mitgenommen (L-3) oder gehört nach der Umarmung (L-16) und nur durch einen Blick nicht mehr zur Person (L-24).

Allerdings besteht auch die Möglichkeit, daß 'das Herz' eigentlich als Verstand zu interpretieren sei. Aus der Faszination für die geliebte Person kann sich ergeben, daß man nicht länger bei Verstand ist, weil der von der Frau (L-24) oder dem Mann (L-16) 'geraubt' wurde. In den gerade erwähnten Beispielen wird das Wort $j b$ 'Herz' als Objekt zu dem Verb jtj gebraucht und konstatiert, daß dieses infolge einer Umarmung (L-16) oder durch die bloße Präsenz des "Bruders" (L-24) geraubt worden sei. In Beispiel L-3 wird das Herz - hier hỉtj ohne solche Tätigkeiten oder Mittel mitgenommen, ebenso wie in Beispiel L-30 und L-32, in denen das Verb $j \underline{t}$ ’ einmal mit $j b$ und einmal mit $h 3 t j$ gebraucht wird. Man kann davon ausgehen, daß $j b$ und $h 3 t j$ hier in allen Fällen 'Verstand'266 bedeuten. Dasselbe trifft zu für eine Stelle, an der es vordergründig darum geht, den Raub oder die Entführung des Herzens zu vermeiden, und das Herz durch die liebende Person aufgefordert wird (L-23: smn=tw jr-tnw $s h 3=k s w j b=j j m=k j f d$ ) 'Bleibe fest jedesmal, wenn du an ihn denkst, mein Herz, und fliehe nicht!'.

Vor dem Hintergrund der analysierten Beispiele lassen sich die Rollen des Herzens in den Liebesliedern folgendermaßen zusammenfassen: Eine große Gruppe besteht aus positiven und negativen Gefühlen und aus den Reaktionen der Person auf die Liebe. Eine andere Gruppe sind diejenigen, in denen das Herz als die Stimmung, der Verstand, der Wunsch, der Charakter oder die Seele zu interpretieren ist. In der folgenden Tabelle lassen sich all diese Gruppen wiederfinden:

\begin{tabular}{|c|c|c|c|c|c|c|c|}
\hline \multicolumn{3}{|c|}{ GEFÜHLE } & \multirow[t]{2}{*}{ STIMMUNG } & \multirow[t]{2}{*}{ VERSTAND } & \multirow[t]{2}{*}{ WUNSCH } & \multirow[t]{2}{*}{ CHARAKTER } & \multirow[t]{2}{*}{ SEELE } \\
\hline POSITIV & NEGATIV & REAKTION & & & & & \\
\hline $\begin{array}{l}\text { sich erbar- } \\
\text { men } \\
(\mathrm{L}-2)\end{array}$ & $\begin{array}{l}\text { das Herz } \\
\text { (mit/fort)neh- } \\
\text { men (L-3, } \\
\text { L-16, L-24, } \\
\text { L-30, L-32) }\end{array}$ & $\begin{array}{l}\text { dahingehen, } \\
\text { um etwas } \\
\text { zu tun (L-3) }\end{array}$ & $\begin{array}{l}\text { harmonische } \\
\text { Stimmung } \\
(\mathrm{L}-5, \mathrm{~L}-11)\end{array}$ & $\begin{array}{l}\text { sich erinnern } \\
(\mathrm{L}-3, \mathrm{~L}-13)\end{array}$ & $\begin{array}{l}\text { Ich will zu } \\
\text { dir (L-4) }\end{array}$ & $\begin{array}{l}\text { mutig sein } \\
(\mathrm{L}-28)\end{array}$ & \begin{tabular}{|l} 
die Seele \\
eines \\
Mannes \\
$(\mathrm{L}-10)$
\end{tabular} \\
\hline
\end{tabular}




\begin{tabular}{|c|c|c|c|c|c|c|c|}
\hline \multicolumn{3}{|c|}{ GEFÜHLE } & \multirow[t]{2}{*}{ STIMMUNG } & \multirow[t]{2}{*}{ VERSTAND } & \multirow[t]{2}{*}{ WUNSCH } & \multirow[t]{2}{*}{ CHARAKTER } & \multirow[t]{2}{*}{ SEELE } \\
\hline POSITIV & NEGATIV & REAKTION & & & & & \\
\hline $\begin{array}{l}\text { sich sorgen } \\
\text { (L-4) }\end{array}$ & $\begin{array}{l}\text { Gefühllos } \\
\text { (L-1)* }\end{array}$ & $\begin{array}{l}\text { in Innern } \\
\text { aufstehen } \\
\text { (L-6) }\end{array}$ & $\begin{array}{l}\text { Erheiterung } \\
\text { der Stim- } \\
\text { mung } \\
\text { (L-11) } \\
\end{array}$ & wissen (L-14) & & $\begin{array}{l}\text { das-Herz-nicht- } \\
\text { haben } \\
(\mathrm{L}-18)^{* *}\end{array}$ & \\
\hline $\begin{array}{l}\text { nicht krän- } \\
\text { ken (L-8) }\end{array}$ & \begin{tabular}{|l} 
nicht sich \\
erbarmen \\
(L-2)
\end{tabular} & $\begin{array}{l}\text { jdn suchen } \\
(\mathrm{L}-7)\end{array}$ & $\begin{array}{l}\text { die Stimmung } \\
\text { erhoben } \\
\text { (L-11) }\end{array}$ & $\begin{array}{l}\text { Gedanken } \\
\text { hingehen, um } \\
\text { etwas zu tun } \\
\text { (L-3) }\end{array}$ & & $\begin{array}{l}\text { töricht sein } \\
\text { (L-22) }\end{array}$ & \\
\hline $\begin{array}{l}\text { sich freuen } \\
(\mathrm{L}-12)\end{array}$ & $\begin{array}{l}\text { kränken } \\
\text { (L-8, L-9) }\end{array}$ & $\begin{array}{l}\text { eilig fliehen } \\
\text { (L-21, } \\
\text { L-23) }\end{array}$ & \begin{tabular}{|l|} 
Die Stim- \\
mung ist \\
gespannt und \\
bereit, zu \\
hören \\
(L-14) \\
\end{tabular} & $\begin{array}{l}\text { den Verstand } \\
\text { vor der Ver- } \\
\text { geßlichkeit zu } \\
\text { bewahren } \\
\text { (L-10) }\end{array}$ & & & \\
\hline \begin{tabular}{|l|} 
froh sein \\
(L-29)
\end{tabular} & $\begin{array}{l}\text { unwillig sein } \\
\text { (L-18) }\end{array}$ & \begin{tabular}{|l} 
einen Boten \\
senden \\
(L-9)
\end{tabular} & & $\begin{array}{l}\text { Erinnerung } \\
\text { (L-10) }\end{array}$ & & & \\
\hline \begin{tabular}{|l|} 
jauchzen \\
(L-29)
\end{tabular} & $\begin{array}{l}\text { unzufrieden } \\
\text { (L-33) }\end{array}$ & $\begin{array}{l}\text { beabsichti- } \\
\text { gen etwas } \\
\text { zu sehen } \\
\text { (L-19) }\end{array}$ & & $\begin{array}{l}\text { der Befehl des } \\
\text { Verstandes } \\
\text { (L-10) }\end{array}$ & & & \\
\hline \begin{tabular}{|l|} 
Herzvergnü- \\
gen (L-4, \\
L-15, L-31) \\
\end{tabular} & \begin{tabular}{|l|} 
das Herz \\
betörten \\
(L-17) \\
\end{tabular} & \begin{tabular}{|l|} 
aufgeregt \\
sein \\
$(\mathrm{L}-24)$ \\
\end{tabular} & & $\begin{array}{l}\text { unwissend } \\
\text { (L-20) }\end{array}$ & & & \\
\hline \begin{tabular}{|l|} 
in Jubeln \\
ausbrechen \\
(L-14) \\
\end{tabular} & & & & $\begin{array}{l}\text { das Herz fort- } \\
\text { nehmen (L-16, } \\
\text { L-24) }\end{array}$ & & & \\
\hline \multicolumn{8}{|l|}{\begin{tabular}{|l|} 
entspann \\
sein (L-8) \\
\end{tabular}} \\
\hline \begin{tabular}{|l|} 
Das Herz \\
trösten \\
$(\mathrm{L}-10)$ \\
\end{tabular} & & & & & & & \\
\hline
\end{tabular}

* Im Beispiel L-1 beklagt sich die Geliebte über das Verhalten des Geliebten, der sie am nächsten Morgen verläßt. Allerdings ist diese Interpretation unsicher, da der Text nur fragmentarisch erhalten ist und seine ersten Zeilen vollständig verloren sind. Meiner Meinung nach wäre diese Passage als ein Vorwurf der Geliebten an ihren Geliebten aufzufassen, dessen Herz nicht mit dem ihren vereint ist. Der Inhalt dieser Anklage ließe sich wie folgt deuten: seine Gedanken konzentrieren sich auf andere Dinge, oder er empfindet keine Liebe zu ihr.

** Das Beispiel L-18 enthält den Ausdruck njwty $j b=f$ 'einer, der sein Herz nicht hat', der an die Stelle aus der Lehre des Ani (W-137) erinnert (jmj=k jry njwty $h 3 i j=f$ 'du sollst dich nicht unbedacht (Gedankenlos) verhalten'). Das Auftreten in beiden Texten beweist, daß sich das Herz an dieser Stelle nicht mit der Liebe in Verbindung bringen läßt, sondern mit einem Charakterzug, der durch den Verstand definiert ist. Da die Geliebten 'das-Herz-nicht-haben', nämlich nicht klar denken können, kommt keine Kommunikation zwischen ihnen zustande. Aus diesem Grund kennt der Geliebte den Wunsch der Geliebten nicht, und als Konsequenz sendet er keine Mitteilung über sie an die Mutter. 


\subsection{Die Erheiterung des Herzens}

Der Begriff shmh-jb hat mehrere Bedeutungen, zu denen beispielsweise "sich belustigen", "das Herz erheitern" und ab der Zeit des Neuen Reiches "(das Lied der) Erheiterung" gehören. ${ }^{267}$ Über seine korrekte Übersetzung bestehen unterschiedliche Meinungen. Hermann (1959: 149) schlägt "Große Herzensfreude" vor, während Fox (1985: 244) "entertainment" oder "diversion", Guglielmi (1996: 341) "Herzenserheiterung", "Herzensfreude", "Sprüche des großen Herzensfreude" oder "Lieder der Herzensfreude", und Mathieu (1996: 26) "la grande dipensatrice de divertissement" anbieten. Nach Meinung von Fox und Assmann läßt sich mit dem Terminus die "Unterhaltungsliteratur" bezeichnen. ${ }^{268}$ Allerdings ist Guglielmi (1996: 342) anderer Meinung, da ihrer Ansicht nach ähnliche Bezeichnungen auch für andere Texte vorkämen. ${ }^{269}$ Sie vermutet daher, daß "Sprüche (oder Lieder) des $s h m h-j b$ " als die thematisierten Erscheinungen einer "Gegenwelt" zu bezeichnen seien.

In den Beispielen L-4, L-11 und L-15 bildet $s h m h$-jb den Titel des Liedes, während er sich im Beispiel L-31 im Zusammenhang mit Musik, Instrumenten, Gesang und dem Konzept eines "schönen Tags" bringen läßt. Mit dem Ausdruck shmh h-jb wird folglich, wenn man es ganz allgemein fassen möchte, ein Zustand beschrieben, in dem sich das Herz in guter Stimmung befindet.

In Zusammenhang mit diesem Begriff findet man unter der Liebespoesie die Gruppe der Harfnerlieder, mit der eine typische Gattung der ägyptischen Literatur bezeichnet wird. ${ }^{270}$ Man nimmt wegen der Bankettszenen aus der Grabdekoration der 18. Dynastie an, daß derartige Lieder während solcher Veranstaltungen gespielt wurden, in denen gleichzeitig gutes Essen und Trinken serviert wurde. ${ }^{271}$ Vor dem Hintergrund dieses Kontextes ergibt sich eine Situation ausgelassener Stimmung als Rahmen der Harfnerlieder, durch die das Herz in Freude gerät.

Das Beispiel L-10 stammt aus dem Lied des Antef aus dem Papyrus Harris 500, in dem sich das Wort 'Herz' nicht nur mit der Liebe in Verbindung bringen läßt, sondern auch als 'Verstand' und 'Seele' zu verstehen ist. Die Erklärung dafür liegt an der Besonderheit dieses Liedes, das eine kreative und didaktische Absicht haben soll. Die "Gattung" Harfnerlied wurde von Otto (1969: 150) als eine "Aufforderung zum carpe diem" verstanden. Assmann (1977: 83) meint, daß die ägyptischen Harfnerlieder nicht als philosophische Abhandlungen zu verstehen seien, da sie nicht die Wahrheit verkünden wollten. Eher seien sie als Reflexe einer "Philosophie des Festes" zu bezeichnen. Es wurden Szenen aus der Realität in den Gräber abgebildet, die auch für den Besucher des Grabes eingerichtet sind. In den späteren Harf-

$267 \mathrm{~Wb}$ IV 252,10-253-5.

268 Fox (1982: 289 und 367, Anm. 37; 1985: 55), Gardiner (1931: 30f) und Assmann (1991: 900).

269 Zum Beispiel der Satyrische Brief des pAnastasi I,8 (siehe Fischer-Elfert 1986: 72f und 1992: 82) und literarische Amunshymnen mit dem Titel "Andere Ermahnungen des Gesichtserfreuens".

270 Lichtheim (1945: 178-212), Wente (1962: 118-128), Assmann (1977: 55-84), Osing (1992), Martin (1985), Fox (1977: 394, Anm. 6).

271 Fox (1985: 244). 
nerliedern können auch didaktische Maximen ( $s b 3 . y)$ integriert sein, was eher ungewöhnlich für diese Gattung ist. Nach Meinung von Fox (1977: 399) hätte der Dichter in solchen Fällen durch das Vehikel der sterblichen Glückseligkeit darauf abzielen, den lebenden Leser zu belehren. Ein solcher Text wäre demnach ein Lied, das auf gewisse Weise zur ewigen Sicherheit und zum Vergnügen der Verstorbenen beiträgt und gleichzeitig über die Lehren der Totenreligion belehrt. Im Kapitel 5 wurden zahlreiche Beispiele vorgestellt, in denen der Begriff 'Herz' als 'Verstand' oder 'Seele' wiedergeben werden kann. Da das Anteflied den Besucher belehren soll, werden solche Ausdrücke deshalb im Sinne der Maxime aus den

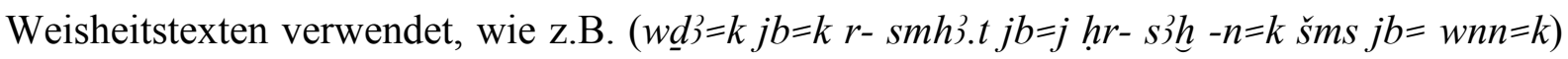
'Du soll dein Verstand $\left({ }^{\circ}\right.$ das $\left.\mathrm{Herz}^{\circ}\right)$ vor der Vergeßlichkeit bewahren (da) deine Erinnerung dir selig werden läßt. Folge deinem Herzen, während du liebst ${ }^{272}$ oder ( $s \underline{d m} . n w r \underline{d}-j b$ sbh.t $t=s n$ $b w \check{s} d n j y=s n j 3 k b j b$ zj $\langle$-〉 jmh.t) 'Der Herzensmüde kann nicht ihre Klageschrei hören, und (deswegen) kann ihren Trauer die Seele eines Mannes aus der Unterwelt nicht retten'. ${ }^{273}$

\subsection{Metaphern in den Liebesliedern}

Die charakteristischerweise für diese Gattung verwendeten Metaphern identifizieren einen Teil des Körpers mit einem kostbaren Objekt, wie etwa Perlen oder Edelsteinen, oder mit einer schönen Eigenschaft der Natur, wie dem Duft des Frühlings oder der Farbe des Himmels während des Sonnenauf- und untergangs. In den ägyptischen Liebesliedern wird die Beschreibung des Körpers manchmal durch die Gleichsetzung mit Blumen, Lapislazuli oder Gold ausgedrückt. ${ }^{274}$ Eine andere Art der Metapher stellt das Beispiel L-14 dar, in dem der Geliebte mit einem königlichen Pferd (ssm.t $n$ - nsw) identifiziert wird, welches rasch Meldungen weiterleiten soll. Das Ziel dieser Metapher ist es, die eilige Wiederkehr des Geliebten auszudrücken, auf den die "Schwester" ungeduldig wartet. Im Beispiel L-30 wünscht sich der Geliebte, ein Siegelring ( $h t m ~ \check{s} r j$ ) zu sein, damit er immer nah bei seiner Geliebten sein kann. In diesen beiden Beispielen wird weder die Kraft noch das Aussehen des Pferdes mit dem Geliebten, weder die Schönheit noch der Wert des Ringes mit der Geliebten verglichen, um eine Metapher auszubilden. Es geht vielmehr um ihre Funktionalität, d.h. der Tenor ist in beiden Fällen die geliebte Person und das Vehikel sind die Schnelligkeit eines königlichen Pferdes und der tägliche Hautkontakt mit dem Ring.

Ein interessantes Beispiel ist L-29, in dem es heißt, daß 'das Herz froh an seiner richtigen Stelle wie ein Nilbarsch in seinem Teich ist' ( $h 3 t j=j w n f h r-m k . t=f m j-w \underline{d} m-p j y=f m s ̌ 3)$. Um die Metapher besser verstehen zu können, sollte der Begriff für das Vehikel, nämlich Fisch, erklärt werden. 
Das Wort $w \underline{d}$ wird im Wörterbuch von Erman \& Grapow als "roter Fisch" übersetzt. ${ }^{275}$ In der Arbeit Gamer-Wallerts (1970: 25 und 110) ${ }^{276}$ über Fische und Fischfang in alten Ägypten wird der Fisch als Tilapia nilotica identifiziert, eine Barschsorte, für die auch der Ausdruck $w \underline{d} d \check{s} r$ "roter Fisch" 277 verwendet wurde.

Die Übersetzung des Wortes $m s \check{3}$ stellt größere Schwierigkeiten dar. Erman \& Grapow verzeichnen es im Wörterbuch nur als Substantiv, ohne eine Erklärung zur Semantik zu bieten. Caminos (1956: 18f.) erläutert diesen Begriff wie folgt: "perhaps mš3 designates the place where the newly caught fishes were cleaned, dressed, and cured". Unabhängig von der Meinung Caminos und der Problematik bei der semantischen Bestimmung des Wortes kann in Bezug auf seinen kontextuellen Zusammenhang festgestellt werden, daß sich der Fisch in dem $m s \check{3}$ wohl fühlt.

Die gerade besprochenen Metaphern lassen sich folgendermaßen darstellen:

\begin{tabular}{||l|l||}
\hline \hline TENOR & \multicolumn{1}{|c|}{ VEHIKEL } \\
\hline Herz & Fisch \\
\hline Geliebter & Lauf eines königlichen Pferdes \\
\hline Geliebter & Tägliches Tragen eines Rings \\
\hline
\end{tabular}

Der Geliebte wird zweimal genannt. Im Beispiel L-14 handelt es sich um eine Metapher, da die Person mit einem Tier identifiziert ist. Auch in diesem Fall ist keine Metapher für Gefühle enthalten, weil - wie es vorne gesagt wurde - das Vehikel hier mit der Schnelligkeit eines königlichen Pferd gleichzusetzen ist. Die mit dem Ring gebildete Metapher drückt ebenfalls indirekt ein Gefühl aus, da der Geliebte sich wünscht, ein Ring zu sein, damit er immer nah bei seiner Geliebter sein kann.

Noch interessanter ist das Beispiel des Fisches. Fox (1985: 34-35) identifiziert den Fisch mit dem Herzen des Jungen, welches das Mädchen gefangen hat. Er fügt hinzu, daß das Motiv des Tilapia-Fisches als sexuelles Symbol, nämlich für den Phallus, verwendet wurde. ${ }^{278}$

Es ist jedoch zu bemerken, daß sowohl das Herz als auch der Fisch durch eine Ortsangabe näher charakterisiert werden, nämlich 'das Herz an seiner Stelle' und der 'Fisch im mšj-Teich'. Diese Metapher wird benutzt, um das Gefühl "froh sein" auszudrücken, wobei im Grunde genommen zu bemerken ist, daß hier eine Vorstellung der Ägypter über die Fische, die sich in diesem $m s \check{s}$-Teich befinden, geäußert wird. Der Fisch befindet sich in seinem Element und ist 'froh'. Im Kapitel über die Emotionen wurde erklärt, daß mit der Freude 'unmotivierte Bewegungen' assoziiert werden. Wahrscheinlich wurden die aufgeregten Bewegungen eines Fisches als Reaktion auf die Freude gedeutet. Diese Interpretation läßt sich durch die Beispiele 
L-21 (jfd $s w j b=j 3 s$ 'er, mein Herz, ist eilig fliehend') und L-24 ( $f f j b=j r$ - $p r$ 'mein Herz ist aufgeregt $\left({ }^{\circ}\right.$ springt $\left.{ }^{\circ}\right)$, um loszugehen') untermauern, in denen das Herz mit der Bewegungstätigkeit in Verbindung steht.

Für all diese Metaphern können zwei Kriterien angewandt werden, nämlich Belebtes-Unbelebtes und Belebtes-Belebtes. ${ }^{279}$ Die Kriterien lassen sich in Zusammenhang mit den Beispielen in der folgenden Tabelle resümieren:

\begin{tabular}{||l|l||}
\hline BELEBTES-BELEBTES & BELEBTES-UNBELEBTES \\
\hline Herz = Fisch & $\begin{array}{l}\text { Geliebter = Tägliches Tragen eines } \\
\text { Ringes }\end{array}$ \\
\cline { 1 - 1 } $\begin{array}{l}\text { Geliebeter = Lauf eines königliches } \\
\text { Pferdes }\end{array}$ & \\
\hline
\end{tabular}

\subsubsection{Der pflanzliche Hintergrund}

Der Garten spielt auch in den Liebesliedern eine wichtige Rolle. Obwohl es kein Beispiel gibt, in dem das Herz mit einer Pflanze oder Blume identifiziert wird, enthält der Garten als Kontext einen metaphorischen Sinn. Mathieu (1996: 184) erstellte eine Tabelle, in der er die Vergleiche und Metaphern der Liebeslieder zusammenfaßt. Es ergab sich, daß ein großer Teil dieser Ausdrücke (38\%) mit Pflanzen konstruiert wird. Es gibt nicht nur Stellen, in denen die Geliebte als eine Blume beschrieben wird ${ }^{280}$, sondern auch solche, in denen der pflanzliche Hintergrund wie im Blumenlied mit Sex und Fertilität verbunden wird (Fox 1985: 284-285). Mathieu (1996: 152) weist auf den städtischen Kontext hin, in dem die Geliebten wohnen und dem sie im Garten, der als Hintergrund für ihre Liebe dient, entkommen. Deswegen wird der Garten nicht nur als literarische Figur verwendet, sondern auch als ein Paradies für die Liebe. Es gab mehrere Arten von Gärten ${ }^{281}$ wie Haus-, Palast-, Tempel- und Grabgärten, die einen metaphorischen Sinn enthalten. Während sich das Keimen und Wachsen der Pflanzen in den Haus- und Palastgärten mit dem Kreislauf des Lebens identifizieren läßt, garantieren die Gärten beim Grab die Wiedergeburt. In den Liebesliedern ist der Garten ${ }^{282}$ des Hauses mit Blumen und Vögel ausgestattet. Der Vogelfang läßt sich mit dem Einfangen der "Schwester" oder des "Bruders" (L-4) identifizieren. Fox (1985: 35 No. 20Ea) interpretiert die Metapher des Herzens und des Fisches (L-29) im gleichen Sinn, nämlich, daß sowohl das 'Herz an seiner Stelle' als auch der Fisch gefangen sind. Obwohl das Herz des "Bruders" durch die "Schwester" gefangen wurde, ist es froh.

279 Siehe Kapitel 3.5 Vorschläge zur Klassifikation von Metaphern.

$280 t w=j m-d=k m j-p 3-h{ }^{3}-n-t 3 s r d . w-n=j m-h r r . w(t) m-\underline{h} 3 w . t n b(. t) s d m$ sty 'Ich bin bei dir wie das Grundstück, welches für mich mit Blume und mit allerlei Kräutern des süßen Duftes wachsen läßt' (Fox 1985: No. 18); jw n3y=s šby.w n- hrr.w(t) n3y=s qs n-js.w 'Thre Halsband sind Blume, ihre Knochen sind Schilfrohr' (Fox 1985: 406, No. 54).

281 LÄ II, 376-377; Hugonot (1989); Moens (1984).

$282 L \ddot{A}$ III, 1048-1049. 


\subsection{Ein Vorschlag zur Klassifikation}

Im Folgenden werden die Textbeispiele der Liebesliedern nach unterschiedlichen Kriterien in Gruppen aufgeteilt. Wenn das Herz der Wille der Person ist, dann kann es als Person handeln. Aber das Herz kann auch der Zentralpunkt sein, auf den die Tat fokussiert wird, d.h. als das direkte Objekt des Verbs dienen.

Wie in den Abschnitten zu den Lehren analysiert wurde, kann 'das Herz' einen Charakterzug ausdrücken. Diese Funktion läßt es sich auf zwei Gruppen verteilen, die Ausdrücke für die Beschreibung des guten oder schlechten Charakters enthalten. Ebenso ist der Begriff 'Herz' für 'Verstand', 'Wunsch', 'Seele' und 'Stimmung' verwendet worden.

Da sich anhand der oben genannten Gruppen ergibt, daß das Herz nicht immer mit Gefühlen in Verbindung zu bringen ist, bilden die Ausdrücke, in denen das Herz in Zusammenhang mit einem Gefühl vorkommt, eine eigene Gruppe, ebenfalls die Metaphern, die vorher analysiert wurden.

Nur ein Beispiel (L-24: jm sw $m$ - $j b=s$ ) enthält den Ausdruck "etwas ins Herz geben". In diesem Fall bezieht er sich nicht auf das Herz als Zentrum des Gefühls, sondern auf den Verstand. Die Geliebte erbittet von der Goldenen, nämlich Hathor, daß sie die Mutter des Geliebten veranlaßt, das Herz und die Liebe der Geliebten kennenzulernen und zu akzeptieren.

Die letzte Gruppe setzt sich aus den Ausdrücken zusammen, die teilweise auf den vorherigen Seiten vorgestellt wurden. Im Anteflied (L-10: $w r \underline{d-j b}$ ) kommt eine Metonymie vor, wegen der Osiris als die Gottheit der Unterwelt, als 'Herzensmüder', bezeichnet wird. ${ }^{283}$ Der

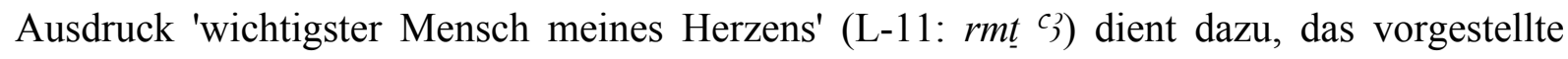
Konzept des 'Besitzes' zu deuten.

GRUPPE 1

Das Herz als Subjekt (handelt als Person)

\begin{tabular}{||l|l||}
\hline das Herz erbarmt sich der Liebe & L-2 \\
\hline das Herz geht dahin, um etwas zu tun & L-3 \\
\hline das Herz erinnert sich an jdn/etwas & L-3*; L-13 \\
\hline das Herz liebt jdn & L-4 \\
\hline das Herz sorgt sich um etwas & L-4 \\
\hline das Herz will zu jdm & L-4 \\
\hline das Herz ist gleich harmonisch & L-5 \\
\hline das Herz steht im Innern auf & L-6 \\
\hline das Herz sucht jdn & L-7 \\
\hline das Herz gibt keine Ruhe $\left({ }^{\circ}\right.$ das Herz schweigt nicht $\left.{ }^{\circ}\right)$ & L-9 \\
\hline das Herz schickt einen Boten aus & L-9 \\
\hline das Herz ist harmonisch & L-11 \\
\hline das Herz freut sich über etwas & L-12 \\
\hline das Herz ist auf etwas gespannt & L-14 \\
\hline das Herz ist bereit zu hören & L-14 \\
\hline das Herz jubelt & L-14 \\
\hline das Herz weißt etwas & L-14 \\
\hline \hline
\end{tabular}




\begin{tabular}{||l|l||}
\hline das Herz beabsichtigt etwas zu sehen & L-19 \\
\hline das Herz ist fliehend & L-21 \\
\hline das Herz bleibt fest & L-23 \\
\hline das Herz flieht & L-23 \\
\hline das Herz ist aufgeregt $\left({ }^{\circ}\right.$ springt $\left.^{\circ}\right)$ & L-24 \\
\hline das Herz jauchzt & L-29 \\
\hline
\end{tabular}

\section{GRUPPE 2}

Das Herz als Objekt

\begin{tabular}{||l|l||}
\hline \hline das Herz legen & L-1 \\
\hline das Herz jdms fortnehmen & L-3*; L-16; L-24 \\
\hline dank dem Herzen & L-5* \\
\hline das Herz leben lassen & L-6 \\
\hline zum Herzen sagen & L-7 \\
\hline das Herz jds nicht kränken & L-8* \\
\hline sich kränken ( $^{*}$ das Herz beschädigen $\left.{ }^{\circ}\right)$ & L-9; L-42 \\
\hline das Herz jds trösten & L-10 \\
\hline dem Herzen folgen & L-10 \\
\hline das Herz (=matt) schlagen & L-10 \\
\hline das Herz jds retten & L-10 \\
\hline das Herz jds erheben & L-11 \\
\hline das Herz betören & L-17 \\
\hline sich unbedacht verhalten $\left(^{\circ}\right.$ einer, der sein Herz nicht hat $\left.{ }^{\circ}\right)$ & L-18 \\
\hline das Herz jds kennen & L-24 \\
\hline das Herz jdms am Leben erhalten & L-26 \\
\hline mit dem Herzen sprechen & L-27* \\
\hline das Herz jds nehmen & L-30*; L-32 \\
\hline \hline
\end{tabular}

\section{GRUPPE 3}

Das Herz für den Ausdruck des Charakters

\begin{tabular}{|l|l||}
\hline das Herz ist unwillig & L-18 \\
\hline das Herz ist unwissend & L-20 \\
\hline das Herz ist töricht & L-22 \\
\hline das Herz ist froh & L-29 \\
\hline mutig sein $\left({ }^{\circ}\right.$ das Herz ist gro $\left.\aleph^{\circ}\right)$ & L-28* \\
\hline
\end{tabular}

GRUPPE 4

Das Herz als Verstand

\begin{tabular}{||l|l||}
\hline \hline mein Herz geht dahin, um etwas zu tun & L-3 \\
\hline mein Herz erinnert sich an etwas & L-3* \\
\hline den Verstand vor der Vergeßlichkeit zu bewahren & L-10 \\
\hline Erinnerung & L-10 \\
\hline Befehl des Verstandes & L-10 \\
\hline das Herz weiß etwas & L-14* \\
\hline den Verstand rauben $\left({ }^{\circ}\right.$ das Herz fortnehmen $\left.{ }^{\circ}\right)$ & $\mathrm{L}-16 ; \mathrm{L}-24$ \\
\hline unbedacht verhalten $\left(^{\circ}\right.$ einer, der sein Herz nicht hat $\left.{ }^{\circ}\right)$ & $\mathrm{L}-18$ \\
\hline unwissend sein & $\mathrm{L}-20$ \\
\hline töricht sein & $\mathrm{L}-22$ \\
\hline Dummheiten machen & $\mathrm{L}-22^{*}$ \\
\hline
\end{tabular}


GRUPPE 5

Das Herz als Wunsch

zu jdm wollen

L-4

GRUPPE 6

Das Herz als Seele

Seele eines Mannes

L-10

GRUPPE 7

Das Herz als Stimmung

die Stimmung ist harmonisch

die Stimmung ist bereit, etwas zu hören

L-5; L-11

$\mathrm{L}-14$

GRUPPE 8

Das Herz als Ort

etwas ins Herzen geben

L-24

GRUPPE 9

Das Herz und das Gefühl

\begin{tabular}{||l|l||}
\hline das Herz erbarmt sich der Liebe & L-2 \\
\hline das Herz liebt jdn & L-4 \\
\hline das Herz sorgt sich um etwas & L-4 \\
\hline das Herz ist entspannt & L-8* \\
\hline das Herz jds nicht kränken & L-8* \\
\hline kränken $\left({ }^{\circ}\right.$ das Herz beschädigen $\left.{ }^{\circ}\right)$ & L-9 \\
\hline das Herz jds trösten & L-10 \\
\hline das Herz jds erheben & L-11 \\
\hline das Herz freut sich über etwas & L-12 \\
\hline das Herz ist gespannt & L-14* \\
\hline das Herz jubelt & L-14 \\
\hline das Herz ist unwillig & L-18 \\
\hline undankbar verhalten $\left({ }^{\circ}\right.$ einer, der sein Herz nicht hat $\left.{ }^{\circ}\right)$ & L-18 \\
\hline das Herz ist froh & L-29* \\
\hline das Herz jauchzt & L-29 \\
\hline das Herz ist nicht zufrieden & L-33 \\
\hline
\end{tabular}

GRUPPE 10

Die Metapher des Herzens

das frohe Herz ist wie ein Nilbarsch

L-29

\section{GRUPPE 11}

Sonstiges

Herzensvergnügen

der Herzensmüde (=Osiris)

der wichtigste Mensch des Herzens

L-1; L-4; L-31

L-10

L-11 


\subsection{Textbeispiele}

pHarris 500 (Fox 1985)

Quelle:

Datierung:

Textausgaben:

pHarris 500 1,1-6,3

XIX Dynastie 283

Übersetzungen:

Maspero (1883: III, 230-251, Pl. I-VIII.), Müller (1899: Pl. 2-12), Budge (1923: Pl. XLI-XLIV), Fox (1985: 370-378), Mathieu (1996: Pl. 8-13).
Erman (1927: 244-248), Müller, (1899: 13-26), Schott (1950: 50-53), Donadoni (1969: 435-441), Kischkewitz (1973: 68-77), Foster (1974: 65-76), Lichtheim, (1976: II, 189-192), White (1978: 169-172), Fox, (1985: 7-25), Hornung (1990: 153-158), Vernus (1992: 74-82); Mathieu (1996: 56-63).

\section{Erste Gruppe}

\section{L-1 1,1}

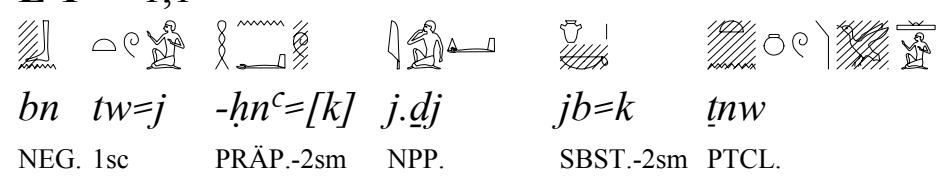

Bin ich nicht mit dir? Wo liegt dein Herz?

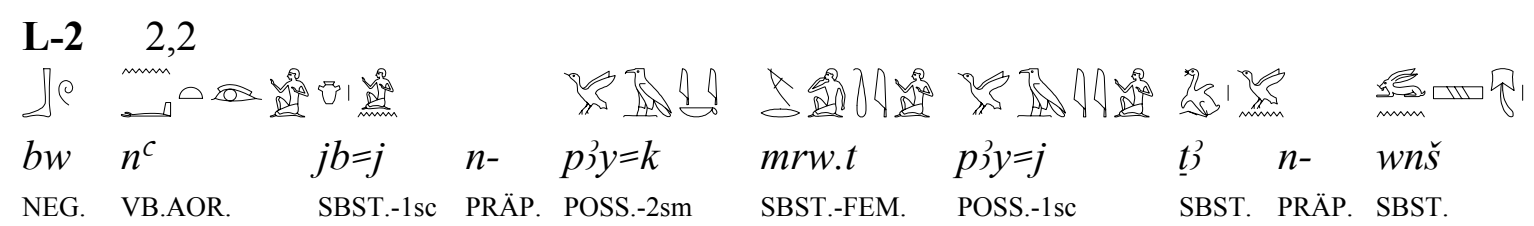

Mein Herz erbarmt sich nicht deiner Liebe, mein junger Wolfschakal!

\section{L-3 3,2-3,8}

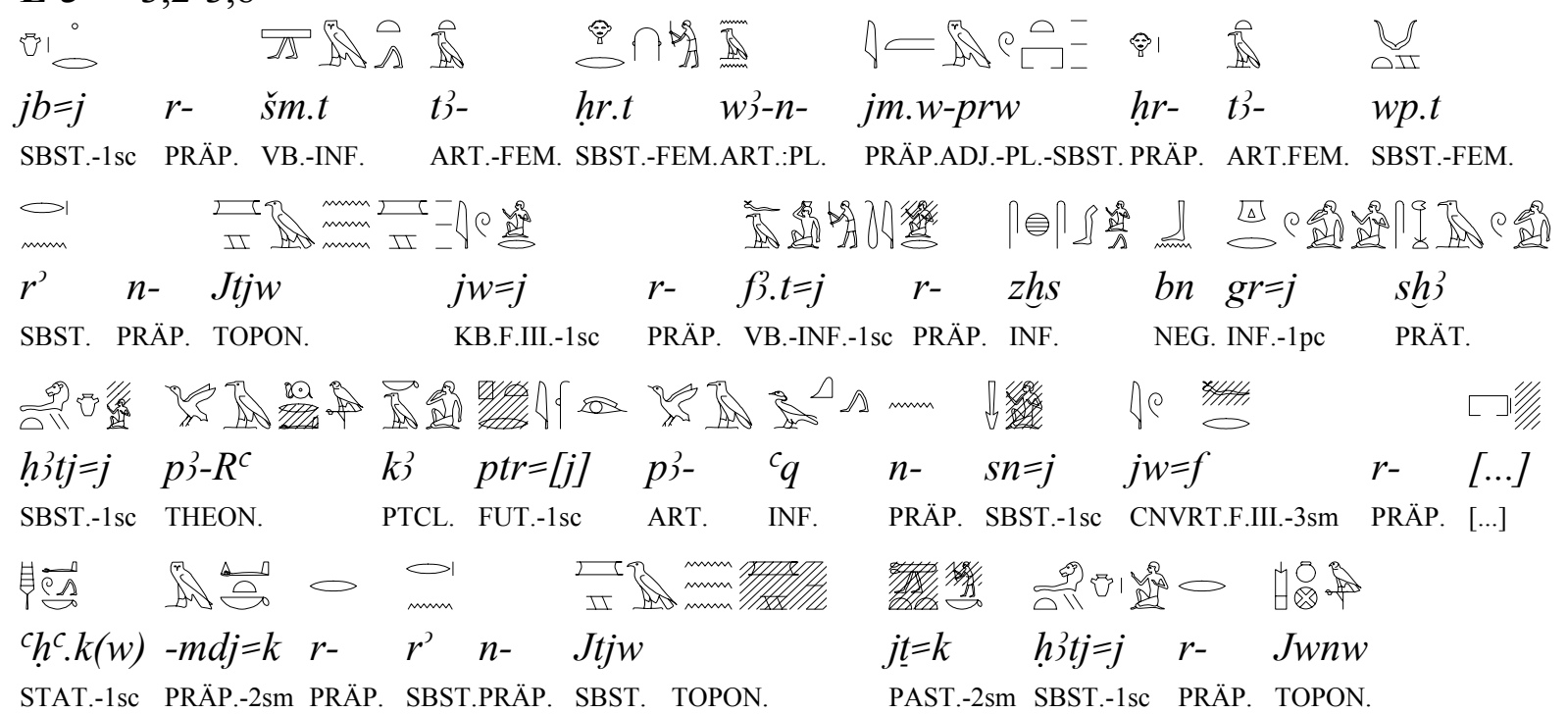

Mein Gedanke geht dahin, die Vorbereitung der Hausbewohner auf die Öffnung der Mündung des Itjw-Kanal durchzuführen, und ich werde mich daranmachen, pausenlos zu 
rennen. ${ }^{284}$ Mein Herz hat sich an den Sonnengott erinnert. Ich kann den Eintritt meines "Bruders" sehen, wenn er dem [... $]^{285}$ dem Gebäude nährt. Ich stehe mit dir an der Mündung des Itjw-Kanals. Du hast mein Herz nach Heliopolis mitgenommen. ( ${ }^{\circ}$ mein Herz ${ }^{\circ}$ )

\section{Zweite Gruppe}

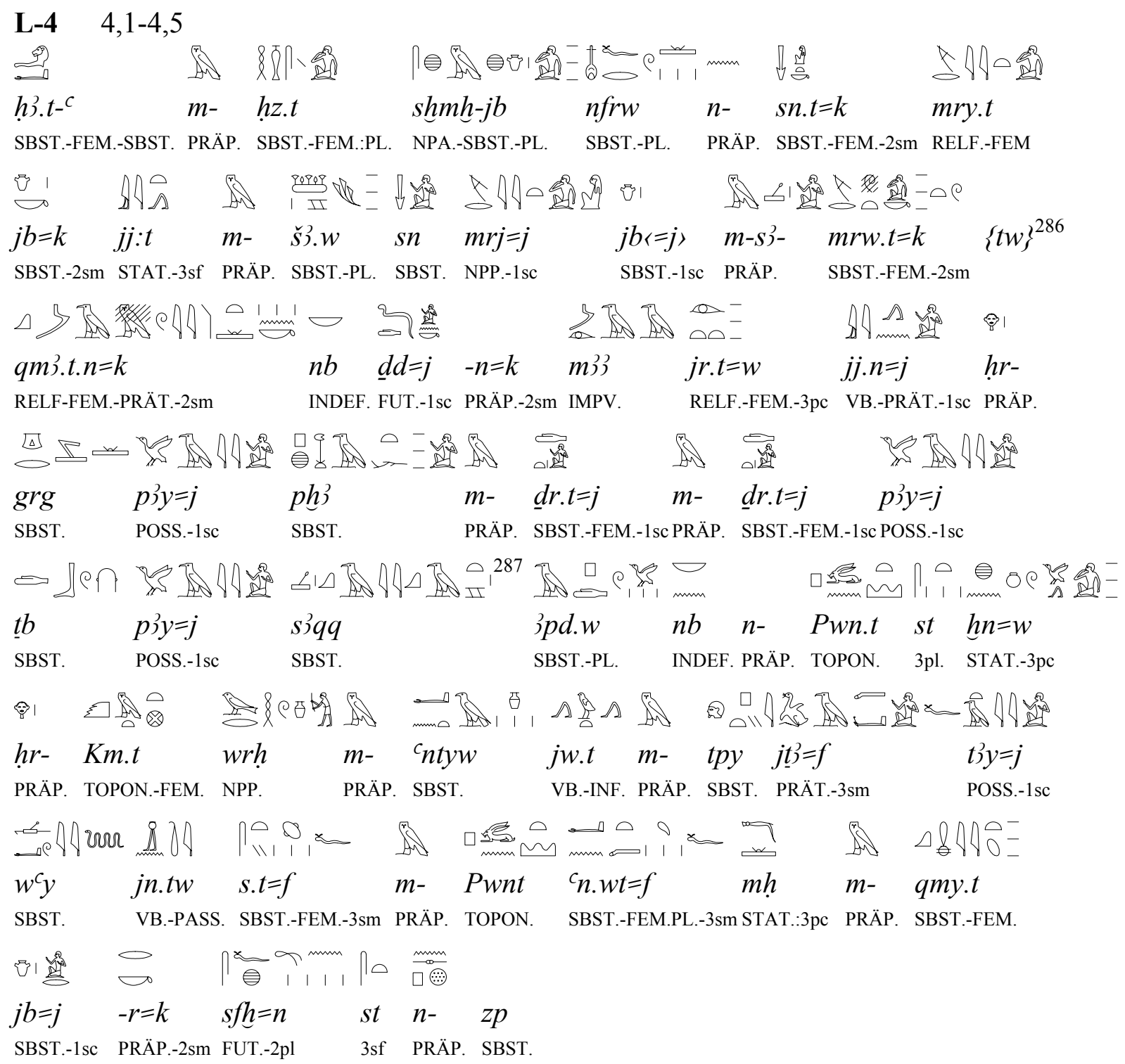

Beginn der herzerfreuenden schönen Lieder deiner "Schwester", die dein Herz liebt, wenn sie den Feldern heimkehrt. Mein geliebter "Bruder", ich sorge mich um deine Liebe und um

284 "I'll shall too hurry, and shall not pause" Fox (1985: 14); "Puis je me mettrai à courir sans cesse" (Mathieu 1996: 59). Das Wort sgr bedeutet 'schweigen' oder 'ruhig, leidenschaftslos sein' (Wb V 179,9-180,7) was als einen Zustand nach meiner Meinung interpretiert werden kann, in dem man aufgeregt sei. Hintergrund für diese Interpretation ist die Gedanke des Mädchens an seines Treffen mit seinem Geliebter, darauf es auf diese Weise reagiert.

285 Vernus (1992: 77) übersetzt "Quand il se dirigera vers le «Domaine»"; Mathieu (1996: 72 Anm. 190, Pl. 10) ergänzt $j w=f r$ Pr-w.t-c "quand il sera dans le Parc".

$286 t w$ gehört zu $m r w t=k$, siehe Fox (1985: 15).

287 Fox (1985: 17d) und Mathieu (1996: 73 Anm. 201) erkennen $s q 3 q 3$ mit $s 3 q$ (Wb. IV 26,14-16) als eine Reduplikation des Wortes mit dem Sinn etwa "weave mat"; Müller (1899: 21) und Vernus (1992: 78) übersetzen "ècran". 
alles, was du geschaffen hast. Ich werde dir erzählen: "Siehe dir an, was man getan hat. Ich bin gekommen, um eigenhändig meine Vogelfalle in meiner Hand aufzustellen und meine Vogelkasten und meine Matte. Alle Vögel aus Punt lassen sich auf Ägypten wieder. Einer, der mit Myrrhen gesalbt ist, kommt als der erster und hat schon meine Made geschnappt. Sein Duft wurde aus Punt herbeigebracht, seine Flügel sind voll mit Gummiharz. Ich will zu dir. Mögen wir es zusammen ablösen. ( ${ }^{\circ}$ mein Herz ${ }^{\circ} /{ }^{\circ}$ mein Herz will nach dir $^{\circ}$ )

L-5 4,10-4,11

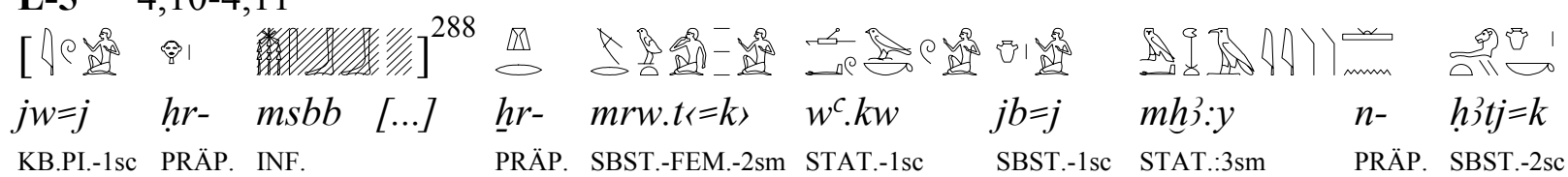

nm

$n n \quad w 3 y=j \quad r-\quad n f r w=k$

NEG. FUT.-1sc PRÄP. SBST.-2sc

Ich jubele über deine Liebe, wenn ich allein bin. Meine Stimmung ist harmonisch dank deinem Herzen. Möge ich von deiner Schönheit nicht fern sein. ( ${ }^{\circ}$ mein Herz ist im Gleichgewicht wegen deines Herzens ${ }^{\circ}$ )

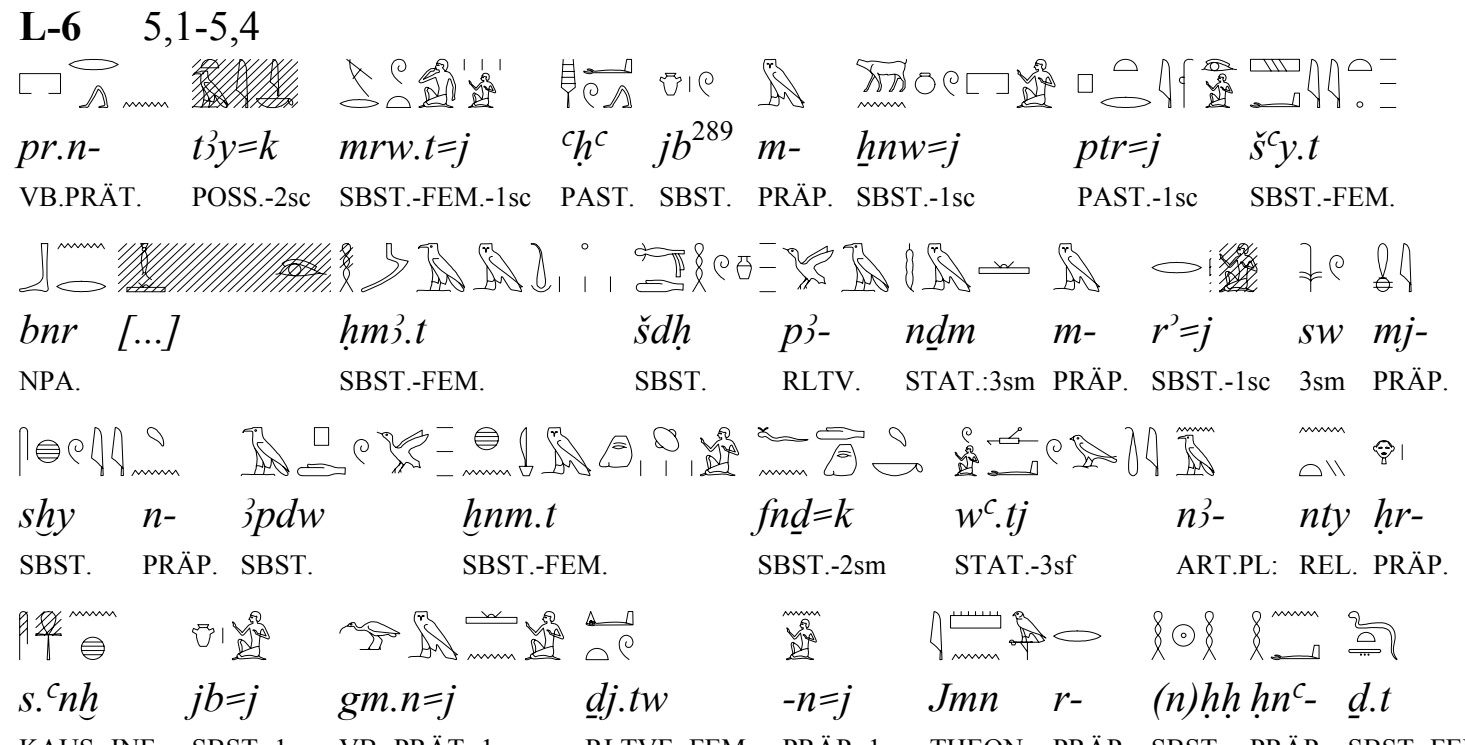

KAUS.-INF. SBST.-1sc VB.-PRÄT.-1sc RLTVF.-FEM. PRÄP.-1sc THEON. PRÄP. SBST. PRÄP. SBST.-FEM.

Als deine Liebe zu mir ans Licht gekommen ist, stand das Herz in meinem Innern auf. Ich sah süßen Kuchen, Salz und Wein, doch das Süße in meinem Mund war wie Vogelgalle. Allein der Geruch deiner Nase ist das, was mich am Leben erhält, nachdem ich entdeckt habe, was mir Amun für alle Ewigkeit zugeteilt hat. $\left({ }^{\circ}\right.$ mein $\left.\mathrm{Herz}^{\circ}\right)$ 
L-7 5,3-5,6

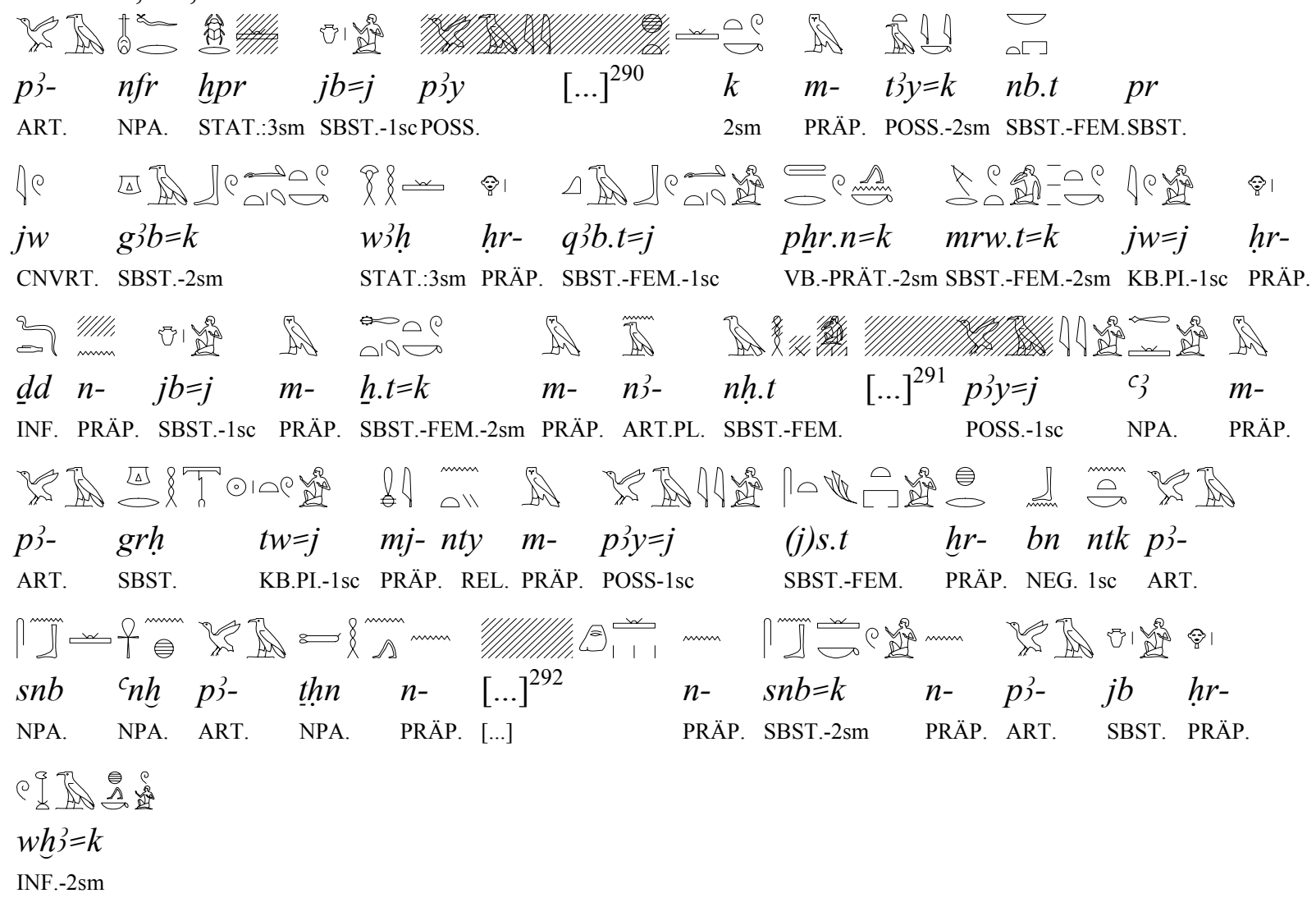

Das Gute ist passiert. Mein Herz [...] deine Hausherrin, während dein Arm auf meiner Brust lag und du deine Liebe umdrehtest. Ich sage zu meinem Herzen: "Beherrsche dich mit diesem Wunsch [...] [gib mir] meinen Großen in dieser Nacht oder ich bin wie eine, die sich in 〈meinem〉 seinem Grab befindet. Bist du nicht einer, der gesund ist und lebt. Das Treffen [...] für deine Gesundheit ist das, weswegen das Herz dich sucht".

\section{L-8 $\quad 5,7-5,8$}

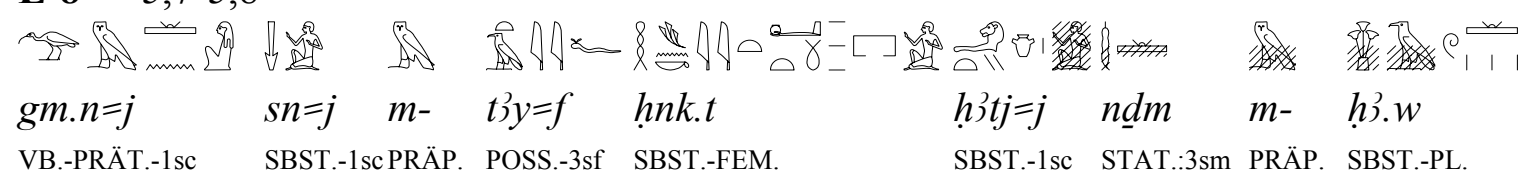

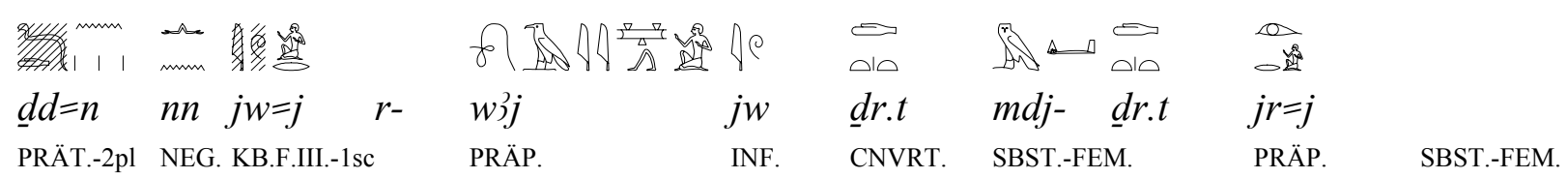

AUX::F.III.-1sc

290 Mathieu (1996: 75, Anm. 223) liest den Satz wie folgt: $p 3-n f r$ hpr $j b=j$ [r- $m 33$ nfrw=k] $m$ t3y=k nb.t "Ce serait beau que se réalise mon désir [de voir ta beauté] sous ta tonelle".

291 Mathieu (1996: 75 Anm. 225) liest die ganze Passage wie folgt: $J w=j h r d d n j b=j m$ h. $t=k m n$ j- $n n h . w t$ $[d=t w n=j p 3] y=j c_{3} m p 3$ - grh "je ne cesse de dire à mon coeur: «Rentre!». En priant [pour avoir] mon prince cette nuit". Fox übesetzt (1985: 22 "I say to my heart within $<$ me > in prayer: ["Give me] my orince tonight".

292 Fox (1985: 23) fügt ein: $n-h r=k d j=f r \check{s} w . t$ "of your face will give (me) joy" und Mathieu (1996: 76, Anm. 227) $n-n f r w=k d=f r s ̌ w . t$ "ta beauté donne la joie". 


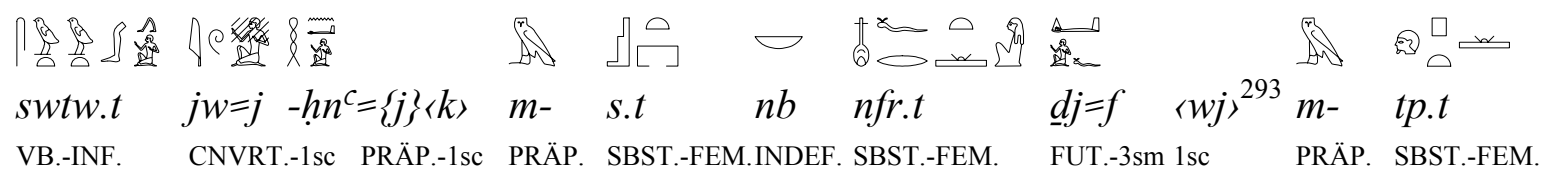

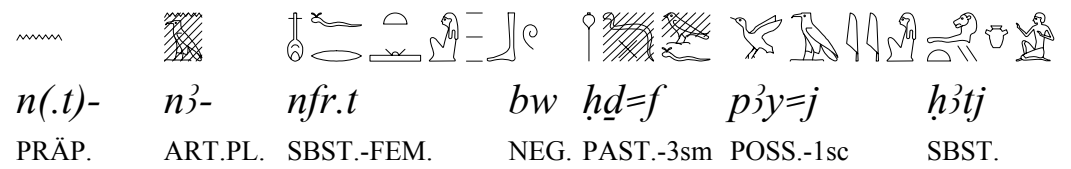

Ich fand meinen "Bruder" in seinem Schlafzimmer und mein Herz war ganz entspannt. Wir sagten: "Ich werde nie fern sein, sondern Hand an Hand, und ich werde spazierengehen und mit dir an jedem schönen Platz sein. Er wird (mich) an die Spitze der Schönheiten stellen und wird mich niemals kränken". ( ${ }^{\circ}$ mein Herz war sü $\beta^{\circ} /{ }^{\circ}$ das Herzen schädigen $\left.{ }^{\circ}\right)$

L-9 $\quad 5,8-5,12$

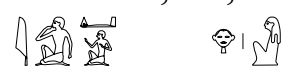

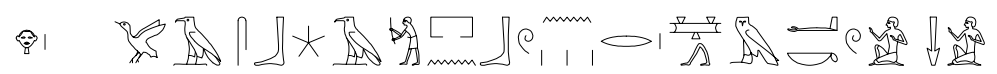

$j \cdot \underline{d} j=j$

$h r=j \quad h r-p 3-$

$s b 3$

$n-b l-$

$m k$

$s n=j$

EMPH.VB.-1sc SBST.-1sc PRÄP. ART. SBST.

ADV.

PTCL.

SBST.-1sc

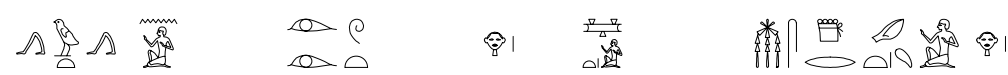

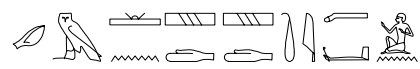

jw.t $\quad-n=j \quad$ jr.ty $\quad h r-\quad w 3 . t$

$m s \underline{d r} . w y=j \quad h r-\quad s \underline{d} m \quad n \check{s} d \check{s} d . t=j \quad n-$

VB.-INF. PRÄP.-1sc SBST.-FEM.du. PRÄP. SBST.-FEM. SBST.du-1sc PRÄP. INF. FUT.-1sc PRÄP.

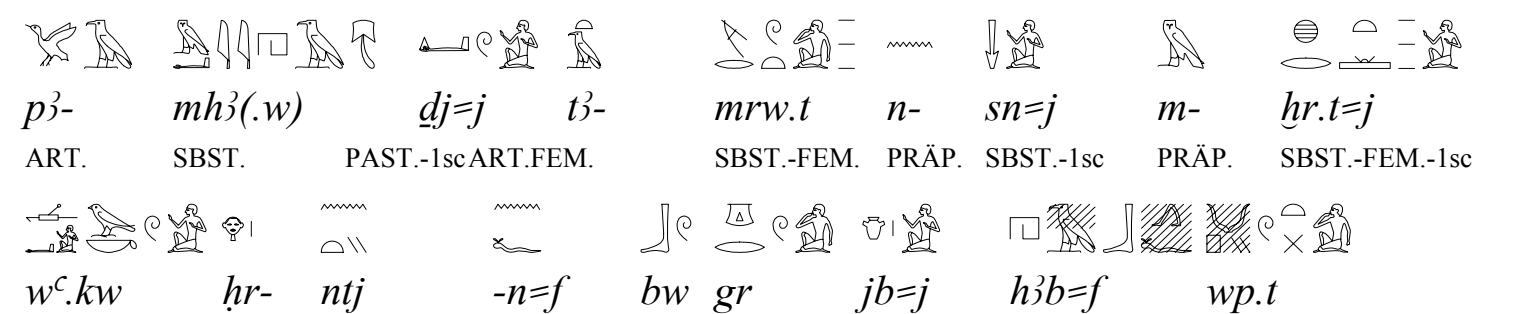

STAT.-1sc PRÄP. REL.PRON. PRÄP.-3sm NEG. AOR. SBST.-1sc PRÄT.-3sm SBST.-FEM.

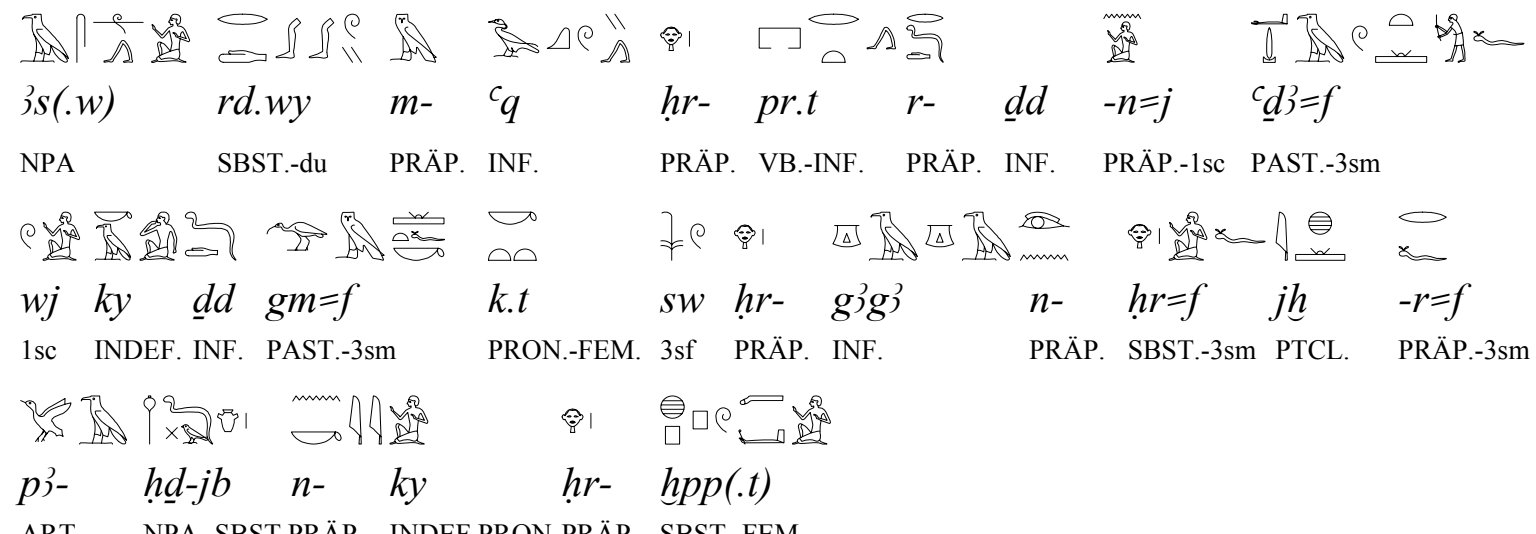

ART. NPA.-SBST.PRÄP. INDEF.PRON.PRÄP. SBST.-FEM.

Ich wende mein Gesicht nur der Außentür zu. Siehe! Mein "Bruder" kommt zu mir. Die Augen richten sich auf den Weg und meine Ohren lauschen. ${ }^{294}$ Ich werde dem Vergeßlichen die Hölle heißmachen. Ich habe meinem "Bruder" die Liebe als meinen (ganzen) Besitz

293 Fox (1985: 377) fügt das Pronomen ein.

294 Das an dieser Stelle meistens angesetzte Verb $\check{s} d \check{s} d$ hat keine eindeutig bestimmbare Bedeutung (Wb IV 569,4). Lichtheim (1976: 191) übersetzt "warten" und Mathieu (1996: 63) "bruits" (Wb IV 562,14). Für die Deutung siehe Fox (1985: 24). Man könnte alternative erwägen, anders zu segmentieren und $n \check{s} d \check{s} d=j \mathrm{zu}$ lesen. Ein Verb nšdšd wäre genauso ein Hapax wie $\check{s} d \check{s} d$, doch wir hätten es mit einer nicht ganz ungewöhnlichen Bildungsklasse (fünfradikaliges Verb primae $-n$, mit reduplizierter Wurzel) zu tun und könnten es mit dem freilich erst später bezeugten Lexem $n \check{s} d$ 'zerfleischen' verbinden. 
geschenkt, und jetzt bin ich wegen dem, was nun ihm gehört, allein. Mein Herz gibt keine Ruhe und hat einen Boten ausgeschickt, der sich sputet, hier reinrennt, dort rausrennt, um mir schließlich zu sagen, er betrüge mich. Ein andere sagt, er hätte eine andere gefunden und sie starre ihm ständig ins Gesicht. Was soll denn das, den anderen wegen einer Dahergelaufenen zu kränken? ( ${ }^{\circ}$ mein Herz schwiegt nicht ${ }^{\circ}{ }^{\circ}$ das Herz schädigen ${ }^{\circ}$ ) 


\section{Das Lied des Antef aus pHarris (Fox 1985)}

Quelle:

Datierung:

Textausgaben:

Übersetzungen:
pHarris 500 6,2-7,3

XIX Dynastie ${ }^{295}$

Maspero (1883: I, 177-185, Pl. I-VIII), Budge (1923: Pl. XLV-XLVI), Müller (1899: Pl. 12-14), Fox (1985: 378-380).

Lichtheim (1945: 178-212, Pl. XVI-XIX), Wilson (1969: 467), Simpson et al. (1972: 296-315), Fox (1977: 393-423), Assman (1977: 55-84), White (1978: 175176), Hornung (1990: 163-164), Osing (1992).

L-10 6,2-7,3

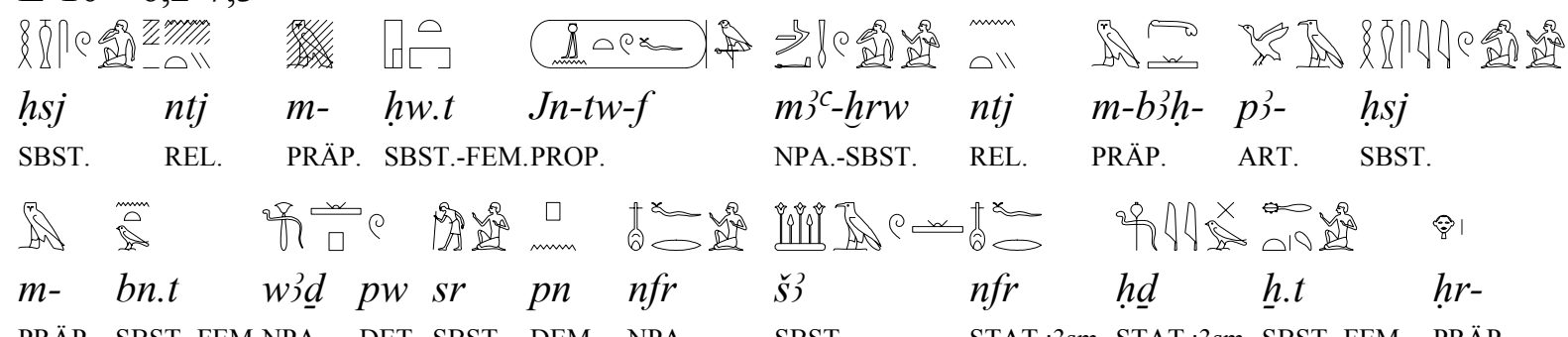
PRÄP. SBST.-FEM.NPA. DET. SBST. DEM. NPA. SBST. STAT.:3sm STAT.3sm SBST.-FEM. PRÄP.

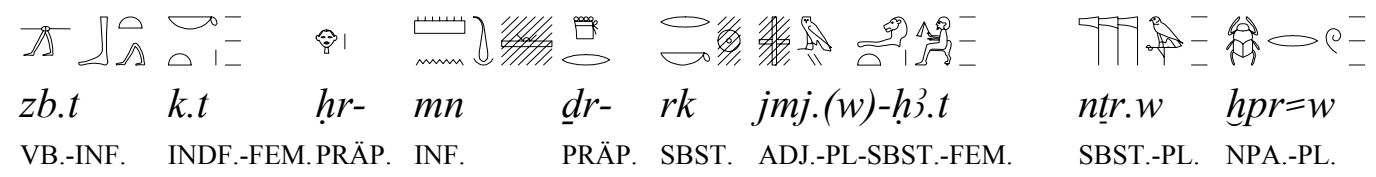

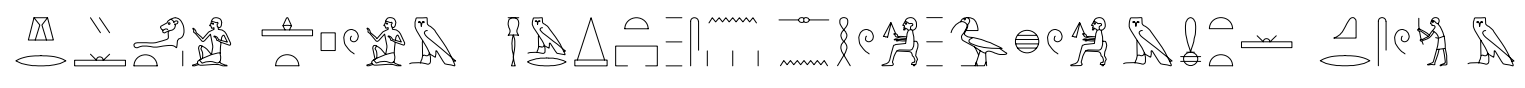

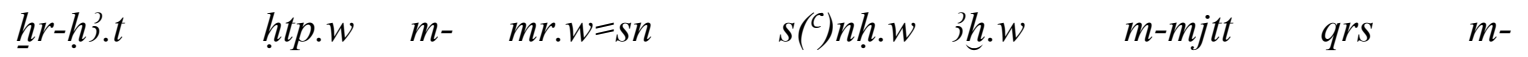
$\begin{array}{llll}\text { PRÄP.-SBST.-FEM. STAT.-3pc PRÄP. SBST.PL.-3pc SBST.PL } & \text { VB.-NPA. ADV. } & \text { STAT.:3sc PRÄP. }\end{array}$

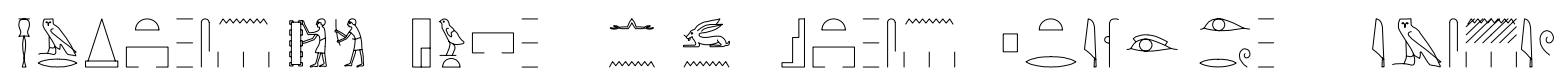
$m r . w=s n \quad q d(. w) h w . t \quad n n \quad w n \quad$ s.t $=s n \quad$ ptr $\quad j r=w \quad-j m=s n \quad j w$ SBST.-PL.-3pc NPA.-PL. SBST.-FEM.PL. NEG. PRÄT. SBST.-FEM.-3pc INTG. RLTVF.-3pc PRÄP.-3pc TOP. ODNm通 sdm.n=j mdw.t Jj-m-ḥtp $\quad h n^{c}-H r w-\underline{d} d=f \quad$ s.dd.tj $\quad m-$ $\begin{array}{lll}\text { VB.-PRÄT.-1sc } & \text { SBST.-FEM.PL. PROP. } & \text { PRÄP. PROP. }\end{array}$

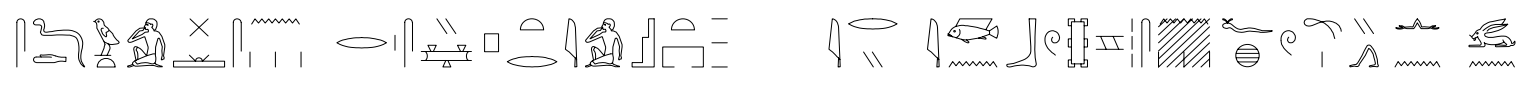
s. $d d w . t=s n \quad$ rsj $\quad$ ptr.$w t \quad$ jry jnb.w=sn fh.w $\quad$ nn wn KAUS.-SBST.-FEM.-3pc POSTP. IMPV. SBST.-FEM.PL. PRTCL. SBST.-PL.-3pc $\quad$ STAT.-3pc NEG. PRÄT.

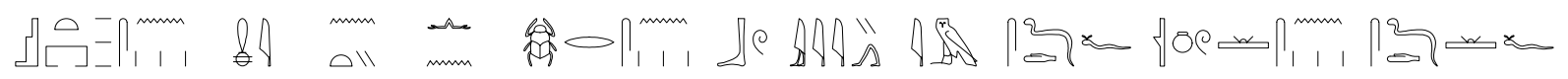
s.wt $=s n \quad m j-\quad n t j \quad n n \quad h p r=s n \quad b w j j(=w) j m \quad s \underline{d d}=f \quad q d=s n \quad s \underline{d d}=f$ SBST.-FEM.-3pc PRÄP. RLTVF.NEG. PRÄT.-3pc NEG. AOR.-3pc PRÄP. FUT.-3sm SBST.-3pc $\quad$ FUT.-3sm

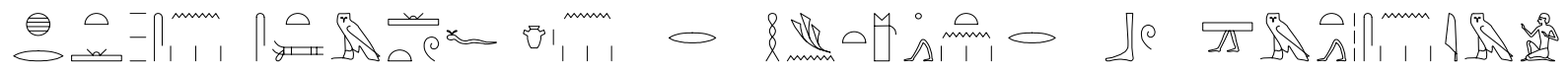
$h r w . t=s n \quad s . t m=f \quad j b=n \quad r-\quad h n . t=n \quad r-\quad b w \quad s ̌ m . t=s n \quad j m$ SBST.-FEM.PL.-3pc KAUS.-FUT.3sm SBST.-1pc PRÄP. TERM.-1pc PRÄP. SBST. VB.-RLTVF.-3pc PRÄP. Q U W ש

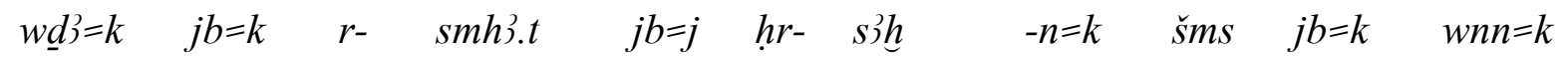


FUT.-2sm SBST.-2sm PRÄP. SBST.-FEM. SBST.-1sc PRÄP. INF.

PRÄP.-2sc IMPV. SBST.-2sc AOR.-2sc

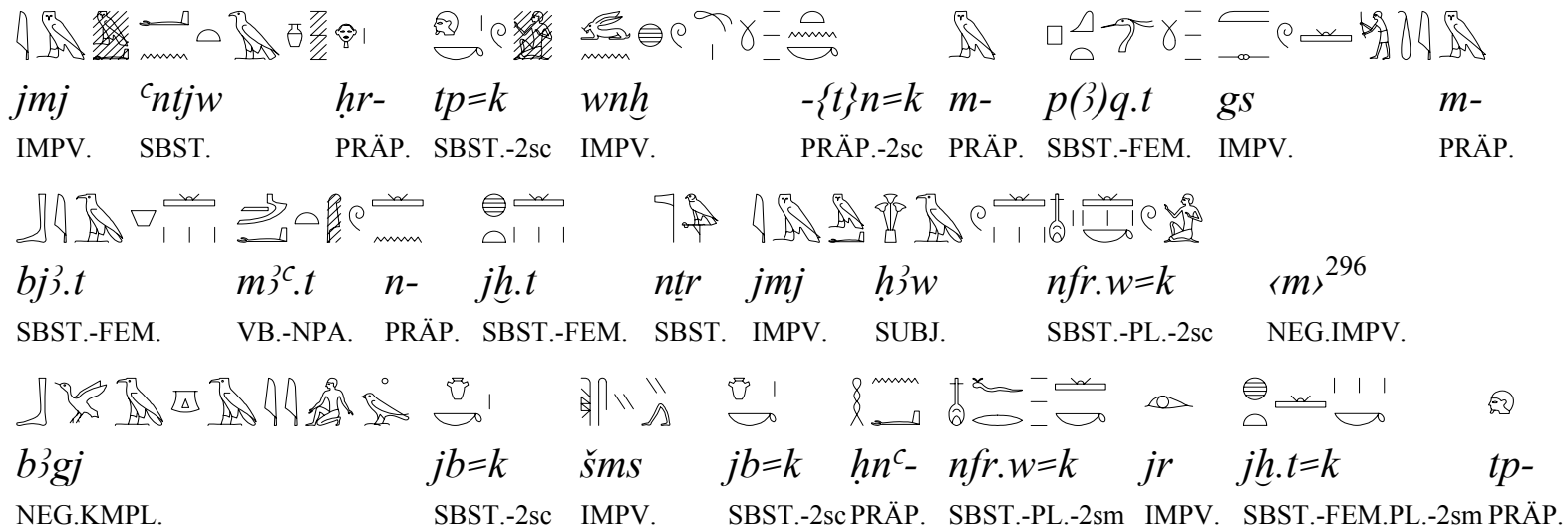

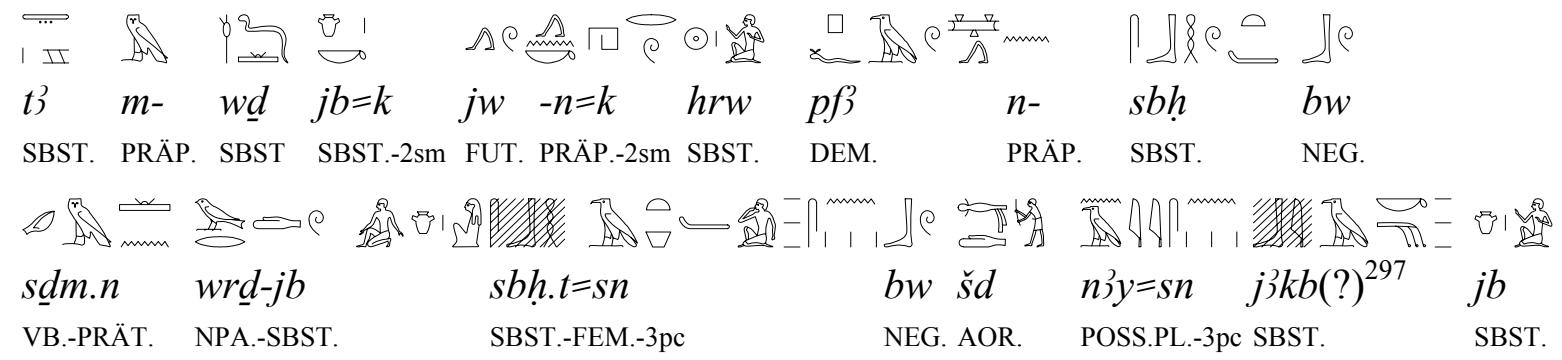

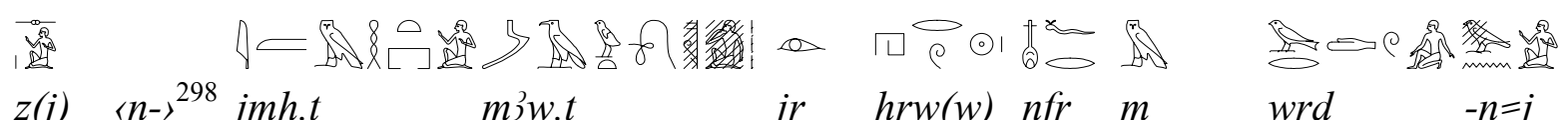

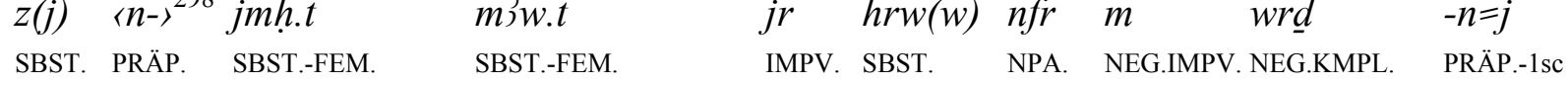

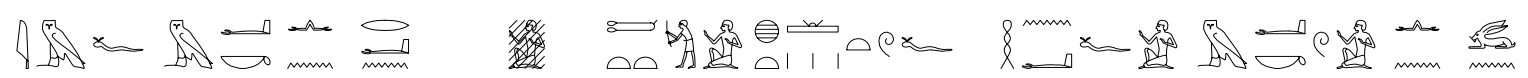
$-j m=f \quad m k \quad n n \quad r d . n \quad z(j) \quad j t j . t \quad j h . t=f \quad-h n^{c}=f \quad m k \quad n n \quad w n$

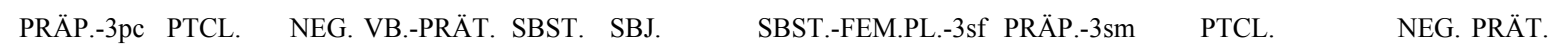

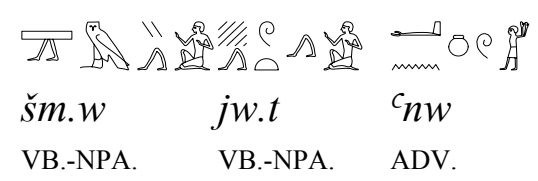

Das Lied, welches im Grab des seligen Königs Antef (zu finden) ist und vor dem Harfner steht. Dieser edle Würdenträger ist ein Glücklicher - egal ob das Schicksal günstig ist oder zerstörerisch. Eine Generation geht, die andere bleibt, (so ist es) seit der Zeit der Vorfahren. Die Göttlichen, die früher existierten, ruhen in ihren Pyramiden. Die vestorbenen Edlen ruhen ebenso in ihren Pyramiden. Die, die Gräber bauten, haben keine eigenen Bestattungsplätze. Was ist mit ihnen geschehen? Ich habe die Worte des Imhotep und des Djedefhor gehört, wenn über ihre Reden immer wieder gesprochen werden. Siehe doch ihre Gräber! Ihre Mauer sind zerfallen. Ihre Plätze existieren nicht mehr wie solche, die nie gestanden wären. Keiner kommt von dort, so daß er weder ihre Art noch ihre Bedürfnisses weiter ermittelt, und daß er unser Herz tröstet, bis wir zum Platz gelangen, wohin sie gegangen sind. Du sollt deinen Verstand vor der Vergeßlichkeit bewahren, (da) deine Erinnerung dich selig werden läßt.

296 pHarris unterschlägt $m$ - (Fox 1985: 380, 6,11b).

297 Aufgrund des Determinatives wird es möglicherweise als $j 3 k b$ gelesen, vgl. Patanè (1988: 101) und Fox (1977: 411, 37).

298 pLeyden K.6 führt $m$ - ein (Fox 1985: 380, 7,1e). 
Folge deinem Herzen, während du lebst. ${ }^{299}$ Lege Myhrren auf dein Haupt, kleide dich mit feinstem Leidenstoff, salbe dich mit dem echtem Wundermittel aus dem ${ }^{300}$ Götteseigentum. Vermehre dein Wohlbefinden und laß dein Herz nicht müde werden. Folge deinem Herzen und deinem guten Wesen. ${ }^{301}$ Tue deine Angelegenheiten auf der Erde durch den Befehl deines Verstandes $^{302}$, bis jener Tag des Klageschreis zu dir kommt. Der Herzensmüde kann nicht ihr Klageschrei hören, und (deswegen) kann ihre Trauer die Seele eines Mannes aus der Unterwelt nicht retten.

Wiederholung: ${ }^{303}$ Verbringe einen schönen Tag, aber laß dir nicht davon ermüde werden. Siehe! Es ist noch keinen gegeben, seine Habe mit sich nehmen zu können. ${ }^{304}$ Siehe! Es war keiner, der ging und zurückkam. $\left({ }^{\circ}\right.$ dein Herz ${ }^{\circ} /{ }^{\circ}$ dein Herz ${ }^{\circ} /{ }^{\circ}$ deines Herzens ${ }^{\circ} /{ }^{\circ}$ das Herz ${ }^{\circ}$ )

299 Fox (1977: 404) übersetzt "Be hale! while your heart is directed toward self-forgetfulness which performs the $s 3$ h-rites for you. Follow your heart while you exist", Assmann (1977: 55) übersetzt "Du aber erfreue dein Herz und denke nicht daran! Gut ist für dich, deinem Herzen zu folgen, solange du bist", Hornung (1990: 163) übersetzt "Du aber erfreue dein Herz, um das alles zu vergesssen - es tut dir gut, deinem Herzen zu folgen, solange du lebst", Osing (1992: 12) übersetzt "Que tu sois prospère avec ton coeur afin que le coeur oublie cela - ce qui est utile pour toi! Suis ton coeur tant que tu existes (...)".

300 Assmann (1977: 55) und Hornung (1990: 163) übersetzen "Öl".

301 Assmann (1977: 56) übersetzt "Folge deinem Herzen in Gemeinschaft der Geliebten", ähnlich Hornung (1990: 163).

302 Fox (1977: 407) übersetzt "Let not your heart be injured", Assmann (1977: 56) übersetzt "tu deine Arbeit auf der Erden ohne dein Herz zu kränken", Hornung (1990: 163) übersetzt "verrichte dein Werk auf Erden und kränke dein Herz nicht", Osing (1992: 12) übersetzt "Fais tes affaires sur terre, et ne fais pas ton à ton coeur (var. d'après l'ordre de ton coeur)".

303 Siehe Assmann (1977: 56 Anm. 3) und Fox (1977: 411, 38) und Brunner (1966: 131).

304 Fox (1977: 412) übersetzt "No one can make his property go with him". 


\section{Das Blumenlied des pHarris (Fox 1985)}

Quelle:

Datierung:

Textausgaben:

Übersetzungen:
pHarris 500 7,3-8,3

XIX Dynastie $\mathrm{e}^{305}$

Maspero (1883: III, 253-259, Pl. I-VIII), Budge (1923: Pl. XLVI), Müller (1899: Pl. 14-15), Fox (1985: 380-382), Mathieu (1996: Pl. 13-14).

Erman (1927: 248-249), Müller (1899: 26-28), Schott (1950: 56-57), Donadoni (1969: 441-442), Kischkewitz (1973: 78), Foster (1974: 35-38), Lichtheim (1976: II, 192), White (1978: 176-177), Fox (1985: 26-29), Hornung (1990: 158-159), Vernus (1992: 81-82), Mathieu (1996: 63-65).

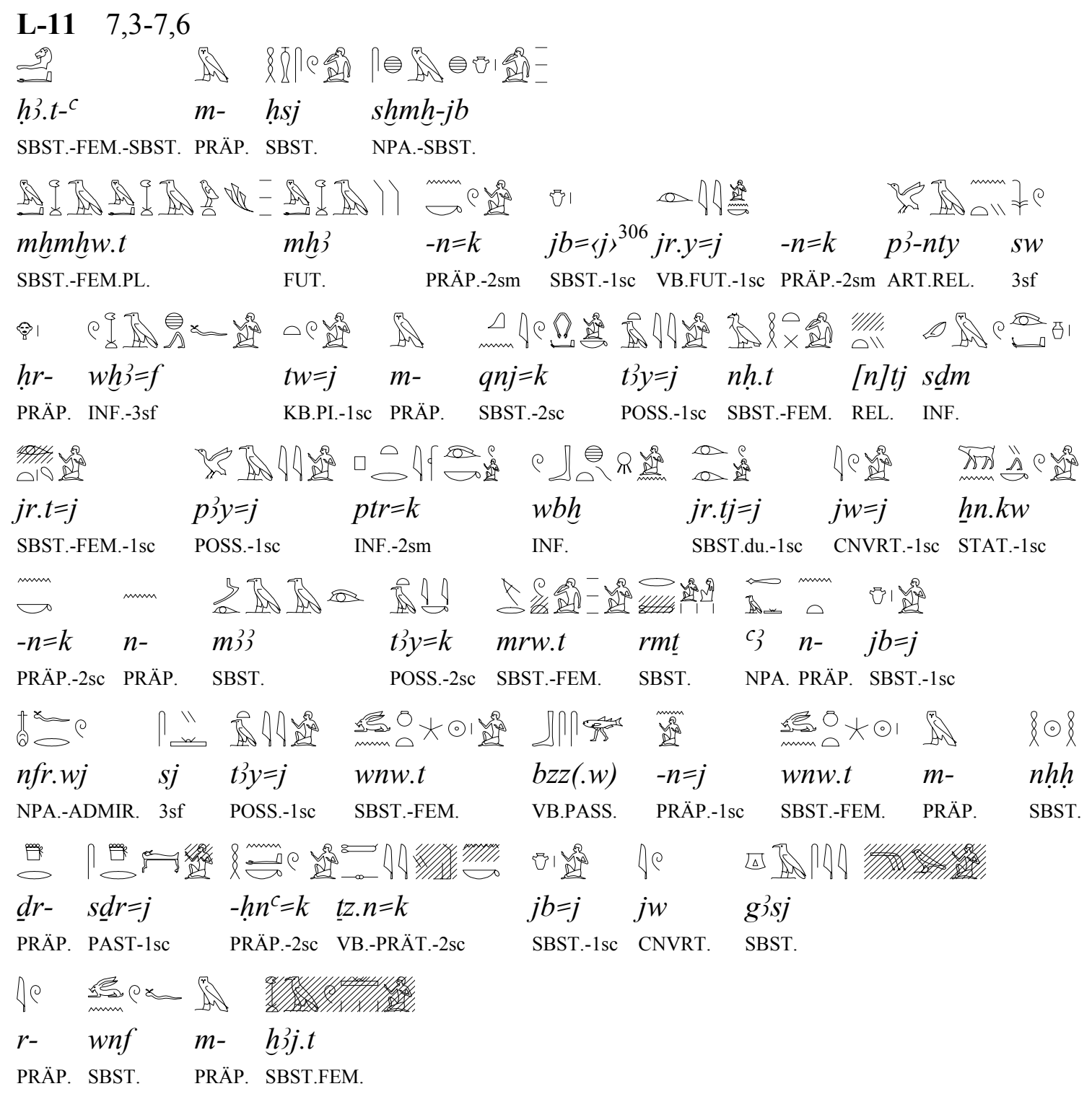

Anfang des Liedes zur Erheiterung der Stimmung. ( ${ }^{\circ}$ Erheiterung des Herzens ${ }^{\circ}$ )

Mhthhw.t-Blumen. Meine Stimmung möge harmonisch für dich sein. Ich werde für dich tun, was er sich wünscht. Ich bin in deiner Umarmung. Meine Sehnsucht (ist es), die mein Auge "schminkt". Wenn ich dich erblicke, leuchten meine Augen. Ich nähre mich dir, damit ich deinen Liebreiz wahrnehmen kann, du wichtigster Mensch ${ }^{307}$ meines Herzens. Wie wunderbar ist doch meine Stunde, die mir geschah. Eine Stunde ist eine Ewigkeit, seit ich mit 
dir geschlafen habe und du meine Stimmung gehoben hast. Selbst ein Trauernder wird sich bei Jammer freuen. ${ }^{308}\left({ }^{\circ}\right.$ das Herz möge ausgeglichen für dich sein ${ }^{\circ} /{ }^{\circ}$ mein Herz ${ }^{\circ}$ )

L-12 7,9-7,10

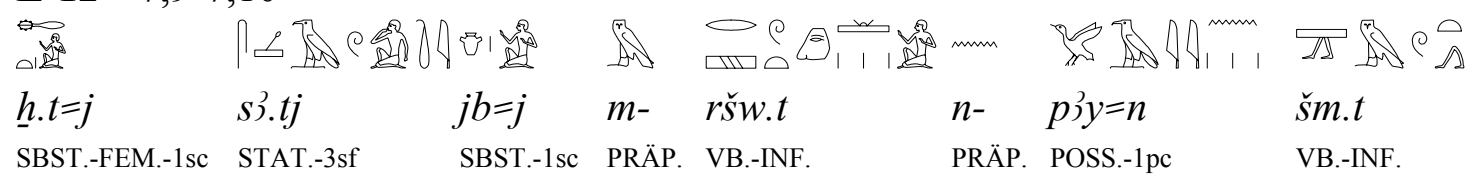

$n-\quad z p$

PRÄP. SBST.

Mein Körper ist satt, mein Herz freut sich über unser Zusammengehen.

\section{L-13 5,12}

\begin{tabular}{|c|c|c|}
\hline$j b=j$ & {$\left[s h{ }^{3}\right]$} & $m r w \cdot t=k$ \\
\hline BST.-1sc & STAT.:3sm & SBST.-FEM.-2sm \\
\hline
\end{tabular}

Mein Herz erinnert sich an deine Liebe.

308 Die Passage wird hier anders aufgrund der unsicheren Lektur des Wortes hjj.t interpretiert, Fox (1985: 26) übersetzt "In sorrow and joy, you have exalted my heart. Do not [leave] me"; Vernus (1992: 82) übersetzt "Reprends-toi, mon coeur, dans la peine ou dans la joie, ne m'abandonne pas!; Mathieu (1996: 64) übersetzt "... relève donc mon coeur, [qu'il se lamente ou soit heureux], ne m'abandonne pas". 


\section{Die drei Wünsche (Gardiner 1931)}

Quelle:

Datierung:

pChester Beatty I G1,1-G2,5

Textausgaben:

XX Dynastie ${ }^{309}$

Übersetzungen:

Gardiner (1931: Pl. XXIX-XXX), Fox (1985: 399-400), Mathieu (1996: Pl. 5-6).

Gardiner (1931: 35-36), Donadoni (1969: 433-434), Kischkewitz (1973: 27-28), Foster (1974: 79-80), Lichtheim (1976: II, 186-187), White (1978: 181-183), Fox (1985: 66-68), Vernus (1992: 69-70), Mathieu (1996: 31-32).

L-14 P. Chester Beatty I, $v^{\circ}$ G 1,1-G 2,1

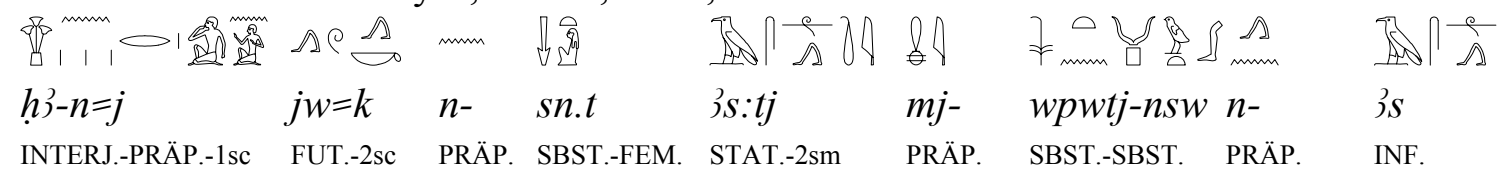

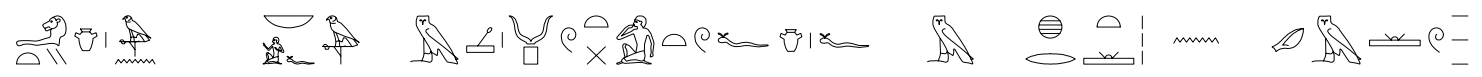

$h 3 t j \quad n-\quad n b=f \quad m-s\}-w p . t=f \quad j b=f \quad m-\quad h r . t \quad n-\quad s d m=w$

SBST.-3sm PRÄP. SBST.-3sm PRÄP. SBST.-FEM.-3sm SBST.-3sm PRÄP. SBST.-FEM.PRÄP INF.-3pc

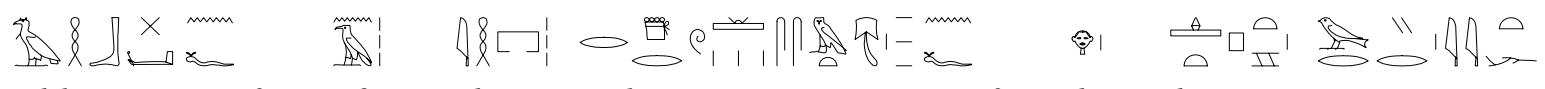

$n h b \quad-n=f \quad n j-\quad j h . w \quad r-d r w=w \quad$ ssm.t $\quad-n=f \quad h r-$ htp.t wrrj.t

PAST. PRÄP.-3sm ART.PL. SBST.-PL.PRÄP.-3pc SBST.-FEM.PRÄP-3sm PRÄP. SBST.-FEM.SBST.-FEM.

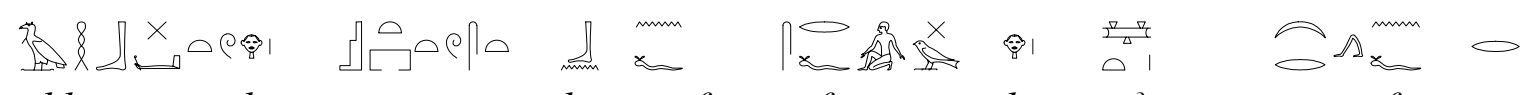

nhb.t $\quad h r-\quad$ s.t $=s \quad$ bn $-n=f \quad$ srf $\quad h r-\quad$ w..$t \quad$ spr.n=f $\quad r-$

STAT.-3sf PRÄP. SBST.-FEM.-3sf NEG. PRÄP.-3sm INF. PRÄP. SBST.-FEM. VB.-PRÄT.-3sm PRÄP.

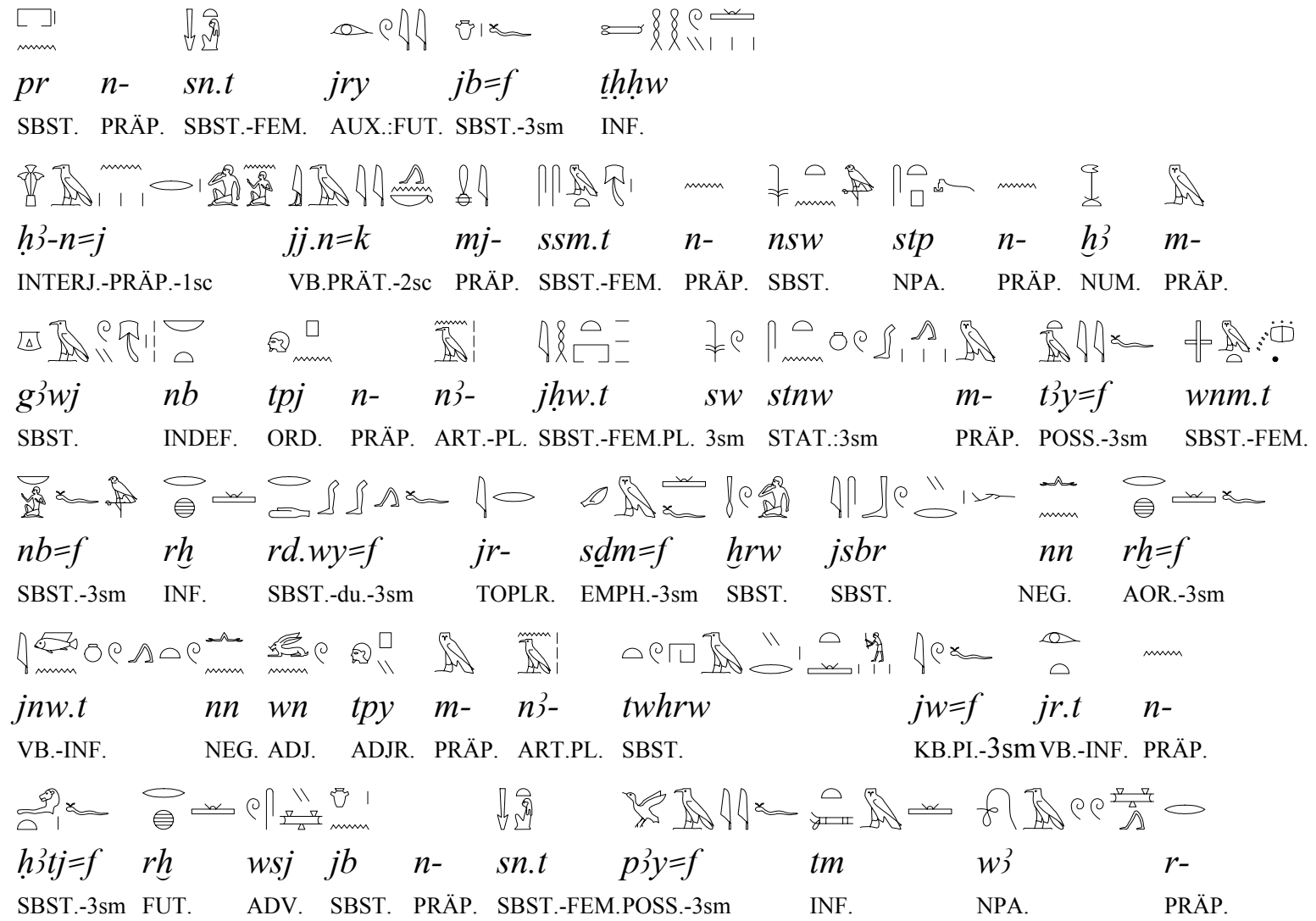

309 Fox (1985: 51). 


\section{$\sqrt{3}$ 备}

sn.t

SBST.-FEM.

Ich wünschte mir, du kämest eilends zur "Schwester" wie ein königlicher Eilbote. Das Herz seines Herrn ist auf seine Botschaft gespannt, und es ist bereit, sie zu hören. Alle Ställe sind gerüstet für ihn, die Pferde für ihn warten an den Rastplätzen, und der Wagen steht angeschirrt an seinem Platz. Unterwegs gibt es keine Pause für ihn. Ist er beim Haus der "Schwester" angekommen, wird sein Herz in Jubel ausbrechen.

Ich wünschte mir, du würdest wie ein königliches Pferd kommen, das aus Tausenden edelster Vollblüter im Stall ausgewählt wurde. Es schreitet weit aus in seinem Futter. Sein Herr kennt seine Läufe. Hört es die Stimme der Peitsche, kennt es keine Zurückhaltung. Nicht einmal der beste unter den Läufern vermag mit ihm mitzuhalten. Dann wüßte das Herz der Geliebte genauer, daß er nicht fern von ihr ist. 
Die sieben Stanzen (Gardiner 1931)

Quelle:

Datierung:

Text:ausgaben
Übersetzungen:

pChester Beatty I C1,1-C5,2

XX Dynastie 310

Gardiner (1931: P1. XXII-XXVI), Fox (1985: 393-399), Mathieu (1996: Pl. 1-5).

Gardiner (1931: 30-34), Gilbert (1942: 188-195), Donadoni (1969: 428-433),

Kischkewitz (1973: 7-19), Foster (1974: 43-61), Lichtheim (1976: II, 189-186),

White (1978: 177-181), Fox (1985: 52-64), Hornung (1990: 147-152), Vernus (1992: 63-69), Mathieu (1996: 26-30).

\section{Erste Stanze}

L-15 pChester Beatty I, $v^{\circ}$ C 1,1

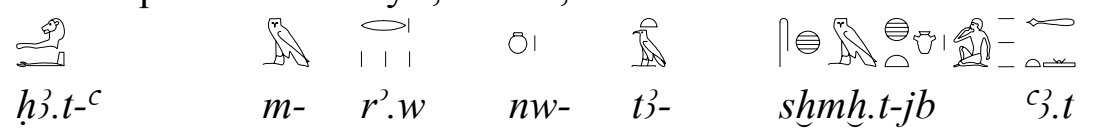

SBST.-FEM.-SBST. PRÄP. SBST.-PL. DET.-PL. ART.FEM. NPA.-FEM.-SBST. NPA.-FEM.

Anfang der Sprüche des großen Herzensvergnügens

L-16 pChester Beatty I, ${ }^{\circ}$ C 1,5-C 1,6

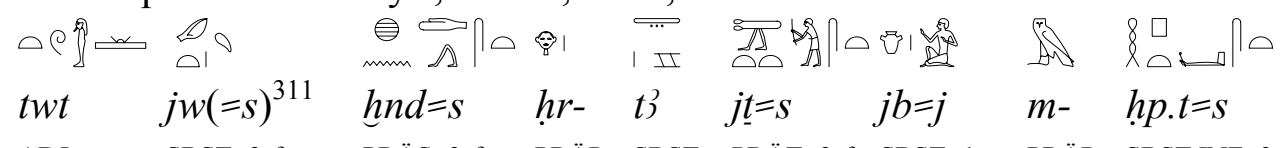

ADJ. SBST.-3sf PRÄS.-3sf PRÄP. SBST. PRÄT.-3sf SBST.-1sc PRÄP. SBST.INF.-3sf

Ihr Kommen ist schön, wenn sie auf die Erde geht. Sie raubte meinen Verstand mit ihrer Umarmung ( ${ }^{\circ}$ nahm mein Herz fort $\left.{ }^{\circ}\right)$

\section{Zweite Stanze}

L-17 P. Chester Beatty I, $\mathrm{v}^{\circ} \mathrm{C} 1,8$

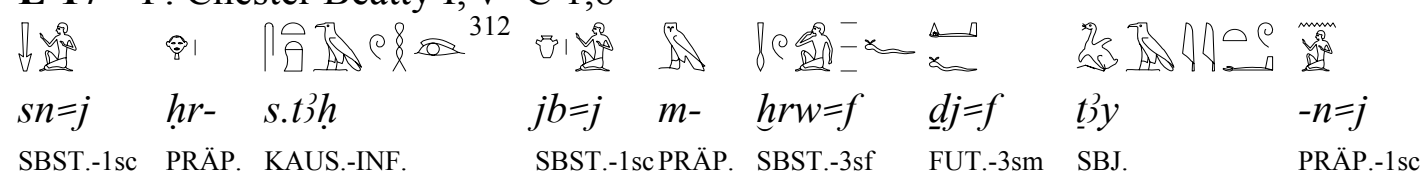

$\therefore 110^{-}$

hijj.t

SBST.-FEM.

Mein Brüder betört mein Herz mit seiner Stimme. Er veranlaßt, daß das Leid mich ergreift.

L-18 P. Chester Beatty I, $v^{\circ}$ C 2,1-C 2,3

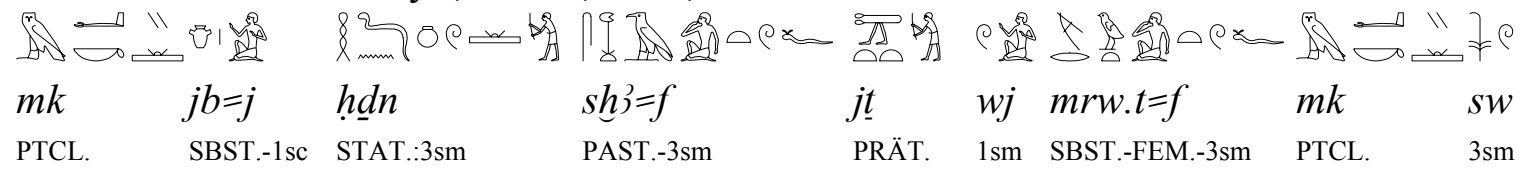

310 Fox (1985: 51).

311 Siehe Mathieu (1996: 37,37) und Fox (1985: 394, C1,5a-a).

312 Für die kausative Form des Verbs s.t3h siehe Gardiner (1931: 31) und Posener (1969: 16, Anm. 1). 


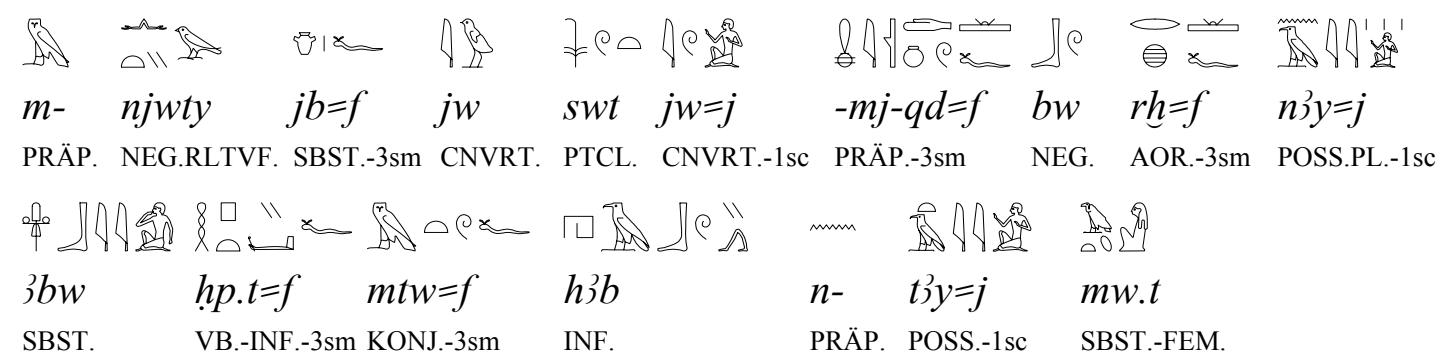

Siehe! Mein Herz ist unwillig, wenn es sich erinnert, daß seine Liebe mich fortgenommen hat. Siehe! Er ist einer, der sich unbedacht verhält, aber ich bin ebenso wie er. Er kennt meinen Wunsch, ihn zu umarmen, nicht, und (deswegen) sendet er keine (Mitteilung) zu seiner Mutter. ( ${ }^{\circ}$ der sein Herz nicht hat $\left.{ }^{\circ}\right)$

\section{Dritte Stanze}

L-19 P. Chester Beatty I, $v^{\circ}$ C 2,4-C 2,5

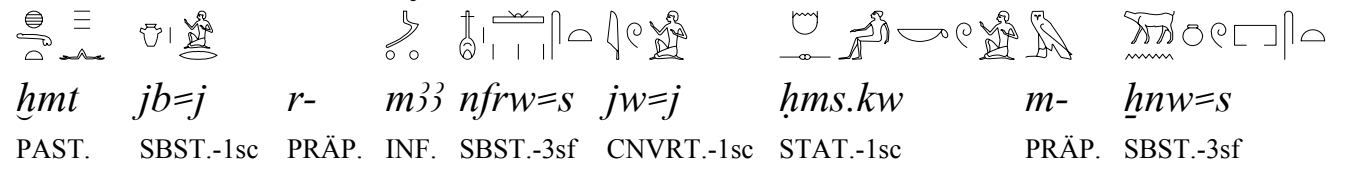

Mein Herz beabsichtigte, ihre Schönheit zu sehen, wahrend ich in ihrem Raum saß.

L-20 P. Chester Beatty I, $v^{\circ}$ C 2,7

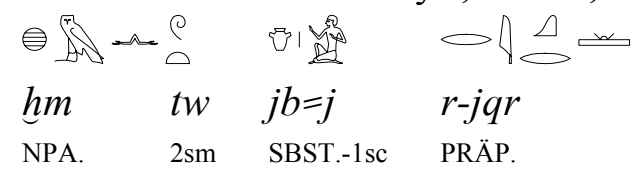

Du bist völlig unwissend, mein Herz.

\section{Vierte Stanze}

L-21 P. Chester Beatty I, $v^{\circ}$ C 2,9-C 2,10

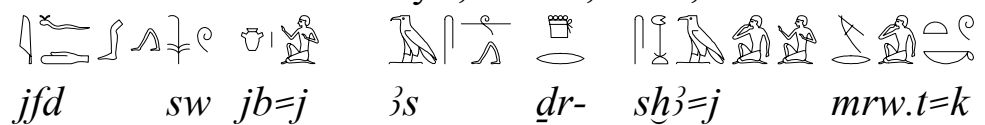

NPA. $\quad 3 s m$ SBST.-1sc STAT.:3sm PRÄP. PRÄS.-1sc SBST.-FEM.-2sc

Er, mein Herz, ist eilig auf der Flucht, seit ich an deine Liebe denke.

L-22 P. Chester Beatty I, v $v^{\circ}$ 3,2-C 3,3

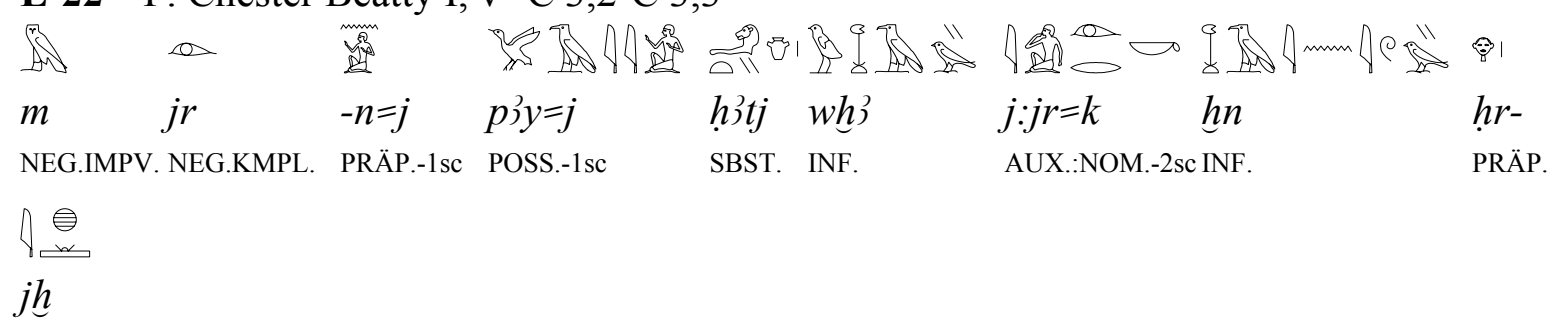

PTCL.

Mache mir keine Dummheiten, mein Herz. Wieso handelst du töricht? 
L-23 P. Chester Beatty I, $v^{\circ}$ C 3,4

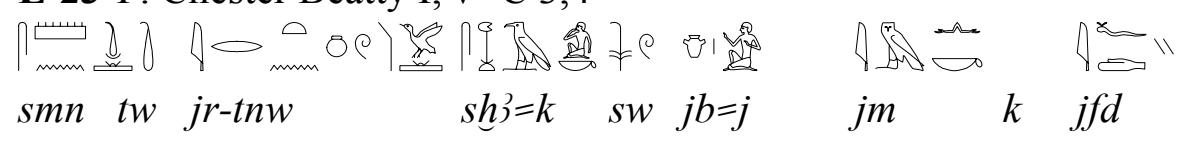

IMPV. 2sm PTCL. PRÄS.-2sm 3sf SBST.-1sc NEG.IMPV. 2sm NEG.KMPL.

Bleibe fest, wann immer du an ihn denkst, mein Herz, und fliehe nicht.

\section{Sechste Stanze}

L-24 P. Chester Beatty I, $v^{\circ}$ C 3,10- C 4,6

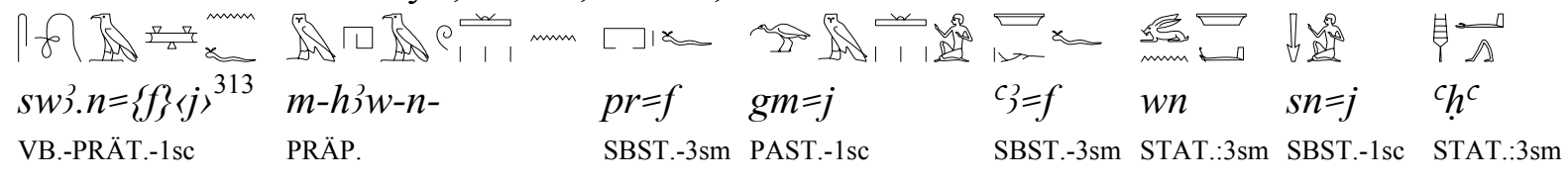

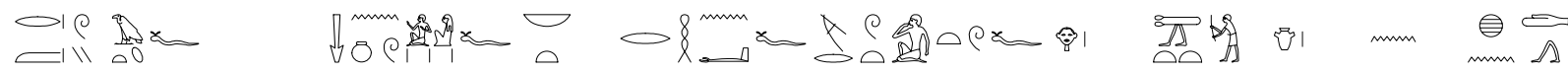
$r$-gs $\quad m w . t=f \quad s n . w=f \quad n b \quad-r-h n^{c}=f \quad m r w . t=f \quad h r-j \underline{t . t} \quad j b \quad n-\quad$ hnd PRÄP. SBST.-FEM.-3sm SBST.-PL.-3sm INDEF. PRÄP.-3sm SBST.-FEM.-3sm PRÄP. VB.-INF. SBST. PRÄP. NPA.

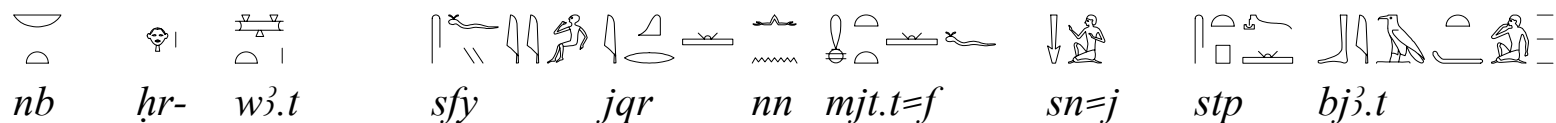

INDEF. PRÄP. SBST.-FEM. SBST. STAT.:3sm NEG. SBST.-FEM.-3sm SBST.-1sc STAT.:3scSBST.-FEM.

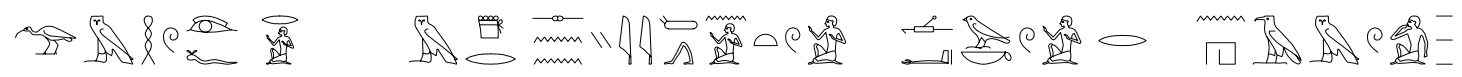

$g m h=f \quad-r=j \quad m-d r-s n . n=j \quad t w=j \quad w^{c} . k w \quad r-\quad n h m$

PAST.-3sm PRÄP.-1sc PRÄP. VB.-PRÄT.-1sc KB.PI.-1sc STAT.-1sc PRÄP. INF.

m

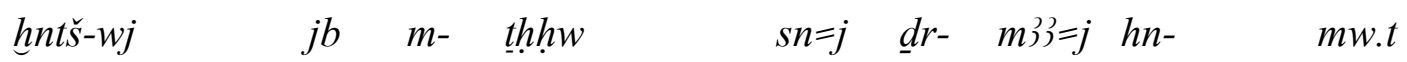

NPA.-ADMIR. SBST. PRÄP. SBST. SBST.-1sc PRÄP. PAST.-1scINTERJ. SBST.-FEM.

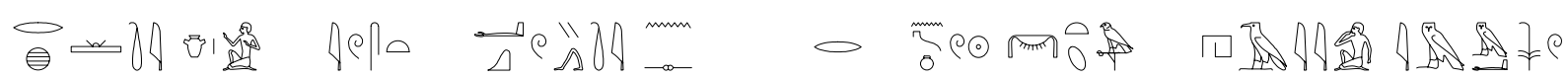
rh.tj $\quad j b=j \quad j w=s \quad{ }^{c} q . t j \quad-n=s \quad r-n w$ Nbw.t h3y $\quad n m \quad s w$ STAT.-3sf SBST.-1sc KB.PI.-3sf $\quad$ STAT.-3sf PRÄP.-3sm PRÄP. SBST. THEON.-FEM. INTERJ. IMPV. 3sm

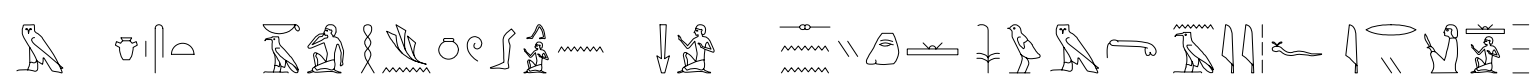
$m-\quad j b=s \quad k j \quad h n=j \quad n-\quad s n=j \quad s n(=j)^{314} \quad s w \quad m-b 3 h h \quad n j y=f \quad j r j . w$ PRÄP. SBST.-3sf PRTCL. FUT.-1sc PRÄP. SBST.-1scFUT.-1sc 3sm PRÄP. POSS.PL.-3sm SBST.-PL.

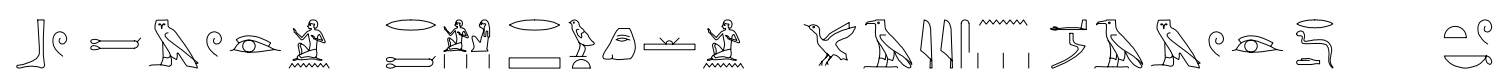
$b w \underline{t} m^{315}=j \quad n-\quad r m \underline{t} \quad r \check{s} w=j \quad n-\quad p 3 y=s n \quad c_{m} \quad r-d d \quad t w=k$

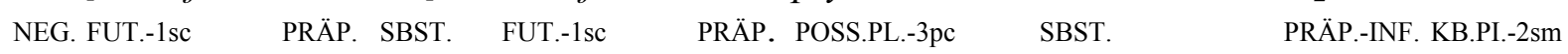

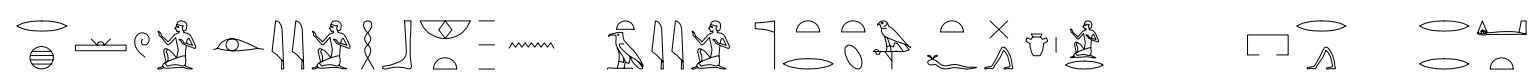
$r h \underline{h}=j \quad j r y=j \quad h b . w \quad n-\quad t 3 y=j \quad n t r . t \quad t f \quad j b=j \quad r-\quad p r \quad r-\quad r d . t$ INF.-1sc FUT.-1sc SBST.-PL. PRÄP. POSS.1sc SBST.-FEM. NPA. SBST.-1sc PRÄP. INF. PRÄP. VB.-INF.

313 Korregiert durch $\{j\}$, siehe Fox (1985: 60, N. 36,a); vgl. Mathieu (1996: 41,80).

314 Siehe Fox (1985: 60 N. 36,g); vgl. Mathieu (1996: 42,88).

315 Über die Schreibung des Wortes țm (Wb V 367,2-4) siehe Gardiner (1931: pl. XXV und 1932: 45a, Anm. 6,14b); vgl. Fox (1985: 60, 36h), Mathieu (1996: 42 Anm. 88). 


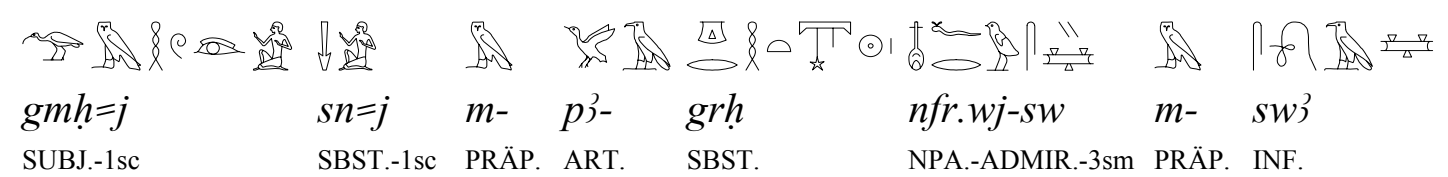

Ich $(\{E r\})$ ging in der Nähe seines Hauses vorbei und ich stellte fest, daß seine Tür geöffnet war und mein "Bruder" neben seiner Mutter stand. Alle seine Geschwister waren bei ihm. Seine Liebe raubt den Verstand einer jeden Person, die auf dem Weg vorübergeht. Der Knabe ist vollkommen und hat nicht Seinesgleichen. Mein "Bruder" hat einen erlesenen Charakter. Er blickte auf mich, als ich vorbeiging, aber ich war allein beim Jubeln. Wie glücklich im Überschwang ist doch mein Herz, "Bruder", seit ich (dich) sah. Ach wenn Mutter meine Gefühle kennen würde, würde sie dafür zur (rechten) Zeit eintreten. Oh Goldene, gib es in ihr Herz, dann werde ich zu meinem "Bruder" gehen, ihn vor seinen Genossen küssen und mich nicht vor den Menschen schämen. Und ich werde mich über ihre Wahrnehmung freuen, daß du mich erkennst. Ich werde ein Fest für meine Göttin feiern. Mein Herz ist aufgeregt, um loszugehen, damit ich meinen "Bruder" heute Nacht sehe. Wie schön ist er im Vorbeigehen! ( ${ }^{\circ}$ immt das $\operatorname{Herz}^{\circ} /{ }^{\circ}$ mein Herz ${ }^{\circ} /{ }^{\circ}$ das Herz springt ${ }^{\circ}$ )

\section{Siebte Stanze}

\section{$\mathbf{L - 2 5}^{316}$ P. Chester Beatty I, $\mathrm{v}^{\circ} \mathrm{C} 4,7-\mathrm{C} 4,8$}

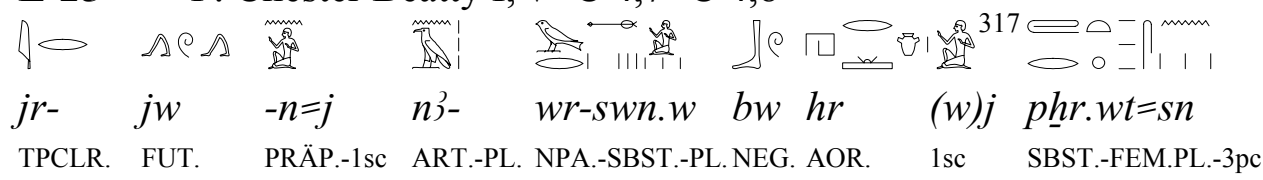

Wenn die wichtigsten Ärzte zu mir kommen, können ihre Heilmittel mich nicht beruhigen.

L-26 P. Chester Beatty I, v $\mathrm{v}^{\circ} \mathrm{C} 4,9-\mathrm{C} 4,10$

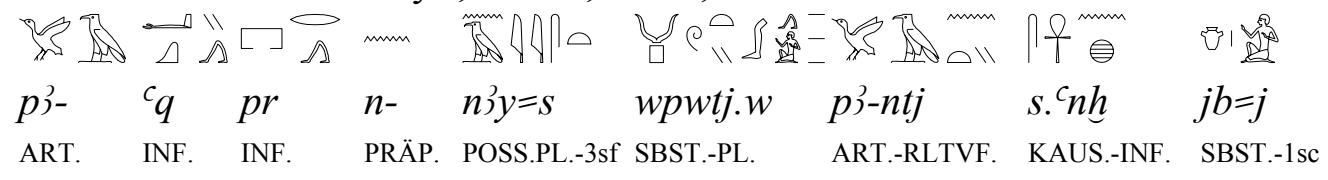

Das Eintreten und Hinausgehen ihrer Gesandten ist es, was mich am Leben erhält $\left({ }^{\circ}\right.$ mein $\operatorname{Herz}^{\circ}$ )

316 Dieses Beispiel wird hier auf Grund einer neuen Interpretation vorgestellt, obwohl das Wort 'Herz' nicht vorkommt.

317 Mathieu (1996: 43, Anm. 95) liest $h r j b=j(m) p h r . w=s n$ "si viennent à moi les chefs-médicins, mon coeur ne peut se clamer par leurs remèdes", wobei er die Präposition m- einführt. Fox (1985:55) liest auch das Herz aber übersetzt die Stele als "their medicines could not ease my heart", wobei das Subjekt gemäß seiner Übersetzung nicht das Wort 'Herz' sondern 'Heilmittel' ist, obwohl $j b$ zur ersten Position nach dem Verb steht. Nach meiner Meinung ist das Determinativ des Verbs $h r$ nicht zu lesen (Wb III 496), wie es seit Ende des Neuen Reiches oft war, und das Determinativ der Menschen für das enklitische Pronomen der ersten Person zu interpretieren ist. Diese ist auch die Erklärung, deswegen das enklitische Pronomen wj vor dem Wort phr.w steht. 


\section{Das Lied des Nacht-Sobek (Gardiner 1931)}

Quelle: pChester Beatty $\mathrm{r}^{\circ} 16,9-17,13$

Datierung: XX Dynastie $\mathrm{C}^{318}$

Textausgaben: Gardiner (1931: Pl. XVI-XVII), Fox (1985: 400-404), Mathieu (1996: P1. 6-7).

Übersetzungen:

Gardiner (1931: 36-38), Donadoni (1969: 445-448), Kischkewitz (1973: 20-25), Foster (1974: 5), Lichtheim (1976: II, 187-189), White (1978: 183-185), Fox (1985: 68-77), Vernus (1992: 70-73), Mathieu (1996: 32-35).

\section{L-27 P. Chester Beatty I $r^{\circ} 17,3-4$}

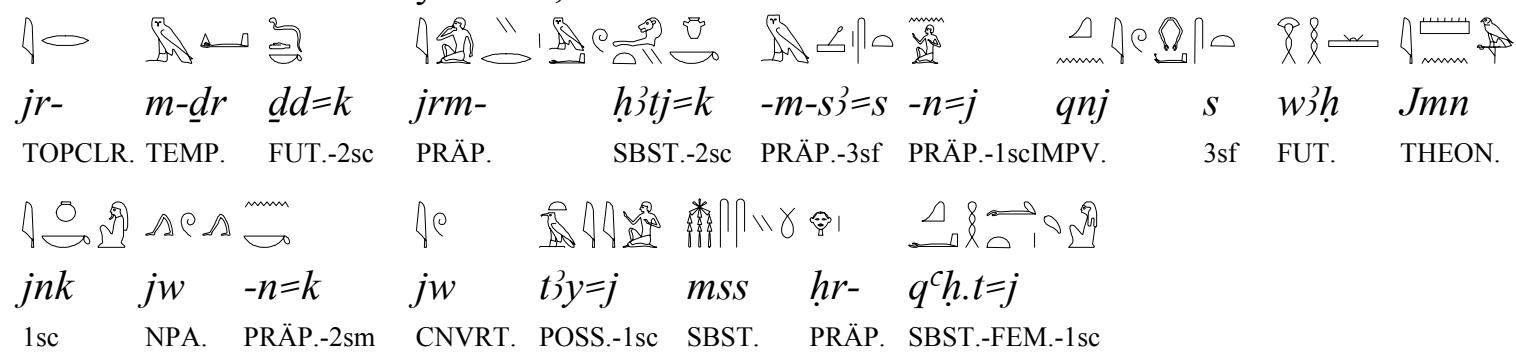

Statt daß du mit dir selbst sprichst, oder hinter ihrem Rücken oder zu mir, umarme sie. "So wahr Amun währt, bin ich es, die zu dir kommt, und mein Hemd hängt über meiner Schulter". $\left({ }^{\circ}\right.$ deinem Herzen $\left.{ }^{\circ}\right)$ 


\section{O. DM 1266 + O. CGC 25218 (Posener 1951-1972)}

Datierung: $\quad$ XIX/XX Dynastie ${ }^{319}$

Textausgaben: $\quad$ Spiegelberg (1981: 118), Müller (1899: P1. 17), Posener (1951-1972: XVIII, (II/3), 43ff., Pl. 75-79), Fox (1985: 383-389), Mathieu (1996: Pl. 17-21).

Übersetzungen: $\quad$ Spiegelberg (1981: 117-121), Müller (1899: 41-44), Ermann (1927: 243ff.), Kischkewitz (1973: 43-48), Foster (1974: 17-30), Lichtheim (1976: II, 193), White (1978: 187-189), Fox (1985: 29-44), Hornung (1990: 161), Vernus (1992: 87-92), Mathieu, (1996: 96-111).

L-28 11-13

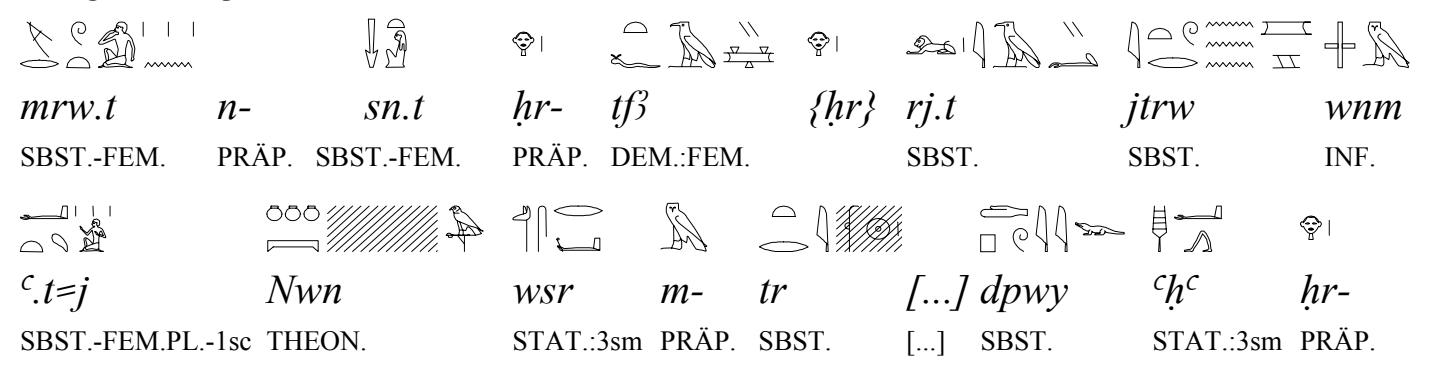

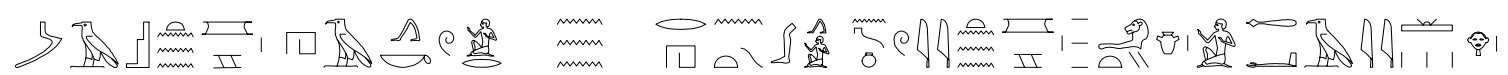

mis.t hi.kw r- $\quad m w \quad r h n=j \quad$ nw.t $\quad h 3 t j=j \quad$ c3 $\quad$ hr-

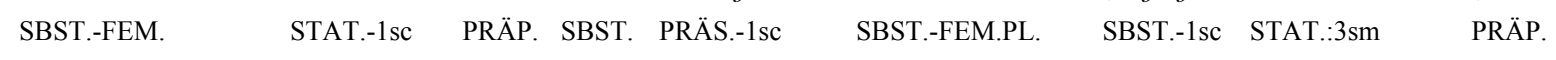

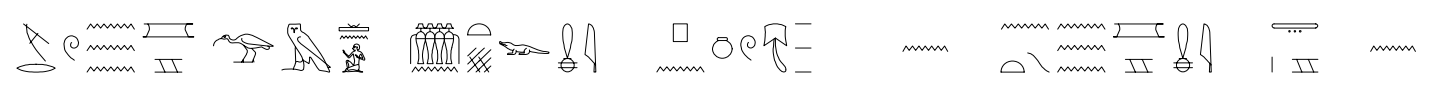

mrw gm.n=j hn.ty mj- pnw [...]n- n.t mj- t3 n-

SBST VB.-PRÄT.-1sc SBST. PRÄP. SBST.[...] PRÄP. SBST.-FEM. PRÄP. SBST. PRÄP.

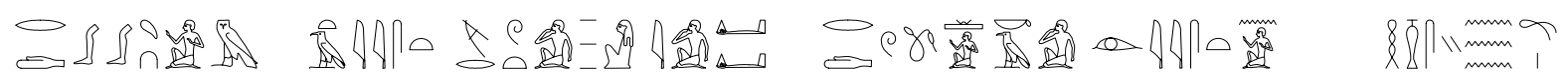
$r d . w j=j \quad m-\quad t 3 y=s \quad m r w . t \quad j \underline{d} \underline{d} \underline{d} \quad r w \underline{d}=j \quad k j \quad j r y=s \quad-n=j \quad h s j-m w$ SBST.du.-1sc PRÄP. POSS.-3sf $\quad$ SBST.-FEM. PRÄF.-NPA. SBJ.-1sc PTCL. FUT.-3sf PRÄP.-1sc SBST.-SBST.

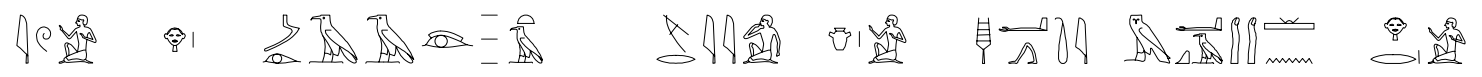
$j w=j \quad h r-m 33 \quad t 3-\quad m r w(. t) \quad j b=j \quad{ }^{c} h^{c} . t j \quad m^{-}{ }^{c} q-\quad n-\quad h r=j$ KB.PI-1sc PRÄP. INF. ART.FEM. SBST.-FEM. SBST.-1sc STAT.-3sf PRÄP PRÄP. SBST.-1sc

Die Liebe der "Schwester" ist auf jener Seite. Der Fluß schluckt meinen Körper; Nun ist mächtig zu der Zeit (...) $)^{320}$, und ein Krokodil wartet auf der Sandback. Ich bin aber schon ins Wasser gestiegen und durchwate die Fluten, (weil) ich auf dem Kanal mutig bin. Ich fand, daß das Krokodil wie eine Maus war und die Wasserflut für meine Füße wie festes Land ist. Ihre Liebe ist es, die mich stark sein läßt, und sie kann mir eine Beschwörung des Wassers machen, wenn ich sehe, wie die Geliebte meines Herzens mir gegenüber steht. ( ${ }^{\circ}$ mein Herz ist gro $\beta^{\circ}$ )

L-29 14-15

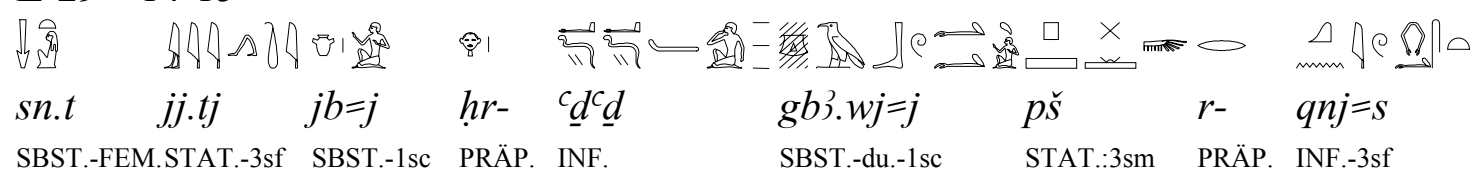

319 Fox (1985: 29).

320 Mathieu (1996: 105) ergänzt $n w=f$, "der Überschwemmung". 


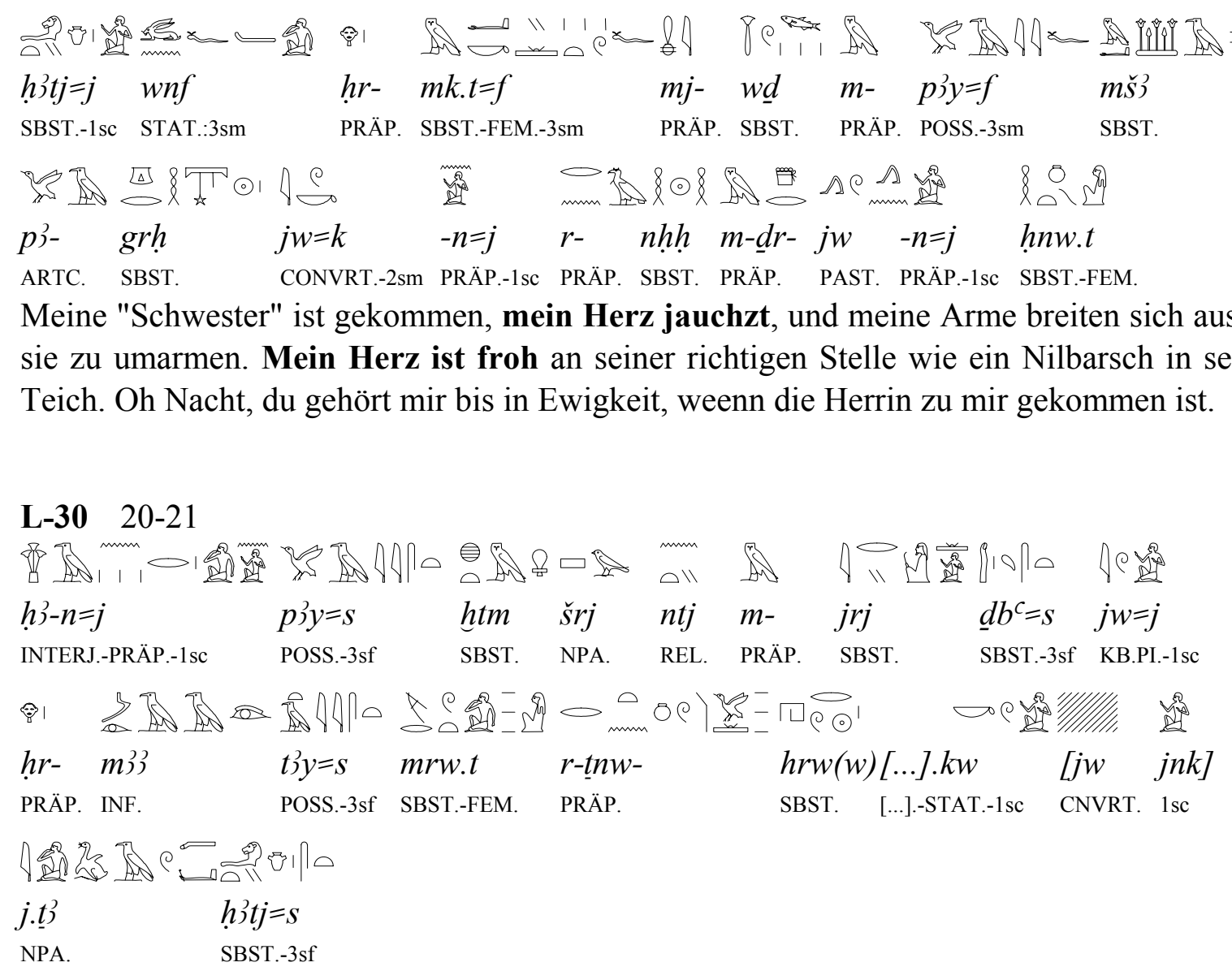

Ach, wenn ich ihr kleiner Siegelring wäre, der der Begleiter ihres Fingers ist, dann sähe ich täglich ihre Liebe (...), der ihr Herz nehmen wird. 


\section{O. Borchardt 1 et O. CGT 57367, $\mathrm{r}^{\circ}$ (Mathieu 1996)}

Datierung: $\quad$ XIX-XX ${ }^{321}$ Dynastie

Textausgaben: $\quad$ López (1982: p. 22ff und pl. 114-114a), Mathieu (1996: Pl. 22-24).

Übersetzungen: Mathieu (1996: 114).

\section{L-31 $\mathrm{r}^{\circ} 1-5$}

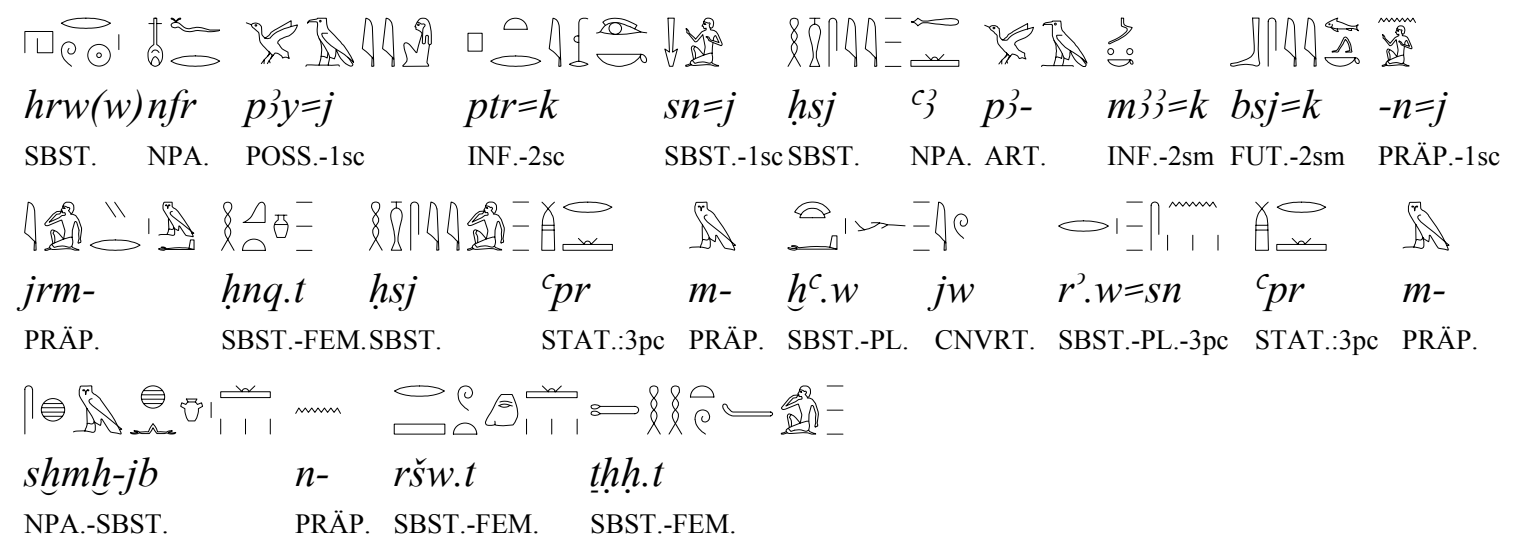

Dich zu sehen bedeutet einen schönen Tag für mich, "Bruder". Dich zu sehen ist ein großes Lied. Du trittst heraus zu mir ein mit Bier und Sängern, die mit Instrumenten ausgestattet sind, und deren Münder mit Herzensvergnügen für Freude und Jubeln versehen sind. 


\section{O. Gardiner 304 (Černy-Gardiner 1957)}

Datierung: $\quad$ XX Dynastie 222

Textausgaben: $\quad$ Černý - Gardiner (1957:I, 11ff., Pl. XXXVIII), Fox (1985: 406), Mathieu (1996: Pl. 26).

Übersetzungen: $\quad$ Fox (1985: 81), Vernus (1992: 93), Mathieu (1996: 114).

\section{L-32 $\quad 4-7$}

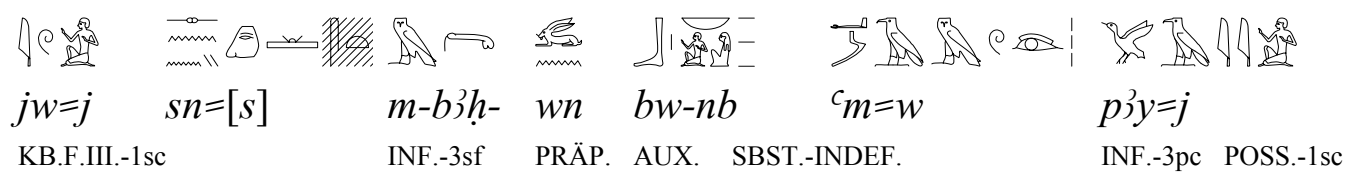

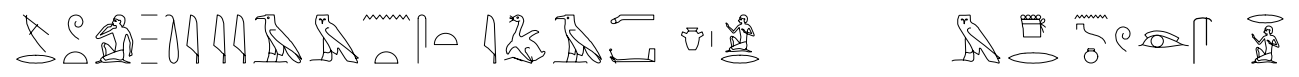

$\begin{array}{lllll}m r w . t & j 3 & n t s & j . \underline{3} & j b=j \quad(j) r-\quad m-\underline{d} r-n w=s \quad-r=j\end{array}$

$\begin{array}{llllll}\text { SBST.-FEM. } & \text { PRÄP. } 3 \mathrm{sf} & \text { NPA. } & \text { SBST.-1sc } & \text { PTCL. TEMP. PÄST.-3sf } & \text { PRÄP.-1sc }\end{array}$

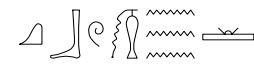

$q b w$

STAT.:3sm

Ich werde sie vor allen Leuten küssen, damit sie meine Liebe erfahren können. Oh, sie ist es, die mein Herz nahm. Nachdem sie mich ansah, wurde es kühl. 


\section{O. DM 25761 (Černý 1935)}

Datierung: $\quad$ XIX Dynastie 323

Textausgaben: $\quad$ Černý (1935:I, 80, 93, Pl. XCV), Mathieu, (1996: P1. 28).

Übersetzungen: Schott (1950: 88), Kischkewitz (1973: 33), Vernus (1992: 95), Mathieu (1996: $118)$.

\section{L-33}

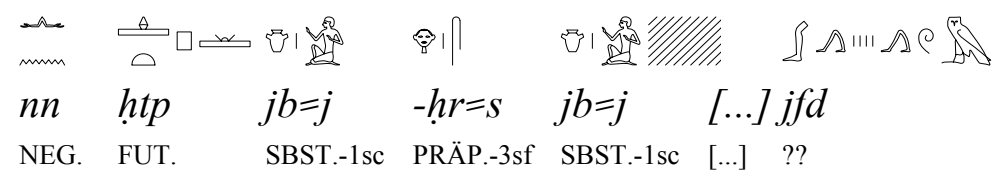

Mein Herz wird ihretwegen nicht zufrieden. Mein Herz [...] fliehen [...]. ${ }^{324}$ 



\title{
7. Kapitel
}

\section{DAS HERZ IN DEN ERZÄHLUNGEN}

\author{
"Sneewittchen aber wuchs heran und wurde immer schöner, und als es sieben \\ Jahr alt war, war es so schön wie der klare Tag und schöner als die Königin \\ selbst. Als dies einmal ihren Spiegel fragte: \\ »Spieglein, Spieglein an der Wand, \\ so antwortete er: \\ wer ist die schönste im ganzen Land?«, \\ »Frau Königin, Ihr sein die schönste hier, \\ aber Sneewittchen ist tausendmal schöner als Ihr.« \\ Da erschrak die Königin und ward gelb und grün vor Neid. Von Stund an, \\ wenn die Sneewittchen erblickte, kehrte sich ihr das Herz im Leibe herum, so \\ haßte sie das Mädchen. Und der Neid und Hochmut wuchsen sie ein Unkraut \\ in ihrem Herzen immer höher, daß sie Tag und Nacht keine Ruhe mehr hatte. \\ Da rief sie einen Jäger und sprach: »Bring das Kind hinaus in den Wald, ich \\ will's nicht mehr vor meinen Augen sehen. Du sollst es töten und mir Lunge \\ und Leber zum Wahrzeichen mitbringen.« Der Jäger gehorchte und führte es \\ hinaus, und als er den Hirschfänger gezogen hatte und Sneewittchens \\ unschuldiges Herz durchbohren wollte, fing es an zu weinen und sprach: \\ »Ach, lieber Jäger, laß mir mein Leben; Ich will in den wilden Wald laufen \\ und nimmermehr wieder heimkommen.« Und weil so schön war, hatte der \\ Jäger Mitleiden und sprach: »So lauf hin, du armes Kind.« »Die wilden Tiere \\ werden dich bald gefressen haben«, dachte er, und doch war's ihm, als wär \\ ein Stein von seinem Herzen gewälzt, weil er es nicht zu töten brauchte". \\ (Sneewittchen, Kinder- und Hausmärchen der Brüder Grimm).
}

\subsection{Die Erzählung und der Begriff 'Herz'}

In den Erzählungen werden Situationen beschrieben, in denen sich die beteiligten Personen nach ihrem Wunsch, gemäß ihrer Emotion oder ihrem Verstand entsprechend benehmen. Dieses alltägliche Leben läßt sich nicht nur mit dem Verstand, wie der Fall der Weisheiten zeigt, oder mit der Liebe, wie in den Liebesliedern geschildert wird, sondern mit allen möglichen Zuständen in Verbindung bringen. Innerhalb der Erzählungen kann das Lexem 'Herz' benutzt werden, um den Charakter (E-5 und E-11: $n h t$ 'stark sein'), die Emotionen (E-36: s. 3w 'erfreuen'; E-79: $r \check{s} w$ 'sich freuen'), den Willen (E-37: $z h n(j)-j b=k$ 'Planung deines eigenen Herzens'), den Verstand (E-14: th $j b$ 'das Herz vergißt') oder andere innere Zustände des Menschen (E-47: $j b=s \underline{d} w$ 'niedergeschlagen sein') auszudrücken. Es kann aber auch als Metonymie für den Begriff "Willen" (E-81; 
E-64) oder als "Ort" gebraucht werden, in dem sich entweder eine Absicht (E-39: $n(n)=s(j) m$ $j b=j$ 'sie (die Flucht) war unüberlegt') oder eine Meinung (E-7: $m-n f m-j b=f^{\prime} \ldots$ und was in seinem Herzen Unrechtes war') befinden.

Diese und andere Gebrauchsweisen des Wortes 'Herz' werden im folgenden im Zusammenhang mit der in den vorigen Kapiteln dargestellten Information analysiert und in getrennte Gruppe geordnet.

\subsubsection{Das Herz und der Verstand}

Wenn man davon auszugehen hat, daß das Herz in einer bestimmten Kultur als der zentrale Punkt des Individuums aufgefaßt wird, so ist auch $\mathrm{zu}$ erwarten, daß es bei einer Vielzahl von Tätigkeiten (neben seiner rein organischen Funktion) eine Rolle spielt. Daß das im pharaonischen Ägypten tatsächlich der Fall war, zeigen die analysierten Texte. Besonders in den Weisheitstexten sind Passagen zahlreich, in denen man Ausdrücke für den Verstand findet. Oben wurde bereits der metonymische Gebrauch des Herzens und seine Verbindung mit dem von Maat abgeleitetem Konzept der Harmonie und Gerechtigkeit dargestellt. ${ }^{325}$ In den Erzählungen finden sich zumindest zwei Textpassagen (E-27; E-41), die als einleuchtende Exempel für eben diesen Gebrauch herangezogen werden können. In ihnen wird der Begriff 'Herz' metonymisch für 'Sinn' oder 'Verstand' verwendet. In beiden Passagen wird gesagt, 'mein Herz war nicht in meinem Leib', was man natürlich besser mit 'mein Verstand war nicht mehr in meinem Leib' oder sogar 'ich hatte den Verstand verloren', 'ich war von Sinnen' wiedergeben sollte. Folglich ist die Reaktion des Helden ein Irrtum. Auf diese Weise läßt sich erklären, warum Sinuhe weggelaufen ist (E-27: $h 3 t j=j n(j) n t f m$ - h. $. t=j$ ): Seine zeitweilige Unfähigkeit, zu denken, war das Motiv für die Flucht. Noch interessanter ist das Beispiel E-41 $\left(b j=j j z . w h^{c} . w=j 3 d . w\right.$ hijtj=j nn $n t f m-\underline{h} . t=j$ 'meine Seele war dahingegangen, mein Leib war matt, und mein Herz, das war nicht in meinem Körper'), in dem Seele, Leib und Herz, letzteres für den Verstand stehend, genannt werden. Da Leib und Seele "direkt" und nicht etwa durch den metonymischen Gebrauch des Wortes für 'Herz', wie es auch möglich wäre, ausgedrückt werden, besteht kein Zweifel an der Bedeutung des Wortes hỉtj als 'Verstand'.

Es läßt sich darüber hinaus auch belegen, daß das Wort 'Herz' nicht nur spezifisch den Sinn 'Verstand' haben kann, sondern auch die Betätigung des Denkens oder die Überlegung an sich auszudrücken vermag. Das ist etwa der Fall in den Passagen aus der Erzählung des Sinuhe und der Erzählung des Wenamun, in denen das Herz eine besondere Rolle spielt, die sich in einen Zusammenhang mit der Tätigkeit des Denkens bringen läßt.

325 Siehe Kapitel 5 Das Herz als Verstand. 
Ausdrücke wie 'die Planung des Herzens' (E-37) zeigen, daß das Herz als ein rationales Organ verstanden werden kann. Der Hintergrund im Beispiel E-37 ist die Angst, die Sinuhe überfällt. Man muß davon ausgehen, daß der Held, in dieser Situation nicht klar denken konnte und die (freiwillige, aber im Nachhinein falsche). Entscheidung traf, wegzulaufen. Die Passage aus der Erzählung des Wenamun, in der die Sängerin Tananat durch ihren Tanz, gutes Essen und Trinken verhindern soll, daß Wenamun an etwas denkt, könnte ebenso interpretiert werden (E-82: wm swr

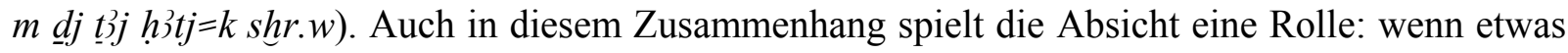
geplant wird, setzt es eine besondere Absicht, ein Ziel oder einen Willen voraus, aufgrund dessen Plan verwirklicht werden soll. Da beide Tätigkeiten auf diese Weise miteinander verbunden sind, kann das Herz in ägyptischen Texten zuweilen unmißverständlich mit der Bedeutung 'Willen' oder 'Absicht' verstanden werden. Das macht deutlich, daß im Beispiel E-39 Sinuhe nicht die Absicht im Herzen hatte, zu flüchten (js $w^{c}$ r.t tn jr.t.n bjk $n(j) h m . t=s n n=s(j) \quad m-j b=j$ 'diese Flucht, welche "der Diener" machte, sie war nicht geplant, sie war unüberlegt'). Man muß davon ausgehen, daß der Text aussagt, er habe sich auf etwas Unbedachtes eingelassen. Deshalb kann in diesem Fall das Herz auch mit dem Verstand und mit der überlegten oder (wie hier) unüberlegten Reaktion identifiziert werden. Diese Interpretation erlangt durch den Vergleich mit dem Beispiel E-38 Gewicht, in dem 'sein Gedanke $\left({ }^{\circ} \mathrm{das} \mathrm{Herz}^{\circ}\right)$ den Diener auf falsche Wege in fremde Länder führte' ( $b 3 k$ th. $n=f j b=f r$ - hiss.t $\underline{d}$ d $\underline{d} r y . t h r$ - $h m$ ), wobei sich auf das Herz bzw. die irrige Überlegung zu verlassen, diesen Fehler provozieren kann.

Das Wort 'Herz' im Beispiel E-55 ( $j w j b=f r$-) könnte auch als Ausdruck für 'Wille' oder 'Absicht' verstanden werden. In Zusammenhang mit dem kontextuellen Hintergrund der Passage, ist der jüngere Bruder in der Lage seinem Bruder zu helfen. Zu diesem Zweck geht er zur Frau seines Bruders, damit sie ihm das nötige Saatgut bereitstellt. Er ist es aber selber (und nicht die Frau), der in den Stall geht. Man kann vermuten, daß er sich vorher darüber Gedanken machte, was er aus dem Stall mitnehmen sollte. Deshalb ist es kein unbedachtes Bedürfnis oder spontaner Wunsch, der hinter seiner Handlung steht, sondern eine sehr wahrscheinlich auf dem Weg nach Hause angestellte Überlegung über das, was er braucht, um seinem Bruder helfen zu können.

Im Beispiel E-15 appelliert der Bauer an seinen Herrn, damit dieser die Maat erkennt und dadurch richtig handelt ( $w 3 \hat{h} j b=k r h=k m^{3}$..$t$ ). Um dieses Ziel zu erreichen, sollte der Herr seine Augen und sein Herz nutzen, wobei die Augen sehen sollen (sgmh jr.tj) und das Herz mitteilsam sein soll $(s . w \underline{d}\}$ tw jb). An dieser Stelle spiegelt das Herz durch einen metonymischen Gebrauch den Verstand wider. Noch deutlicher ist das Beispiel E-9, in dem der Bauer die ungerechte Behandlung seinem Herren mitteilen möchte (s. $\left.w^{d}{ }^{3}=j j b=k h r-p^{3} h n n-m d w . t\right)$.

Als letztes Beispiel wäre die Beschreibung einer falschen Handlung zu erwähnen, deretwegen die Person nicht mehr sehen, hören und sich an etwas erinnern kann (E-14: $h r=f \check{s} p r-m$ 3’.t=f $z h j$ 
$r-s \underline{d} m . t=f$ th $j b \underline{h r} r-s . h j j . t-n=f$ 'sein Gesicht ist blind gegen das, was er sieht und taub gegen das, was er hört. Das Herz (d.h. der Verstand) vergißt, woran es sich erinnern sollte'). Jede dieser Tätigkeiten wird mit einem körperlichen Organ verbunden, nämlich mit dem Gesicht und dem Herzen. Das Gesicht ist mit dem Sehen und mit dem Hören verbunden, wobei diese Funktionen auf etwas außerhalb des Körpers Vorgehendes Bezug nehmen. Das Herz ist mit der Erinnerung und dem Vergessen verbunden, Funktionen, die sich ebenso im Innern des Körpers abspielen wie etwa der Verstand. Man muß davon ausgehen, daß das Herz in diesem Fall keine unmittelbareVerbindung mit dem Gefühl hat.

\subsubsection{Das Herz und die Charakterschilderung}

Um den Begriff "Temperament" oder "Verhaltensweise" auszudrücken, wird das Wort bj3.t am häufigsten benutzt. ${ }^{326}$ Grammatisch gesehen werden entweder substantivierte Partizipien oder noch häufiger substantivierte Partizipien und Adjektive mit Bestimmungssubstantiv verwendet. Ein gutes Beispiel ist der Begriff ${ }^{c} w n-j b$ mit der negativen Bedeutung 'der Habgierige' (E-11; E13; E-20 und E-23). ${ }^{327}$ Andere Ausdrücke geben den Charakter weniger deutlich wieder und bilden statt dessen Wendungen aus, z.B. 'stehendes Herz' d.h. 'unbeugsamer Mut' (E-28: $\left.{ }^{c} h^{c}-j b\right)$, 'dickes Herz' d.h. 'unerschütterliche Kaltblütigkeit' (E-28: wmt-jb), 'großes Herz', d.h. 'kühner sein' (E-3 und E-5: $\left.{ }^{3} j b\right)$ ' 'groß an Kraft' (E-73: ${ }^{c}$ p ph.tj) oder 'mutig' (E-6: $\left.r w \underline{d}\right)$.

All diese Beispiele lassen sich nicht mit Gefühlen verbinden, da das Temperament der Person nicht temporär oder spontan, sondern eine Eigenschaft ist, die sich im Lauf der Jahre auf die eine oder andere Weise im Inneren der Person entwickelt hat. Im Beispiel E-28 werden die Verhaltensweise und das Temperament des neuen Königs Sesostris durch die Ausdrücke 'stehendes Herz' und 'dickes Herz' wiedergegeben, welche als 'einer mit unbeugsamen Mut' und 'einer mit unerschütterlicher Kaltblütigkeit' ${ }^{\prime 328}$ übersetzt werden können. Mit dem Adjektiv c3 bildet sich eine Art der Charakterschilderung, was als 'Kühnheit' interpretiert werden kann (E-3; E-5) und die sich mit dem Kampf in Zusammenhang bringen läßt.

Als letztes Beispiel ist die Kollokation 'das Herz ist leicht' (E-15: jz jb) zu erwähnen, die mit dem Denken in Verbindung gebracht werden kann. Dies läßt sich durch einen Vergleich der Deutung mit der Interpretation der obengenannten Begriffe 'dickes' oder 'festes Herz' begründen. Man ging anscheinend davon aus, daß ein "dickes" Herz einen stabilen Charakter mit einem impliziten positiven Sinn beschreibt, während ein "leichtes Herz" einen negativen Sinn enthält und

326 Graefe (1971: 67-78); LÄ I 904-906.

327 Siehe Kapitel 5.2.2, Das Herz und die Personalität und die Gruppe 4 Das Herz für den Ausdruck des Charakters; vgl. Fecht (1951).

$328 \mathrm{~Wb}$ II 306,12-13. 
als 'instabiler Charakter' interpretiert werden kann. Wenn außerdem angenommen wird, daß in Beispiel E-15 das 'leichte Herz' ein Hindernis ist, um rational zu handeln, wäre dieser Begriff etwa als 'leichtfertig sein' wiederzugeben.

Es wurde oben schon erwähnt, daß die durch einen Ausdruck mit 'Herz' bezeichnete Eigenschaft entweder positiv oder negativ sein kann, obwohl das Herz in den Lehren infolge seiner engen Verbindung mit der Maat und der Gerechtigkeit eigentlich keinen negativen Sinn enthalten sollte. ${ }^{329}$ Da die Lexeme für 'Herz' nicht nur zum Ausdruck von Charaktereigenschaften benutzt wird, sondern das Herz auch als das Zentrum eines Menschen verstanden wird, können in ihm solche tieferen Aspekte der Persönlichkeit, wie der Charakter, der Wille und alle Gefühle lokalisiert werden, unabhängig davon, ob sie negativ und positiv sind.

\subsection{Emotionale und nicht-emotionale Zustände des Herzens}

Wie das Herz sich fühlt oder in welchem Zustand es sich befindet, spielt eine wichtige Rolle, wenn es um eine Emotion geht. Egal, ob das Herz sich dauerhaft zu einem Zustand in Beziehung setzen läßt oder etwas nur momentan im Herzen passiert, kann das Lexem 'Herz' dazu dienen, eine Emotion zu bezeichnen. Wenn der Zustand des Herzens bzw. der Person sich aufgrund einer Reaktion verändert, entsteht ein neuer Zustand, welcher möglicherweise mit einem Gefühl in Verbindung stehen kann. ${ }^{330}$ Wenn der Zustand des Herzens dauerhaft ist, kann man es als Bild des Charakters einer Person interpretieren. Im Gegensatz dazu steht das Herz für Gefühle, wenn es sich nur unter einer bestimmten Bedingung oder in einer bestimmten Situation auf eine konkrete Weise verhält, die zeitlich begrenzt ist. Im folgenden werden Zustände des Herzens aus den Passagen der Erzählungen kommentiert, um die Zustände, die man mit Gefühl assoziieren kann, von denen, die nicht mit Gefühlen verbunden sind, zu unterscheiden.

'Das Herz wird schön' enthält einen positiven Zustand an sich, als z.B. Ruddjedet ihrem Mann von dem Wunder erzählte (E-46: $n f r$ ). Die Passage läßt sich als "Zufriedenheit" oder "Befriedigung" erklären, obwohl es keinen eindeutigen Beweis dafür gibt. Im Beispiel E-46 wird als Konsequenz ein schöner Tag verbracht (hms.t pw jr.n=sn hr- hrw nfr), wobei sich Rawoser in einem positiven und aufgekratztem emotionalen Zustand befindet.

In der Erzählung des Schiffbrüchigen (E-1) wird der Fürst mit der Formel $w \underline{d} j j b=k$ begrüßt. Dieser Begriff wird oft mit der Bedeutung "froh" ${ }^{331}$ wiedergegeben, obwohl zu bemerken ist, daß dieser Sinn nicht der einzige oder auch nur der wichtigste ist. Er kann nicht nur einen wohlbehal-

329 Siehe Kapitel 2.4 Ägyptisches Konzeptes des Herzens, Gruppe 7 und Kapitel 5.3 Das Herz in Metaphern.

330 Siehe Kapitel 4.6 Bespiele für Emotionen und Reaktionen auf Emotionen.

331 Wb I 400,9-10. 
tenen Zustand, sondern auch den seelischen Zustand äußern. Interpretationen wie 'sei zuversichtlich' oder 'sei optimistisch' erscheinen durchaus denkbar.

Zuerst werden die Zustände behandelt, die mit einem körperlichen Zustand verbunden werden. Dazu gehört etwa das Herz Sinuhes, das wegen der Nachricht des Königstodes 'matt' wird (E-27: $3 d w$ ) oder das Herz des Verwunschenen Prinzen, welches müde werden soll (E-68: $b 3 g j$ ). Im beiden Fällen hat das Herz weniger 'Kraft', so daß Sinuhe nicht klar denken konnte, weil das Herz d.h. der Verstand sich nicht auf die richtige Weise benahm und der Held infolgedessen die irrationale Entscheidung traf, zu flüchten. Das Herz des Prinzen soll durch die Gewährung eines Geschenkes in Form eines Hundes matt werden. Wie Galán (1998: 153) vorschlägt, kann das ägyptische Wort bigj in Zusammenhang mit dem wohl etymologisch verwandten semitischen Begriff ba-ra-ga als 'zufrieden sein' übersetzt werden. Unter der Voraussitzung, daß das Herz auch die Bedeutung 'Willen' enthält, läßt sich ein Ausdruck "sein Wille soll matt werden", als 'seinen Wunsch erfüllen' oder 'seinen Wunsch befriedigen' interpretieren. In diesen beiden Fälle wäre das Herz nicht mit Gefühlen verbunden, sondern mit dem Verstand (des Sinuhe) und mit dem Willen (des Prinzen).

Als der jüngere Bruder auf dem Weg zu seinem Haus im Tal der Zeder ist, begegnet ihm die Götterneunheit, deren Herzen wegen seiner Situation 'krank waren' also um seinetwillen litten (E60: $m r$ ). Als die Leute erfahren, daß Sinuhe kämpfen muß, 'leiden die Herzen' (E-32: $m r$ ). Beide Beispiele beeinhalten die Schilderung des Zustands bzw. des Zustandswechsels einer Person, der mit Schmerzen verbunden ist. Es wurde im Kapitel über die Emotionen ausgeführt, daß die "psychischen" Schmerzen die Symptome sind, um die Trauer zu beschreiben. Die Herzen reagieren auf den Anblick einer Person, die sich in einer für sie belastenden Situation befindet. Eine andere Möglichkeit der Interpretation des Begriffes $m r$ wäre "Mitleid haben", wobei das implizierte Leid von der betroffenen und auch der anwesenden Person und miteinander geteilt wird. Beide Subjekte empfinden das selbe Gefühl, allerdings in zwei unterschiedlichen Perspektiven (Leid und Mitleid).

Bisher wurden die Zustände vorgestellt, die einen positiven Sinn enthalten. Ein schlechter Zustand kann nach einer lang andauernden belastenden oder ungerechten Situation entstehen. Dies ist der Fall in dem Zweibrüdermärchen, als der Oberwäscher des Pharaos aufgrund seiner unzulänglich verrichteten Arbeit täglich Rechenschaft vor dem König ablegen muß (E-62: jw

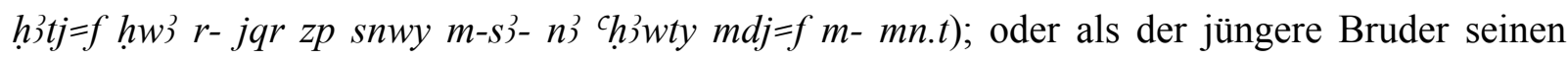
älteren Bruder auffordert, sieben Jahre lang nach seinem Herzen zu suchen (E-58: jr jry $=k s f h . w$ rnp.wt $n-w h 3=f m$-dj.t $f t h i j t j=k)$, und als der Oasenbewohner unter einer ungerechten Situation leidet $(\mathrm{E}-18: j b=j 3 t p)$. Diese negativen Zustände können ein negatives Gefühl ergeben, welches unterschiedlich interpretiert werden kann. 
Der ältere Bruder soll vermeiden, der Suche überdrüssig zu werden. Dieser Zustand könnte zum einen durch die Hoffnungslosigkeit hervorgerufen werden, aus der sich ein trauriges Gefühl entwickeln kann. Zum anderen könnte bei der langen Suche nach dem Herzen die schwindende Motivation die Ursache für das schlechte Befinden sein. Der Oberwäscher des Pharaos ist verdrießlich und mürrisch wegen seines täglichen Treffens mit dem Pharao. Das Herz des Bauern enthält ein negatives Gefühl an sich, welches die Person noch tiefer berührt. Es kann sogar als ein seelisches Niveau beschrieben werden und deswegen wird sowohl der Zustand des Körpers als auch der des Herzens (d.h. der Seele) erwähnt.

Interessant ist das Wort $\underline{d} w$, welches in den Beispielen E-44; E-47, E-67, E-74 und E-75 vorkommt und einen neuen Zustand beschreibt, der als Emotion definiert werden kann. In allen Fällen spielt eine Mitteilung über etwas eine Rolle, die der Auslöser dafür ist, daß die Person auf eine bestimmte Weise reagiert. Diese eher spontane Reaktion ist der Grund, weswegen der von $j b=f \underline{d} w$ ausgedrückte Zustand eindeutig als Emotion zu interpretieren ist. Als wohl treffendste Übersetzung für $j b=f \underline{d} w$ ('sein Herz ist schlecht') bietet sich 'er ist niedergeschlagen' oder 'es ist in niedergeschlagener Stimmung' oder 'er ist am Boden' an. Im Beispiel E-44 reagiert 'das Herz Seiner Majestät' auf die Prophezeiung über die bevorstehende Geburt der Kinder $(h m=f j b=f w 3 r$ $\underline{d} w-h r=s$ '(dann sagte) Seine Majestät, dessen Stimmung sich daraufhin zu Niedergeschlagenheit verschob'). Im Beispiel E-47 fühlt sich das Herz Ruddjedets auch 'niedergeschlagen', weil sie erfahren hat, daß ihre Dienerin den König über die Geburt der Kinder informieren will ( $g m . n=f$

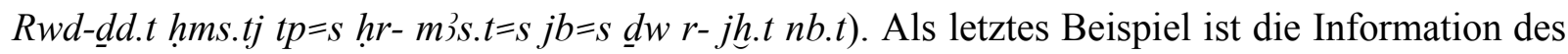
Königs in der Erzählung vom Verwunschenen Prinzen über eine zukünftige Tat zu erwähnen,

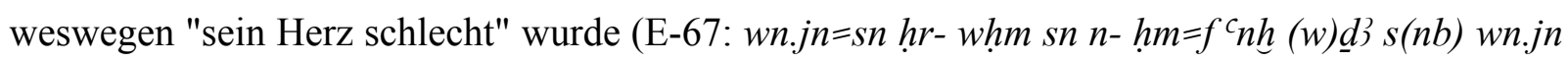
$h m=f^{c} n h(w) \underline{d}$ ) $s(n b) h r h p r j w j b=f \underline{d} w r$ - ${ }^{3} . t w r . t$ 'Sie erzählten es seiner Majestät, möge er leben, wohlbehalten und gesund bleiben. Daraufhin verfiel seine Majestät, möge er lebe, wohlbehalten und gesund bleiben, in eine ganz niedergeschlagene Stimmung'). In allen diesen Fälle spielt der zeitliche Faktor eine Rolle: Man reagiert auf eine Nachricht, über etwas, was in der Zukunft geschehen wird. Diese Mitteilung versetzt die Person in einen Zustand, welcher mit den Gefühlen 'Sorge' und 'Traurigkeit' assoziiert werden kann. ${ }^{332}$ Wenn jemand sich um etwas sorgt, befindet er sich in einem unruhigen Zustand, in dem man nicht weiß, was passieren kann. Wenn dieser Zustand der Ungewißheit zusätzlich durch das ägyptische Wort $\underline{d} w$ ausgedrückt wird, welches als Determinativ den "schlechten Vogel" hat, kann man erwarten, daß der Hintergrund nicht

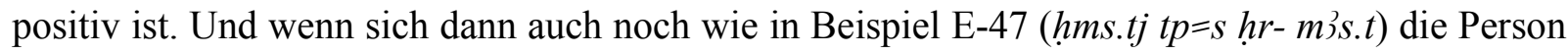

332 Nach Wierzbickas Klassifikation wird dieses Art von Gefühlen unter der Gruppe Etwas schlimmes kann passieren (1999: 49-122), siehe Kapitel 4.5 Vorschläge zur Klassifikation von Emotionen. 
'sitzend mit dem Kopf auf dem Knie' befindet, so dient diese Haltung zur Beschreibung eines "Krankheitssymptoms", das nicht mit dem Körper, sondern mit der Seele zu tun hat. ${ }^{333}$

In der Erzählung von Horus und Seth wird dem Gott Pre-Harachti durch das Götterkollegium der Vorwurf gemacht, daß sein Schrein leer sei ${ }^{334}$, weswegen er sehr betroffen ist. Er reagiert darauf, indem er sich auf den Rücken wirft (E-74: $j w=f n m^{c}=f \underline{h} r-p s \underline{d}=f j w j b=f r-\underline{d} w w^{c} 3-w r^{\prime} \ldots$ und er legte sich auf seinen Rücken, und wurde ganz niedergeschlagen'). Nach allgemeiner Forschungsmeinung bringt diese Passage die Wut des Re-Harachti zum Ausdruck. ${ }^{335}$ Das Wort šnn bedeutet laut Erman \& Grapow 'Krankheit' oder 'Kummer'. ${ }^{336}$ Der kranke Zustand des Herzens wäre an dieser Stelle mit Traurigkeit zu verbinden. Im folgenden wird er abermals von dem Götterkollegium angesprochen, worauf er sich wieder auf seinen Rücken legt und allein sein möchte (E-75: ${ }^{c} h^{c} . n$ p $n t \underline{t r}{ }^{c} 3 h r-j r . t w^{c} h r w j w=f n m^{c} h r-p s \underline{d}=f m-p 3 y=f z h j w j b=f(r-) \underline{d} w{ }^{c} 3-w r j w=f$ $w^{c} . t=f$ 'Dann verbrachte dieser große Gott einen Tag damit, in seinem Pavillon auf seinem Rücken zu liegen, während er ganz niedergeschlagen war und allein blieb'). Da dieselbe grammatische Konstruktion sowohl im Beispiel E-74 als auch im Beispiel E-75 verwendet wird, lassen sich die Textpassagen auf dieselbe Weise interpretieren. Außerdem kann der Wunsch "allein zu sein und im Bett zu liegen" als eine körperliche und seelische Reaktion verstanden werden, die mit Traurigkeit und Niedergeschlagenheit in Verbindung gebracht werden kann. Die Ursache für diese Reaktion ist wohl, daß Re-Harachti sich schämt.

Der Unterschied zwischen diesen zwei Gruppen ist das diachronische Konzept, d.h. die Beispiele E-44, E-47 und E-67 beschreiben eine zukünftige Tat, während die Beispiele E-74 und E75 eine gegenwärtige Handlung schildern.

\subsection{Das Herz und die Gefühle}

Oben wurden Beispiele diskutiert, von denen einige die teilweise mit einem Gefühl zu tun haben, das aber nicht durch ein Gefühlswort ausgedrückt wird. Im folgenden werden Beispiele vorgestellt, die ein Gefühl enthalten und über deren Bedeutung kein Zweifel besteht.

Die einfachste Klassifikation der Gefühle könnte darin bestehen, zwischen positiven oder negativen Gefühlen zu unterscheiden. Bei einem Gefühl handelt es sich zu weilen um die Reaktion auf ein bestimmtes Ereignis, die auch mit einer körperlichen Veränderung verbunden sein

333 Siehe Kapitel 4.9.2 Trauer.

334 Junge interpretiert diese Aussage als eine Entsprechung für das Deutsche: "Du hast wohl nicht alle Tassen im Schrank!", (1995: 938, Anm. 3,10 a).

335 Junge (1995: 938; vgl. 1994: 90).

$336 \mathrm{~Wb}$ IV 515. 
kann. ${ }^{337}$ Allerdings sind ägyptische Texte, die sowohl das auslösende Ereignis als auch das daraus resultierende Gefühl beschreiben, nicht zahlreich. Man kann zwischen den Beschreibungen unterscheiden, in denen ein Gefühl hervorgerufen wird, und denen, in denen auf ein Gefühl reagiert wird. Für die Untersuchung der Ausdrücke für Emotionen ist es entscheidend, wie man auf ein Gefühl reagiert. Allerdings ist es für die ägyptischen Beispiele auch von Bedeutung, den Grund für das Entstehen einer Emotion zu klären.

Im Papyrus Westcar (E-42) kommt ein Beispiel vor, in dem das "Herz der Majestät" beim Anblick der schönsten Frauen des Palastes 'erfrischt wird' (jb $n(j)-h m=k r-q b b n-m 3 \hat{\jmath} \underline{h n} n=s n \underline{h} n . t$ $m$ - hld $m$ - hnt 'Die Stimmung deiner Majestät wird sich verbessern beim Zusehen, wie sie hin und her rudern'). Das Wort $q b b$ könnte in Beispiel L-32 aus den Liebesliedern als Ausdruck für ein angenehmes Gefühl interpretiert werden (jr- $m-\underline{d} r-n w=s-r=j q b b$ 'als sie mich ansah, wurde es kühl'). Eine Person sucht Erfrischung, wenn sie sich zunächst in einem warmen Zustand befindet und dieser als unangenehm empfundenen Situation entkommen will. Wenn beide Konzepte sich auf einem metaphorischen Niveau mit der Emotion verbinden, wäre 'warm sein' mit einem unangenehmen oder aufgeregten Zustand und 'kühl sein', 'sich erfrischen' dagegen mit einem angenehmen Zustand bzw. dem Wechsel in einen angenehmen Zustand verbunden. Im Beispiel E-42 wird "das Herz" auch in einen angenehmen Zustand versetzt, in dem ein froher Sinn oder eine gute Stimmung impliziert ist. Die danach folgende Passage bestätigt diese Idee, da "das Herz" seiner Majestät zufrieden wird, als er die Frauen aus dem Palast beim Rudern sah. (E-43: wn.jn=sn hr-

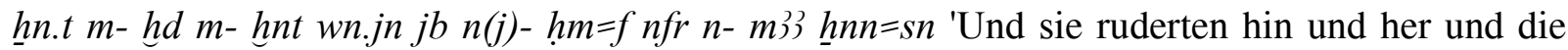
Stimmung Seiner Majestät war gehoben beim Zusehen, wie sie ruderten').

Es wurde schon erläutert, wie jemand beim Hören einer schlechten Mitteilung in einen negativen, nämlich traurigen, frustrierten, niedergeschlagenen Zustand geraten kann. Es ist umgekehrt verständlich, daß sich jemand in einer guten Stimmung befindet, wenn eine an ihn ergangene Mitteilung nicht negativ ist. Wie oben erwähnt, passiert dies dem Mann der Ruddjdedet (E-46:

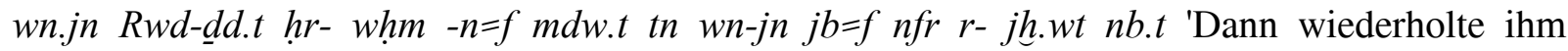
Rudjdedet diese Rede, woraufhin sein Herz über alle Maße glücklich wurde'), als sie ihm das Wunder erzählte oder dem Fürsten von Naharina, als er erfuhr, daß jemand das Fenster seiner Tochter erreicht hat (E-71: wn.jn=f ḩr- šm.t $r$ - snd $\underline{j}$ jb $n(j)-p 3 y=s j t(j)$ 'Dann ging er, um die Stimmung ihres Vaters zu heben' oder 'Dann ging er, um ihrem Vater die erfreuliche Nachricht zu übermitteln'). Die Kollokation $s n \underline{d} m$ jb ('das Herz erquicken') wird fast immer als Beschreibung einer Handlung verwendet, die aus dem Erhalten einer dem Adressaten bisher unbekannten und von ihm als positiv empfundenen Information resultiert, bedeutet also im Grunde das Herz (durch 
Weitergabe einer guten Nachricht) erquicken. In vielen Fällen dürfte sich eine Übersetzung 'die erfreuliche Nachricht übermitteln' als passend erweisen.

Als Horus den Thron seines Vaters übernimmt und zum König von Ägypten berufen wird, ist seine Mutter Isis in einer Hochstimmung, in der sie laut gesprochen und ihr Herz sich darüber

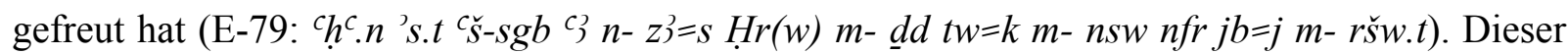
Fall läßt sich so interpretieren, daß die Göttin sich in einem sehr aufgeregten Zustand befand, weswegen sie laut aufschrie. Es erscheint schwierig, die Reaktion der Isis aufgrund der zeitlichen Sequenz als eine emotionale Reaktion der Freude zu verstehen. Im Gegensatz dazu wäre sie als eine von ihrer Aufregung abgeleitete Emotion zu interpretieren.

Bisher wurden die positiven Gefühle erwähnt, die in den Erzählungen vorkommen. Im folgenden werden die negativen Emotionen, die bereits teilweise bei der Darstellung der emotionalen Zustände erklärt wurden (E-44; E-47; E-67; E-74 und E-35), diskutiert.

Es ist anzumerken, daß in ägyptischen Texten die Beschreibungen für negative emotionale $\mathrm{Zu}$ stände im Vergleich mit den positiven erheblich zahlreicher sind. Dieser Befund läßt sich auch anhand der Beispiele bestätigen, die das Gefühl Trauer zum Ausdruck bringen. In fünf der acht Stellen, in denen dieses Gefühl vorkommt, findet man eine Beschreibung des Zustandes. Die Frage, ob diese Zustände als Reaktion auf das Gefühl zu verstehen sind oder nicht, ist im folgenden zu diskutieren. Im Beispiel E-65 wird Seine Majestät sehr betroffen, weil seine Frau von ihm verlangt, das Rind zu schlachten $\left(j w=f \underline{h} r-s \underline{d} m j: \underline{d} d=s t n b . t j m j\right.$ tw $w n m=j n(j)-t 3 m j s . t n(j)-p^{3} j \underline{h}$ p'-wn $n(n) j w=f r-j r . t n k . t j n$ st $h r-\underline{d} d d-n=f^{\prime}$ Er hörte alles, was sie sagte: "Laß mich von der Leber dieses Rindes essen, dann wird er nichts machen", so sagte sie ihm'). An dieser Stelle wurde nicht "das Herz" Seiner Majestät krank, sondern er selber (jw=f hr- šn.t n- $p^{3} j .<d \underline{d}>=s t r$ - jqr zp sn.wy

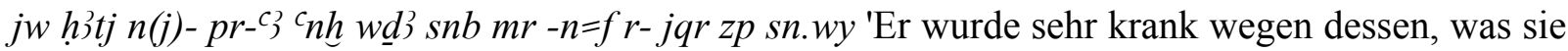
sagte und das Herz des Pharao hatte großes Mitleid mit ihm'). Das Krankwerden seiner Majestät kann in Zusammenhang mit den oben vorgestellten Beispielen (E-44; E-47, E-67, E-74 und E-75) als Reaktion der Trauer verstanden werden. Die Reaktion des Pharao auf diese Trauer drückt sich in einem Mitleidsgefühl mit dem Tier aus.

In der Erzählung des Sinuhe wird der Zustand der Gesellschaft beschrieben, nachdem der König gestorben ist. Dieses Beispiel (E-24: jw hnww m- sgr jb.w m- gmw 'Die Residenz war in Stille, die Herzen waren in Betrübnis') ist interessant, da es sich hier nicht nur um "das Herz" einer Person, sondern um "die Herzen" einer Gemeinschaft handelt. In dem Text kommen zwei parallel gesetzte Beschreibungen vor, die sowohl den offiziellen-emotionalen Zustand einer Gemeinschaft nämlich 'die Residenz war in Stille ...' und 'das Doppeltor war geschlossen ...'. als auch den der Personen, '... die Herzen waren in Betrübnis' und '...der Hofstaat war gramgebeugt' beschreiben. Die zu erst genannte Stelle läßt sich so interpretieren, daß weder eine bürokratische noch eine 
andere Art von Tätigkeit im Palast zu dieser Zeit stattfand, während das im zweiten Texte Geschilderte als Zeichen der Trauer, d.h. als emotionale Reaktion einzelner Personen verstanden werden kann. Es wurde bei der Analyse der Trauer erwähnt ${ }^{338}$, daß Passivität als eine der Reaktionen auf diese Emotion angesehen werden kann. In Zusammenhang mit einer Gemeinschaft und nicht nur mit dem Individuum stellt die absolute Untätigkeit der Bürokratie die unter Umständen sogar von oben verordneten Kollektive Haltung einem unglücklichen - d.h. für die Gesellschaft unglücklichen - Ereignis gegenüber. Bezüglich des Individuums kann festgehalten werden, daß das Herz sehr betroffen ist und die Person in dieser Situation eine bestimmte Körperhaltung einnimmt und mit dem Ausstoß des Klagerufs reagiert.

Im Beispiel E-47 nahm Ruddjedet die gleiche Körperhaltung ein, die hier als Zeichen der Trauer und der Sorge interpretiert werden kann. Eine andere körperliche Reaktion auf diese Emotion läßt sich auch in den oben behandelten Beispielen E-74 und E-75 erkennen. Die unmotivierte Reaktion der Ruddjedet und des Re-Harachti dient als Beweis einer Passivität, wegen der sich die betroffenen Personen in einer tiefen körperlichen und geistigen Lethargie befinden.

Diese Art der Trauer unterscheidet sich von der Traurigkeit, wegen der eine sorgenvolle Stimmung entsteht, wie etwas in der Situation als Sinuhe kämpfen muß und die Menschen des-

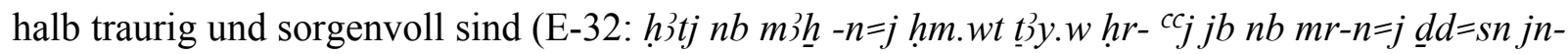
$j w$ - wnn ky nh.t ${ }^{c} h{ }^{3}-r=f^{\prime}$ 'jedes Herz hatte Angst um mich. Die Frauen und die Männer redeten durcheinander. Alle hatten Mitleid mit mir, und sie sagten: "Gibt es ebenso Starken, der gegen ihn kämpfen kann?"'). Unter diesen Umständen stellt sich die Frage, ob ein anderer Gegner gefunden werden könnte, der statt Sinuhe hätte kämpfen können. Im diesen Fall fokussiert sich die Trauer nicht in der Seele, sondern im Verstand, wobei keine Passivität ausgedrückt, sondern im Gegensatz dazu eine Lösung gesucht wird.

Diese Angst, die die Leute um Sinuhe haben, läßt sich durch einen Zustand des Herzens, nämlich "angsterfüllt" ${ }^{339}$ und "ein krankhaftes Verhalten des Herzens", ausdrücken. ${ }^{340}$ Das Herz wird zwei Mal genannt; zuerst wird das Herz mit dem Zentrum des Gefühles identifiziert, während das Herz bei seiner zweiten Erwähnung als Verstand zu interpretiert ist. Die Veränderung des Verhaltens läßt sich durch die Reaktion der Menschen auf eine Emotion erklären. ${ }^{341}$ In Zusammenhang mit der oben behandelten 'Trauerigkeit' und 'Sorge' bildet die Textpassage einen sehr aufgeregten und sorgenvollen Zustand der Gemeinschaft ab, da sie wegen des bevorstehenden Kampfens zwischen Sinuhe und dem Helden aus Retenu betroffen ist.

338 Siehe Kapitel 4.9.2 Trauer.

339 Wb I 169,5.

340 Wb I 169,12 und 173,4.

341 Die körperlichen Veränderung wegen der Reaktion eines Gefühles wurden in Kapitel 4.6 dargestellt. 
Eine andere Art der Angst kommt in der Erzählung der Vernichtung des Menschengeschlechtes vor, als die Menschen vor Angst flüchten (E-49: st $w^{c} r r$ - h 3 s.t jb. $w=s n$ sn $\underline{d} h r-\underline{d} d=[j-n]=s n$ 'sie fliehen in die Wüste und ihre Herzen haben Angst davor, was ich zu ihnen sagen werde').

Die Passage, in der Sinuhe die Nachricht vom Tod des Königs hörte, läßt sich ähnlich interpretieren. Sein Herz bekam Angst, und die Reaktion darauf ist das Ausbreiten seiner Arme als Zeichen des Erschreckens (E-25: $j w=f h r-m d w . t j w=j m-{ }^{c} r(w) w 3 . t p s h j b=j z \check{s}{ }^{c} \cdot w y=j$ 'Mein Verstand war verwirrt und ich streckte starr die Arme von mir). ${ }^{342}$ Unter den möglichen körperlichen Reaktionen auf die Angst wurden die Bewegungslosigkeit und die zusammengekrümmte Körperhaltung erwähnt. ${ }^{343}$ Obwohl das Ausbreiten der Arme weder unmittelbar mit Bewegungslosigkeit noch ohne weiteres mit einer verkrampften Körperhaltung assoziiert werden kann, mag es sehr wohl sein, daß es sich um einen typischen, d.h. möglicherweise gesellschaftlich konventionalisierten Gestus zum Ausdrücken von Angst handeln.

Gemäß der Erklärung von Wierzbicka (1999: 123ff.) ${ }^{344}$ wäre das Beispiel E-32 ein Fall für Angst vor etwas Konkretem, nämlich die Angst vor dem Kampf und dem Tod Sinuhes, während das Beispiel E-49 und das Beispiel E-25 die Angst vor etwas Unbekannten schildern. Da weder Sinuhe noch die Menschen wissen können, was die Gottheit sagen oder tun werden oder was die neue Situation bringen wird.

Interessant ist die ägyptische Konzeption von Angst in Zusammenhang mit dem Herzen. Normalerweise wird ein "gebranntes Herz" mit der "Wut" und dem "Konzept des Warmen" verwendet. An dieser Stelle (E-32) sind die Leute ängstlich und traurig, weil sie sich Sorgen um Sinuhe machen, wie in der ganzen Passage beschrieben wird. Dieser Prozeß kann in der folgenden Tabelle reproduziert werden:

ANGST BEKOMMEN (= DAS HERZ BRENNT)

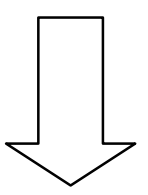

angsterfülltes; ungewohntes Verhalten
TRAURIG SEIN (= MITLEID HABEN)

\section{REAKTION}

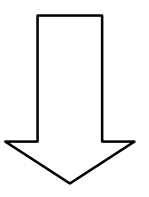

sich Sorgen machen (= Frage)

342 Wb III 482,24.

343 Siehe Kapitel 4.9.3 Angst.

344 Siehe Kapitel 4.6.1 Gegenstand und Wortbedeutung. 
Die Bedeutung des Wortes $m \underline{3} \underline{h}$ ist "verbrennen durch Feuer" ${ }^{345}$ und heißt zusammen mit der Präposition $n$, wie für die Erzählung des Sinuhe belegt, "Angst um jdm. haben". ${ }^{346}$ Im Deutschen wird die Beschreibung der Angst durch den abrupten Wechsel zwischen warmem und kaltem Zustand ausgedrückt, nämlich mir wird heiß und kalt.

Die Textpassage E-32 aus der Erzählung des Sinuhe kann man so interpretieren, daß die Leute sich sehr große Sorgen um ihn machten, welche sich auf ihre Herzen als Zentrum für die Emotionen fokussieren lassen. Dieses Konzept der 'Warme' könnte dazu dienen, die Intensität der Sorge hervorzuheben. Es wurde erklärt, wie sich der Begriff "warm" durch einem positiven Sinn mit der Liebe in Verbindung bringen läßt. ${ }^{347}$ Auf diese Weise wäre der Ausdruck "jedes Herz brannte um mich" als brennende Sorge zu verstehen, die einen positiven Sinn enthält. Das soll nicht bedeuten, daß diese Art der Zuneigung mit der Liebe aus den Liebesliedern zu identifizieren ist, sondern daß die Leute ein leidenschaftliches Mitgefühl für Sinuhe empfanden.

Zum Schluß soll ein letztes negatives Gefühl vorgestellt werden und zwar das des emotionalen Leidens. Dieser Begriff wird mit dem Kummer, der Betrübnis und der Sorge verbunden. In Beispiel E-34 leidet das Herz Gottes solidarisch mit dem Herzen des Sinuhe $(j b=f m r n(j) d q r . n=f r$ $c_{n h} h r-h{ }^{3} s . t$ 'Den sein Herz Mitleid hat mit dem, den er dazu verbannt hatte, im Ausland zu leben'); im Beispiel E-77 ist es das Herz der Isis, welches wegen Seth leidet (wn-jn s ḩr- šnn h̆̉tj=s $-n=f r$ - jqr zp snwy 'Da litt sie (Isis) seinetwegen (Seth) sehr an ihrem Herzen') und im Beispiel

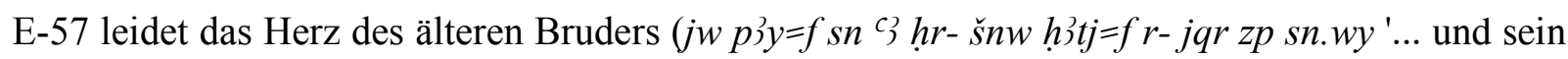
ältere Bruder litt sehr an seinem Herzen...'). In all diesen Beispielen leidet man wegen eines unglücklichen Geschehens; so leidet Sinuhe an seinem Aufenthalt in einem fremden Land, Isis an dem Unfall des Seth und Anubis an der Entmannung von Bata. Nur ein Fall beschreibt eine Reaktion, der sich interessanterweise in der menschlichen Sphäre vollzieht. Der ältere Bruder litt an seinem Herzen und begann zu weinen, wobei ein trauriges Gefühl implizit ist. Zu bemerken ist, daß Anubis nicht nur weint, sondern daß er laut weint.

Zusammenfassend läßt sich festhalten, daß die Passagen, die eine Reaktion auf ein positives Gefühl enthalten, im Vergleich mit denen, die eine negative Emotion ausdrücken, in den ausgewerteten Texten weniger zahlreich sind. Beispiele wie "Angst haben" (E-25: psh ; E-32: mỉh oder "traurig werden/sein" (E-24: gm; E-47: $\underline{d} w$; E-74: $\underline{d} w$ und E-57: $\underline{h} z j)$ belegen die körperliche Antwort auf eine Emotion.

$345 \mathrm{~Wb}$ II 31,8 .

$346 \mathrm{~Wb}$ II 31,9 .

347 Siehe Kapitel 4.8 Emotionen und Metaphern. 


\subsection{Die Metapher und das Herz}

Im Folgenden werden die mit dem Lexem 'Herz' gebildeten Metaphern vorgestellt und kommentiert. Ferner werden auch die Passagen aus dem Zweibrüdermärchen aufgrund des metonymischen und metaphorischen Gebrauchs des Begriffes 'Herz' analysiert.

Zuerst wird die Identifikation des Herzens mit dem Löwen in Beispiel E-3 dargestellt. In diesem Fall wird das Herz als Zentrum des Charakters verstanden, als der Schiffbrüchige die Besatzung des Schiffes beschreibt. 'Ihre Herzen waren kräftiger als die von Löwen', sagt er und erklärt weiterhin ihre außergewöhnlichen Fähigkeiten. Das Motiv des Löwen wird sehr häufig als Bild für den König angewendet, so wird beispielsweise Amenophis III. als der Löwe der Könige 348 oder Thutmosis III. als der Löwe der Herrscher ${ }^{349}$ bezeichnet. Ebenso lassen sich die sogenannten Vergleiche - nach Grapows Meinung (1924: 71) - von Thutmosis III. wie ein Löwe, der auf der Lauer liegt ${ }^{350}$ oder die Bezeichnung eines Äthiopenkönigs als stark wie Month und groß an Kraft wie ein Löwe ${ }^{351}$ verstehen. Das Vehikel 'Löwe', wurde auch für eine Gottheit verwendet wie der große Löwe, der seine Feinde schlägt ${ }^{352}$ als Bezeichnung für Horus. Neben dem König und den Göttern werden in den ägyptischen Texten in erster Linie Soldaten, aber gelegentlich auch Angehörige anderer Berufe oder normale Menschen mit dem Löwe identifiziert, obwohl die Belege für die Gleichsetzung von 'König' und 'Löwe' und 'Gott' und 'Löwe' zahlreicher sind als die Vergleiche zwischen dem Tier und den oben genannten Gruppen. Beispielsweise wurden die Soldaten als Löwen nach dem Kampf des Königs Kamose gegen den Hyksos beschrieben ${ }^{353}$, ebenso wie die Truppe von Ramses II. $^{354}$ und die Gegner im Petubastisroman. ${ }^{355}$

Das Motiv des Löwen als Vehikel wurde wegen der Kraft und Wildheit, der Tapferkeit und des Gebrülls des Tiers benutzt. ${ }^{356}$ In der Stelle des Schiffbrüchigen wird die Kraft eines Menschen mit der eines Löwen identifiziert. Diese Metapher des Löwen wird heute noch mit dem gleichen Sinn, nämlich für eine mutige, kräftige und verwegene Person gebraucht. ${ }^{357}$

Eine andere Art der Metapher kommt in Beispiel E-4 vor, als der Schiffbrüchige drei Tage auf der Insel verbrachte, indem er allein war $\left(j r . n=j h r . w h m . t w^{c} . k w\right)$. Das Herz wird als "der Ge-

348 Wb Zettel Louvre A 18 (nach Grapow 1924).

349 Urk. IV 557, 9 (Sethe 1961).

350 Urk. IV 184, 15 (Sethe 1961).

351 Urk. III 60, 15 (Schäffer 1905).

352 III 17g (Mariette 1870).

353 Carnavon Tablet 1, 15 (Gardiner 1916).

354 Med. Habu Greene fouilles II 21 (Breasted \& Nelson 1930).

355 Pap. Spiegelberg 5, 1-3 (Spiegelberg 1910).

356 L. Ä. III 1080-1091.

357 Siehe Kapitel 3.2 Was ist eine Metapher? 
nosse" $(j b=j m-s n . w y=j)$ identifiziert, da es als einziges bei der Person verblieben ist. Der Gebrauch des Herzens hat in diesem Fall das Ziel, die Einsamkeit auszudrücken. Das Herz identifiziert die Person selbst, d.h. den Schiffbrüchigen, der mit einem nicht anwesenden Genossen gleichgesetzt wird. Tatsächlich handelt es sich aus zwei Gründen nicht um eine Metapher:

- Zunächst einmal wird der Begriff des Herzens als ein metonymischer Gebrauch verstanden, nämlich für "ich".

- Zweitens wird das Herz, nämlich die Person, mit einer anderen Person identifiziert, wobei keine Metapher gefunden werden kann, da Tenor als auch Vehikel aus der selben Eigenschaft bestehen.

Außerdem ist diese Verwendung des Herzens wichtig, um das Gefühl besser ausdrücken zu können. 'Allein zu sein' ist die beste Definition für die Einsamkeit. Wenn dieser Zustand nicht nur eine Situation, sondern auch ein Gefühl beschreibt, läßt sich diese subjektive Absicht durch den Ausdruck 'allein mit mir selbst sein' intensivieren. Mit diesem Ziel wird der metonymische Gebrauch des Herzens in dieser Passage verwendet. Die mögliche deutsche Wiedergabe als 'mutterseelenallein' ist ganz analog zu bewerten.

Die letzte Metapher, die unter den Belegen aus den Erzählungen zu finden ist, stammt aus dem Zweibrüdermärchen (von E-58 bis E-64). Die ganze Passage handelt von dem Herzen Batas, welches aus seinem Körper entfernt und auf die Blüten der Pinie gelegt wurde. Das Herz wird hier als Platz des Lebens verstanden, wie das Beispiel E-63 beweist (jw=sn spr $r-p 3 c^{c_{S} j w} j=s n h r-\check{s}^{c} d t$ ) hrr.t nty hijtj $n(j)-B 3-t$ ) $-h r=s j w=f h 3 y . t m w t m-t 3$ wnw.t wr.t 'sie (scil. die Soldaten) erreichten die Zeder und schnitten diese Blüte ab, auf der das Herz des Bata lag, und er fiel im selben Moment tot darnieder'. Außerdem bestätigt das Beispiel E-64 dieses Ereignis, als Anubis seinen Bruder tot auffindet $\left(j w=f r m j m-\underline{d} r . t-p t r<=f p j y=f>s n \check{s} r j \underline{d} \underline{d} r m-r^{c}-m t\right)$. Das erste Problem ist die Identifikation des Wortes $c_{S}^{\check{S}}$ als "Zeder" oder "Pinie". Lorets (1916: 33ff.). ${ }^{358}$ identifiziert $c_{S}$ als Abies, vermutlich Abies cilicica oder Pinus Pinea, welche aus dem Libanon nach Ägypten exportiert worden sind. Meigss (1982) empfiehlt in den Kapiteln 13 und 14 seiner Arbeit über die Bäume in der alten mediterranen Welt die Übersetzung des Wortes als "Zeder".

Die umfassendste Forschungsgeschichte zu dem Zweibrüdermarchen bietet Hollis in ihrer Arbeit (1990: 114-118), in der sie zentrale Punkte der Erzählung herausgreift und diskutiert. Nach diesen Studien kommt sie zu folgenden Interpretationen:

$\Rightarrow$ Das Motiv des $\check{c}^{\breve{S}}$-Baums bringt sie mit den Sargtexten (I, 267f-268a) und den Mahnworten des Ipuwer (3, 6-8) in Zusammenhang. 
$\Rightarrow$ Die Interpretation der Rolle des Herzens und seine Wiederkehr zum Körper lasse sich mit einer ägyptischen Tradition des Totenkults verbinden. ${ }^{359}$

$\Rightarrow$ Die Rolle des Wassers lasse sich mit der Wiederbelebung erklären.

$\Rightarrow$ Die Präsenz des Herzens Batas in einem außerägyptischen Kontext wird auch mit der Erzählung von Sinuhe in Verbindung gebracht, da in beiden Texten das Exil und der Tod des Helden in einem fremden Land eine bedeutende Rolle spielten.

Zum Schluß deutet Hollis: "Thus Bata's existence in the valley must be considered as one of an exile with all its attendant implications, a life in the Otherworld, death to his old life". ${ }^{360}$

Das Motiv von dem Herzen, das auf der Blume einer Pinie liegt, wird als ein Symbol der Wiedergeburt und der Regeneration interpretiert ${ }^{361}$ und kann dadurch mit den Sargtexten in Verbindung gebracht werden. Im Spruch 275 wird der Verstorbene mit einem ${ }^{C} \breve{S}$-Baum identifiziert, der sich gegenüber von Osiris befindet. ${ }^{362}$ Das ist ein Schlüssel, um die Rolle des Baumes und des Wassers wie sie Koemoths (1994: 133-134) zu deuten sieht.

"L'image d'Osiris qui s'en dégage est d'abord celle d'un dieu mort cherchant à se régénérer au contact du Noun. L'arbre près duquel il séjourne, ou qui va lui servir de cercueil, est conçu comme un être sans cesse imbibé par ce Noun. Qu'il s'agisse du sycomore ou d'une autre espèce, il était sans soute censé aspirer le Noun par ses racines, devenant du même coup une hypostase du démiurge primordial, mais aussi la source d'une eau qui revivifie (...)."

Die Rolle des Wassers im Zusammenhang mit dem Prozeß der Wiederbelebung findet sich auch in anderen Texten, wie:

- Pyr. 1995b

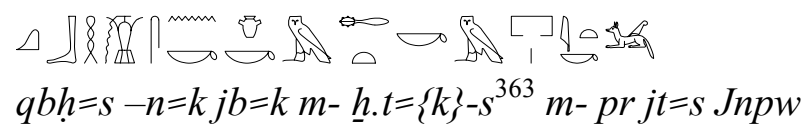

"Sie erfrischt dir dein Herz in/aus ihrem Körper im Haus ihres Vaters Anubis".

359 Pyr §3; 1640a; 1786b; 1885; 1891; 1892a; 1916b; 2097c; CT I 80a-b; CT I, 264e-f; CT V, 332h; TB K. 26 ; vgl. Hollis (1990: 118-123), Jacobsohn (1955).

360 Hollis (1990: 118).

361 Hollis (1990: 124).

362 Das ist nicht der einzige Zusammenhang, in dem Osiris auftaucht. Es kann auch die Textpassage, in der Bata seinen Phallus abschneidet, mit dem Phallus des Osiris in Verbindung gebracht werden, siehe dazu Hallis (1990: 103-109).

363 Korrektur des $k$ zum $s$ von Faulkner (1969: 288, Anm. 3). 
- TB Kapitel 173

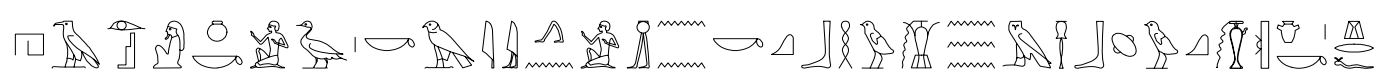

h3 Wsir jnk s\}=k Hr jj. $n=j$ jn. $n=[j]-n=k$ qbh.w $m$ - 3bw qbh $j b=k \underline{h r}=f$

"Oh Osiris, ich bin dein Sohn Horus. Ich bin gekommen, und ich habe dir kühles Wasser aus Elephantine gebracht, (damit) dein Herz sich mit ihm erfrischen kann".

All diese Informationen deuten den Kontext der Szene an. Was interessant ist und durch die oben dargelegte Erklärung trotzdem unklar bleibt, ist die Identifikation des Herzens mit einer Weintraube. Nach Brunner-Traut (1997: 292) könnte die Metapher aufgrund der Ähnlichkeit zwischen der Form des Herzens und der Frucht der Pinie, welche Farbe, Gestalt und Größe eines menschlichen Herzens habe, erklärt werden. ${ }^{364}$ Das läßt sich ihrer Meinung nach dadurch bestätigen, daß der ältere Bruder das Herz des Bata so lange nicht finden konnte. Wahrscheinlich basiert diese Interpretation auf der Lesung des Wortes $A \mathbb{N}, \mathbb{N}_{1}$ als $j 3 r^{365}$, welches sie als 'Frucht' ${ }^{366}$ wieder-

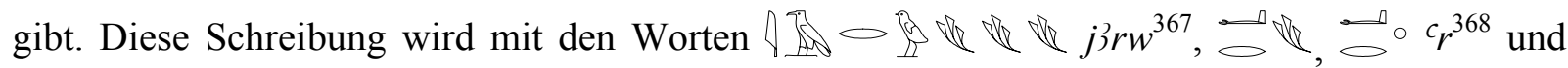

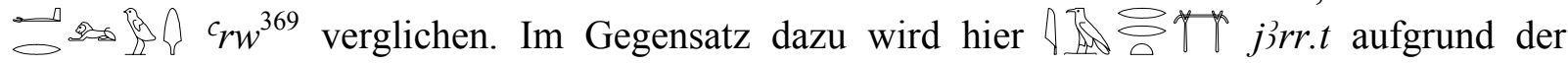
neuägyptischen Schreibung gelesen, welches seit dem Alten Reich als "Weinstock", "Weintraube" oder "Weinbeere" belegt ist. ${ }^{370}$

Der Gebrauch einer Weintraube als Vehikel läßt sich folgendermaßen erklären:

- wegen einer ähnlichen äußeren Form zwischen dem Herzen und der Weintraube(?),

- wegen eines tieferen Inhalts des Begriffes 'Weintraube' als 'Frucht',

- wegen der Nichtexistenz eines Wortes für den Begriff 'Zapfen'. ${ }^{371}$ Man kann vermuten, daß der ägyptische Schreiber durch ein Gedankenspiel das Wort 'Weintraube' für 'Zapfen' verwendet. Diese Behauptung läßt sich aufgrund der Ähnlichkeit zwischen der Form einer Weintraube und einem geöffneten Zapfen erklären.

Angenommen, daß das Herz ähnlich wie die genannte Frucht aussieht, so handelt es hier nicht um eine Metapher, sondern um einen Vergleich. ${ }^{372}$ Die Ähnlichkeit besteht nicht nur aus der gewöhnlichen Form beider Objekte, sondern möglicherweise aus dem Zustand eines Herzens,

364 Siehe $L \ddot{A}$ IV, Sp. 697-704.

365 Wb I 32,4, "Pflanze oder eine Pflanzenteil".

366 Zur Interpretation dieses Wortes als Metapher siehe Grapow (1924: 103-105).

367 Wb I 32,5 "Binsen"?, "Sumpfgras"?.

368 Wb I I 208,5-7 "Binse" und Wb I 208,13 "Kerne (einer Frucht)"?.

369 Wb I 210,9-11. Die Diskussion über diese Wort siehe Charpentier (1981: 255 und 258); Germer (1985: 201); Keimer (1984: 74, 6).

$370 \mathrm{~Wb}$ I 32,12-13.

371 Germer (1985: 9).

372 "Gemeinsamkeit einer Eigenschaft zwischen mehreren (mindesten zwei) Dingen", vgl. Lausberg (1976: §400406). 
welches seit vier Jahre tot ist und sicherlich trocken und braun aussah. Die Vorstellung von einem solchen Herzen läßt sich mit einem Zapfen, einer braunen und festen Furcht, in Verbindung bringen.

Es ist wichtig, zu bemerken, daß die Erfrischung des Herzens im Wasser den Bruder ins Leben zurückbringt. Da eine Frucht durch das Wasser erfrischt wird, ergäbe sich für das Herz als Frucht seine Wiederbelebung durch das Wasser $(=$ Nun). Allerdings wurde oben erklärt, daß das Wasser in Zusammenhang mit dem Gott Osiris und dem Totenkult assoziiert wird. Deswegen spielt das Wasser in diesem Fall eine andere Rolle als die Erfrischung einer Pflanze.

\subsection{Andere Gebrauchsweisen des Begriffs 'Herz'}

Der Begriff 'Herz' wird wie in den Weisheitstexten auch in den Erzählungen verwendet, um das Konzept 'Willen' auszudrücken. Die Beispiele aus der Erzählung des Sinuhe (E-31: hr.t jb 'Herzenswunsch'), der Erzählung des Wenamun (E-81: $j: j r n$ - hỉ $t j=j$ 'tue nach meinem Wunsch') oder der Erzählung von Horus und Seth (E-76: $h r j b=j r$ - $d j . t$ 'mein Wille will geben') stehen stellvertretend für weitere Textpassagen, in denen das Herz mit einem metonymischen Gebrauch oder mit dem Sinn 'Wille' benutzt wird. Es findet sich häufig der Ausdruck 'das Herz will etwas machen' (E-31; E-76), wobei ein Wunsch impliziert ist. Der Ausdruck 'was im Herzen ist' läßt sich in den Beispielen E-54 (j.šm j.wn p3 $m h r m t w=k j n-n=k$ j -nty $m-j b=k$ 'Geh und öffne den Speicher und hole dir, was dein Herz begehrt') und E-8 (dd.jn Nmtj-nht pn m3j=f(3.w n(j)- shtj pn c $3 b . y w h r-j b=f$ 'dann sagte Nemti-nacht als er die Esel sah, die begehrenswert auf seinem Herzen waren') als ein Begriff für 'Wunsch' interpretieren. In der Erzählung des Bauern kommt der Ausdruck 'auf das Herz nicht hören' (E-22: $m s \underline{d} m m$ - jb) vor. Lichtheim übersetzt desire (1975: 181), während andere Bearbeitungen keine Übersetzung dieser Passage anbieten. Meiner Meinung nach sollte man das Wort 'Herz' im Sinne Lichtheims interpretieren und übersetzen, da das Herz in dieser Art von Texten häufig einen positiven Sinn enthält. In diesem Beispiel kommt das Wort 'Herz' in Zusammenhang mit dem Verb 'parteiisch sein' vor, wobei das Herz nicht als guter Ratgeber handelt und man deshalb nicht auf es hören solle. Deswegen wird hier vorgeschlagen, das 'Herz' entweder als 'Wunsch" entsprechend Lichtheims Übersetzung oder als 'Absicht' widerzugeben. Angenommen, daß eine Person, die parteiisch ist, eine subjektive Absicht hat, so wäre es passend den Ausdruck in diesem Sinn zu interpretieren.

In den Beispielen E-38 und E-15 kommt der Ausdruck w3h -jb vor. Die Bedeutung dieser Wendung kann als zweifellos gute Eigenschaft interpretiert werden. ${ }^{373}$ Nicht nur 'geduldig', son-

373 Wb I 256,18. 
dern auch 'wohlgesinnt', 'freundlich', 'wohlwollend' lauten die unterschiedlichen Bedeutungsvorschläge für dieses Wort. Im Fall des Sinuhe läßt es sich als eine wohlwollende Absicht des Königs interpretieren (E-38: $n f r$ w3h-jb $n h m^{c} w j m^{-}{ }^{c}-m t$ 'so gut also ist die Milde ('Herz-Legung'), dessen, der mich vor dem Tod errettet'). Lichtheim übersetzt es als attentive und fügt hinzu, daß die Verwendung dieses Ausdruckes seit der 11. Dynastie mit dieser Bedeutung besser paßt als die bis dahin gebrauchte Bedeutung 'Geduld' oder 'geduldig', was sie durch den Hinweis auf verschiedene Exempel belegt (1997: 78-81). Die Interpretation des Begriffs als 'Aufmerksamkeit' leitet sie von der Grundbedeutung des Wortes 'wohlwollend' im Zusammenhang mit der oben genannten guten Absicht der Person ab. Im Fall des Bauern bemerkt sie richtig, daß mit der positiven Eigenschaft an dieser Stelle die Geduld gemeint ist, durch die die Maat erkannt werden kann

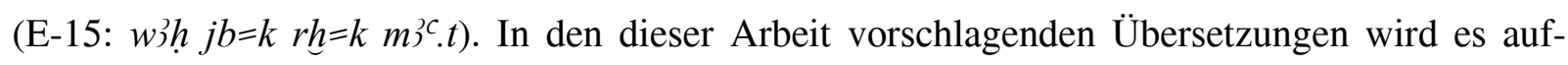
grund des Vergleichs mit den anderen Beispielen aus den Lehren als 'Zurückhaltung' wiedergegeben. ${ }^{374}$

Im Beispiel E-26 'erhob' (țs) Sinuhe sein Herz. Die Interpretation dieses Ausdrucks läßt sich nur durch den Kontext und die Beschreibung des Zustands Sinuhe deuten. Das Herz befindet sich am Rande des Todes, was die Hoffnungslosigkeit des Protagonisten ausdrückt. Als Sinuhe allerdings Angst bekommen hat, reagiert er darauf und erholt sich seelisch $(\underline{t z} . t=j j b=j$ 'ich richte mein Herz auf') und körperlich ( $s^{3} q=j h^{c} \cdot w=j$ 'ich riß meine Glieder zusammen'), damit er den Mut wieder erlangte, um die unerwartete Situation ertragen zu können. Diese plötzliche Besserung ist nicht nur auf den Körper fokussiert, sondern auch auf die Seele des Sinuhe. Dieses 'Erheben' des Herzens läßt sich als Reaktion auf einen ängstlichen Zustand interpretieren, welcher von ihm überstanden werden soll. In Kapitel 4 wurde zu der Angst festgestellt, daß dieses Gefühl auch als 'Feind' angesehen werden konnte. Die Person soll gegen diesen metaphorischen Feind kämpfen und ihn überwinden, damit sie die Situation beherrschen kann. Dies ist genau das, was Sinuhe tut. Dafür muß man aber auch klar denken und vernünftig handeln können, wobei der Verstand auch das Mittel ist, um die erforderliche Ermutigung finden zu können. ${ }^{375}$

Ein weiterer interessanter Ausdruck ist die Kollokation 'das Herz ist nicht im Leib', der zuvor kommentiert wurde, als das Wort 'Herz' als Ausdruck für 'Verstand' betrachtet wurde. Hier wird nun die These aufgestellt, daß der Körper in diesem Ausdruck als geschlossener Raum zu interpretieren ist. In Verbindung mit den Emotionen wird der Körper als ein Behälter gesehen, in dem

374 Siehe W-34, W-37, W-43, W-55, W-79, W-83, W-112, W-115.

375 Für die Übersetzung war es aber doch problematisch, diesen Hintergrund auszudrücken. Eine wörtliche Übersetzung ist 'das Herz erhoben'; eine sehr freie Übersetzung wäre 'sich erholen', in der sowohl der seelische als auch der rationale Sinn impliziert sind. Eine mittelmäßig freie Übersetzung und auch für die hier vorgestellte Problematik mögliche Option ist diejenige, die im Beispiel E-26 vorgeschlagen wurde, nämlich das Herz als 'Verstand' wiederzugeben. 
sich die Gefühle befinden und auf unterschiedliche Weise hervorgerufen werden (z.B. als Flüssigkeit im Fall der Wut). Für die Ägypter dient der Körper als Behälter des Verstandes. Das Konzept vom Körper als Innenseite - Außenseite wäre als eine universale Bildmetapher zu definieren, wenn in all diesen Fällen das Herz in Verbindung mit den Emotionen gebracht werden könnte. Das ist aber nicht der Fall, da das Herz, obwohl es sich in einem Raum befindet, d.h. im Leib, nicht mit Emotionen, sondern mit dem Verstand zu identifizieren ist.

Bemerkenswert ist der Ausdruck "das Herz waschen", welcher als 'erfreuen'1376 oder als 'den Mut (an den Feinden) kühlen' ${ }^{\prime 37}$ wiedergegeben wird. Die Beispiele E-33 (jw mjn $j b=f j^{c}$ 'Heute fühlte er sich erleichtert') und E-15 ( $j^{c} j b=f^{\prime}$ 'der sich entspannt') enthalten diesen Ausdruck, welcher meiner Meinung nach kein Gefühl, sondern einen Zustand beschreibt. In einem solchen Zustand beruhigt sich die Person durch die Befriedigung eines Wunsches (der Jäger beim Jagen) oder durch eine Handlung, die auf eine andere Person gerichtet ist (der Gott zu Sinuhe). ${ }^{378}$ Das läßt sich im Grunde genommen mit der Hauptbedeutung des Wortes "waschen" in Verbindung bringen. Etwas 'Gewaschenes' ist etwas, was gereinigt und erfrischt ist, womit ein positiver Zustand impliziert ist. Man kann den Sinn extrapolieren, um ihm auch in Beispiel E-33 anzuwenden. Der Gott wird freundlich zu Sinuhe, wobei davon auszugehen ist, daß der Gott früher ein eher negatives Gefühl gegenüber Sinuhe empfand. Im Kapitel über die Emotionen wurde beschrieben, wie sich das Gefühl 'Wut' oder 'böse sein' mit dem Konzept der Wärme in Verbindung bringen läßt. Um dieses Gefühl zu überwinden bedarf es einer Erfrischung, welche das Herz des Gottes dadurch erfährt, daß es 'gewaschen wird'. Ebenfalls beruhigt wird das Herz im Beispiel E15 , da sein Wunsch erfüllt wird.

\subsection{Ein Vorschlag zur Klassifikation}

Im Folgenden werden die Ausdrücke mit dem Begriff 'Herz' gemäß ihres Sinns, ihrer Bedeutung oder ihrer grammatikalischen Funktion in Gruppen geordnet.

$376 \mathrm{~Wb}$ I 39,9-10.

377 Wb I 39,11 .

378 In den Beispielen W-9 und W-10 aus der Lehre des Ptahhotep ist die Bedeutung 'sich beruhigen' treffender. 
GRUPPE 1

Das Herz als Subjekt (handelt als Person)

\begin{tabular}{||l|l||}
\hline \hline das Herz vergißt & E-14 \\
\hline das Herz wurde matt & E-27 \\
\hline Angst haben $\left({ }^{\circ}\right.$ das Herz $^{\circ}$ brennt $\left.^{\circ}\right)$ & E-32* \\
\hline das Herz verweilt & E-34 \\
\hline das Herz leidet & E-34 \\
\hline das Herz führt & E-38 \\
\hline das Herz leitet & E-40 \\
\hline das Herz will $($ jdn $)$ kennenlernen & E-56 \\
\hline das Herz fällt zu Boden & E-58* \\
\hline das Herz wünscht sich etwas & E-64* \\
\hline das Herz nimmt Wasser auf & E-64* \\
\hline das Herz geht dahin, dafür zu sorgen & E-76 \\
\hline das Herz denkt an eine Angelegenheit & E-82* \\
\hline
\end{tabular}

\section{GRUPPE 2}

Das Herz als Objekt

\begin{tabular}{||l|l||}
\hline \hline das Herz erkennen & E-21 \\
\hline das Herz erheben (sich erholen) & E-26 \\
\hline das Herz erfreuen & E-36 \\
\hline das Herz auf einer Weise haben & E-47 \\
\hline das Herz nicht fliehen lassen & E-48 \\
\hline $\begin{array}{l}\text { die Motivation nicht nachlassen }\left({ }^{\circ} \text { das Herz nicht }\right. \\
\left.\text { überdrüssig sein lassen }{ }^{\circ}\right)\end{array}$ & E-58* \\
\hline das Herz auf die Blüte der Pinien legen & E-58*; E-59*; E-61*; E-63* \\
\hline die Gedanken enthüllen $\left(^{\circ}\right.$ das Herz jdm. öffnen $\left.{ }^{\circ}\right)$ & E-61* \\
\hline das Herz finden & E-61* \\
\hline das Herz suchen & E-64* \\
\hline das Herz in eine Schale kühles Wassers legen & E-64* \\
\hline das Herz Wasser trinken lassen & E-64* \\
\hline das Herz holen & E-78* \\
\hline \hline
\end{tabular}

GRUPPE 3

Das Herz für den Ausdruck des Charakters

\begin{tabular}{||l|l||}
\hline die Herzen sind kühner als die von Löwen & E-3 \\
\hline das Herz ist kühner & E-5 \\
\hline das Herz ist mutig & E-6 \\
\hline gieriges Herz; das Herz ist gierig; das Herz ist habgierig & E-10; E-11; E-13; E-19; E-20; E-23 \\
\hline Zurückhaltung/Milde $\left({ }^{\circ}\right.$ Herz-Legung $\left.{ }^{\circ}\right)$ & E-15; E-38 \\
\hline das Herzen streitet & E-18 \\
\hline unbeugsamer Mut) $\left({ }^{\circ}\right.$ stehendes Herz $\left.{ }^{\circ}\right)$ & E-28 \\
\hline unerschütterliche Kaltblütigkeit $\left({ }^{\circ}\right.$ dickes Herz $\left.{ }^{\circ}\right)$ & E-28 \\
\hline Feindseligkeit & E-30 \\
\hline $\begin{array}{l}\text { die Motivation nicht nachlassen }\left({ }^{\circ} \text { das Herz nicht }\right. \\
\left.\text { überdrüssig sein lassen }{ }^{\circ}\right)\end{array}$ & E-58* \\
\hline \hline
\end{tabular}




\begin{tabular}{|l|l||}
\hline das Herz ist groß an Kraft & E-73 \\
\hline \hline
\end{tabular}

GRUPPE 4

Das Herz als Verstand

\begin{tabular}{||l|l||}
\hline \hline mit dem Herzen zu jdm sprechen & E-2 \\
\hline das Herz vergißt & E-14 \\
\hline die Gedanken erkennen & E-21 \\
\hline das Herz ist nicht im Leib & E-27*; E-41* \\
\hline das Herz führt & E-38 \\
\hline unüberlegt $\left({ }^{\circ}\right.$ die Flucht nicht im Herzen haben $\left.^{\circ}\right)$ & E-39 \\
\hline die Gedanke enthüllen $\left({ }^{\circ}\right.$ das Herz jdm öffnen $\left.{ }^{\circ}\right)$ & E-61* \\
\hline das Herz denkt an eine Angelegenheit & E-82* \\
\hline
\end{tabular}

GRUPPE 5

Das Herz als Wunsch

\begin{tabular}{||l|l||}
\hline das Herz will kämpfen & E-31 \\
\hline Herzenswunsch & E-31 \\
\hline die Planung des Willens & E-37 \\
\hline das Herz ist gerichtet auf etwas & E-52 \\
\hline das Begehren ist gerichtet auf etwas & E-54 \\
\hline das Herz will jdn kennenlernen & E-56 \\
\hline das Herz wünscht sich etwas & E-64*; E-66 \\
\hline nach dem Willen handeln & E-69*; E-81* \\
\hline nach dem Willen rüsten & E-70 \\
\hline das Herz will für etwas sorgen & E-76 \\
\hline
\end{tabular}

\section{GRUPPE 6}

Das Herz als Absicht

\begin{tabular}{||l|l||}
\hline \hline eine Gedanke nicht absichtlich gegen jdn sein & E-37 \\
\hline unüberlegt $\left({ }^{\circ}\right.$ die Flucht nicht im Herzen sein $\left.^{\circ}\right)$ & E-39 \\
\hline seine Absicht & E-55 \\
\hline
\end{tabular}

\section{GRUPPE 7}

Das Herz als Seele

E-18

GRUPPE 8

das Herz als Stimmung

E-40; E-42; E-43; E-44; E-47;

E-62*; E-67; E-71; E-80

GRUPPE 9

das Herz als Meinung

E-2; E-7; E-8; E-12; E-29; E-51 
GRUPPE 10

Das Herz als Ort

\begin{tabular}{||l|l||}
\hline \hline Unrechtes im Herzen haben (nach der Meinung) & E-7 \\
\hline was im/auf dem Herzen ist & E-8; E-17; E-18; E-66; E-69 \\
\hline etwas ist leicht auf dem Herzen (nach der Meinung) & E-12 \\
\hline nutzbringend im Herzen sein (nach der Meinung) & E-29 \\
\hline die Flucht nicht im Herzen haben (unüberlegt) & E-39 \\
\hline was im Herzen (des Gottes) ist & E-69 \\
\hline
\end{tabular}

GRUPPE 11

Das Herz für den Ausdruck eines Zustandes

\begin{tabular}{||l|l||}
\hline das Herz ist wohlbehalten & E-1 \\
\hline allein mit dem Herzen sein (mutterseelenallein) & E-4 \\
\hline das Herz ist beladen & E-18 \\
\hline die Herzen sind in Betrübnis & E-24 \\
\hline das Herz ist verwirrt & E-25 \\
\hline das Herz wurde matt & E-27; E-67 \\
\hline Ruhe geben $\left({ }^{\circ}\right.$ das Herz wird müde $\left.{ }^{\circ}\right)$ & E-68* \\
\hline das Herz ist müde & E-35 \\
\hline das Herz wurde schön $($ glücklich) & E-46 \\
\hline $\begin{array}{l}\text { die Motivation nicht nachlassen }\left({ }^{\circ} \text { das Herz nicht }\right. \\
\left.\text { überdrüssig sein lassen }{ }^{\circ}\right)\end{array}$ & E-58* \\
\hline das Herz war verdrießlich & E-62* \\
\hline \hline
\end{tabular}

GRUPPE 12

Das Herz und das Gefühl

\begin{tabular}{||l|l||}
\hline \hline etwas ist auf dem Herzen begehrenswert & E-8 \\
\hline die Herzen sind in Betrübnis & E-24 \\
\hline das Herz ist verwirrt & E-25 \\
\hline Angst haben $\left({ }^{\circ}\right.$ das Herz brennt $\left.{ }^{\circ}\right)$ & E-32* \\
\hline Mitleid mit jdm haben $\left({ }^{\circ}\right.$ das Herz war/wurde krank $\left.^{\circ}\right)$ & E-32; E-60*; E-65* \\
\hline das Herz hatte Mitleid $\left({ }^{\circ}\right.$ das Herz leidet $\left.{ }^{\circ}\right)$ & E-34 \\
\hline das Herz erfreuen, das Herz freut sich, das Herz ist froh & E-36; E-71; E-79; E-80 \\
\hline angenehm werden $\left({ }^{\circ}\right.$ das Herz erfrischt sich $\left.^{\circ}\right)$ & E-42 \\
\hline das Herz ist gehoben & E-43 \\
\hline niedergeschlagen sein $\left({ }^{\circ}\right.$ das Herz war/wurde schlecht $\left.{ }^{\circ}\right)$ & E-44; E-45; E-47; E-67; E-74; E-75 \\
\hline das Herz ist froh $/$ zufrieden $^{*}$ E-45 \\
\hline das Herz wurde schön $($ glücklich) & E-46 \\
\hline das Herz hat Angst vor etwas & E-49 \\
\hline sich entspannen $\left({ }^{\circ}\right.$ das Herz war sü $\left.{ }^{\circ}\right)$ & E-53 \\
\hline am Herzen leiden & E-57*; E-77* \\
\hline das Herz war verdrießlich & E-62* \\
\hline sich entspannen $\left({ }^{\circ}\right.$ das Herz angenehmen für jdn machen $\left.{ }^{\circ}\right)$ & E-72 \\
\hline \hline
\end{tabular}


GRUPPE 13

Die Metapher des Herzens

\begin{tabular}{|l|l||}
\hline die Herzen sind kühner als die von Löwen & E-3 \\
\hline das Herz ist eine Weintraube & E-64* \\
\hline
\end{tabular}

GRUPPE 14

Sonstiges

\begin{tabular}{||l|l||}
\hline \hline das Herz als Genosse & E-4 \\
\hline Gefolgsleute des Herzens & E-9 \\
\hline sich entspannen $\left({ }^{\circ}\right.$ das Herz waschen $\left.{ }^{\circ}\right)$ & E-15; E-33 \\
\hline das Herz ist leicht & E-15 \\
\hline Zurückhaltung/Milde $\left({ }^{\circ}\right.$ Herz-Legung $\left.^{\circ}\right)$ & E-15; E-38 \\
\hline vertrauen $\left({ }^{\circ}\right.$ erfüllen das Herz $\left.{ }^{\circ}\right)$ & E-16 \\
\hline unbeugsamer Mut $\left({ }^{\circ}\right.$ stehendes Herz $\left.{ }^{\circ}\right)$ & E-28 \\
\hline unerschütterliche Kaltblütigkeit $\left({ }^{\circ}\right.$ dickes Herz $\left.{ }^{\circ}\right)$ & E-28 \\
\hline Mitleid mit jdm haben $\left({ }^{\circ}\right.$ das Herz war/wurde krank $\left.^{\circ}\right)$ & E-32; E-60* \\
\hline niedergeschlagen sein $\left({ }^{\circ}\right.$ das Herz war/wurde schlecht $\left.{ }^{\circ}\right)$ & E-44; E-47; E-67; E-74; E-75 \\
\hline Motivation & E-58* \\
\hline \hline
\end{tabular}




\subsection{Textbeispiele}

\section{Die Erzählung des Schiffbrüchigen (Blackman 1972)}

Quellen:

Datierung:

Textausgaben:

Übersetzungen:
pSt. Petersburg $1115=$ pGolenishchev

XII. Dynastie ${ }^{379}$

Golenishchev (1912), ib. (1916: Pl. 1-8), de Buck (1948: 100-106), Blackman (1972: 41-48).

Erman (1923: 56-63), Brunner-Traut (1963: 5-10), Simpson (1972: 50-56), Lichtheim (1975: I, 211-215), Parkinson (1997: 89-101), Galán (1998: 35-39), Burkard \& Thissen (2003: 141-148).

\section{E-1 $\quad 1-2$ \\ Bd \\ $w d{ }^{3} \quad j b=k \quad h 3 . t j-c=j$ \\ FUT. $\quad$ SBST.-2sm SBST.-1sc}

Sei wohlgemut, Fürst. ( ${ }^{\circ}$ Möge dein Herz wohlbehalten sein $\left.^{\circ}\right)^{380}$

$$
\begin{aligned}
& \text { E-2 } \quad 12-21
\end{aligned}
$$

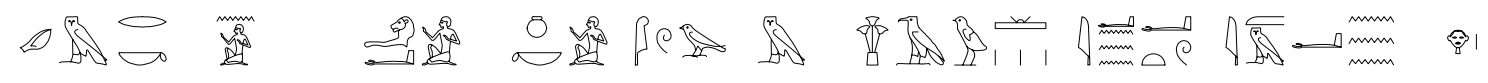

$$
\begin{aligned}
& s \underline{d} m \quad r k \quad-n=j \quad h h_{j} . t j-{ }^{c}=j j n k \quad \check{s} w \quad[m-] \quad h 3 . w \quad j^{c} \quad \text { twjmj } \quad m w \quad h r- \\
& \text { IMPV. PTCL. PRÄP.-1sc SBST.-1sc 1sc NPA. PRÄP. SBST.-PL. IMPV. 2smIMPV. SBST. PRÄP. }
\end{aligned}
$$

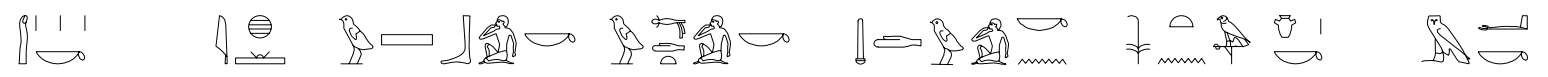

$$
\begin{aligned}
& \underline{d} b^{c} \cdot w=k \quad j h \quad w s ̌ b=k \quad w \check{s} d . t(w)=k \quad m d w=k \quad n-\quad n s w \quad j b=k \quad-m_{-}{ }^{c}=k \\
& \text { SBST.-PL.-2sm PTCL. FUT.-2sm PRÄS.-PASS.-2sm FUT.-2sm PRÄP. SBST. SBST.-2sm PRÄP.-2sm }
\end{aligned}
$$

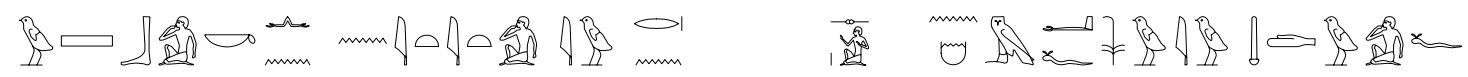

$$
\begin{aligned}
& w s ̌ b=k \quad n n \text { njtj.t } \quad j w \quad r^{\prime} \quad n(j)-z(j) \quad n h m=f \quad s w \quad j w \quad m d w=f \\
& \begin{array}{llll}
\text { FUT.-2sm NEG. VB.-INF. } & \text { TOP. SBST. DET. SBST. FUT.-3sm } 3 \mathrm{sm} \text { TOP. SBST.-3sm }
\end{array}
\end{aligned}
$$

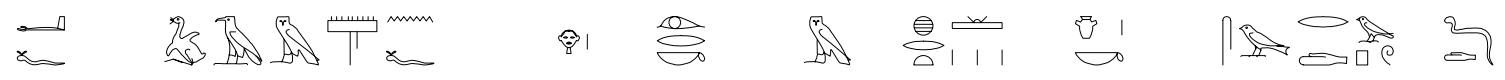

$$
\begin{aligned}
& \underline{d j}=f \quad \underline{t} 3 m \quad-n=f \quad h r-\quad j r=k \quad m-\quad h r . t \quad j b=k \quad s w r \underline{d} \quad p w \quad \underline{d d} \\
& \text { PRÄS.-3sm SUBJ. PRÄP.-3sm SBST. FUT.-2sm PRÄP. SBST.-FEM. SBST.-2sm INF. DEM. INF. }
\end{aligned}
$$

Höre mir zu, oh Fürst. Ich bin frei von Übertreibung. Wasche dich. Benetze deine Finger mit Wasser. Du sollst erst antworten, wenn du gefragt wirst. Mögest du mit Verstand zum König sprechen ${ }^{381}$ und Antworten, ohne zu stammeln. Der Mund eines Mannes ist es, der ihn rettet.

379 Galán (1998: 19); Parkinson (1997: 91); Quirke (1996: 387).

380 "Alégrate, capitán" (Galán 1998: 35); "Take heart, my lord" (Lichtheim 1975: 212).

381 Galán (1998: 35) übersetzt "con el corazón en la mano" mit dem Sinn ehrlich zu sein. Meiner Meinung nach ist diese Interpretation nicht ganz erfolgreich wegen des folgenden Satzes. "Antworten ohne zu 
Sein Gespräch, das veranlaßt, daß das Gesicht sich für ihn verhüllt. Mögest du gemäß deiner Meinung handeln. Es ist müde, zu dir zu sprechen. ( ${ }^{\circ}$ während dein Herz bei dir ist ${ }^{\circ} /{ }^{\circ}$ deines Herzens $^{\circ}$ )

E-3 29-30*

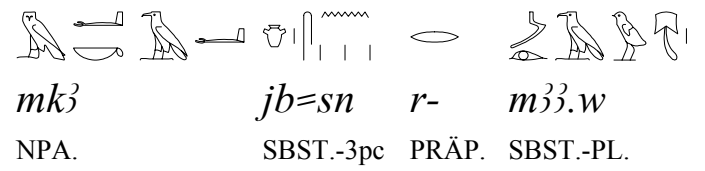

Sieh! Ihre Herzen waren kühner als die von Löwen.

* Gleich bei $96-97$

\section{E-4 39-42}

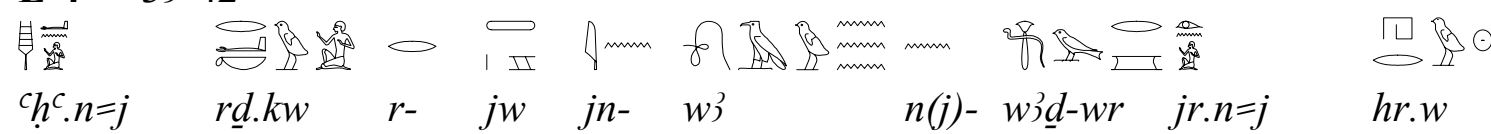

VB.-PRÄT.-1sc STAT.-1sc PRÄP. SBST. PRÄP. SBST. SEM. SBST. VB.-PRÄT.-1sc SBST.-PL.

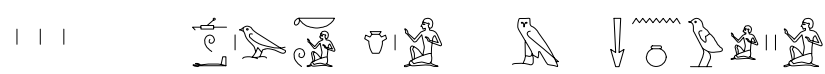

hm.t $\quad w^{c} . k w \quad j b=j \quad m-\quad s n . w y=j$

NUM.-FEM STAT.-1sc SBST.-1sc PRÄP. SBST.-du.-1sc

Dann wurde ich von einer Welle des Meeres auf eine Insel geworfen. Ich verbrachte drei Tage mutterseelenallein. ( ${ }^{\circ}$ ich war allein und mein Herz war mein Genossen ${ }^{\circ}$ )

E-5 99-100

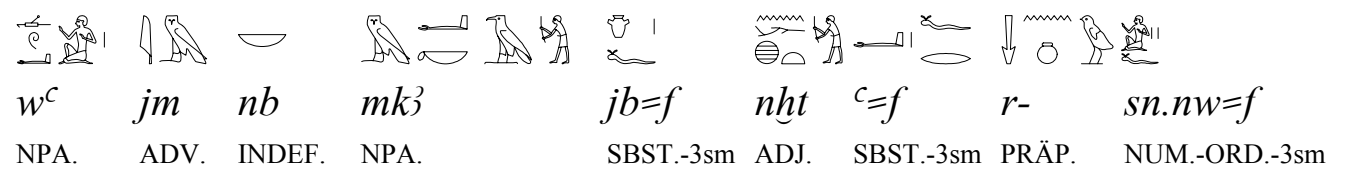

Einer davon hatte ein kühneres Herz und einen stärkeren Arm als der andere. $\left({ }^{\circ}\right.$ Ein jeder von denen, sein Herz war kühner und sein Arm stärker als die seiner Kameraden ${ }^{\circ}$ )

E-6 132-134

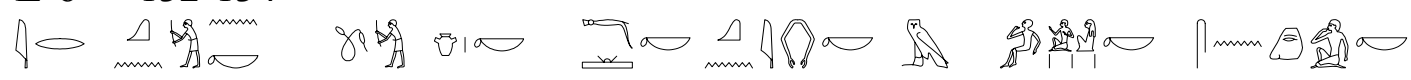

$$
\begin{aligned}
& \text { jr } q n . n=k \quad r w \underline{d} j b=k \quad m \underline{h}=k \quad q n j=k \quad m-\quad \underline{h r d} . w=k \quad s n=k \\
& \text { TOP. VB.-PRÄT.-2sm NPA. SBST.-2sm FUT.-2sm SBST.-2sm PRÄP. SBST.-PL.-2sm FUT.-2sm }
\end{aligned}
$$

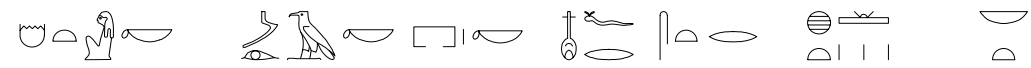

$$
\begin{aligned}
& \text { hm.t }=k \quad m 33=k \quad p r=k \quad \text { nfr } \quad \text { st } r \text { - (j)h.t nb.t } \\
& \text { SBST.-FEM.-2sm FUT.-2sm SBST.-2sm ADJ. 3sf PRÄP. SBST.-FEM. INDEF.-FEM. }
\end{aligned}
$$

stammeln" impliziert eine Kontrolle des Charakters bei einer Situation wie beispielsweise diese, die in dieser Passage beschrieben wird. "You must speak to the king with presence of mind" (Lichtheim 1975: 212). 
Wenn du stark bleibst und dein Herz mutig ist, dann wirst du deine Kinder in die Arme schließen können, deine Frau küssen und dein Haus (wieder)sehen. ${ }^{382}$ Das ist schöner als alles andere.

\section{E-7 149

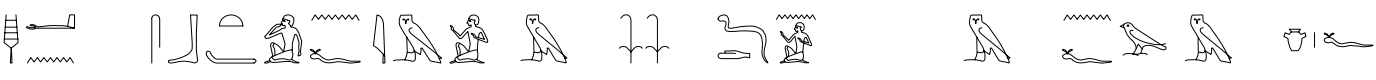 \\ ${ }^{c} h^{c} . n \quad$ sbt.n. $=f \quad-j m=j \quad m-\quad n n \quad \underline{d} d . n=j \quad m-\quad n f \quad m-\quad j b=f$}

VB.-PRÄT. VB.-PRÄT.-3sm PRÄP.-1sc PRÄP. DEM. RLTVF.-PRÄT.-1sc PRÄP. SBST. PRÄP. SBST.-3sm

Dann lachte er mit mir über das, was ich erzählte und was nach seiner Meinung Unrechtes war. $\left({ }^{\circ}\right.$ in seinem Herzen ${ }^{\circ}$ )

382 "If you are brave and control your heart, you shall embrace your children,, you shall kiss your wife, you shall see your home" (Lichtheim 1975: 213); "If you are brave, master your heart, and you will fill your embrace with your children, kiss your wife, and see your house!" (Parkinson 1997: 95); "Si tú eres valiente, tienes coraje y confianza, te abrazarás con tus hijos, besarás a tu mujer, verás tu casa" (Galán 1998: 38). 


\section{Die Klagen des Bauern (Parkinson 1991)}

Quellen:

Datierung:

Textausgaben:

Übersetzungen:
pBerlin 3023, pBerlin 3025, pBerlin 10499, pButler 527 = pBM 10274

Mittleres Reich ${ }^{383}$

Vogelsang-Gardiner (1908), Vogelsang (1932), Blackman (1972: 48), Parkinson (1991).

Gardiner (1923: 5-25), Erman (1923: 157-175), von Bissing (1955: 155-170), Wilson (1969: 407-410), Lichtheim (1975: I, 169-184), Parkinson (1997: 54-88), Burkard \& Thissen (2003: 157-163).

E-8 B1 20-22

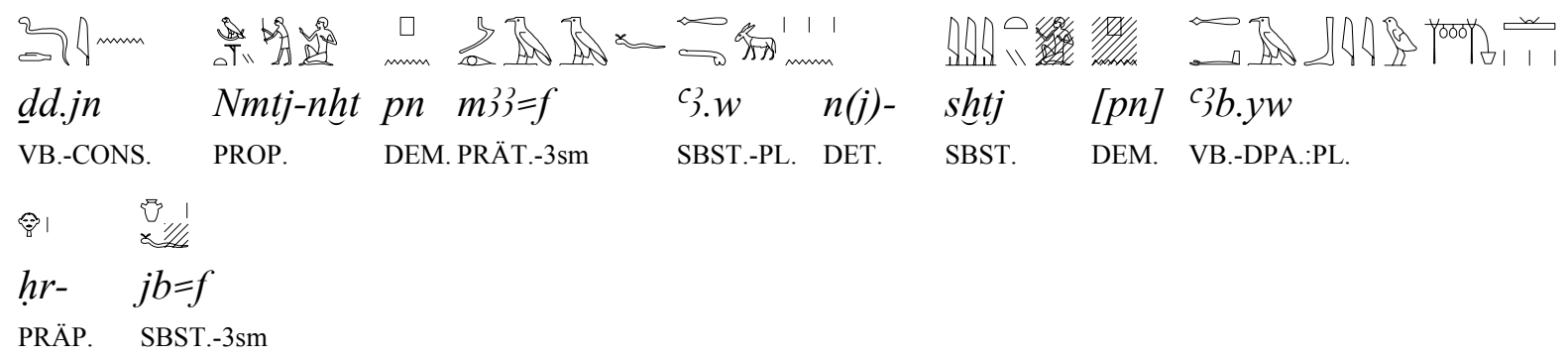

Dann sagte dieser Nemtj-nacht, als er die Esel dieses Bauern sah, die seiner Meinung nach begehrenswert waren. ( ${ }^{\circ}$ auf seinem Herzen ${ }^{\circ}$ )

\section{E-9 B1 67-71}

\begin{tabular}{|c|c|c|c|c|c|c|c|c|c|}
\hline $218 \mathrm{~mm}$ & Alin: & $\square$ & 陪及 & & 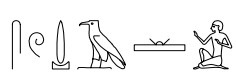 & 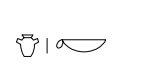 & & & $\theta$ \\
\hline dd.jn & shtj & $p n$ & $h 3-$ & $r \underline{d} . t(w)$ & $s . w \underline{d})=j$ & $j b=k$ & $h r-$ & $p^{3-}$ & hn \\
\hline VB.-CONS. & SBST. & DEM. & PRTCL. & VB.-PASS. & KAUS.-SUBJ.-1sc & SBST.-2sm & PRÄP. & DEM. & SBST. \\
\hline
\end{tabular}

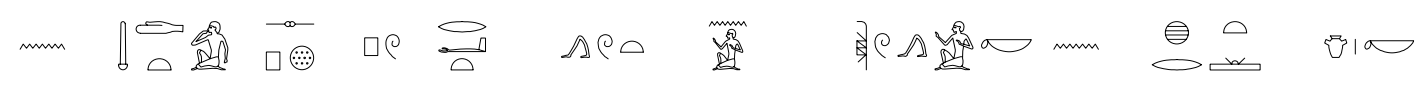
$n(j)-m d w . t \quad z p \quad p w r \underline{d . t} \quad j w . t \quad-n=j \quad \check{s} m s=k \quad n(j)-\underline{h r} . t \quad j b=k$ DET. SBST.-FEM.SBST. DEM. VB.-INF. SUBJ.-INF. PRÄP.-1sc SBST.-2sm DET. SBST.-FEM. SBST.-2sm

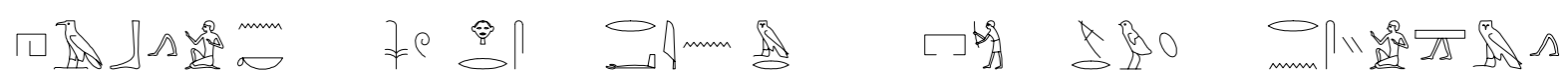
$h i b=j \quad-n=k \quad s w \quad-h r=s \quad r d j . n \quad j m j-r^{\prime} \quad p r-w r \quad M r w s 3 \quad R n s y \quad \check{s} m$ FUT.-1sc PRÄP.-2sc 3 ssm PRÄP.-3sf VB.-PRÄT. NISB.-SBST. SBST.-NPA.PROP. SBST. PROP. SUBJ.

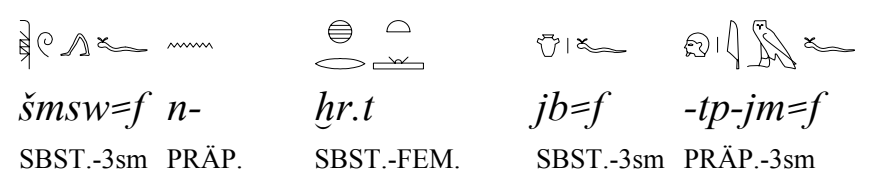

Da sprach dieser Bauer: "Es sei gestattet, daß ich dich wegen dieser Quisquilie belästige. ${ }^{384}$ Es handelt sich darum, zu verlassen, daß einer deiner Gefolgsleute nach deinem

383 Quirke (1996: 387); Blumenthal (1996: 131); Berlev (1987: 78-83).

384 Dies, der deutschen Idiomatik und den Höflichkeitsfloskeln entsprechend, ist eine freie Wiedergabe dessen, was im Ägyptische so ausgedrückt wurde, als sagte man statt "Darf ich Sie belästigen mit ...?", "Darf ich Ihre Laune heben mit ...?". 
Wunsch zu mir kommt, und ich ihn dir deswegen zurück sende". ${ }^{385}$ Da ließ der Obergüterverwalter Rensy, Sohn des Meru einen seiner Gefolgsleute nach seinem Wunsch direkt $\mathrm{zu}$ ihm gehen. ( ${ }^{\circ}$ Möge man gestatten, daß ich dein Herz wegen dieser Sache einer Angelegenheit erfreue ${ }^{\circ} /{ }^{\circ}$ deines Herzens ${ }^{\circ} /{ }^{\circ}$ seines Herzens ${ }^{\circ}$ )

\section{E-10 B1 96-97}

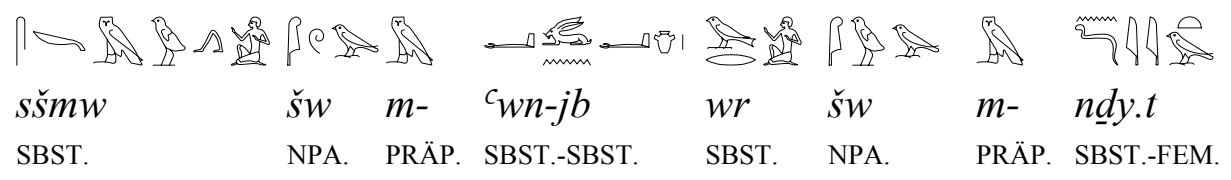

Führer, ohne Gier, o Großer, ohne Geiz. $\left({ }^{\circ}\right.$ der frei von Gier des Herzens ist $\left.{ }^{\circ}\right)$

E-11 B1 147-148

$$
\begin{aligned}
& \text { Wa } \\
& m k \quad t w \text { nht. }(t) j \quad \text { wsr.tj }{ }^{c}=k \quad \text { pr } \quad j b=k \quad c_{w n} \quad z f n \quad \text { sw? }
\end{aligned}
$$

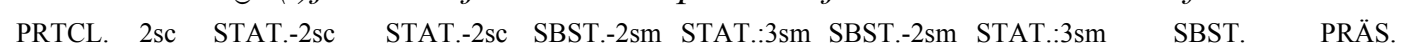

$$
\begin{aligned}
& \overbrace{-h r=k}^{\circ} \sigma
\end{aligned}
$$

Siehe! Du bist stark und mächtig. Dein Arm holt aus und dein Herz ist gierig, und die Milde geht an dir vorbei.

\section{E-12 B1 164-165}

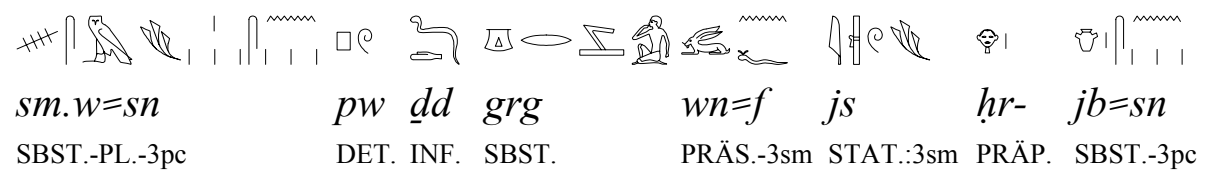

Ihr Futter ist das Lügen, leicht ist es nach ihrer Meinung. ( ${ }^{\circ}$ auf ihren Herzen ${ }^{\circ}$ )

E-13 B1 196-201

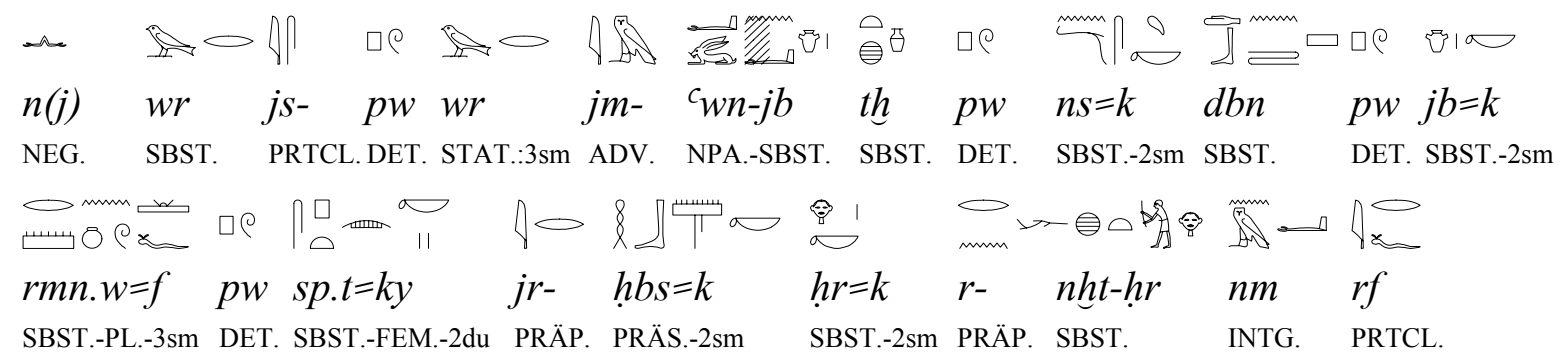

385 "This peasant said: 'May I be allowed to acquaint you with this complaint? Might a servant of your choice be sent to me, through whom I could inform you of it?" (Lichtheim 1975: 171); "An this peasant said: 'Might I acquaint you with this complaint! There is a reason to send one of your choice followers to me, about with I shall send him back to you" (Parkinson 1997: 60). 


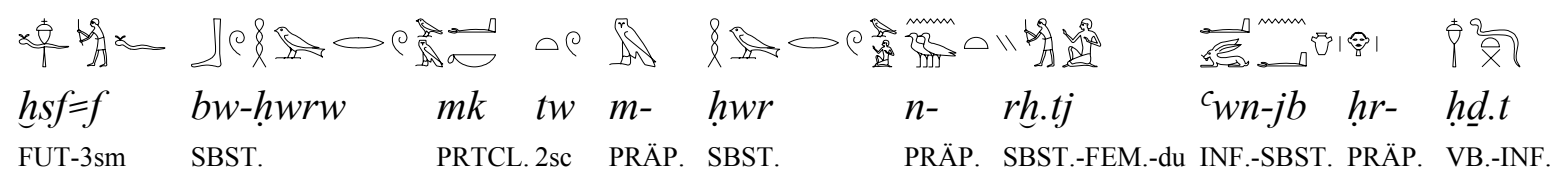

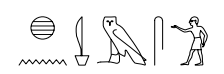

hnms

SBST.

Ein Großer, der habgierig ist, ist nicht wirklich groß. Deine Zunge ist das Lot, dein Herz ist das Gewicht, deine Lippen sind ihre Balken. Wenn du dein Gesicht vor dem Starken verhüllst, wer wird dann das Elend abwehren?

Sieh! Du bist ein Elender für den Wäscher. Gierigkeit zerstört die Freundschaft. $\left({ }^{\circ}\right.$ dessen Herz habgierig ist ${ }^{\circ} /{ }^{\circ}$ Gier des Herzens ${ }^{\circ}$ )

E-14 B1 218-220

\begin{tabular}{|c|c|c|c|c|c|c|c|c|}
\hline $\begin{array}{l}28 \mathrm{~mm} \\
\underline{d} d . j n\end{array}$ & 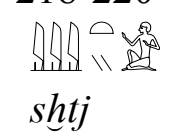 & $\operatorname{man}_{p n} z^{\circ}$ & $\begin{array}{l}\sum_{M r w}{ }^{2} \\
M r w\end{array}$ & $\begin{array}{l}\text { tnm. } h r=f \\
\mathbb{A}\end{array}$ & $\theta x$ & $h r=f$ & $\begin{array}{l}\square \infty \\
\square p\end{array}$ & $\infty$ \\
\hline VB.CONS. & SBST. & DEM. SBST. & PROP. & VB.-DEB.-3sm & & SBST.-3sm & STAT.:3sm & PRÄP. \\
\hline & & & & $\stackrel{\square}{\sim} \mathbb{A}$ & (⿻) & & & \\
\hline & zhj & $r-$ & & th & $h r-$ & s.ḩjj.t & $-n=1$ & \\
\hline 2 & STAT & m PRÄP. & $3 \mathrm{sm}$ & PRÄS. & PRÄP. & KAUS.-VB. & 3.-NPP. PRÄP & P. $-3 \mathrm{sm}$ \\
\hline
\end{tabular}

Da sprach dieser Bauer: Der Sohn des Meru, er geht ständig in die Irre. Sein Gesicht ist blind gegen das, was er sieht, und taub gegen das, was er hört. Der Verstand vergißt, woran er sich erinnern sollte. $\left({ }^{\circ}\right.$ das Herz $\left.{ }^{\circ}\right)$

E-15 B1 236-244

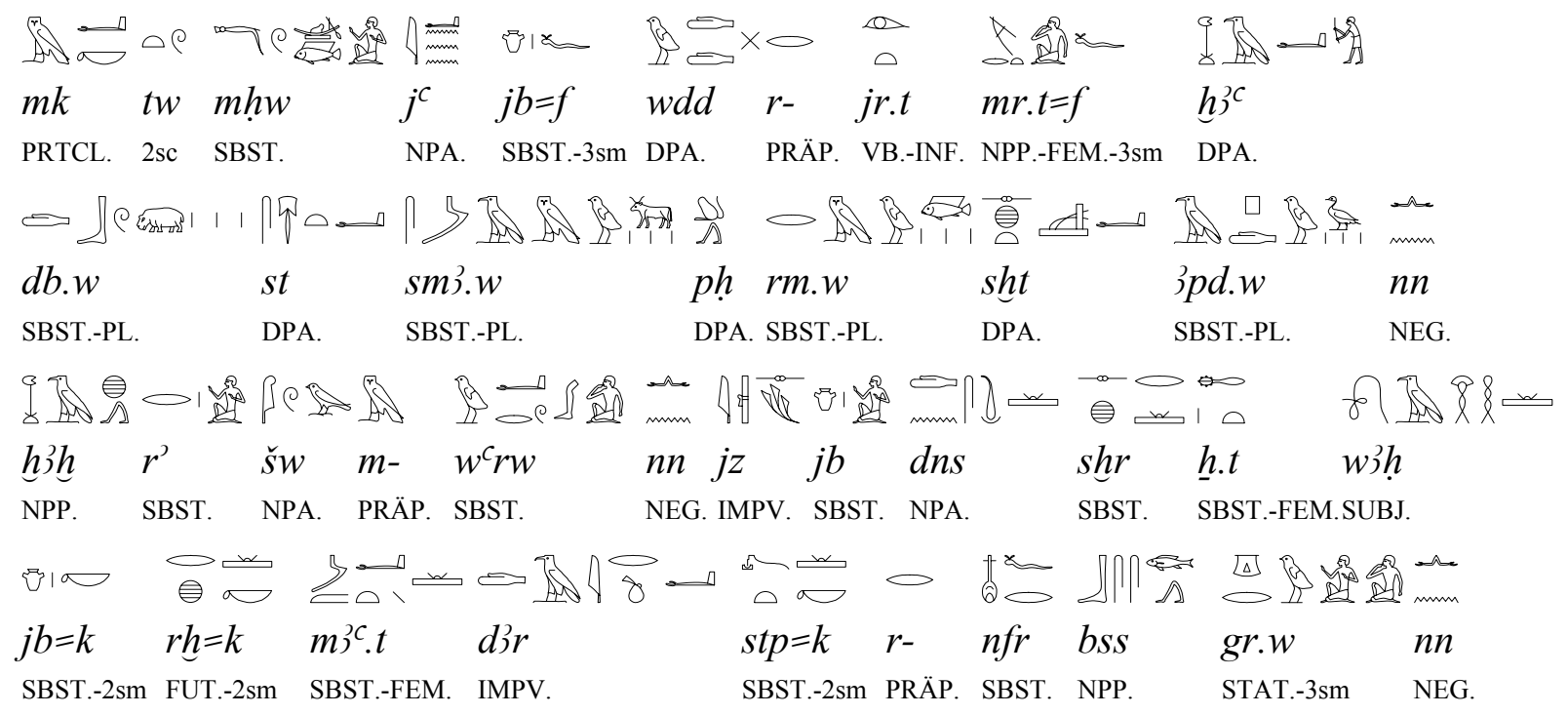




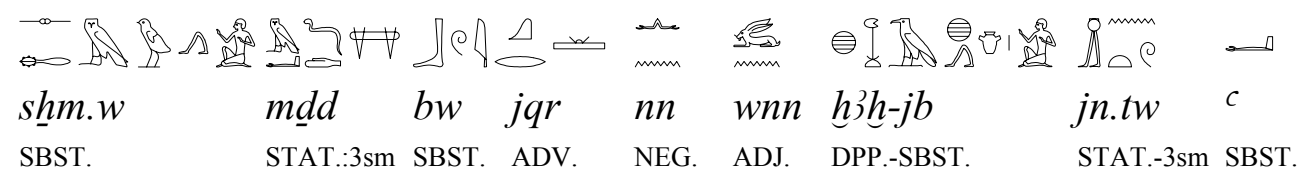

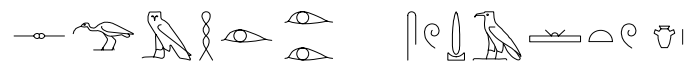

sgmh $\quad$ jr.tj s.wd 3 tw $j b$

FUT. $\quad$ SBST.-du KAUS.-FUT. 2sm SBST.

Siehe dich doch an, du Jäger, der sich entspannt, der (alles) daran setzt, das zu tun, was er will, der Nilpferde harpuniert, Wildstiere schießt, Fische erbeutet und Vögel fängt. ${ }^{386}$ Einer mit vorlautem Mund ist nicht frei von Hast. Einer mit leichtem Herzen hat keine schwere Körperkonstitution. Halte dich zurück, damit du die Maat erfährst. Bezwinge deine Wahl bis der Schweiger eintritt. Kein Schroffer befolgt das Gute/Vortreffliche, keiner, der impulsiv ist. Halte die Faust zurück, laß die Augen sehen, und halte den Verstand in Ordnung. $\left({ }^{\circ}\right.$ sein Herz wäscht ${ }^{\circ} /{ }^{\circ}$ dein Herz legen ${ }^{\circ}{ }^{\circ}$ schnell am Herzen ${ }^{\circ} /{ }^{\circ}$ das Herz ${ }^{\circ}$ )

\section{E-16 B1 266-268}

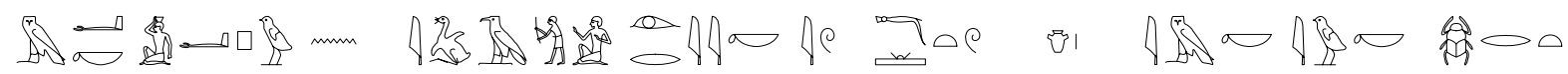

$$
\begin{aligned}
& m k \quad f 3 \quad p w n(j)-\underline{t} 3 \quad j r . y=k \quad j w \text { mh-tw jb -jm=k jw=k hpr.t } \\
& \text { PTCL. SBST. DET. DET. SBST. } \quad \text { VB.-FUT.-2smTOP. PRÄS.-indef SBST. PRÄP.-2sm TOP.-2sm VB.-INF. }
\end{aligned}
$$

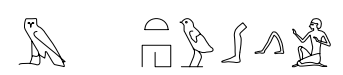

$$
\begin{aligned}
& \text { m- th.w } \\
& \text { PRÄP. VBB.-DPP. }
\end{aligned}
$$

Siehe, was du tust, du belädst den Räuber. Man vertraut dir, aber du wurdest zu einem Missetäter. ( ${ }^{\circ}$ das Herz erfüllen $\left.{ }^{\circ}\right)$

E-17 B1 286-287

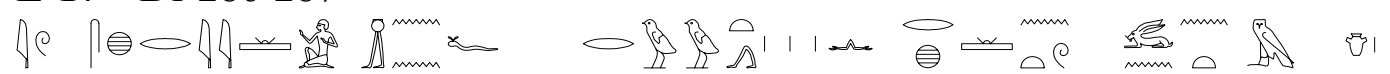

$$
\begin{aligned}
& j w \quad s h r y=j \quad j n \quad-n=f \quad \text { rww.t } \quad \text { n(j) rh.n.tw wnn.t } m-j b \\
& \text { TOP. SBST.-1sc NPA. PRÄP.-3sm SBST.-FEM. NEG. VB.-PRÄT.-indef VB.-DPP. PRÄP. SBST. }
\end{aligned}
$$

Mein Plan bringt ihm die Abreise. Man kann nicht wissen, was im Herzen ist.

386 "Lo, you are a hunter who takes his fill, bent on doing what he pleases; spearing hippopotami, shooting bulls, catching fish, snaring birds. (But) none quick to speak is free from haste, none light of heart is weighty in conduct. Be patient so as to lean justice, restrain your [anger] for the good of the humble seeker. No hasty man attains excellence, no impatient man is leaned upon. Let the eyes see, let the heart take notice" (Lichtheim 1975: 177); "Look, you are a hunter who slakes his desire, who reaches out and does what he wants, who harpoons hippopotami and shoots wild bulls, catches fish and snares fowl. Yet none hasty-mouthed is free from recklessness; none light of heart is caution of intent. Your heart should be patient, so that you will know Truth! Suppress your choice for the good of him who would depart quietly. No rapid man cleaves to excellence; no hasty-hearted man will exist. Stretch out to act, now your eyes are opened! Inform the heart!" (Parkinson 1997: 68). 
E-18 B1 301-307

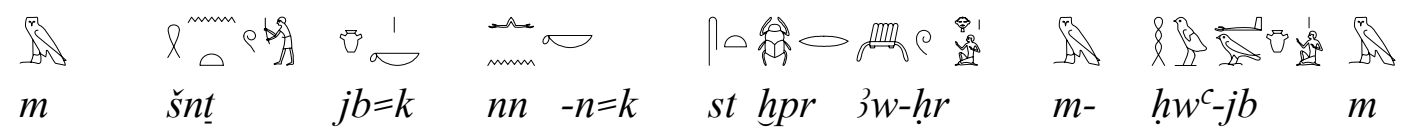
NEG.IMPV. NEG.KMPL. SBST.-2sm NEG. PRÄP.-2sm 2sf FUT. DPP.-SBST. PRÄP. DPP.-SBST. NEG.IMPV.

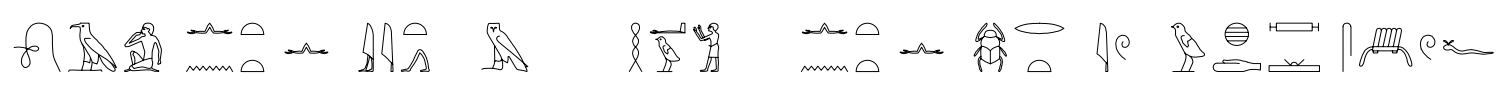
w) $\quad n t t \quad n(j) j j . t \quad m \quad h^{c} j \quad n t t \quad n(j)$ hpr.t jw whd $\quad$ s.3w=f

NEG.KMPL. RLTVF.NEG. VB.-NPP. NEG.IMPV. NEG.KMPL. RLTVF.NEG. VB.-NPP. TOP. SBST. KAUS.-PRÄS.-3sm

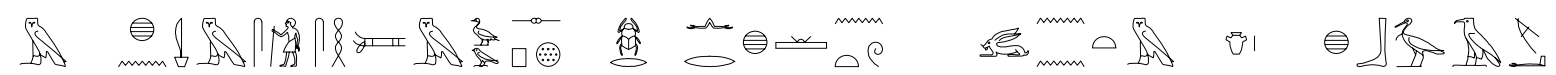
$m$ - hnnms shtm zp hpr n(j) rh.n.tw wnn.t $m$ - jb hbb

PRÄP. SBST. STAT.:3sm SBST. NPP. NEG. VB.-PRÄT.-indef VB.-DPP. PRÄP. SBST. INF.

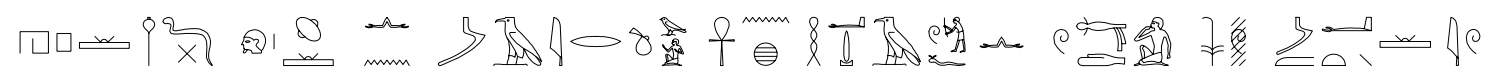

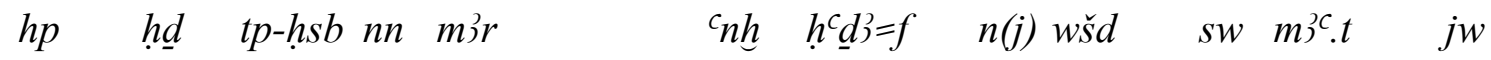

SBST. INF. SBST. NEG. SBST. NPA. PRÄS.-3sm NEG. PRÄS. 3sm SBST.-FEM. TOP.

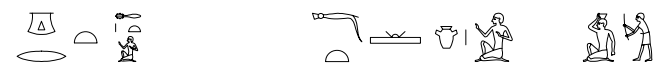

gr.t $\underline{h} . t=j \quad$ mh.t $\quad j b=j \quad 3 t p$

PRÄP. SBST.-FEM.-1sc VB.-INF. SBST.-1sc INF.

Sei nicht streitsüchtig. ${ }^{387}$ Das ist nicht für dich. Der, der offener Meinung ist, wird zu einem, der von engem Verstand ist. ${ }^{388}$ Mach dir keine schlechten Gedanken, um das, was nicht gekommen ist. Freue dich nicht über das, was noch nicht passiert ist. Die Geduld verlängert die Freundschaft, zerstörend, was einmal geschah. Man kann nicht wissen, was es im Herzen gibt/gab. Der Zerhacker des Gesetzes und Zerstörer der Ordnung, kein Elender mehr ist lebendig, den er beraubte. Hat die Maat ihn nicht zu Rede gestellt? Mein Körper ist vollgefüllt und meine Seele aber ist beladen. $\left({ }^{\circ}\right.$ dein Herz darf nicht streiten ${ }^{\circ} /{ }^{\circ}$ kurzem Herzen ${ }^{\circ}{ }^{\circ}$ mein Herz ${ }^{\circ}$ )

E-19 B1 312-313

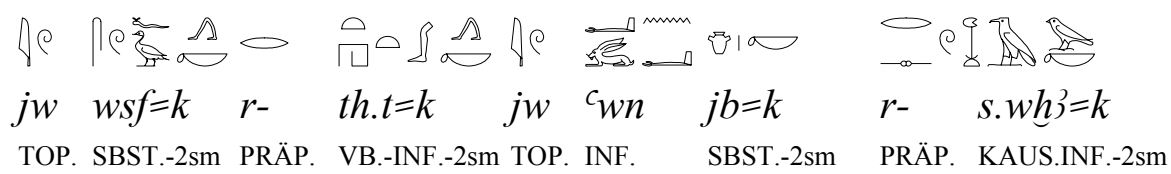

Deine Trägheit wird sich gegen Dich wenden. Deine Habgier wird dich narren. $\left({ }^{\circ} \mathrm{Gier}\right.$ des Herzens $^{\circ}$ )

387 "Be not quarrelsome" (Parkinson 1997: 71), "Don't be angry" (Lichteim 1975: 179).

388 Suys (1923: 160) übersetzt bienveillant, Gardiner (1923: 18, n.1) far-sighted, Parkinson (1997: 71) confident man, und Brunner (1988: 365) Vorrauschauende. 
E-20 B1 321-323

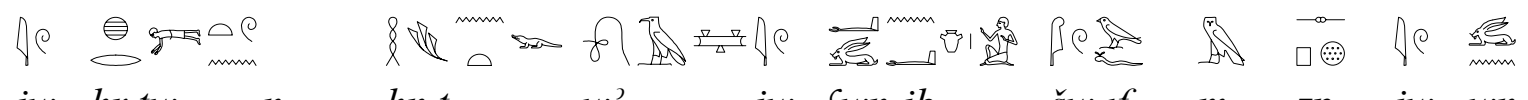
$j w$ hr.tw n- hn.t w3 jw $c_{w n-j b} \quad \check{s} w=f \quad m-\quad z p \quad j w \quad w n$ TOP. PRÄS.-indef PRÄP. $\quad$ SBST.-FEM. STAT.3sm TOP. NPP.-SBST. PRÄS.-3sm PRÄP. SBST. TOP. PRÄT.

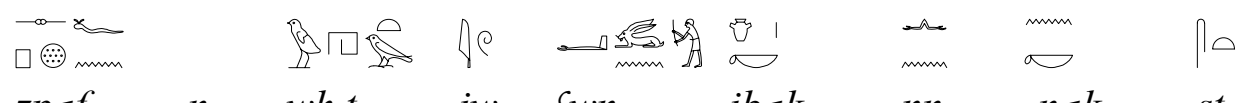
$z p=f \quad n-\quad$ wh.t jw $c_{w n} \quad j b=k \quad n n \quad-n=k \quad s t$ SBST.-3sm PRÄP. SBST.-FEM. TOP. PRÄS. SBST.-2sm NEG. PRÄP.-2sm 3sn Man fällt wegen der Gier und ist dann weg (vom Fenster). Ein Habgieriger ohne Erfolg, und sein Erfolg ist für die Katz? Bis du habgierig, so ist das nichts für dich. ( ${ }^{\circ}$ dein Herz ist habgierig ${ }^{\circ}$ )

E-21 B1 329

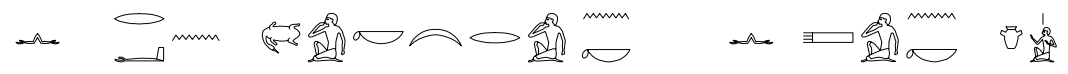

$n(j) \quad r \underline{d} . n \quad s n \underline{d}=k \quad s p r=(j) \quad-n=k \quad n(j) s j 3 . n=k \quad j b=j$

NEG. VB.-PRÄT. SBST.-2sm SBJ.-1sc PRÄP.-2sm NEG. VB.-PRÄT.-2sm SBST.-1sc

Dein Angst gestattet nicht, daß ich mich an dich wende, du erkennst meine Gedanken nicht.

E-22 B2 104-105

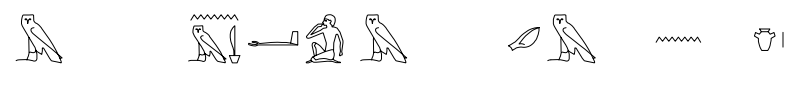

$m \quad n m^{c} \quad m \quad s \underline{d m} \quad n-j b$

NEG.IMPV. NEG.KMPL. NEG.IMPV. NEG.KMPL. PRÄP. SBST.

Sei nicht parteiisch. Höre nicht auf die Begierde. $\left({ }^{\circ}\right.$ das $\left.\operatorname{Herz}^{\circ}\right)$

E-23 B2 110-111

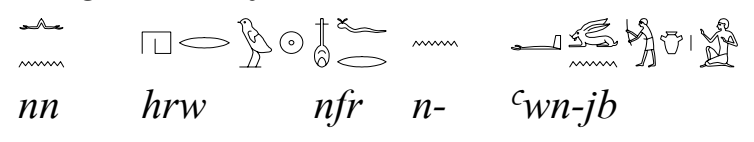

NEG.EX. SBST. ADJ. PRÄP. NPA.-SBST.

Es gibt keinen guten Tag für den, der habgierig ist. ( ${ }^{\circ}$ der ein gieriges Herz hat ${ }^{\circ}$ ) 


\section{Die Erzählung von Sinuhe (Koch 1990)}

Quellen:

Datierung: pBerlin 3022, pBerlin 10499, Ashmolean Museum Ostracon, oBM. 5629

Textausgaben: XII./XIII. Dynastie ${ }^{389}$

Übersetzungen:

Daressy (1901: 41)Gardiner (1916: 120-151), Sethe (1924: 3-17), Blackman (1932: 1-41), Barns (1952), Grapow (1952), Koch (1990), Foster (1993: 1-37).

Gardiner (1916: 168-176), Erman (1923: 39-56), Simpson (1972: 57-74), Assmann (1975: 474-476), Lichthteim (1975: I, 222-236), Hornung (1990: 31-51), Foster (1993: 38-63), Blumenthal (1995: 884-911), Parkinson (1997: 21-53), Galán (1998: 82-96), Le Guilloux (2002), Burkard \& Thissen (2003: 110-119).

E-24 R 8-11

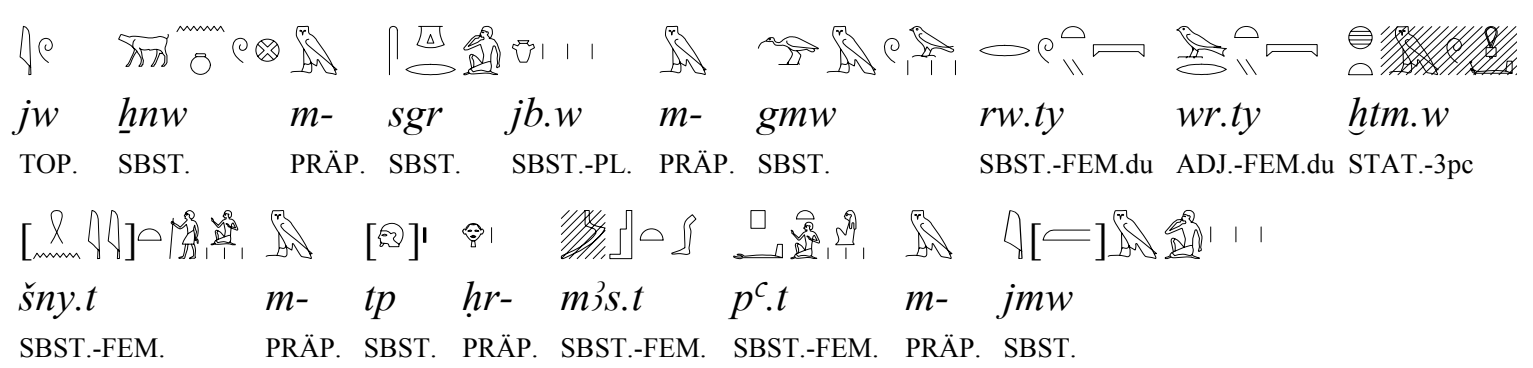

Die Residenz war in Stille, die Herzen waren in Betrübnis. Das große Doppeltor war geschlossen, der Hofstaat war gramgebeugt, und die Bevölkerung war ins Klagen verfallen.

E-25 B 1-3

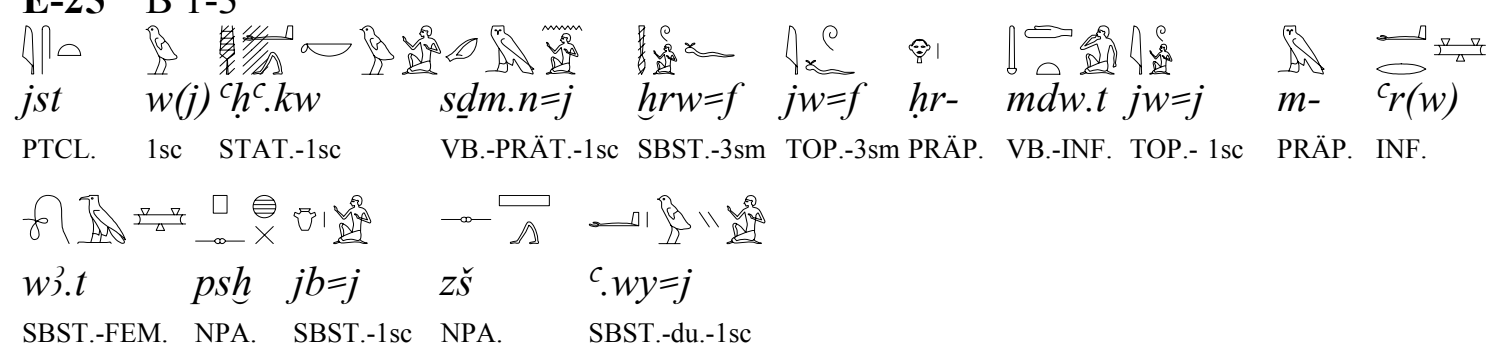

(Man rief einen jeden), während ich dabeistand und seine Stimme hörte, als er sprach, denn ich befand mich in der Nähe. Mein Verstand war verwirrt, und ich streckte starr die Arme von mir. ( ${ }^{\circ}$ mein $\left.\mathrm{Herz}^{\circ}\right)$

E-26 B 21-25

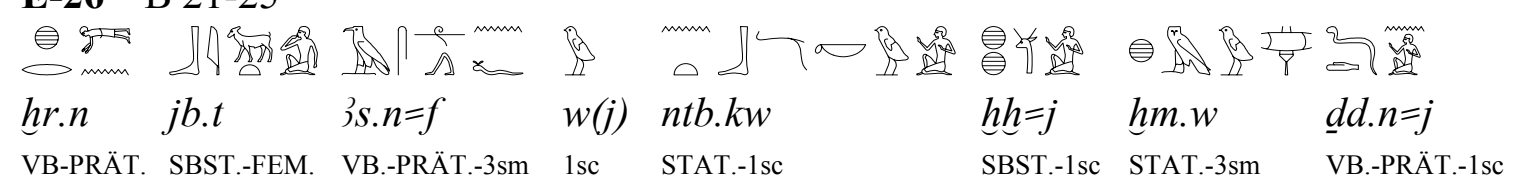

389 Möller (1927: 15); Galán (1998: 63-64); Blumenthal (1996: 128); Parkinson (1996: 310); Quirke (1996: 387-389). Für die Datierung der Ostraka siehe (Quirke 1996: 392-393); Galán (1998: 64) 


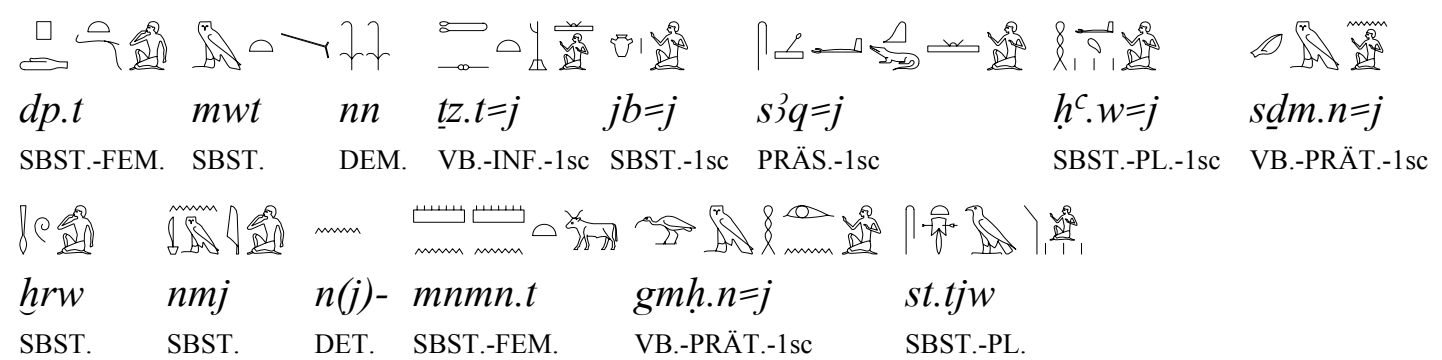

Rasend schnell ereilte mich Durst, ich drohte zu verschmachten, meine Kehle war schon ganz ausgetrocknet, und ich sagte zu mir: "Das ist der Vorgeschmack des Todes." Meinen Verstand aufrichten ${ }^{390}$ und meine Glieder zusammenreißen konnte ich dann aber doch, als ich ein Geräusch, das Brüllen einer Herde, vernahm und dann Beduinen erblickte. ( ${ }^{\circ}$ erhob mein $\mathrm{Herz}^{\circ}$ )

E-27 B 38-40

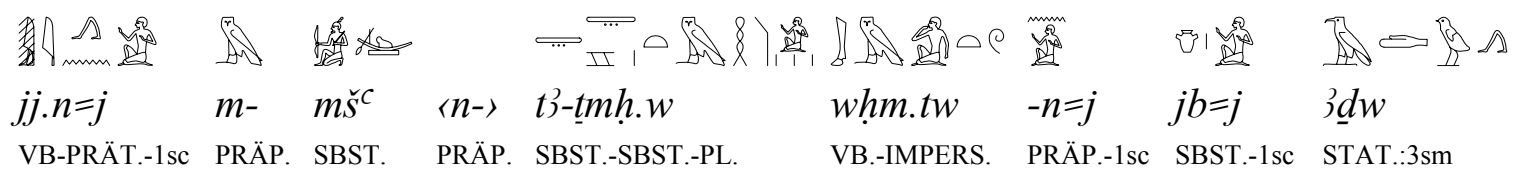

具曷 $h 3 i t j=j \quad n(j) n t f \quad m-\quad \underline{h} . t=j \quad$ jn. $n=f \quad$ wj $\quad h r-\quad w 3 . t \quad w^{c r}$ SBST.-1sc NEG. $3 \mathrm{sm} \quad$ PRÄP. $\quad$ SBST.-FEM.-1sc VB-PRÄT.-3sc 1sc PRÄP. SBST.-FEM.INF.

Ich war mit der Armee zum Land der Libyer gezogen, als mir davon berichtet wurde. Mein Herz wurde matt, und mein Verstand, der war nicht mehr in meinem Leib. ${ }^{391}$ Es brachte mich auf den Weg der Flucht. $\left({ }^{\circ}\right.$ mein $\left.\mathrm{Herz}^{\circ}\right)$

E-28 B 57-59

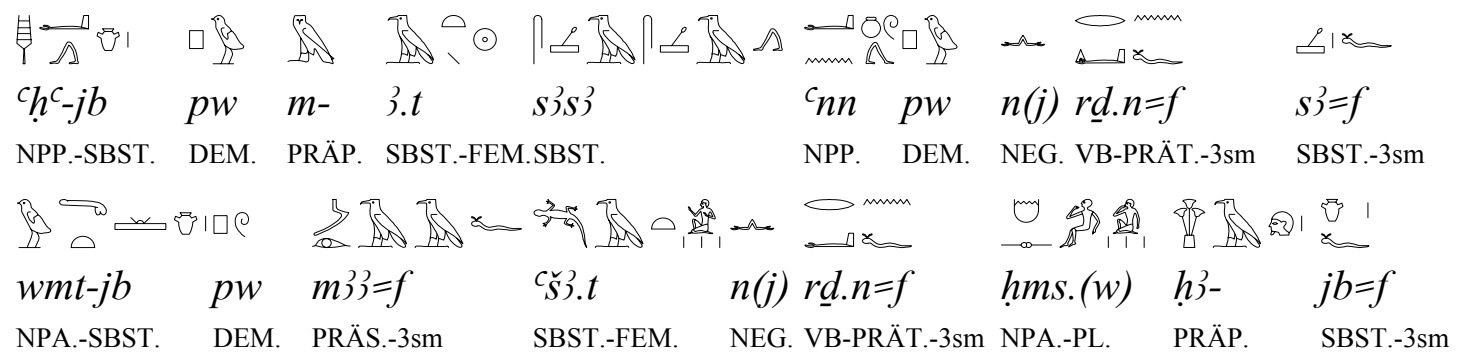

Er ist einer mit unbeugsamen Mut im Moment des Anstürmens. Er ist einer, der immer wieder umkehrt, ohne seine Rücken zu zeigen. Er ist einer mit unerschütterlicher

390 "I raised my heart and collected myself ..." (Lichtheim 1975: 224); "Dann erhob ich mein Mut und raffte meine Glieder zusammen" (Blumenthal 1995: 890).

391 "I have come from the expedition to the Libyan land: it was reported to me, and my heart failed and carried me off on the ways of the flight" (Parkinson 1997: 29); "I returned from the expedition to the land of the Tjemeh, it was reported to me and my heart grew faint. It carried me away on the path of flight, ..." (Lichtheim 1995: 225); "cuando volvía de una expedición en la tierra de los Tchemehu, me fue comunicado y mi corazón palpitó. Mi corazón se me salía del cuerpo y me condujo por el camino de la huida" (Galán 1998: 84). 
Kaltblütigkeit, wenn er die Menge sieht und er läßt nicht $\mathrm{zu}$, daß um seine Beherztheit herum Trägheit herrscht. ( ${ }^{\circ}$ mit stehendem Herzen ${ }^{\circ} /{ }^{\circ}$ mit dickem Herzen ${ }^{\circ} /{ }^{\circ}$ Herz $^{\circ}$ )

E-29 B 104-107

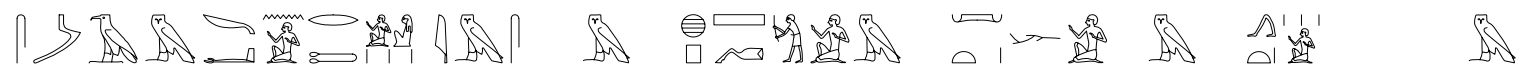

$$
\begin{aligned}
& \text { smi.n=j rmt.w }-j m=s \quad m-\quad h p \check{s}=j \quad m-\quad p \underline{d} . t=j \quad m-\quad n m t . t=j \quad m- \\
& \text { VB.-PRÄT.-1sc SBST.-PL.PRÄP.-3sf PRÄP. SBST.-1sc PRÄP. SBST.-FEM.-1sc PRÄP. SBST.-FEM.-1sc PRÄP. }
\end{aligned}
$$

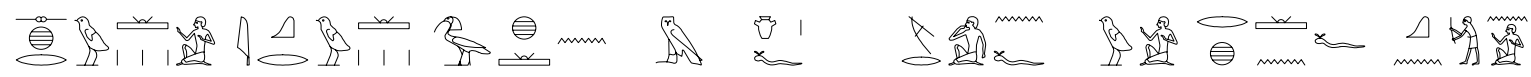

$$
\begin{aligned}
& \text { shr.w }=j \quad j q r . w \quad 3 h . n=(j) \quad m-\quad j b=f \quad m r . n=f \quad \text { wj } \quad r h . n=f \quad q n . n=j \\
& \text { SBST.-PL.-1sc } \quad \text { ADJ.-PL. } \quad \text { VB.-PRÄT.-1sc PRÄP. SBST.-3sm VB.-PRÄT.-3sm 1sc } \quad \text { VB.-PRÄT.-3sm VB.-PRÄT.-1sc }
\end{aligned}
$$

Ich tötete die Leute in ihm (im Land) mit meinem starken Arm, mit meinen Bogen, auf meinen Feldzüge durch meine guten Pläne. Ich war seiner Meinung nach nutzbringend, und

\begin{tabular}{|c|c|c|c|c|c|c|}
\hline 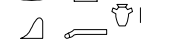 & 口 & $\sum_{0}^{\infty}$ & Q & 입 & $\infty$ & \\
\hline$r q . t-j b$ & pw hrr- & $m 33=f$ & $w j$ & $h r-$ & jr.t & $w p \cdot t=f^{39}$ \\
\hline VB.-INF.SBST. & DEM. PRÄP. & INF.-3sm & $1 \mathrm{sc}$ & PRÄP. & VB.-INF & VB.-INF.-3sm \\
\hline
\end{tabular}
er schätzte mich, weil er wußte, daß ich tapfer war. ${ }^{392}$ ( ${ }^{\circ}$ in seinem Herzen ${ }^{\circ}$ )

E-30 B 116-117

Oder sei das Feindseligkeit ${ }^{394}$, weil er mich bei der Ausführung deiner Aufträge sieht? $\left({ }^{\circ}\right.$ Trotz des Herzens ${ }^{\circ}$ )

\section{E-31 B125}

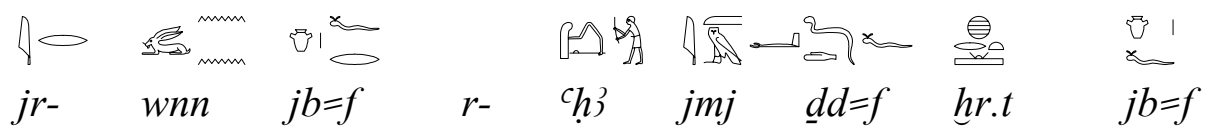

TOP. PRÄS. SBST.-3sm PRÄP. INF. IMPV. SUBJ.-3sm SBST.-FEM. SBST.-3sm

Wenn es sein Wunsch ist, zu kämpfen, laß ihn sein Herzenswunsch ruhig aussprechen. ( ${ }^{\circ}$ sein Herz auf Kämpfen ausgerichtet ist ${ }^{\circ} /{ }^{\circ}$ Zustand seines Herzens ${ }^{\circ}$ )

E-32 B131-134

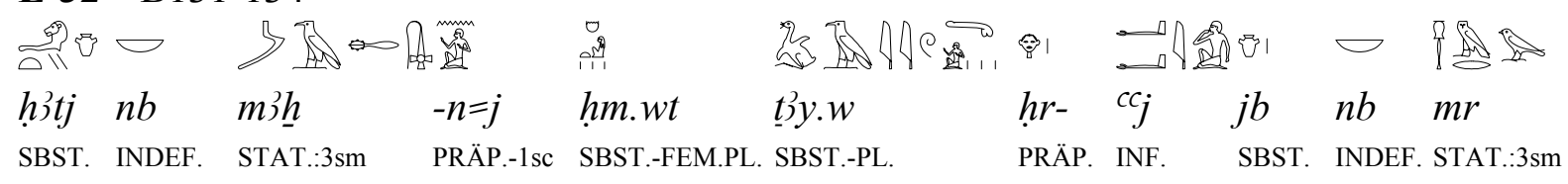

392 "I won his heart and he loved me, for he recognized my valor" (Lichtheim 1995: 227).

393 Wechsel des Personalpronomms $<\mathrm{f}>$ für $<\mathrm{k}>$ wegen der indireckte Rede, siehe Kammerzell \& Peust (2002:317-319 und Conclusions) und Peust (1996: 60-61).

394 "Envy" (Lichtheim 1995: 227); "Bosheit des Herzens" (Blumenthal 1995: 18); "resentement" (Parkinson 1997: 33); "rabia" (Galán 1998: 88). 


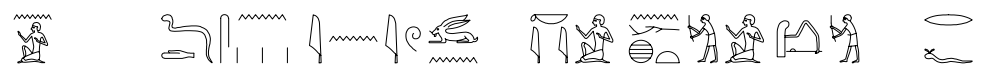 \\ $-n=j \quad d d=s n \quad j n-j w-w n n$ ky $n h t \quad$ chj $\quad-r=f$ \\ PRÄP.-1scFUT-3pc PRÄP. KONV. INDEF. NPA. STAT.:3sm PRÄP.-3sm}

Jedes Herz hatte Angst um mich. ${ }^{395}$ Die Frauen und die Männer redeten durcheinander. Alle hatten Mitleid mit mir, und sie sagten: Gibt es einen ebenso Starken, der gegen ihn kämpfen kann? ( ${ }^{\circ}$ jedes Herz litt meinetwegen ${ }^{\circ}$ )

E-33 B147-149

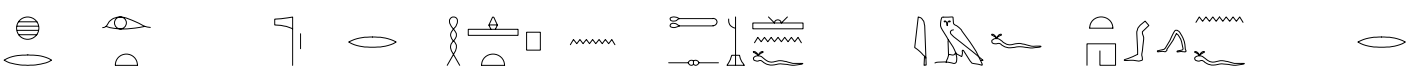

$$
\begin{aligned}
& \text { hr- } j r . t \quad n t r r-\quad h t p \quad n-\quad \underline{t} z . n=f \quad-j m=f \quad t h . n=f \quad r- \\
& \text { PRÄP. VB.-INF. SBST.PRÄP. INF. PRÄP. RLTVF.-PRÄT.-3sm PRÄP.-3sm RLTVF.-PRÄT.-3sm PRÄP. }
\end{aligned}
$$

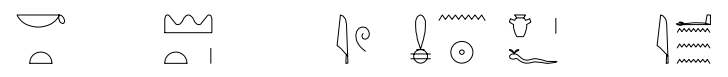

$$
\begin{aligned}
& \text { k.t his.t jw mjn } j b=f \quad j^{c}
\end{aligned}
$$

DEM.-FEM. SBST.-FEM. TOP. ADV. SBST.-3sm STAT.:3sm

Jetzt agierte Gott, um freundlich zu sein zu dem, den er dort ausgesetzt hatte, den er in ein fremdes Land geführt hatte. Heute fühlte er sich erleichtert. ( ${ }^{\circ}$ sein Herz ist gewaschen ${ }^{\circ}$ )

\begin{tabular}{|c|c|c|c|c|c|c|c|c|c|c|c|}
\hline & $k$ & $r-$ & $r \underline{d j} . t$ & $m 33=j$ & $b w$ & $w r \check{s} . w$ & $j b=j$ & $j m$ & $p t r$ & $w r . t$ & $r-$ \\
\hline PTCL & $2 \mathrm{sm}$ & PRÄP. & VB.-INF. & SBJ.-1sc & SBST. & VB.-DPP. & SBST & c ADV. & INTG. & SBST.- & $\mathrm{P}$ \\
\hline
\end{tabular}

\section{E-34 B158-162}

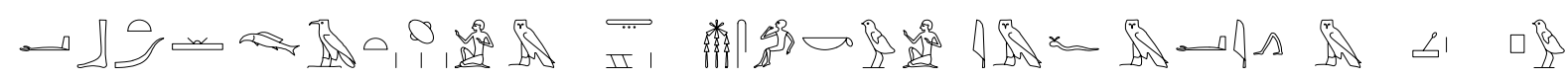
cb.t $\quad \underline{h} . t=j \quad m-\quad t 3 \quad m s . k w \quad-j m=f \quad m j \quad m-\quad s 3 \quad p w$ SBST.-FEM. SBST.-FEM.-1sc PRÄP. SBST. STAT.-1sc PRÄP.-3sm IMPV. PRÄP. SBST. DEM.

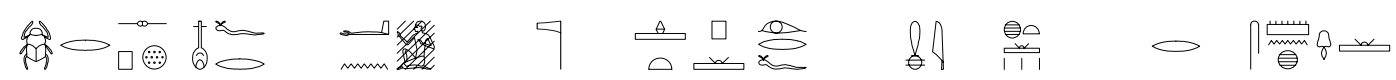

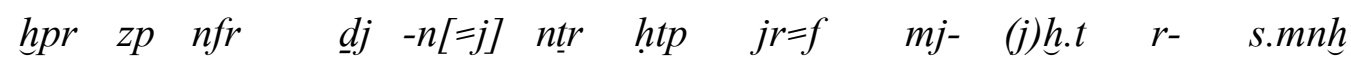
FUT. SBST.STAT.:3sm FUT. PRÄP.-1sc SBST. SBST. FUT.-3sm PRÄP. SBST.-FEM.PRÄP. KAUS.-INF.

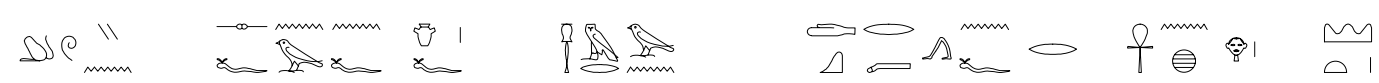
phwj $n(j)-s f n . n=f \quad j b=f \quad m r \quad n-\quad d q r . n=f \quad r-\quad c_{n \underline{h}} \quad h r-\quad \underline{h} 3 s . t$ SBST. DET. VB.-RLTV.-3sm SBST.-3sm STAT.3sm PRÄP. VB.-RLTV.-3sm PRÄP. INF. PRÄP. SBST.-FEM.

Vielleicht wirst du mich den Platz (wieder) sehen lassen, an dem mein Herz verweilt. Was ist wichtiger als die Vereinigung meines Leichnams mit dem Land, in dem ich geboren wurde? Das bedeutet: Komm mir zu Hilfe, damit die Angelegenheit gut wird. Gott möge mir Frieden schenken und in einer Weise handeln, um das Ende von einem, dem er Schwierigkeiten

395 "and yet every breast burned for me, the wives jabbered, and every heart was sore for me ..." (Parkinson 1997: 33); "jedes Herz, es brannte für mich, die verheirateten Frauen jammerten, jedes Herz, es litt um mich..." (Blumenthal 1995: 897); "Todos los corazones ardían por mí, mujeres y hombres alborotando; todos sufrían por mí... (Galán 1998: 88). 
bereitet hat, zum Guten zu wenden. Denn sein Herz hat Mitleid mit dem, den er dazu verbannt hatte, im Ausland zu leben.

E-35 B168-171

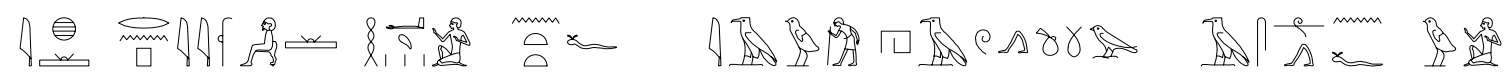

$$
\begin{aligned}
& \text { jh rnpy } \quad h^{c}=j \quad(n-) n t t\{f\} \quad j 3 w \quad h 3 w \quad \text { wgg } 3 s . n=f \quad w j \\
& \begin{array}{lllll}
\text { KNJK. FUT. } & \text { SBST.-1sc PRÄP.-CMPL. STAT. SBST. SBST.-3sm VB.-PRÄT.-3sm } 1 \text { ssc }
\end{array}
\end{aligned}
$$

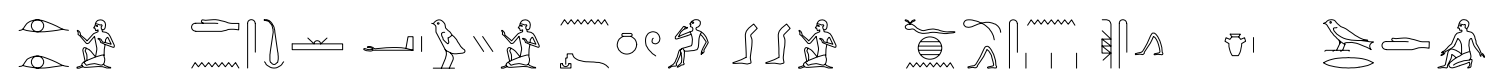

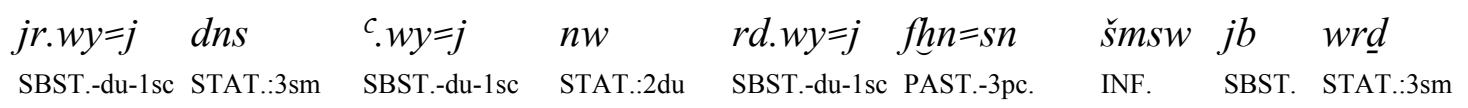

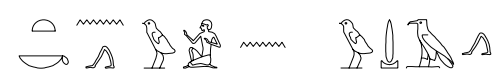

$$
\begin{aligned}
& \text { tkn wj } n-w \underline{d} \text { ? } \\
& \text { INF. 1sc PRÄP. SBST. }
\end{aligned}
$$

Daher möge mein Leib jünger werden. Das Alter ist hereingebrochen und Schwäche hat mich eingeholt, meine Augen sind schwer, meine Arme schwächlich geworden und meine Beine haben aufgehört, (einander) $\mathrm{zu}$ folgen. ${ }^{396}$ Müde ist mein Herz, (ich) nähere mich dem Dahingehen.

\section{E-36 B175-176}

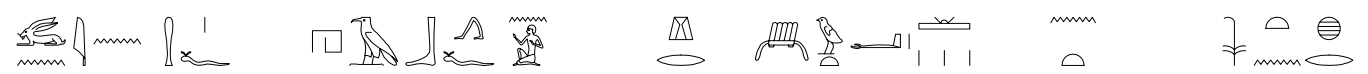

$$
\begin{aligned}
& \text { wn.jn- } h m=f \quad h 3 b=f \quad-n=j \quad \underline{h r}-\quad 3 w . w t_{-}{ }^{c} \quad \text { n.t- } h r-n s w \\
& \text { VB.-CONS. PRÄS.-3sm PAST.-3sm PRÄP.-1sc PRÄP. SBST.-FEM.PL.-SBST. DET.-FEM. PRÄP.-SBST. }
\end{aligned}
$$

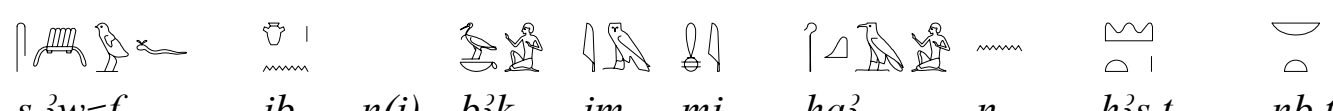$$
s .3 w=f \quad j b \quad n(j)-b 3 k \quad j m \quad m j-\quad h q 3 \quad n-\quad h 3 s . t \quad n b . t
$$

KAUS.-PAST.-3sm SBST.DET. SBST.ADV. PRÄP. SBST. PRÄP. SBST.-FEM. INDEF.-FEM.

Da sandte seine Majestät mir königliche Geschenke und erfreute das Herz meiner Wenigkeit, als ob (ich) der Herrscher eines Fremdlandes (wäre).

\section{E-37 B 182-185}

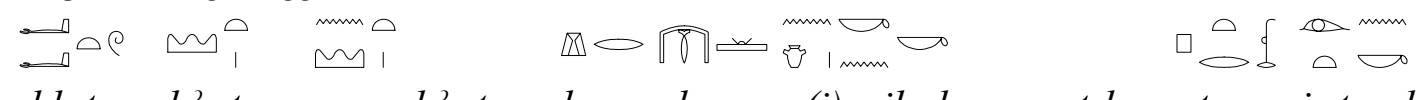

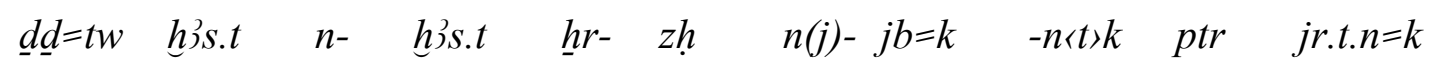

PRÄS.-2sm SBST.-FEM.PRÄP. SBST.-FEM.PRÄP. SBST. DET. SBST.-2sm 2sm PTCL. V VB.-RLTVF.-PRÄT.-2sm

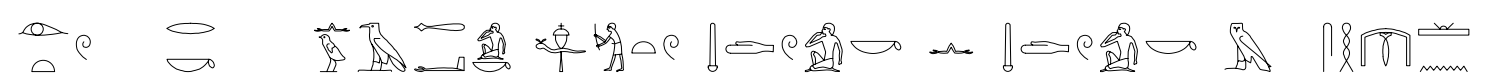

jr.tw $\left.\quad-r=k \quad n(j) w^{c}\right\}=k \quad h s f . t w \quad m d w=k \quad n(j) m d w=k \quad m-\quad z h \quad n(j)-$

SUBJ.-IMP. PRÄP.-2sm NEG. PRÄS.-2sm VB.-PASS. SBST.-2sm NEG. PRÄT.-2sm PRÄP. SBST. PRÄP.

396 "...meine Füße, sie haben aufgehört, dem müden Herzen zu folgen..." (Blumenthal 1995: 899). 


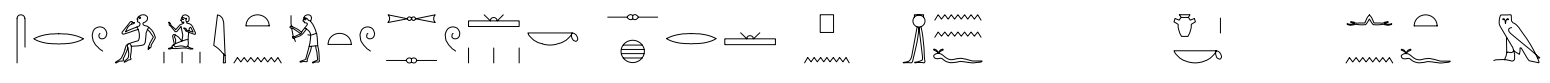

$$
\begin{aligned}
& \text { srw jtn.tw tzw } w=k \quad \text { h } r \quad \text { pn } \quad j n \quad-n=f \quad j b=k \quad n(n) n t f m- \\
& \begin{array}{llllll}
\text { SBST. } & \text { SUBJ.-PASS. SBST.PL.-2sm SBST. } & \text { DEM. NPP. PRÄP.-3sm } & \text { SBST.-2sm NEG. 3sm PRÄP. }
\end{array} \\
& \text { अ } \\
& j b \quad-r=k \\
& \text { SBST. PRÄP.-2sm }
\end{aligned}
$$

$\mathrm{Da} ß$ dich ein Fremdland an das andere weitergereicht hat, geschah gemäß Planung deines eigenen Willens. Was hast du eigentlich getan, damit man gegen dich hätte vorgehen sollen? Du hast doch wohl nicht rumgelästert, so daß man dein Gerede bestrafen wollte? Und du hast doch wohl nicht in der Ratsversammlung zu den Würdenträgern so gesprochen, daß man sich deinen Reden hätte widersetzen müssen? Dieser Gedanke, zu dem dein Herz sich hat hinreißen lassen, der war nicht absichtlich gegen dich. $\left({ }^{\circ}\right.$ dein Herz gebracht wurde ${ }^{\circ} /{ }^{\circ}$ war nicht im Herzen ${ }^{\circ}$ )

E-38 B 202-203

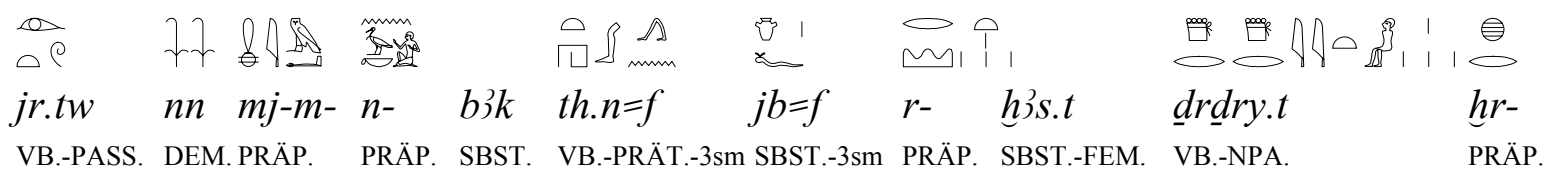

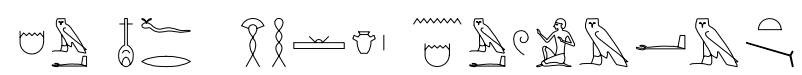

$h m \quad n f r \quad$ wihh-jb $\quad n h m^{c} w j \quad m^{-}{ }^{-}$mw.t

SBST. ADJ. INF.-SBST. NPA. 1sc PRÄP. SBST.-FEM.

Wie kann so etwas für einen Diener, den seine Gedanke auf falsche Wege in fremde Länder führte, getan werden? So gut also ist die Milde, dessen der mich vor dem Tod errettet ${ }^{397}$. $\left({ }^{\circ}\right.$ sein Herz ${ }^{\circ} /{ }^{\circ}$ Herz-Legung ${ }^{\circ}$ )

E-39 B223-224

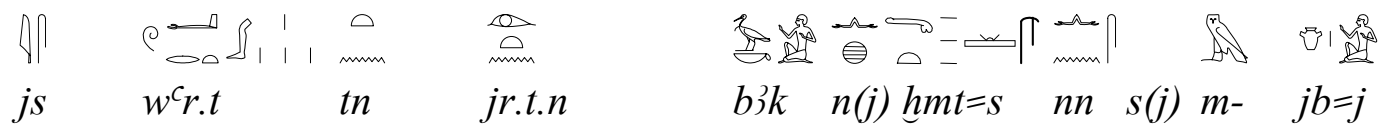

PTCL. SBST.-FEM. DEM.FEM. VB.-RLTVF.-PRÄT. SBST. NEG. PRÄT.-3sf NEG. 3sf PRÄP. SBST.-1sc

Diese Flucht, welche "der Diener" machte, sie war nicht geplant, sie war unüberlegt. ( ${ }^{\circ}$ nicht in meinem Herzen $^{\circ}$ )

E-40 B226-230

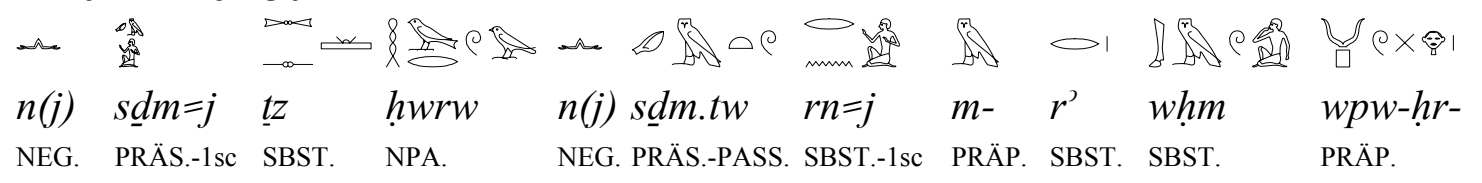

397 "Nun aber, gut ist die Langmut,, die mich vom Tod errettet!" (Blumenthal 1995: 902); "So good is the kindness which saves me form death!" (Parkinson 1997: 37); "Cuán buena es la benevolencia que me rescata de la muerte..."(Galán 1998: 91). 


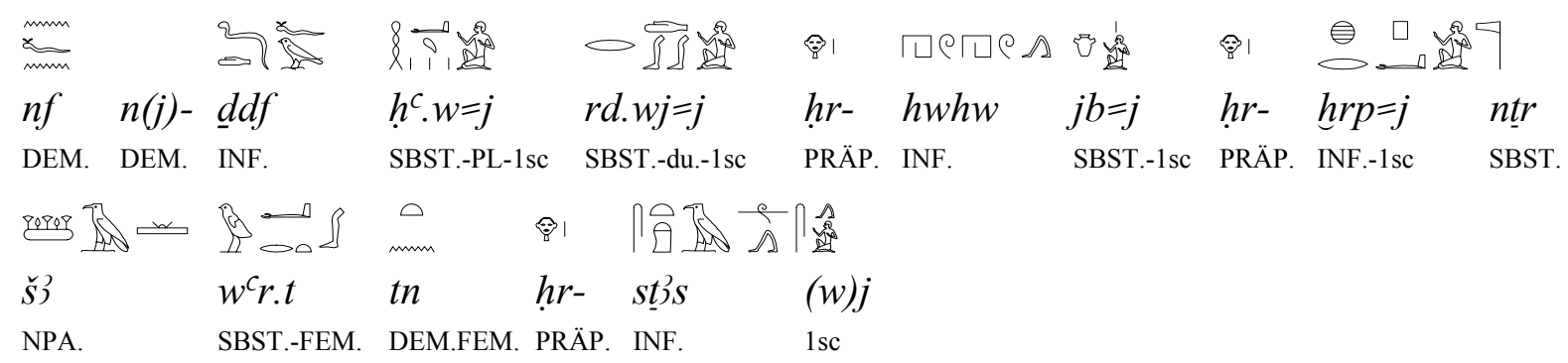

Ich hörte keine Verurteilung, und mein Namen war nicht im Mund des Herolds zu hören. (Da war) bloß dieses Zittern meiner Glieder, meine Füße hasteten, meine Stimmung leitete mich, der Gott, der diese Flucht anordnete, trieb mich an. $\left({ }^{\circ}\right.$ mein Herz $\left.{ }^{\circ}\right)$

E-41 B254-256

Ae照 f

$j w=j \quad m j-\quad z(j) \quad j t . w \quad m-\quad j h h w w \quad b 3=j \quad j z . w \quad h^{c} . w=j \quad 3 d . w$

TOP.-1sc PRÄP. SBST. STAT.3sm PRÄP. SBST. SBST.-1sc STAT.-3sm SBST.-PL-1sc STAT.-3sm

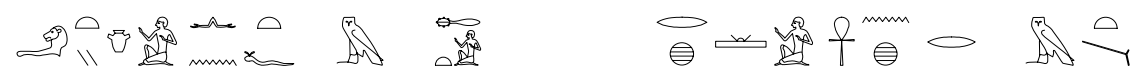

$h 3 t j=j \quad n n \quad n t f \quad m-\quad \underline{h} . t=j \quad \quad r h=j \quad c_{n h} \quad r-\quad m w t$

SBST.-1sc NEG. 3sm PRÄP. SBST.-FEM.-1sc PRÄT.-1sc SBST. PRÄP. SBST.

Ich war wie ein Mann, der von der Dunkelheit ergriffen wurde. Meine Seele war dahingegangen, mein Leib war matt, und mein Verstand war nicht in meinem Körper, so daß ich nicht in der Lagewar, Leben von Tod zu unterscheiden. ( ${ }^{\circ}$ mein Herz ${ }^{\circ}$ ) 


\section{Papyrus Westcar (Blackman 1988)}

Quelle: pBerlin 3033

Datierung: Zweite Zwischenzeit ${ }^{398}$

Textausgaben: Erman (1890), Sethe (1924: 26-36), Blackman (1988).

Übersetzungen:

Erman (1923: 64-77), Schott (1950: 176-187), Brunner-Traut (1963: 11-24), Lichtheim (1976: II, 215-221), Parkinson (1997: 102-127), Burkard \& Thissen (2003: 177-187).

\section{E-42 5,1-5,7}

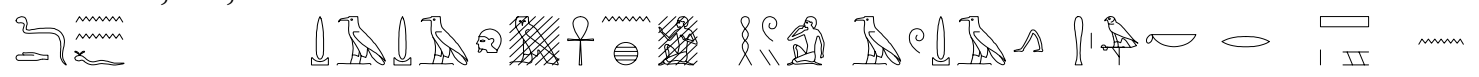 $\underline{d d . n} \quad-n=f \quad \underline{D} 3-\underline{d} 3-[m]-c_{n} \underline{h} \quad h w-3 \quad w \underline{d} 3 \quad h m=k \quad r-\quad \check{s} \quad n(j)-$ VB-PRÄT. PRÄP.-3sm PROP. PTCL. FUT. $\quad$ SBST.-2sm PRÄP. SBST. DET.

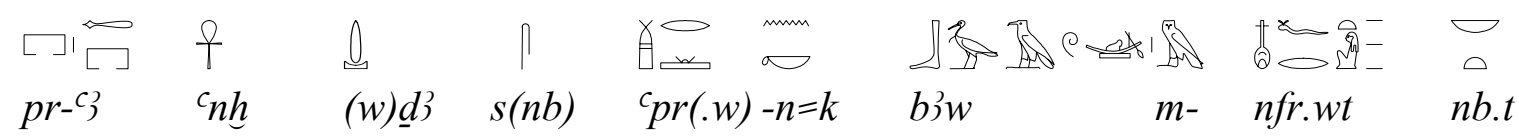
SBST.-SBST. STAT.:3sm STAT.:3sm STAT.:3sm CONV. PRÄP.-2sm SBST. PRÄP. SBST.-FEM.PL. INDEF.-FEM.

m n.t- $\quad \underline{h} n w-\quad c h=k \quad j b \quad n(j)-h m=k \quad r-\quad q b b \quad n-\quad m 33 \quad \underline{h} n n=s n$ DET.-FEM. PRÄP. SBST.-2sm SBST. DET. SBST.-2sm PRÄP. INF. PRÄP. INF. PRÄS.-3pc

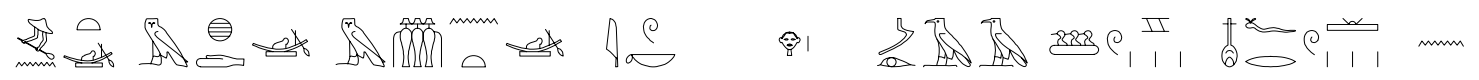

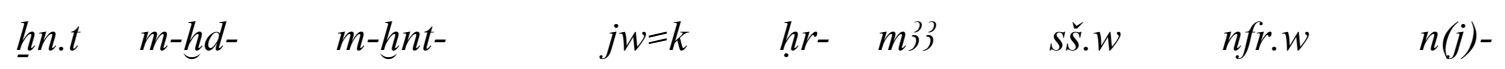
VB.-INF. PRÄP.-INF. PRÄP.-INF. $\quad$ CMPLR.-2sm PRÄP. INF. SBST.-PL. NPA.-PL. DET. ए耳 $\check{s}=k \quad j w=k \quad h r-\quad m 33 \quad$ sh.t $=f \quad$ hf $33 . t=f \quad$ nfr.w $\quad j w \quad j b=k$

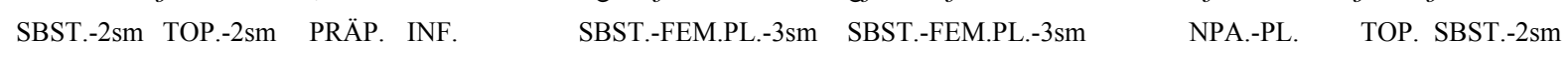

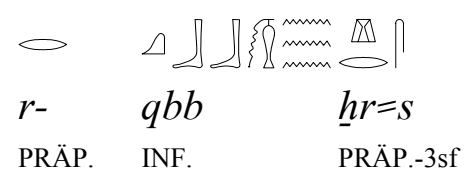

Djadjamanch sagte zu ihm: Ach, möge deine Majestät zum See des Palastes, möge er leben, wohlbehalten und gesund bleiben, gehen, und dir ein Schiff mit den schönsten Frauen aus dem Innern deines Palastes ausrüsten. Die Stimmung deiner Majestät wird sich verbessern beim Zusehen, wie sie hin und her rudern. Du kannst die lauschigen Plätze deines Parks besichtigen und seine schönen Gefilde und Ufer ansehen, und deine Stimmung wird angenehm dabei. $\left({ }^{\circ} \mathrm{d}\right.$ as Herz deiner Majestät wird sich erfrischt ${ }^{\circ} /{ }^{\circ}$ dein Herz erfrischt sich $\left.^{\circ}\right)$ 
E-43 5,13-5, 15*

慗

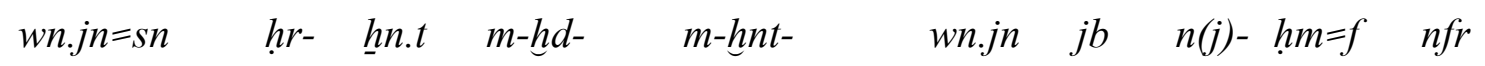
VB.-CONS.-3pc PRÄP. VB.-INF. PRÄP.-INF. PRÄP.-INF. VB.-CONS. SBST. DET. SBST.-3sm STAT.:3sm

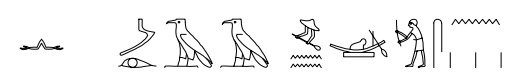

$n-\quad m 33 \quad \underline{h} n n=s n$

PRÄP. INF. PRÄS.-3pc

Und sie ruderten hin und her und die Stimmung Seiner Majestät war gehoben beim Zusehen, wie sie ruderten. $\left({ }^{\circ}\right.$ das Herz war schön $\left.{ }^{\circ}\right)$

*Gleich bei 6,1-6,2

E-44 9,10-9,13

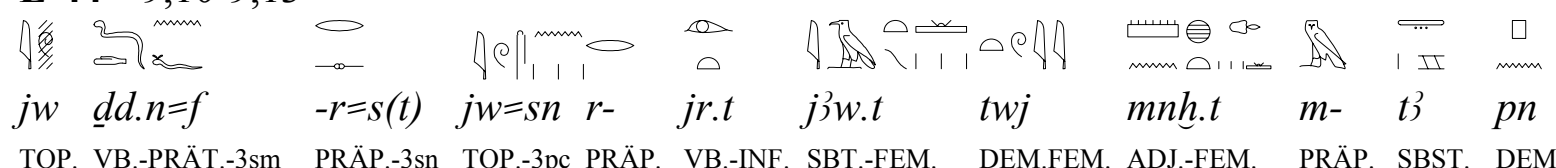

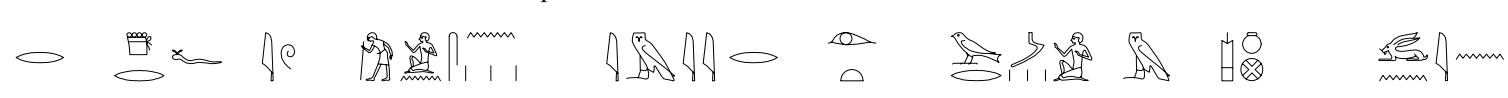

$r-\quad \underline{d} r=f \quad j w \quad s m s w-n=s n$ jmy $\quad r-\quad j r . t \quad w r-m 3 w \quad m-\quad J w n w \quad w n . j n$

PRÄP. SBST.-3sm TOP. SBST. PRÄP.-3pc ADV. PRÄP. VB.-INF. SBST.-SBST. PRÄP. TOPON. VB.-CONS.

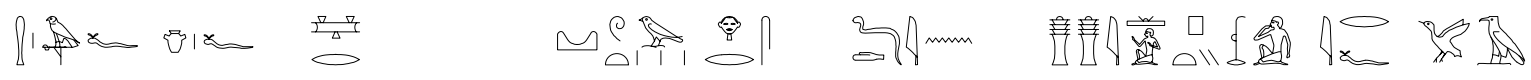

$\underline{h m=f} \quad j b=f \quad$ w3 $\quad r-\quad \underline{d} w \quad-h r=s \quad \underline{d} d-j n-\quad \underline{D} d j \quad$ ptr $\quad r f \quad p$; SBST.-3sm SBST.-3sm STAT.:3sm PRÄP. SBST. PRÄP.-3sf VB.-CONS. PROP. PTCL. PTCL. ART.

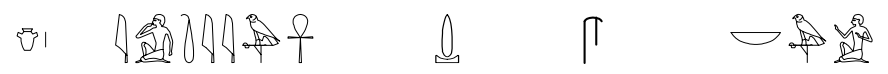

jb jty $\quad c n h \quad(w) d\} \quad s(n b) \quad n b=j$

SBST. SBST. STAT.3sm STAT.:3sm STAT.:3sm SBST.-1sc

Er sagte über sie (die zukünftigen Kinder): "Sie werden dieses vortreffliche Amt im ganzen Land ausüben. Der Älteste von ihnen wird Hohepriester in Heliopolis sein". Die Stimmung Seiner Majestät verschob sich daraufhin zu Niedergeschlagenheit. Dann sagte Djedi: "Was ist denn (mit) der Stimmung der Majestät, möge er Leben, wohlbehalten und gesund bleiben, meines Herrn?". ${ }^{399}\left({ }^{\circ}\right.$ sein Herz ${ }^{\circ} /{ }^{\circ}$ dem Herzen $^{\circ}$ )

E-45 11,3-11,6

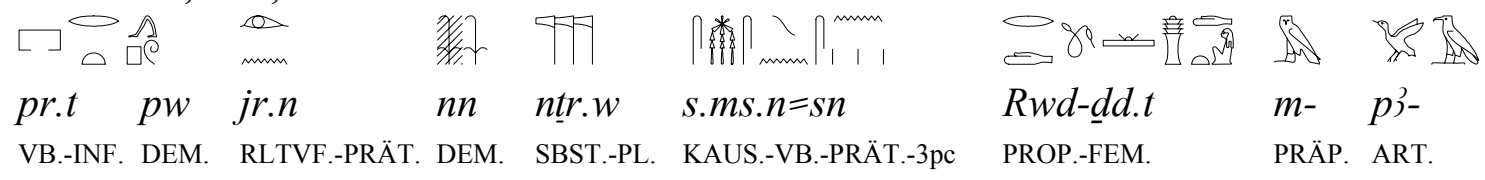

399 "And his Majesty fell into a bad mood at this. And Djedi said, 'What's this mood, Sovereign, my lord'?" (Parkinson 1997: 115). 


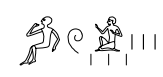

hmt.w-hrd.w

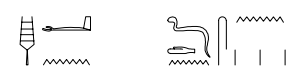

NUM.-CARD.-SBST.-PL. PTCL.

近) 通111

hmt.w-hrd.w

NUM.-CARD.-SBST.PL.

Diese Götter gingen weg, nachdem sie Rudjedjet von drei Kinder entbunden hatten. Dann sagten sie: Möge dein Herz zufrieden sein, Rauser. Siehe! Drei Kinder sind dir geboren.

E-46 12,7-12,8 wn.jn Rwd-dd.t $\quad h r-\quad w h m \quad-n=f \quad m d w . t \quad$ tn $\quad w n . j n \quad j b=f \quad n f r$ VB.-CONS. PROP.-FEM. PRÄP. INF. PRÄP.-3sm SBST.-FEM. DEM.FEM. VB.-CONS. SBST.-3sm STAT.:3sm

\begin{tabular}{|c|c|c|c|c|c|c|c|c|}
\hline$\infty$ & 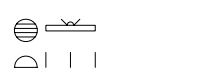 & $v_{0}$ & 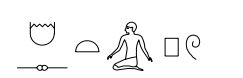 & $\prod_{1}^{\infty} \prod_{1}^{m m}$ & 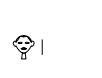 & & பऽৎ॰। & 20 \\
\hline$r-$ & (j)h.(w)t & nb.t & ḥms.t & $j r . n=s n$ & $h r-$ & {$[j r . t]$} & $h r w$ & $n f r$ \\
\hline RÄP. & SBST.-FEM.PL. & INDEF.-FEM. & VB.-INF. & RLTVF.-PRÄT.-3pc & PRÄP. & VB.-INF. & SBST. & NPA. \\
\hline
\end{tabular}

Dann wiederholte ihm Rudjedjet diese Rede, woraufhin sein Herz über alle Maße glücklich wurde. Sie setzten sich hin und verbrachten einen schönen Tag.

E-47 12,20-12,23

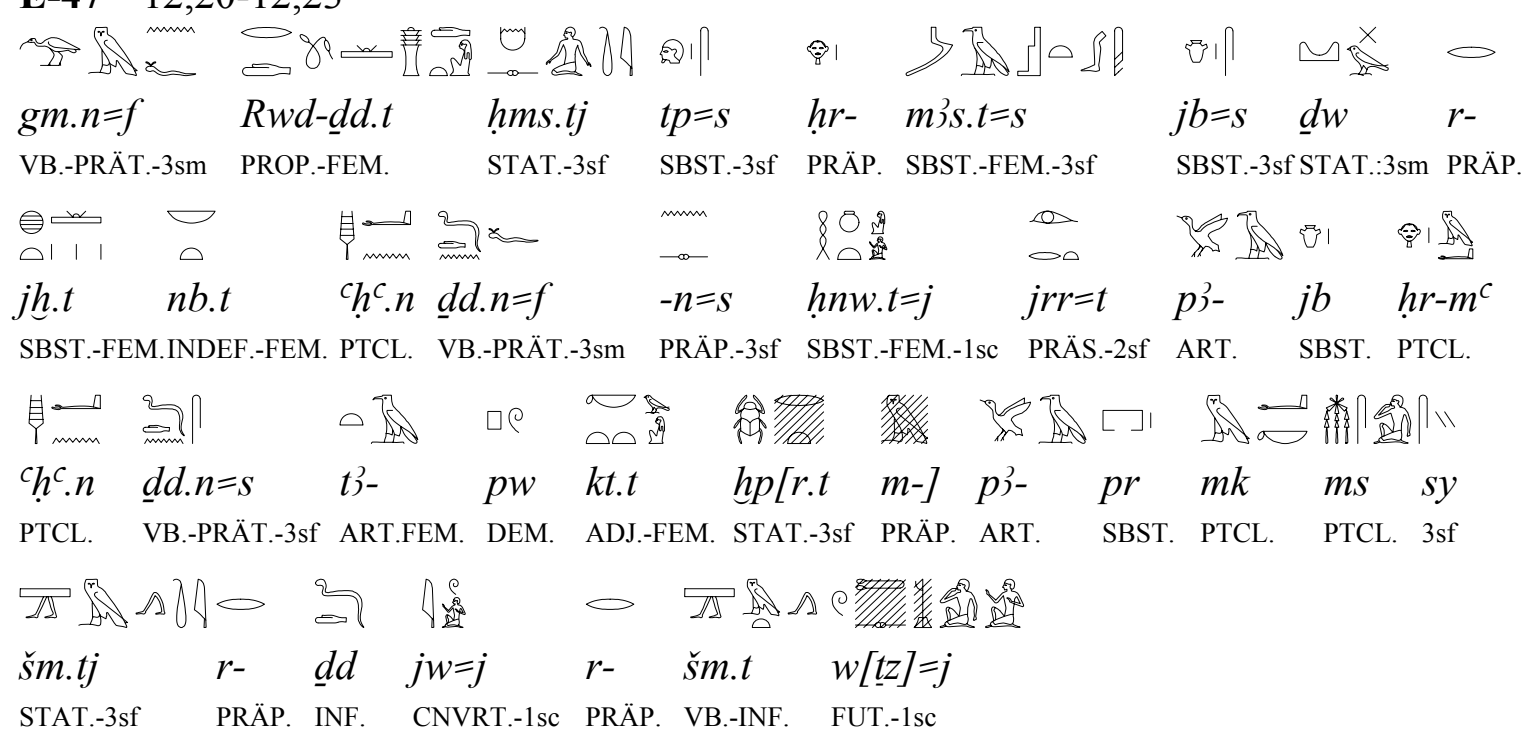

Er fand Rudjedjet, wie sie mit dem Kopf auf dem Knie dahockte und ganz niedergeschlagen war. Dann sagte er zu ihr: "Meine Herrin, warum hast Du diese Stimmung?" Dann sagte sie: "Es ist diese Kleine, die sich im Haus aufhält ist. Siehe, sie ist doch mit den Worten losgegangen: "Ich werde gehen, und (es) ausplaudern". ( ${ }^{\circ} \mathrm{ihr}$ Herz war schlecht ${ }^{\circ} /{ }^{\circ}$ dieses Herz ${ }^{\circ}$ ) 


\section{Die Vernichtung des Menschengeschlechts (Hornung 1982)}

Quelle:

Datierung: Buch von der Himmelskuh

Textausgaben: XVIII. Dynastie 400

Übersetzungen:

Maystre (1941: 53-115), Lefébvre (1886: Pl. 15-18), Hornung (1982).

Naville (1876: 1-19), Erman (1923: 77-79), Brunner-Traut (1963: 69-72), Wilson (1969: 10-11), Lichtheim (1976: II, 197-199).

E-48 S.I, 4

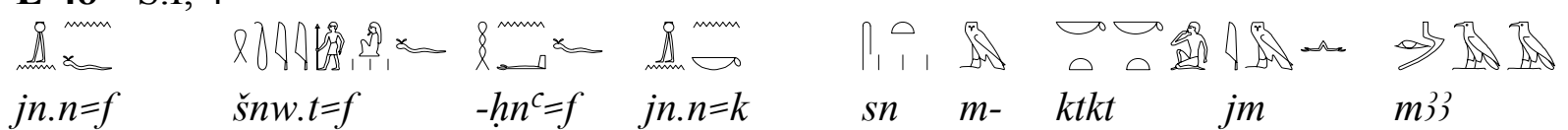

$\begin{array}{lllllllll}j n . n=f & s ̌ n w . t=f & -h n^{c}=f & j n . n=k & s n & m- & k t k t & j m & m 33 \\ \text { VB.-PRÄT.-3sm } & \text { SBST.-FEM.-3sm } & \text { PRÄP.-3sm } & \text { VB.-PRÄT.-2sm } & \text { 3pc } & \text { PRÄP. } & \text { NPA. } & \text { NEG.IMPV. } & \text { NEG.KMPL. }\end{array}$

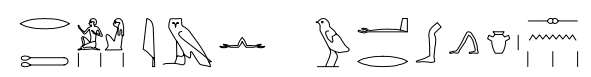

rmt jmj $\quad w^{c} r \quad j b=s n$

SBST. NEG.IMPV. NEG.CMPL. SBST.-3pc

Und er (der Gott Nun) soll seine Gefolgsleute mitbringen und du holtest sie heimlich. Laß die Menschen es nicht sehen und laß ihre Herzen nicht fliehen.

\section{E-49 S.I, 11}

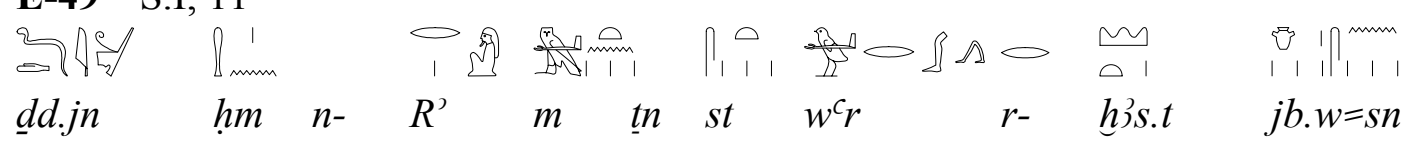

VB.-CONS. SBST. PRÄP. THEON. IMPV. 2pc 3pc STAT.:3pc PRÄP. SBST.-FEM. SBST.-PL.-3pc

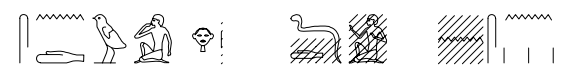

snd $\quad h r-\underline{d}-\underline{d}=\left[\begin{array}{ll}j & -n]=s n\end{array}\right.$

STAT.:3pc PRÄP. RLTVF-1sc PRÄP.-3pc

Dann sagte die Majestät des Re: Seht, sie fliehen in die Wüste, und ihre Herzen haben Angst davor, was ich zu ihnen sagen werde.

E-50 S.I, 14

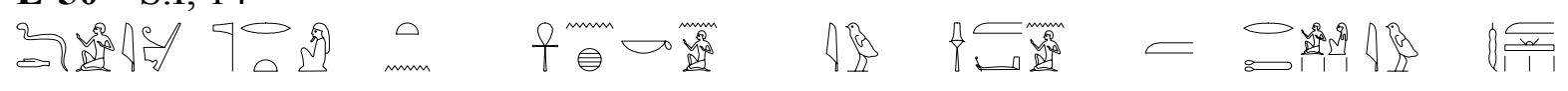

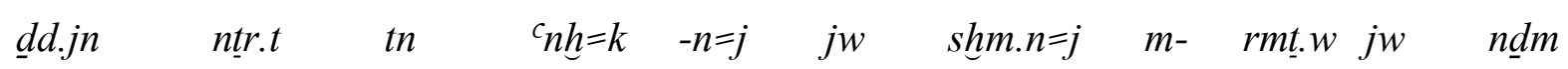
VB.-CONS. $\quad$ SBST.-FEM. DEM.FEM. AOR.-2sm PRÄP.-1sc CNVRT. VB.-PRÄT.-1sc PRÄP. SBST.-PL.CNVRT. SBST.

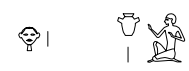

$h r-\quad j b=j$

PRÄP. SBST.-1sc

Dann sprach diese Göttin: So wahr du für mich lebst. Ich habe mich der Menschen bemächtigt und ein angenehmes Gefühl war in meinem Herzen. ${ }^{401}$

400 Lichtheim (1976: 197); Loprieno (1996: 291).

401 "As you live for me, I have overpowered mankind, and it was balm to my heart" (Lichtheim 1976: 199). 
E-51 S.I, 22

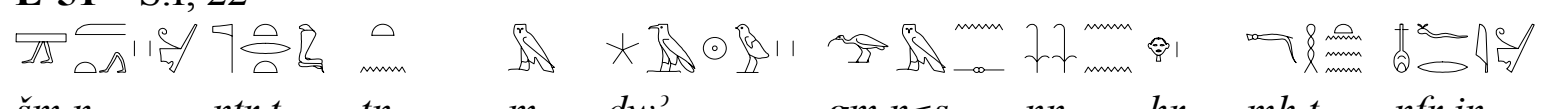
šm.n ntr.t $\quad$ th $\quad m-\quad d w 3 \quad$ gm.n=s $n n \quad$ hr- mh.t $n f r . j n$ VB.-PRÄT. SBST.-FEM.DEM.FEM. PRÄP. SBST. VB.-PRÄT.-3sf DEM.PL. PRÄP. VB.-INF. VB.-CONS.

ilo 4 S $h r=s \quad j m \quad w n . j n=s t \quad h r-\quad s w r \quad n f r(. t j) h r \quad j b=s$

SBST.-3sf ADV. VB.-CONS.-3sf PRÄP. INF. STAT.3sf SBST. SBST.-3sf

Dann ging am Morgen diese Göttin los und stellte fest, daß es [das Land] überschwemmt war. Dadurch wurde ihr Gesicht schön. Sie trank und war daraufhin ihrer Ansicht nach schön. $\left({ }^{\circ}\right.$ das Gesicht ihres Herzens $\left.{ }^{\circ}\right)$ 


\section{Wahrheit und Lüge (Gardiner 1932)}

Quellen: $\quad$ pChester Beatty $\mathrm{II}=$ pBM 10682

Datierung: XIX. Dynastie ${ }^{402}$

Textausgaben: $\quad$ Gardiner (1932: 30-36), ib. (1935: I, 2-6 u. 135; II, Pl. 1-4).

Übersetzungen: $\quad$ Schott (1950: 205-208), Brunner-Traut (1963: 40-44), Simpson (1972: 127-132), Lichtheim (1976: II, 211-214).

\section{E-52 8,7-9,1}

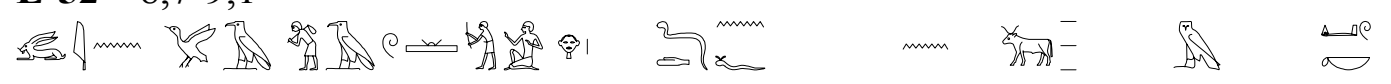

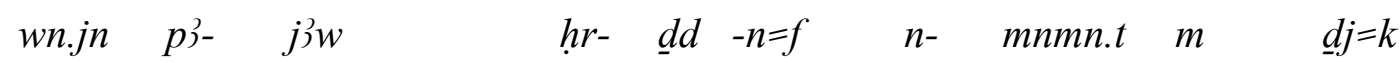

$$
\begin{aligned}
& \text { VB.CONS. ART. SBST. PRÄP. INF. PRÄP.-3sm PRÄP. SBST.-FEM. NEG.IMPV. NEG.KMPL.-2sm }
\end{aligned}
$$

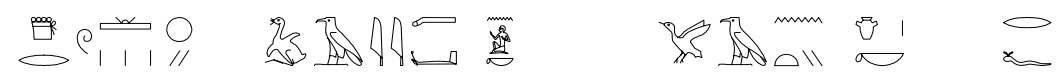

$$
\begin{aligned}
& \underline{d r . w} \quad z p \quad \underline{t} \text { y } \quad-n=k \quad \text { pi-nty } \quad j b=k \quad r f \\
& \text { SBST.-PL. SBST. IMPV. PRÄP.-2sm ART.-RLTVF. SBST.-2sm PTCL. }
\end{aligned}
$$

Dann sagte der alte Mann ihm wegen des Viehs: Gib nicht alles, gib nicht alles! Nimm Dir, worauf dein Begehren gerichtet ist. $\left({ }^{\circ}\right.$ dein $\left.\operatorname{Herz}^{\circ}\right)$ 


\section{Die Erzählung von den zwei Brüdern (Gardiner 1932)}

Quellen: $\quad$ pd'Orbiney $=$ pBM 10183

Datierung: XIX. Dynastie ${ }^{403}$

Textausgaben: $\quad$ Select Papyri in the Hieratic Character from the Collections of the British Museum (1860: II, P1. 9-19), Möller (1927: 1-20), Gardiner (1932: 9-29).

Übersetzungen: Schott (1950: 193-204), Brunner-Traut (1963: 28-40), Simpson (1972: 92-107), Lichtheim (1976: II, 203-211), Hollis (1990).

E-53 2,5-2,7

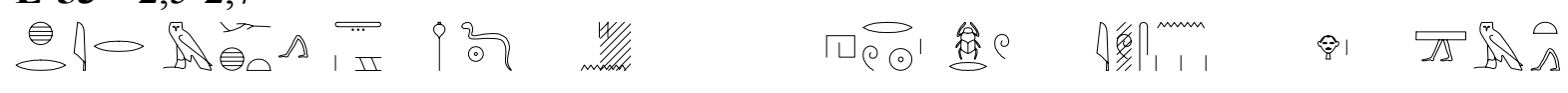

$h r-j r \quad m-h t^{2} \quad t 3 \quad h \underline{d} \quad[s n w y] n-\quad h r w \quad h p r . w \quad j w=s h \quad h r-\quad \check{s} m . t$

PTCL. ADV. SBST. STAT.3sm NUM.-du PRÄP. SBST. STAT.-3sm KB.PRÄS.I.-3pc PRÄP. VB.-INF.

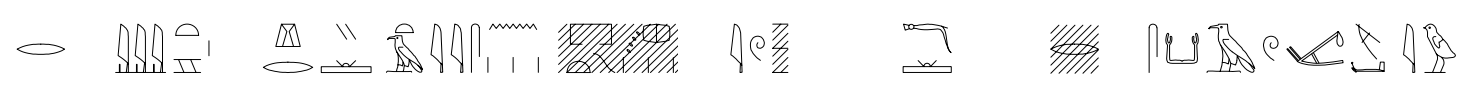

$r-\quad s h . t \quad \underline{h r}-\quad t 3 y=s n \quad[p r . t] \quad j w=w \quad m h \quad[r-] \quad s k 3 \quad j w$

PRÄP. SBST.-FEM.PRÄP. POSS.-3pc SBST.-FEM. CNVRT-3pc STAT.3pc PRÄP. INF.

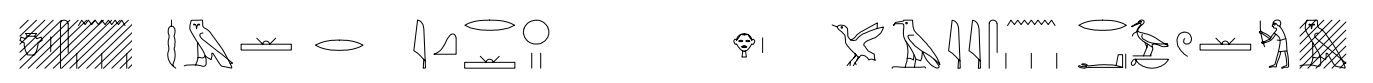

$[j b=s n] n d m \quad r-\quad j q r \quad z p-s n . w y \quad h r-p 3 y=s n \quad r^{2}-c_{-} b 3 k \quad[m-p 3 y=s n]$

SBST.-3pcSTAT.:3pc PRÄP. ADV. $\quad$ SBST.-NUM.-du PRÄP. POSS.-3pc $\quad$ SBST.-SBST. PRÄP. POSS.-3pc

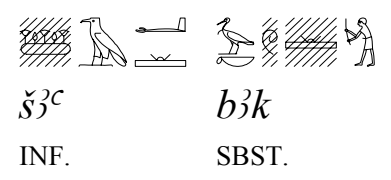

Bei Anbruch des folgenden Tages gingen sie auf's Feld mit ihrem Saatgut, und sie beendeten das Pflügen, dann entspannten sie sich völlig von ihrer Tätigkeit bei ihrer Arbeit. ( ${ }^{\circ} i h r e$ Herzen waren sü $\beta^{\circ}$ )

E-54 3,1-3,2

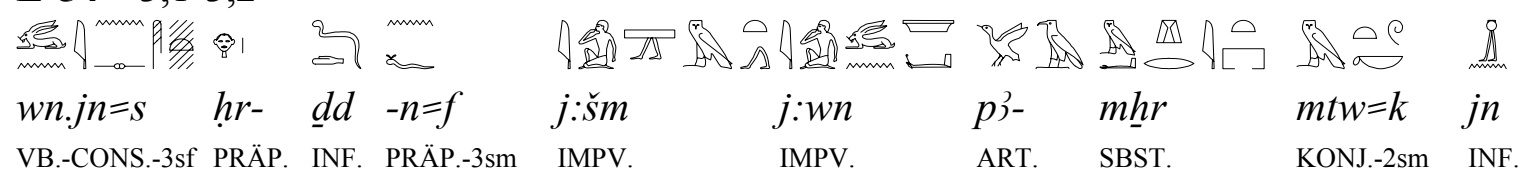

$\infty$

- $n=k \quad$ pi-nty $\quad m-\quad j b=k$

PRÄP.-2sm ART.-REL. PRÄP. SBST.-2sm

Da sagte sie zu ihm: "Geh und öffne den Speicher und hol Dir, was dein Herz begehrt".

403 Lichtheim (1976: 203); Quirke (1996: 388). 
E-55 3,2-3,3

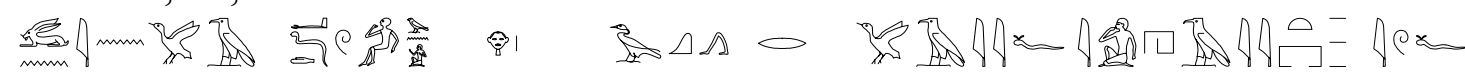
wn.jn pj- ${ }^{c} \underline{d} d\{-n=j\} h r-\quad{ }^{c} q \quad r-\quad p 3 y=f \quad j h . w t \quad j w=f$ $\begin{array}{llll}\text { VB.-CONS. ART. SBST. PRÄP. INF. PRÄP. POSS.-3sm SBST.-FEM.PL. KB.PRÄS.I.-3sm } & \end{array}$

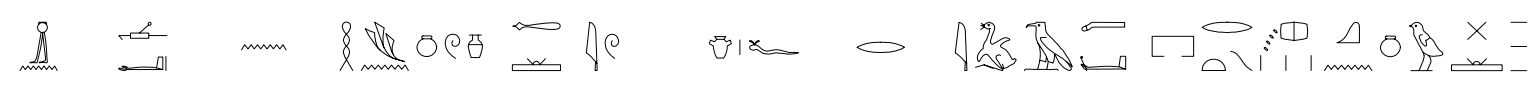
$j n \quad w^{c} \quad n-\quad h n w \quad{ }^{3} j \quad j w \quad j b=f \quad r-j t^{3} \quad$ pr.t $\quad q n w$ INF. NUM. PRÄP. SBST. ADJ. CNVRT. SBST.-3sm PRÄP. INF. SBST.-FEM. ADJ. Da ging der Jüngling in seinen Stall und holte einen großen Topf, denn seine Absicht war, verschiedenes Saatgut zu holen. $\left({ }^{\circ}\right.$ sein $\left.\mathrm{Herz}^{\circ}\right)$

E-56 3,5-3,6

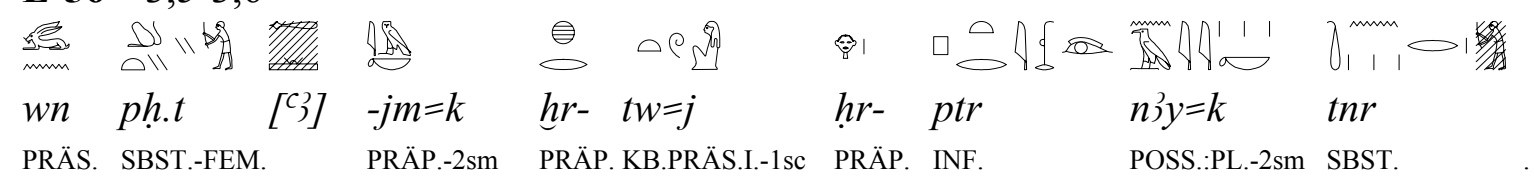

栵

$m-\quad m n . t \quad j w \quad\langle r-\rangle \quad j b=s \quad r h=f \quad m-\quad r h \quad n-\quad[c h 3 w t j]$

PRÄP. SBST.-FEM.CNVRT. PRÄP. SBST.-3sf INF.-3sm PRÄP. SBST. PRÄP. SBST

"Du bist sehr stark, denn ich sehe täglich deine Kräfte." Ihr Wunsch ging dahin, ihn kennenzulernen, und zwar kennenzulernen als Mann. $\left({ }^{\circ}\right.$ ihr Herz $\left.{ }^{\circ}\right)$

E-57 8,1

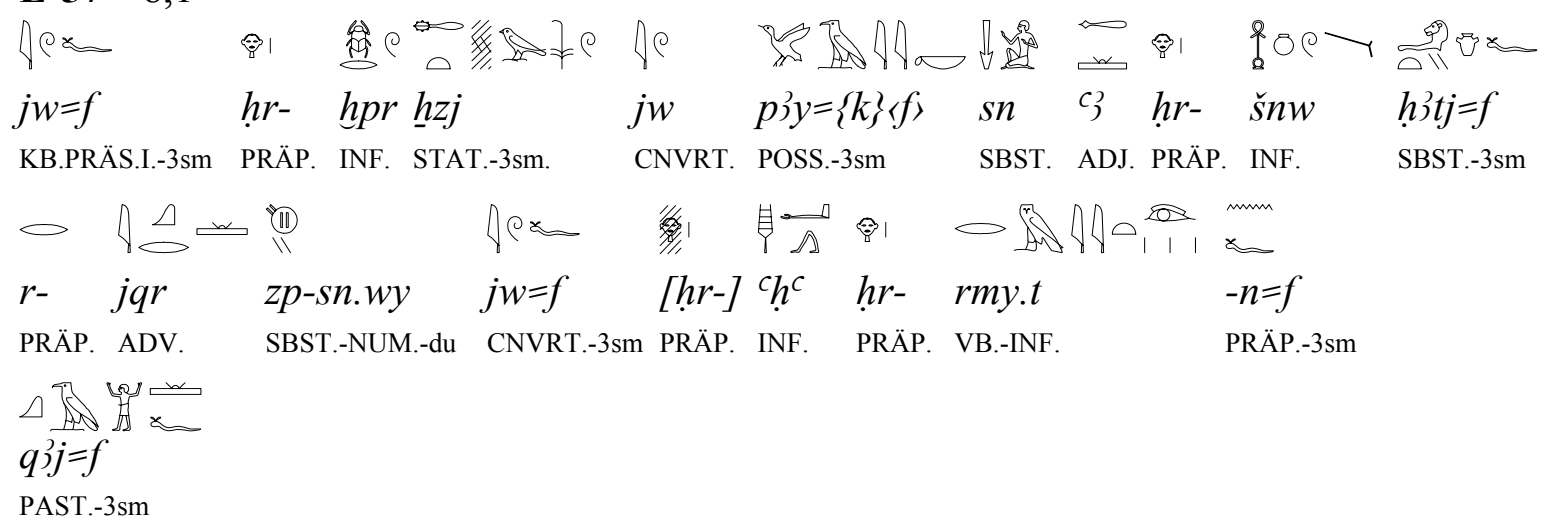

(...) und er wurde schwach, und sein ältere Bruder litt sehr an seinem Herzen, und er begann, sehr laut um ihn zu weinen.

E-58 $8,3-8,5$

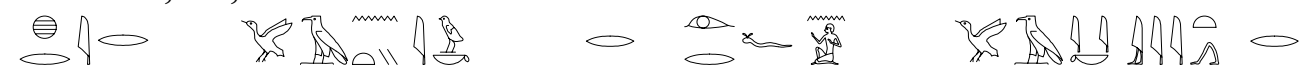

hr-jr- p3-nty jw=k r- jr=f $\quad-n=j \quad p 3 y=k \quad j j . t \quad r-$

PTCL.-PTCL. ART.-RLTVF. KB.FIII.-2sm PRÄP. INF.-3sm PRÄP.-1sc POSS.-2sm VB.-INF. PRÄP. 


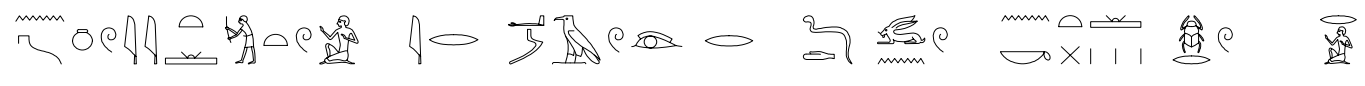

$$
n w . t=j
$$ \\ VB.-INF.-1sc \\ Doch gibt es etwas, was du für mich tun kannst: das ist zu kommen, um dich um mich zu kümmern. Wie wirst du nun erfahren, daß mir etwas zugestoßen ist? Ich werde mein Herz nehmen und es auf die Blüte der Pinie legen. Fällt man die Pinie und fällt es (das Herz) zu Boden, sollst du kommen und es suchen. Selbst wenn du 7 Jahre mit der Suche zubringst, laß deine Motivation nicht nachlassen. ${ }^{404}\left({ }^{\circ}\right.$ dein Herz nicht überdrüssig sein $\left.{ }^{\circ}\right)$}

E-59 8,9

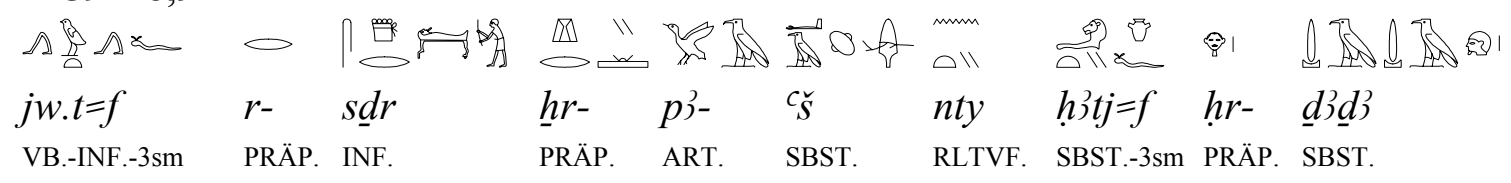

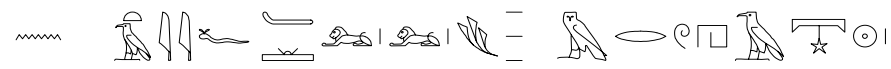

$n-\quad t 3 y=f$ hrr.t m-rwh3

PRÄP. POSS-3sm SBST.-FEM. ADV.

Er ging abends zurück, um unter dem Baum zu schlafen, auf dessen Blüte sein Herz lag.

E-60 9,5-9,6

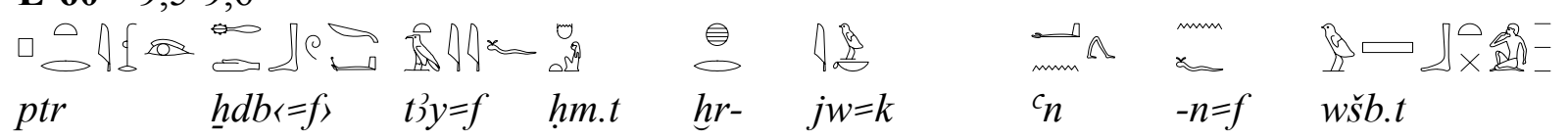

IMPV. PAST.-3sm POSS.-3sm SBST.-FEM.PTCL. KB.PRÄS.I.-2sm STAT.:2sm PRÄP.-3sm SBST.-FEM.

404 "If you spend seven years searching for it, let your heart not be disgusted" (Lichtheim 1976: 206); "If you spend seven years seeking it, do not let your heart show dislike..." (Hollis 1990: 9). 


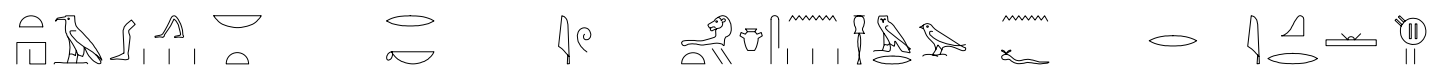

$$
\begin{aligned}
& \text { th3 nb.t }-r=k \quad j w \quad h 3 t j=s n \quad m r \quad-n=f \quad r-\quad j q r \quad z p-s n \\
& \text { SBST. INDEF.-FEM. PRÄP.-2sm CNVRT. SBST.-3pc STAT.:3pc PRÄP.-3sm PRÄP. ADV SBST.-NUM. }
\end{aligned}
$$

Sieh, er hat seine Frau getötet, und kehrst du zu ihm zurück, so wird die Verantwortung für jegliche Untat auf dir lasten. Und sie hatten überaus tiefes Mitleid mit ihm. ( ${ }^{\circ}$ die Herzen waren sehr krank ${ }^{\circ}$ )

E-61 10,1-10,4

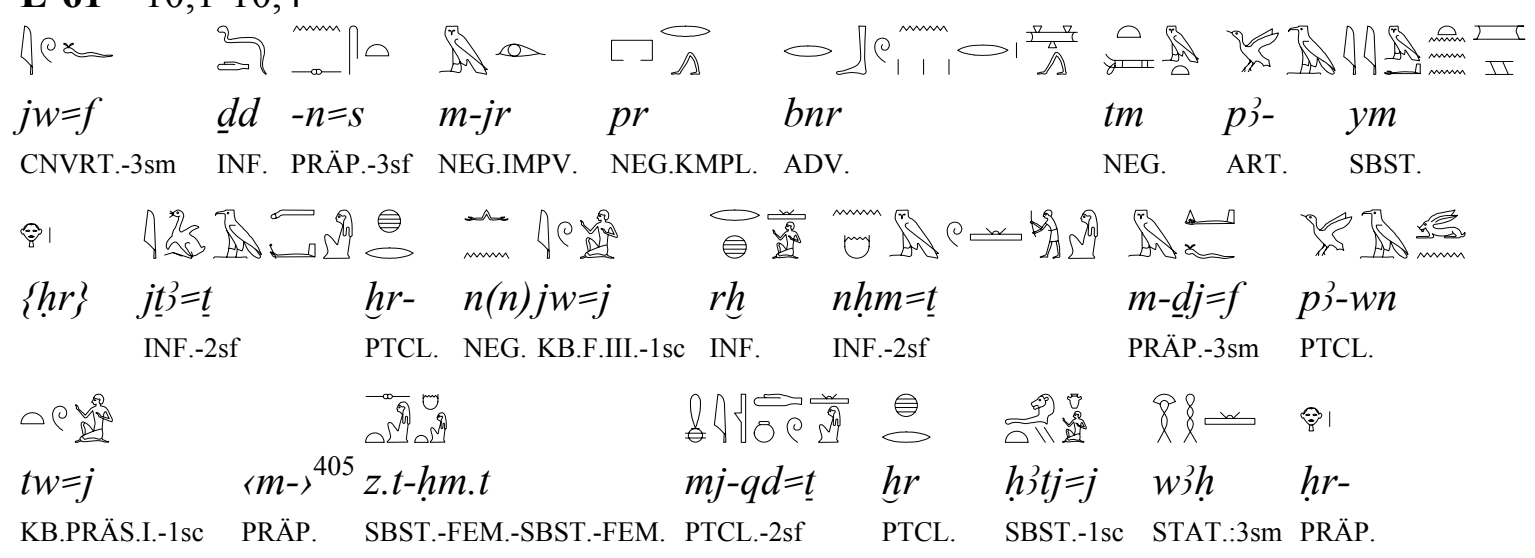

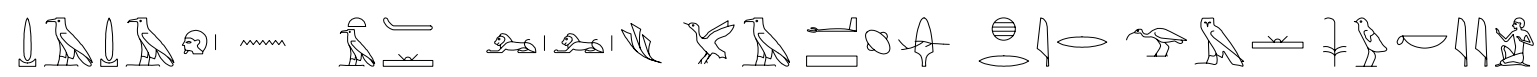

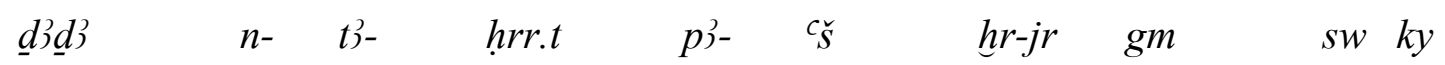

SBST. PRÄP. DEM.FEM. SBST.-FEM. ART. SBST. PTCL. FUT. 3 sm INDEF.

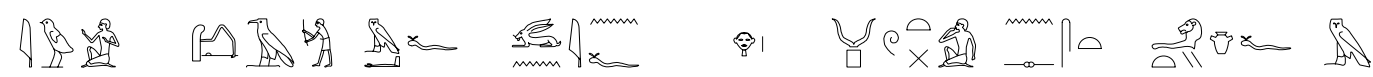

$j w=j \quad$ chj $\quad-m_{-}{ }^{c}=f \quad w n . j n=f \quad h r-\quad w p . t \quad-n=s \quad h 3 i t j=f \quad m-$

KB.F.III.-1sc INF. PRÄP.-3sm VB.-CONS.-3sm PRÄP. VB.-INF. PRÄP.-3sf SBST.-3sm PRÄP.

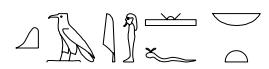

$q j=f \quad n b^{406}$

SBST.-3sm INDEF.

Und er sagte zu ihr: Geh nicht hinaus, damit das Meer dich nicht fortnehmen kann. Denn ich werde dich nicht vor ihm retten können, da ich eine Frau wie du bin, denn mein Herz liegt auf der Blüte der Pinie. Sollte ein anderer es finden, muß ich mit ihm kämpfen. Und so enthüllte er ihr seine Gedanken in jeder Weise jeglicher Art. ( ${ }^{\circ}$ sein Herz öffnen $\left.{ }^{\circ}\right)$

E-62 11,1-11,2

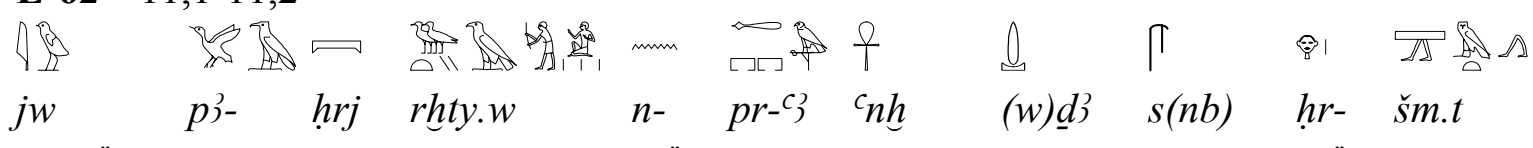

KB.PRÄS.I. ART. SBST. SBST.PL. PRÄP. SBST. STAT.:3sm STAT.:3sm STAT.:3sm PRÄP. VB.-INF.

405 Ergänzung nach Gardiners Vorschlag (1932: 19a).

$406 t$ ist nicht zu lesen. 


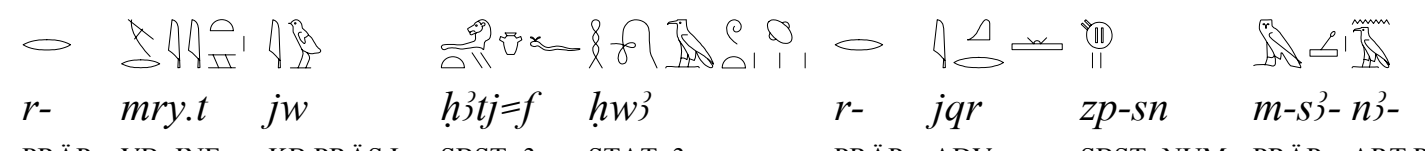

PRÄP. VB.-INF. KB.PRÄS.I. SBST.-3sm STAT.:3sm PRÄP. ADV. SBST.-NUM. PRÄP. ART.PL.

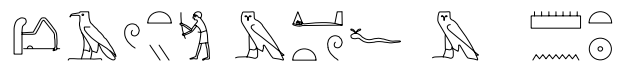

chiwty $\quad-m d j=f \quad m-\quad m n . t$

SBST. PRÄP.-3sm PRÄP. SBST.-FEM.

Der Oberwäscher des Pharao, möge er leben, wohlbehalten und gesund bleiben, ging zum Uferdamm und seine Stimmung war sehr verdrießlich wegen der täglichen Auseinandersetzungen mit ihm. $\left({ }^{\circ} \operatorname{sein} \mathrm{Herz}^{\circ}\right)$

E-63 12,4-12,7

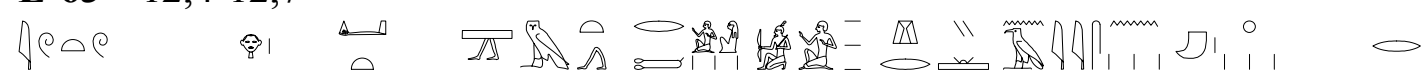
jw.tw $\quad h r-\quad \underline{j} . t \quad \check{s} m . t \quad r m \underline{t} \quad m \check{s}^{c} \quad \underline{h r}-\quad n j y=s n \quad \underline{h m} .(w) t \quad r-$ KB.PRÄS.I-indef PRÄP. VB.-INF. SUBJ. SBST. SBST. PRÄP. POSS.:PL.-3pcSBST.-PL.FEM. PRÄP.

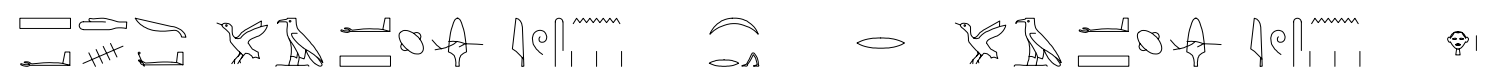
$\check{s}^{c} d \quad p 3-\quad c_{\breve{S}} \quad j w=s n \quad s p r \quad r-\quad p 3-\quad c_{\breve{S}} \quad j w=s n \quad h r-$ INF. ART. SBST. KB.PRÄS.I.-3pc INF. PRÄP. ART. SBST. KB.PRÄ.I-3pc PRÄP.

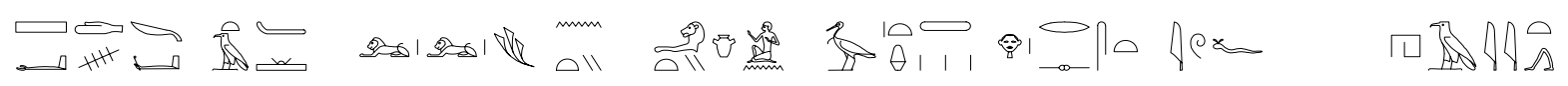
$\check{s}^{c} d \quad$ t3- hrr.t nty $h 3 t j n-\quad B 3-t 3 \quad-h r-=s \quad j w=f \quad$ h $3 y . t$ INF. ART.FEM. SBST.-FEM. RLTVF.SBST. PRÄP. PROP. PRÄP.-3sf KB.PRÄS.I.-3sm VB.-INF.

Non 1 in

$m w t \quad m-\quad t 3-\quad$ wnw.t wr.t

STAT.:3sm. PRÄP. ART.FEM. SBST.-FEM. ADV.

Man schickte gemeine Soldaten mit ihren Waffen, um die Zeder zu schneiden. Sie erreichten die Zeder und schnitten diese Blüte ab, auf der das Herz des Bata lag, und er fiel im selben Moment tot darnieder.

E-64 13,3-14,3

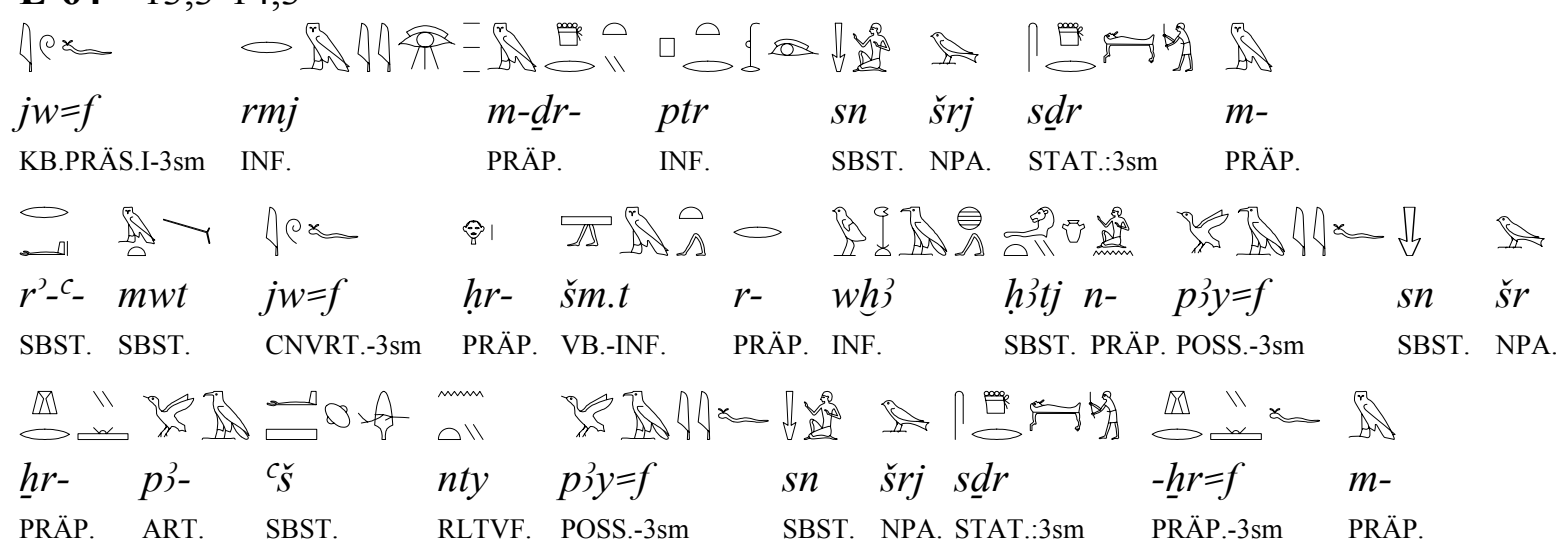




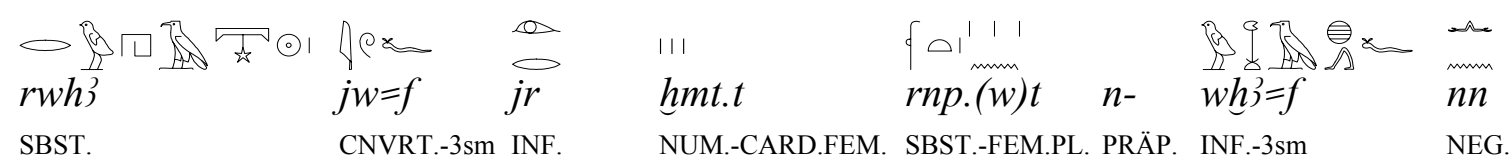

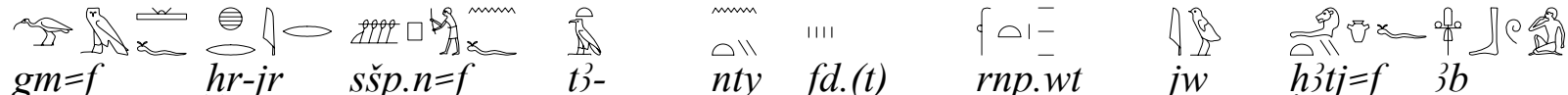
INF.-3sm TOPLR. VB.-PRÄT.-3sm ART.FEM. RLTVF.NUM.-CARD. SBST.-FEM.PL. CNVRT. SBST.-3sm INF.

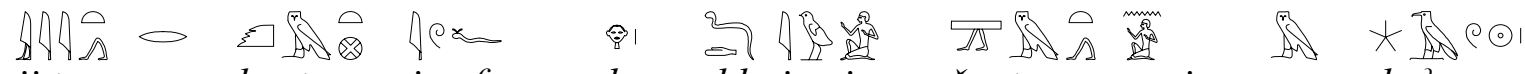
$j j . t \quad r-\quad k m . t \quad j w=f \quad h r-\underline{d d} j w=j \quad \check{s} m . t \quad-n=j \quad m-d w 3 w$ VB.-INF. PRÄP. SBST.-FEM. CNVRT.-3sm PRÄP. INF. KB.F.III.-1sc VB.-INF. PRÄP.-1sc PRÄP. SBST.

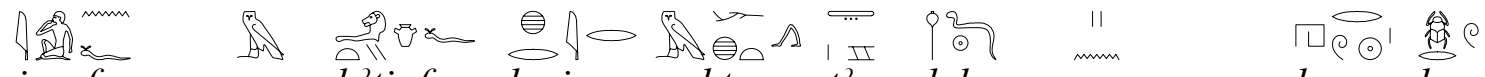

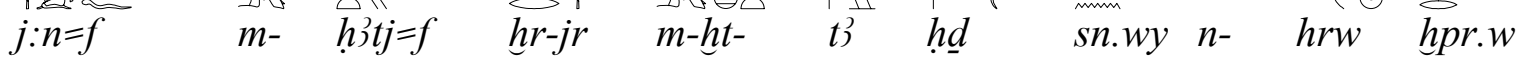
INF.-PRÄT.-3sm PRÄP. SBST.-3sm TOPLR. PRÄP. SBST. STAT.:3sm NUM.-du PRÄP. SBST. STAT.-3sm

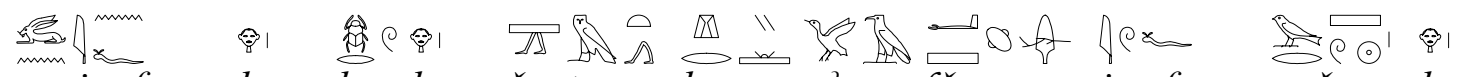

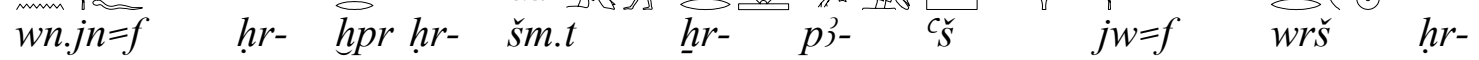
VB.-CONS.-3sm PRÄP. INF. PRÄP. VB.-INF. PRÄP. ART. SBST. CNVRT.-3sm SBST. PRÄP.

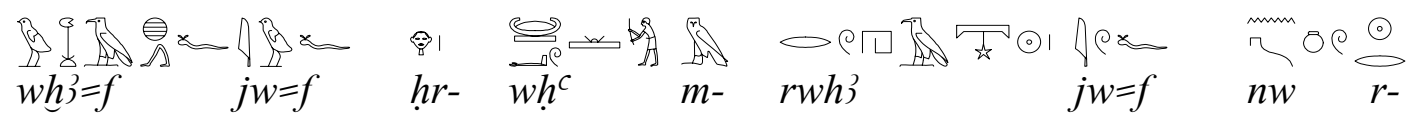
INF.-3sm CNVRT.-3sm PRÄP. INF. PRÄP. SBST.

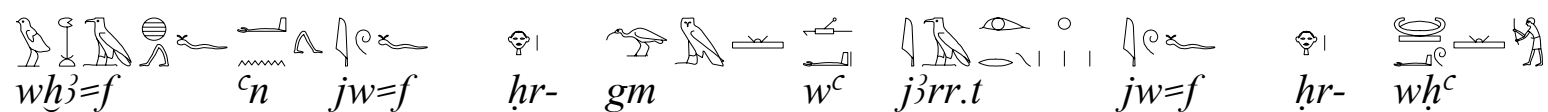
INF.-3sm ADV. CNVRT.-3sm PRÄP. INF. NUM. SBST.-FEM. CNVRT.-3sm PRÄP. INF.

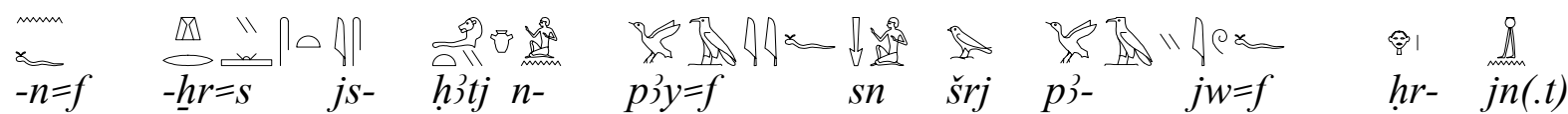
PRÄP.-3sm PRÄP.-3sf PTCL. SBST. PRÄP. POSS.-3sm SBST. NPA. ART. CNVRT.-3sm PRÄP. INF.

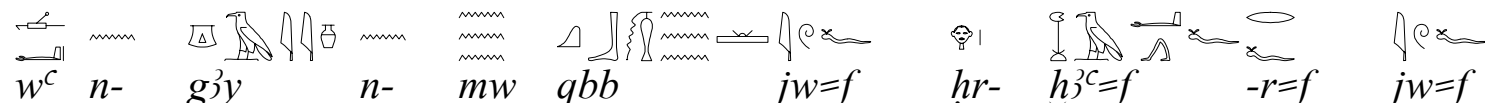
NUM.PRÄP. SBST. PRÄP. SBST. NPA. $\quad$ CNVRT.-3sm PRÄP. INF.-3sm PRÄP.-3sm CNVRT.-3sm

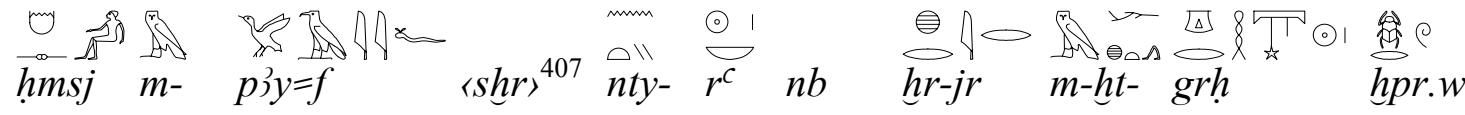
INF. PRÄP. PAST.-3sm INF. PRÄP. SBST. INDEF. TOPLR. PRÄP. SBST. STAT.-3sm

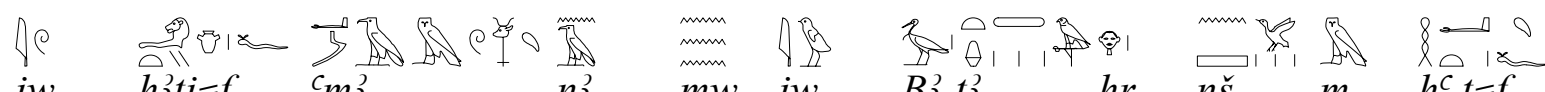

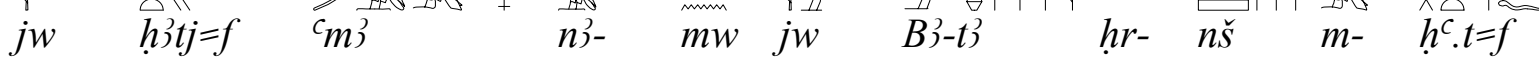
CNVRT. SBST.-3sm INF. ART.PL. SBST. CNVRT. PROP. PRÄP. SBST. PRÄP. SBST.-FEM.-3sm

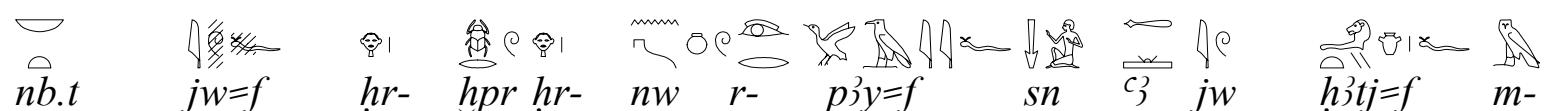
INDEF.-FEM. CNVRT.-3sm PRÄP. INF. PRÄP. INF. PRÄP. POSS.-3sm SBST. NPA. CNVRT. SBST.-3sm PRÄP. 


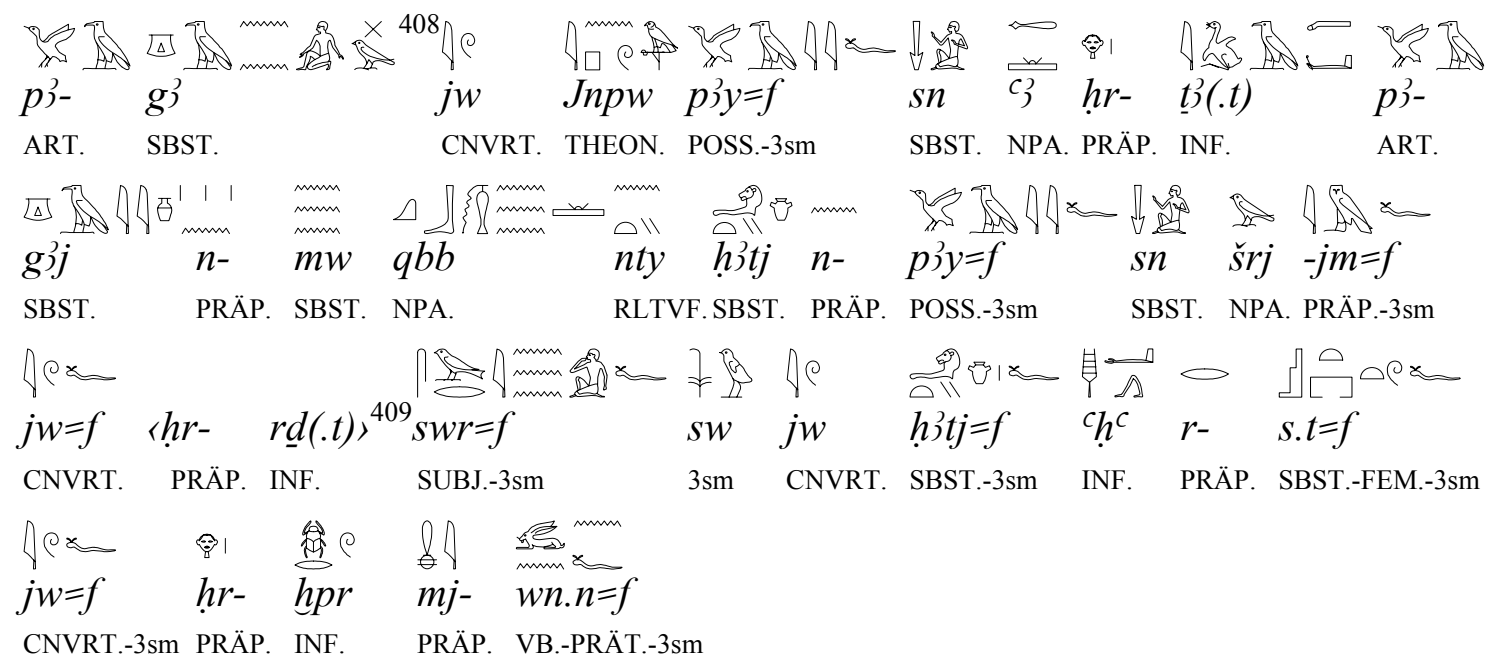

... und er weinte, als er den jüngeren Bruder im Zustand des Todes nieder liegend sah. Dann ging er, um das Herz seines jüngeren Bruders unter der Zeder zu suchen, unter der sein jüngerer Bruder am Abend schlief. Er verbrachte drei Jahre mit der Suche, ohne ihn zu finden. Nachdem das vierte Jahr fast um war, wünschte sein Herz, nach Ägypten zurückzukehren. Und er dachte: "Morgen werde ich aufbrechen." - das sagte er in seinem Herzen.

Nachdem es hell geworden und der nächste Tag angebrochen war, ging er unter die Zeder und verbrachte den Tag mit der Suche nach ihm. Am Abend hörte er auf, schaute sich aber noch einmal suchend um, und fand eine Weintraube. Er nahm sie mit und beendete seine Suche. Dies war das Herz seines jüngeren Bruders. Er holte eine Schale kühlen Wassers und er legte sie hinein. Denn er setzte sich, wie es jeden Tag machte.

Nachdem es Nacht geworden war, nahm sein Herz dies Wasser auf. Da erschauerte Bata an allen seinen Gliedern und begann, seinen älteren Bruder anzusehen, während sein Herz in der Schale war. Anubis, sein älterer Bruder, nahm diese Schale mit kühlem Wasser, in der das Herz seines jüngeren Bruders war, und er ließ es ihn trinken, und sein Herz befand sich wieder fest an seiner Stelle, und er wurde, wie er gewesen war.

E-65 16,4-16,6

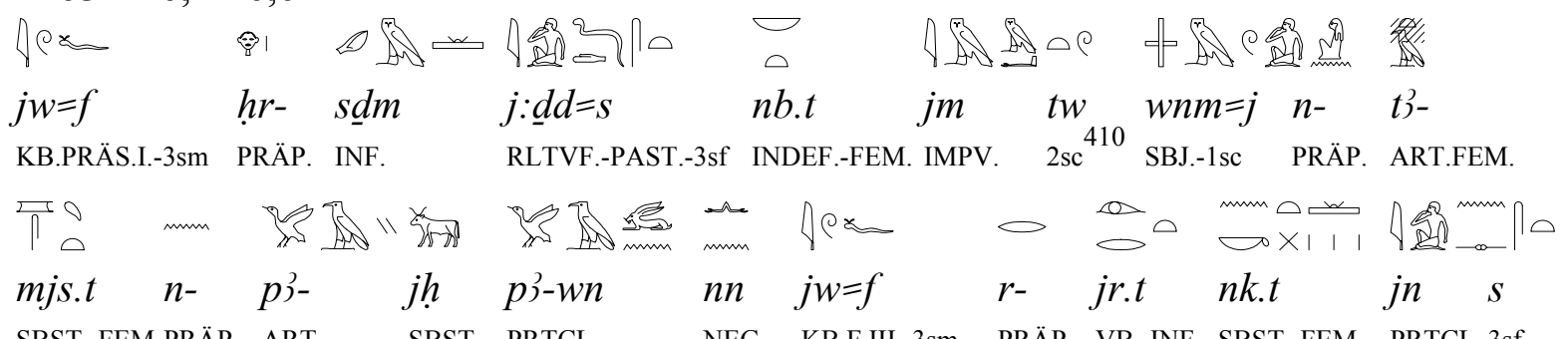

408 Das ist eine seltsame Schreibung für 'Schale', vielleicht wäre es zu lesen: $j w$ ḩ̉jj=fm $m$ 3- [g $3 j]$ gnn 'während sein Herz in der [Schale] schwach war'.

409 Ergänzung nach Gardiners Vorschlag (1932: 24a).

410 Wechseln der Person wegen der indirekten Rede, siehe dazu Peust, (1995). 


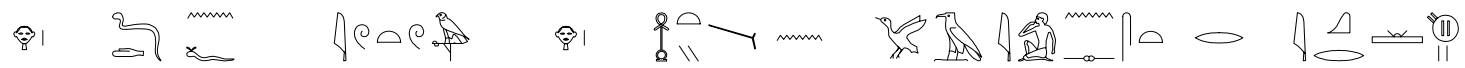

$$
\begin{aligned}
& h r-\quad \underline{d} d-n=f \quad j w=f \quad h r-\quad \check{s} n . t \quad n-\quad p j-\quad j . n=s \quad r-\quad j q r \quad z p \quad s n \text {. } \\
& \text { PRÄP. INF. PRÄP.-3sm KB.PRÄS.I.-3sm PRÄP. VB.-INF. PRÄP. RLTVF. VB.-PRÄT.-3sf PRÄP. ADV. SBST.NUM. }
\end{aligned}
$$

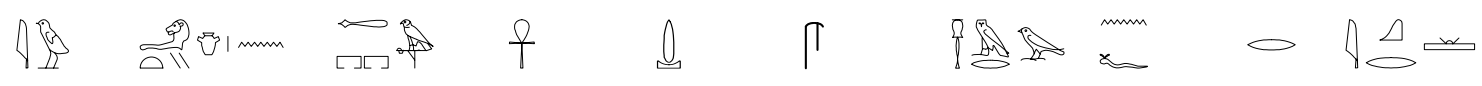

$$
\begin{aligned}
& \left.j w \quad h i j t j n-\quad p r-c^{3} \quad c_{n h} \quad(w) \underline{d}\right) \quad s(n b) \quad m r \quad-n=f \quad r-\quad j q r
\end{aligned}
$$

CNVRT. SBST. PRÄP. SBST.-SBST. STAT.:3sm STAT.3sm STAT.:3sm STAT.:3sm PRÄP.-3sm PRÄP. ADV.

(III)

$z p-s n$

SBST.-NUM.

Er hörte alles, was sie sagte: "Laß mich von der Leber dieses Rindes essen, dann wird er nichts machen," so sagte sie ihm. Er wurde sehr krank wegen dessen, was sie sagte, und das Herz des Pharao, er möge leben, wohlbehalten und gesund bleiben, hatte großes Mittleid mit ihm. ( ${ }^{\circ}$ das Herz war schlecht seinetwegen ${ }^{\circ}$ )

\section{E-66 18,5-18,6}

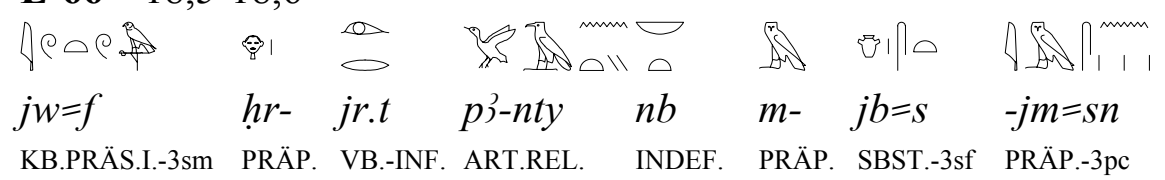

(Die Prinzessin wurde geschwängert) ... und er machte alles, was sie wünschte. $\left({ }^{\circ}\right.$ was in ihrem Herz war ${ }^{\circ}$ ) 


\section{Der verwunschene Prinz (Gardiner 1932)}

Quellen:

Datierung:

Textausgaben:

Übersetzungen:
pHarris $500=\mathrm{pBM} 10060$

XIX./XX. Dynastie ${ }^{411}$

Budge (1923: Pl. XLVIII-LII), Möller (1927: 21-24), Gardiner (1932: 1-9).

Brunner-Traut (1963: 24-28), Simpson (1972: 85-91), Lichtheim (1976: II, 200203), Galán (1998: 153-157).

E-67 4,4-4,5

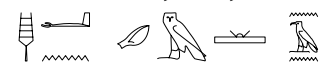

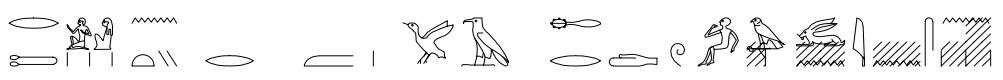

${ }^{c} h^{c} \cdot n s \underline{d} \quad n 3$

n3- $\quad n-\quad r m \underline{t}$ nty $r-\quad g s$ p3-

hrd.w

$w n . j n=s n$

PTCL. PAST.

ART.FEM. PRÄP. SBST. REL. PRÄP. SBST. ART.

SBST.-PL.

VB.-CONS.-3pc

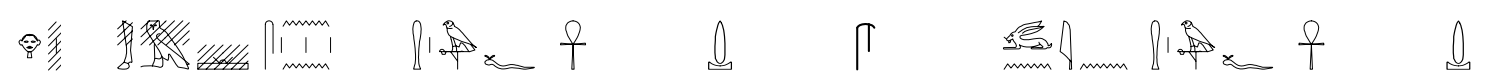

$\left.h r-\quad w h m \quad s n n-\quad h m=f \quad c_{n h} \quad(w) \underline{d}\right) \quad s(n b) \quad$ wn.jn $\quad h m=f \quad c_{n \underline{h}} \quad(w) \underline{d} 3$

PRÄP. INF. 3pc PRÄP. SBST. STAT.:3sm STAT.:3sm STAT.:3sm VB.-CONS. SBST.-3sm STAT..3sm STAT..3sm

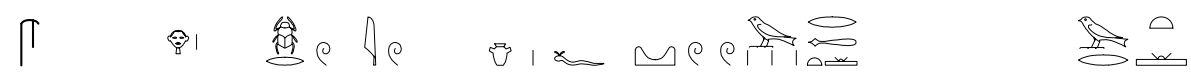

$s(n b) \quad h r-h p r \quad j w \quad j b=f \quad \underline{d} w \quad$ r $3 . t \quad$ wr.t

STAT.:3sm PRÄP. INF. CNVRT. SBST.-3sm ADJ. PRÄP. SBST.-FEM. ADV.-FEM.

Da hörten dies Leute, die bei dem Jungen waren. Sie erzählten es seiner Majestät, er möge leben, wohlbehalten und gesund bleiben. Daraufhin verfiel seine Majestät, er möge leben, wohlbehalten und gesund bleiben, in eine ganz niedergeschlagene Stimmung. $\left({ }^{\circ}\right.$ sein Herz wurde schlecht ${ }^{\circ}$ )

E-68 4,10

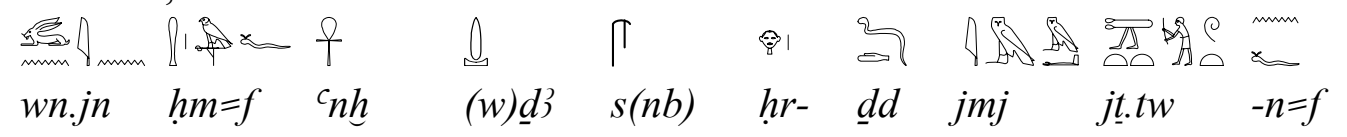

VB.-CONS. SBST.-3sm STAT.3sm STAT.3sm STAT.3sm PRÄP. INF. IMPV. SBJ.-PASS. PRÄP.-3sm

占盛

$w^{c} \quad n-\quad k t k t \quad \check{s} r j \quad\left[\begin{array}{lll}r- & b j g j] & h 3 t j=f\end{array}\right.$

INDEF.ART. PRÄP. NPA. NPA. PRÄP. INF. SBST.-3sm

Seine Majestät, er möge leben, wohlbehalten und gesund bleiben, sagte: "Laß ihm einen kleinen Welpen bringen, damit er endlich Ruhe gibt. ${ }^{412}\left({ }^{\circ}\right.$ daß sein Herz müde wird $\left.{ }^{\circ}\right)$

E-69 4,12-4,13

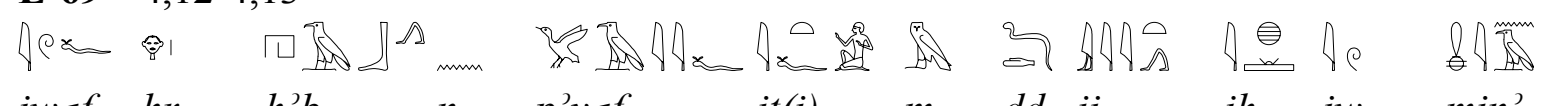

$j w=f \quad h r-\quad h 3 b \quad n-\quad p 3 y=f \quad j t(j) \quad m-\quad \underline{d} d j j \quad j h \quad j w \quad m j n 3$

TOP.-3sm PRÄP INF. PRÄP. POSS.-3sm SBST.PRÄP. INF. FUT. PTCL. CNVRT. ADV.

411 Quirke (1996: 388); Galán (1998: 131).

412 "Que le lleven un perro cachorro, (para) que esté contento" (Galán 1998: 153). 


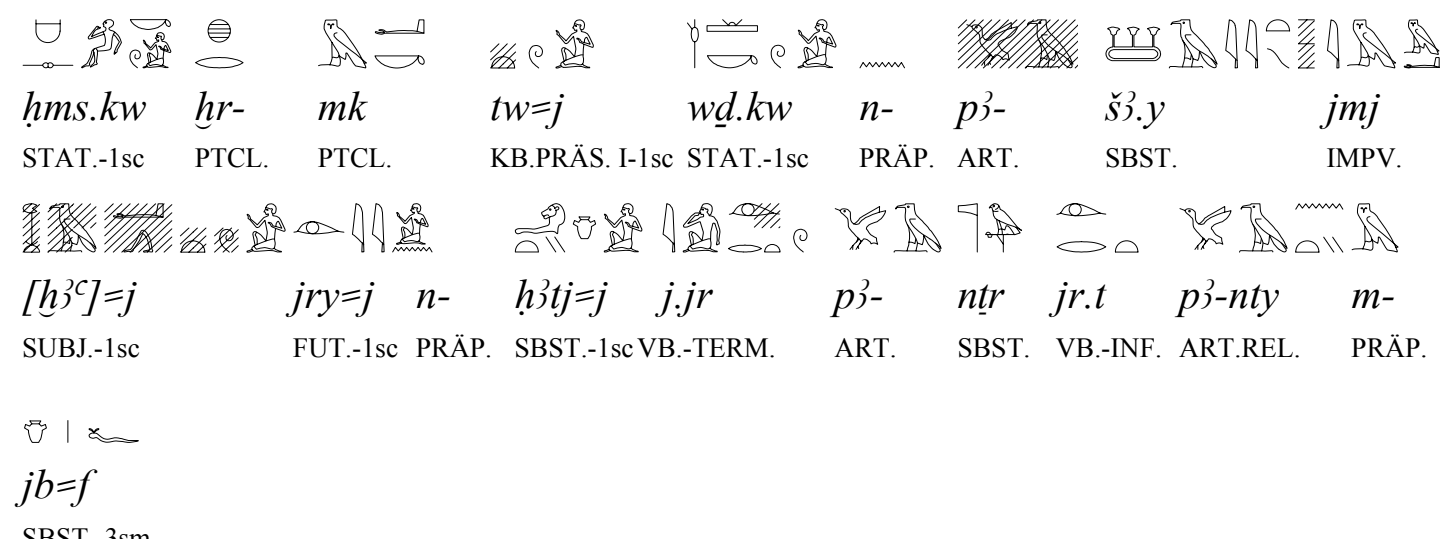

SBST.-3sm

Er (der Prinz) schrieb seinem Vater: "Was wird kommen, während ich hier sitze? Nun bin ich dem Schicksal anbefohlen. Laß mich frei und ich werde nach meinem Willen handeln, bis der Gott macht, was in seinem Herzen ist". ( ${ }^{\circ}$ meinem Herzen $\left.{ }^{\circ}\right)$

\section{E-70 5,2}

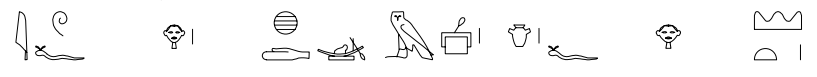

$j w=f \quad h r-$ hd $\quad m-s 3-j b=f \quad h r-h$ his.t

TOP.-3sm PRÄP. INF. PRÄP. SBST.-3sm PRÄP. SBST.FEM.

Und ganz nach seinem Willen rüstete er nach Norden ins Ausland. ( ${ }^{\circ}$ seinem Herz ${ }^{\circ}$ )

E-71 6,7

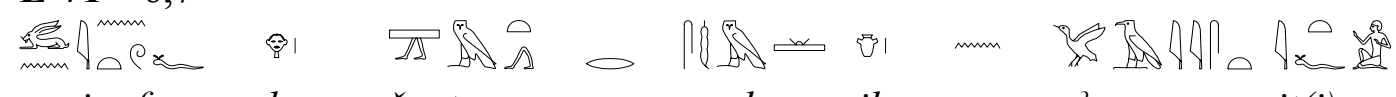

$w n . j n=f \quad h r-\quad \check{s} m . t \quad r-\quad s . n \underline{d} m \quad j b \quad n-\quad p 3 y=s \quad j t(j)$

VB.-CONS.-3sm PRÄP. VB.-INF. PRÄP. KAUS.-INF. SBST. PRÄP. POSS.-3sf SBST.

Dann ging er, um die Stimmung ihres Vaters zu heben. ( ${ }^{\circ}$ das Herz ihres Vaters zu erfreuen ${ }^{\circ}$ ) 


\section{Horus und Seth (Gardiner 1932)}

Quelle:

Datierung:

pChester Beatty I, Recto

Textausgaben:

XIX./XX. Dynastie ${ }^{413}$

Übersetzungen:

Gardiner (1931: 8-26), ib. (1932: 37-62).

Spiegel (1937), Brunner-Traut (1963: 93-107), Simpson (1972: 108-126), Lichtheim (1976: II, 214-223), Junge (1994: 83-102), Junge (1995: 930-949).

E-72 1,6

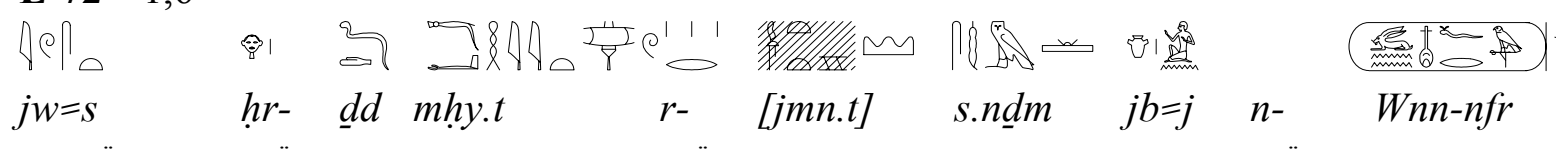

KB.PRÄS.I.-3sf PRÄP. INF. SBST.-FEM. TRÄP. SBST.-FEM. KAUS.-IMPV. SBST.-1scPRÄP. THEON.

f

$\left.c_{n h} \quad(w) \underline{d}\right\} \quad s(n b)$

STAT.:3sm. STAT.:3sm STAT.:3sm

Sie sagte: Nordwind! Zum Westen. Möge ich Wenenefer entspannen. ${ }^{414}$ ( ${ }^{\circ}$ möge mein Herz angenehm für Wenenefer $\operatorname{sein}^{\circ}$ )

E-73 1,12-2,1

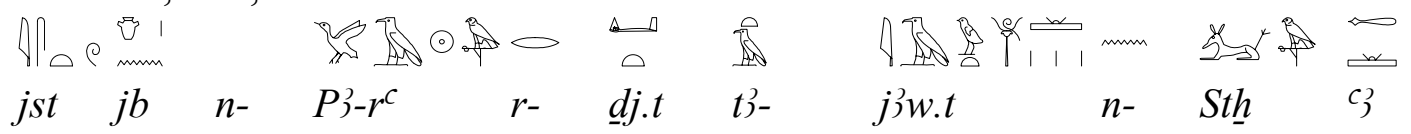

PTCL. SBST. PRÄP. THEON. PRÄP. VB.-INF. ART.FEM. SBST.-FEM. PRÄP. THEON. ADJ.

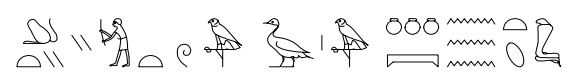

ph.ty z3 Nw.t

SBST.-FEM. SBST.THEON.FEM.

Der Wille des Pa-Re neigte aber dazu, dieses Amt an Seth, groß an Kraft, Sohn der Nut, zu geben. $\left({ }^{\circ}\right.$ das $\left.\mathrm{Herz}^{\circ}\right)$

E-74 3,10-3,11

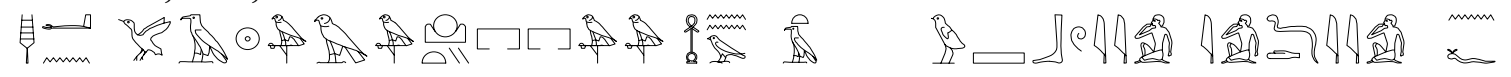

${ }^{c} h^{c} . n P 3-r^{c}-H r-3 h . t j \quad \quad \check{s} n n$ tj- wšb.t j.

PTCL. THEON.

INF. ART.FEM. SBST.-FEM. RLTVF.-VB.-PASS. PRÄP.-3sm

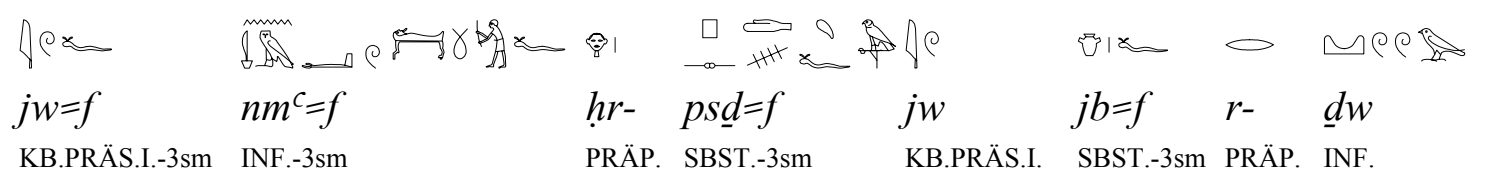

413 Quirke (1996: 389); Baines (1996: 371-376); Lichthteim (1976: 214); Junge (1995: 930).

414 "Northwind, go west, give the news to Wennofer!" (Lichthteim 1976: 214); "Nordwind, nach Westen; laß das Herz des Wenen-nefer sich freuen" (Junge 1995: 934). 


\section{$=8$ \\ C3-wr}

ADV.

Re-Harachti aber litt sehr unter der Antwort, die ihm gegeben wurde, und er legte sich auf seinen Rücken, und wurde ganz niedergeschlagen. ${ }^{415}$ ( ${ }^{\circ}$ sein Herz wurde sehr schlecht ${ }^{\circ}$ )

E-75 $3,13-4,1$

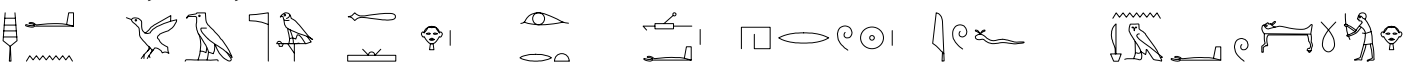

${ }^{c} h^{c} . n \quad p 3-\quad n t r \quad$ c) $h r-\quad j r . t \quad w^{c} \quad h r w \quad j w=f \quad n m^{c} \quad h r-$

PTCL. ART. SBST. NPA. PRÄP. VB.-INF. NUM. SBST. CNVRT.-3sm INF. PRÄP.

$\square\left[\begin{array}{l}n \\ -\infty\end{array}\right.$

$p s \underline{d}=f \quad m-\quad p 3 y=f \quad z h \quad j w \quad j b=f \quad(r-) \quad \underline{d w} \quad$ 3-wr $\quad j w=f$

INF.-3sm PRÄP. POSS.-3sm SBST. CNVRT. SBST.-3sm PRÄP. INF. ADV. CNVRT.-3sm

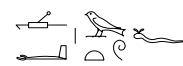

$w^{c} \cdot t=f$

VB.-INF.-3sm

Dann verbrachte dieser große Gott einen Tag damit, in seinem Pavillon auf seinem Rücken zu liegen, während er ganz niedergeschlagen war und allein blieb. ${ }^{416}$ ( ${ }^{\circ}$ sein Herz sehr war schlecht $\left.{ }^{\circ}\right)$

E-76 6,11-6,12

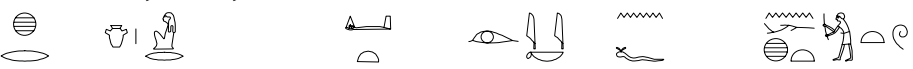

$h r-\quad j b=j \quad r-\quad \underline{d j} . t \quad j r y=k \quad-n=f \quad n h t$

PRÄP. SBST.-1sc PRÄP. VB.-INF. SUBJ.-2sm PRÄP.-3sm SBST.

Mein Willen geht dahin, dafür zu sorgen, daß du für ihn den Starken (Beschützer) machst. $\left({ }^{\circ}\right.$ mein $\left.\mathrm{Herz}^{\circ}\right)$

E-77 9,5

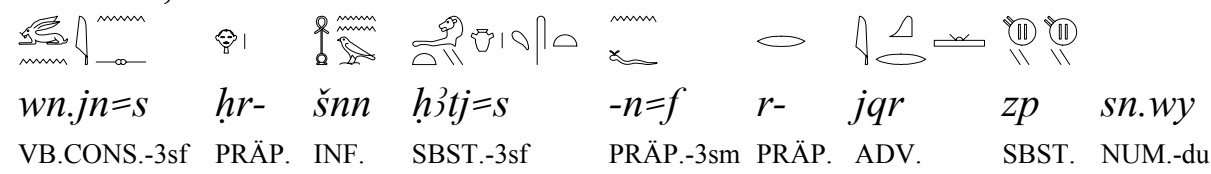

Da litt sie (Isis) seinetwegen (Seth) sehr an ihrem Herzen.

415 "... und er warf sich auf den Rücken, aufs äußerte übelgelaunt." (Junge 1995: 938)

416 "Der Große Gott aber lag einen Tag lang in seiner Amtshalle auf dem Rücken, aus äußerte übelgelaunt und mit sich allein" (Junge 1995: 938). 
E-78 $15,4-15,6$

$$
\begin{aligned}
& \text { AOMS IIIIII } \\
& j r-p 3-\quad t 3 \quad \text { nty } \quad t w=j \quad-j m=f \quad s w \quad m h \quad m-\quad w p w(t . w) \\
& \text { TOP. ART. SBST. REL. KB.PRÄS.I.-1sc PRÄP.-3sm 3sf STAT.:3sm PRÄP. SBST.-PL. }
\end{aligned}
$$

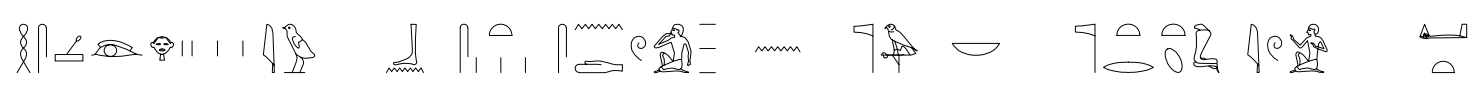

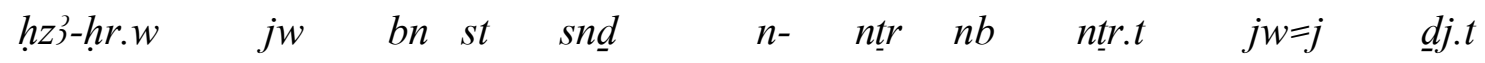

$$
\begin{aligned}
& \text { NPA.-SBST.-PL. CNVRT. NEG. 3pc INF. PRÄP. SBST. INDEF. SBST.-FEM. CNVRT.-1sc VB.-INF. }
\end{aligned}
$$

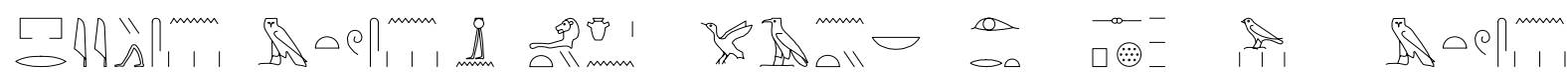

$$
\begin{aligned}
& \text { pr=sn mtw=sn jn hijtj } n-\quad \text { j3-nty } n b \quad j r . t \quad z p . w \quad \underline{d} w . w \quad m t w=s n \\
& \begin{array}{lll}
\text { SBJ.-3pc KONJ }-3 p c \quad \text { INF. SBST. PRÄP. ART.-RLTVF. INDEF. VB.-INF. SBST.-PL. NPA.-PL. KONJ.-3pc }
\end{array}
\end{aligned}
$$

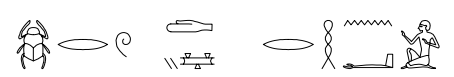

$$
\begin{aligned}
& h p r \quad d j \quad-r-h n^{c}=j \\
& \text { INF. ADV. PRÄP.-1sc }
\end{aligned}
$$

Das Land, in dem ich mich befinde, das ist voll mit Boten mit grimmigen Gesichter. Sie fürchten weder irgendeinen Gott noch eine Göttin. Ich werde sie herauslassen, und sie werden das Herz eines jeden, der übele Dinge tut, holen, und sie werden hier sein, um mit mir zu sein.

E-79 $16,2-16,3$

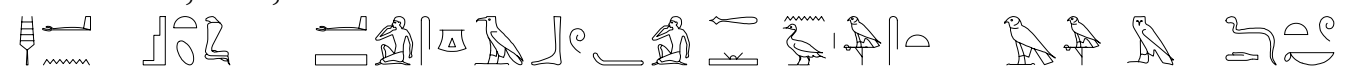

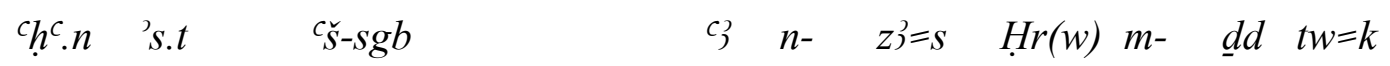

PTCL. THEON.FEM. INF. ADV. PRÄP. SBST.-3sf THEON. PRÄP. INF. KB.PRÄS.I.-2sm

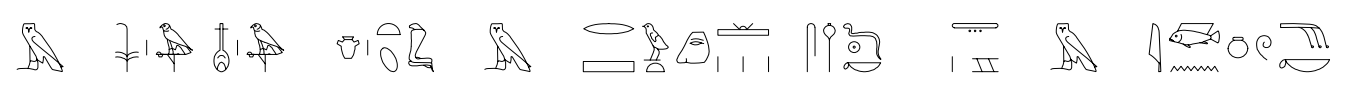

$m$ - $\quad n s w$ nfr $j b=j \quad m-\quad r s ̌ w . t \quad s h \underline{d}=k \quad t 3 \quad m-\quad j w n=k$

PRÄP. SBST. NPA. SBST.-1sc PRÄP. VB.-INF. SUBJ.-2sm SBST. PRÄP. SBST.-2sm

Dann schrie Isis sehr laut auf vor ihrem Sohn: Du bist der perfekte König. Mein Herz freut sich. Mögest du das Land mit deiner Farbe erleuchten.

E-80 16,7

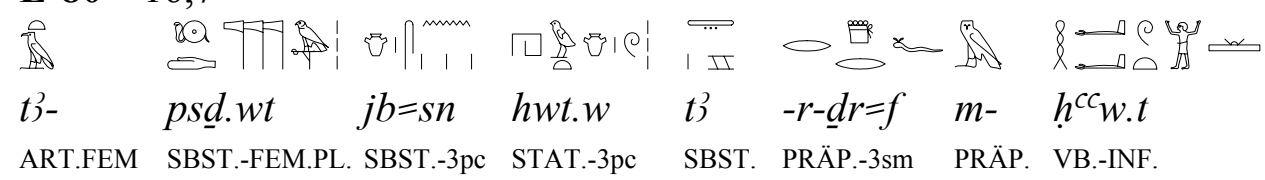

Die Neunheit, deren Stimmung ist froh. Das ganze Land jubelt. $\left({ }^{\circ} \mathrm{ihr} \mathrm{Herz}{ }^{\circ}\right.$ ) 


\section{Wenamun (Gardiner 1932)}

Quelle:

Datierung: pMoskau 120

Textausgaben: XXI. Dynastie ${ }^{417}$

Übersetzungen:

Golenischeff (1889: 74-102), Möller (1927: 29), Gardiner (1932: 61-76), Korostovtsev (1960).

Erman (1923: 225-237), Wilson (1969: 25-29), Gardiner (1961: 306-313), Simpson (1972: 142-155), Lichtheim (1976: II, 224-232), Blumenthal (1982: 27-40), Galán (1998: 200-208).

E-81 2,49

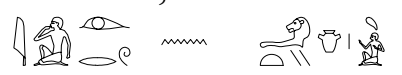

$j: j r \quad n-\quad h 3 t j=j$

IMPV. PRÄP. SBST.-1sc

Handle nach meinem Wunsch. $\left({ }^{\circ}\right.$ meinem Herzen $\left.{ }^{\circ}\right)$

E-82 2,68-2,69

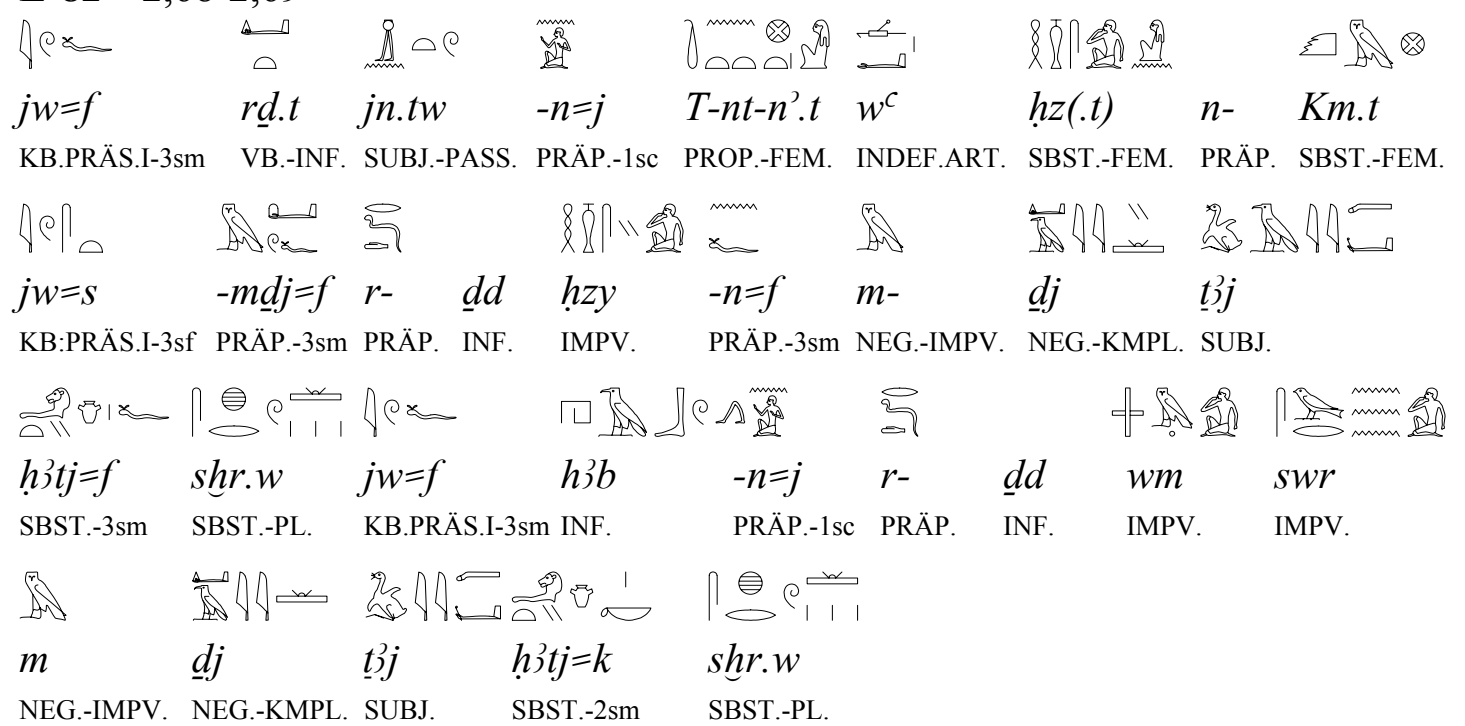

Er schickte Tananat zu mir, eine Sängerin aus Ägypten, die bei ihm war, mit den Worten: "Singe für ihn, laß nicht zu, daß sein Verstand an die Angelegenheit denkt, und ließ mir ausrichten: $\mathrm{I} \beta$, trink und laß nicht $\mathrm{zu}$, daß dein Verstand an die Angelegenheit denkt". ${ }^{418}$ $\left({ }^{\circ} \operatorname{sein} \operatorname{Herz}^{\circ} /{ }^{\circ}\right.$ dein $\left.\operatorname{Herz}^{\circ}\right)$

417 Galán (1998: 181); Caminos (1979: 3-5); Lichtheim (1976: 224); Baines (1996: 159 u. 171-172); Quirke (1996: 389)

418 "Sing for him! Do not let his heart be anxious'. And he sent to me, saying: 'Eat, drink; do not let your heart be anxious" (Lichtheim 1996: 229); "Cántale. No permitas que se preocupe' Y él me escribió, diciendo: 'Come; bebe; no te preocupes'..." (Galán (1998: 207). 


\section{Kapitel}

\section{SCHLUSSFOLGERUNGEN}

\subsection{Grammatische Kontexte der Lexeme}

In den im Rahmen dieser Untersuchung behandelten Textbeispielen kommen sowohl $j b$ als auch $h j i j$ in unterschiedlichen syntaktischen Kontexten vor. Jedes der beiden Lexeme kann beispielsweise mit oder ohne suffigiertes Personalpronomen erscheinen, ein Indefinitpronomen bei sich haben, als Komplement von einer Präposition abhängen, den Nukleus eines Nominalkompositums oder eines anderen Possessivausdrucks bilden, im Plural auftreten, oder im Singular mit suffigiertem Pluralpronomen. Die folgende Tabelle gibt einen groben Überblick über die häufiger oder auch nur gelegentlich auftretenden syntaktischen Umgebungen, in denen $j b$ und $h 3 t j$ innerhalb des ausgewerteten Korpus erscheinen.

\begin{tabular}{||l|l|l||}
\hline \hline SYNTAKTISCHE UMGEBUNG & BEISPIELE MIT $j b$ 'HERZ' & BEISPIELE MIT $h$ htj 'HERZ' \\
\hline artikellos und ohne Suffixpronomen & W-1, W-4, W-5, W-12, W-15, W-18, & W-70, W-77, W-109, W-141, \\
& W-19, W-20, W-31, W-36, W-38, W49, & W-143, W-145, W-146, \\
& W-51, W-53, W-56, W-58, W-60, W62, & W-149, W-151, W-157 (10 \\
& W-65, W-67, W-68, W-70, W71, W-72, & Stellen) \\
& W-77, W-91, W-94, W109, W-132, & \\
& W-142, W-148 (30 Stellen); & \\
& E-14, E-15, E-22, E-35 (4 Stellen) & \\
& L-4; L-6; L-11; L-24 (4 Stellen) & \\
\hline artikellos mit Suffixpronomen & (zahlreiche Stellen) & (zahlreiche Stellen) \\
\hline als Komplement einer Präposition, & W-10, W-11, W-58, W-63, W-78, & \\
ohne Suffixpronomen & W105, W-106 (7 Stellen); & \\
& E-17, E-18, E-37 (3 Stellen); & \\
& L-24 & \\
\hline als Komplement einer Präposition, & W-100, W-102 (2 Stellen); \\
mit Suffixpronomen & E-52, E-54, E-66, E-69 (4 Stellen) & \\
\hline mit bestimmtem Artikel & W-152; & \\
& E-44, E-47 (2 Stellen); & \\
\hline L-7 & W-163 & L-8, L-22 (2 Stellen) \\
\hline mit Possessivartikel & W-67; & \\
& E-32 & E-32 \\
\hline als Nukleus oder Satellit eines & W-21, W-44, W-49, W-70, & \\
\hline Kompositums ("direkter Genitiv") & W-96 (5 Stellen); & \\
& E-44 & \\
\hline & L-10 & \\
\hline
\end{tabular}




\begin{tabular}{|c|c|c|}
\hline SYNTAKTISCHE UMGEBUNG & BEISPIELE MIT $j b$ 'HERZ' & BEISPIELE MIT ḥitj 'HERZ' \\
\hline $\begin{array}{l}\text { als Nukleus eines oder Satellit "in- } \\
\text { direkten Genitivs" }\end{array}$ & $\begin{array}{l}\text { W-9, W-28, W-41, W-45, W-48, W-61, } \\
\text { W-62, W-77, W-104, W-111, W-119, } \\
\text { W-156 (12 Stellen); } \\
\text { E-36, E-42, E-43, E-71, E-72, } \\
\text { E-73 (6 Stellen) } \\
\text { L-14 }\end{array}$ & $\begin{array}{l}\text { W-144, W-166 (2 Stellen) } \\
\text { E-63, E-64, E-65, } \\
\text { E-78 (4 Stellen) }\end{array}$ \\
\hline im Plural mit Suffixpronomen & $\begin{array}{l}\text { W-92, W-138 (2 Stellen); } \\
\text { E-49 }\end{array}$ & \\
\hline im Plural ohne Suffixpronomen & $\begin{array}{l}\text { W-46, W-49, W-61, W-70, W-109, } \\
\text { W-110 (6 Stellen); } \\
\text { E-24 }\end{array}$ & W-75, W-159 (2 Stellen) \\
\hline $\begin{array}{l}\text { im Singular mit pluralischem Suf- } \\
\text { fixpronomen }\end{array}$ & $\begin{array}{l}\text { W-59, W-75, W-92, W-118, W-121, } \\
\text { W124, W-133 (7 Stellen); } \\
\text { E-3, E-12, E-53, E-60, E-80 (5 Stellen); } \\
\text { L-10 }\end{array}$ & $\mathrm{W}-121$ \\
\hline
\end{tabular}

Bei den nicht einzeln nachgewiesenen Beispielen handelt es sich durchgängig um solche, in denen $j b$ oder $h i j t j$ im Status pronominalis, d.h. mit einem suffigierten (singularischen) Personalpronomen versehen, erscheinen, im Singular stehen und nicht von einer Präposition abhängen. Auf eine statistische Auswertung der Aufstellung wird aus mehreren Gründen verzichtet:

(1) Die Aufteilung der Gebrauchsweisen in einzelne Untergruppen ist keine nach strengen Kriterien durchgeführte Klassifikation, sondern bloß eine für praktische Zwecke vorgenommene Sortierung des Materials. So ist dabei etwa nicht berücksichtigt, daß mit nicht vergleichbaren Merkmalen gearbeitet wird und einige der Gruppen im Grunde Teil einer anderen sind (die pluralischen Verwendungen oder die - artikellosen - Fälle des Gebrauchs in Abhängigkeit von einer Präposition gehören natürlich eigentlich mit in die Gruppen "artikellos mit/ohne Suffixpronomen"). Die Tabelle soll hauptsächlich dazu dienen, charakteristische Verwendungsweisen herauszustellen.

(2) Um nicht eine zu starke Zersplitterung in winzige Untergruppen zu erhalten, wurde das Material nicht zeitlich differenziert. Das wäre aber für eine statistische Betrachtung, bei der Vorhandensein oder Fehlen des definiten Artikels ein Kriterium darstellt, notwendig, denn dieses Merkmal ist nur in jüngeren Texten sinnvoll, weil das Alt- und Mittelägyptische normalerweise überhaupt keine Artikel verwenden.

(3) Die geringe Zahl der Belege für bestimmte Gebrauchsweisen würde vermutlich keine signifikanten Ergebnisse erbringen.

Wenn alle Vorkommensweisen der Wörter für 'Herz' miteinander verglichen und einander gegenübergestellt werden, sollten sich vielleicht einige Feststellungen darüber machen lassen, inwiefern bestimmte Konstruktionen bestimmte Bedeutungen implizieren können. Darum werden im Folgenden wird jede der syntaktischen Distributionen gesondert betrachtet. 


\section{$\Rightarrow \quad$ Artikellos und ohne Suffixpronomen}

Bei näherer Betrachtung der Beispiele, muß man feststellen, daß $j b$ und $h 3$ j $t j$ besonders häufig in den Weisheitstexten vorkommen und dann oft ohne Suffix und ohne Artikel stehen. Wenn man die Beispiele dieser Gruppe genauer betrachtet und nach inhaltlichen Gemeinsamkeiten sucht, ergeben sich folgende Beobachtungen:

- Auslassung des Suffixes,

- In etlichen Fällen bietet sich eine Interpretation des Lexems für 'Herz' als 'Verstand' an,

- Angeredetes Kollektiv

Die erste Gruppe Auslassung des Suffixes enthält die Beispiele, in denen eine Person spricht oder über eine Person gesprochen wird, zu der das 'Herz' gehört. Das entsprechende Suffixpronomina mit den Lexemen tritt also nicht auf.

In der zweiten Gruppe ist das 'Herz' als 'Verstand' zu verstehen, wobei in mindestens zwei von drei Beispielen die Besonderheit auftritt, daß das Herz bzw. der Verstand nicht derjenigen Person gehört, die im Mittelpunkt der Aussage steht. In W-68 wird gesagt: 'Ach hätte ich für mich ein Herz mit Wissen, welches ertragen kann' ( $h j-n=j$ jb $m$ - rh $w h d$ ), in W-149: 'Deine Ausführungen hingegen sagen dem Herzen zu, so daß der Verstand dazu neigen wird, sie

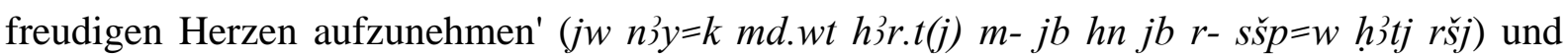
schließlich in E-14: 'Der Verstand vergißt, woran er sich erinnern sollte' (jb hr- s.h.jj.t $-n=f)$. Das letzte Beispiel könnte man auch so verstehen, daß das 'Herz' sich auf den Sohn des Meru bezieht. Man könnte es jedoch - wie in den anderen Beispielen - auch so verstehen, daß das 'Herz' ganz allgemein den Verstand bezeichnet und als generelles Konzept des Vernünftigen $\mathrm{zu}$ verstehen ist.

Zur dritten Gruppe werden die Beispiele gezählt, die als 'das Herz eines Kollektivs' interpretiert werden können. In allen Beispielen dieser Gruppe, die bemerkenswerterweise nur in den Weisheitstexten vorkommen, ist eine Anonymität anwesend. Für solche Texte, die Maxime oder Sprüche beinhalten, ist die Anonymität des Subjekts ein Charakteristikum. Dies ermöglicht, daß jeder sich angesprochen fühlt (Lichtheim 1996: 243-262 und Loprieno 1996: 403-414).

Die Beispiele, die unter das Stichwort unter Befinden eingeordnet wurden, sind schon in Kapitel 5 analysiert worden. In beiden Fällen läßt sich das Lexem $j b$ nicht nur auf eine Weise interpretieren, sei als Wort für ein Körperorgan oder den Charakter in W-1, sei es als Teil eines metaphorischen Ausdrucks für 'Schmerzen' in W-58. Die anderen Beispiele (siehe Kapitel 5, Gruppe 3), in denen eines der Lexeme für 'Herz' als Bezeichnung für das Körperorgan verstanden werden sollte, zeichnen sich durch das Vorhandensein eines Suffixpronomens aus. Man könnte erwägen, ob die Abwesenheit des Suffixes in den Beispielen W-1 und W-58 der Grund dafür ist, das man es nicht als körperliches Organ zu interpretieren hat. Man kann aber diese Behauptung nicht sicher aufstellen, da die anderen 
Beispiele auch fragwürdig zu verstehen sind. ${ }^{419}$

Der letzte Gruppe enthält diejenigen Beispiele, in denen das Herz als 'Stimmung' wiedergegeben wurde.

Die gesamten Beispiele lassen sich folgendermaßen ordnen:

\begin{tabular}{||l|l|l|l||}
\hline & \multicolumn{1}{|c|}{ WEISHEITSTEXTE } & ERZÄHLUNGEN & \multicolumn{1}{|c||}{ LIEBESLIEDER } \\
\hline $\begin{array}{l}\text { Auslassung eines } \\
\text { Suffixes }\end{array}$ & $\begin{array}{l}\text { W-38, W-62, W-60, W-72; W-132, W-141*, } \\
\text { W-142*20, W-145* }\end{array}$ & E-15, E-22, E-35 & $\begin{array}{l}\text { L-4, L-6, L-11, } \\
\text { L-24 }\end{array}$ \\
\hline Verstand & $\begin{array}{l}\text { W-5; W-15; W-19; W-20; W-65; W-68; W- } \\
71 ; \mathrm{W}-143^{*} ; \mathrm{W}-148 ; \mathrm{W}-149^{*}\end{array}$ & E-14 & $\varnothing$ \\
\hline anonymes Kollektiv & $\begin{array}{l}\text { W-1, W-4, W-31, W-36,W-49, W-53, W-56, } \\
\text { W-67, W-70*, W-91, W-94, W-109, } \\
\text { W-146*, W-151 }\end{array}$ & $\varnothing$ & $\emptyset$ \\
\hline körperliches Befinden & W-1, W-58 & & \\
\hline Stimmung & W-18; W-77*; W-148; W-157* & $\varnothing$ & $\emptyset$ \\
\hline
\end{tabular}

\section{$\Rightarrow \quad$ als Komplement einer Präposition, ohne oder mit Suffixpronomen}

Es gibt bestimmte Ausdrücke, in denen das Lexem $j b$ in Abhängigkeit von einer Präposition, aber ohne suffigiertes Suffix vorkommt. Hingegen ist hỉtj als Komplement von Präpositionen in dem bearbeiteten Korpus nicht belegt. Ob das Zufall ist, oder eine sprachgeschichtliche Besonderheit darstellt, ist unklar. Auf jeden Fall steht fest, daß zumindest im Jüngeren Ägyptisch auch $h 3$ itj in Präpositionalphrasen erscheinen kann.

Bei den Beispielen handelt es sich um Adverbialphrasen, die nicht von einem Verb abhängig sind, so daß eine spezifische Bedeutung der Präposition, die sich aus ihrem Verhältnis zum Verb ergäbe (etwa als ein mit zur Verbalrektion gehörendes Element), ausgeschlossen werden kann. Die Beispiele nach einer Präposition und ohne Suffixpronomen sind die folgenden:

\begin{tabular}{||l|l|l|l||}
\hline \multicolumn{1}{|c|}{ PRÄPOSITION } & \multicolumn{1}{|c|}{ WEISHEITSTEXTE } & \multicolumn{1}{|c||}{ ERZÄHLUNGEN } & LIEBESLIEDER \\
\hline - $h r$ - 'auf' & W-10, W-11, W-63, W-78 & E-12 & $\varnothing$ \\
\hline$m$ - 'in' & W-58, W-106 & E-17, E-18, E-37 & L-24 \\
\hline
\end{tabular}

Wenn man diese Fälle mit jenen vergleicht, in denen die Lexeme mit denselben Präpositionen, aber mit suffigiertem Suffix vorkommen, stellt man keinen Unterschied fest. Sowohl mit Suffix als auch ohne haben die Präpositionen die gleiche Funktion, nämlich das räumliche Verhältnis zu der Örtlichkeit zu bezeichnen, an der etwas Abstraktes (W-10: 'Böses', W-11 und W-63: 'die Rede', W-58: 'Schmerzen', W-78: 'Geschrei der Sünde', 'etwas': E-17, E-18) oder auch Konkretes (E-12: 'das Futter') lokalisiert wird. 
Bisher wurde nur festgestellt, daß die Lexeme $j b$ und $h 3 t j$ am häufigsten im Status pronominals, also mit einem suffigierten Personalpronomen, das den Possessor ausdrückt, vorkommen. ${ }^{421}$ Hingegen gibt es nur wenige Beispiele, in denen die Lexeme mit einem definiten Artikel, einem Demonstrativum oder einem Indefinitpronominen auftreten. Diese Fälle sind die folgenden:

\begin{tabular}{||l|l|l|l||}
\hline & WEISHEITSTEXTE & ERZ̈̈HLUNGEN & LIEBESLIEDER \\
\hline mit bestimmtem Artikel & W-152, & E-44, E-47 & L-7 \\
\hline mit Possessivartikel & W-163 & $\varnothing$ & L-8*, L-22* \\
\hline \hline
\end{tabular}

Die Beispiele mit dem bestimmten Artikel (W-152: p3- ḩ3tj hlm.w 'du begriffsstutziges Herz', E-44: $p 3-j b j t y$ 'das Herz der Majestät', E-47: $h n w . t=j$ jrr $=t p 3-j b h r-m$ 'Meine Herrin, warum bist Du in der Stimmung?', L-7: $p 3-j b h r-w h 3=k{ }^{\prime}($ das, ) weswegen das Herz dich sucht') oder mit dem Possesivartikel (W-163: hms $p^{3}-j^{c} n$ r-gs- $t 3$ mh3y.t jw p3y=f jb $m$ - $d h$ her Pavian hockt neben der Waage und sein Herz dient als Lot'; L-8: $\underline{d j}=f\langle w j\rangle m-\operatorname{tp} . t n(. t)-n\}-n f r . t b w$ $h \underline{d}=f p 3 y=j h h^{3} t j$ 'Er wird (mich) an die Spitze der Schönheiten stellen und wird mich niemals kränken'; L-22: $m$ jr $-n=j p 3 y=j$ ḩ3tj 'Mache keine Dummheiten, mein Herz') zeigen keine so deutlichen Gemeinsamkeiten, daß daraus weitergehende Schlußfolgerungen gezogen werden könnten. Daß der Artikel oder Possessivartikel überhaupt stehen kann, hängt natürlich damit zusammen, daß wir es hier mit Belegen aus den zu den jüngeren Texten des Korpus zählenden Quellen zu tun haben. Als eines der für das Neuägyptische, Demotisch und Koptische typischen Merkmale fehlt der Artikel in älteren Texten normalerweise ganz. Aber in der Regel kommen auch im Jüngeren Ägyptisch in Verbindung mit Substantiven, die Körperteile oder andere inalienable Dinge bezeichnen, Artikel und Possessivartikel nicht vor. Daher ist es nicht überraschend, daß sich nur wenige Beispiele dafür finden. Eventuell läßt sich vor dem Hintergrund sogar eine gemeinsamen Kriterium für wenigstens einige der genannten Textabschnitte formulieren: in E-47 liegt $j b$ in der Bedeutung 'Stimmung' vor, und Stimmung ist im Gegensatz zu anderen Größen, auf die sich die Lexeme beziehen können, kein konstanter Bestandteil einer Person, sondern veränderbar (und damit sozusagen "veräußerlich"). In W-152 wird das Herz als Gesprächspartner angeredet, und in L-7 ist es Subjekt einer aktiven Handlung. In beiden Fällen kann man daher von einer Personifizierung sprechen, und auch das ist ein Fall, in dem es nicht um einen unveräußerlichen Körperbestandteil geht. Im Rückschluß heißt das, daß das Auftauchen eines Artikels oder Possessivartikels an Substantiven, die normalerweise Unveräußerliches bezeichnen, als Hinweis auf eine spezielle Bedeutung der entsprechenden Lexeme in dem jeweiligen Kontext gewertet werden darf.

421 Die Beispiele, die in der Tabelle nicht explizit genannt wurden, sind solche, in denen das jeweilige Lexem für 'Herz' mit einem suffigierten Personalpronomen vorkommt. 
$\Rightarrow$ mit Indefinitpronomen

Bemerkenswert sind auch die wenigen Beispiele, in denen eines der Lexeme für 'Herz' in Verbindung mit dem adjektivischen Indefinitpronomen $n b$ 'jeglicher' oder dem substantivischen Indefinitpronomen $k y$ 'anderer' vorkommt.

\begin{tabular}{|l|l|l|l||}
\hline & WEISHEITSTEXTE & ERZÄHLUNGEN & LIEBESLIEDER \\
\hline Indefinitpronomen & W-67 $(\mathrm{ky})$ & $\mathrm{E}-32^{*}(\mathrm{nb})$ & $\varnothing$ \\
\hline \hline
\end{tabular}

Es gibt dafür insgesamt nur zwei Belege im Korpus: 'Das heißt, ein anderes Herz wäre gebeugt' (W-67, ks pw ky jb), und 'Jedes Herz hatte Angst um mich. Die Frauen und die Männer

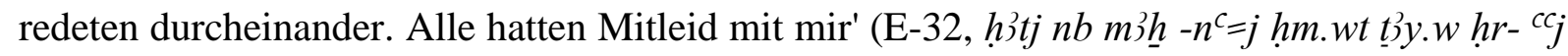
jb $n b m r-n=j)$.

In dem Abschnitt aus den Klagen des Chacheperreseneb (W-67) geht es darum, daß der Erzähler sich wünscht, sich anderes verhalten zu können. Er fühlt sich aber belastet und kann nicht vermeiden, dies zu äußern. Er beschreibt, wie die erwünschte Verhaltensweise aussehen sollte, nämlich 'stark zu sein' (jr- jb qn m- s.t-qsn.t sn $p w n-n b=f$ 'Ein Herz, das auch in einer bösen Situation stark ist, ist der Genosse seines Herrn'). Das Indefinitpronomen $k y$ bezieht sich also, wie von seiner Semantik her nicht anders zu erwarten, nicht auf das eigene Herz des Sprechers, sondern auf eine entferntere, außerhalb der Sprechsituation befindliche Größe. Das könnte darauf hinweisen, daß eine gewisse Gemeinsamkeit zwischen diesem Beispiel und denen aus der im vorangehenden Abschnitt behandelten Gruppe (mit Artikel oder Possessivartikel) besteht. Aber natürlich ist ein einziges Beispiel nicht ausreichend, um eine belastbare Verallgemeinerung zu formulieren.

Zum Schluß dieses Abschnitts ist das Beispiel aus der Erzählung des Sinuhe zu behandeln. Es handelt sich um eine der Ausdrucksmöglichkeiten, um sich (wenigstens implizit) auf eine Mehrzahl, die nicht unbedingt als Kollektiv in Erscheinung treten muß, zu beziehen: 'jegliches Herz' ist zwar grammatisch eine Singularform, impliziert jedoch eine Mehrheit, ohne das deren einzelne Vertreter irgendetwas gemeinsam oder gleichzeitig tun müssen. Unten wird gezeigt, daß die Lexeme $j b$ und $h 3 t j$ durchaus im Plural vorkommen und mit einem suffigierten Personalpronomen im Plural stehen können. Wenn ein Possessor nicht ausdrücklich genannt wird, aber eine Mehrzahl womöglich unabhängig voneinander agierender Individuen gemeint ist, erscheint das Lexem für 'Herz' entweder allein im Plural, oder es wird singularisch mit dem Indefinitpronomina $n b$ 'jedes, jegliches' konstruiert. Somit sind die folgenden Ausdrucksmöglichkeiten inhaltlich fast äquivalent:

jb.w'die Herzen' (E-24)

hỉtj $n b$ 'jedes Herz' (E-32)

jb $n b$ 'alle Herzen' (E-32)

Der Unterschied in der Wiedergabe der beiden letzten Fälle - hier der Singular 'jedes Herz', 
dort der Plural 'alle Herzen' - ist allein ein übersetzungssprachliches Phänomen und verdeutlicht die funktionale Gleichwertigkeit von suffixlosem Plural und Singular mit Indefinitpronomen.

$\Rightarrow \quad$ als Nukleus oder Satellit eines Kompositums (des sogenannten "direkten Genitivs") oder als Nukleus eines mit n(j)-gebildeten Possessionsausdrucks (des sogenannten "indirekten Genitivs")

Da sich die Ausdrücke für 'Herz' (unter anderem) auf einen menschlichen Körperteil beziehen, ist es nur natürlich, wenn oft auch die Person erwähnt wird, der das Herz gehört. Aus diesem Grund sind die Ausdrücke, in denen eines der ägyptischen Lexeme für 'Herz' als Besessenes in einem Possessivausdruck vorkommt, nicht besonders selten. Die folgende Tabelle enthält die einschlägigen Beispiele:

\begin{tabular}{|c|c|c|c|c|c|c|}
\hline & \multicolumn{2}{|c|}{ "WEISHEITSTEXTE } & \multicolumn{2}{|c|}{ ERRZ̈̈HLUNGEN } & \multicolumn{2}{|c|}{ ב LIEBESLIEDER } \\
\hline "direkter & \multicolumn{2}{|c|}{$\mathrm{W}-21, \mathrm{~W}-44, \mathrm{~W}-159^{*}$} & \multicolumn{2}{|c|}{ E-44 } & \multicolumn{2}{|c|}{ L-10 } \\
\hline & $j b / h 3 t j n-\mathrm{X}$ & $\mathrm{X} n-j b / h 3 t j$ & $j b / h i t j n-X$ & $\mathrm{X} n-j b / h i t j$ & jb/hỉtj n-X & $\mathrm{X} n-j b / h i t j$ \\
\hline $\begin{array}{l}\text { "indirekter } \\
\text { Genitiv" } \\
\text { (mit } n(j)- \\
\text { gebildet) }\end{array}$ & $\begin{array}{l}\text { W-9, W-28, } \\
\text { W-45, W-49, } \\
\text { W-61, W-62, } \\
\text { W-70, W-77, } \\
\text { W-104, W-111, } \\
\text { W-119, W-144, } \\
\text { W-156, } \\
\text { W-166* }\end{array}$ & $\begin{array}{l}\text { W-41, } \\
\text { W-48, } \\
\text { W-96 }\end{array}$ & $\begin{array}{l}\text { E-36, E-42, } \\
\text { E-43, E-63*, } \\
\text { E-64*, E-65*, } \\
\text { E-71, E-72, } \\
\text { E-73, E-78* }\end{array}$ & $\varnothing$ & L-14; L-24 & L-14* \\
\hline
\end{tabular}

Die Gruppen der mit dem sogenannten "direkten" oder "indirekten Genitiv" gebildeten Ausdrücke mit einem Lexem für 'Herz' können jeweils in zwei Untergruppen aufgeteilt werden:

(1) die Fälle, in denen das Lexem als Nukleus auftritt und das Herz einer Person oder Gottes gemeint ist (W-9, W-28, W-36, W-49, W-61, W-62, W-70, W-77, W-104, W-111, W-119, W-144, W-156, W-166, E-42, E-43, E-44, E-63, E-64, E-65, E-71, E-72, E-73, E-78, L-10, L-14, L-24), und

(2) die Fälle, in denen eines der Lexeme für 'Herz' als Erweiterung zu einem anderen Substantiv auftritt (W-21; 'Kummer des Herzens', W-41: 'das Endziel des Herzens', W-44: 'Kummer des Herzens', W-45: 'die Atmosphäre des Hausstands', W-48: 'Bezeugung des Herzens', W-96: 'Stunde des Gutseins des Herzens', W-159: 'Klumpigwerden der Herzen', L-10: 'Befehle deines Verstandes').

In der Gruppe des indirekten Genitivs wurden die Beispiele gemäß der Art der grammatischen Konstruktion eingeteilt. Auf dieser Weise kann beobachtet werden, daß die Form $j b / h 3$ tj $n(j)$ $X$ 'das Herz von $X$ ', in denen das Herz als Nukleus vorkommt, in Vergleich mit dem Typus $X$ $n$ - $j b / h i$ itj, in denen das Herz als Satellit vorkommt, häufiger verwendet wurde.

Die vergleichende Betrachtung der Beispiele läßt keine eindeutigen Zusammenhänge zwi- 
schen der Verwendung einer Konstruktverbindung oder eines sogenannten "indirekten Genitivs" und einer bestimmten Funktion des Ausdrucks feststellen. Bei der Entscheidung für eine der möglichen Possessivkonstruktionen spielt anscheinend die Art des Possessors keine Rolle: das 'Herz' einer anonymen Person erscheint etwa in W-9, W-28, W-49, W-62, W-144, W-166, L-10 und L-24, das 'Herz' einer konkret identifizierbaren Person in W-70, E-63, E-64, E-71, E-72 und L-14, das 'Herz' oder die 'Herzen' einer Personengruppe in W-61 und W-111, das 'Herz' eines Gottes in W-77, W-104, W-119, W-156 und E-73, das 'Herz' des Königs in E-42, E-43, E-44, E-65.

\section{$\Rightarrow \quad$ im Plural mit Suffixpronomen / im Plural ohne Suffixpronomen / im Singular mit plura- lischem Suffixpronomen}

Wenn eines der Lexeme für 'Herz' im Plural auftritt, wird es meistens ohne Suffix gebraucht. In einem der Beispiele aus der Lehre für Merikare (W-92) ist das Lexem $j b$ im Papyrus Petersburg und in Papyrus Carlsberg ohne Pluralendung geschrieben, so daß die im moskauer Papyrus stehende Pluralform als eine Variante oder ein Schreibfehler angesehen werden kann. Bei dem Beispiel aus der Lehre des Ani (W-138) haben wir es sich mit demselben Phänomen zu tun: im Textzeugen aus Kairo (pBoulaq 4) kommt das Lexem in seiner Pluralform vor, während im Papyrus Deir el-Medineh I der Singular verwendet wird.

Das Lexem $j b$ im Plural bezieht sich auf eine Mehrzahl. Dies wird insbesondere deutlich im Gespräch des Lebensmüden, in dem zwischen pluralischem ( $j b . w)$ und einzelnem Subjekt (W-46: jb.w z (j) $n b$ hr-jt.t jh.t snw=f'Die Herzen sind habgierig, und jedermann ist dabei, das Eigentum seines Mitmenschens unter den Nagel zu reißen', W-49: jb.w ${ }^{c} w n n(n)$ wn jb $n(j)-$ $z(j) r h n=t w-h r=f$ 'Die Herzen sind habgierig, und es gibt kein Herz einer Person, auf das man sich stützen kann') unterschieden wird.

Beispiele, in denen eines der beiden Lexeme für 'Herz' im Singular mit einem suffigierten Personalpronomina im Plural erscheint, sind ebenfalls geläufig, siehe etwa: 'unser Herz' (L-10), 'euer Herz' (W-59, W-75) 'ihr Herz' (W-92, W-118, W-121, W-124, W-133). Der Singular des Substantivs ist hier wohl aus dem Grund vermieden worden, um anzudeuten, daß jede der betreffenden Personen über genau ein Herz verfügt. Diese Gebrauchsweise entspricht ziemlich genau der im Deutschen üblichen.

\subsection{Die Lexeme für 'Herz' und ihr Wortfeld}

Die grundlegende Subklassifizierung der Verwendungsweisen der Lexeme für 'Herz', durch die sich zwei Gruppen ergeben, ist die Unterteilung in das "kardiologische Herz" und das "kordiologische Herz". Die erste Gruppe bereitet inhaltlich keine Schwierigkeit: das Herz wird als Organ des menschlichen oder tierischen Körpers, d.h. biologisch verstanden. Die zweite Gruppe enthält die zahlreichen metaphorischen Ausdrücke und Redewendungen, 
insbesondere auch solche, die sich mit den Emotionen, mit der Seele oder mit dem Verstand in Verbindung bringen lassen. Diese unterschiedlichen Verwendungen und Bedeutungen von 'Herz' lassen sich in den meisten der seit der Antike bezeugten Sprachen des europäischen, nahöstlichen und nordafrikanischen Raums beobachten. In Kapitel 2 wurde als Resultat eines kursorischen Überblicks über eine Reihe von Sprachen eine zusammenfassende Tabelle geboten. Darin ließen sich sechs Hauptbedeutungen ausmachen, die in allen alten Sprachen erscheinen. Es sind die folgenden: ${ }^{422}$

- 'Herz' als Körperteil (8)

- 'Herz' als Verstand (7)

- $\quad$ 'Herz' als Wunsch (8)

- 'Herz' als Charakter (5)

- 'Herz' zur Bezeichnung von Gefühlen (8)

- 'Herz' als innerer Mittelpunkt (6)

Es ist interessant zu sehen, wie das Herz als Zentrum des Lebens - vermutlich gerade wegen seiner besonderen Bedeutung für die Existenz eines jeden Lebewesens - auch in anderen Sphären des Menschen eine Rolle spielt und die sprachlichen Mittel, die sich auf es beziehen, für vielfältige andere Funktionen eingesetzt werden. Der Umstand, daß ein Begriff in den unterschiedlichsten Sprachen in einem sehr ähnlichen Sinn verstanden wird, ist auch eine der Voraussetzungen dafür, daß wir ägyptische Textstellen, in denen eines der Wörter für 'Herz' vorkommt, verstehen können (und eine Untersuchung wie die vorliegende überhaupt möglich ist). In konkreten Fällen ließen sich auf diese Weise auch schwierige Passagen in den Texten einer Sprache mit Hilfe ähnlicher Formulierungen in Texten anderer Sprachen interpretieren. Ein entsprechendes Beispiel, in dem man die Bibel als Hilfsmittel zur Erklärung von Textstellen aus der ägyptischen Zweibrüdergeschichte herangezogen hat, ist in Kapitel 2.4.4 besprochen worden.

Ungeklärt - und auch im Rahmen dieser Studie überhaupt nicht berührt - ist die Frage nach den Ursachen für derartige Parallelen. Ob es sich dabei um die Auswirkungen sprachlicher Universalien handelt, oder die Gemeinsamkeiten von Sprachen wie dem Lateinischen, Griechischen, Hethitischen, Akkadischen, Hebräischen, Arabischen, Ägyptischen - untereinander und mit den modernen europäischen Sprachen - darauf zurückzuführen sind, daß zwischen all diesen Sprachen und Kulturen ganz enge historische Beziehungen bestanden haben, ist unklar. Beantwortet werden könnte diese Frage nur durch ein noch weiteres Ausholen, indem man auch Sprachen ganz anderer Areale berücksichtigt, um etwaige Unterschiede beobachten zu können. Das jedoch ist ebenso wenig Thema dieser Arbeit gewesen wie die detaillierte Untersuchung der zweifellos vorhandenen gegenseitigen Übernahmen und Beeinflussungen, die womöglich dazu führen konnten, daß in unterschiedlichen, zeitlich und räum-

422 In Klammern steht, in wie vielen der herangezogenen Sprachen die entsprechenden Lexeme mit dem jeweiligen Sinn vorkommen. Insgesamt wurden berücksichtigt: Latein, Griechisch, Hethitisch, Akkadisch, Hebräisch, Arabisch, Koptisch und Ägyptisch. 
lich weit voneinander getrennten Sprachen ähnlich gebildete Ausdrücke auf eine manchmal frappierend ähnliche Weise verstanden werden.

Was allerdings geboten werden soll, ist eine Aufstellung, aus der hervorgeht, daß die weiter oben in Kapitel 2 behandelten Verwendungsweisen der entsprechenden 'Herz'-Lexeme in den schon in der Antike bezeugten Sprachen, ganz gleichartig auch in modernen Sprachen vorkommen können. Aus praktischen Gründen werden dafür die Bedeutungen und Gebrauchsweisen von spanisch corazón und deutsch Herz gegenübergestellt. Das geschieht in der nachstehenden Tabelle in Analogie zu den Verwendungen der entsprechenden Wörter in den alten Sprachen. Das Ziel besteht darin, die grundsätzliche Vergleichbarkeit der modernen und der antiken Verwendungen der Begriffe für 'Herz' zu unterstreichen. Das ist für diese Untersuchung insgesamt von erheblicher Wichtigkeit, weil sich nur auf diese Weise mein Vorgehen rechtfertigen läßt, die ägyptischen Lexeme $j b$ und $h 33 t j$ zuweilen "intuitiv" auf eine ziemlich freie Weise zu übersetzen. Die folgenden Ausdrücke wurden dem spanischen Diccionario de la Real Academia de la Lengua Española und dem deutschen Duden. Sinnund sachverwandte Wörter, Bedeutungswörterbuch und Redewendungen entnommen. In Klammern stehen Paraphrasen der Redewendungen, einander gegenüberstehende deutsche und spanische Kollokationen sind nicht unbedingt Übersetzungen voneinander.

\begin{tabular}{||l|l||}
\hline \multicolumn{2}{||c||}{ KÖRPERTEIL } \\
\hline - In der Brust befindliches Organ, das den \\
$\begin{array}{l}\text { Kreislauf des Blutes durch regelmäßiges } \\
\text { Sichzusammenziehen und Dehnen in Gang hält }\end{array}$ & $\begin{array}{l}\text { órgano de naturaleza muscular, común a todos los } \\
\text { vertebrados y a muchos invertebrados, que actúa } \\
\text { como impulsor de la sangre y que en el hombre está } \\
\text { situado en la cavidad torácica }\end{array}$ \\
\hline
\end{tabular}

\begin{tabular}{|c|c|}
\hline \multicolumn{2}{|c|}{ VERSTAND } \\
\hline $\begin{array}{l}\text { - etwas auf Herz und Nieren prüfen (etwas sehr } \\
\text { gründlich prüfen / untersuchen) } \\
\text { - jmd. etwas ans Herz legen (vorschlagen) }\end{array}$ & $\begin{array}{l}\text { - darle, o decirle, a alguien el corazón algo (etwas ah- } \\
\text { nen) } \\
\text { - declarar alguien su corazón (die Absicht, das Leid } \\
\text { oder die Gier vertraulich zeigen) } \\
\text { - el corazón no es traidor (Vorgefühl zukünftiger Ereig- } \\
\text { nissen) }\end{array}$ \\
\hline
\end{tabular}

\begin{tabular}{||l|l||}
\hline \multicolumn{2}{|c||}{ WUNSCH } \\
\hline - $\begin{array}{l}\text { sein Herz an etwas hängen (wünschen) } \\
\text { - etwas liegt jmd. am Herzen (wünschen) }\end{array}$ & - haber a corazón (etwas vorhaben) \\
- im Herzen tragen & \\
- $\begin{array}{l}\text { mit allen Fasern des Herzens anhängen } \\
\text { - innigster Herzenswunsch }\end{array}$ & \\
\hline
\end{tabular}




\begin{tabular}{|c|c|}
\hline \multicolumn{2}{|c|}{ CHARAKTER } \\
\hline 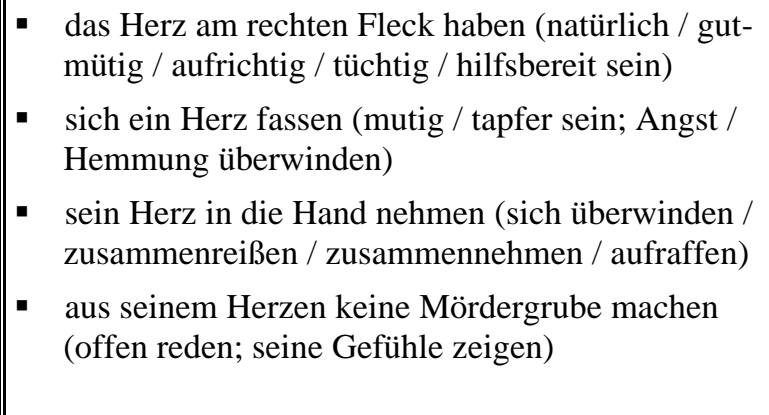 & $\begin{array}{l}\text { - } \text { ánimo, valor, temple (Mut) } \\
\text { - } \text { buena voluntad (guter Wille) } \\
\text { - } \text { abrir el corazón a alguien (Mut einflößen) } \\
\text { - de corazón (von Herzen) } \\
\text { - } \quad \text { blando de corazón (weichherzig, empfindlich) } \\
\text { - llevar alguien el corazón en la mano, o en las } \\
\text { - manos (das Herz auf der Zunge haben) } \\
\text { no tener corazón (herzlos) }\end{array}$ \\
\hline $\begin{array}{l}\text { - jmd. schlagen alle Herzen entgegen / fliegen alle } \\
\text { Herzen zu, alle Herzen im Sturm erobern, sich in } \\
\text { die Herzen [der Menschen] stehlen (sympathisch } \\
\text { sein) } \\
\text { - Hand aufs Herz (ehrlich / aufrichtig sein) } \\
\text { - jdn. hat ein weiches, falsches, gutes, reines Herz } \\
\text { (jdn. ist falsch, gut, rein, weich) }\end{array}$ & $\begin{array}{l}\text { - } \quad \text { no tener corazón para decir, hacer, presenciar, etc., } \\
\text { algo (jd. wagt es nicht zu sagen) } \\
\text { - } \quad \text { ser todo corazón (großzügig) } \\
\text { - } \quad \text { tener mucho corazón (edelmütig sein) } \\
\text { - } \quad \text { tener un corazón de bronce (hartherzig sein, Mut } \\
\text { - } \text { haben) } \\
\text { - } \quad \text { dener un corazón de oro (hochherzig sein) } \\
\text { - } \quad \text { corazón de oro (treue Seele) } \\
\text { - no caberle a alguien el corazón en el pecho (groß- } \\
\text { herzig sein) }\end{array}$ \\
\hline
\end{tabular}

\begin{tabular}{|c|c|}
\hline \multicolumn{2}{|c|}{ GEFÜHLE } \\
\hline $\begin{array}{l}\text { - } \text { sein Herz auf der Zunge tragen (offen sein; seine } \\
\text { vorgeht; aussprechen, was man empfindet) } \\
\text { - etwas nicht über das Herz bringen können, Skrupel } \\
\text { haben (sentimental sein) } \\
\text { - jemandem fällt ein Stein vom Herzen (jemand ist } \\
\text { erleichtert / froh (z.B. weil ein erwartetes schlim- } \\
\text { mes Ereignis doch nicht eingetreten ist) } \\
\text { - ein großes Herz haben (großzügig / hilfsbereit / } \\
\text { human / menschlich sein) } \\
\text { - jemandem das Herz brechen (jemanden sehr un- } \\
\text { glücklich machen; jemandem sehr großen Kummer } \\
\text { bereiten; jemanden, der einen liebt, verlassen) } \\
\text { - jemandem rutscht / fällt / sinkt das Herz in die Hose } \\
\text { (jemand bekommt plötzlich große Angst / einen } \\
\text { großen Schreck; jemand ist aufgeregt; jemand spürt } \\
\text { Nervenkitzel) } \\
\text { - es zerreißt jemandem das Herz (jemand ist traurig / } \\
\text { bestürzt / entsetzt / betroffen / erschüttert / aufge- } \\
\text { wühlt / ergriffen; jemand hat großes Mitleid) } \\
\text { - sein Herz verlieren (sich verlieben) } \\
\text { - jmd. blutet das Herz (betroffen sein) } \\
\text { - jmd. schlägt das Herz bis zum Hals (aufgeregt sein) } \\
\text { sich etwas zu Herzen nehmen (schwer nehmen) }\end{array}$ & $\begin{array}{l}\text { - } \text { el corazón en un puño (ängstlich, beängstigend) } \\
\text { ben) } \\
\text { - clavarle, o clavársele, a alguien en el corazón algo } \\
\text { (jdm. großes Leid hervorrufen) } \\
\text { - cubrírsele a alguien el corazón (sehr traurig } \\
\text { werden) } \\
\text { - helársele a alguien el corazón (wegen einer schlech- } \\
\text { ten Nachricht oder eines Schrecken erstaunt wer- } \\
\text { den) } \\
\text { meterse alguien en el corazón a otra persona (sich } \\
\text { bei jdm. einschmeicheln) } \\
\text { - herir el corazón sin romper el jubón (jdn. schlau } \\
\text { und heimlich beleidigen) }\end{array}$ \\
\hline
\end{tabular}




\begin{tabular}{|c|c|}
\hline \multicolumn{2}{|c|}{ INNERER MITTELPUNKT } \\
\hline $\begin{array}{l}\text { - im Grunde seines Herzens (im tiefsten Innern) } \\
\text { - im Herzen eines Landes } \\
\text { - im Grunde seines Herzens (in seinem tiefsten In- } \\
\text { neren) } \\
\text { - etwas auf Herz und Nieren prüfen (etwas sehr } \\
\text { gründlich prüfen / untersuchen) }\end{array}$ & $\begin{array}{l}\text { - dentro de algo. El corazón de una manzana (Ap- } \\
\text { felkerne) }\end{array}$ \\
\hline
\end{tabular}

Man kann aus der Aufstellung leicht den Eindruck gewinnen, daß das Konzept des Begriffs 'Herz' in unterschiedlichen Sprachen und Zeiten etwas sehr Komplexes und Kompliziertes gewesen ist - und immer noch ist. Im Fall der ägyptischen Termini ist der Grad an Komplexität noch höher, da zwei Termini, nämlich $j b$ und hỉtj, denselben Begriff zu bezeichnen scheinen. Mögliche Eingrenzungen des Sinns der beiden Lexeme wurden in Kapitel 2 diskutiert. Dabei stellte sich heraus, daß die wiederholt von Ägyptologen unternommenen Versuche, eine durchgängige semantische Abgrenzung zwischen den beiden Wörtern vorzunehmen und etwa das eine Lexem ausschließlich als Bezeichnung des Organs und das andere als bloß übertragen gebrauchtes Wort zu bestimmen, sich beim Arbeiten mit ägyptischen Texten nicht bewährt. Zumindest für das genauer ausgewertete Korpus kann festgehalten werden, daß ein konsistenter semantischer Unterschied zwischen $j b$ und $h j$ itj nicht besteht. Beide Lexeme werden deshalb gleichermaßen als Ausdrücke für 'Herz' analysiert, eine signifikante Verteilung bestimmter übertragener und metaphorischer Gebrauchsweisen auf eines der beiden Lexeme wurde nicht entdeckt. Das semantische Problem wurde freilich nicht vertieft, stattdessen wurden mögliche Bedeutungen der beiden Wörter anhand einer textnahen Analyse der in dieser Arbeit untersuchten Quellen verdeutlicht.

\subsection{Der rhetorische Gebrauch des Begriffs 'Herz'}

Wie eben gezeigt, ist der Begriff 'Herz' in den Lehren am häufigsten als 'Verstand' oder 'Charakter' zu interpretieren. Der Grund dafür ist verhältnismäßig leicht anzugeben: Die Lehren enthalten Maximen, in denen das Herz als für die Charakterschilderung oder für das gerechte Benehmen eines Menschen maßgebliches Organ verstanden werden soll.

Junge (2003: 114-115) schreibt in seiner kurz vor Abschluß dieser Arbeit erschienenen Studie über die Lehre des Ptahhotep über das Herz und seine Bedeutungen in diesem Literaturwerk:

$J a b$ ist hier von mir in der Übersetzung der Lehre, in prinzipieller Übereinstimmung mit dem Wörterbuch und der allgemeinen Ansicht, wechselweise als "Geist" und als "Gesinnung", "Sinnesart", aber auch als "Sinn", "Gemüt" oder auch als "Gewissen" wiedergeben worden. Diese Bedeutungen lassen sich in zwei Hauptgruppen zusammenfassen, zum Ersten in das was man die Gesamtheit der inneren Befindlichkeiten des Menschen nennen könnte, zum anderen das, was sich daraus als denkenden Inneres ausgrenzen läßt. 
Die Gesamtheit der inneren Befindlichkeiten entspricht etwa dem, was man mit "Gemüt", "Stimmung" oder "Gesinnung" wiedergeben will (...)

Für einen selbst, in der Innensicht, ist Jab, der Geist, das Organ des denkenden Inneren, der Wahrnehmung und der Verarbeitung von Außenwirkungen und Innenimpulsen, der Ort der Einsichten und Reflexionen, des Sinnes und Nachsinnens (...).

Der Gebrauch des Begriffes mit allen diesen und anderen Bedeutungen ist das, was im Kapitel 5 als "Metonymie", "Prosopopöie", "Vergleich" und "Metapher" beschrieben wurde. Dieses Phänomen läßt sich außer in den Lehren auch in anderen Texten finden, da die Interpretation der Termini, sei es $j b$ oder $h \grave{i} t j$, nicht allein zu einer bestimmten Gattung gehört, sondern auch ganz generell zur Sprache, zum Individuum und zur Kultur. Durch die Analyse des Begriffs kann in den hier vorgestellten Beispielen feststellt werden, daß die meisten Anwendungen von $j b$ oder $h i t j$ als Fälle von Metonymie zu klassifizieren sind. Zu dieser Gruppe gehören all diese Bedeutungen, in denen das Wort für 'Herz' als 'Verstand', 'Seele' oder 'Willen' wiedergeben wurde.

Es wurden neue Übersetzungsmöglichkeiten für das Wort 'Herz' zusätzlich (und als Alternativen) zu denen, die bis jetzt in den Bearbeitungen der Texten zu finden sind, vorgeschlagen. Bei diesen Wiedergaben des Begriffs wurde vom außersprachlichen Kontext, von den Vergleichen unterschiedlicher Gattungen, vom innertextlichen Ko(n)text, von der Funktion der Sprache und von der Verbindung mit den Emotionen ausgegangen. Die drei hier genannten Gattungen wurden jeweils zwar exemplarisch, doch auf einer möglichst breiten textlichen Basis bearbeitet, damit sich genügend verallgemeinerbare Erkenntnisse ergeben. In der folgenden Tabelle sind Beispiele für die drei rhetorischen Gebrauchsweisen des Begriffs 'Herz' zusammen dargestellt:

\begin{tabular}{||l|l|l||}
\hline METONYMIE & \multicolumn{1}{|c||}{ VERGLEICH } & \multicolumn{1}{|c|}{ METAPHER } \\
\hline W-7, W-9, W-11, W-17, W-18, W-24, W-28, W-36, & E-64 & W-103, W-130, W-141, \\
W-42, W-58, W-72, W-73, W-74, W-86, W-92, W-96, & & W-154, W-155, W-163, \\
W-101, W-109, W-115, W-124, W-128, W-129, W-136, & & W-166 \\
W-137, W-138, W-143, W-146, W-148, W-157, W-158, & & E-3 \\
W-164 & & L-14, L-29, L-30 \\
E-8, E-9, E-18, E-31, E-37, E-39, E-40, E-42, E-43, E-44, & & \\
E-47, E-55, E-54, E-56, E-62, E-67, E-68, E-70, E-71, & & \\
E-73, E-76, E-81 & & \\
L-5, L-10, L-11, L-14, L-26, L-27, L-28, L-37 & & \\
\hline
\end{tabular}

Um diesen Gebrauch zu erläutern, werden in der folgenden Tabelle alle Beispiele unter diesen - in einigen Fälle neuen - Interpretationen des Wortsinnes geordnet. Einige Vorschläge sind nicht neu, da beispielsweise der metonymische Gebrauch der Worten als 'Verstand' oder 'Seele' in der Bearbeitung der ägyptischen Texte - besonders in den Lehren - schon lange bekannt war. Andere Interpretationen sind jedoch hier erstmals vorgeschlagene, die in den entsprechenden Kapiteln begründet wurden. Die Beispiele in der folgenden Tabelle sind sol- 
che, in denen die ägyptischen Wörter für 'Herz' exakt durch den jeweiligen Begriff wiedergegeben wurde, also beispielsweise deutsch Verstand oder Charakter als übersetzungssprachliche Entsprechung zu $j b$ auftritt. Die Kollokationen, in denen eines der beiden Lexeme für 'Herz' für die Beschreibungen eines Zustandes oder eines Charakters mit einer anderen deutschen Entsprechung wiedergegeben wird, werden weiter unten vorgestellt.

\begin{tabular}{|l|l||}
\hline \hline VERSTAND & W-15, W-100, W-120, W-108, W-129, W-147, W-148, W-149, W-161 \\
& E-2, W-14, E-15, E-18, E-25, E-26, E-27, E-41, E-82 \\
& L-10, L-16, L-24 \\
\hline MEINUNG & W-33, W-34, W-105, W-150, W-156 \\
& E-2, E-7, E-8, E-12, E-29 \\
\hline CHARAKTER & W-42, W-73, W-124, W-128, W-164, \\
\hline STIMMUNG & W-7, W-17, W-18, W-28, W-92, W-129, W-138, W-146, W-148, W-157, W-158 \\
& E-40, E-42, E-43, E-44, E-47, E-62, E-67, E-71, E-80 \\
& L-5, L-11, L-14 \\
\hline LAUNE & W-24, W-36, W-86, W-148 \\
\hline SEELE & W-9, W-58, W-109 \\
& E-18 \\
& L-10 \\
\hline ENTSPANNUNG & W-72, W-96 \\
\hline PERSONALPRONOMINA & W-101, W-115, W-136, W-137, W-143 \\
& L-26, L-27, L-28 \\
\hline SINNE & W-11, \\
\hline ABSICHT & W-74 \\
\hline WUNSCH & E-37, E-55 E-31, E-52, E-54, E-56, E-68, E-81 \\
\hline WILLEN & E-37, E-69, E-70, E-73, E-76 \\
\hline
\end{tabular}

\subsection{Die Interpretation ägyptischer Metaphern}

\subsection{1 'Herz' in Metaphern zum Ausdruck von Emotionen}

Die Verwendung eines Worts für 'Herz' zur Bildung von Emotionsausdrücken ist ein in den Sprachen der Welt weit verbreitetes Phänomen und begegnet auch außerhalb der in dieser Studie genauer betrachteten Bereiche. Beispiele für den Gebrauch derartiger Metapher finden sich etwa auch im afrikanischen Zulu, wo das Herz mit Emotionszuständen wie Wut, Geduld und Ungeduld, Toleranz und Intoleranz verbunden werden kann (vgl. Taylor/Mbense 1988). Im Chinesischen wird das Herz mit Freude in Verbindung gesetzt und man kann etwa sagen 'Freude ist Blumen im Herzen' (Yu 1995). In Japan wird der Körper metaphorisch als ein Haus verstanden, in dem die Vorderseite das Gesicht bezeichnet, während die Innenseite durch den Wortschatz der Gefühlsdomäne, insbesondere durch die Konzepte von 'Herz', 'Seele' und 'Denken' umrissen wird (vgl. Köpping 2000: 221). Solche Fälle unterscheiden sich 
grundsätzlich nur wenig von uns vertrauteren Gebrauchsweisen wie beispielsweise der auch im Englischen ganz üblichen Assoziierung das Herzens mit Zuständen wie Liebe, Affektiertheit und ähnlichem.

\subsubsection{Die übersetzungssprachliche Wiedergabe der ägyptischen Lexeme für 'Herz'}

Die Problematik der richtigen Übersetzung ägyptischer Metaphern ist einer der zentralen Gegenstände dieser Arbeit. Die Wichtigkeit des textlichen Kotexts und des allgemeinen Kontexts (z.B. der Textsorte) für die Erschließung des Sinns wurde schon im Kapitel 3 hervorgehoben. Das allein bietet noch keine Gewähr für eine richtige Übersetzung. Diese Behauptung soll das folgende Beispiel erläutert werden.

In der Lehre des Ptahhotep (W-32) wurde gesagt ${ }^{c} n \underline{h} w \underline{d}$ ) $\operatorname{snb} n(j)-z j j b=f$. Dieser Satz wird - nach meiner Interpretation - als 'Leben, Wohlbefinden und Gesundheit eines Menschen sind sein Herzenswunsch' wiedergegeben. Die Erwägungen, die zu dieser Entscheidung führten, wurden auf den Seiten 121-122 vorgestellt. Allerdings ist der Vorschlag von Junge (2003: 203 und 259) "seine Sinnesart ist für den Menschen Leben, Wohlergehen und Gesundheit" auch passend. Diese mehrfache Interpretationsmöglichkeit der Passage läßt sich erklären, weil die Lexeme für 'Herz' in den Weisheitstexten sowohl in der Bedeutung 'Sinn' wie auch als 'Wunsch' häufiger auftreten. In diesem Fall ist also die Textsorte, die in anderen Fällen beim Versuch zu einer eindeutigeren Klärung hilfreich sein kann, kein Entscheidungskriterium.

Auf der anderen Seite findet man Metaphern in den ägyptischen Texten, die auch in den modernen europäischen Sprachen gebraucht werden und heutzutage immer noch aktuell sind. Dazu gehört etwa die Metapher des Schiffes (siehe Seite 55). Wenn also in besser bekannten Sprachen Metaphern vorkommen, die mit den gleichen Lexemen (d.h. natürlich den in der jeweiligen Sprache den ägyptischen entsprechenden Wörtern) gebildet werden, ist es naheliegend, zu schauen, ob eine analoge Interpretation in dem jeweiligen textlichen Zusammenhang passend ist und bei der Analyse des ägyptischen Textabschnitts weiterhelfen kann. Wenn das der Fall ist, kann man davon ausgehen, daß diese ägyptische Metapher tatsächlich analog zu den ihr formal entsprechenden Ausdrücken gegenwärtiger Sprachen übersetzt werden darf. Daß man derartige Fälle von Analogien nicht vorschnell verallgemeinern darf, sondern jeden Einzelfall gesondert untersuchen muß, ist selbstverständlich. Generell zeigt sich, daß die Zahl an Übereinstimmungen zwischen ägyptischen Metaphern und denen in den modernen europäischen Sprachen relativ hoch ist.

Diese Überlegung wirft auch die Frage auf: Warum haben Ägypter auch Metaphern benutzt? Die Gründe dafür, warum dieses rhetorische Mittel in der geschrieben oder gesprochenen Sprache auftaucht, wurden im Kapitel 3 unter Einbeziehung der aktuellen Forschung zum Thema diskutiert. Metapherngebrauch ist ein Phänomen, das in allen Sprachen präsent ist, und das zum Individuum gehört. Jede Person äußert ihre Individualität durch ihre eigenen Ausdrücke; aber gleichzeitig sind sowohl die Person selbst als auch ihre Art und Weise, sich auszudrücken, Teil einer Gemeinschaft (siehe Kapitel 3.7). Wenn man in 
den ägyptischen Liebesliedern auf eine Metapher stößt, sollte man die Frage stellen, ob diese im entsprechenden Kontext der individuelle Reflex einer persönlichen Redeweise des jeweiligen Schreibers wird, oder ob wir es mit einer Redewendung $\mathrm{zu}$ tun haben, die in weiteren Kreise der Sprachgemeinschaft bekannt war und generell von ihren Angehörigen angewendet wurde. Diese Frage wirft natürlich erhebliche Probleme auf und wird allenfalls in einzelnen Fällen überhaupt zu beantworten sein. Wenn eine Metapher häufiger, womöglich sogar über einen längeren Zeitraum und in ganz verschiedenen Textsorten, bezeugt ist, handelt es sich wohl um eine mit einem weiten Verbreitungsgrad in der Gesellschaft. Umgekehrt kann aber selbst aus einer nur ein einziges Mal belegten Metapher nicht automatisch geschlossen werden, daß es sich hierbei bloß um das persönliche Stilmittel eines Individuums handelt. Im Fall der im letzten Absatz erwähnten Metapher des Schiffes geht man - auch wegen der Verbreitung über Ägypten hinaus und wohl mit Recht - davon aus, daß es tatsächlich eine allgemeiner gebrauchte Metapher war, die womöglich sogar von den sie Benutzenden unbewußt gebraucht und gar nicht mehr als Metapher empfunden wurde. Das Gegenteil dazu bildet womöglich das Beispiel aus der Lehre des Ptahhotep, das man eher auf den Individualstil des Verfassers dieses Literaturwerks zurückführen wird.

Solche Schwierigkeiten beim Umgang mit Metaphern vergrößern sich, wenn man den richtigen Sinn einer Übersetzung aus den Paraphrasen einiger ägyptische Ausdrücke zu erschliessen versucht. Ein Beispiel: $m h j b$ bedeutet wörtlich "das Herz füllen", das ergibt im Deutschen unmittelbar keinen Sinn (obwohl das Konzept des "vollen Herzens" nicht ganz unbekannt ist, vgl. Luthers wes das hertz vol ist, geht der mund vber, Matth. 12,34). Deswegen wurde die Kollokation $m h j b$ von im Wörterbuch der ägyptischen Sprache (Wb III 118) als "das Vertrauen jmds. haben" wiedergegeben. Damit werden auch Charakterschilderungen bezeichnet. Wenn aber schon die Wiedergabe einer ägyptischen Kollokation mit Unsicherheiten behaftet ist, wird ihre etwaige Verwendung in einer Metapher noch mehr Probleme aufwerfen.

\subsubsection{Das Vehikel in den ägyptischen Metaphern}

Metaphern mit $j b$ oder $h 3 t j$ als Tenor sind in den hier bearbeiteten Texten nicht zahlreich. Die meisten Fälle kommen in den Lehren vor. Als Erklärung dafür läßt sich vermuten, daß dabei die Zielsetzung dieser Texte als Maximen, in denen das Handeln des Menschen in Vordergrund steht und er belehrt werden soll, eine Rolle spielte. Denn aus dieser Funktion der Weisheitstexte ergibt sich ein metaphysisches Konzept des Herzens, welches etwa im Fall der Lehre des Ptahhotep eine solche Komplexität erreicht, daß es mit Ansätzen der klassischen Philosophie in Verbindung gebracht werden kann (vgl. dazu Junge 2003: 120-121).

In den Erzählungen und in den Liebesliedern sind die Beispiele für Metaphern mit einem Lexem für 'Herz' deutlich seltener. Stilistisch zeichnet sich jene Art von Texten nach Ansicht von Gugliemi (1996: 465-497) dadurch aus, daß in ihnen alltägliche Situationen geschildert werden und dazu auch umgangssprachliche Redewendungen verwendet werden können. 
Darum wird zumindest jene Sorte von Metaphern, bei denen es sich um ein Mittel zur besonderen rhetorischen und literarischen Formung eines Texts handelt, nicht häufig benutzt. Trotzdem lassen sich natürlich solche rhetorischen Mittel auch in diesen Texten finden. Der gebrauchte Tenor sind die Termini $j b$ oder $h 3$ itj, während die Vehikel nach den folgenden Klassifikationskriterien geordnet werden können:

\begin{tabular}{||l|l|l|l||}
\hline & \multicolumn{1}{|c|}{ WEISHEITSTEXTE } & ERZÄHLUNGEN & \multicolumn{1}{||}{ LIEBESLIEDER } \\
\hline PERSON & 'Torwächter' (W-141) & & \\
\hline KÖRPERTEIL & $\begin{array}{l}\text { 'Nase' W-103); } \\
\text { 'Hände' (W-166) }\end{array}$ & & \\
\hline TIER & & 'Löwe (E-3) & 'Fisch' (L-29) \\
\hline ABSTRAKTES & $\begin{array}{l}\text { 'Leben, Wohlbefinden und } \\
\text { Gesundheit' (W-32) }\end{array}$ & $\begin{array}{l}\text { 'Lauf eines königlichen Pferdes' (L-14); } \\
\text { tägliches Tragen eines Rings' (L-30) }\end{array}$ \\
\hline SACHE & $\begin{array}{l}\text { 'Damm' (W-130); } \\
\text { 'Schloß am Herzen' (W-155); } \\
\text { 'Lot' (W-163) }\end{array}$ & 'Gewicht' (E-3) & \\
\hline
\end{tabular}

Man kann davon ausgehen, daß die Ägypter auf der Suche nach Vehikeln für Metaphern viel Phantasie gezeigt haben. Sowohl belebte als auch unbelebte Objekte konnten metaphorisch verwendet werden. In den Weisheitstexten - inklusive das Beispiel E-13 - sind die Vehikel von Metaphern in stärkerem Maße von spezifischen Konzepten der ägyptischen Gesellschaft abhängig als die in den Erzählungen oder Liebesliedern verwendeten Vehikel. 'Löwe', 'Fisch', 'Pferd' oder 'Ring' sind Konzepte, die der Welt der alltäglichen Erfahrungen des Menschen im allgemeinen näher stehen als solche Konzepte wie 'Torwächter', 'Nase (Gottes)', 'Damm', 'Schloß', 'Lot' oder 'Gewicht', die in stärkerem Maße Reflex der pharaonisch-ägyptischen Gesellschaft sind. Gleichzeitig ist es nicht überraschend, daß infolge der Zielsetzung der unterschiedlichen Textsorten die Vehikel oder die Metaphern als ganze in den Weisheitstexten eher abstrakt sind, während sie in den Liebesliedern und Erzählungen im Durchschnitt einfacher (d.h. alltäglicher) sind.

\subsection{Die Emotionen in den ägyptischen Texten}

\subsection{1 Überblick}

Im Kapitel 4 wurde dargestellt, worin die besonderen Schwierigkeiten bei der Behandlung von Emotionen bestehen, nämlich einerseits in den je nach Sprache unterschiedlichen Strategien zur Versprachlichung von Emotionen und in der übereinzelsprachlichen Vergleichbarkeit von Emotionsausdrücken und andererseits in der allgemeinen Definition einer Emotion. Es ist nicht nur außerordentlich schwierig, die Emotionen in Bezug auf das Individuum oder eine bestimmte Sprachgemeinschaft oder Kultur zu klassifizieren, sondern im Fall des Ägyptischen oft genug schon problematisch, die sprachlichen Ausdrucksmittel für Emotionen richtig zu interpretieren und die Bedeutung mutmaßlicher Emotionsausdrücke mit einiger 
Sicherheit zu bestimmen. Es hat sich herausgestellt, daß auf dem Weg dahin durch die Berücksichtigung von Emotionsreaktionen (siehe 4.9) gewisse Fortschritte erzielt und sogar eine Reihe besserer Interpretationen ägyptischer Textstellen gewonnen werden können. Das ist vor allem der Fall bei den Beispielen, in denen eines der ägyptischen Lexeme für 'Herz' als 'Stimmung' oder 'Laune' wiedergegeben wurde (siehe dazu den Anhang), oder bei den im Zuge dieser Untersuchung neu analysierten Kollokationen, in denen die entsprechenden Wörter in Verbindung mit bestimmten Verben als eine Emotion oder Emotionsreaktion übersetzt werden kann.

Eine wesentliche Problematik ist jedoch die Bestimmung, welche Rolle die Gefühle innerhalb einer bestimmten Kultur spielen und auf welche Weise sie sich manifestieren. Eine bestimmte Emotion kann in unterschiedlichen Kulturen durchaus mit ganz unterschiedlichen Situationen verknüpft sein, für ganz unterschiedliche Personengruppen typisch oder untypisch sein, auf ganz unterschiedliche Weise geäußert werden und schließlich auch ganz unterschiedlich bewertet werden. Die Erklärung dafür ist wohl die, daß insbesondere die gesellschaftliche Rolle von Emotionen (vermutlich nicht so sehr die individuellen Aspekte) von Konventionen und Bräuchen einer Gesellschaft abhängig ist. Wie man sich in einer bestimmten emotionalen Situation fühlt, ist Sache des Individuums und wenn auch vielleicht nicht universal, so doch auf jeden Fall weniger kulturabhängig als einerseits die möglichen Ursachen für ein bestimmtes Gefühl und andererseits die Art und Weise, ob und wie man diesem Gefühl Ausdruck verleiht. Als Illustration dieses Sachverhalts ist der Fall des Schamgefühls in China im Vergleich zum europäischen Kontext angesprochen worden (siehe 4.6.4). Vor diesem Hintergrund ist eine passende Interpretation von Beispielen aus der ägyptischen Kultur besonders schwierig, da wir es hierbei mit einer nicht mehr lebenden Sprache zu tun haben und weder die Emotionsreaktionen noch die in der ägyptischen Gesellschaft üblichen kognitiven Prozesse überprüft werden können. Es bleiben nur die Texte, die oft genug eine Menge Schwierigkeiten aufwerfen, wenn es darum geht, die passende Übersetzung zu finden und den richtigen Sinn zu treffen. Deswegen ist versucht worden, die Theorie des universalen Konzeptes als angemessenen Weg zu verwenden, um dieses Problem wenigstens teilweise zu lösen.

In Kapitel 4.4 wurden die drei Phasen der Beteiligung emotionalen Kognitionsprozessen vorgestellt, nämlich:

- der kognitive Prozeß,

- die Wahrnehmung des inneren Zustands eines Individuums und

- das Identifizieren einer bestimmten Emotion.

Diese komplizierte und nicht immer exakt trennbare "Melange" aus Kognition und Emotion wird auch in der Sprache widergespiegelt, etwa dadurch, daß der Begriff 'Herz' sowohl in Ausdrücke für Emotionen als auch in solchen, die mit dem Verstand zu tun haben, - und womöglich noch mit anderen Bedeutungen - gebraucht wird. Dasselbe Phänomen ist auch bei der Analyse der unterschiedlichen Wiedergaben des Begriffs in den Übersetzungen ägyptischer Texte zu beobachten. Daß Kollokationen mit einem Lexem für 'Herz' sich auf den 
Verstand wie auch auf das Gefühl beziehen können, tritt nicht nur in der pharaonischägyptischen Kultur auf, sondern andere alte wie auch moderne Sprache zeichnen sich ebenfalls dadurch aus, daß sie den entsprechenden Lexemen ganz ähnliche oder sogar fast identische Bedeutungen zuordnen. Man kann auch aus diesem Grund davon ausgehen, daß sowohl die nur durch die Analyse lebender Sprachen gewonnenen aktuellen Theorien über kognitive Prozesse als auch das, was man universal human concepts genannt hat, bei der Interpretation und Überprüfung ägyptischer Texte angewendet werden dürfen und sich als nützlich erweisen.

\subsubsection{Emotionen und Reaktionen auf Emotionen in den ägyptischen Texten}

Bei der Besprechung der Emotionen in Kapitel 4.2, wurde festgestellt, daß sich sowohl körperliche als auch psychische Reaktionen ergeben können. Nach einer vergleichenden Analyse der Beispiele aus den ägyptischen Texten unter Berücksichtigung dieser Gesichtspunkte bildet sich ein bemerkenswertes Ergebnis heraus. Um den Sachverhalt deutlicher darzustellen, werden in den folgenden Tabellen alle Beispiele aufgelistet, in denen eine unmittelbare Reaktion auf eine Emotion, sei sie physisch oder psychisch (siehe dazu die Kapitel 5.4, 7.3, 6.2), beschrieben wurde.

\begin{tabular}{||l|l|l|l||}
\hline \hline & WeISHEITSTEXTE & \multicolumn{1}{|c||}{ ERZÄHLUNGEN } & LIEBESLIEDERN \\
\hline $\begin{array}{l}\text { POSITIVE } \\
\text { EMOTION }\end{array}$ & $\varnothing$ & E-65, E-79 & L-6, L-11, L-24, L-29 \\
\hline $\begin{array}{l}\text { NEGATIVE } \\
\text { EMOTION }\end{array}$ & W-67, W-91 & $\begin{array}{l}\text { E-24, E-25, E-32, E-47, E-49, } \\
\text { E-57, E-74, E-75 }\end{array}$ & L-9 \\
\hline
\end{tabular}

Auffällig ist die geringe Anzahl von Beispielen, in denen eine Reaktion auf eine positive Emotion beschrieben wird. In den ausgewerteten Textstellen aus den Lehren findet man überhaupt kein Beispiel. Das läßt sich wohl erneut durch die Art der Textsorte erklären, die Maximen und vorbildliche Verhaltensweise enthalten und in viel stärkerem Maße soziale als individuelle Aspekte berücksichtigen, so daß der Adressat als individueller Mensch gegenüber seiner sozialen Rolle und der Gemeinschaft in den Hintergrund tritt. In erster Linie ist der Mensch anonym angeredet, so daß die individuellen emotionalen und persönlichen Reaktionen nicht von Interesse sind - zumindest soweit sie nicht das harmonische Funktionieren der Gesellschaft stören (wie es bei negativen Emotionen der Fall sein kann).

Die Beschreibung einer negativen Emotion - insbesondere in den Erzählungen - (siehe Kapitel 7.3) kommt generell viel häufiger vor als die einer positiven. Man kann zwischen einer körperlichen Reaktion und einer Verhaltensweise unterscheiden. Daraus ergibt sich das Folgende: 


\begin{tabular}{|c|c|c|}
\hline & KÖRPERLICHE REAKTION & VERHALTENSREAKTION \\
\hline $\begin{array}{l}\text { POSITIVE } \\
\text { EMOTION }\end{array}$ & $\begin{array}{l}\text { E-79 ('schreien') } \\
\text { L-11 ('die Augen leuchten') }\end{array}$ & $\begin{array}{l}\text { E-65 ('Mitleid haben') } \\
\text { E-79 ('schreien') } \\
\text { L-6 ('das Herz steht im Innern einer Person auf') } \\
\text { L-24 ('aufgeregt sein') } \\
\text { L-29 ('die Arme breiten sich aus') }\end{array}$ \\
\hline $\begin{array}{l}\text { NEGATIVE } \\
\text { EMOTION }\end{array}$ & $\begin{array}{l}\text { W-67 (sich beugen') } \\
\text { W-91 (mit den Händen nicht locker lassen) } \\
\text { E-25 (die Arme strecken') } \\
\text { E-47 ('der Kopf auf dem Knie') } \\
\text { E-74 ('sich auf den Rücken legen') }\end{array}$ & $\begin{array}{l}\text { W-67 (sich beugen'), } \\
\text { W-91 (mit den Händen nicht locker lassen) } \\
\text { W-138 ('weinen') } \\
\text { W-143 ('sich entspannen') } \\
\text { E-24 ('in Stille sein', 'in Betrübnis sein', ins Klagen } \\
\text { verfallen') } \\
\text { E-25 (die Arme strecken') } \\
\text { E-32 ('durcheinander reden') } \\
\text { E-47 ('niedergeschlagen sein') } \\
\text { E-47 ('der Kopf auf dem Knie') } \\
\text { E-49 ('Angst haben') } \\
\text { E-57 ('weinen') } \\
\text { E-74 ('niedergeschlagen sein') } \\
\text { E-74 ('sich auf den Rücken legen') } \\
\text { E-75 ('niedergeschlagen sein') } \\
\text { L-9 ('einen Boten ausschicken') }\end{array}$ \\
\hline
\end{tabular}

In Kapitel 4 wurden die unterschiedlichen körperlichen Reaktionen auf die Emotionen untersucht. Analysiert man die oben genannten Beispiele im Zusammenhang mit den im Kapitel 4 besprochenen Reaktionsmuster, stellt man folgendes fest:

- Im Zusammenhang mit der Emotion Liebe entspricht der Ausdruck 'die Augen leuchten' (L-11) einer physischen Reaktion, die auch Sprechern der meisten modernen europäischen Sprachen vertraut sein dürfte. Bei Freude kann ein lautes Lachen entstehen, im Beispiel E-79 stößt Isis statt lautem Lachen einen lauten und aufgeregten Schrei als Zeichen ihres fröhlichen Zustands aus.

- Im Fall der Trauer ist von einem 'sich beugen' oder 'in sich zusammensinken' die Rede (W-67), worunter einerseits eine Reaktion auf den psychischen Schmerz verstanden werden könnte. Man könnte andererseits jedoch auch an eine Art konventionalisierten Trauergestus denken, der aus einem Zusammenkauern besteht. Die Beispiele 'mit dem Kopf auf dem Knie' (E-47) und 'auf dem Rücken legen' (E-74) sind wohl analog zu verstehen.

- Im letzen Fall kann 'mit den Händen nicht locker lassen' (W-91) verstanden werden als ein Zeichnen der 'Passivität', durch die Trauer auch charakterisiert wird.

- Das Ausbreiten der Arme von Sinuhe (E-25) kann vielleicht mit Bewegungslosigkeit, die als einer der möglichen körperlichen Reaktionen auf Angst erwähnt wurde (siehe Kapitel 9.4.3), verbunden werden. Ganz sicher ist das jedoch nicht.

Bemerkenswert ist, daß die negativen Emotionen nicht nur öfter, sondern auch ausführlicher als die positiven beschrieben wurden. Man hat wohl davon auszugehen, daß in den Texten mit der Beschreibung der körperlichen Reaktion oder des Benehmens als Folge einer Emotion das Ziel verbunden war, die emotionalen Befindlichkeiten der handelnden Personen hervorzuheben und besonders eindringlich zu schildern. 


\subsubsection{Mitteilungen als Auslöser einer Reaktion}

Eine Mitteilung oder eine Rede zu hören (oder zu äußern) kann je nach der Situation unterschiedliche Reaktionen hervorrufen. In den Weisheitstexten wurde die Fähigkeit 'jemandem zuzuhören' als eine erwünschte Eigenschaft angesehen. Desgleichen wurde es als gutes Verhalten angesehen, mit Gehörtem diskret und respektvoll umzugehen. Das ist etwa in den Lehren des Ptahhotep (W-17, W-33), des Ani (W-146, W-148, W-143) oder des Amenemope (W-146, W-166, W-164) beschrieben worden.

Man kann die Mitteilung als möglicher Auslöser einer Emotion interpretieren. Die hervorgerufenen Reaktionen deswegen werden in den ägyptischen Texten dargestellt, in denen die negativen Gefühle vergleichend mit den positiven zahlreicher sind. Bei indiskreter oder unbedachter Äußerung, was in den Lehren regelmäßig als schlechte Eigenschaft angesehen wird, enthält die Rede eine schlechte Absicht z.B.:

- 'Die Sprichwörter werden auf das Herz treffen wie Feuer.' (W-63),

- 'Dann könnte ich mich untätig auf es (scil. das Herz) stützen, es mit Klagen über das Elend beladen und so schließlich mein Leid auf seine Kosten vertreiben' (W-68),

- 'Schneller als die Böen des Mündungbereichs ist die Rede, wenn das Herz gekränkt ist.' (W-158),

- 'Grüße deinen Feind nicht, indem du Unrecht (tust) und kränke dein eigenes Herz nicht' (W-160),

- 'Laß nicht zu, daß man deine Rede nach außen weiterträgt, damit dein Herz nicht verbittert wird.' (W-166).

Wenn diese Absicht der Rede oder der Mitteilung böse oder schlechte ist, wird eine negative Emotion hervorgerufen, z.B.:

- 'Er sagte über sie (die zukünftigen Kinder): "Sie werden diese vortreffliche Amt im ganzen Land ausüben. Der Älteste von ihnen wird Hohepriester in Heliopolis sein". Seine Majestät, dessen Stimmung verschob sich daraufhin zu Niedergeschlagenheit' (E-44),

- 'Er fand Rudjededet, wie sie mit dem Kopf auf dem Knie dahockte und ganz niedergeschlagen war' (E-47),

- 'Sie erzählten es seiner Majestät (...) . Daraufhin verfiel seine Majestät, er möge leben, wohlbehalten und gesund bleiben, in eine ganz niedergeschlagene Stimmung' (E-67),

- 'Pre-Harachti aber litt sehr unter der Antwort, die ihm gegeben wurde, und er legte sich auf seinen Rücken und war ganz niedergeschlagen' (E-74 und E-75),

- 'Ein anderer sagt, er hätte eine andere gefunden, und sie starre ihm ständig ins Gesicht. Was soll denn das, den anderen wegen einer Dahergelaufenen zu Kränken?' (L-9).

Die Beispiele aus den Weisheitstexten mit einer positiven Reaktion auf eine Rede bilden aber keinen neuen emotionalen Zustand aus, sondern sind sie eher als eine Verhaltensbeschreibung $\mathrm{zu}$ verstehen. Die in solchen Texten beschriebenen Gefühle gehören nicht zu einer konkreten Person, sondern zu einer Gesellschaft. Man soll diese Gefühle als anonyme Gefühle 
verstehen. Auf diesem Grund werden Reaktionen von anonymen Subjekten dargestellt, die eher als Bild eines korrekten statt leidenschaften Verhaltens eines Menschen interpretiert werden sollen.

Im Gegenteil dazu wird das emotionelle Verhalten eines Menschen in den Erzählungen und Liebesliedern häufiger dargestellt. Es wurde gesagt:

- 'Dann wiederholte ihm Rudjedet diese Rede, woraufhin sein Herz über alle Maßen glücklich wurde' (E-46),

- 'Keiner kommt von dort, so daß er weder ihre Art noch ihre Bedürfnisse weiter ermittelt, und daß er unser Herz tröstet, bis wir zum Platz gelangen, wohin sie gegangen sind' (L-10).

\subsubsection{Eine Tabelle der ägyptischen Determinative für Emotionswörter}

Es wurde dargelegt (Kapitel 4), daß die Emotionen positiv oder negativ klassifiziert werden können; im Ägyptischen wird das in einigen Fälle durch Determinative auch in der Schrift explizit gemacht. In der folgenden Tabelle werden die Beispiele aus den Weisheitstexten, Liebesliedern und Erzählungen in zwei Gruppen eingeordnet. Die erste Gruppe enthält die positiven Emotionen und die zweite die negativen. Dazu wird jedesmal angegeben, welches Determinativ oder welche Determinative in den entsprechenden Schreibungen auftauchen.

\section{Positive EMotionen}

\begin{tabular}{|c|c|c|}
\hline $3 w . t-j b . w$ & 'Freude' & $\varnothing(\mathrm{W} 113)$ \\
\hline$j^{c} j j b$ & $\begin{array}{l}\text { 'sich erleichtern', } \\
\text { 'sich entspannen' }\end{array}$ & $\varnothing(\mathrm{E}-15, \mathrm{E}-33)$ \\
\hline${ }^{c} n b$ & 'erfreulich' & $(\mathrm{W}-122)$ \\
\hline${ }^{c} \underline{d}^{C} \underline{d}$ & 'jauchzen' & $=$ und $2 \mathbb{R}$ (L-29) \\
\hline$w n f$ & 'froh sein' & 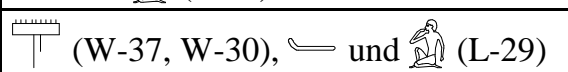 \\
\hline$m r j$ & 'lieben' & 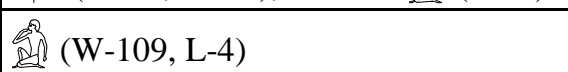 \\
\hline$n f r$ & 'erfreulich' & $\varnothing(\mathrm{W}-98, \mathrm{E}-43, \mathrm{E}-46, \mathrm{E}-51)$ \\
\hline$n \underline{d} m$ & $\begin{array}{l}\text { 'entspannt sein', } \\
\text { 'zufrieden sein' }\end{array}$ & $\Longleftarrow(\mathrm{W}-143, \mathrm{~W}-157, \mathrm{E}-45, \mathrm{~W}-53, \mathrm{~L}-8)$ \\
\hline$r \check{s} w$ & 'sich freuen' & A und $(\mathrm{E}-79, \mathrm{~L}-12)$ \\
\hline$h w t$ & 'froh sein' & $\emptyset(\mathrm{E}-80)$ \\
\hline$h r$ & 'zufrieden sein' & $w(W-51)$ \\
\hline ḥtp & 'zufrieden sein' & $\Longleftarrow(\mathrm{W}-36, \mathrm{~W}-92, \mathrm{~L}-33)$ \\
\hline$h n t \check{s}$ & 'sich freuen' & (2) $(\mathrm{W}-120, \mathrm{~L}-24)$ \\
\hline siw & 'sich erfreuen' & $\emptyset(\mathrm{W}-23, \mathrm{E}-36)$ \\
\hline sndm & 'sich erfreuen' & $\Longleftarrow(\mathrm{W}-199, \mathrm{E}-71, \mathrm{E}-72)$ \\
\hline$s h m \check{s}$ & 'Herzensvergnügen' & $\emptyset(\mathrm{W}-116), \mathrm{D}^{2}(\mathrm{~L}-4, \mathrm{~L}-10, \mathrm{~L}-15, \mathrm{~L}-31)$ \\
\hline thhhw & 'jubeln' & (L-14) \\
\hline
\end{tabular}




\section{NegATIVE EMOTIONEN}

\begin{tabular}{|c|c|c|}
\hline $3 \underline{d}$ & 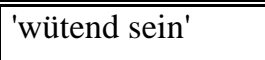 & De $(\mathrm{W}-8)$ \\
\hline$j k n w$ & 'bitter sein' & (W-164) \\
\hline$m s \underline{d j}$ & 'widerwillig' & $\times$ u. $(\mathrm{W}-144)$ \\
\hline$r m j$ & 'weinen' & $\pi(\mathrm{W}-136)$ \\
\hline$h w^{3}$ & 'verdrießlich sein' & $\otimes(\mathrm{E}-62)$ \\
\hline$h \underline{d}$ & 'krank werden' & (W-29, W-87, W-90, W-148, W-158, W-160, L-8, L-9) \\
\hline$h \underline{d} \underline{d n}$ & 'unwillig sein' & u. \\
\hline snm & 'traurig sein' & $D(W-70)$ \\
\hline snd & 'Angst haben' & (E-49) \\
\hline$\check{s} n w$ & 'leiden' & u. $(\mathrm{E}-57, \mathrm{E}-77)$ \\
\hline$q s n$ & böse sein & $N(\mathrm{~W}-67)$ \\
\hline$g m w$ & in Betrübnis sein & $\therefore(\mathrm{E}-24)$ \\
\hline$d n d n$ & wütend sein & $\succeq(\mathrm{W}-81)$ \\
\hline$\underline{d} w$ & $\begin{array}{l}\text { niedergeschlagen } \\
\text { sein }\end{array}$ & $\therefore$ E-44, E-47, E-67, E-74, E-75 \\
\hline
\end{tabular}

Die am meisten verwendeten Determinative sind [MANN MIT HAND AM MUND] (siehe dazu etwa Wiesmann 1922: 73-75), $\Longleftarrow$ [BUCHROLLE] (vgl. dazu Wiesmann 1922: 75-76), und ['SCHLECHTER' VOGEL] (vgl. dazu ausführlich David 2000). Die Buchrolle steht vor allem für etwas Geschriebenes oder für etwas Abstraktes. Auf der Grundlage der Auflistung in der Tabelle muß davon ausgegangen, daß dieses Determinativ in unserem Zusammenhang fast ausschließlich für Positives gebraucht werde (einzige Ausnahme: die Gruppe willig sein'). Das ist etwas überraschend, denn intuitiv würde man das Determinativ [BUCHROLLE] eher für "neutral" halten. Hingegen wird jedoch das Hieroglyphenzeichen ['SCHLECHTER' VOGEL] durchgängig für Negatives verwendet und erfüllt damit die Erwartungshaltung. Determinative, die einen Menschen oder auch nur einen menschlichen Körperteil abbilden (z.B. die Person mit der Hand am Mund 题, der Schlagende 炀), können sowohl mit einem positiv als auch mit einem negativ konnotierten Wort vorkommen.

Geht man davon aus, daß durch den Gebrauch der Determinative oder Klassifikatoren unterschiedliche Kategorien konstituiert werden, und ordnet deswegen die Lexeme nach den Determinativen, mit denen sie geschrieben werden können, so ergeben sich folgende Klassen:

\begin{tabular}{||l|l|l||}
\hline KLASSIFIKATOR & \multicolumn{1}{|c||}{ LEXEME } & \multicolumn{1}{|c||}{ ART DER EMOTIONEN } \\
\hline$\varnothing$ & $\begin{array}{l}3 w . t-j b . w \text { 'Freude', } \\
j c j j b \text { 'sich erleichtern, sich entspannen', } \\
n f r \text { 'erfreulich', } \\
h w t \text { 'froh sein', } \\
\text { sjw 'sich erfreuen', } \\
\text { shmś 'Herzensvergnügen' }\end{array}$ & \\
\hline
\end{tabular}




\begin{tabular}{|c|c|c|}
\hline KLASSIFIKATOR & LEXEME & ART DER EMOTIONEN \\
\hline 20 & $c_{n b}$ 'erfreulich' & positiv \\
\hline & $\begin{array}{l}m r j \text { 'lieben', } \\
\text { shrmš 'Herzensvergnügen', } \\
\text { snd 'Angst haben' }\end{array}$ & positiv oder negativ \\
\hline$=Q^{2}$ & $\begin{array}{l}{ }^{c} \underline{d}^{c} \underline{d} \text { 'jauchzen', } \\
w n f \text { 'froh sein' }\end{array}$ & positiv \\
\hline " שس & $w n f^{\prime}$ froh sein' & positiv \\
\hline$w$ & 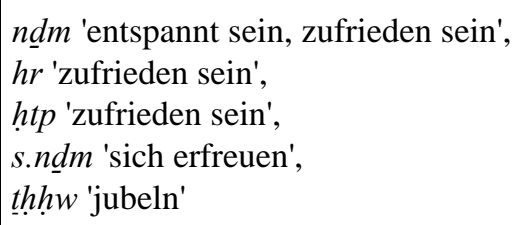 & positiv \\
\hline 国w & $r \check{s} w$ 'sich freuen' & positiv \\
\hline 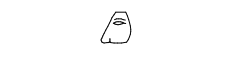 & hntšs 'sich freuen' & positiv \\
\hline 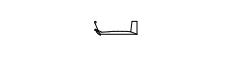 & $d n d n$ 'wütend sein' & negativ \\
\hline$w$ & $h \underline{d} n n$ 'unwillig sein' & negativ \\
\hline 20 & $3 \underline{d}$ 'wütend sein' & negativ \\
\hline 2 & $\begin{array}{l}j k n w \text { 'bitter sein', } \\
h \underline{d} \text { 'krank werden', } \\
\text { snm 'traurig sein', } \\
q s n \text { 'böse sein', } \\
g m w \text { 'in Betrübnis sein' } \\
\underline{d} w \text { 'niedergeschlagen sein' }\end{array}$ & negativ \\
\hline$x \underline{2}$ & $m s \underline{d} j$ 'widerwillig' & negativ \\
\hline$\gamma$ ins & šnw 'leiden' & negativ \\
\hline $4 \pi$ & $r m j$ 'weinen' & negativ \\
\hline$\varnothing$ & $h w z^{\prime}$ 'verdrießlich sein' & negativ \\
\hline
\end{tabular}

Eine Deckungsgleichheit in dem Sinne, daß eine bestimmte Art des Klassifikatorgebrauchs einem ganz konkreten Emotionstyp entspräche, ergibt sich nicht ohne weiteres. Trotzdem wäre es natürlich aufschlußreich, genauer zu untersuchen, auf welche Weise in der ägyptischen Schrift Emotionsausdrücke mit Hilfe der Determinative zu bestimmten Klassen zusammengefaßt werden. Dazu wäre es aber erforderlich, sich nicht allein auf die mit einem der Lexeme für 'Herz' gebildeten Ausdrücke zu beschränken. Das ist ein Thema für eine eigene Untersuchung. 


\section{6 Ägyptische Kollokationen zum Ausdruck von Charakter, Gefühlen oder allgemeinen Zustände}

Lexikalisch-semantische Fragen nach dem genauen Unterschied zwischen den ägyptischen Lexemen für 'Herz' oder nach einer etwaigen diachronen Veränderung von Lexembedeutungen stehen - das wurde schon vorher dargelegt - in dieser Arbeit nicht im Zentrum des Interesses. Es gibt jedoch bestimmte Ausdrücke für die durch eine vergleichende Analyse des gesamten erfaßten Materials über Emotionen und die Reaktionen darauf neue Übersetzung angeboten werden können. Im folgenden werden noch einmal kurz solche Kollokationen besprochen, für die ich meine, im Zuge dieser Untersuchung eine exaktere Klärung ihrer Bedeutung gefunden zu haben. Eine ausführlichere Besprechung ist in dem entsprechenden Kapitel zu finden ist.

\subsection{1 $h r$ - jb- 'nach Dafürhalten von'}

Die übliche Übersetzung der Konstruktion $h r$ - jb lautet nach dem Wörterbuch der ägyptischen Sprache "der Mittelpunkt, die Mitte" (Wb III 136,7-138,16). Diese Verwendungsweise kommt tatsächlich oft vor, in dem hier untersuchten Korpus haben wir es jedoch auch mit einer anderen Funktion der gleichen Wortverbindung zu tun: In der Erzählung des Bauern (E-8, E-12) wird das Wort 'Herz' als Komplement der Präposition $h r$ - verwendet. In beiden Fällen wurden die Lexeme von mir als 'Meinung' wiedergegeben, wobei eine passende Übertragung der ganzen Konstruktion 'nach der Meinung von jemandem' oder 'nach Dafürhalten von jemandem' lauten kann. In Beispiel E-51, in dem das Lexem als 'Ansicht' übersetzt wurde, liegt der gleiche Sinn vor, und die Beispiele W-77 ('es ist nach dem Dafürhalten Gottes') und W-104 ('im Sinne Gottes') sind weitere eindeutige Fälle, die eine derartige Analyse unterstiutzen. Ein scheinbares Gegenbeispiel ist der Textausschnitt E-63, doch handelt es sich dabei nicht um die Kollokation $h r-j b$-, sondern um die Verbindung eines mit $h r$ - konstruierten Verbs mit dem Präpositionalobjekt $j b$.

\subsection{2 $j^{c} j j b$ 'sich Entlastung verschaffen'}

Diese Kollokation soll nach den Wörterbüchern von Erman \& Grapow und Hannig (1995) so etwas wie 'jdn. erfreuen' (Wb I 39,9), 'erfreut werden' (Wb I 39,10), 'den Mut an den Feinden kühlen' (Wb I 39,11) oder 'seinen Gefühlen Luft machen' (Hannig 1995: 29) bedeuten. In dieser Arbeit wurde die Kollokation $j^{c} j \mathrm{j} b$ im Zusammenhang mit den Gefühlen und auf der Grundlage eines Vergleichs aller einschlägigen Beispiele aus dem Korpus analysiert und ein neuer Übersetzungsvorschlag erarbeitet. In den Beispielen W-9, W-16 und W-59 wurde es als 'sich etwas von der Seele reden' wiedergegeben, während es in Beispiel E-15 mit 'sich entspannen' und in E-33 als 'sich erleichtert fühlen' übersetzt wird (siehe 5.4 und 7.3). In allen Fällen wird diese Kollokation als 'sich Entlastung/Erleichterung/Entspannung verschaffen' verstanden, was doch einen deutlichen Unterschied etwa zu den Angaben der Nachschlagewerke darstellt. In Grunde genommen stellen die Übersetzungen von Erman \& Grapow (Wb I 
39) und Hannig (1995: 29) nur eine ganz allgemeine Wiedergabe eines Mehrwortausdrucks mit positiver Konnotation dar. Es ist aber möglich, durch die hier vorgenommene Analyse eine Nuance herauszufiltern, die eine wesentlich präzisere Wiedergabe der Kollokation ermöglicht.

\subsection{3 wỉh jb 'Zurückhaltung an den Tag legen'}

Diese Kollokation soll nach den Wörterbüchern von Erman \& Grapow (Wb I 256,14-19) und Hannig (1996: 175) (unter anderen) mit 'wohlgesinnt', 'freundlich', 'geduldig' zu übersetzen sein. Im Zuge der Arbeit mit dem für die vorliegende Studie untersuchten Korpus hat es sich allerdings herausgestellt, daß eine Wiedergabe mit 'sich zurückhalten' bzw. 'Zurückhaltung' vielfach passender ist (siehe Anhang). Die meisten Beispiele kommen in den Weisheitstexten vor. Meine Analyse deckt sich insoweit mit der der Wörterbücher, als zweifellos eine positive Eigenschaft gemeint ist. Für die einschlägigen Beispiele aus den Weisheitstexten und Erzählungen ist meiner Meinung nach freilich die an den entsprechenden Stellen vorgeschlagene Übertragung die bessere Übersetzung (siehe Kapitel 7.5 und die Beispiele E-15 und E-38).

\subsection{4 snd $\underline{d}$-j $b$ 'mit einer guten Nachricht beglücken' und $\underline{d} w$-jb 'von einer schlechten Nachricht erschüttert sein'}

Bei diesen beiden Kollokationen ist es wichtig, sie parallel zu analysieren. Es wurde oben dargelegt, wie eine Mitteilung eine Emotion auslösen kann. Eine positive Emotion ist die Reaktion der Rudjededet, als sie bzw. ihr Herz aufgrund der erfreulichen Mitteilung der Geburt der Kinder über alle Maße glücklich ( $s n d m$ ) wurde (E-46), genauso reagieren der Fürst von Naharina, als er erfährt, daß jemand das Fenster seiner Tochter erreicht hat (E-71), und der Herrscher ('Goldhorus'), nachdem ihn ein amtliches Schreiben mit guten Nachrichten erreicht hat (W-119).

Im Gegenteil dazu ist eine unerfreuliche Mitteilung der Auslöser einer negativen Emotion. Das ist der Fall in den Beispielen E-44 E-47, E-67, E-74, E-75 und L-9. Mit Ausnahme von Beispiel L-9, in dem sich das verwendete Lexem $h \underline{d}$ 'krank werden' auch mit einem schlechten Zustand in Verbindung bringen läßt, enthalten alle Beispiele das Lexem $\underline{d} w$. Der emotionale Zustand wurde schon in dem entsprechenden Abschnitt weiter oben kommentiert und erläutert (siehe Kapitel 7.2). Laut Wörterbuch der ägyptischen Sprache ist die Übersetzung des Wortes 'traurig werden' (Wb V 548,16). Die Bedeutung kann jedoch meiner Meinung nach durch eine Übersetzung '(von einer schlechten Nachricht) niedergeschlagen/erschüttert sein/werden' exakter erfaßt werden. 
In der Spalte der ägyptischen Einträge steht jeweils die Wurzel. Als deutsche Entsprechungen werden entweder Infinitive oder - im Fall der Nennung eines Subjekts - finite Formen in Präsens ausgeführt.

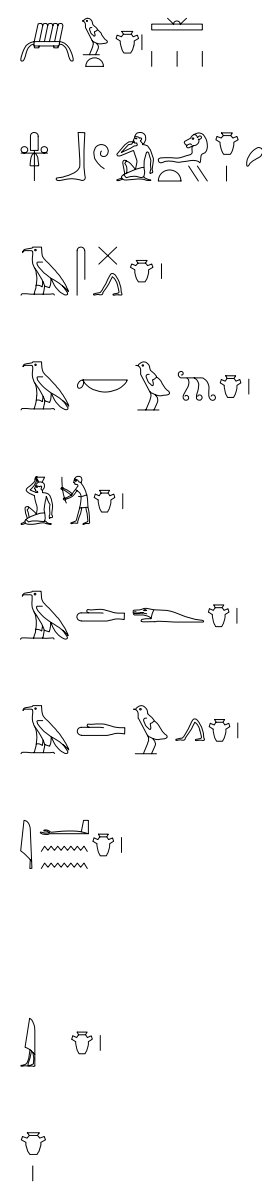

3w.t-jb.w

'Freude': W-113

¡b his $t j$

'das Herz wünscht sich etwas': E-64

$3 s-j b$

'Ungestümer': W-56

$3 k w j b$

'das Herz ist verkommen': W-13, W-15

$3 t p j b$

'die Seele ist beladen': E-18

’d $j b$

'innerlich wütend sein': W-8

$\jmath d w j b$

'das Herz wird matt': E-27

$j^{c} j b$

'(etwas) von der Seele reden': W-9, W-16, W-59

'sich entspannen': E-15

'sich erleichtert fühlen': E-33

jj jb

'das Herz kommt': W-69

jb

'Herzenswunsch': W-32

'Meinung': W-33, W-39, W-105, W-111, W-150, W-156, E-2, E-7, E-8, E-12, E-29, E-51

'Gedanke': W-88, W-94, E-37, E-38, L-3

'Charakter': W-42, W-73, W-124, W-128, W-164

'Streben': W-152

'Begierde': E-22

'Beherztheit': E-28

'Wunsch': E-9, E-31, E-52, E-54, E-56

'Stimmung': W-7, W-17, W-18, W-28, W-77, W-92, W-129, W-138, W-148, W-158, E-40, E-42, E-43, E-44, E-47, E-67, E-71, E-80, L-10, L-11

'Absicht': W-74, W-140, E-56

'Wille': E-37, E-69, E-70, E-73, E-76, E-81

'Erinnerung': L-10

'Seele':W-9, W-16, W-59, E-4, E-18, L-10

'Verstand': W-15, W-58, W-108, W-120, W-135, W-148, W-149, E-2, E-14, E-15, E-25, E-26, L-10, L-16, L-24

'Gefühl': W-87, L-24

'Laune': W-24, W-36, W-148

'Kraft': W-36

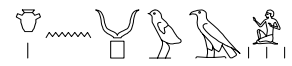

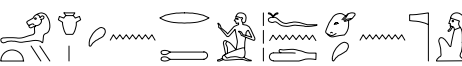

jb n-wpw.t.w

'die Atmosphäre des Hauszustands': W-45

hỉtj $n(j)-r m \underline{\text { f }}$ fnd $n(j)-n \underline{\text { tr }}$

'das Herz eines Menschen ist die Nase Gottes': W-166 


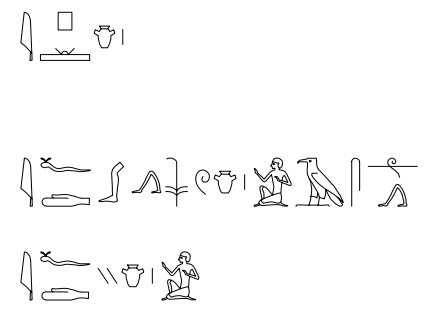

101

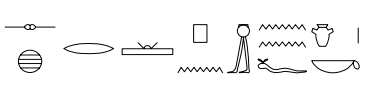

$\cos$
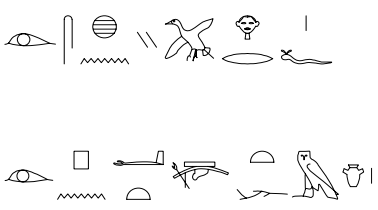

$\left.\sin \frac{9}{\square 11}\right\}$
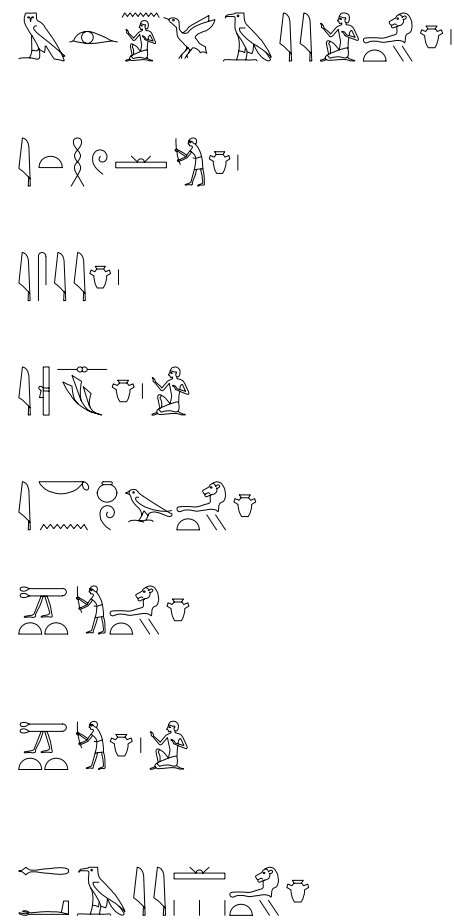

jp jb

'verständig sein': W-120, W-127

'der Verstand beurteilt etwas richtig': W-135

$j f d s w j b=j$ is

'er, mein Herz, ist eilig auf der Flucht': L-21

jfd $j b$

'das Herz flieht': L-23, L-33(?)

jn

'das Herz kommt hinweg': W-97

'impulsiv sein': E-15

'das Herz holen': E-78

shr pn jn $-n=f j b=k$

'dieser Gedanke, zu dem dein Herz sich hat hinreißen lassen': E-37

$j r$

'das Herz macht etwas': W-13, W-15

'das Herz funktioniert' (gemäß der Bestimmung): W-34, W-35

jr shny $-h r=f(j b)$

'auf dem Herzen eine Pause machen': W-68

jr pncj.t m-jb

'als Schloß am Herzen dienen': W-155

jr $n-h i j t j$

'nach dem Willen handeln': E-69, E-81

$m j r-n=j p 3 y=j h 3 t$

'Mache mir keine Dummheiten, mein Herz': L-22

jh.t jb

'das Herz einschüchtern': W-106

jsy jb

'das Herz erleichtern': W-9

$j z j b$

'einer mit leichtem Herzen': E-15

jknw ḩitj

'das Herz wird verbittert': W-166

jt $\underline{h} 3 \mathrm{itj}$

'das Herz mitnehmen': L-3, L-30

$j \underline{j} j b$

'den Verstand rauben': L-16, L-24

'das Herz nehmen': L-32

C) hitj

'das Herz ist groß': W-131

'das Herz ist mutig': L-28 


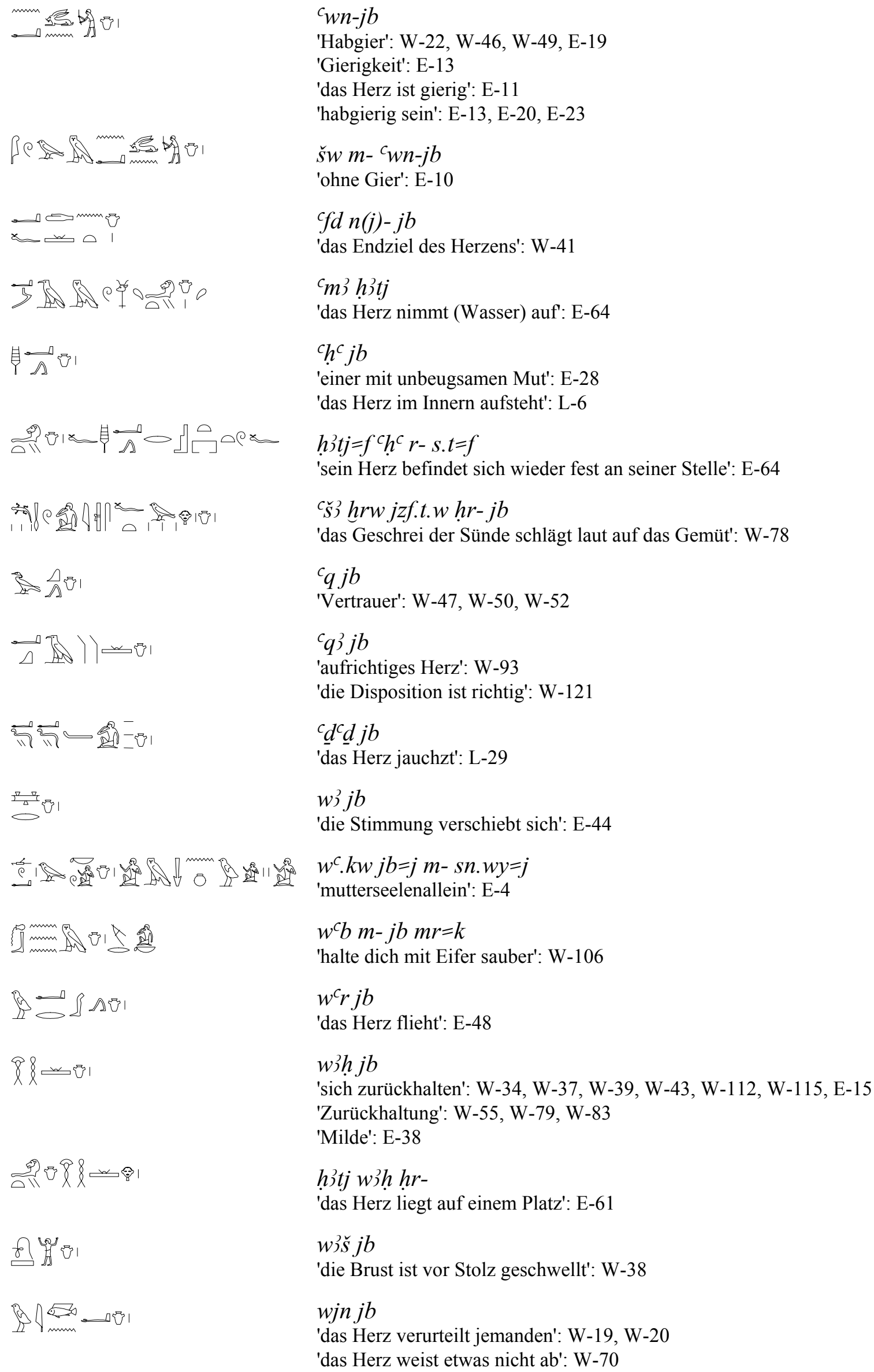




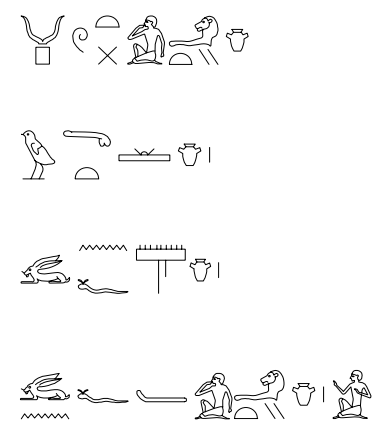

$\sum_{\sin }^{3} v^{\prime}$

$\infty<$

स—

$\stackrel{2}{\rightleftarrows}$

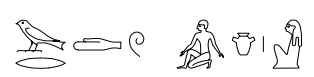

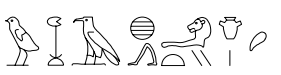

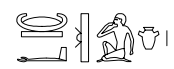

$\stackrel{\square}{\rightleftarrows}$

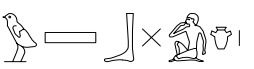

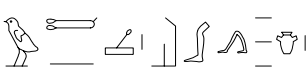

on 2

B. wpj ḩ’tj

'die Gedanken jmds. Enthüllen': E-61

wmt jb

'einer mit unerschütterlicher Kaltblütigkeit': E-28

wnf jb

'übermütig sein': W-27, W-30

'Übermütige': W-30

wnf hitj

'das Herz ist froh': L-29

wnn jb

'das Herz ist offen': W-2

$w r j b$

'der Großherzige': W-14

$w r \check{s} j b$

'das Herz verweilt (an einem Ort)': E-34

wrd jb

'das Herz ist müde': W-3, E-35

wrd jb

'der Herzensmüde': L-10

whi hitj

'das Herz suchen': E-64

'das Herz sucht jdn': L-7

$w h^{c} j b$

'das Herz erklärt': W-69

'klug': W-122

wh $)$ jb hry-c

'dem Verstand des Untergebenen Flügel verleihen': W-58

$w \check{s} b j b$

'das Herz antwortet': W-66, W-69

$w \underline{t z} j b$

'die Absicht verraten': W-140

$w \underline{d} j b$

'den Befehl des Verstandes': L-10

$w \underline{d}) j b$

'wohlgemut sein': E-1

'den Verstand vor etwas bewahren': L-10

b3g3 histj

'Ruhe mit dem Wunsch geben': E-68

b) 3 j $j$

'das Herz wird müde': L-10

bjn.t ḥr-jb

'Böses wird im Schilde geführt': W-10 


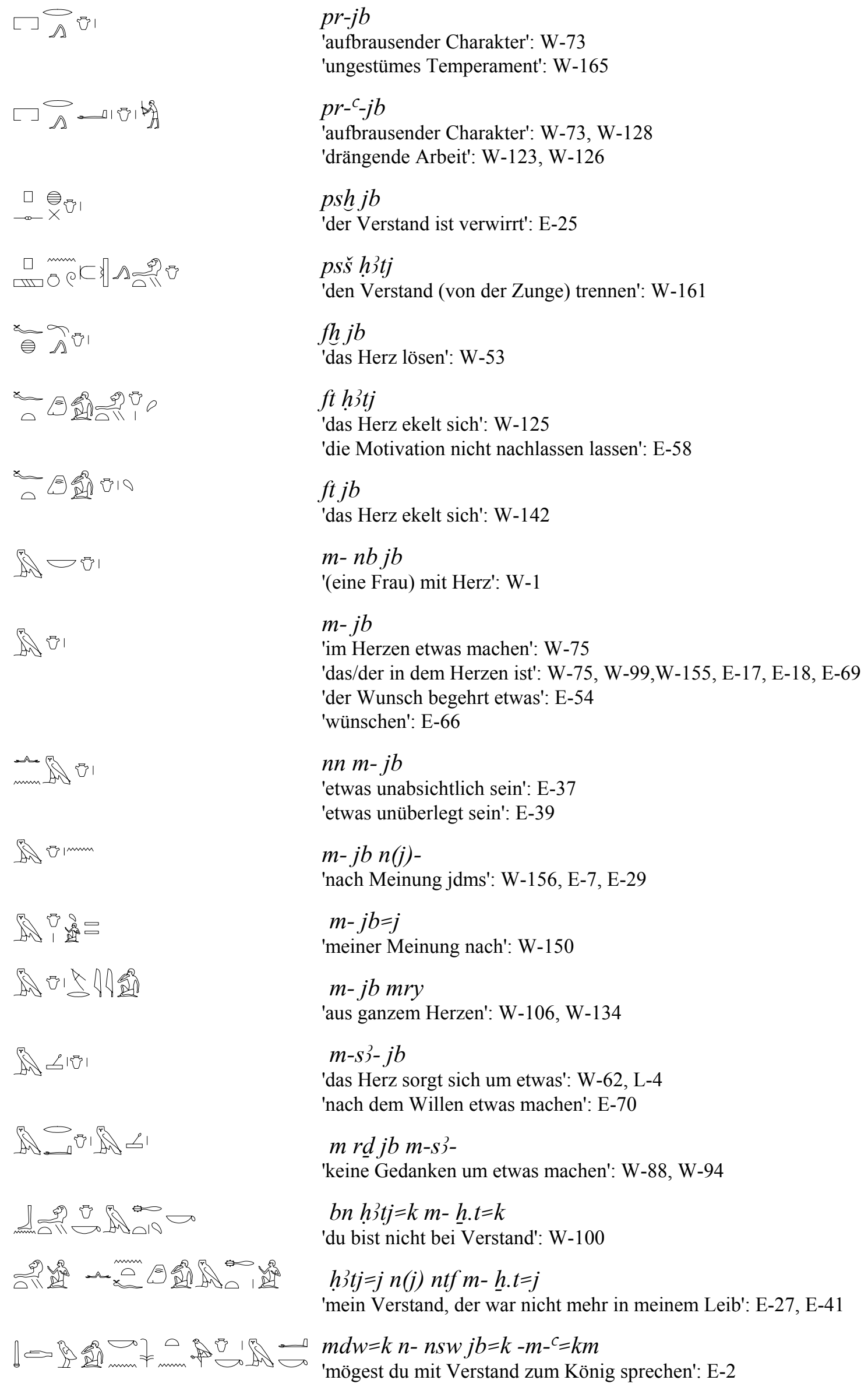

'mein Verstand, der war nicht mehr in meinem Leib': E-27, E-41

'mögest du mit Verstand zum König sprechen': E-2

$p r-j b$

'aufbrausender Charakter': W-73

'ungestümes Temperament': W-165

pr-c $-j b$

'aufbrausender Charakter': W-73, W-128

'drängende Arbeit': W-123, W-126

$p s h j b$

'der Verstand ist verwirrt': E-25

pš̌ ḩ̉tj

'den Verstand (von der Zunge) trennen': W-161

$f$ h $j b$

'das Herz lösen': W-53

$f t$ hỉtj

'das Herz ekelt sich': W-125

'die Motivation nicht nachlassen lassen': E-58

$f t j b$

'das Herz ekelt sich': W-142

$m-n b j b$

'(eine Frau) mit Herz': W-1

$m-j b$

'im Herzen etwas machen': W-75

'das/der in dem Herzen ist': W-75, W-99,W-155, E-17, E-18, E-69

'der Wunsch begehrt etwas': E-54

'wünschen': E-66

$n n-j b$

'etwas unabsichtlich sein': E-37

'etwas unüberlegt sein': E-39

$m-j b n(j)-$

'nach Meinung jdms': W-156, E-7, E-29

$m-j b=j$

'meiner Meinung nach': W-150

$m-j b m r y$

'aus ganzem Herzen': W-106, W-134

$m-s 3-j b$

'das Herz sorgt sich um etwas': W-62, L-4

'nach dem Willen etwas machen': E-70

$m r \underline{d} j b m-s\}-$

'keine Gedanken um etwas machen': W-88, W-94

bn $h 3 t j=k m-\underline{h} . t=k$

'du bist nicht bei Verstand': W-100 


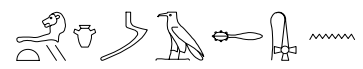

mm

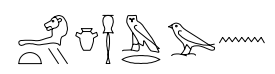

अ1

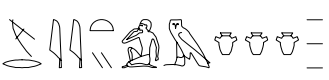

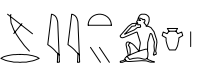

An Deen?

Wy।

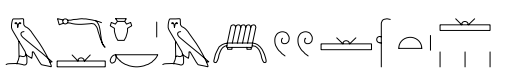

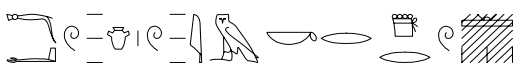

Dn $\cos$
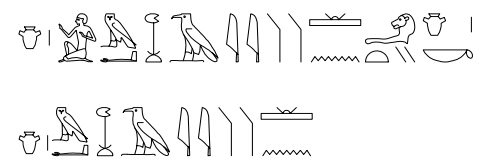

粼

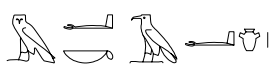

$\underset{\infty}{\infty} w_{0}^{m m}$

$\underset{\infty}{\infty}) \ldots$

वाI हn-

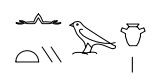

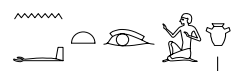

histj mỉh $n$ -

'das Herz hat Angst um jdn': E-32

$m n h$ jb

'das Herz ist tadellos': W-53

h’itj mr n-

'Mitleid mit jdm. haben': E-60, E-65

jb $m r n-$

'Mitleid mit jdm haben': E-32, E-34

mrj.tj $m-j b . w$

'der Beliebte in den Herzen': W-109

$m r j j b$

'das Herz liebt jdn': L-4

$m h j b$

'das Herz ist vergeßlich': W-4

$m h j b$

'jemandem vertrauen': W-94, E-16

'Vertrauensperson': W-38

$m m h j b=k m-3 w w$ rnp. $w t$

'der Treuherzige': W-84

$m h=w j b=w-j m=k r-\underline{d} r$

'auf die Länge der Jahren vertrauen': W-85

$m$-jr $m h$ jb

'sie werden dir völlig vertrauen': W-118

'sich (auf etwas) nicht verlassen': W-136, W-150

$j b=j m h 3: y n-h i t j=k$

'meine Stimmung ist harmonisch dank deinem Herzen': L-5

jb $m \underline{h} 3 n-$

'die Stimmung ist harmonisch für jdn': L-11

ms $\underline{d} \underline{d} h{ }^{3} j$

'widerwillig': W-144

$m k$ j $j b$

'das Herz ist kühn': E-3, E-5

mtr.t

'Leumundszeugnis': W-48

$m t r-j b$

'aufrichtiges Herz': W-89

njwty hìtj

'sich unbedacht verhalten': W-137

njwty jb

'sich unbedacht verhalten': L-18

$n^{c} j b$

'das Herz erbarmt sich': L-2 


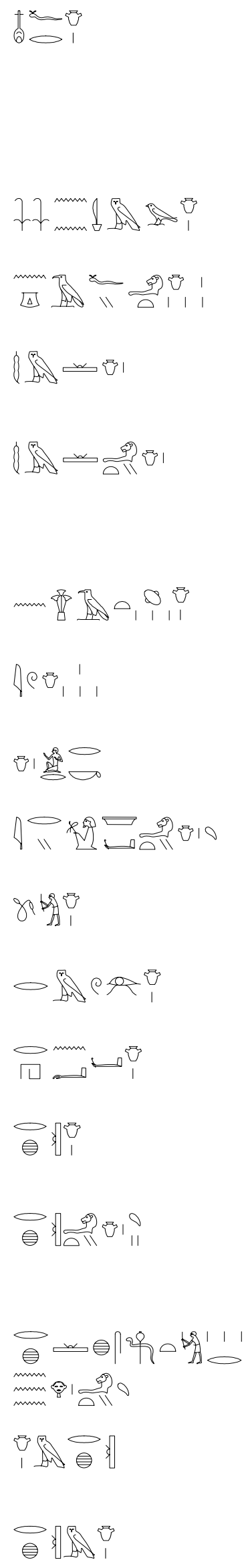

$n f r j b$

'ganz im Sinne sein': W-11

'Entspannung': W-96

'Glücksgefühl': W-98

'etwas wird glücklich': E-46

'die Stimmung ist gehoben': E-43

$n n m$ jb

'der Verstand geht in die Irre': W-15

$n g f h i t j . w$

'Klumpigwerden der Herzen': W-159

$n \underline{d} m j b$

'entspannt sein': W-143, E-53

'das Herz ist zufrieden': E-45

$n \underline{d} m \underline{h}{ }^{t} j$

'entspannt sein': W-143

'das Herz ist entspannt': L-8

'in entspannter Stimmung sein': W-157

$n h$. $j \mathrm{jb}$

'es ist herzzerreißend': W-44

$r-j b .(w)$

'der Stimmung entsprechend': W-138

$j b=j-r=k$

'ich will zu dir': L-4

jry- ${ }^{3}$ h hitj

'das Herz ist der Torwächter': W-141

$r w d j b$

'das Herz ist mutig': E-6

rmj jb

'das Herz weint': W-4

rhn jb

'sich auf das Herz stützen': W-49, W-92

$r h j b$

'der Wunsch jmds. kennt jdn. lernen': E-56

'die Gefühle jmds. kennen': L-24

rh hỉtj

'das Herz erfährt etwas': W-133

'das Herz weiß etwas': L-14

rh h hsf.t r-mw hr- hỉtj

'Widerstand gegen das Wasser auf dem Antlitz erkennen': W-29

jb m-rh

'ein Herz mit Wissen': W-68

$r h m-j b$

'etwas im Herzen erkennen': W-107 


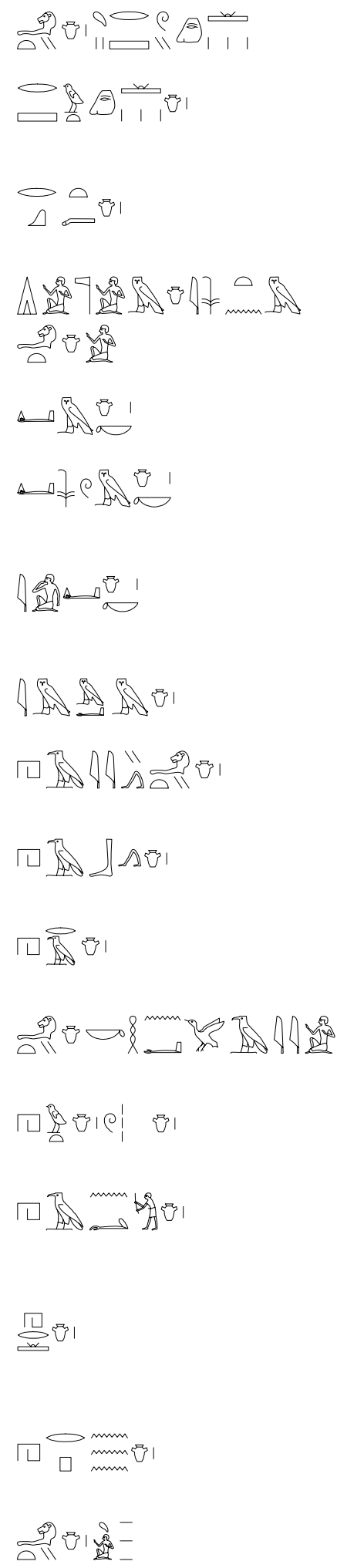

$h \grave{h}$ tj $r \check{s} j \mathrm{j}$

'freudige Herzen': W-149

$r \check{s} j j b$

'das Herz erfreut sich': E-79, L-12

rq.t jb

'Feindseligkeit': E-30

$d j=j n t r=j m-j b=j n z w m-h 3 i t j=j$

'mein Gott stand bei mir ebenso im Mittelpunkt, wie mir der König am Herzen lag': W-80

dj $m-j b$

'das Herz einsetzen': W-155

dj $s w m-j b=k$

'es dir zu Herzen nehmen': W-105, W-139, W-155, W-167

$\underline{d j} j b=k$

'wo dein Herz liegt': L-1

jm $m-j b$

'etwas ins Herz geben': L-24

hiy histj

'das tritt in einem Ort ein': W-154

hib jb

'das Herz (in den Kampf) senden': W-57

hir jb

'dem Herzen sagen': W-149

$h 3 t j=k h n^{c}-p j y=j$

'dein Herz ist bei dem meinigen': W-102

$h w t j b$

'die Stimmung ist froh': E-80

hn jb

'Zuwendung zeigen': W-39, W-40

'der Verstand neigt zu etwas': W-148, W-149

$h r j b$

'das Herz ist zufrieden': W-51, W-70

'beruhigend auf die Stimmung wirken': W-148

hrp jb

'die Meinung unterdrücken': W-33, W-39

hitj

'einziges Bedürfnis': W-153

'Wunsch': E-68

'Verstand': W-100, W-129, W-147, W-161, E-27, E-41, E-82

'Stimmung': W-157, E-62, L-5

'Gefühle': W-103

'Seele': W-109, W-11

hit jb

'Kummer des Herzens': W-21 

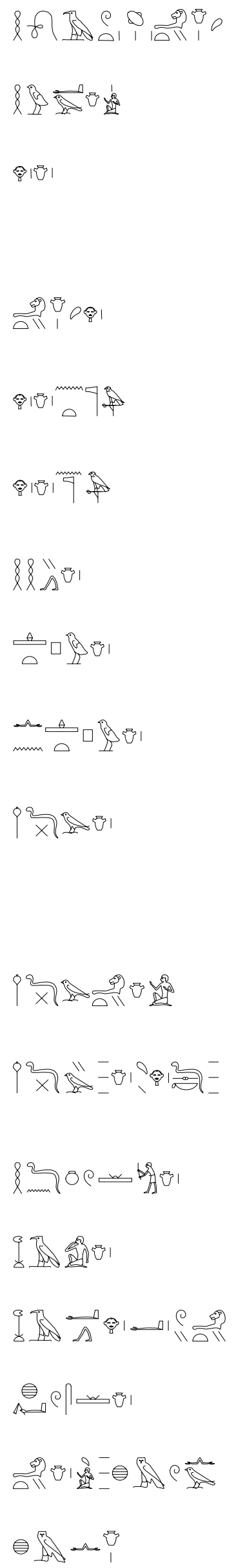

hw' hỉ 3 tj

'die Stimmung ist verdrießlich': E-62

$h w^{c} j b$

'einer mit engem Verstand': E-18

$h r-j b$

'etwas auf das Herz treffen': W-63

im Herzen sein': E-50

'nach Meinung jdms': E-8, E-12

'nach Ansicht': E-51

hijtj hr-

'das Herz liegt auf (etwas)': E-59, E-63

$h r-j b$ n.t- ntr

'nach dem Dafürhalten Gottes': W-77

$h r-j b n-n t r$

'im Sinn Gottes': W-104

hhy jb

'das Herz sucht etwas': W-65

htp jb

'die Laune ist zufriedengestellt': W-36

'die Stimmung ist zufrieden': W-92

nn htp jb

'das Herz ist (nicht) zufrieden': L-33

$h \underline{d} j b$

'das Herz zermürben': W-29

'das Gefühl ist verletzt': W-87

'das Herz stören': W-90

'das Herz kränken: W-160

'kränken werden': L-9

hd $\underline{h}$ itj

'kränken werden': L-8

$h \underline{d} j b h r-\underline{d} s=k$

'die Stimmung ist gekränkt': W-158

'die Stimmung aus persönlichen Gründen kränken': W-148

$h \underline{d} \underline{d} \mathrm{jb}$

'das Herz ist unwillig': L-18

hij $j b$

'das Herz erinnert sich an etwas': W-4

h3 hr- ${ }^{c}-w y$ hijtj

'sich abhängig von Gefühlen machen': W-103

hwws jb

'das Herz regt sich': W-61

hitj hm.w

'begriffsstutziges Herz': W-152

$h m j b$

'das Herz ist unwissend': L-20 


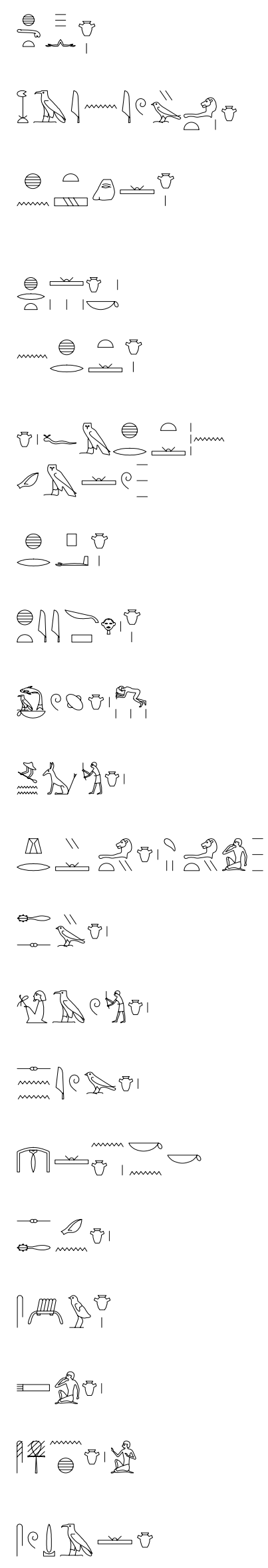

hmt jb

'das Herz beabsichtigt etwas zu tun': L-19

hn hỉ tj

'das Herz handelt töricht': L-22

hntš jb

'das Herz freut sich': W-120

'das Herz ist glücklich': L-24

hr.t $j b=k$

'der Plan deiner Meinung': E-2

$n-h r . t j b$

'nach Wunsch jmds': E-9

$j b=f m-\underline{h} r . t n-s \underline{d} m=w$

'sein Herz ist bereit, sie (die Botschaft) zu hören': L-14

hrp jb

'die Stimmung leitet jdn': E-40

$h t h r-j b$

'(die Lehren) sind im Herzen eingraviert': W-117

$\underline{h} 3 k-j b$

'Übelgesinnter': W-64

hnn jb

'Streitsüchtiger': W-81

hry-hỉt-hijtj

'ein hervorragendes Herz': W-151

hzj jb

'das Herz ist schwach': W-91

$z 3 w j b$

'das Herz wacht': W-95

znnj jb

'am Herzen leiden': W-67

$z h n(j)-j b=k-n=\langle t\rangle k$

'Planung deines eigenen Willens': E-37

$z h n n-j b$

'taub für das Herz sein': W-60

s3w jb

'das Herz erfreuen': W-23, E-36

$s j 3 j b$

'das Herz erkennen': E-21

s. ${ }^{c}$ hh $j b$

'etwas erhält mich am Leben': L-7, L-26

s.wd ${ }^{3} j b$

'jdn. belästigen': E-9

'den Verstand in Ordnung halten': E-15 


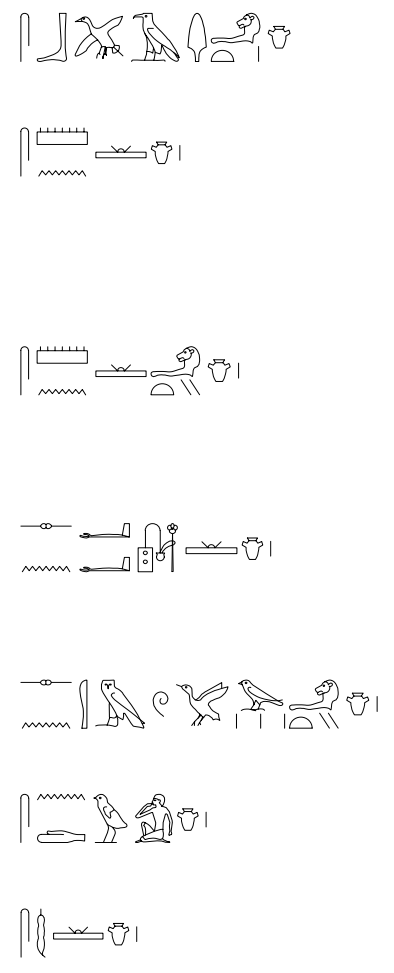

$1 \Leftrightarrow \rho g 9 y_{-}^{-}$
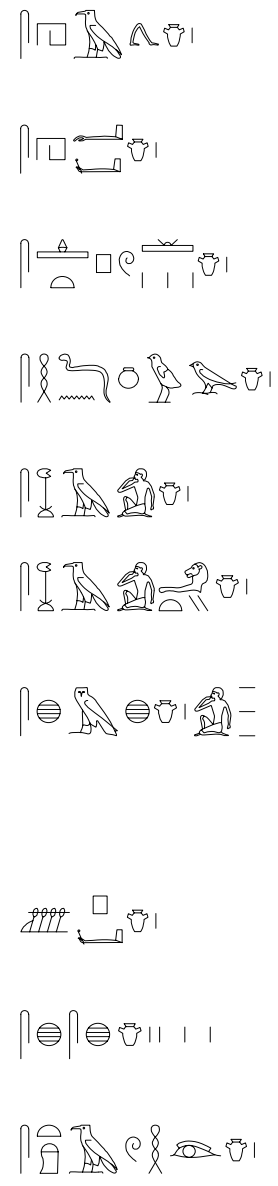

$s b 3 q$ hỉj

'die Seele erleuchtet': W-109

smn $j b$

'die Kondition stärken': W-36

'das Herz standfest machen': W-114

'die Stimmung ist gefestigt': W-129

'das Herz bleibt fest': L-23

smn ḩ’ $t j$

'das Herz standfest machen': W-164

'die Stimmung aufrichten': W-146

$s n^{c c} j b$

'die Stimmung glätten': W-17, W-18

'die Laune besänftigen': W-24

snm hỉtj

'das Herz ist traurig': W-70

snd $j b$

'das Herz hat Angst': E-49

$s n \underline{d m}-j b$

'Entspannung': W-72

'das Herz erfreuen': W-119

'die Stimmung heben': E-71

'jdn entspannen': E-72

srd jb.w

'die Herzen werden gefestigt: W-110

shj $j b$

'das Herz (im Körper) ist verdorben': W-162

shd $j b$

'das Herz in Ruhe versetzen': W-61

shtp jb

'die Laune verbessern': W-148

shd $\underline{d} \mathrm{j} b$

'die Stimmung verderben': W-28

$\operatorname{sh} 3 j b$

'das Herz erinnert sich an etwas': W-5, E-14, L-13

shj hitj

'das Herz erinnert sich an etwas': L-3

$s h m s ̌-j b$

'Herzerfreuende' : L-4

'Erheiterung der Stimmung': L-10

'Herzensvergnügen': L-15, L-31

szp jb

'das Herz empfängt (die Wahrheit)': W-71

shsh-jb

'Belustigung': W-116

s.tị $\mathrm{j} b$

'das Herz betören': L-17 


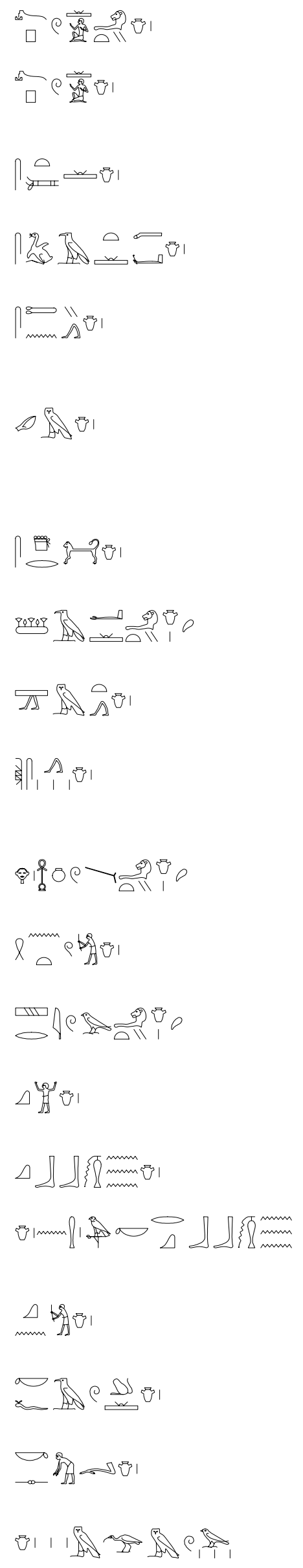

stp ḩ3tj

'ausgewählt an der Seele': W-111

stp jb

'mit überragendem Verstand': W-108

stm $j b$

'das Herz trösten': L-10

$s t 3 j b$

'das Herz für sich einnehmend sein lassen': W-76

$\operatorname{stn} j b$

'das Herz (von Gott) abwenden': W-54

'das Herz ist abgekommen': W-62

$s d m j b$

'das Herz ist dem Wünschen hörig': W-12

'der Verstand hört (auf seinen Körper)': W-15

'das Herz hört zu': W-31

$s \underline{d} r j b$

'das Herz schläft': W-4

$\check{s}\}$ h 3 tj

'das Herz beginnt etwas zu tun': W-96

šm jb

'die Gedanke geht dahin': L-3

šms jb

'dem Herzen folgen': W-59, L-10

'der eigenen Laune folgen': W-86

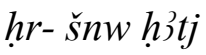

'jdn. leidet am Herzen': E-57, E-77

šnt jb

'streitsüchtig sein': E-18

šrj $h 3 t j$

'die Motivation wird weniger': W-121

$q^{3} \mathrm{j} b$

'hochmütig sein': W-25

$q b b j b$

'die Stimmung wird angenehm': E-42

$j b n(j)-h m=k r-q b b$

'die Stimmung deiner Majestät wird sich bessern': E-42

$q n j b$

'starkes Herz': W-67

$k f j b$

'die Absicht enthüllen': W-74

$k s j b$

'das Herz ist die Verbeugung': W-67

jb.w m-gmw

'die Herzen sind in Betrübnis': E-24 


\begin{tabular}{|c|c|}
\hline 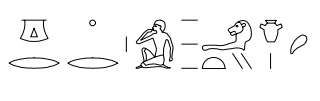 & $\begin{array}{l}\text { grw ḩ’tj } \\
\text { 'das Herz hat zu schweigen': W-143 }\end{array}$ \\
\hline 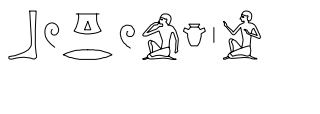 & $\begin{array}{l}b w \operatorname{gr} j b=j \\
\text { 'das Herz gibt keine Ruhe': L-9 }\end{array}$ \\
\hline & $\begin{array}{l}\text { t) jb } \\
\text { 'Heißsporn': W-15, W-26 }\end{array}$ \\
\hline 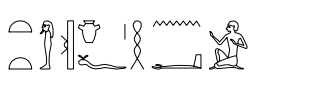 & $\begin{array}{l}\text { twt } j b=f-h n^{c}=j \\
\text { 'sein Charakter gleicht meinem': W-42 }\end{array}$ \\
\hline 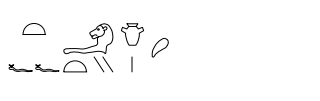 & $\begin{array}{l}\text { tff } h{ }^{3} t j \\
\text { 'das Herz abstoßen': W-77 }\end{array}$ \\
\hline & $\begin{array}{l}t f j b \\
\text { 'das Herz ist aufgeregt': L-24 }\end{array}$ \\
\hline$\Leftrightarrow \xi$ & $\begin{array}{l}\text { tm jb } \\
\text { 'das Herz ist erledigt': W-5 }\end{array}$ \\
\hline $\begin{array}{l}\circ \\
\triangleright .5\end{array}$ & $\begin{array}{l}\text { th } \mathrm{jb} \\
\text { 'der Verstand vergißt': E-14 }\end{array}$ \\
\hline & $\begin{array}{l}t k n j b \\
\text { 'dem Herzen nahestehen': W-56, W-77 } \\
\text { 'das Herz ist jdm. nahe': W-98 }\end{array}$ \\
\hline$\eta$ & $\begin{array}{l}\underline{t}^{3} j b \\
\text { 'im Herzen vorwurfsvoll sein': W-6 }\end{array}$ \\
\hline Aम—象证 & 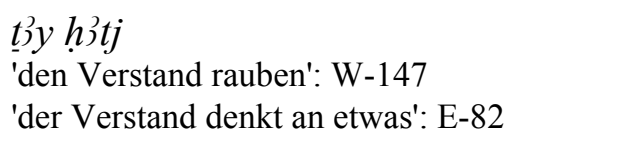 \\
\hline$\left\{\subseteq \frac{9}{\triangle 11}\right\}$ & 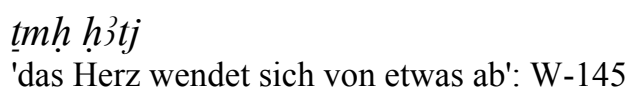 \\
\hline 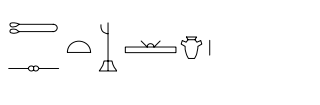 & $\begin{array}{l}\underline{t} z j \mathrm{j} b \\
\text { 'den Verstand aufrichten': E-26 }\end{array}$ \\
\hline 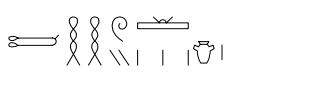 & 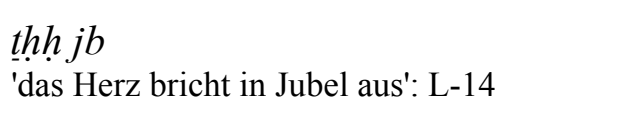 \\
\hline 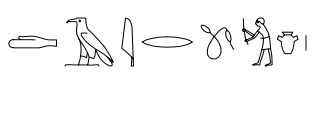 & $\begin{array}{l}\text { d3r jb } \\
\text { 'Kontrolle der Stimmung': W-7 } \\
\text { 'Selbstbeherrschung': W-36 }\end{array}$ \\
\hline $\int_{\rightleftharpoons}^{\operatorname{mnn}} \square \xi$ & $\begin{array}{l}d b n j b \\
\text { 'das Herz ist das Gewicht': E-13 }\end{array}$ \\
\hline 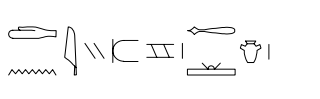 & $\begin{array}{l}\text { dnj.t }{ }^{C} 3(. t) \text { jb } \\
\text { 'das Herz wird ein mächtiger Damm': W-130 }\end{array}$ \\
\hline
\end{tabular}





\section{BIBLIOGRAPHIE}

Antike Klassiker

Albius Tibullus, Select elegies of Propertius (Hrg. John P. Postgate 1962).

Archilochus, Poetae lyrici Graeci (Hrg. Theodor Bergk 1913ff).

Aristophanes, Acharnenses, Equites, Nubes, Vespas, Pacem, Aves continens (Frederick W. Hall \& William M. Geldart 1985).

Aristoteles, Aristotel's Poetics (Hrg. Sephen Halliwell 2000).

Aulus Gellius, Noctium Atticarum libri (Hrg. Carolus Hosius 1981).

C. Valerius Flaccus, Argonauticon (Hrg. Otto Kramer 1913).

Diogenes, Oenoandensis fragmenta (Hrg. Iohannes William 1907).

Geminus, de Ostentis (Hrg. Christopher Wachsmuth 1897).

Hippocrates, Prorretikon (Hrg. Emile Littré 10 Bde. 1839-1861).

Homerus, Odissee (Hrg. David B. Monro \& Thomas William Allen 1999). Ilias (Hrg. David B. Monro \& Thomas William Allen 1999).

L. Annaeus Seneca, Controversiae (Hrg. Michael Winterbottom Bd. 7-10 1974. 7 - 10).

M. Cornelius, The correspondence of Marcus Cornelius Fronto with Marcus Aurelius Antoninus, Lucius Verus, Antoninus Pius, and various friends (95N) (Hrg. Charles R. Haines 1988).

M. Tullius Cicero, De finibus bonorum et malorum (Hrg. Theodor Schiche 1993).

Epistvlae ad Atticvm (Hrg. Ludovicus Claude Purser 1903).

Marcus Porcius Cato, De agri cultura liber (De agricultura) (Hrg. Georgius Goetz 1937).

Novus Testament. Evangelium Lukas (Hrg. Alexander Souter 1910).

P. Vergilius Maronis, P. Vergili Maronis opera (Hrg. Roger Aubrey Baskerville Mynors 1968).

Sex Propertus, The Elegies (Hrg. Harold E. Butler \& Eric Arthur Barber 1964).

Silius Italicus, Punica (Hrg. James D. Duff 1989).

Sophocles, Tragoediae. Antigone (Hrg. Alfred C. Pearson 1987).

T. Macci Plavti, Comoediae (Hrg. Wallace Martin Lindsay 1991).

Theophrastus, Historia Plantarum (Hrg. Fridericus Wimmer 1854-1862).

Thucydides, Historiae (Hrg. Henricus Stuart Jones 1966).

Vetus Testament Graece redditum (Hrg. Henry Barclay Swete 1901).

Adelung, Johann Christoph. 1732-1806. Grammatisch-kritisches Wörterbuch der hochdeutschen Mundart: mit beständiger Vergleichung der ybrigen Mundarten, besonders aber der Oberdeutschen, Leipzig.

Ahlwardt, Wilhelm (Hrg.). 1870. The divans of the six ancient poets Ennābiga, 'Antara, Tharafa, Zuhair, 'Alqama und Imruulqais, London.

Arnold, Magda Blondiau. 1960. Emotion and personality, New York.

Asch, Solomon. 1958. The metaphor a psychology inquiry, in: Renato Tagiuri \& Luigi Petrullo (Hrg.) Person perception and interior behaviour, Cambridge.

Assmann, Jan. 1996. Zur Geschichte des Herzens im Alten Ägypten, in: Georg Berkemer \& Guido Rappe (Hrg.) Das Herz im Kulturvergleich. Lynkeus. Studien zur Neuen Phänomenologie, Bd. 3, Berlin, 143-172. 1993. Zur Geschichte des Herzens im Alten Ägypten, in: Jan Assmann (Hrg.) Die Erfindung des inneren Menschen. Studien zur religiösen Anthropologie, Gütersloh, 81-113.

1991. Ägyptische Hymnen und Gebete, in: Otto Kaiser (Hrg.) Lieder und Gebete II, in: Texte aus der Umwelt des Alten Testaments II, Lieferung 6, Gütersloh, 827-928.

1990. Ma'at. Gerechtigkeit und Unsterblichkeit im Alten Ägypten, München.

1988. Kultur und Gedächtnis, Frankfurt a.M.

1979. Weisheit, Loyalismus und Frömmigkeit, in: Erik Hornung \& Othmar Keel (Hrg.) Studien zu altägyptischen Lebenslehren. Orbis Biblicus et Orientalis, Bd. 28, Freiburg (CH)/Göttingen, 11-72. 
1977. Fest des Augenblicks, Verheissung der Dauer, die Kontroverse der ägyptischen Harfnerlieder, in: Jan Assmann, Erika Feucht \& Reinhard Grieshammer, Fragen an die altägyptische Literatur: Studien zum Gedenken an Eberhard Otto, Wiesbaden, 53-84.

1975. Ägyptische Hymnen und Gebete, Zürich/München.

1974. Der literarische Text im Alten Ägypten. Versuch einer Begriffsbestimmung, in: Orientalische Literaturzeitung 69, 117-126.

Aubry, Alain. (Hrg.), 1996- Encyclopcedia universalis, Paris.

Avalon, Arthur. 1975. Die Schlangenkraft, Bern/München/Wien.

Averill, James R. 1996. Intellectual emotions, in: Rom Harré \& W. Gerrod Parrot (Hrg.) The emotions, social, cultural and biological dimension, London, 24-38.

1980. A costructivist view of emotion, in: Robert Plutchik \& Henry Kellerman (Hrg.) Theories of emotion, New York.

Bains, John. 1996. Classicism and modernism in the literature of the New Kingdom, in: Antonio Loprieno (Hrg.) Ancient egyptian literature. Probleme der Ägyptologie, Bd. 16, Leiden/New York/Köln, 157-174.

1990. Interpreting the story of the shipwreckend sailor, in: Journal of egyptological archaeology 76, 5572.

1982. Interpreting Sinuhe, in: Journal of egyptological archaeology 68, 31-44.

Barns, John. W. B. 1972. Some readings and interpretations in sundry Egyptian texts, in: Journal of egyptological archaelogy 58, 159-166.

1956. Five Ramesseum papyri, Oxford.

Barta, Winfried. 1971. Zu einigen Textpassagen der Prophezeiung des Neferti, in: Mitteilungen des deutschen archäologischen Institut 27, 35-45.

------- 1969. Das Gespräch eines Mannes mit seinem BA (Papyrus Berlin 3024). Münchener Ägyptologische Studien, Bd. 18, Berlin.

Battacchi, Marco W., Thomas Suslow \& Marguerita Renna. 1997 Emotion und Sprache: zur Definition der Emotion und ihren Beziehungen zu kognitiven Prozessen, dem Gedächtnis und der Sprache, Frankfurt a.M. [u.a.].

Beardsley, Monroe. 1967. Metaphor, in: P. Edwards (Hrg.), Encyclopaedia of philosophy, Bd. 5, New York.

Berlev, Oleg Dmitrievic. 1987. The date of the 'eloquent peasant', in: Jürgen Osing \& Günter Dreyer (Hrg), Form und Maß. Beiträge zur Literatur, Sprache und Kunst des alten Ägypten. Festschrift für Gerhard Fecht. Ägypten und Altes Testament, Bd. 12, Wiesbaden, 78-83.

Berggren, Douglas. 1962. The use and abuse of metaphor, in: Review of metaphysics 16 (2), 237-258.

Berner, Paul. 1988. Emotion, affect and mood: a terminological introduction, in: Psychopathology 21, 65-69.

Bickerton, David M. 1969. Prolegomena to a linguistic theory of metaphor, Foundations of language 5, 34-53.

Birch, Charles. 1995. Feelings, Sydney.

Black, Max. 1962. Metaphor, in: John Margolis (Hrg.), Philosophy looks at the arts, New York, 218-235. 1954-1955. Metaphor, in: Proceeding of the aristotelian society 55, 273-294.

Blackman, Aylward Manley. 1988. The story of king Kheops and the magicians, transcribed from papyrus Westcar, Berlin Papyrus 3033, in: W.Vivian Davies (Hrg.), Reading, Berkshire. 1972. Middle-Egyptian Stories. Bibliotheca Aegyptica, Bd. 2, Bruxelles.

Blumenthal, Elke. 1996. Die literarische Verarbeitung der Übersetzungszeit zwischen altem und mittlerem Reich, in: Antonio Loprieno (Hrg.) Ancient egyptian literature. Probleme der Ägyptologie, Bd. 16, Leiden/New York/Köln, 105-136.

1995. Die Erzählung des Sinuhe, in: Elke Blumenthal et al. Mythen und Epen, Texte aus der Umwelt des Alten Testaments III, Lieferung 5, 884-911.

1984. Die Lehre des Königs Amenemhet, in: Zeitschrift für die ägyptische Sprache und Altertumskunde 111, 85-107.

1982. Die Prophezeiung des Neferti, in: Zeitschrift für die ägyptische Sprache und Altertumskunde 109, $1-27$.

1982. Altägyptische Reiseerzählungen, Leipzig.

1980. Die Lehre für König Merikare, in: Zeitschrift für die ägyptische Sprache und Altertumskunde 107, $5-41$.

1974. Eine neue Handschrift der Lehre eines Mannes für seinen Sohn (Pap. Berlin 14374), in: Ägyptisches Museum East Berlin (Hrg.) Festschrift zum 150 jährigen Bestehen des Berliner ägyptischen Museums, Staatliche Museen zu Berlin. Mitteilungen aus der Agyptischen Sammlung, 8, Berlin, 55-66.

Bolton, Nancy. 1982. Forms of thought, in: Geoffrey Underwood (Hrg.) Aspects of consciousness 3, New York. Bonnet, Hann. 1971. Reallexicon der ägyptische Religionsgeschichte, Berlin/New York. 
Borghouts, Joris Frans. 1983. Review of G. Posener. Catalogue des ostraca hiératiques littéraires de Deir el Médineh III, Nos. 1607-1675, Chronique d'Égypte 58, 111-115.

Bradbury, Louise. 1986. Nefer's inscription: on the death date of Queen Ahmose-Nefertary an the deed found pleasing to the King, in: Journal of the american research center in Egypt 22, 73-95.

Brunner, Helmut. 1982. Papyrus Anastasi I, in: Lexikon der Ägyptologie IV, 674-679.

Breasted, James Henry \& Harold Hayden Nelson, 1930-1964. Der große Tempel Ramses III. in Medinet Habu, Chicago.

Brentano, Franz. 1874. Psychologie vom empirischen Standpunkt, Hamburg.

Brockhaus, Helmut. 1988. Das Große Bibellexikon, Wuppertal/Zürich.

Brunner, Helmut. 1988. Das hörende Herz. Orbis Biblicus et Orientalis, Bd. 80, Freiburg (CH)/Göttingen, 3-44. 1988. Altägyptische Weisheit, Zürich/München.

1984. Zentralbegriffe ägyptischer und israelitischer Weisheitslehren, in: Saeculum 35, 185-199.

1980. Literatur, in: Lexikon der Ägyptologie I, 1067-1072.

1968. Eure Rede sei "ja ja, nein nein" im Ägyptischen, in: Festschrift Siegfried Schott, Wiesbaden, 712.

1963. Der freie Wille Gottes in der ägyptsichen Weisheit, in: Les sagesses des Proche-Orient ancien, colloque de Strasbourg, 17-19 mai, 1962, Paris, 103-117.

1965. Das Herz im ägyptischen Glauben, in: Karl Thomae GMBH (Hrg.) Das Herz im Umkreis des Glaubens 1, Biberach, 81-106.

1961. Wiederum die ägyptischen "Make Merry" Lieder, in: Journal of near eastern studies 25, 130-131.

1954. Das Herz als Sitz des Lebensgeheimnisses, Archiv für Orientforschung 5, 140-141.

1944. Die Lehre des Cheti, Sohnes des Duauf. Ägyptologische Forschungen, Bd. 13, Glückstadt.

1980. Herz, in: Lexikon der Ägyptologie II, 1158-1168.

Brunner-Traut, Emma. 1963. Die Altägyptische Märchen, München.

1940. Die Weisheitslehre des Djedef-Hor, in: Zeitschrift für die ägyptische Sprache und Altertumskunde 76, 3-9.

Buck, Adrian de. 1948. Egyptian readingbook: exercises and Middle Egyptian texts, Leiden.

Buck, Ross, R. E Miller, \& W. F. Caul. 1974. Sex, personality and physiological variables in the communication of affect via facial expression, in: Journal of personality and social psychology 30, 587-596.

Buck, Ross. 1986. The psychology of emotion, in: Joseph E. Le Doux \& William Hirst (Hrg.) Mind and brain, Cambridge.

1984. The communication of emotion, New York. 1976. Human motivation and emotion, New York.

Budge, Ernest A. Wallis. 1923. Facsimiles of egyptian hieratic papyri in the British Museum, London. 1898. The egyptian Book of the Dead. The chapters of coming forth by day: The egyptian text in hieroglyphic edited from numerous papyri, London.

Bühler, Karl. 1934. Sprachtheorie: die Darstellungsfunktion der Sprache, Jena.

Burkard, Günter. 1993. Überlegungen zur Form der ägyptischen Literatur. Die Geschichte des Schiffbrüchigen als literarisches Kunstwerk. Ägypten und Altes Testament, Bd. 22, Wiesbaden. 1991. Die Lehre des Ptahhotep, in : Günter Burkard et al. (Hrsg.) Weisheiten, Mythen und Epen, Texte aus der Umwelt des Alten Testaments III, Lieferung 2, Gütersloh, 195-221. 1988. Ptahhotep und das Alter, in: Zeitschrift für die ägyptische Sprache und Altertumskunde 115, 1930.

1988. Ptahhotep und das Alter, in: Zeitschrift für die ägyptische Sprache und Altertumskunde, 19-30.

1977. Textkritische Untersuchungen zu altägyptsichen Weisheitslehren des Alten und Mittleren Reiches. Ägyptologische Abhandlungen, Bd. 34, Wiesbaden.

Burkard, Günter \& Heinz J. Thissen. 2003. Einführung in die altägyptische Literaturgeschichte. Einführungen und Quellentexte zur Ägyptologie, Bd. 1, Münster/Hamburg/London.

Bynum, B. 2001. Lovesickness, in: The lancet Feb 3, 357 (9253): 403.

Caminos, Ricardo Augusto. 1979. A tale of Woe, Oxford. 1956. Literary fragments in the hieratic script, Oxford.

Campos, Joseph, R. G. Campos \& M. E. Barret. 1898. Emergent themes in the study of emotional development and emotion regulation, in: Development psychological 25, 394-402.

Canavan, Anthony G. M. \& Gudrun Sartory. 1990. Klinische Neuropsychologie, Stuttgart.

Cannon, Walter Bradford. 1928. Neural organisation for emotional expression, in: Martin L. Reymert (Hrg.)

Feelings and emotions: the Wittenberg symposium, Worcester.

Carr, Harvey. 1929. Psychology: a study of mental activity, New York. 
Carruba, Onofrio. 1972. Beiträge zum Palaischen, Publications de l'institut historique et archéologique neérlandais de Stambul 31, Leiden.

Černý, Jaroslav. 1935. Catalogue général du Caire, $n^{\circ}$ 25501-25832. Ostracas hiératiques, Bd. I, Institut français d'archéologie orientale, Le Caire.

Černý, Jaroslav \& Alan Henderson Gardiner. 1957. Hieratic ostraca, Oxford.

Černý, Jaroslav \& Sarah-Israel Groll. 1975. A Late Egyptian grammar, Studia Phol: Series Major, Rom.

Charpentier, Gustave. 1981. Recueil de matériaux épigraphiques relatifs à la botanique de l'Égypte antique, Paris.

Civil, Miguel et al. 1973. The assyrian dictionary of the Oriental Institute of the University of Chicago, ChicagoGlückstadt.

Clère, Jacques Jean. 1989. ‘kj-jb "honnête, loyal", in: Bulletin de l'institut français d'archéologie orientale 89, 67-71.

Clynes, Manfred. 1977. Sentics: the touch of emotions, New York.

Collier, Marc. 1994. Grounding, cognition an metaphor in the grammar of Middle Egyptian, in: Lingua Aegyptia 4, 57-87.

Corneille, Pierre. 1857. Oeuvres complètes, Bibliothèque Elzevirienne 5,3, Paris.

Couroyer, Bernard. 1961. Égypte ou Israel?, Cahiers de la Revue Biblique 68, Paris.

Dagut, Menachem B. 1976. Can metaphor be translated?, in: Babel XXII(1), 21-33.

Dahl, Hartvig. 1979. The appetite hypothesis of emotion, in: Carroll E. Izard (Hrg.) Emotion and personality and psychopathology, New York.

Damasio, Antonio R. 1994. Descartes' error: emotion, reason, and the human brain, New York.

Daressy, Georges. 1901. Ostraca (Catalogue général des Antiquities Égyptiennes de Musée de Caire); Kairo.

Darwin, Charles. 1872-1965. The expression of the emotions in man and animals, Chicago.

David, Virginia, L. 1980. Remarks on Michael V. Fox's 'The Cairo love songs', in: Journal of the american oriental society 100, 111-114.

Davis, Arlette. 2000. De l'infériorité à la perturbation, Göttinger Orientforschungenen IV, Bd. 38, Wiesbaden.

Derrida, Jacques. 1976. Of grammatology, Baltimore/London.

Dévaud, Eugène. 1916. Les Maximes de Ptahhotep, Fribourg.

Donadoni, Sergio. 1969. Letteratura e poesia dell'antico Egitto. Torino.

Donzel, Emeri van et.al. (Hrg.) 1978. The Encyclopaedia of Islam, Leiden.

Drioton, Etienne. 1954. Amon, refuge du coeur, in: Zeitschrift für die ägyptische Sprache und Altertumskunde 79, 3-11.

Duden. 2001. Deutsches Universalwörterbuch, Mannheim [u.a.].

Duffy, Elisabeth. 1941. The conceptual categories of psychology: a suggestion for revision, in: Psychological review 48, 177-203.

Dumas, Georges. 1932. La douleur et le plaisir, in: George Daumas, (Hrg.) Nouveau traité de psychologie, Paris, II, $251 \mathrm{ff}$.

Düwel, Klaus. 1974. Das Bild von den "Knien des Herzens" bei Heinrich von Kleist: zur Geschichte der Herzmetaphorik, Euphorion 68, 185-197.

Eberhard, Wolfram. 1977. Über den Ausruck von Gefühlen im Chinesischen: vorgetragen im Sommer 1976, Bayerische Akademie der Wissenschaften (München) Philosophisch-Historische Klasse, Heft 3, München.

Edzard, Dietz Otto (Hrg.). 1932-1997. Reallexikon der Assyriologie und Vorderasiatischen Archäologie, Berlin/New York.

Eichler, Eckhard. 2001. Zur Datierung und Interpretation der Lehre des Ptahhotep, in: Zeitschrift für die ägyptische Sprache und Altertumskunde 128, 97-107.

Elliot Smith, Grafton \& Warren R. Dawson. 1924. Egyptian mummies, London.

Erman, Adolf. 1933. Neuägyptische Grammatik, Leipzig. 1927. The Literature of Ancient Egyptians, London.

1923. Die Literatur der Ägypter, Leipzig.

1901. Bruchstück eines Liebesliedes, in: Zeitschrift für die ägyptische Sprache und Altertumskunde 39, 147.

1896. Gespräch eines Lebensmüden mit seiner Seele, Berlin.

1890. Die Märchen des Papyrus Westcar, Mitteilungen aus den orientalischen Sammlungen, Bde. 5-6, Berlin.

Erman, Adolf \& Hermann Grapow. 1926-1963. Wörterbuch der ägyptischen Sprache, 12 Bde. Berlin. 
Evangelische Kirche in Deutschland \& Bund der Evangelischen Kirchen in der DDR (Hrsg.). 1985. Die Bibel: nach der Übersetzung Martin Luthers; mit Apokryphen (Bibeltext in der rev. Fassung von 1984). Stuttgart.

Ewert, Otto. 1983. Ergebnisse und Probleme der Emotionsforschung, in: Hans Thomae (Hrg.) Motivation und emotion. 1. Band: Theorien und Formen der Motivation, Göttingen.

-------- 1970. The attitudinal character of emotion, in: Magda B. Arnold (Hrg.) Feelings and emotions, New York.

Faulkner, Raymond Oliver. 1969. The Ancient Egyptian Pyramid Texts, Oxford.

-------- 1962. A concise dictionary of Middle Egyptian, Oxford.

-------- 1955. The Installation of the Vizier, in: Journal of egyptological archaeology 41, 18-29.

Fecht, Gerhard. 1991. Die Belehrung des Ba und der "Lebensmüde", in: Mitteilungen des deutschen archäologischem Institut 47, 113-126.

-------- 1965. Literarische Zeugnisse zur "Persönlichen Frömmigkeit" in Ägypten: Analyse den Beispiele aus den ramessidischen Schulpapyri. Abhandlung der Heidelberger Akademie der Wissenschaften, Bd. 1, Heidelberg.

1996. Die Wiedergewinnung der altägyptischen Verskunst, Mitteilungen des deutschen archäologischem Institut 19, 54-96.

--------- 1951. Der Habgierige und die Maat in der Lehre des Ptahhotep. Abhandlungen des deutschen archäologischen Institut Kairo, Bd. 1, Glückstadt.

Fehr, B. \& James A. Russell. 1984. Concept of emotion viewed from a prototype perspective, in: Journal of experimental psychology 113, 464-486.

Fischer-Elfert, Hans-Werner. 1997. Persönliche Frömmigkeit und Bürokratie. Zu einer neuen Edition der Lehre des Ani, Die Welt des Orients, Göttingen, 18-30.

-------- 1997. Lesefunde im literarischen Steinbruch von Deir el-Medineh, Kleine ägyptische Texte, Bd. 12, Wiesbaden, 20-33.

1983. Die satirische Streitschrift des Papyrus Anastasi I. Ägyptologische Abhandlungen, Bd. 44, Wiesbaden.

Foster, John L. 1993. Thought couplets in The tale of Sinuhe: verse text and translation; with an outline of grammatical forms and clause sequences and an essay on the tale as literature. Münchener ägyptologische Untersuchungen, Bd. 3, Frankfurt a.M. [u.a.].

1992. Echoes of Egyptian voices. An anthology of ancient Egyptian poetry. Oklahoma series in classical culture, Bd. 12, Oklahoma, 53-55.

1984. Oriental Institute Ostracon \#23074: "Menna's lament" or "letter to a wayward son", in: Journal of the society for the study of egyptian antiquities 14, No. 4.

-------- 1977. Thought couplets and clause sequences in a literary text: the maxims of Ptah-hotep. Society for the study of egyptian antiquities, Bd. 5, Toronto.

1974. Love songs of the New Kingdom, Austin.

Fox, Michael V. 1985. The song of songs and the Ancient Egyptian love songs, Wisconsin.

- 1982. The entertainment song genre in egyptian literature, in: Sarah Israelit-Groll (Hrg.) Egyptological Studies. Scripta Hierosolymitana, Bd. 28. Jerualem, 268-316.

------ 1981. Love in the love songs, in: Journal of egyptological archaeology 67, 181-182. 1977. A study of Antef, in: Orientalia 46, 393-423.

Freud, Simon. 1915-1940. Gesammelte Werke. Band 10 (Die Verdrängung), Frankfurt a.M.

Frevert, Ute. 2000. Vertrauen. Historische Annäherungen an eine Gefühlshaltung, in: Claudia Benthien et al. (Hrg.) Emotionalität. Zur Geschichte der Gefühle, Literatur-Kultur-Geschlecht 16, Wien, 178-197.

Fridja, Nico H. 1986. The emotions, Cambridge.

Fridja, Nico H. et al. 1995. Emotions and emotion word, in: James A. Russell et al. (Hrg.) Everyday conceptions of emotion, Dortrecht, 121-143.

Fuller, Margaret. 1843. The great lawsuit. MAN versus MEN. WOMAN versus WOMEN, Dial 4, 1-47.

Gaballa, A. 1970. Nufer, third prophet of Amon, in: Mitteilungen des deutschen archäologischen Institut 26, 4954.

Gainotti, Guido. 1988. Neuropsicologia delle emozioni, in: Valentina d'Urso \& R. Trentin (Hrg.) Psicologia delle emozioni, Bologna.

Galán, José Manuel. 1998. Cuatro viajes en la literatura del Antiguo Egipto, Madrid.

Gamer-Wallert, Ingrid. 1970. Fische und Fischkulte im alten Ägypten, Wiesbaden.

Gardiner, Alan Henderson. 1970. Die Lehre des Bwa-htjj, Wiesbaden.

-------- 1969. The admonition of an egyptian sage, Hildesheim. 
1961. Egypt of the pharahons, Oxford.

1957. Egyptian grammar, Oxford.

1955. The Ramesseum papyri, Oxford.

1947. Ancient egyptian onomastica, London.

1946. The instruction addressed to Kagemni and his brethren, in: Journal of egyptological archaeology

32, 71-74.

1935. Hieratic papyri in the British Museum, London.

1932. Late-Egyptian stories, Bibliotheca Aegyptiaca I, Bruxelles.

1931. The library of A. Chester Beatty: The Chester Beatty Papyri, No. I., London.

1923. The eloquent peasant, in: Journal of egyptological archaeology 9, 5-25.

1916. The defeat of the Hyksos by Kamose: The Carnavon tablet, No. I, in: Journal of egyptological archaeology 3, 95-110.

1916. Notes on the story of Sinuhe, Paris.

1914. New literary works from Ancient Egypt, in: Journal of egyptological archaeology 1, 20-36.

Garnier, J. \& Prudent Maran. 1739. Basilii opera omnia 1-3, Paris.

Gaylin, Willard. 1979. Feelings: our vital signs, Boston.

Georges Karl Ernst (Hrg.). 1972. Ausführliches Lateinisch-Deutsches Handwörterbuch, 13 Aufl., Hannover.

Germer, Renate. 1985. Flora des pharaonischen Ägypten. Sonderschrift des Deutschen Archäologischen Institut, Bd. 14, Abteilung Kairo, Mayenz.

Gilbert, Pierre. 1942. Le grand poème d'amour du Papyrus Chester-Beatty, in: Cronique d'Égypt 17, 185-198.

Glare, P. G. W. et al. 1968. Oxford Latin Dictionary, Oxford.

Glück, Helmut (Hrg.). 2000. Metzler-Lexikon Sprache, Stuttgart.

Gnirs, Andrea M. 1996. Die ägyptische Autobiographie, in: Antonio Loprieno (Hrg.) Ancient egyptian literature. Probleme der Ägyptologie, Bd. 16, Leiden/New York/Köln, 191-242.

Goatly, Andrew. 1998. The language of metaphors, London.

Goedicke, Hans. 1988. Studies in the instruction of king Amenemhet I. for his son. Varia Aegyptiaca suppl. 2, San Antonio, Texas.

1987. Menna's Lament, in: Revue d'égyptology 38, 63-80.

1962. Neglected wisdom text, in: Journal of egyptological archaeology 48, 6-12.

Goldwasser, Orly. 1995. From icon to metaphor: studies in the semiotics of the hieroglyphs, Orbis Biblicus et Orientalis 142, Switzerland/Göttingen.

Golenischeff, W. 1952. Sur trois passages du Lebensmüder, in: Revue d'égyptology, 155-157.

1916. Les papyrus hiératiques nos. 1115, 116 A et 1116 B de l'ermitage impérial à St-Petersbourg, Sankt Peterburg.

1912. Le conte du naufragé, in: Bibliotèque d'étude 2, Le Caire.

1889. Papyrus hiératique de la collection W. Golenishchev, contenant du voyage de l'Egyptien OunouAmon en Phénicien, in: Recueil du travaux 22, 74-102.

Gombrich, Ernst Hans. 1972. Aims and limits of iconology. Symbolics Images: Studies in the arts of the renaissance, London.

Gottschalk, Louis A. 1995. Content analysis of verbal behaviour, Hillsdale.

Götze, Albrecht (Hrg.). 1930. Vertreute Boghazköi-Texte, Marburg.

Grapow, Hermann. 1924. Die bildlichen Ausdrücke des Ägyptischen, Leipzig.

Grapow, Hermann, Hildegard von Deines \& Wohlfahrt Westendorf. 1954-1973. Grundriß der Medizin der alten Ägypter, Bd. 9, Berlin.

1952. Untersuchungen zur ägyptischen Stilistik I. Der stilistische Bau der Geschichte des Sinuhe. Deutsche Akademie der Wissenschaften zu Berlin, Institut für Orientforschung, Veröffentlichung Band 10, Berlin.

Gray, Jeffrey A. 1990. Brain systems that mediate both emotion and cognition, in: Cognition and emotion 4, 269-288.

Griffiths, John Gwyn. 1990. "Love a disease", in: Sarah Israelit-Groll (Hrg.) Studies in egyptology, Jerusalen, 349-364.

Groll, Sarah-Israelit. 1992. The di-s tm.s stp formations in poetic Late Egyptian, in: Ulrich Luft (Hrg.) The Intelectual heritage of Egypt. Studies presented to László Kákosy. Studia Aegiptiaca, Bd. 14, Budapest, 229-234.

1975-1976. The literary and the non-literary verbal systems in Late Egyptian, Orientalia Lovaniensia Periodica 6-7, Leuven, 237-246. 
Gründer, Karlfried. 1958. Figur und Geschichte: Johann Georg Hamanns "Biblische Betrachtungen" als Ansatz einer Geschichtsphilosophie, Freiburg im Breisgau/München/Alber.

Guglielmi, Waltraud. 1996. Die ägyptische Liebespoesie, in: Antonio Loprieno (Hrg.) Ancient Eyptian Literature. Probleme der Ägyptologie, Bd. 16, Leiden/New York/Köln, 335-347. 1996. "Der Gebrauch rhetorischer Stilmittel in der ägyptischen Literatur." in: Antonio Loprieno (Hrg.) Ancient egyptian literature. Probleme der Ägyptologie, Bd. 16, Leiden/New York/Köln, 465-498. 1994. Berufssatiren in der Tradition des Cheti, in: Zwischen den beiden Ewigkeiten, Festschrift Thausing, 44-72.

1983. Eine 'Lehre' für einen reiselustigen Sohn (Ostrakon Oriental Institute 12074), in: Die Welt des Orients 14, 147-166.

Guillaume, Paul. 1937. La psychologie de la forme, Paris.

Gunn, Battiscombe. 1912. The Instruction of Ptah-Hotep and the Instruction of Ke'gemni: The Oldest Books in the World, London/New York.

Gurmendez, Carlos. 1984. Teoría de los sentimientos, México.

Hajal, Fady. 1994. Diagnosis and the treatment of lovesickness: an Islamic medieval case study, in: Hospital Community psychiatry, Jul. 45(7), 647-650.

Halliday, Michael Alexander Kirkwood. 1975. Learning how to be mean. Explorations in the development of language, London.

Hannig, Rainer. 1995. Die Sprache der Pharaonen. Großes Handwörterbuch Ägyptisch-Deutsch. Hannig-Lexika, Bd. 1. Kulturgeschichte der Antiken Welt, Bd. 64, Mainz. 1979. Erzählung und Rede im Papyrus Westcar (unveröffentl. Magisterarbeit).

Harré, Rom. 1986. An outline of the social constructionist viewpoint, in: Rom Harré (Hrg.) The social construction of emotion, Oxford.

Hebb, Donald Olding. 1966. A textbook of psychology, Philadelphia.

Heider, Karl G. 1991. Landscapes of emotion: mapping three cultures of emotion in Indonesia, Cambridge.

Helck, Wolfgang. 1984. Die Lehre des Djedefhor und die Lehre eines Vaters an seinen Sohn. Kleine ägyptische Texte, Bd. 8, Wiesbaden.

1977. Die Lehre für König Merikare. Kleine ägyptische Texte, Bd. 5, Wiesbaden.

1972. Zur Frage der Entstehung der ägyptischen Literatur, in: Wiener Zeitschrift für die Kunde des Morgenlandes 63/64, 6-26.

1970. Die Prophezeiung des Nfr.tj. Kleine ägyptische Texte, Bd. 2, Wiesbaden.

1970. Die Lehre des Dw3-Htjj. Kleine ägyptische Texte, Bd. 3, Wiesbaden.

1969. Der Text der Lehre Amenenmhets I. für seinen Sohn. Kleine ägyptische Texte, Bd. 1, Wiesbaden. 1961. Urkunden der 18. Dynastie, Berlin. 1956. Urkunden der 18. Dynastie, Berlin.

Helck, Wolfgang \& Eberhard Otto (Hrg.) 1975-1992. Lexikon der Ägyptologie, 7 Bde.Wiesbaden.

Hermann, Adolf. 1961. Das steinharte Herz. Zur Geschichte einer Metapher, in: Jahrbuch für Antike und Christentum 4, $77 \mathrm{ff}$. 1959. Altägyptische Liebesdichtung, Wiesbaden.

1955. Beiträge zur Erklärung der ägyptische Liebesdichtung. Berlin

1954. Steuerruder, Waage, Herz und Zunge in ägyptischen Bildreden, in: Zeitschrift für die ägyptische Sprache und Altertumskunde 79, 106-115.

Heymans, Gerardus \& Enno Dirk Wiersma. 1908. Beiträge zur speziellen Psychologie auf Grund einer Massenuntersuchung, in: Zeitschrift für Psychologie und Psychologie den Sinnesorgane, 45, 1-72.

Hillman, James. 1979. The thought of the heart, in: Eranos Jahrbuch 1979 (Mystische Bildwelt), 48, 133-182.

Hintze, Fritz. 1955. Zu den Wörtern für "Herz" und "Magen" im Ägyptischen, in: Otto Firchow (Hrg.) Ägyptische Studien. Deutsche Akademie der Wissenschaften zu Berlin Institut für Orientforschung, 29, Berlin, 140-142.

Ho, David. 1976. On the concept of face, in: American journal of sociology 81, 867-884.

Hoch, James E. 1991-1992. The teaching of Dua-Kheti: A new look at the satire of the trades, in: Journal of the society for the study of egyptian antiquities 21/22, 88-100.

Hochschild, Arlie Russell. 1983. The managed heart, Berkeley.

Hollis, Susan T. 1990. The ancient Egyptian "Tale of two brothers": the oldest fairy tale in the world, Oklahoma.

Hölzer, Michael, N. Scheytt \& H. Kächele. 1992. Das Affektive Diktionär Ulm als eine Methode der quantitativen Vokabularbestimmung, in: Cornelia Züll \& Peter Ph. Mohler (Hrg.) Textanalyse. Anwendungen der computergestützten Inhaltsanalyse, Opladen.

Hörmann, Hans. 1977. Psychologie der Sprache, Berlin. 
Hornung, Erik. 1990. Gesänge vom Nil. Dichtung am Hofe der Pharaonen. Ausgewählte, übesetzt und erläutert, Zürich-München.

1982. Der Ägyptische Mythos von der Himmelskuh. Orbis Biblicus et Orientalis, Bd. 46, Freiburg/Göttingen.

Hornung, Erik \& Othmar Keel. 1979. Studien zu altägyptischen Lebenslehren. Orbis Biblicus et Orientalis, Bd. 28, Freiburg-Göttingen.

Hugonot, Jean-Claude. 1989. Le jardin dans l'Egypte ancienne, Publications universitaires européennes XXXVIII, 27, Frankfurt a.M. [u.a.].

Iser, Wolfgang. 1991. Das Fiktive und das Imaginäre. Perspektiven literarischer Anthopologie, Frankfurt a.M. 1990. Fingieren als anthropologische Dimension der Literatur. Konstanzer Universitätsreden, Bd. 175, Konstanz.

1989. Towards a literary anthropology, in: R. Cohen (Hrg.) The future of literary theory, New York/London, 108-228.

Izard, Carroll E. et al. 1974. The differential emotions scale: a method of measuring the subjective experience of discrete emotion, Nashville.

Izard, Carroll E. 1977. Human emotions, New York. 1972. Patterns of emotions: a new analysis of anxiety and depression. New York.

Jacobsohn, Helmuth. 1955. Die dogmatische Stellung des Königs in der Theologie der alten Ägypter. Ägyptologische Forschung, Bd. 8, Glückstadt.

Jakobson, Roman. 1960-1974. Aufsätze zu Linguistik und Poetik, München.

James, William. 1890. The principles of psychology, London.

Jansen-Winkeln, Karl. 1992. Das "Zeugende Herz", in: Lingua Aegyptia 2, 147-149.

Jéquier, Gustave. 1911. Le Papyrus Prisse et ses variantes, Paris.

Junge, Friedrich. 2003. Die Lehre Ptahhoteps und die Tugenden der ägyptischen Welt. Orbis Biblicus et Orientalis, Bd. 193, Freiburg/Göttingen.

1999. Einführung in die Grammatik des Neuägyptischen, Wiesbaden.

1995. Die Erzählung vom Streit der Götter Horus und Seth um die Herrschaft, in: Elke Blumenthal et al., Mythen und Epen III. Texte aus der Umwelt des Alten Testaments III, Lieferung 5, Gütersloh, 930949.

1994. Mythos und Literarizität: Die Geschichte vom Streit der Götter Horus und Seth, in: Heike Behlmer (Hrg.) Festgabe für Wohlfahrt Westendorf zu seinem 70. Geburtstag, Göttingen, 83-102. 1974. Zu Fehldatierung des sog. Denkmals memphitischer Theologie oder der Beitrag der ägyptischen Theologie zur Geistesgeschichte der Spätzeit, Mitteilungen des deutschen archäologischen Instituts 29, 195-204.

Junker, Hermann. 1940. Die Götterlehre von Memphis, Berlin.

Kahl, Jochem. 1994. Das System der ägyptischen Hieroglyphenschrift in der 0. - 3. Dynastie. Göttinger Orientforschungen IV, Bd. 29, Wiesbaden.

Kakosy, László. \& Z. I. Fabian. 1995. Harper's song in the tomb of Djehutimes (TT 32), Studien zur altägyptischen Kultur, 22, 211-225.

Kämmerer, Thomas R. \& Dirk Schwiderski. 1998. Deutsch-Akkadiches Wörterbuch, Münster.

Kammerzell, Frank (im Druck). Old Egyptian and Pre-Old Egyptian. Tracing linguistic diverstiy in archaic Egypt and the creation of the egyptian language. 2000. Egyptian possessive construction: a diachronic typological perspective, in: Peter Siemund (Hrg.) Methodology in linguistic typology, Sprachtypologie und Universalforschung 53/I, Berlin, 97-108. 1986. Die Prophezeiung des Neferti, in: Manfried Dietrich et al., Ägyptische Prophetien und Orakel, Texte aus der Umwelt des Alten Testaments II, Lieferung 1, Gütersloh, 102-110.

Kammerzell, Frank \& Carsten Peust. 2002 Reported speech in Egyptian, in: Tom Güldemann \& Manfred von Roncador (Hrgs.) Reported discourse. A meeting ground for different linguistic domains, Typological studies in languages 52, Amerdam/Philadelphia, 289-322.

Keimer, Ludwig. 1984. Die Gartenpflanzen im alten Ägypten. Sonderschrift des Deutschen Archäologischen Instituts, Abteilung Kairo, Band 13.II, Mayence.

Kischkewitz, Hannelore. 1973. Liebe Sagen, Leipzig. 1973. Lyrik aus dem ägyptischen Altertum. Leipzig.

Kitchen, Kenneth Anderson. 1969. Studies in Egyptian Wisdom Literature, in: Oriens Antiquus 8, 189-208.

Klaembet, Hans. 1969. Die Staatslehre für König Merikare, in: Armant 3, Köln, 157-171.

Kleinginna, P. R. \& A. M. Kleinginna. 1981. A categorised list of emotion definitions, with suggestions for a consensual definition, in: Motivation and cognition 5, 345-379. 
Koch, Roland. 1990. Die Erzählung des Sinuhe. Bibliotheca Aegyptiaca, Bd. 17, Bruxelles.

Koehler, Ludwig \& Walter Baumgartner. 1967-1996. Hebräisches und Aramäisches Lexikon zum Alten Testament, Leiden.

Köhler, Wolfgang. 1985. Lexicon in Veteris Testamenti. Libros, Leiden. 1975. Untersuchungen zur grammatischen Struktur und kommunikativen Funktion von Metaphern, Stuttgart.

Koemoth, Pierre. 1994. Osiris et les arbres. Aegyptia Leodiensia, Bd. 3, Liège.

Köpping, Klaus-Peter. 2000. Bauch haben. Die Inszenierung von Gemeinschaftsgefühl in Japan, in: Claudia Benthien et al. (Hrg.) Emotionalität. Zur Geschichte der Gefühle. Literatur-Kultur-Geschlecht, Bd. 16, Wien, 213-237.

Korostovtsev, Mikhail Aleksandrovich. 1960. Puteshestviye Un-Amuna v Bibl. Egipetskiy iyeraticheskiy papirus $n^{\circ} 120$ Gosudarstvennogo muzeya izobrazitel'nykh iskusstv im A. S. Pushkina v Mokve, Moskau.

Kövecses, Zoltán. 2000. Metaphor and emotion: language, culture, and body in human feeling, Cambridge [u.a.].

Kronasser, Heinz. 1962-1966. Etymologie der hethitischen Sprachen I, Wiesbaden.

Kügler, Joachim. 1993. Wenn das Herz uns auch verurteilt... Ein Nachtrag, in: Biblische Notizen 13, München.

Kurth, Dieter. 1999. Altägyptische Maximen für Manager: die Lehre des Ptahhotep, Darmstadt.

Kurz, Gerhard. 1982. Metapher, allegorie, symbol, Göttingen.

Labat, René. 1951. Traité akkadien de diagnostics et pronostics médicaux, Paris/Leiden.

Lakoff, George \& Mark Johnson. 1980. Metaphors. We live by, Chicago.

Lakoff, George \& Mark Turner. 1989. More than cool reason. A field guide to poetic metaphor, Chicago/London.

Lalouette, Claire. 1984. Textes sacrés et textes profanes de l'ancienne Egypte. Des pharaons et des hommes. Traduction et commentaires, Connaissance de l'Oriente. Collection UNESCO d'ouvrés représentatives. Série Égypte ancienne, Paris, 50-57.

Lange, Hans Otto. 1925. Das Weisheitsbuch des Amenenmope, Kopenhagen.

Lantermann, Ernst Dieter. 1983. Kognitive und emotionale Prozesse beim Handeln, in: Heinz Mandl \& Günter L. Huber (Hrg.) Emotion und Kognition, München.

Laoust, Henri. 1970. La Politique de Ghazātī, Paris.

Larthomas, Pierre. 2001. Le langage dramatique: sa nature, ses procédés, Paris.

Lausberg, Heinrich. 1976. Elemente der literarischen Rhetorik, München.

Lazarus, Richard Stanley. 1984. On the primacy of cognition, in: American Psychologist 39, 124-129.

1982. Thoughts on the relation between emotion and cognition, in: American psychologist 37, 10191024.

1975. A cognitively oriented psychologist looks at feedback, in: American psychologist 37, 1019-1024.

Leclant, J. 1979. Les sagesses de l'Égypte pharaonique. État de la bibliographie récente, in: Sagesse et religion. Colloque de Strasbourg (octobre 1976), Bibliothèque des centres d'études supérieures spécialises. Travaux du centre d'études supérieures spécialise d'Histoire des religion de Strasbourg, Paris, 7-19

Leeper, Robert Ward. 1970. The motivational and perceptual properties of emotions as indicating their fundamental character and role, in: Magda B. Arnold (Hrg.) Feelings and emotions: The Loyola symposium, New York.

Le Guilloux, Patrice. 2002. Les aventures de Sinouhé: texte hiéroglyphique, translittération et traduction commentée, Cahiers de l'Association d'Egyptologie Isis 4, Angers.

Legrain, Georges Albert. 1906. Statues et statuettes de rois et de particuliers, Caire.

Leontjew, Aleksej Nikolajewitsch. 1979. Tätigkeit, Bewußtsein, Persönlichkeit, Berlin.

Lesko, Leonard H. 1994. Pharao's workers; the villagers of Deir el-Medina. Ithaca [u.a.].

Lewis, Michael. 1992. Shame: the exposed self. New York.

Lexa, Franticek. 1928. Enseignement de Ptahhotep et fragment de l'enseignement de Kagemni, Prague.

Libraria editoria Vaticana (Hrg.) 1998. Neues Latein Lexikon, Deutsche Ausgabe, Bonn.

Lichtheim, Miriam. 1997. Moral values in Ancient Egypt. Orbis Biblicus et Orientalis, Bd. 155, Freiburg/Göttingen. 1996. Didactic literature, in: Antonio Loprieno (Hrg.) Ancient egyptian literature. Probleme der Ägyptologie, Bd. 16, Leiden/New York/Köln, 243-262. 1988. Ancient egyptian autobiographies chiefly of the Middle Kingdom. A study and an anthology, Fribourg. 1975-1980. Ancient egyptian literature, Bde. I-III, Berkley/Los Angeles/London. 
1969. Three philological notes, in: John A. Wilson (Hrg.) Studies in honour of John A. Wilson, Studies in ancient oriental civilisation 35, Chicago, 66-68.

1945. The song of the harper, in: Journal of near eastern studies 4, 178-212.

Lidell, Henry George, \& Robert Scott. 1996. A Greek-English lexicon, Oxford.

Lohmann, Katherina. 1998. Das Gespräch eines Mannes mit seinem B3, in: Studien zu altägyptischen Kultur 25, 207-236.

Long, Bernard. 1986. Le $j b$ et ḩ̉.tj dans les Textes Médicaux de l’Égypte Ancienne, in: François Daumas (Hrg.) Hommages à François Daumas, Montpellier, 483-494.

Lopez, Jesús. 1992. Le verger d'amour (P. Turin 1966, Recto), in: Revue d'égyptologie 43, 133-143. 1982. Ostraca ieratici. Catalogo del Museo Egizio di Torino III/3, Milan.

Loprieno, Antonio. 1996. The King's Novel, in: Antonio Loprieno (Hrg.) Ancient egyptian literature. Probleme der Ägyptologie, Bd. 16, Leiden/New York/Köln, 277-296.

1996. Loyalistic instructions, in: Antonio Loprieno (Hrg.) Ancient egyptian literature. Probleme der Ägyptologie, Bd. 16, Leiden/New York/Köln, 403-414.

1988. Topos und Mimesis. Zum Ausländer in der ägyptischen Literatur. Ägyptologische Abhandlungen, Bd. 48, Wiesbaden.

Lorenzer, Alfred. 1976. Psychoanalytische Erkenntnis, Frankfurt a.M.

Loret, Victor. 1916. Quelques notes sur l'arbre âch, in: Annales du service des antiquités de l'Égypte XIV, 33 51.

Lorton, David. 1968. The Expression šms-jb, in: Journal of the american research center in Egypt 7, 41-54.

Lucas, Alfred \& John Richard. Harris. 1962. Ancient egyptian materials and industries, London.

Mandler, George, Jean Matter Mandler \& E. T. Uviller. 1980. On throwing out the baby with the bathwater: a reply to Black \& Wilensky's evaluation of story grammars, in: Cognitive science 4, 305-312.

Mandler, George. 1984. Mind and body: psychology of emotion and stress, New York.

Mariette, Auguste Edouard. 1871. Les papyrus égyptiens du musée de Boulaq, Paris. 1870-. Dendérah. Description générale du gran temple, Bde. I-IV, Paris.

Martin, Geoffrey Thorndike et al. 1985. The Tomb-chapels of Paser of and Ra'ia at Saqqâra. London.

Mason, K. 1982. Metaphor and translation, in: Babel XXVIII(3), 140-149.

Maspero, Gaston. 1883. Les chants d'amour du Papyrus de Turin et du Papyrus Harris n 500, Études égyptiennes, Paris, 217-259.

Mathieu, Bernard. 1996. La poésie amoureuse de l'Égypte ancienne, Bibliothèque d'étude 115, Caire.

Mayenowa, Maria Renata. 1979. Poetyka teoretyczna. Zagadnienia jezeyka, Wroclaw.

Maystre, Charles. 1941. Le livre de la vache du ciel dans les tombeaux de la Vallée des Rois, in: Bulletin de l'institut français d'archéologie orientale 40, 53-115.

Mearns, J. 1991. Coping with a breakup: negative mood regulation expectancies and depresion following the end of a romantic relationship, in: Journal of personal social psychology, Feb. 60, 327-334.

Meeks, Dimitri. 1980. Liebeslieder, in: Lexikon der Ägyptologie III, 1048-1052.

Meiggs, Russell. 1982. Trees and timber in the ancient mediterranean world. Oxford.

Meyer, Max F. 1933. That whale among the fishes - theory of emotion, in: Psychological review 40, 292-300.

Migne, Jacques Paul. 1857-1866. Patrologia graeca, Paris.

Miosi, Frank T. 1996. Prolegomena to the futur, study of egyptian ethic, in: Journal of the society for the study of egyptian antiquities 26, 67-80.

Mishkin, Mortimer \& Tim Appenzeller. 1987. The anatomy of memory, in: Scientific american 256, 80-89.

Moers, Gerald. 2001. Fingierte Welten in der ägyptsichen Literatur des 2. Jahrtausends v. Chr., Leiden/Boston/Köln.

Moens, Marie-Francine. 1984. The ancient egyptian garden in the New Kingdom, Orientalia Lovaniensia Periodica 15, Leuven, 11-53.

Möller, Georg. 1927. Hieratische Lesestücke II, Leipzig.

Mooij, Jan Johann Albinn. 1976. A study of metaphor, Amsterdam.

Morenz, Ludweig D. 1999. Der (akrobatische) jb3-Tanz. Ein Bild/Schiftspiel auf einer frühdynastischen Prunkkeule, in: Lingua Aegyptia 6, 99-103.

1997. Maxime aus der Sammlung weisheitlicher Sprüche des Papyrus Ramesseum II, in: Discussion in Egyptologie 39, 65-70.

Morenz, Siegfried. 1975. Der Schrecken Pharaos, in: Elke Blumenthal \& Siegfried Herrmann unter Mitarb. von Angela Onasch (Hrg.) Religion und Geschichte des alten Ägypten. Gesammelte Aufsätze von Siegfried Morenz, Köln, 139-150. 
Moret, Alexandre. 1893. De l'expression $\oint_{\operatorname{man}}^{\operatorname{man}}$, in: Recueil du travaux 14, 120-123.

Morschauser, Scott. 1994. The opening lines of K3.gm.n.i (P. Prisse I 1-3a), in: Betsy Bryan and David Lorton (Hrg.) Essays in egyptology in honour of Hans Goedicke, Texas, 177-185.

Müller, Wilhelm Max. 1932. Die Liebespoesie der Alten Ägypter, Leipzig. 1909-1912. Hieratische Paläographie. Die Ägyptische Buschschrift in ihrer Entwicklung von der fünften Dynastie bis zur Römischen Kaiserzeit, Bde. II-III, Leipzig.

Munro, Pamela. 1991. ANGER IS HEAT: Some data for a crosslinguistic survey. Unpublished manuscript, department of linguistic, university of California at Los Angeles.

Nager, Frank. 1993. Das Herz als Symbol, Basel.

Naguib, Saphinaz-Amal. 1998. The weighing of the heart: iconics, image and symbol, in: In search of symbols. An explorative study occasional papers $1,68-88$.

Naville, Edouard. 1876. La destruction des hommes par le dieux, in: Transactions of the society of biblical archaeology 4, 1-19.

Neu, Erich \& Christel Rüster (Hrg.) 1973. Festschrift Heinrich Otten, Wiesbaden.

Newmark, Peter. 1981. Approaches to translation, Oxford [u.a.].

Nibbi, Alexandra. 1996. Cedar again, in: Discussion in the egyptologie 34, 37-60.

Nietzsche, Friedrich. 1920-1929. Gesammelte Werke, Musarionausg - München.

Noopen, Jean-Pierre van, Sabine de Knop \& René Jongen. 1985. Metaphor. A bibliography of post-1970 publications, Amsterdam.

Oatley, Keith. 1992. Best laid schemes, Cambridge.

Ockinga, Boyo. 1983. The burden of Kha-kheperre-sonbu, in: Journal of egyptological archaeology 69, 88-95.

Ogdon, Jorge R. 1998. Another hitherto unrecognised metaphor of death in coffin text, spells 162-72, in: Göttinger Miszellen 162, 65-71.

Olton, David S., James T. Becker \& Gail Handelmann. 1979. Hippocampus, space an memory, in: Behavioural \& Brain sciences 2, 313-322.

Ortony, Andrew. 1988. Towards a cognitive theory of emotion, in: Cognition and emotion 1 (1), 29-50.

Osgood, Charles E. 1964. Semantic differential technique in the comparative study of cultures, in: American anthropologist 66, 171-200.

Osing, Jürgen. 1992. Aspects de la culture Pharaonique, Mémoires de l'Académie des Inscriptions et BellesLetrres XII, Paris. 1976. Der spätägyptische Papyrus BM 10808, Wiesbaden.

Otto, Eckart. 1969. Wesen und Wandel der ägyptischen Kultur, Berlin/Heidelberg/New York.

Pachnicke, Erwin. 1985. Wörterbuch der Philosophie, Göttingen.

Parkinson, Richard B. 1999. The dream an the knot: contextualizing Middle Kingdom literatur, in: Gerald Moers (Hrg.) Definitely: egyptian literatur. Proceedings of the symposium "Ancient egyptian literatur: history and forms", Los Angeles, March 24-26 1995. Lingua Aegyptia: Studia Monographica 2, Göttingen, 6382.

1997. The tale of Sinuhe and other ancient egyptian poems 1940-1640 BC, Oxford.

1997. New readings of EA 5645 and an unpublished ostrakon, in: Journal of egyptological archaeology 83, 55-58.

1996. Individual and society in Middle Kingdom literature, in: Antonio Loprieno (Hrg.) Ancient egyptian literature. Probleme der Ägyptologie, Bd. 16, Leiden/New York/Köln, 137-156.

1991. The tale of the eloquent peasant, Oxford.

Patanè, Massimo. 1987. A propos du chant du harpiste d'Antef, in: Société d'égyptologie 11, 99-110.

Paul, Lothar. 1989. Wo und wie existieren sprachliche Bedeutungen? Semantik und Situation, in: Gerhard Pasternack (Hrg.) Tatsache, Bedeutung, Konstruktion, Bremen.

Peet, T. Eric. 1925. The legend of the capture of Joppa and the story of the foredoomed prince, in: Journal of egyptological archaeology 11, 227-229.

Peust, Carsten. 1996. Indirekte Rede im Neuägyptischen, Göttinger Orientforschungen IV, Bd. 33, Wiesbaden.

Piankoff, Alexandre. 1930. Le coeur dans les textes égyptiens, Paris.

Pieper, Max. 1929. Die Ägyptische Literatur, Potsdam [u.a.].

Pisarska, Alicja . 1989. Creativity of translators. The translation of metaphorical expressions in non-literary texts, Poznán.

Plutchik, Robert. 1984. A psychoevolutionary theory, in: Klaus Rainer Scherer \& Paul Ekman (Hrg.) Approaches to emotion, Hillsdale. 
1980. A general psychoevolutionary theory of emotion, in: Robert Plutchik \& Henry Kellerman (Hrg.) Emotion theory research and experience, New York.

Posener, Georges. 1976. L'enseignement loyaliste, Genève.

------- 1951-1972. Catalogue des ostraca hiératiques littéraires de Deir el-Médineh II, fasc. 3, n 1109-1226, Documents de fouilles de l'insitut français d'archéologie oriental du Caire XVIII, Le Caire.

-------- 1966. Quatre tablettes scolaires de basse époque (Aménémopé et Hardjédef), in: Revue d'égyptologie 18, 45-65.

1966. Philologie et archéologie égyptiennes. Annuaire due collège de France, Bd. 66, Paris, 339-346.

1956. Littérature et politique dans l'Égypte de la XII dynastie. Paris.

1955. L'exorde de l'intruction èducative d'Amennakhte, in: Revue d'égyptologie 10, 61-72.

1952. Compléments aux 'richesses inconnues', in: Revue d'égyptologie 9, 117-120.

1951. Les richesses inconnues de la littérature égptienne (Recherches littéraires I), in: Revue

d'égyptologie 6, 27-48.

Pott, Peter H. 1966. Yoga and yantra: their interrelation and their significance for Indian archaeology, Le Hague.

Prechtl, Peter. 1999. Metzler-Philosophie-Lexikon: Begriffe und Definitionen, Stuttgart [u.a.].

Pribram, K. H. 1970. Feelings as monitors, in: Magda B. Arnolds (Hrg.) Feelings an emotions, New York.

Quack, Joachim Friedrich. 1994. Die Lehre des Ani. Orbis Biblicus et Orientalis, Bd. 141, Freiburg/Göttingen. 1992. Studien zur Lehre für Merikare. Göttinger Orientforschungen IV, Bd. 23, Wiesbaden.

Quirke, Stephen. 1996. Archive, in: Antonio Loprieno (Hrg.) Ancient egyptian literature. Probleme der Ägyptologie, Bd. 16, Leiden/New York/Köln, 379-402.

1996. Narrative literatur, in: Antonio Loprieno (Hrg.) Ancient egyptian literature. Probleme der Ägyptologie, Bd. 16, Leiden/New York/Köln, 263-276.

Rado, Sandor. 1969. Adaptional psychodynamics: motivation and control, New York.

Real Academia Española (Hrg.) 2001. Diccionario de la lengua española, Madrid.

Reisenzein, Reiner. 1983. The schachter theory of emotion: two decades later, in: Psychological bulletin 94, 239-264.

Richards, Ivor Armstrong. 1936. The philosophy of rhetoric, London.

Ricoeur, Paul. 1994. The rule of metaphor: multi-discilinary studies of the creation of meaning in language, London. 1950. Philosophie de la volonté. La volontaire et l'involontaire, Paris.

Robinson, H.Wheeler. 1911. The christian doctrine of man, Ediburgh.

Roccati, Alessandro. 1994. Spienza egizia. Testi del Vicino Oriente Antico 1, letteratura egiziana classica 4. Brescia.

Roetz, Heiner. 1984. Mensch und Natur im Alten China, Frankfurt a.M.

Rosseau, Jean-Jacques. 1947. Les rêveries d'un promeneur solitaire, Pierre Grosclaude (Hrg.), Paris. 1799-1800. La nouvelle heloise ou lettres de deux amans, habitants d'une petit ville au pied des Alpes, Paris.

Sacks, Sheldon. (Hrg.) 1979. On metaphor, Chicago.

Sánchez Rodriguez, Angel. 1996. Las instrucciones para Ka-gem-ni, in: Boletín de la Asociación española de egiptología 6, 97-110.

Sandern-Handersen, Constantin Emil. 1956. Die Texte der Metternichstele. Analecta Aegyptiaca, Bd. 7, Kopenhagen.

Sartre, Paul. 1948. The emotion: outline of a theory, New York. 1939. Esquisse d'une théorie des émotions, Paris.

Schachter, Stanley. 1971. Emotion, obesity, and crime, New York.

-------- 1970. The assumption of identity and peripheralist-centralist controversies in motivation and emotion, in: Magda B. Arnold (Hrg.) Feelings and emotions. New York.

Schäfer, Heinrich. 1905. Urkunden der älteren Äthiopenkönige, Leipzig.

Schenkel, Wolfgang. 1996. Ägyptische Literatur und ägyptologische Forschung: eine wissenschaftsgeschichtliche Einleitung, in: Antonio Loprieno (Hrg.) Ancient egyptian literature. Probleme der Ägyptologie, Bd. 16, Leiden/New York/Köln, 21-38.

1964. Eine neue Weisheitslehre?, in: Journal of egyptological archaeology 50, 6-12.

Schermer, Franz J. (Hrg.) 1988. Einführung in Grundlagen der Psychologie, Würzburg.

Scherer, Klaus Rainer \& Paul Ekman. 1984. Approaches to emotion, Hillsdale.

Schipperges, Heinrich. 1989. Die Welt des Herzens Sinnbild, Organ, Mitte des Menschen, Frankfurt am Main. 
Schmitz, Hermann. 1996. Leibliche Quellen der Herzmetaphorik, in: Georg Berkemer \& Guido Rappe (Hrg.)

Das Herz im Kulturvergleich. Lynkeus. Studien zur Neuen Phänomenologie, Bd. 3, Berlin, 13-22.

Schmidt, Torsten. 1984. Der Einfluss der Metapher auf die Sprache des Hörers, Berlin.

Schott, Siegfried. 1950. Altägyptische Liebeslieder, Zürich.

Schroer, Silvia \& Thomas Staubli. 1998. Die Körpersymbolik der Bibel, Darmstadt.

Seibert, Peter. 1967. Die Charakteristik: Untersuchungen zu einer altägyptischen Sprechsitte und ihren Ausprägungen in Folklore und Literatur, Teil I: Philologische Bearbeitung der Bezeugungen. Ägyptologische Abhandlungen, Bd. 17, Wiesbaden.

Seidensticker, Tilman. 1992. Altarabisch 'Herz' und sein Wortfeld. Wiesbaden.

Select papyri in the hieratic character from the collections of the British Museum II, 1860. London.

Sethe, Kurt. 1961. Urkunde der 18. Dynastie, Leipzig.

--------- 1934. Zur Vorgeschichte der Herzskarabäen. Mémoires de l'institut français XIV, Melanges Maspero I, Cairo, 113-120.

1928. Dramatische Texte zu altägyptischen Mysterienspielen. Untersuchungen zur Geschichte und Altertumskunde Ägyptens, Bd. 10, Hildesheim.

1924. Ägyptische Lesestücke, Leipzig.

1908ff. Die altägyptischen Pyramidentexte, Leipzig.

Shirun-Grumach, Irene. 1991. Die Lehre des Amenemope, in: Günter Burkard et al., Weisheitstexte II, Texte aus der Umwelt des Alten Testaments III, Lieferung 2, Gütersloh, 222-250.

1972. Untersuchen zur Lebenslehre des Amenemope. Münchener Ägyptologische Studien, Bd. 23, Berlin.

Shaver, Phillip, J. Schwartz, D. Kirson \& C. O’connor. 1987. Emotional knowledge: further examination of a prototype approach, in: Journal of personality and social psychology 52, 1061-1086.

Shupak, Nili. 1993. Where can wisdom be found? Orbis Biblicus et Orientalis, Bd. 130, Freiburg/Göttingen.

------- 1983. Some idioms connected with the concept of heart in Egypt and the Bible, in: Sarah Israelit-Groll (Hrg.) Pharaonic egyptian, Jerusalem, 202-212.

Shweder, Richard A. 1991. Thinking through cultures: expeditions in cultural psychology, Cambridge.

Silverman, David P. 1991. Text from the Amarna period and their position in the development of Ancient Egyptian, in: Lingua Aegyptia 1, 301-314.

Simpson, William Kelly (Hrg.). 1996. Belles lettres and propaganda, in: Antonio Loprieno (Hrg.) Ancient egyptian literature. Probleme der Ägyptologie, Bd. 16, Leiden/New York/Köln, 435-446. 1972. The literature of Ancient Egypt: an anthology of stories, instructions, and poetry, Yale.

Sliwa, Joachim. 1975. Studies in Ancient Egyptian Handicraft, Warschau [u.a.].

Smith, Grafton Elliot \& Warren R. Dawson. 1924. Egyptian mummies, London.

Solomon, Robert. 1984. Getting angry: the Jamesian theory of emotion in anthropology, in: Richard A. Shweder \& Robert A. LeVine (Hrgs.), Culture theory, Cambridge, 238-255. 1976. The passions, New York.

Sommer, Ferdinand \& Adam Falkenstein. 1938. Die hethitische-akkadische Bilingue des Hattušili I. Labarna II, München.

Spiegel, Joachim. 1937. Die Erzählung vom Streite des Horus und Seth. Leipziger Ägyptologische Studien, Bd. 9, Glückstadt.

Spiegelberg, Wilhelm. 1930. Das Herz als zweites Wesen des Menschen, in: Zeitschrift für die ägyptische Sprache und Altertumskunde 66, 35-37.

1910. Der Sagenkreis des Königs Petubastis nach dem Strassburger demotischen Papyrus sowie den Wiener und Pariser Bruchstücken. Demotischen Studien, Bd. 3, Leipzig.

1897. Eine neue Sammlung von Liebesliedern, in: Georg Ebers (Hrg.) Aegyptiaca. Festschrift für Georg Ebers, Leipzig, 117-121.

Spielberger, Charles D. 1972. Anxiety as an emotional state, in: Charles D. Spielberger (Hrg.) Anxiety: current trend in theory and research (vol. 1), New York.

Stearns, Peter N. 1994. American cool: Constructing a twentieth-century emotional style, New York.

Stein, Donald G. \& Jeffrey J. Rosen. 1974. Motivation and emotion, New York.

Stemmler, Theo. 1990. Liebe als Krankheit. Kolloquium der Forschungsstelle für europäische Lyrik des Mittelalters, Mannheim.

Sternberg el-Hotabi, Heike. 1991. Einleitung, in: Günter Burkard et al., Weisheitstexte II, Texte aus der Umwelt des Alten Testaments III, Lieferung 2, Gütersloh, 191-194.

Stracmans, Maurice. 1961. Les termes jb et ḩitj. Considérés sans l'angle métaphorique dans la langue de l'ancien empire. Bibliothèque d'étude, Bd. 32, Le Caire, 125-132. 
Strasser, Stephan. 1970. Feeling as basis of knowing and recognising the other as an ego, in: Magda B. Arnold (Hrg.) Feelings and emotions, New York.

1956. Das Gemüt: Grundgedanken zu einer phänomenologischen Philosophie und Theorie des menschlichen Gefühlslebens, Utrech.

Suys, Emile. 1935. La sagesse d'Ani: Texte traduction et commentaire. Analecta Orientalia, Bd. 11, Rome. 1934. Le papyrus magique due Vatican, Orientalia 3, 63-87. 1933. Étude sur le conte du fellah plaideur, Rome.

Szemerényi, Oswald J. L. 1970. The Indo-European name of the 'heart', in: Velta R $\bar{u}$,ke-Dravi,na (Hrg.) Donum Balticum: to Professor Christian S. Stang on the occasion of his seventieth birthday 15 March, Stockholm .

Taylor, John R. \& Thandi Mbense. 1998. Red dog and rotten mealies: How Zulus talk about anger, in: Angeliki Athanasiadou \& Elzbieta Tabakowska (Hrg.) Speaking of emotion: Conceptualisation and expression, Berlin, 191-226.

Taylor, John R. 1996. Guilt and Remose, in: Rom Harré \& W. Gerrod Parrot (Hrg.) The emotions, social, cultural and biological dimension, London, 57-73.

Thériault, Carolyn A. 1993. The instruction of Amenemhet as propaganda, in: Journal of the american research center in Egypt 30, 151-160.

Thompson, Della. (Hrg.). 1995. The concise Oxford dictionary, Oxford.

Tischer, Bernd. 1993. Die vokale Kommunikation von Gefühlen, Weinheim.

Tischler, Johann. 1983-1994. Hethitisches Etymologisches Glossar, Innsbrucker Beiträge zur Sprachwissenschaft, Innsbruck.

Tomkins, Silvan Samuel. 1980. Affect as amplification: some modifications in theory, in: Robert Plutchik \& Henry Kellerman (Hrg.) Emotion I, Theories of emotions, New York. 1970. Affect as the primary motivational system, in: Magda B. Arnold (Hrg.) Feelings and emotions, New York.

Ullmann, Manfred \& Anton Spitaler (Hrsg.). 1970-. Wörterbuch der klassischen arabischen Sprache, unter Mitwirkung der [...] hrsg. durch die Deutschen Morgenländische Gesellschaft. Begr. von Jörg Kraemer und Helmut Gätje. In Verb. mit Anton Spitaler bearb. von Manfred Ullmann, Wiesbaden (bis 2001 sind erschienen Band 1 sowie 4 Teile von Band 2).

Van den Broeck, R. 1981. The limits of translatability exemplified by metaphor translation, in: Poetics today II (4), 73-87.

Van de Walle, Badouin. 1963. Une tablette scolaire provenant d'Abydos, in: Zeitschrift für die ägyptische Sprache und Altertumskunde 90, 118-123.

Van Dijk, Stephen J. P. 1995. Entering the house of hearts: an addition to chapter 151 in the Book of the Dead of Quenna, in: Oudheidkundige Mededelingen uit Het Rijksmuseum van Oudheden te Leiden 75, 7-12.

Vernus, Pascal. Le début de l'enseignement de Ptahhotep: un nouveau manuscrit, in: Cahier de Recherches de l'institut de papyrologie et d'égyptologie de Lille 18, 119-0140. 1992. Chants d'amor de l'Égypte antique, Paris.

Vico, Giambattista. 1816. Principi di scienza nuova d'intorno alla comune natura delle nazioni: colla vita dell'autore scritta da lui medesimo, Milano.

Vogelsang, Friedrich. 1932. Kommentar zu den Klagen des Bauern. Untersuchungen zur Geschichte und Altertumskunde Ägyptens, Bd. 6, Leipzig.

Vogelsang, Friedrich \& Alan Henderson Gardiner. 1908. Die Klagen des Bauern. Literarische Texte des Mittleren Reiches I, Berlin.

Voltaire, François de. 1856-1857. Oeuvres complètes de Voltaire: Dictionnaire philosophique, Paris.

Von Bissing, Friedrich Wilhelm. 1955. Altägyptische Lebensweisheit, Zürich.

Vowinckel, Gerhard. 1983. Von politischen Köpfen und schönen Seelen. Ein soziologischer Versuch über die Zivilisation der Affekte und ihres Ausdrucks, München.

Vycichl, Werner. 1983. Dictionnaire étymologique de la langue copte, Leuven.

Wahrig, Gerhard. 2000. Deutsches Wörterbuch, Gütersloh/München.

Wahrmund, Adolf. 1970. Handwörterbuch der arabischen und deutschen Sprache, Graz.

Walker, James H. 1996. Studies in ancient egyptian anatomical terminology. The australian centre for egyptology: Studies, Bd. 4, Warminster.

Wallon, Henri. 1949. Les origines du caractère chez l'enfant, Paris.

Wander, Karl Friedrich Wilhelm (Hrg.). 1987. Deutsches Sprichwörter-Lexicon, Stuttgart.

Weber, Frauke. 1993. Denken in Metaphern, Frankfurt a.M. [u.a.].

Wehr, Hans. 1958. Arabisches Wörterbuch für die Schriftsprache der Gegenwart, Wiesbaden. 
Wente, Edward F. 1992. Letters from Ancient Egypt, in: Journal of the american research center in Egypt 29, 217-218.

1962. The egyptian 'Make-Merry' songs reconsidered, in: Journal of Near Eastern studies 21, 118-128.

Westenholz, Joan Goodnick. 1995. Love lyrics from the ancient Near East, in: Civilisation of the ancient near east IV, 2471-2484.

White, John Bradley. 1978. A study of the language of love in the song of songs and ancient egyptian poetry, in: Howard C. Kee \& Douglas A. Knight (Hrg.) Society of Biblical literature dissertations series 38, Missoula, Montana.

Wickens, Delos D. \& Donald R. Meyer. 1961. Psychology, New York.

Wierzbicka, Anna. 1999. Emotions across languages and cultures, Cambridge. 1995. Everyday conceptions of emotion: A semantic perspective, in: James Russell et al. (Hrg.) Everyday conception of emotion, Kluwer, 17-45. 1972. Semantic primitives, Frankfurt.

Wiesmann, Hermann. 1922. Die Determinative des sprechenden Mannes und der Buchrolle in den Pyramiden Texten, Zeitschrift für die ägyptische Sprache und Altertumskunde 57, 73-77.

Williams, R. 1964. The seed of wisdom, in: W. S. McCullough (Hrg.) Essays in honour of T. J. Meek, Toronto. Wilson, John Albert. 1969. Ancient Near Eastern texts relating to the Old Testament, in: James B. Pritchard (Hrg.) Princeton. 1956. The culture of ancient Egypt, Chicago.

Wittgenstein, Ludwig. 1953. Philosophische Untersuchungen, Oxford.

Young, Paul Thomas. 1943. Emotions in man and animal. Its nature and relation to attitude and motive, New York-London.

Yu, Ning. 1995. Metaphorical expressions of anger and happiness in english and chinese, in: Metaphor and symbolic activity 10 (2), 59-92.

Zába, Zbynek. 1956. Les maximes de Ptahhotep, Prage.

Zajonc, Robert Boleslaw. 1984. On the primacy of affect, in: American psychologist 39, 117-123. 1980. Feelings and thinking. Preferences need no inferences, in: American psychologist 35, 151-175.

Zedler, Johann Heinrich. 1735. Großes unvollständiges Universal Lexicon aller Wissenschaften und Künste, Halle-Leipzig. 


\section{ABKÜRZUNGEN FÜR DEN TEXT}

$\begin{array}{ll}\text { AEO } & \text { Ancient Egyptian Onomastica } \\ \ddot{A F} & \text { Ägyptologische Forschungen } \\ \text { ÄS } & \text { Ägyptologische Studien } \\ \text { BÄ } & \text { Bibliotheca Aegyptiaca, Brüssel } \\ \text { Bas. } & \text { Basilius Caesariensis Cappadociae, siehe Garnier } \\ \text { CT } & \text { Coffin Text } \\ \text { GCS } & \text { Die griechischen christlichen Schriftsteller der ersten drei Jahrhunderte } \\ \text { KBo } & \text { Keilschrifttexte aus Boghazköi, Heft 1-6, WVDOG Bde. 30 u. 36, Leipzig, 1916-23. } \\ \text { KVB } & \text { Keilschrifturkunden aus Boghazköi I-XXXIV, Berlin, 1921-44. } \\ \text { LA } & \text { Lexikon der Ägyptologie. } \\ \text { Patres Prop. } & \text { Sex. Propertus } \\ \text { TCL } & \text { Textes Cuneiformes du Louvre } \\ \text { TDP } & \text { Siehe Labat } \\ \text { Urk. } & \text { Siehe Sethe (1961) u. Schäfer (1905) } \\ \text { Wb. } & \text { Wörterbuch der ägyptsichen Sprache } \\ \text { ZA } & \text { Zeitschrift für Assyriologie und verwandte Gebiete bzw. Vorderasiatische Archäolo- } \\ & \text { gie (Berlin). } \\ \text { Zuhair } & \text { Siehe Ahlwardt }\end{array}$

\section{ABKÜRZUNGEN FÜR DIE GLOSSIERUNG}

$\begin{array}{ll}3 & \text { dritte Person } \\ \mathrm{c} & \text { Genus communis } \\ \mathrm{d} & \text { Dual } \\ \mathrm{f} & \text { Femininum } \\ \mathrm{m} & \text { Maskulinum } \\ \mathrm{p} & \text { Plural } \\ \mathrm{s} & \text { Singular } \\ \text { ADJ } & \text { Adjektiv (das nicht auf der Basis } \\ & \text { einer verbalen Wuzel gebildet ist) } \\ \text { ADJR } & \text { Adjektivierer ("Nisbe") } \\ \text { ART. } & \text { Artikel } \\ \text { AUG. } & \text { Augment } \\ \text { AUX. } & \text { Auxiliares Verb } \\ \text { CMPLR. } & \text { Complementizer } \\ \text { DEM. } & \text { Demonstrativpronomen } \\ \text { DETER. } & \text { Determinativpronomen } \\ \text { DPA. } & \text { distributives ("imperfektives") Partizip Aktiv } \\ \text { DU. } & \text { Dualffix } \\ \text { EMPH. REFL. } & \text { emphatisches Reflexivpronomen } \\ \text { FEM. } & \text { Femininaffix } \\ \text { FUT. } & \text { Futur } \\ \text { IMPV. } & \text { Imperativ } \\ \text { INDEF. } & \text { Indefinitpronomen } \\ \text { INF. } & \text { Infinitiv } \\ \text { INTG. } & \text { Interrogativpronom } \\ \text { KB PRÄS.I. } & \text { Neuägyptisches Präsens I } \\ \text { KB F.III. } & \text { Neuägyptisches Futur III } \\ \text { KNVTR. } & \text { Konverter } \\ \text { KONJ. } & \text { Konjuntiv } \\ \text { NEG. } & \text { Negation } \\ \text { NMLR. } & \text { Nominalisierer } \\ \text { NPA. } & \text { neutrales ("perfektives") Partizip Aktiv } \\ \text { NPF. } & \text { neutrales ("perfektives") Partizip Prospektiv } \\ & \end{array}$




$\begin{array}{ll}\text { NPP. } & \text { neutrales ("perfektives") Partizip Passiv } \\ \text { NUM. } & \text { Kardinalzahlwort } \\ \text { PAST. } & \text { Neuägyptisches Präteritum } \\ \text { PASS. } & \text { Passiv } \\ \text { PL. } & \text { Pluralaffix } \\ \text { POSS. } & \text { Possesivpronomen } \\ \text { POSTP. } & \text { Postposition } \\ \text { PREP. } & \text { Präposition } \\ \text { PREP. ADJ. } & \text { Präpositionaladjektiv } \\ \text { PRES. } & \text { Präsens } \\ \text { PRET. } & \text { Präteritum } \\ \text { PROP. } & \text { Personennamen } \\ \text { PTCL. } & \text { Partikel } \\ \text { RLTVF. } & \text { Relativform } \\ \text { REFL.PRON. } & \text { Reflexivspronom } \\ \text { SBST. } & \text { Substantiv } \\ \text { STAT. } & \text { Stativ } \\ \text { SUBJ. } & \text { Subjuntiv } \\ \text { TERM. } & \text { Terminativ } \\ \text { THEON. } & \text { Göttername } \\ \text { TOP. } & \text { "Dummy Topic" (jw) } \\ \text { TOPLR. } & \text { Topikalisierung } \\ \text { VB. } & \text { Verb }\end{array}$

